\title{
Conceptual Planning of Managed Aquifer Recharge \\ in the Context of Integrated Water Resources Management \\ for a semi-arid and a tropical Case Study in Palestine and Brazil:
}

A new Integrated MAR Planning Approach

\author{
Dissertation \\ zur Erlangung des mathematisch-naturwissenschaftlichen Doktorgrades \\ "Doctor rerum naturalium" \\ der Georg-August-Universität Göttingen \\ im Promotionsprogramm Geoscience \\ der Georg-August University School of Science (GAUSS)
}

Florian Walter

Göttingen, 2018 


\section{Betreuungsausschuss}

Prof. i. R. Dr. Gerhard Gerold

Georg-August-Universität Göttingen, Abt. Physische Geographie

Dr.-Ing. Bernd Rusteberg

Rusteberg Water Consulting UG

Mitglieder der Prüfungskommission

Referent: $\quad$ Prof. i.R. Dr. Gerhard Gerold

Georg-August-Universität Göttingen, Abt. Physische Geographie

Korreferent: $\quad$ Dr.-Ing. Bernd Rusteberg

Rusteberg Water Consulting UG

Weitere Mitglieder der Prüfungskommission:

Prof. Dr. Martin Sauter

Georg-August-Universität Göttingen, Abt. Angewandte Geologie

Prof. i. R. Dr. Heinz Hötzl

ehemals Karlsruher Institut für Technologie

Prof. Dr. Martin Kappas

Georg-August-Universität Göttingen, Abt. Kartographie, GIS und Fernerkundung

Dr. Elco Luijendijk

Georg-August-Universität Göttingen, Abt. Strukturgeologie

Tag der mündlichen Prüfung: 30. Juli 2018 


\section{EXECUTIVE SUMMARY}

This thesis focuses on the development, application and evaluation of new integrative approach for the planning of Managed Aquifer Recharge (MAR) concepts in the context of Integrated Water Resources Management (IWRM). The approach combines issues of quantitative water resources management with the idea of MAR to artificially enhance groundwater recharge. To test the approach MAR is applied for two fundamentally different case studies: the tropical coastal region around the city of João Pessoa in Northeast Brazil and the city of Jericho with its neighboring Auja village in the semi-arid Lower Jordan Valley of Palestine.

In the tropical case study area of João Pessoa, no acute threats for the local groundwater resources could be detected for the present. The water resources system does, however, reveal a high sensitivity and risk for overexploitation under the assumptions of various scenarios for future development. The results show that this risk could be reduced if addressed in time. A decentralized implementation of several MAR facilities throughout the study area operated with surface runoff from the river network, has been identified as a potential measure to support a sustainable development of the water resources system even under challenging future conditions and a potential increase of the highly water demanding sugarcane plantations. It is suggested to install at least two MAR test facilities in the area, testing surface infiltration technology at one location and direct injection at the other.

The semi-arid case study of Jericho-Auja nowadays already suffers from immense water shortage in addition, to high seasonal and annual fluctuations in water supply, coming mostly from several natural springs in the region. A set of measures is suggested that might be combined with a MAR implementation in order to increase the amount of water availability on one hand and reduce the volatility of supply security on the other. The most promising measure of activating new water sources is the implementation of additional deep groundwater wells that penetrate the aquifer beneath the shallow alluvial fan which is strongly overexploited presently. Future scenarios revealed even higher deficits in water supply that could, after the exploitation of all available local water sources and the implementation of a MAR system, only be covered by additional water imports. Also for this case study the installation of at least one MAR pilot plant is recommended, in addition, to immediate actions with regard to the implementation of at least one new deep well. Political restrictions have been neglected for this study.

In both studies the application of the suggested new approach lead to valuable results and an increased understanding of the local water resources system. Extended recommendations are given for both areas with a special focus on the enhancement of monitoring systems, since data scarcity is a big challenge in both studies. Without a profound data basis, water resources management is limited to many assumptions and approximations, increasing the level of uncertainty for any results. 


\section{ZUSAMMENFASSUNG}

Die vorliegende Arbeit setzt den Fokus auf die Entwicklung, Anwendung und Beurteilung eines neuen integrativen Planungsansatzes für die kontrollierte Grundwasseranreicherung (engl. MAR Managed Aquifer Recharge) im Kontext eins integrierten Wasserressourcenmanagements (engl. IWRM -Integrated Water Resources Management). Der Ansatz kombiniert Themen des quantitativen Wasserressourcenmanagements mit der Grundidee des MAR, die Grundwasserneubildung künstlich zu erhöhen. Um den Ansatz zu testen, wird er für zwei fundamental unterschiedliche Fallstudien angewendet: die tropische Küstenregion um die Stadt João Pessoa im Nordosten Brasiliens, sowie die Stadt Jericho und das angrenzende Dorf Auja im semi-ariden Unteren Jordantal, Palästina.

Für die tropisch geprägte Fallstudie João Pessoa kann keine akute Gefährdung der örtlichen Grundwasserressourcen festgestellt werden. Das Wasserressourcensystem zeigt jedoch eine hohe Sensitivität und Gefahr für Übernutzung unter der Annahme verschiedener Szenarien zukünftiger Entwicklung. Die Ergebnisse zeigen, dass dieses Risiko erheblich reduziert werden kann, wenn entsprechende Maßnahmen zeitnah durchgeführt werden. Eine dezentrale Implementierung von mit Oberflächenwasser betriebenen MAR Anlagen wurde als potentielle Maßnahme identifiziert, um eine nachhaltige Entwicklung der Wasserressourcen, selbst unter herausfordernden möglichen Entwicklungen zu unterstützen. Es wird empfohlen, an mindestens zwei Standorten MAR Pilotanlagen zu errichten, um jeweils Infiltrations-und Injektionstechnologien im Gelände zu testen.

Die semi-aride Fallstudie Jericho-Auja leidet bereits heute unter enormer Wasserknappheit und einer zusätzlichen Belastung durch hohe saisonale und jährliche Schwankungen der Wasserversorgung. Eine Reihe von Maßnahmen wird empfohlen, welche in Kombination mit einer MAR Implementierung die Menge an bereitgestelltem Wasser erhöhen und die Volatilität der Wasserversorgung reduzieren könnten. Als die vielversprechendste Maßnahme wird hierbei die Errichtung mehrerer Tiefbrunnen empfohlen. Szenarien zukünftiger Entwicklung zeigen einen weiter steigenden Wasserbedarf an, welcher selbst nach Aktivierung sämtlicher lokaler Wasserressourcen nur über weitere Importe gedeckt werden könnte. Auch für diese Fallstudie wird die Installation einer MAR Pilotanlage in direkter Verbindung mit der Installation wenigstens eines Tiefbrunnens empfohlen. Politische Einschränkungen werden für diese Studie nicht beachtet.

In beiden Fallstudien hat die Anwendung des vorgeschlagenen neuen Planungsansatzes zu wertvollen Ergebnissen und einem verbesserten Verständnis des lokalen Wasserressourcensystems geführt. Ausführlichere Empfehlungen werden für das Monitoring der Ressourcen ausgesprochen, da beide Regionen durch einen Mangel an Daten geprägt sind. Ohne eine solide Datengrundlage wird jegliches Wasserressourcenmanagement auf zahlreiche Vermutungen und Schätzungen limitiert, welche einen erhöhten Grad an Unsicherheit gewonnener Ergebnisse bewirken. 


\section{ACKNOWLEDGEMENT}

First and foremost I would like to express my sincere gratitude to Bernd Rusteberg and Prof. Gerhard Gerold for supervision of my thesis and continuous support of my work.

I started to work with Bernd Rusteberg more than six years ago as a student. Since then I learned a lot from him about the issue of water resources management and to work and think on a larger scale within the context of interdisciplinary projects in the Middle East and Northeast Brazil. He enabled me to work independently, but was always available in times of need. He encouraged my ability to solve problems creatively and think outside the box. Without him neither the project framework nor the thesis itself would have been realized.

Prof. Gerold enabled my contribution in the BRAMAR project. He gave many great advice and was a patient source of continuous support for my studies in Northeast Brazil. He was always available for discussion and enriched my work with his experience.

I want to personally thank Prof. Martin Sauter for enabling my cooperation in the SMART-MOVE project and joining my examination committee. Furthermore, I thank the other members: Prof. Heinz Hötzl, Prof. Martin Kappas and Dr. Elco Luijendijk for putting me to the test.

Many thanks go out to the colleagues and friends I had the honor to work with during the past years, that directly or indirectly contributed to this thesis: Prof. Cristiano Almeida, Lucila Fernandes, Jaqueline Coutinho, Romero Barbosa (UFPB, João Pessoa); Gerald DaSilva (I3S, João Pessoa); Saskia Schimmelpfennig, Prof. Matthias Schöniger and Prof. Günter Meon (TU Braunschweig); Barbara Tsuyuguchi, Prof. Janiro Rêgo and Prof. Carlos Galvão (UFCG, Campina Grande); Prof. Suzana Montenegro and Victor Coelho (UFPE, Brazil); Muath Abu Sadah (HEC, Ramallah); Abdelrahman Tamimi (PHG, Ramallah); Sebastian Schmidt and Torsten Lange (University of Göttingen); Marcos Freitas (ANA, Brasilia); Anna Abels and Prof. Johannes Pinnekamp (RWTH Aachen); all the consortium members of the BRAMAR and SMART-MOVE projects that were not named here personally; and finally the BMBF for financing these projects.

My special gratitude goes to Christoph and Sandra Raab. Their support and cruel honesty during the final stage of my work was beyond measure.

I thank my family and friends for believing in me.

Last, but definitely not least, I want to thank the most important person in my life: My wife, Maj. She is the source of endurance and calmness that kept me going for more than eleven years. And continues to do so. Without her, this would not have been finished. 
IV. TABle OF CONTENTS

I. EXECUTIVE SUMMARY

II. ZUSAMMENFASSUNG

III. ACKNOWLEDGEMENT

IV. TABLE OF CONTENTS IV

V. LIST OF FIGURES VIII

VI. LIST OF TABLES XI

VII. LIST OF ABBREVIATIONS XII

$1 \quad$ INTRODUCTION 1

1.1 MOTIVATION

1.2 PROJECT BASED FRAMEWORK 3

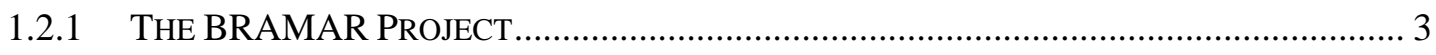

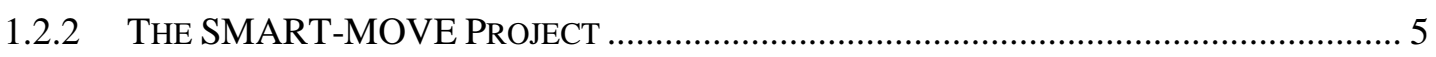

1.3 RESEARCH OBJECTIVES

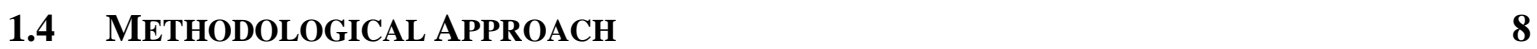

1.5 RESEARCH HYPOTHESIS 9

$\underline{2}$ LITERATURE REVIEW

2.1 Managed AQuifer Recharge 11

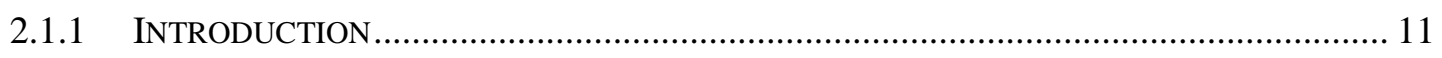

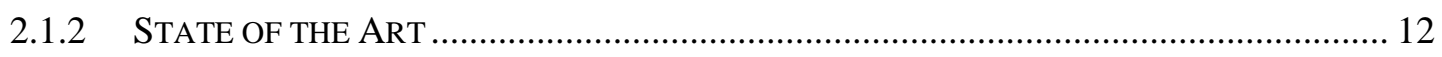

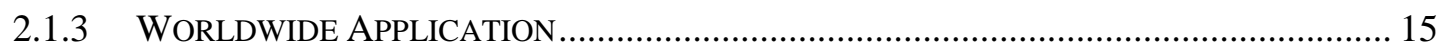

2.1.4 CHALLENGES OF MAR PLANNING ...................................................................... 17

2.2 INTEGRATED WATER RESOURCES MANAGEMENT 19

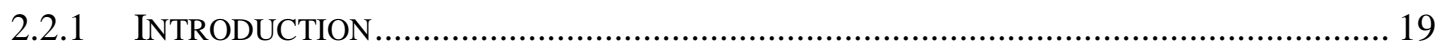

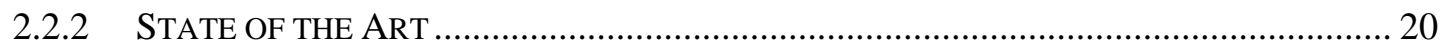

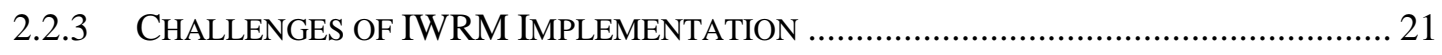

2.3 MAR AS INTEGRAL PART OF IWRM:

NEED FOR AN INTEGRATED PLANNING APPROACH 


\section{$\underline{3}$ METHODOLOGY:}

\section{SUGGESTION OF A NEW INTEGRATED MAR PLANNING APPROACH} 23

\subsection{INTRODUCTION}

3.2 METHODOLOGY:

DETAILED DESCRIPTION OF THE SUGGESTED MAR PLANNING APPROACH 26

3.2.1 STEP 1: DATA ACQUISITION AND ANALYSIS................................................................. 26

3.2.2 STEP 2: GENERAL MAR FEASIBILITY ASSESSMENT …............................................. 27

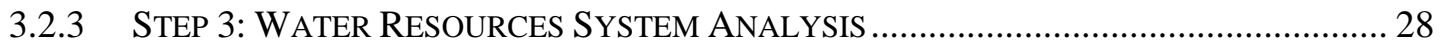

3.2.4 STEP 4: COMBINATION OF MAR CONCEPT AND IWRM MEASURES

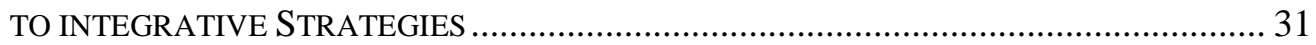

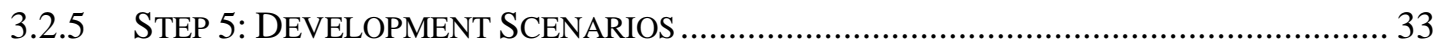

3.2.6 STEP 6: MAR GROUNDWATER BUDGET ASSESSMENT ............................................... 34

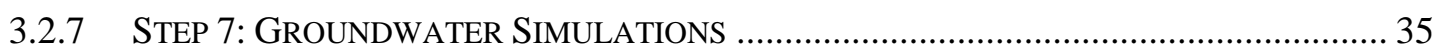

3.2.8 STEP 8: PERFORMANCE AND IMPACT ASSESSMENT ..................................................... 36

3.2.9 STEP 9: RECOMMENDATIONS FOR PILOT PLANT(S) ................................................. 38

3.2.10 STEP 10: TECHNICAL MAR FEASIBILITY STUDY …...................................................... 39

3.3 SUMMARY OF THE SUGGESTED APPROACH

4 CASE STUDIES: JOÃO PESSOA AND JERICHO-AUJA

$\begin{array}{lll}4.1 & \text { INTRODUCTION } & 43\end{array}$

4.2 STEP 1: DATA ACQUISITION AND ANALYSIS

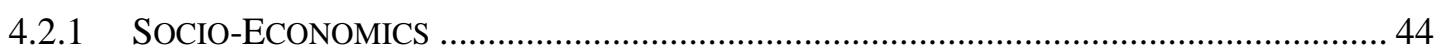

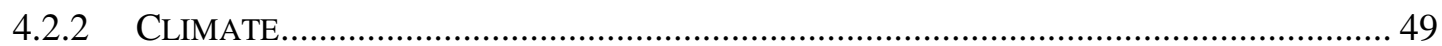

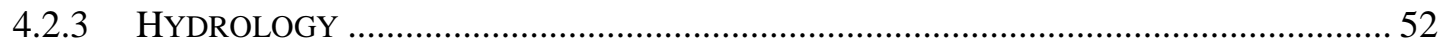

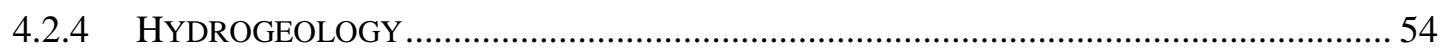

4.3 STEP 2: GENERAL MAR FEASIBILITY ASSESSMENT

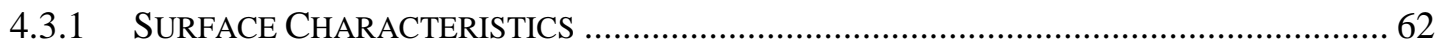

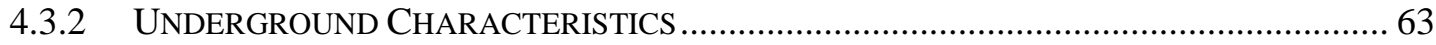

4.4 STEP 3: WATER RESOURCES SYSTEM ANALYSIS

4.4.1 SUBDIVISION OF STUDY AREA INTO MANAGEMENT UNITS ...................................... 64

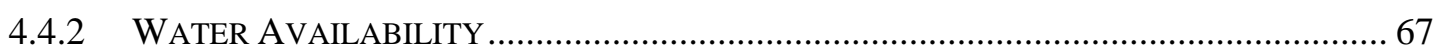

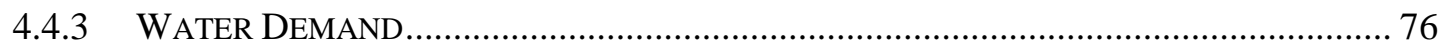

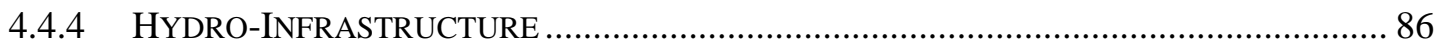

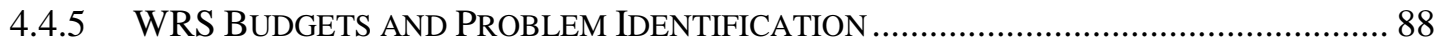


4.5 STEP 4: COMBINATION OF MAR CONCEPT AND IWRM MEASURES

TO INTEGRATIVE STRATEGIES

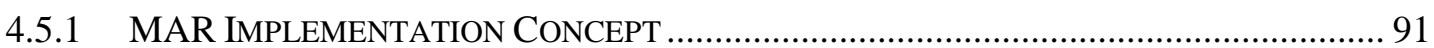

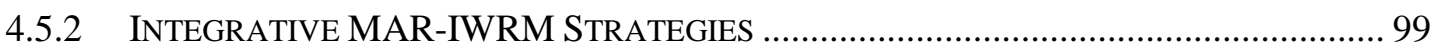

4.6 STEP 5: DEVELOPMENT SCENARIOS 103

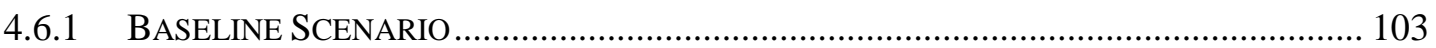

4.6.2 AGRICULTURAL DEVELOPMENT SCENARIO....................................................... 106

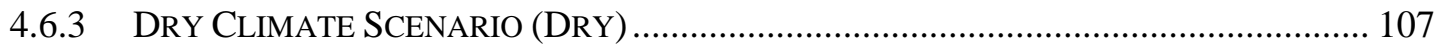

4.7 STEP 6: MAR GROUNDWATER BUdGET ANALYSIS 109

4.7.1 OVERVIEW OF STRATEGY-SCENARIO COMBINATIONS TO BE ANALYZED................ 109

4.7.2 GROUNDWATER BUDGETS FOR SELECTED SCENARIOS AND STRATEGIES ............... 111

4.8 STEP 7: GROUNDWATER SimULATIONS 132

4.8.1 OVERVIEW OF CONDUCTED SIMULATIONS AND MODEL SETUP ............................. 132

4.8.2 SIMULATION RESULTS FOR SELECTED SCENARIOS AND STRATEGIES ..................... 135

4.9 STEP 8: PERFORMANCE AND IMPACT ASSESSMENT 142

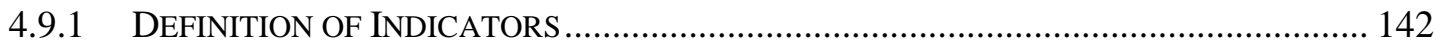

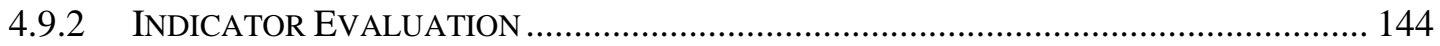

4.9.3 PERFORMANCE MATRICES AND RANKING OF STRATEGIES ................................... 150

4.10 CONCLUSIONS FOR MAR IMPLEMENTATION IN THE CASE STUdiES (STEP 9: RECOMMENDATIONS FOR MAR PILOT PlanTS) 153

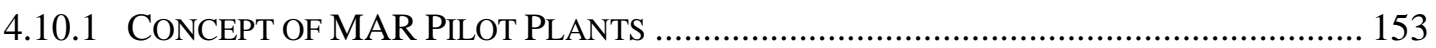

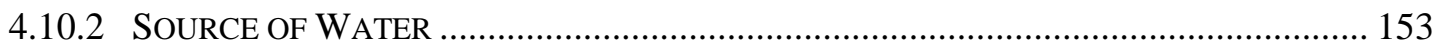

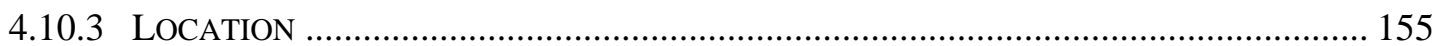

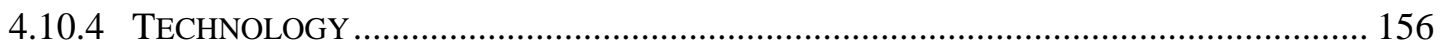

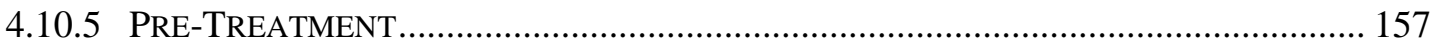

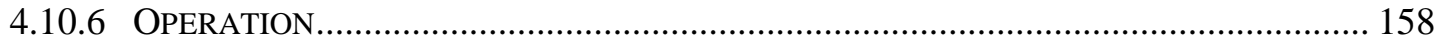

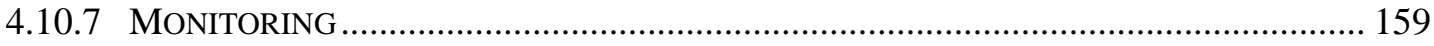

4.10.8 OutLOOK TO STEP 10: TEChNICAL MAR FEASIBILITY STUDY ............................... 159

$\underline{5}$ EVALUATION AND DISCUSSION 161

5.1 REVIEW OF OBJECTIVES AND HYPOTHESIS

5.2 Evaluation ANd Discussion OF Methodology AND MaIn RESUlts 163

5.2.1 STEP 1: DATA ACQUISITION AND ANALYSIS....................................................... 163

5.2.2 STEP 2: GENERAL MAR FEASIBILITY ASSESSMENT ............................................ 164

5.2.3 STEP 3: WATER RESOURCES SYSTEM ANALYSIS .................................................. 165

5.2.4 STEP 4: COMBINATION OF MAR CONCEPT AND IWRM MEASURES

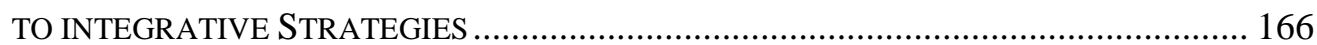


5.2.5 STEP 5: DEVELOPMENT SCENARIOS 168

5.2.6 STEP 6: MAR GROUNDWATER BUDGET ANALYSIS ............................................... 169

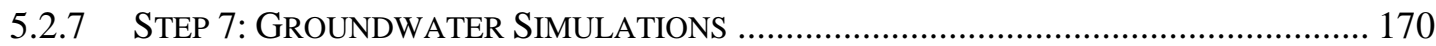

5.2.8 STEP 8: PERFORMANCE AND IMPACT ASSESSMENT ................................................. 171

5.2.9 STEP 9: RECOMMENDATIONS FOR PILOT PLANTS ....................................................... 172

6 CONCLUSION AND RECOMMENDATIONS 175

$\begin{array}{lll}\text { 6.1 SUMMARY } & 176\end{array}$

$\begin{array}{lll}\text { 6.2 CONCLUSION } & 178\end{array}$

6.3 RECOMMENDATIONS

\begin{tabular}{lr} 
REFERENCES & 182 \\
\hline
\end{tabular}

\begin{tabular}{lr} 
APPENDIX & 194 \\
\hline
\end{tabular}

SHORT ACADEMIC CV 


\section{LIST OF FIGURES}

Figure 1-1: BRAMAR Project Research Concept -Work Packages 4

Figure 1-2: Location of the tropical case study area João Pessoa along the coast of

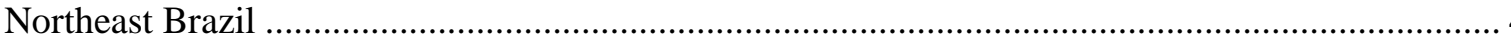

Figure 1-3: SMART-MOVE Project Research Concept -Work Packages......................................... 6

Figure 1-4: Location of the semi-arid case study area Jericho-Auja, Palestine. ................................ 7

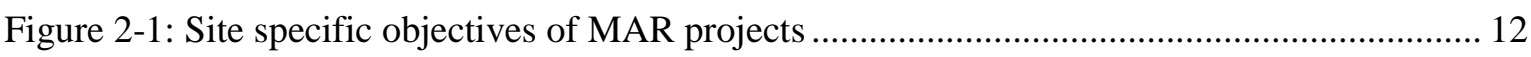

Figure 2-2: Schematic of types of Managed Aquifer Recharge ........................................................ 14

Figure 2-3: Outline of the historical development of MAR in Europe showing the number of MAR sites opened or closed per decade between the 1870s and 2000s ..................................... 16

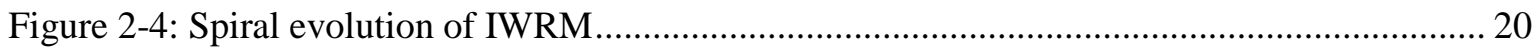

Figure 2-5: Example of pentagram approach to compare alternative IWRM strategies .................. 21

Figure 3-1: Illustrated overview of suggested integrated MAR planning approach. ........................ 24

Figure 3-2: Illustration of MAR Planning Process -Step 1/10 ..................................................... 26

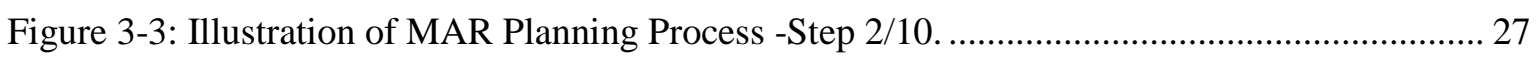

Figure 3-4: Illustration of MAR Planning Process -Step 3/10 ....................................................... 29

Figure 3-5: Illustration of MAR Planning Process -Step 4/10 …..................................................... 31

Figure 3-6: Illustration of MAR Planning Process -Step 5/10 ...................................................... 33

Figure 3-7: Illustration of MAR Planning Process -Step 6/10 ……………………….................. 35

Figure 3-8: Illustration of MAR Planning Process -Step 7/10 ....................................................... 36

Figure 3-9: Illustration of MAR Planning Process -Step 8/10 ……................................................... 37

Figure 3-10: Illustration of MAR Planning Process -Step 9/10 …………………............................. 38

Figure 3-11: Illustration of MAR Planning Process -Step 10/10 .................................................. 39

Figure 3-12: Illustration of the entire suggested MAR planning approach as a whole..................... 41

Figure 4-1: Outline of study area João Pessoa ........................................................................... 45

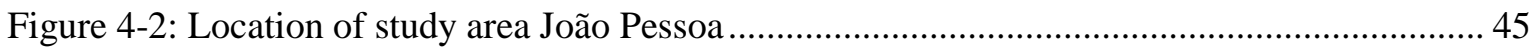

Figure 4-3: Population the the case study area -distribution among municipalities and urban/rural 46

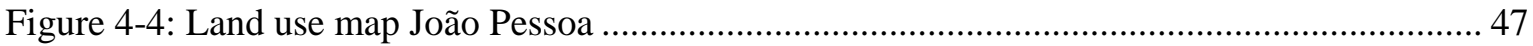

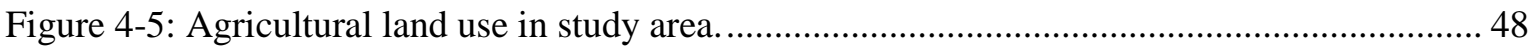

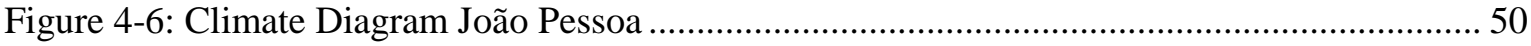

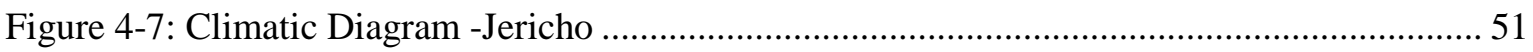

Figure 4-8: Sub-Catchments of Panta Rhei Hydrological Model ..................................................... 52

Figure 4-9: Delineation of the three major watersheds in the study area......................................... 53

Figure 4-10: Aquifer Systems and River Network -State of Paraiba ............................................. 55

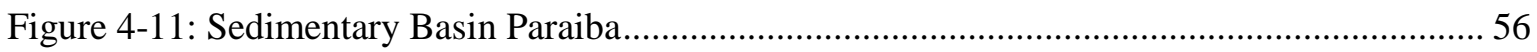

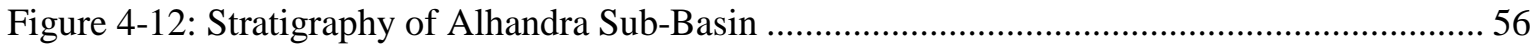

Figure 4-13: Geological map of study area with outcrops of impermeable Gramame formation.... 58 
Figure 4-14: New groundwater monitoring network of the BRAMAR project. 59

Figure 4-15: Geological Formations -Wadi Auja. 61

Figure 4-16: Stratigraphy of case study area Jericho-Auja 61

Figure 4-17: Delineation of Management Units for João Pessoa. 65

Figure 4-18: Delineation of Management Units for Jericho-Auja. 67

Figure 4-19: Total average water availability -João Pessoa. 68

Figure 4-20: Spatial distribution of water availability -João Pessoa. 70

Figure 4-21: Total average water availability -Jericho-Auja 72

Figure 4-22: Spatial distribution of water availability -Jericho-Auja. 73

Figure 4-23: Locations of main spring groups in the study area. 74

Figure 4-24: Historic time series of springs in the study area 75

Figure 4-25: Total average water demand -João Pessoa. 76

Figure 4-26: Spatial distribution of water demand -João Pessoa. 77

Figure 4-27: Distribution of mean annual water demand in study area among demand sectors...... 78 Figure 4-28: Distribution of growth stages over the year to derive mean Kc values for sugarcane 80 Figure 4-29: Overlay of sub-catchments from hydrological and land use map ....

Figure 4-30: Domestic Water Demand per municipality and comparison urban and rural demand $[\mathrm{MCM} / \mathrm{a}]$. 83

Figure 4-31: Total average water demand -Jericho-Auja 85

Figure 4-32: Spatial distribution of water demand -Jericho-Auja. 85

Figure 4-33: Total water budget on average basis -João Pessoa. 89

Figure 4-34: Total water budget on average basis -Jericho-Auja. 90

Figure 4-35: Constraint mapping results 94

Figure 4-36: Suitability Mapping Results 95

Figure 4-37: Schematic preliminary selection of MAR locations based on constraint and suitability mapping. 96

Figure 4-38: Schematic of preliminary MAR site selection for simulations. 98

Figure 4-39: Assumed domestic demand development -João Pessoa ................................................. 104

Figure 4-40: Assumed domestic demand development -Jericho-Auja........................................... 105

Figure 4-41: Assumed agricultural demand development -João Pessoa......................................... 106

Figure 4-42: Assumed agricultural demand development -Jericho-Auja....................................... 107

Figure 4-43: Assumed water availability development -João Pessoa ............................................... 107

Figure 4-44: Assumed water availability development -Jericho-Auja........................................... 108

Figure 4-45: Overview of strategy-scenario combinations -João Pessoa......................................... 109

Figure 4-46: Schematic of MAR Budget parameters.............................................................. 110

Figure 4-47: Overview of strategy-scenario combinations -Jericho-Auja. ..................................... 111

Figure 4-48: Groundwater budget Baseline Scenario João Pessoa -DN......................................... 112 
Figure 4-49: Groundwater budget Baseline Scenario João Pessoa -Strategy A. 113

Figure 4-50: Groundwater budget Baseline Scenario João Pessoa -Strategy B. 115

Figure 4-51: Groundwater budget Baseline Scenario João Pessoa -Strategy C. 115

Figure 4-52: Direct comparison of strategies under Baseline Scenario -João Pessoa. 116

Figure 4-53: Groundwater budget ADS João Pessoa. 118

Figure 4-54: Direct comparison of strategies under ADS -João Pessoa. 119

Figure 4-55: Groundwater budget Dry Scenario João Pessoa. 120

Figure 4-56: Direct comparison of strategies under Dry Scenario -João Pessoa. 120

Figure 4-57: Groundwater budget Baseline Scenario Jericho-Auja -DN. 121

Figure 4-58: Groundwater budget Baseline Scenario Jericho-Auja -Strategy A. 122

Figure 4-59: Groundwater budget Baseline Scenario Jericho-Auja -Strategy B. 123

Figure 4-60: Groundwater budget Baseline Scenario Jericho-Auja -Strategy C............................ 124

Figure 4-61: Groundwater budget Baseline Scenario Jericho-Auja -Strategy D. .......................... 125

Figure 4-62; Groundwater budget Baseline Scenario Jericho-Auja -Strategy E............................. 125

Figure 4-63: Direct comparison of strategies under Baseline Scenario -Jericho-Auja. .................. 126

Figure 4-64: Groundwater budgets ADS Jericho-Auja........................................................... 127

Figure 4-65: Groundwater budget ADS Jericho-Auja -Strategy F(i)............................................ 128

Figure 4-66: Direct comparison of strategies under ADS -Jericho-Auja......................................... 129

Figure 4-67: Groundwater budgets Dry Scenario -Jericho-Auja. ................................................... 130

Figure 4-68: Groundwater budget Dry Scenario Jericho-Auja -Strategy F(ii)............................. 131

Figure 4-69: Direct comparison of strategies under Dry Scenario -Jericho-Auja........................... 132

Figure 4-70: Model environment with boundary conditions and virtual observation wells. ......... 133

Figure 4-71: Direct comparison of strategies under Baseline Scenario, simulated -Jericho-Auja. 135 Figure 4-72: Direct comparison of strategies under Baseline Scenario, simulated

-Jericho \& Auja separated. 138

Figure 4-73: Direct comparison of strategies under ADS, simulated -Jericho-Auja.

Figure 4-74: Direct comparison of strategies under ADS, simulated -Jericho \& Auja separated.. 140 Figure 4-75: Direct comparison of strategies under Dry Scenario, simulated -Jericho-Auja. ....... 141 Figure 4-76: Direct comparison of strategies under ADS, simulated -Jericho \& Auja separated.. 142 Figure 4-77: Indicator assessment Baseline Scenario -João Pessoa................................................. 145

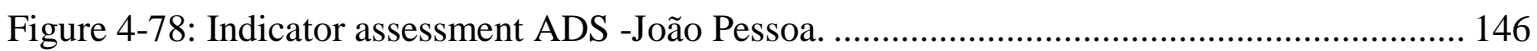

Figure 4-79: Indicator assessment Dry Scenario -João Pessoa. ........................................................ 147

Figure 4-80: Indicator assessment Baseline Scenario -Jericho-Auja............................................ 147

Figure 4-81: Indicator assessment ADS -Jericho-Auja................................................................ 149

Figure 4-82: Indicator assessment Dry Scenario -Jericho-Auja................................................... 149

Figure 4-83: Overall performance of strategies -João Pessoa........................................................... 151

Figure 4-84: Overall performance of strategies -João Pessoa......................................................... 152 


\section{List of Tables}

Table 4-1: Municipalities in Case Study Area João Pessoa -urban and rural population 46

Table 4-2: Overview lithologic formations João Pessoa....................................................................... 57

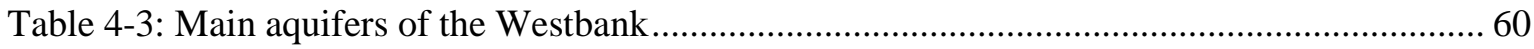

Table 4-4: $\mathrm{K}_{\mathrm{c}}$ values of crops present in João Pessoa study area depending on growth stages ....... 79

Table 4-5: Calculated average $\mathrm{K}_{\mathrm{c}}$ values for each crop and month according to growth stages...... 80

Table 4-6: Population and Domestic Water Demand in the study area 2010 (including losses) ..... 83

Table 4-7: WRS Analysis - Hydro-Infrastructure João Pessoa ............................................................ 86

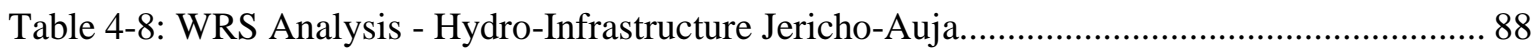

Table 4-9: Selected criteria and thresholds for Constraint Mapping ............................................... 93

Table 4-10: BRAMAR-IDSS Criteria for Suitability Mapping …….............................................. 94

Table 4-11: Overview of developed strategies for case study João Pessoa ....................................... 99

Table 4-12: Overview of developed strategies for case study Jericho-Auja .................................. 101

Table 4-13: Water resources system parameters and corresponding scenarios -João Pessoa ......... 103

Table 4-14: Water resources system parameters and corresponding scenarios -Jericho-Auja....... 105

Table 4-15: Summary of groundwater budgets for Baseline Scenario -João Pessoa ....................... 116

Table 4-16: Summary of groundwater budgets for ADS -João Pessoa............................................ 118

Table 4-17: Summary of groundwater budgets for Dry Scenario -João Pessoa.............................. 120

Table 4-18: Summary of groundwater budgets for ADS -Jericho-Auja ...................................... 128

Table 4-19: Summary of groundwater budgets for Dry Scenario -Jericho-Auja ............................. 131

Table 4-20: Direct comparison of strategies under Baseline Scenario, simulated -Jericho-Auja .. 136

Table 4-21: Direct comparison of strategies under ADS, simulated -Jericho-Auja ......................... 140

Table 4-22: Direct comparison of strategies under ADS, simulated -Jericho-Auja ........................ 142

Table 4-23: Performance matrix -João Pessoa ................................................................................. 150

Table 4-24: Performance matrix -Jericho-Auja.......................................................................... 152

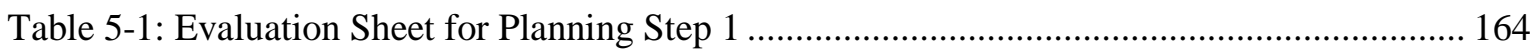

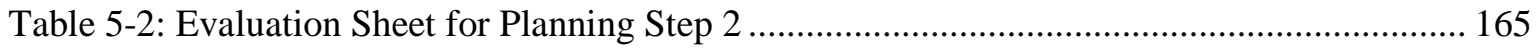

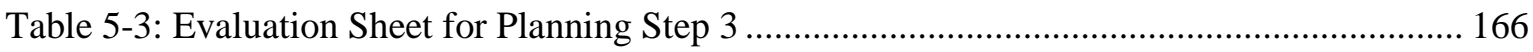

Table 5-4: Evaluation Sheet for Planning Step 4 ....................................................................... 167

Table 5-5: Evaluation Sheet for Planning Step 5 ......................................................................... 169

Table 5-6: Evaluation Sheet for Planning Step 6 ……................................................................. 170

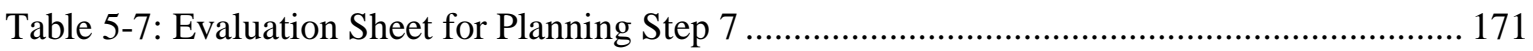

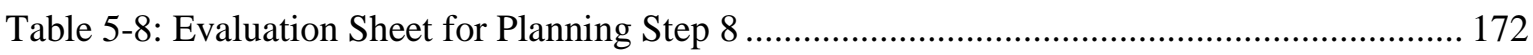

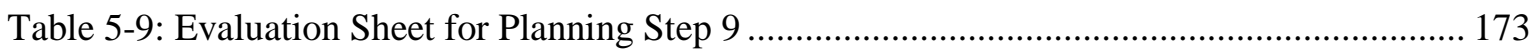




\section{LIST OF ABBREVIATIONS}

ADS

BL

BRAMAR

DN

DW

DWD

ET

GW

IDSS

IWD

IWRM

Ind.

MAR

MARSOL

MCM

MU

$\mathrm{P}$

PHG

PWA

Q

RWC

SAT

SMART-MOVE

SR

TE

TU-BS

UFPB

UMAR

Vol.

WRS
Agricultural Development Scenario

Baseline (Scenario)

Project: Brazil Managed Aquifer Recharge

Do Nothing (Approach)

Deep Well

Domestic Water Demand

Evapotranspiration

Groundwater

Information and Decision Support System

Irrigation Water Demand

Integrated Water Resources Management

Indicator

Managed Aquifer Recharge

Project: Demonstrating Managed Aquifer Recharge as a Solution to Water Scarcity and Drought

Mio. Cubic Meters

Management Unit

Precipitation

Palestinian Hydrology Group

Palestinian Water Authority

Discharge

Rusteberg Water Consulting UG

Soil Aquifer Treatment

Project: Sustainable Management of Available Water Resources with Innovative Technologies - Management Of Highly Variable REsources in semi-arid Regions

Surface Runoff

Treated Effluent

Technical University Braunschweig

Universidade Federal da Paraiba

Unmanaged Aquifer Recharge

Volume

Water Resources System 
1 INTRODUCTION 


\subsection{Motivation}

The management of water resources requires a holistic knowledge of the system. It is not sufficient to focus on isolated components in such a complex structure. Every action that changes one component in a water resources and supply system will have an impact on other parameters. That is why Integrated Water Resources Management (IWRM) tries to achieve a conjunctive management of these systems by addressing all nodes of water supply and water demand. Managed Aquifer Recharge (MAR), the artificial increase of groundwater recharge with surface water resources, represents an intervention to these systems that will consequently impact various parameters. Within this study, MAR and IWRM will not be seen as separated but rather connected tools with the shared goal of improving the management of water resources. By treating MAR as an integral part of IWRM, its potential impact on the entire demand and supply network is considered. This study will give a recommendation for such an integrative MAR planning approach in accordance with IWRM practices. By applying this approach for two different case study sites located in the tropical coastline of Northeast Brazil and the semi-arid Lower Jordan Valley in Palestine, its applicability and potential for transferability to other regions is tested and evaluated.

The aim of this study is to contribute to the state of the art of IWRM and MAR research by suggesting a framework for an implemented planning approach that might serve as a guideline for researchers, water resources managers and other stakeholders, especially in underdeveloped areas where the idea and concept of water resources management is often urgently required, yet not fully implemented due to structural and monetary restrictions. By setting the goal high by trying to recommend actual measures that might be implemented in the case studies in the suggested or a similar form, the study aims at achieving at the very least a more profound and advanced understanding of the individual systems and reveal present knowledge gaps that might be filled by follow-up studies. If the study leads to at least the recognition of what might potentially be possible in the two areas, for example more investments in monitoring to produce more accurate results then it can be considered a success.

The studies presented in this thesis were conducted in the context of two international research and development projects: The BRAMAR and SMART-MOVE project. The author's contributions to these projects, which was enabled by the University of Göttingen and RWC -Rusteberg Water Consulting UG, directly contributed to the two projects' scientific outcomes. Both projects will be briefly introduced in the following to create an understanding of the framework of this study and give recognition to the respective research partners that enabled this work. 


\subsection{Project based Framework}

\subsubsection{The BRAMAR Project}

BRAMAR (Strategies and Technologies for Water Scarcity Mitigation in Northeast of BRAzil: Water Reuse, Managed Aquifer Recharge and Integrated Water Resources Management) was a research and development project in German-Brazilian cooperation with a regular runtime from 2014-2017. Its declared intention was to fill research gaps with regard to water reuse and MAR as part of IWRM response strategies to combat water scarcity and facilitate a sustainable development of Northeast Brazil. The project was funded by BMBF, the German Federal Ministry of Education and Research, and co-financed by Finep, the Brazilian Funding Authority for Studies and Pojects. The research was conducted in cooperation of 25 institutions including three German and three Brazilian universities as well as several industrial and consulting partners and local municipalities, all coordinated by RWTH Aachen.

The main scientific and technical objectives of the project were (ISA RWTH, 2015):

- Mitigation of water scarcity and water related conflicts in Northeast Brazil through sustainable strategies based on the integrated management of all available water resources

- Contribution to the recovery of groundwater levels of coastal and inland aquifer systems of Northeast Brazil by Managed Aquifer Recharge and implementation of measures for groundwater protection and quality

- Foster water pollution control by improved wastewater infrastructure and water reuse

- Promotion of water reuse in all areas, e.g. municipalities, agriculture and industries

- Demonstration of suitable German water reclamation technologies for different reuse applications

To achieve these goals, the project was structured in ten Work Packages (WPs), each committed to its own specific objectives but all connected and interacting as illustrated in Figure 1-1. The MAR specific studies presented in this thesis were located in WP3 in strong cooperation with WP2 on water budgets and hydro(geo)logic modelling, WP7 on decision support tools and WP8 on IWRM strategies. WP3 itself was subdivided in three case studies. For each case study, individual MAR studies have been conducted by different universities. The University of Campina Grande (UFCG) studied the possibilities of artificially recharging a narrow alluvial aquifer in Sumé, a city in the semiarid inland of Northeast Brazil. The University of Pernambuco (UFPE) analyzed potential MAR measures for the urban center of Recife, where overexploitation lead to depleting groundwater quality and salinization of the aquifers. The University of Göttingen cooperated with the University of Paraiba in studying MAR for the area around João Pessoa, a coastal city and capital of the federal state Paraiba. Figure 1-2 gives an overview of location of the study area. 


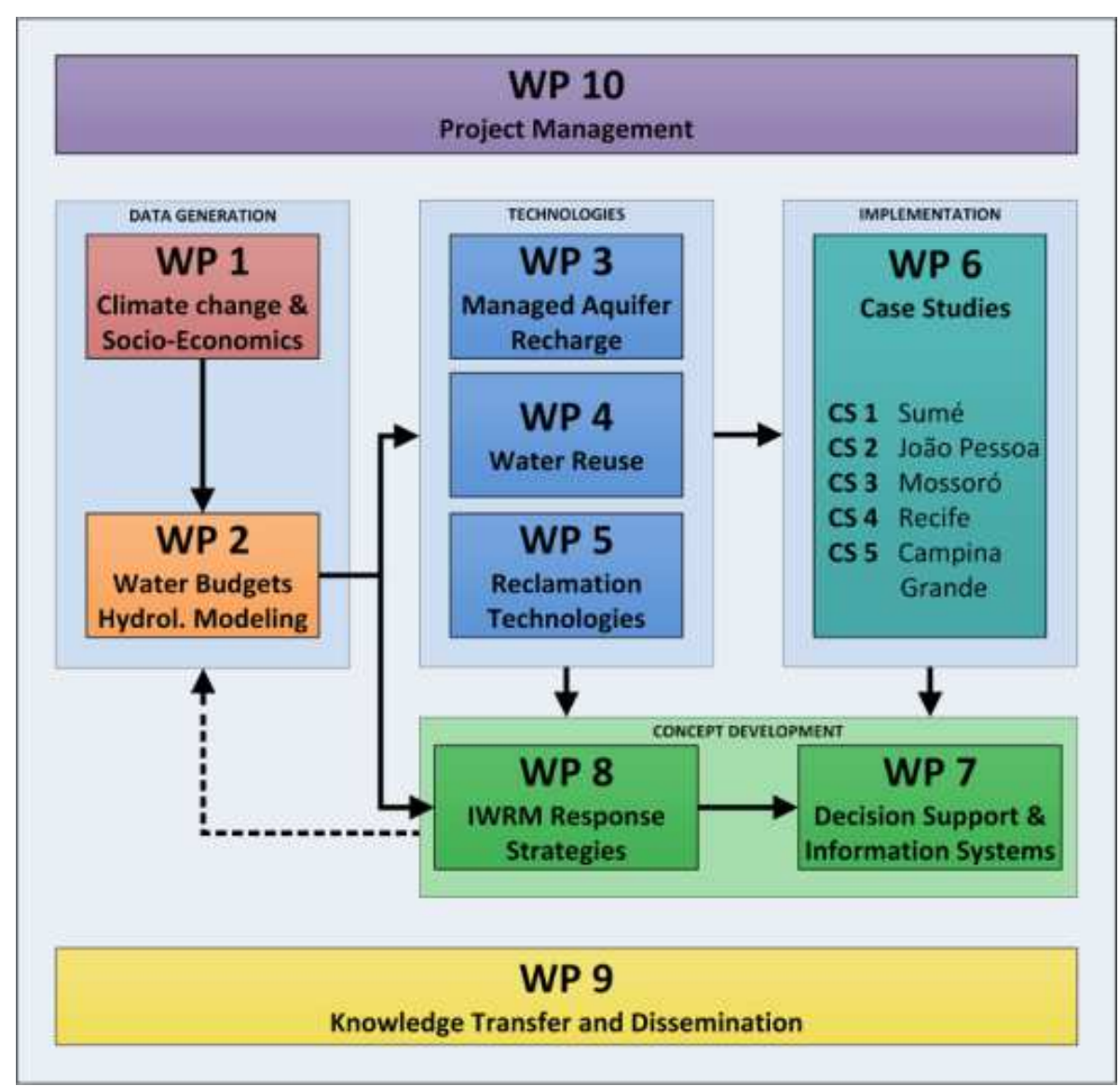

Figure 1-1: BRAMAR Project Research Concept -Work Packages (ISA RWTH, 2015).

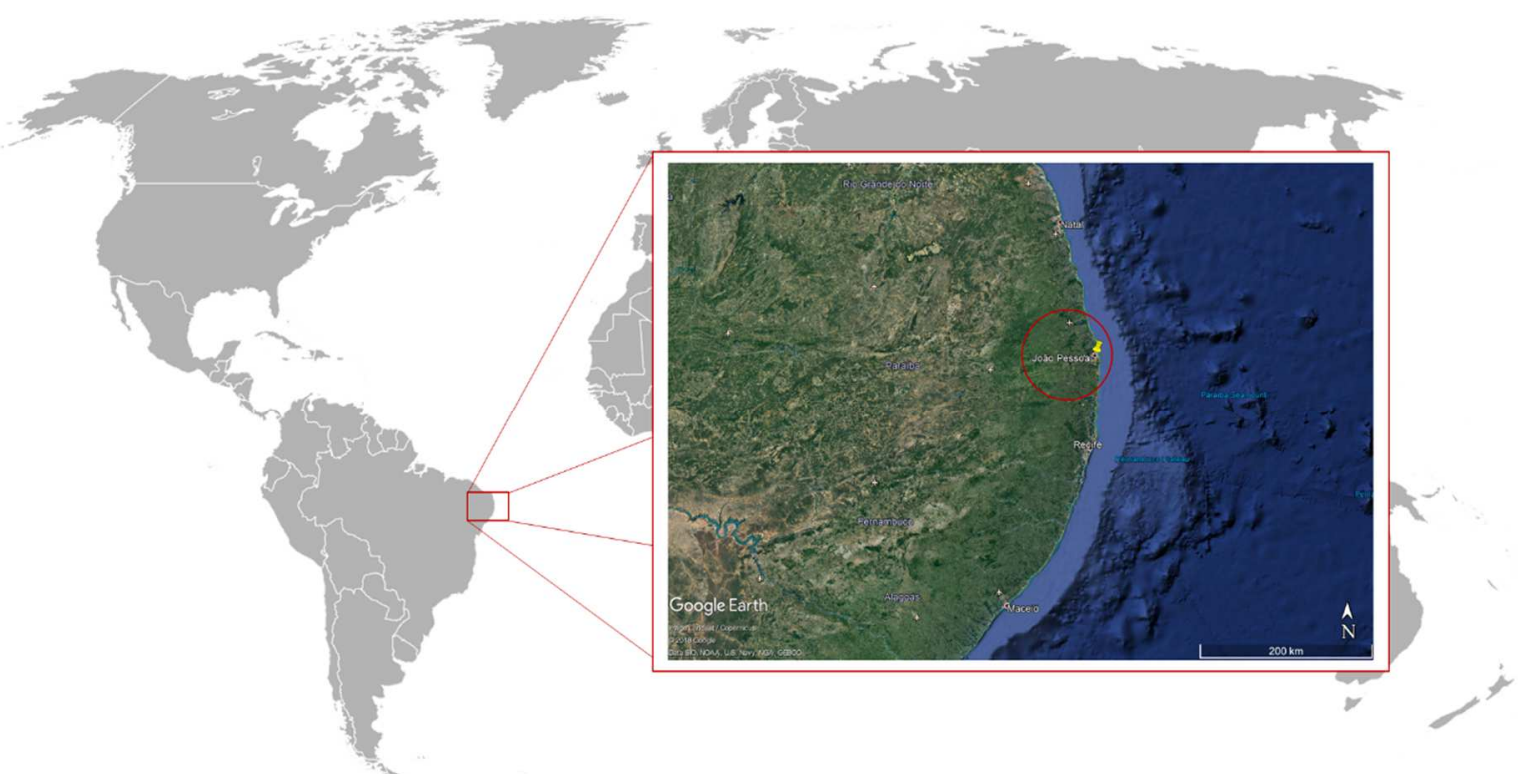

Figure 1-2: Location of the tropical case study area João Pessoa along the coast of Northeast Brazil (Google Inc., 2018).

Over the course of more than three years a lot could be achieved in the BRAMAR project by good cooperation between all partners. Speaking for the case study of João Pessoa with its water resources related research objectives, a good basis for future research has been established. At the beginning 
of the project, data on the different types of water resources at João Pessoa was very scarce. It was due to combined efforts of Brazilian and German partners that the area is now among the best monitored within the Northeast of Brazil. The data collected by the new monitoring networks and the outcomes of this and many other studies that were conducted within the project can support future studies that will have to continue and finish lots of aspects that are still left open. As for MAR planning in João Pessoa in particular, but also in Northeast Brazil in general, this work might support the actual design and implementation of MAR test facilities that are urgently required in order to take MAR planning in the region to the next consequential step.

The main partners in the MAR related studies at the case study João Pessoa were, besides the University of Göttingen, the local Federal University of Paraiba (UFPB, port.: Universidade Federal da Paraiba), the Technical University of Braunschweig, Germany (TU-BS) and Rusteberg Water Consulting UG (RWC) from Germany.

\subsubsection{The SMART-MOVE Project}

SMART-MOVE (Sustainable Management of Available Water Resources with Innovative Technologies -Management $\boldsymbol{O}$ f Highly Variable Water REsources in semi-arid Regions) was a collaborative research and development project located in the Middle East. It is a follow-up of the preceding SMART and SMART II projects, all funded by the BMBF. A total of 26 institutions from Germany, Israel, Jordan and Palestine collaborated in the project. Among these partners were several universities, research center, local authorities and other consulting experts and institutions. The project coordination was conducted by the University of Göttingen. The overall purpose of the project was to test and improve the water resources systems of the Lower Jordan Valley against highly variable hydrological conditions such as extreme droughts or floods by means of innovative technologies.

To achieve this main objective, a variety of approaches has been studied by the SMART-MOVE consortium, such as (Georg-August-Universtiy Göttingen, 2018):

- the development of a generalized IWRM implementation concept for water resources management on the basis of representative catchment area clusters to consolidate the water planning processes of the local stake holders;

- the installation of telemetric monitoring systems for groundwater protection and high resolution observations of extreme runoff events;

- the involvement of industry partners to create an environment of mutual exchange between the companies on the one hand and researchers and local stakeholders with their specific needs on the other hand. 
- the optimization of the cleaning performance and cost efficiency of decentralized waste water treatment technologies;

- the preparation of a roll-out investment project for the implementation of decentralized waste water treatment plants;

- the assessment and demonstration of decentralized waste water treatment and re-use at Fuheis demonstration site both, by applying different technologies and by participative involvement of local stakeholders;

- the controlled groundwater enrichment (managed aquifer recharge) and evaluation of technological approaches with the help of accompanying hydrogeological investigations;

- a capacity development and knowledge dissemination program for the public and industry partner organizations.

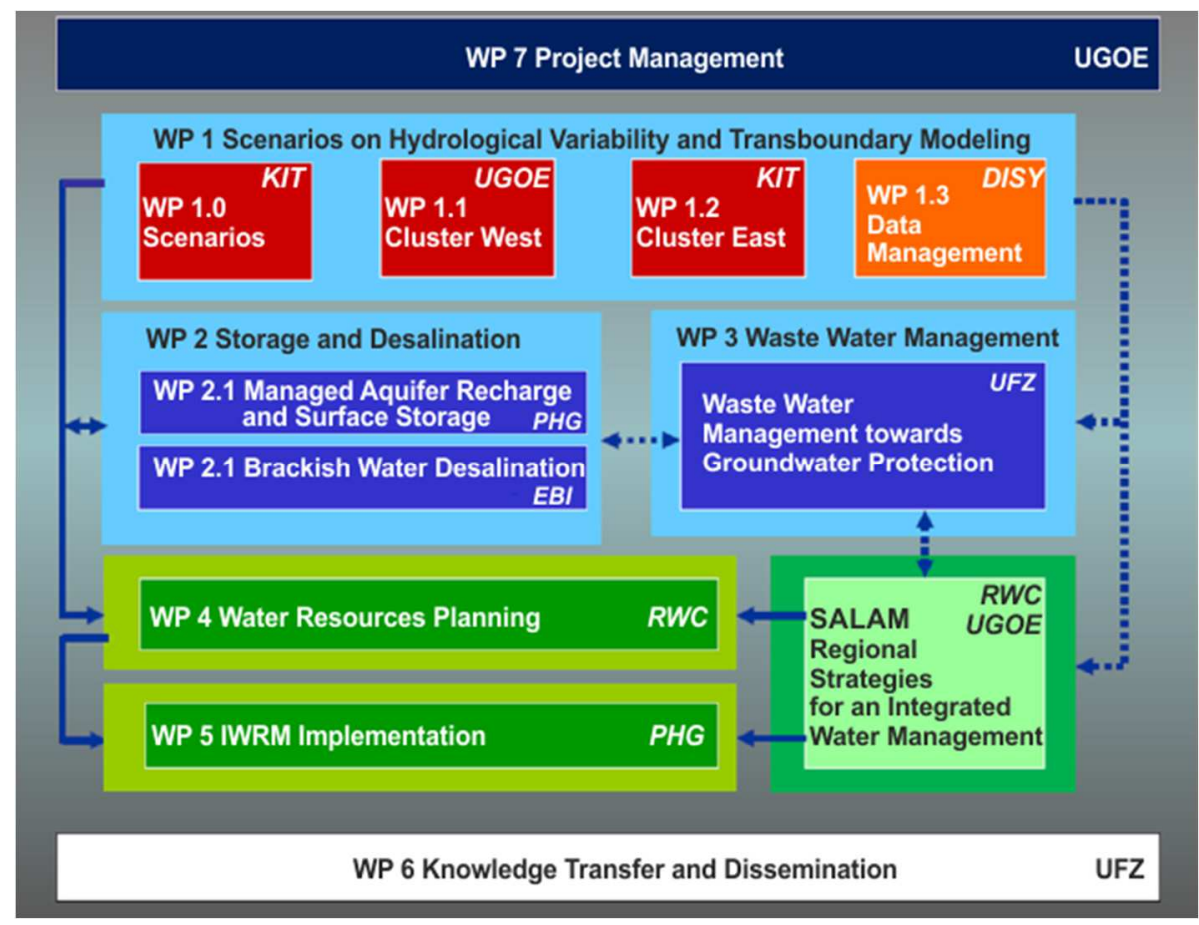

Figure 1-3: SMART-MOVE Project Research Concept -Work Packages (Georg-August-Universtiy Göttingen, 2018).

All these measures were coordinated and structured in Work Packages (WPs), as in the BRAMAR project (Figure 1-3). The work on MAR and IWRM were mainly located in WP2.1 and WP4 on MAR and IWRM, respectively and were subject to research in the predecessor projects (e.g. Rusteberg et al., 2014, Rusteberg et al., 2012, Lutz, 2011). The project was further subdivided into regional clusters. With Cluster West being the focus area of this study. It describes part of the Palestine the Lower Jordan Valley. Hence, the studies and results presented here were mainly conducted in cooperation with Palestinian partners and in accordance with these stakeholders' own 
development goals and constraints for the region. This study might help to contribute to the area's positive future development. In contrast to the tropical case study, no own field investigations or active data acquisition was conducted by the author in this project. All data used in this study was supplied by the project partners. Figure 1-4 illustrates location and rough outline of the study area along the Jordan River.

Besides the University of Göttingen, the main partners for MAR research at the case study JerichoAuja within the context of the SMART-MOVE project were the local partners HEC (Hydro Engineering Consultancy, Ramallah), the Palestinian Hydrology Group (PHG), the Palestinian Water Authority (PWA) and the German partner Rusteberg Water Consulting UG (RWC) who was also involved in the João Pessoa case study.

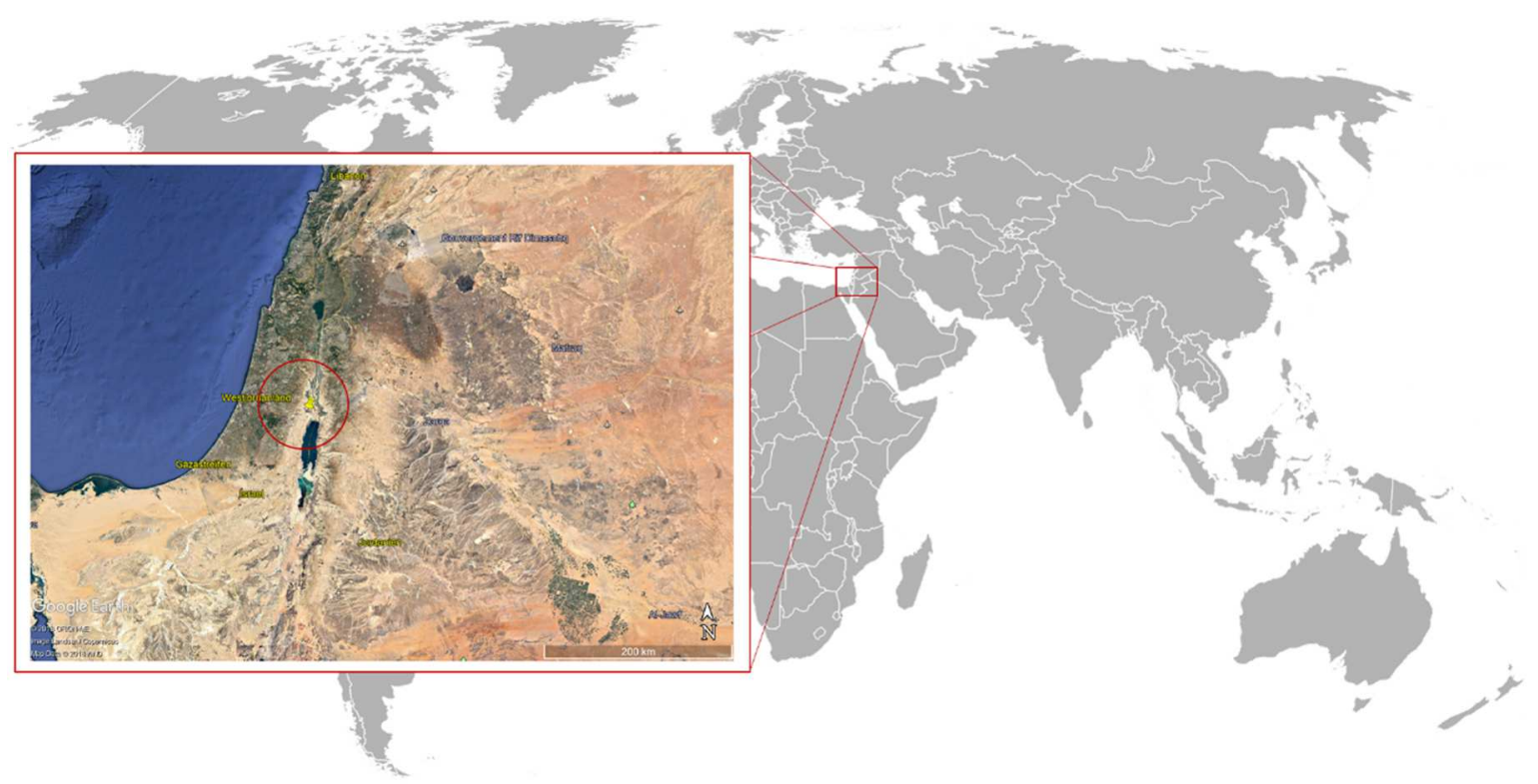

Figure 1-4: Location of the semi-arid case study area Jericho-Auja, Palestine (Google Inc., 2018).

\subsection{Research Objectives}

From the initial motivation and the opportunity to conduct research within the framework of the two projects presented above, two essential objectives have been formulated for this thesis:

1. Development of an overall, transferable and integrative MAR planning approach and application of the approach for both projects and their respective case studies,

2. Formulation of recommendations for the two case studies that aim to improve of the water resources situation under consideration of MAR and IWRM strategies. 
The design of an overall MAR planning process, which is basically a suggestion for a framework for MAR studies in general will be the main product of this thesis. The goal and focus of this study, besides the applied scientific results under main objective \#2, is to design and recommend a process or framework of MAR planning for future projects in their early stages. The designed process should serve as a guideline for areas and stakeholders that have limited to no experience with the MAR technology. Therefore, it is necessary that the process is simple, applicable, transferable, adjustable and reproducible.

The second objective is of a rather applied and practical character and will target two goals. As introduced, two case studies are analyzed within the context of the respective research and development projects. These case studies are inherently different from each other, but the overall objective remains the same: To identify potential strategies of MAR implementation in the context of IWRM. One declared goal is to be able to give recommendations for further studies in the specific areas that aim at the implementation of MAR test facilities and might consequently lead to the actual application of MAR in the respective areas as a measure to mitigate water scarcity. The second goal of this objective is to test and validate the MAR planning approach developed beforehand and show that it can serve as a guideline for similar studies.

\subsection{Methodological Approach}

This thesis is structured in six chapters. The initial motivation, the overall framework of the conducted studies, their objectives and a hypothesis are given in this chapter. The theoretical background presented by means of a literature review is given in Chapter 2 and should inform about the scientific state of the art and application of both, Managed Aquifer Recharge and Integrated Water Resources Management worldwide as well as the potential of integrating the one with the other. This will form the basis of the new MAR planning approach that is the focus of this study. The approach itself is the actual methodology used for both case studies and is presented step by step in Chapter 3 . The application of the approach is thoroughly documented in Chapter 4 for both case studies in parallel. The chapter is designed in a way that the approach itself remains the focus, with a parallel presentation of the individual case study results for each of the planning steps. In Chapter 5 all results and the methodology itself is critically evaluated and both the research objectives and hypothesis are reviewed and the results discussed in detail. A final conclusion and a summary of recommendation will finalize this thesis in Chapter 6. The appendix includes results that were not directly addressed in the other chapters but are of importance and should serve the further illustration and transparency of the conducted research. 


\subsection{Research Hypothesis}

The following thesis will evolve itself around a twofold hypothesis that has been formulated according to the objectives and initial motivation for the research:

The suggested integrative MAR planning approach is transferable and generalized enough to be (a) successfully applied to two inherently different research areas and may serve as a guideline for similar studies, but also specific, effective and goal-oriented enough to successfully develop, test, compare and consequently (b) recommend combined MAR and

IWRM strategies and additional measures for both case studies, that aim at the improvement of the local water resources system and the sustainable development of the respective region.

The first part (a) describes the general assumption, that the new developed MAR planning approach can indeed be applied to a variety of different case studies. Though it may not be quantifiable per se, it is the fundamental hypothesis that must be defined in order to accept any results that are produced by following the suggested methodology. It will be tested by the mere consequent application of the approach to the two introduced case studies in Northeast Brazil and Palestine and a follow-up evaluation of its applicability. The second part (b) formulates the assumption that the process can not only be applied to study areas of vastly different character, but actually produce results in the form of suggestions and recommendations for potential implementations of MAR in combination with IWRM measures and helps identifying potential for improvement of the water resources systems and its management in the current state. 
2 Literature

REVIEW 


\subsection{Managed Aquifer Recharge}

\subsubsection{Introduction}

Managed Aquifer Recharge describes a variety of measures that aim at artificially increasing the recharge of water to an aquifer. MAR has a broad field of application (Page et al., 2018). One purpose of MAR, and the most relevant one for this study, is to take water surpluses during the rainy season and store them underground. The additional recharge to the aquifer will then, within certain limits, be available during the dry period by means of groundwater pumping. This way MAR, if implemented in a sufficient manner, can help mitigate the effects of an uneven temporal water distribution. By increasing the groundwater recharge during the months of high water availability, there is more water in the aquifer during the rest of the year. Meaning that the negative effect of exploitation on the groundwater level might be reduced. Groundwater storage usually offers storage capacities that are much higher than those of surface storage facilities (Pulido-Velazquez, Marques, Harou, \& Lund, 2016). The potential benefits of a MAR implementation are manifold. It can support local economy and bring environmental benefits (Sapiano et al., 2017). Not only on the local level, but potentially for entire regions (Bindu \& Mohamed, 2016). When implementing treated waste water or storm water in a MAR project, it can help gaining public acceptance of the use of such water resources (Mortimer, 2014). Furthermore, MAR can improve the groundwater quality by recharging it with clean water. By direct injection of water to the aquifer at coastal zones, it may serve as a measure against sea water intrusion in heavily exploited coastal aquifers, creating a fresh water plume that prevents further salinization (Arduino et al., 2008). Treated waste water might be used in a Soil Aquifer Treatment (SAT) system, utilizing the vadose zone as a natural filter to further purify the recharged effluent (Wolf et al., 2007). Either way, the main purpose of groundwater management is to extend the amount of water resources and receive higher water quality in times of surplus and distribution in times of shortage (ASCE, 2001). It can provide a cheap solution for some areas since no additional water resources must be activated, but rather the MAR implementation utilizes the already existing sources. This requires a good management of local water resources and the involvement of the local communities (Jadeja et al., 2018).

There has been some overlapping of this study and its project framework with another MAR focused project: the MARSOL project (TU Darmstadt, 2018), an international project with 21 partners from six EU countries that was concluded in late 2016. The project aimed at promoting the advantages of MAR and improve the state of the art, while demonstrating the technology at eight field sites. It also aimed at providing guidelines for water quality requirements at MAR sites (Kübeck \& Nottebohm, 2016), contaminants modelling at MAR sites (Kübeck et al., 2017) and frameworks for legislation (Capone et al., 2015) and legislation (Sapiano et al., 2016). The outcomes of the project will be set in perspective with the results of this thesis in the final conclusion. 


\subsubsection{State of the Art}

As indicated above, MAR in most arid and semi-arid areas where groundwater is either already overexploited or saline, recharge enhancement has potential to store excess runoff, including in fractured rock aquifer (Dillon, 2005). However, numerous techniques and methods exist to implement a MAR system on a regional level. The implementation of MAR to a region is highly site specific and requires a full understanding of the local conditions. It requires careful planning to integrate it into the water resources system and the overall water resources management objectives (Rusteberg, 2008). Knowledge of the quality and quantity of the water source, hydrogeology of the study area, operation and implementation costs and the availability and comparative feasibility of alternatives are of major importance (Bouwer, 1996).

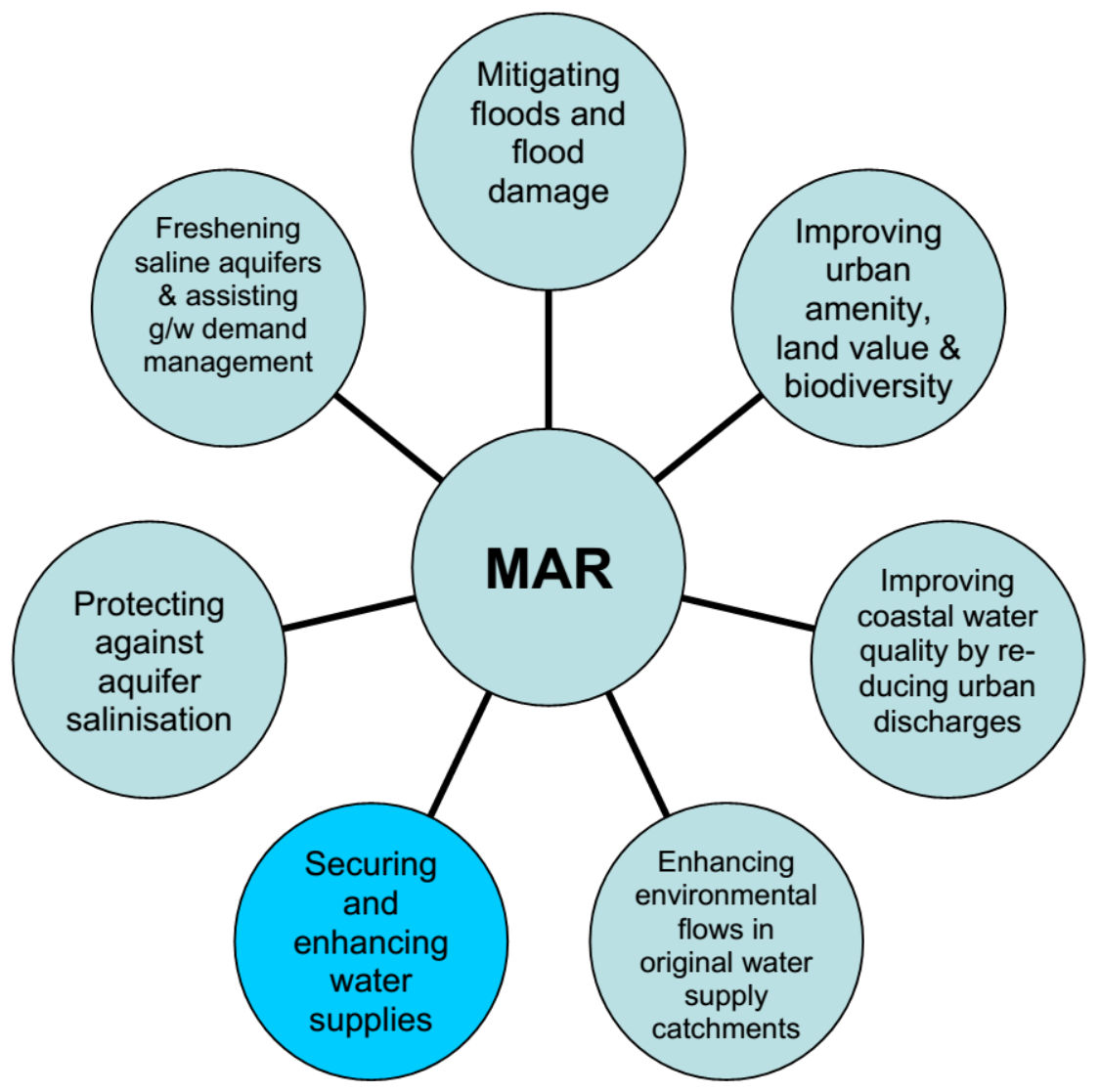

Figure 2-1: Site specific objectives of MAR projects (Dillon et al., 2009).

As Dillon et al. (2009) describe, MAR has many objectives in addition, to water supply that vary from site to site (Figure 2-1). Besides the obvious increase in water security and enhanced water supply, numerous economic, social and environmental objectives may be met with a MAR implementation. The issue of protecting against aquifer salinization has already been addressed. Furthermore, MAR may serve as a method to enhance environmental flow in original water supply catchments or to mitigate floods and their damage. But also the technology of choice is depending 
on site specific parameters. Figure 2-2 gives an overview of the most commonly applied MAR techniques compiled by Dillon (2005). As can be observed the various techniques for MAR can be seen as a response to the local conditions. The construction of underground dams for example requires specific underground conditions that allow blocking the natural groundwater flow by constructing an underground dam at a local bottleneck of hydraulic conductive mediums. In contrast, infiltration ponds require a quite large surface area available for utilization in contrast to injection wells (illustrated here by ASR and ASTR -Aquifer Storage (Transport) and Recovery techniques). But the injection wells on the other hand have a high demand on the quality of the water to be recharged, since they carry a higher risk of contamination for the groundwater resources.

MAR does not describe one specific method with one specific goal. It rather describes a variety of methods, technologies, goals, objectives and measures that are all underlying the conditions and specific surface and underground characteristics of the respective study area (Page et al., 2018). Soil Aquifer Treatment (SAT) is a MAR technique that uses waste water that has be pre-treated to a certain degree in surface approach. It makes use of the natural attenuation capacity of the local soil or aquifer in the vadose zone (Bekele et al., 2018). Kazner et al. (2012) compiled the results of MAR applications that utilized reclaimed water in an SAT approach.

Modelling of groundwater flow and transport processes plays a key role in the planning of an MAR implementation (Moeck et al., 2018). It is the idea of any model to represent the real world conditions as well as possible. This can help the water manager to evaluate the impact of potential actions and measures in a non-invasive manner. The implementation of a MAR facility might even have a negative impact on an ecosystem (Scherberg et al., 2018). Therefore, a well calibrated groundwater model that allows to evaluate potential impacts before actual implementation in the field can vastly improve the planning of MAR in a region and has become, as of today, a necessity. Also optimization schemes that aim at the improvement of a MAR operation, can be much more efficient under the consideration of groundwater models (Fatkhutdinov \& Stefan, 2018).

Despite its broad variety, some universal critical elements for a successful MAR implementation can be summarized (Dillon, et al., 2009):

- a sufficient demand for recovered water;

- an adequate source of water for recharge;

- $\quad$ a suitable aquifer in which to store and recover the water;

- sufficient land to harvest and treat water and

- the capability to effectively manage a project. 

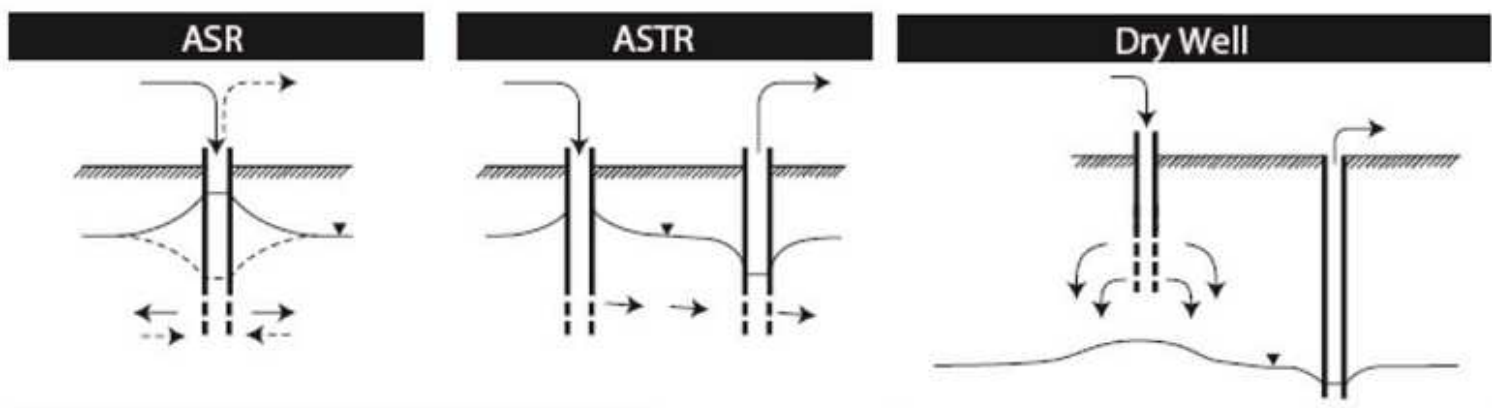

Percolation Tank

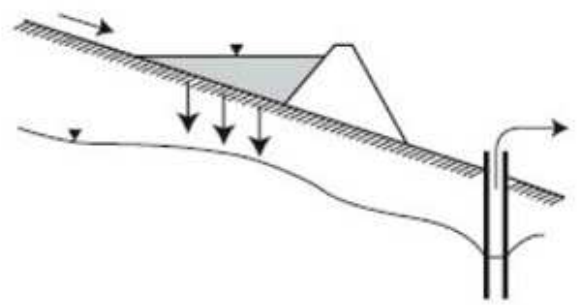

\section{Bank Filtration}

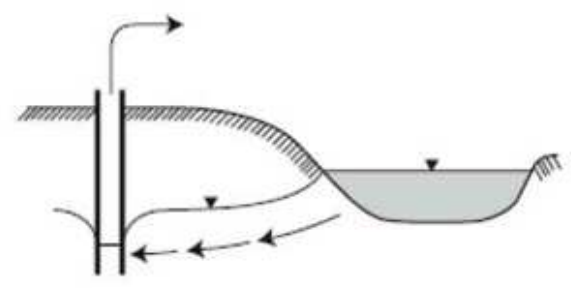

Dune Filtration

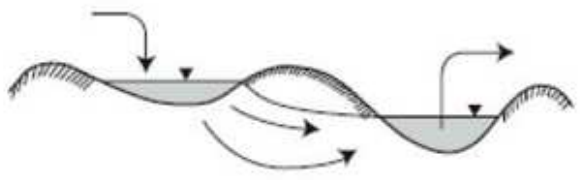

SoilAquifer Treatment

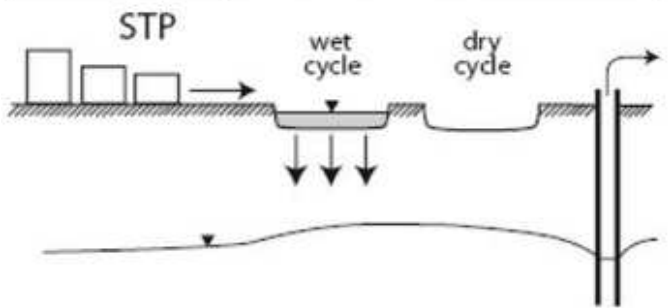

\section{Rainwater Harvesting}

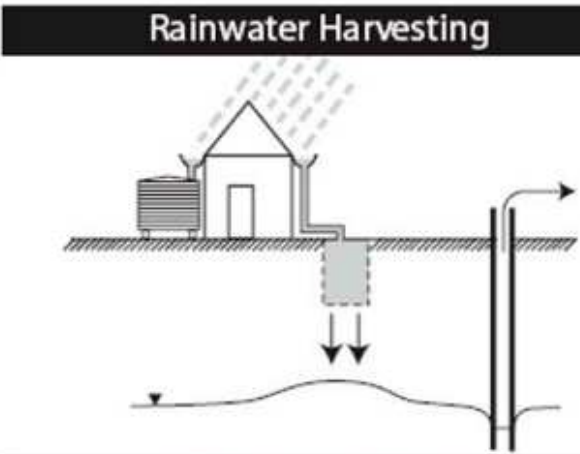

Infiltration Gallery

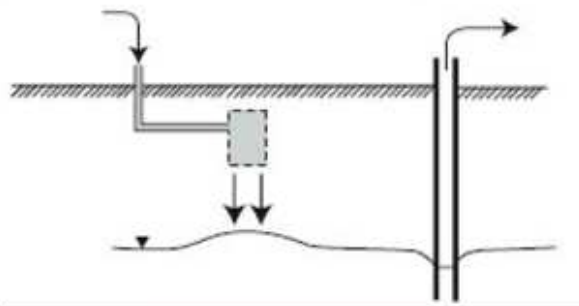

Infiltration Pond

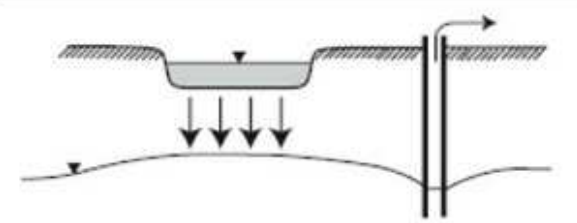

Recharge Releases

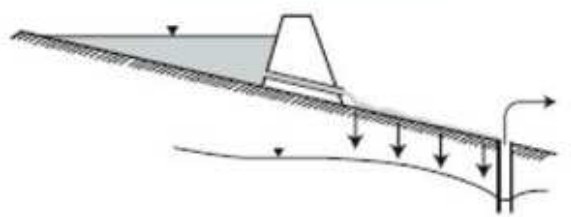

Figure 2-2: Schematic of types of Managed Aquifer Recharge (Dillon, 2005).

If there is no requirement for the additional availability or improved quality of water from the ground, there is no reason to invest in a MAR project. In other words there needs to be a driver, e.g. deficits in water supply, to come up with a strategy that involves MAR. To check the availability of an adequate source of water for recharge requires an understanding of the local water resources system. 
By means of analyzing water potentials from different sources and balancing them with current and prognosticated future water demands, available currently untapped water resources can be identified. These might be activated by adequate measures for the application of MAR. The water sources may also include already used but insufficiently managed water resources. For instance, existing water supply networks may suffer from vast water losses due to poorly maintained hydro-infrastructure. By reducing such losses, for example by modernization or sanitization of said networks, additional resources might be activated. This is where the planning of MAR, in the search of suitable water sources, plays a pivotal role in IWRM. Dillon, Pavelic, et al., 2009 further emphasize on the prerequisite of having a suitable aquifer present in which to store water. They describe the best aquifers for MAR as those that simply can store and convey large units of water. Furthermore, they name high thickness and uniform hydraulic properties as preferable in order to maximize the ability to recover water from the aquifer. The availability of sufficient land to harvest and treat water might be up for discussion, since the land requirements are basically depending on the origin and quality of the water source used for MAR and the corresponding decision which MAR technology to be used. The last point, the ability to effectively manage a project, is of course of major importance for any type of project. In terms of MAR, as will be seen in this study, the management of a MAR facility requires daily adjustments in recharge volumes, especially if the water source origins from highly fluctuating hydrological conditions.

\subsubsection{Worldwide Application}

Since the agricultural revolution, roughly 10,000 years ago, mankind has always struggled with temporal and spatial imbalances of water availability and demand (Hartog \& Stuyfzand, 2017). Groundwater has long been discovered as a more reliable source of water than, e.g. river discharge. In China the exploitation of groundwater resources can be dated back to 1000-2000 B.C. (Wang et al., 2010). Even cases of MAR are reported. For example spreading methods were applied by artificial canals that allowed surface water to infiltrate to the ground, turning saline land into fertile soil for agricultural use. Other cases of dug wells close to rivers are reported, that were periodically flooded by storm water and thus recharged the aquifer, enabling extension of agricultural lands (Wang et al., 2010).

In Europe the modern history of MAR, as Sprenger et al. (2017) named it, began in the $19^{\text {th }}$ century. Figure 2-3 gives a timeline of documented MAR projects in Europe, distinguished by the major technique that was applied. As can be seen, induced bank filtration and spreading methods were among the first techniques. Sprenger et al. (2017) underline that these applications have developed autonomously throughout Europe, the diversity of climatic and hydrogeological conditions creating numerous site specific designs of MAR. 


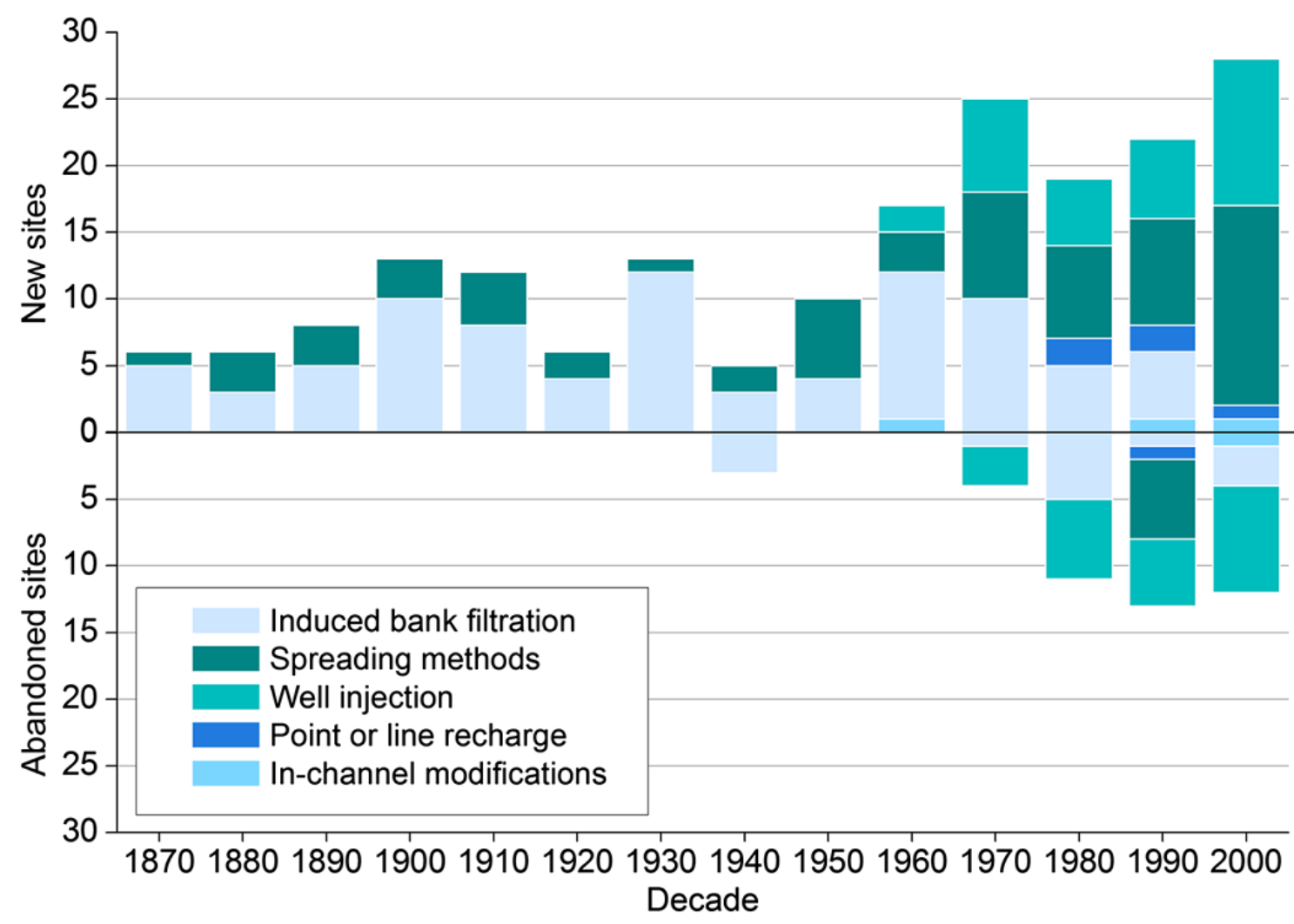

Figure 2-3: Outline of the historical development of MAR in Europe showing the number of MAR sites opened or closed per decade between the 1870s and 2000s (Sprenger et al., 2017).

Today MAR can be seen as a supportive measure to develop the European Union's green economy policies (Sapiano et al., 2017). In addition, it may create new markets, leading to job creation opportunities in dry regions of Europe, such as Spain. Especially in the Mediterranean region, MAR is considered a promising technique along the coastal zone (Sprenger et al., 2017). Italy supports the establishment of MAR systems by providing a legislative framework (De Giglio et al., 2018). Also in the USA MAR is an established measure (Gibson et al., 2018). The state of Idaho for example dedicates 5 Mio US\$ per year to stabilize aquifers with numerous techniques, amongst which MAR can be found (Mortimer, 2014). In the Middle East MAR is being applied for many years. It often plays a role in the planning of new sea water desalination plants in Israel, since the new available water resources must be stored somewhere. For India Gale et al. (2006) estimate a potential of more than 36,000 MCM (Million Cubic Meter), which is roughly $18 \%$ of the annual irrigation water demand of India, of yet unused surface water to be suitable for MAR. Nava et al. (2018) describe the development of a MAR with recycled water in Mexico and underline the country's advances in increasingly applying the technique within the past years.

A lot of experience with MAR can be found in Australia, where research in the field is very advanced. As Dillon et al. (2009) describe, MAR in Australia started in rural areas with the aim of securing water supplies for irrigation. The method then spread to urban centers. They link the development of 
MAR and the broadening field of application with rising water prizes, meaning that economics are the driving force that enables advances in the field.

Globally the pressure intensifies to deal with water challenges due to potential climate change impacts, growing water demand, extended food production and the parallel need for sustaining ecosystems (Sapiano et al., 2017, Sprenger et al., 2017, Huskova et al., 2016), causing MAR to be set more and more into the focus of water management strategies worldwide (Hartog \& Stuyfzand, 2017). Stefan \& Ansems (2017) developed a web-based global inventory of MAR applications. It provides a global overview of MAR suitability maps and MAR case studies and their relevant parameters. Available layers include information on site name, MAR type, year of scheme deployment, the source of infiltration water, the final use of abstracted water, as well as the main objectives of the project (Stegan \& Ansems, 2017).

\subsubsection{Challenges of MAR Planning}

Worldwide there is still a lack and overall deficit with regard to scientific and complete administrative systems for MAR, such as technical criteria for the planning of MAR systems Wang et al., 2014). There are, however, numerous regulations that focus on groundwater quality and protection aspects of MAR implementation, such as in the Australian Guidelines for Water Recycling (Dillon et al., 2009). The main concerns that are addressed by existing regulations are related to health risks that may arise from introducing pathogens or toxic chemical to the groundwater (Asano $\&$ Cotruvo, 2004). While these are very important concerns that require regulation, there is also a need for MAR guidelines that act as a framework for the planning of MAR projects. Many regions, such as Northeast Brazil that is addressed in detail in this study, lack of any experience with the technique. Even in regions that have a long tradition in MAR, such as China, there is still a need for the establishment of guidelines for MAR and the management of such projects (Wang et al., 2014). Some countries, such as Mexico, have established or are currently designig adequate guidelines for MAR implementation (González et al., 2015). One of the main issues is that, as expressed before, MAR is a very site specific method that must be designed according to each individual case study. This makes it difficult to create an overall framework for its planning and implementation. Most legislative approaches addresing groundwater management are designed for individual areas and their specific situation (Mortimer, 2014).

The success of a MAR implementation relies on a complete understanding of the local hydrogeological conditions and the water resources system, including its current state of management and hydro-infrastructure and the potential impacts of the planned measures. Besides this understanding of the system, trained and experienced personnel is important (Page et al., 2013). A 
suitable source of water must be available. This must not be currently used in other ways or should have the potential to be used more effectively when managed accordingly (Gale et al., 2006). In addition, the considered source of water for MAR should be of suitable quality according to local legislation or adequate pre-treatment measures must be addressed (Dillon et al., 2009, Asano \& Cotruvo, 2004). Even apparently high quality water sources might require pre-treatment measures, for instance with regard to reducing the sediment load in storm waters to minimize the clogging effect of recharge facilities (Hartog \& Stuyfzand, 2017, Bekele et al., 2018). Environmental aspects of a potential MAR implementation need to be carefully assessed. Recharging large amounts of surface water will reduce downstream water availability. Similar to the issue of planning a surface reservoir by building a dam. Therefore, it must be considered whether the water intercepted for MAR might collide with downstream water entitlements (Dillon et al., 2009, Gale et al., 2006). The opposite effect can also be achieved by increasing the water availability and the environment can benefit from stabilization of overexploited groundwater resources, which is a most welcome effect of MAR.

The selection of adequate locations for additional groundwater recharge, or simply MAR Site Selection, is a very complex issue and has been subject to many studies (Rusteberg et al., 2012, Rahman et al., 2012). To delineate suitable locations not only physical parameters but also socioeconomic considerations should be assessed (Gale et al., 2006). A comprehensive hydrogeological study should be conducted to achieve a good understanding of local conditions before the site and method of MAR can be selected (Mortimer, 2014). Depending on the source of water that should be used to recharge the aquifer, it must be considered to allow for a sufficient residence time of the water in the underground to use the soil for natural attenuation of potential contaminants (Sprenger et al., 2017). But also the residence time of recharged water is of importance for purely numerical considerations. The longer the water remains within the reach of recovery wells or a predefined area of interest that is supposed to benefit from the MAR measures, the bigger the impact will be and the more resilient a system might become towards drought conditions. To account for the above, the planning of MAR measures requires long term monitoring of water resources and modelling of the system in order to plan for future developments in accordance with water plans and local objectives of water management, as well as potential impacts of the MAR implementation (Casanova et al., 2016). But also during operation MAR implementations require ongoing monitoring, e.g. to be able to react to clogging effects of infiltration facilities (Parimalarenganayaki \& Elango, 2018).

To summarize, a successful planning of MAR requires a very good understanding of the system. Water resources require long term monitoring to identify trends and patterns. Modelling entire systems allows to account for the impact of future scenarios and the comparison of different water management and MAR options. 


\subsection{Integrated Water Resources Management}

\subsubsection{Introduction}

Integrated Water Resources Management (IWRM) is defined as "a process which promotes the coordinated development and management of water, land and related resources, in order to maximize the resultant economic and social welfare in an equitable manner without compromising the sustainability of vital ecosystems" (GWP, 2000). This definition does not specify how the process should be designed. Rather it is supposed to be a guiding framework that should aid managers and stakeholder to implement better water resources management strategies (Chidammodzi \& Muhandiki, 2017). This means IWRM is, just like MAR, a site specific approach that has to be specifically designed for each target area. The framework is guided by the 4 Dublin Principles (ICWE, 1992):

(i) fresh water is a finite and vulnerable resource crucial for the sustenance of life, development and the environment;

(ii) a participatory approach should be the basis of water development and management;

(iii) women play a central role in the provision, management and safeguarding of water; and

(iv) water has an economic value in all its competing uses and should be recognized as an economic good.

In addition, the IWRM framework also relies on these 3 pillars (GWP, 2000):

(i) enabling environment;

(ii) institutional roles and functions of the various administrative levels and stakeholders; and

(iii) management instruments for effective regulation, monitoring and enforcement.

The concept behind IWRM has been applied in several countries for many centuries, while only within the last few decades it has been tried to implement it in a larger scale (Rahaman \& Varis, 2005). Since societies become more and more integrated themselves, resources require adqeuately coordinated management and increased assessment across regions (Hundecha et al., 2016). After the United Nations Conference on Environment and Development in Rio de Janeiro 1992 called for integrated approaches of developing, managing and using water resources in its Agenda 21, over $80 \%$ of countries worldwide made changes in their policies and laws, most effectively in development countries (UN-Water, 2012). The fast uptake of IWRM was followed by critical reassessments in the 2000s, leading to a condensation and focus on its practical elements (Linton, 2014). 


\subsubsection{State of the Art}

As introduced, IWRM describes a process or set of measures, not a specific action or technology. Human activity is evaluated within the context of their impact on ecosystems, e.g. by means of land use changes (Jin et al., 2018). Furthermore it is a highly iterative process that requires constant impact assessment and improvement. In this sense the IWRM approach is very similar to the MAR planning approach introduced before. Figure 2-4 illustrates the progressing development of an IWRM implementation. The suggested approach is divided in five steps and starts with recognition and identification of the water resources system and its drivers, very similar to the MAR planning approach. After the conceptual planning and implementation, constant monitoring and evaluation is required in order to identify the impacts of the implementation and re-evaluate the situation. Without proper monitoring, e.g. of groundwater extractions from a coastal aquifer, negative effects such as seawater intrusion may be triggered (Fatema et al., 2018). If the initial problem could not be solved or new problems occur, the system requires adjustment. This way the IWRM process repeats and improves itself as an iterative process.

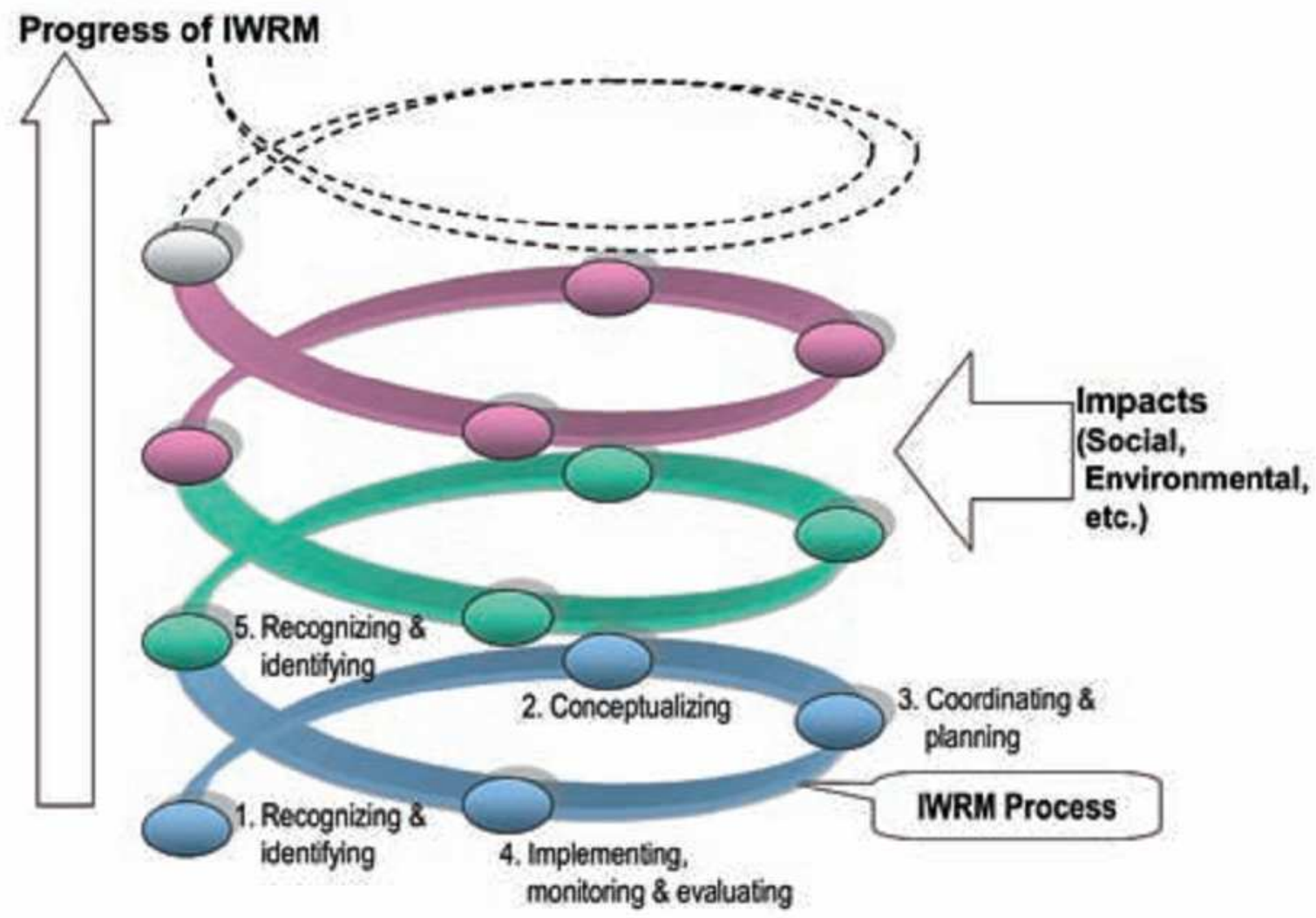

Figure 2-4: Spiral evolution of IWRM (UNESCO, 2009).

A typical measure of an IWRM implementation might be the activation of new, or up to now unused, water sources. As for example the implementation of additional groundwater wells or starting to reuse treated waste water for irrigation. Also the modernization of existing hydro-infrastructures might be a valid measure in underdeveloped regions. Before any of these potential measures might 
be implemented, it is useful to evaluate coexisting strategies beforehand. This way, a first impact assessment in accordance with the iterative planning process shown above can be performed without taking the risk and implement measures without knowing the potential consequences. Different strategies can be compared by means of indicator assessment, utilizing for example models or simple budget calculations. Figure 2-5 gives an example of how indicator assessment can help comparing alternative IWRM strategies. The pentagram illustration of indicator performance allows for a direct comparison of both performances. This is only one example of how a performance assessment can be conducted and interpreted. There is no standardized approach and indicators should be designed according to the specific case study. If, for example, the target area suffers from depleting groundwater levels, one indicator to assess the performance of an option might be the level of stabilization that the groundwater level would potentially receive once the measure is implemented. This underlines the importance of having adequate models before any implementations can be planned and the importance of monitoring the system after measures have been implemented. With their predictive capability, models allow to recognize problems and prospects that come along specific measures of IWRM (Singh, 2010).
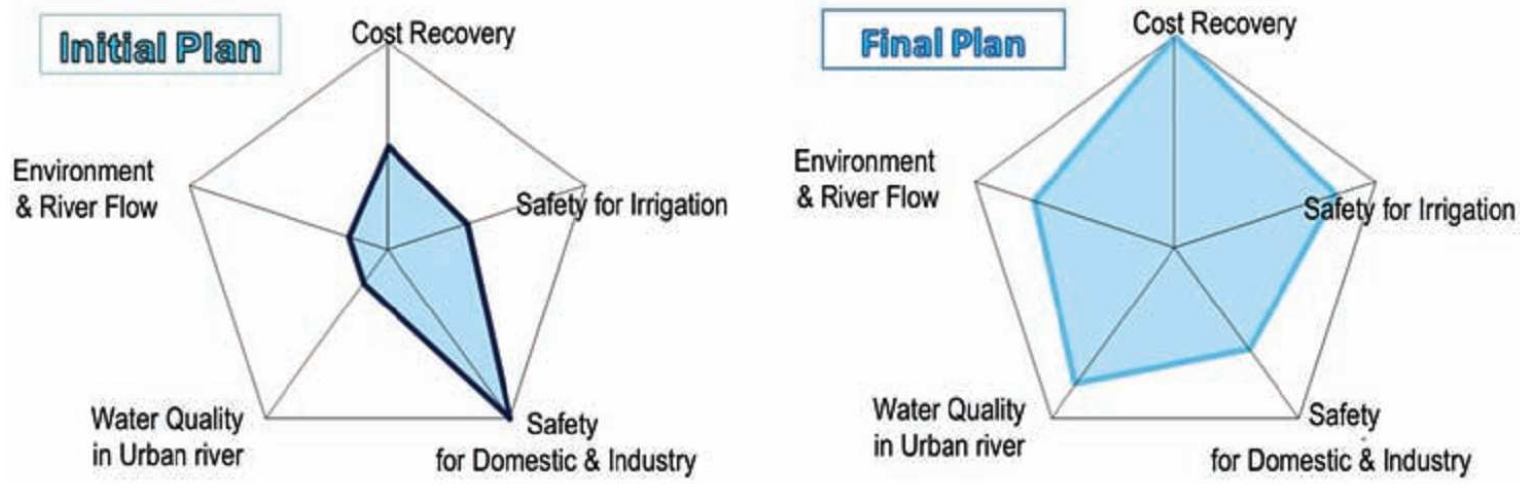

Figure 2-5: Example of pentagram approach to compare alternative IWRM strategies (UNESCO, 2009).

\subsubsection{Challenges of IWRM Implementation}

As introduced, IWRM implementation begins with a complete analysis of the local system. This process can be referred to as Water Resources System Analysis (Rusteberg et al., 2012). In order to implement any proper management system for water resources both the spatial and temporal dimension of water availability must be studied first (Hundecha et al., 2016). Besides quantitative aspects, also water quality aspects must be addressed, though it is much more challenging to monitor on a frequent level (Chittoor, et al., 2016). In addition to knowledge of the existing water resources system, it is of major importance for the development of strategies to consider a broad variety of development scenarios (Kawo et al., 2018). Water supply and demand of the future are hard to estimate due to climate variability, growing agricultural and domestic demands, changing socio- 
economics, etc. (UNESCO, 2009). Furthermore, the conjunctive management of surface and groundwater resources, as is an important aspect of modern IWRM, may be conflicting with existing institutional, legal or simply physical constraints (Pulido-Velazquez et al., 2016). All these challenges can only be adequately addressed if IWRM planning is conducted in accordance with local stakeholders. Stakeholder consultation and participations must be planned carefully in order to achieve benefits for the planning process (UN-Water, 2012). Unfortunately the application of most IWRM concepts is challenged by the lack of practical defintions and methodologies (Grizzetti et al., 2016). An important issue in groundwater management are transboundary aquifers (Fraser et al., 2018). Traditional borders between countries orient on surface characteristics, such as watershed, rivers or mountain areas. Aquifer often cross boundaries and create conflicts of interest. It is therefore an increasingly important task of IWRM to gap the bridge of international water conflicts and work on solutions for cooperation of adjacent countries to manage their groundwater resources together.

\subsection{MAR as integral part of IWRM: Need for an Integrated Planning Approach}

It is obvious that there is a strong parallel between the planning of a MAR system and IWRM. Both are highly site specific in their development and should ideally be planned and conducted in an iterative manner and evaluated based on adequate indicators. IWRM must be seen as an overall framework for water resources planning and management, while MAR is a specific measure. Only the implementation of a MAR concept to a region with overexploited groundwater resources may not be sufficient to restore the system, an additional collective management may facilitate the restoration of the groundwater equilibrium (Dillon et al., 2009). IWRM systems worldwide often rely on the conjunctive management of surface and groundwater resources and are focused mostly on integrating storage and hydro-infrastructure to improve water allocation (Pulido-Velazquez et al., 2016). In the USA and Australia, MAR is already widely adopted and viewed as an important component of IWRM strategies (Sapiano et al., 2017). In North China MAR is considered to be an effective measure in the context of integrated water resources management in regions that face environmental problems such as land subsidence, seawater intrusion and deterioration of water quality (Wang et al., 2014). In this context MAR has to be understood as an optional measure of water resource management (Rusteberg et al., 2012). As such, MAR has the potential to achieve many goals of an IWRM system, such as restore over-allocated or brackish aquifers, protect ecosystems, enhance water supply, improve water security, conserve surface water resources, and others (Dillon \& Arshad, 2016). In the following study, both MAR and IWRM will be analyzed and evaluated as a cohesive union. A MAR planning approach will be presented that tries to cover all findings of above presented literature review and create a framework of MAR planning in the context of Integrated Water Resources Management. 
3 Methodology:

\section{SUGGESTION OF A}

NEW INTEGRATED

MAR PLANNING

APPROACH 


\subsection{Introduction}

This chapter will introduce the methodological approach that is used throughout the thesis in order to achieve the main objectives. It is at the same time a suggestion for a new integrative process for MAR planning that sees the management of aquifer recharge as an integral part of IWRM which will be tested by application to the two introduced case studies. The process, or planning approach, presented here, is the result of literature reviews that identified a lack of such frameworks and six years of experience in the field of conceptual MAR planning. The most prevailing issues or challenges of said planning have been identified in the prior chapter. In addition, to mere literature review, this process has been designed, tested and improved in an iterative manner while working on the two case studies. It is therefore not only the methodology of this thesis, but also a product of the studies related to this thesis and an extended hypothesis in the sense that it is assumed to be of universal applicability for different study areas. First, an overview of the designed process will be given. Followed by a detailed description of all individual suggested steps and iterations of the process. Finally, a complete summary will be illustrated that may serve as a guideline in basic MAR planning research.

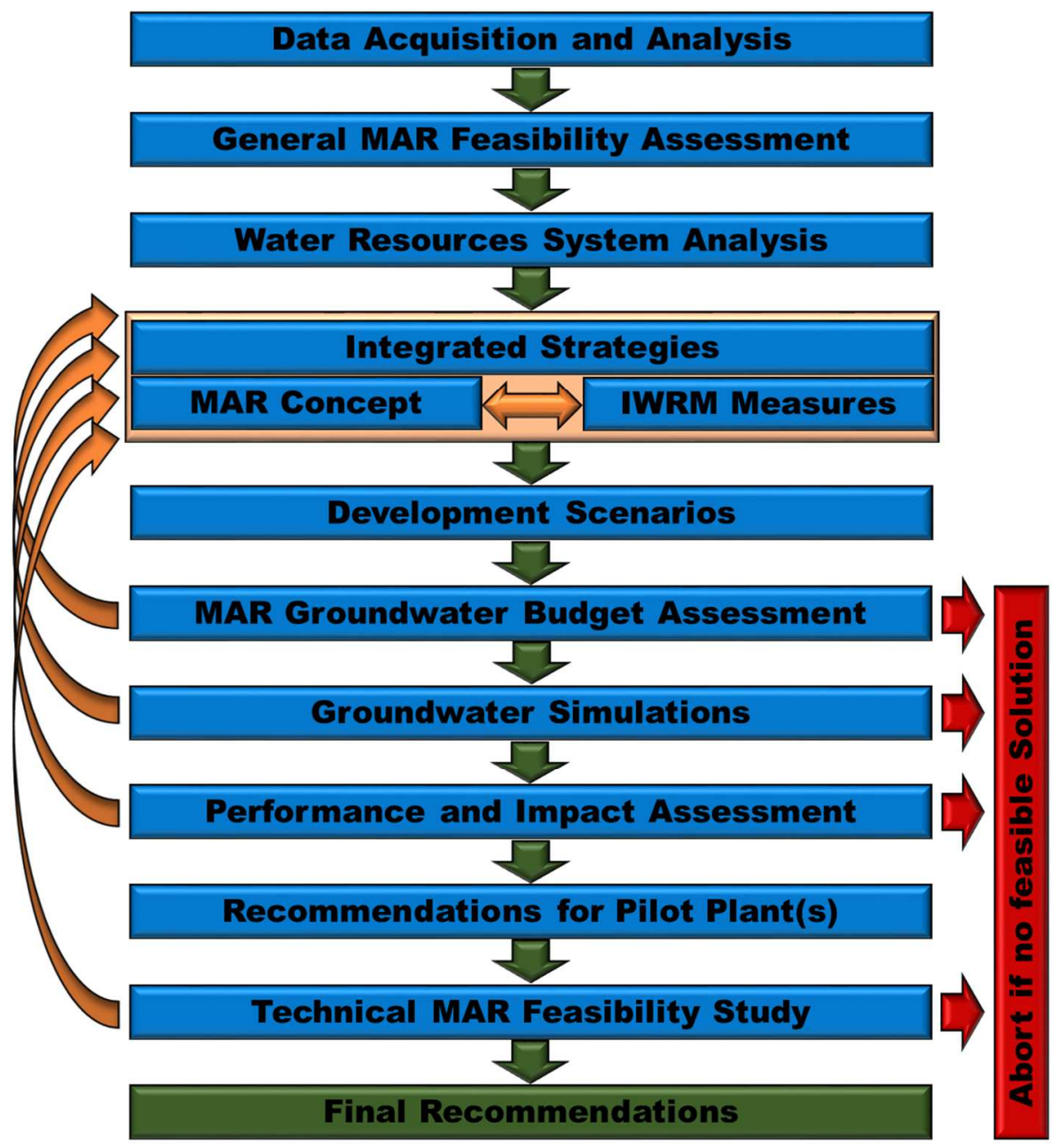

Figure 3-1: Illustrated overview of suggested integrated MAR planning approach. 
An overview of the suggested approach is given in Figure 3-1. It begins with a general acquisition and analysis of data in order to give a first statement on the general feasibility of MAR implementation in the study area. Some examples for these data will be given below. Second step is the analysis of the water resources system. This requires a detailed understanding of water demand and availability in their spatio-temporal distribution over the studied water resources system. It includes surface and groundwater resources and does not view them as separated entities. Once the water resources system is fully understood and characterized and MAR is identified as one potential contribution, the water resources manager begins defining general concepts for a MAR implementation under Step 4. It is the central part of the suggested approach. This is where the actual integration of MAR and IWRM is located.

The conceptual design of MAR is conducted in very close interaction with the identification of potential IWRM measures that aim at increasing water availability or decreasing water demand. Together the two approaches create integrated strategies. These strategies serve the purpose of beginning an iterative process of improvement and increased understanding of the system. To evaluate the strategies, scenarios for the future development are required and formulated in Step 5. They include general assumptions for the future but also specific plans in existence by local authorities or other stakeholders. The scenarios are closely connected to the planning and design of the former strategies and dictate the framework under which they have to perform. The scenarios are used to test the strategies for their applicability and performance under varying conditions. As the illustration shows, most of the steps following this one iterate back to Step 4. All of the following steps are designed to test the suggested strategies under the designed scenarios. According to the results of the individual steps they should be improved with each iteration.

Both, strategies and development scenarios are combined in a series of MAR groundwater budget assessments in Step 6. These are purely numerical studies that should help to judge basic performance issues or identify inconsistencies in the developed scenarios and options. To analyze the actual potential impact of strategies under different scenarios, a good and reliable groundwater flow and transport model is required. By means of simulation under Step 7, a performance and impact assessment of the designed concepts can be conducted under full consideration of the groundwater flow dynamics, which cannot be addressed by means of the mere numerical budget assessment. The actual performance is evaluated and ranked based on adequate indicators in Step 8, leading to recommendation for the implementation of MAR pilot plants under Step 9. The idea is to test and evaluate the MAR approach in the field under real world conditions in a downscaled version. The actual conduction of this so-called technical MAR feasibility assessment forms the final step of the suggested approach. Due to its complexity and duration of preferably several years, this step may include a whole new process. 


\subsection{Methodology: Detailed Description of the suggested MAR Planning Approach}

\subsubsection{Step 1: Data Acquisition and Analysis}

The first and most fundamental point is an initial data acquisition and analysis of that data (Figure 3-2). Without a profound data base it is virtually impossible to develop adequate concepts for MAR or any other form of IWRM measure. It is also basic for the definition of future scenarios and the development of a groundwater model. Models are an attempt to recreate a real system in a simplified manner in order to simulate potential reactions of the analyzed water resources system to changes. No model can represent a real system in a sufficient manner if there is not a good and complete set of different data.

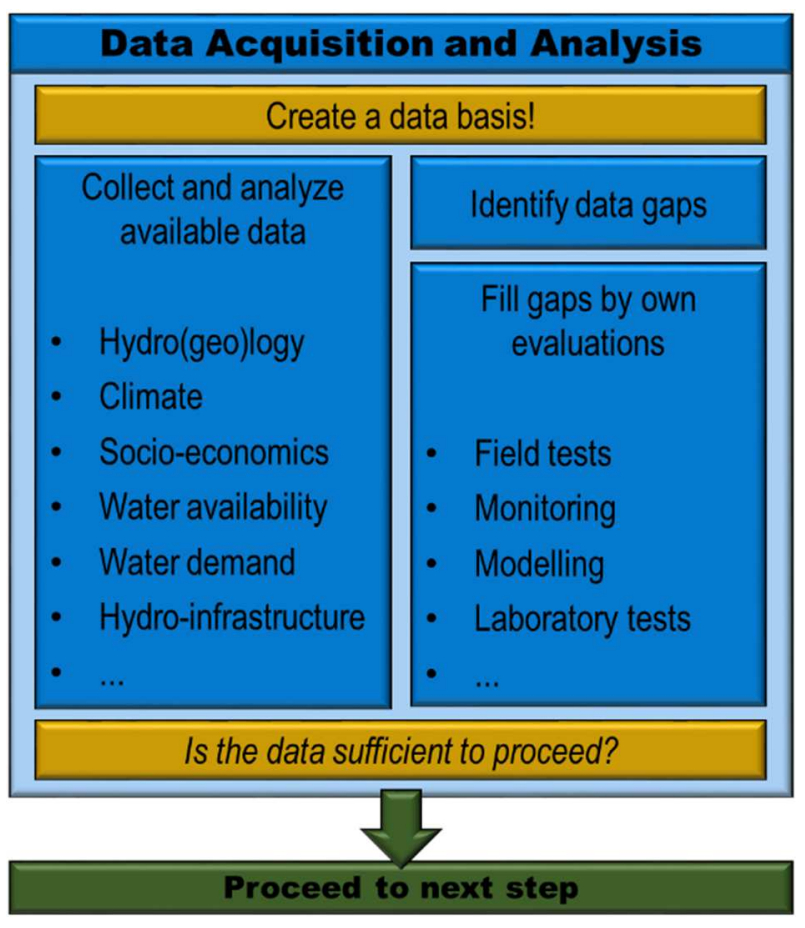

Figure 3-2: Illustration of MAR Planning Process -Step 1/10.

It is recommended that all available data sources of data should be identified first. Besides scientific publications by prior or running studies, local stakeholders should be consulted here. These could include local, regional or federal water authorities, ministries, NGOs, watershed committees, water suppliers, farmers or the municipalities themselves. Once an overview of all available data is established, data gaps can be identified. The list of required data is very site-specific and depends on the local conditions. The water manager should have a general idea of the local conditions before a study begins. Therefore, the set of required data should more or less be clear. When data gaps are identified, which will be the case in most study areas in developing or emerging countries, it is of vast importance to the MAR project to plan and conduct own evaluations to fill these gaps. It is not recommended to rely on a poor data basis. This will only increase the level of uncertainty and may consequently lead to results that may neither represent the actual system nor receive acceptance by 
local stakeholders. Stakeholder acceptance is of major importance if any actual implementation is expected. This issue will be addressed in several steps of the suggested approach.

Own evaluations may include intense field work such as hydrogeological surveys. The water manager should be aware that it might be required to seek assistance of local experts in order to obtain the required data. Often local stakeholders have plans and designs of, for example, monitoring campaigns but lack the required funding or support. When planning for a MAR project, adequate funding must be accounted for to support these evaluations. For example if spatial data on hydraulic parameters, such as hydraulic conductivity, is missing, it should be considered to conduct a campaign of pumping tests in the field. These require, besides personnel and expertise, time and money. These aspects should be taken into account before the actual MAR project starts.

\subsubsection{Step 2: General MAR Feasibility Assessment}

Based on the acquisition of existing and new data, a first judgement must be conducted whether MAR is a feasible technique to be applied in the respective study area or not. The step is illustrated in Figure 3-3. The prevailing surface and underground characteristics might be not suitable for a MAR system. Based on the acquired data, it must be evaluated whether the local physical conditions allow for a MAR implementation. With regard to surface characteristics these criteria include the existing land use patterns. In a dense urban environment it may be more challenging to introduce MAR. Technologically an implementation would then in most cases be limited to direct injection due to the reduced availability of free areas to infiltrate water. Along with this pre-selection of a technology come specific demands on the water quality or enhanced requirements for pre-treatment.

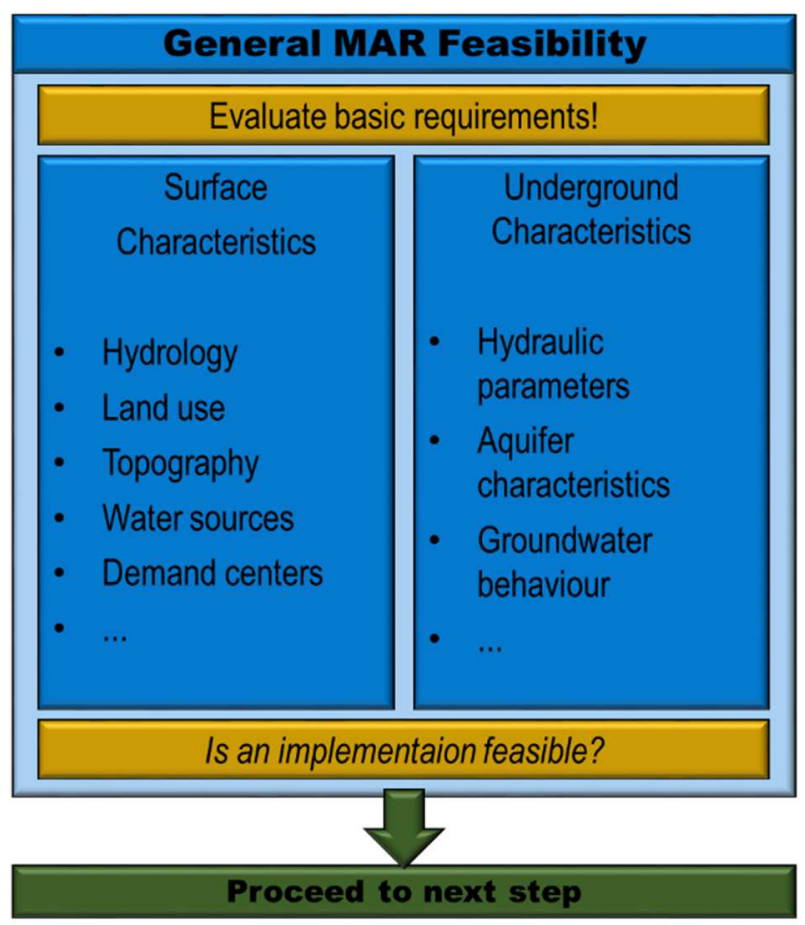

Figure 3-3: Illustration of MAR Planning Process -Step 2/10. 
If there is land available, or easy to acquire, topography may be the limiting surface characteristic. In general, the higher the slopes, the higher the implementation costs for infiltration ponds. Also the spatial distribution of water sources and demand centers plays a key role for general MAR feasibility. Managed recharge should ideally be conducted close to the source of water in order to keep the costs for water transport and additional hydro-infrastructures as low as possible. The costs of MAR schemes vary substantially between MAR types and these site specific conditions (Ross \& Hasnain, 2018, Choi et al., 2018). On the other hand, MAR should add to the water availability which will increase water consumption and subsequently, if an adequate prizing system is applied, to monetary benefits to balance the costs (Kiparsky et al., 2018). The demand centers, meaning the locations where groundwater is mainly extracted from the aquifer, should be located downstream the general groundwater flow direction. Otherwise, the additionally recharged water my take another course and flow away from the pumping wells. This leads to the underground characteristics: There has to be a suitable medium, an aquifer, to be used as storage for MAR. This aquifer, or aquifer system, must allow for additional recharge without reaching the limits of its capacity. Its hydraulic conductivity should be high enough to allow recharge in the respectively required quantities and at the same time keep the water long enough within the vicinity of the extraction wells (Rojas et al., 2018). If the data is insufficient to judge a general feasibility of MAR, Step 1 may not have been conducted in a sufficient manner and should be repeated.

\subsubsection{Step 3: Water Resources System Analysis}

To thoroughly analyze the water resource system is of major importance for all consecutive steps. It creates the basis for any planning of MAR measures or IWRM and development strategies. Figure 3-4 illustrates this step. The main goal of the Water Resources System Analysis (WRS) is to identify the potential of water resources in a region and the required hydro-infrastructural components to activate these resources (Rusteberg et al., 2014a, Rusteberg et al., 2018). By doing so, the WRS also includes a water balance assessment by quantifying the spatio-temporal distribution of water availability and demand. Depending on the analyzed system, or study area, it may be recommendable to discretize a large area into smaller units. These could be based on surface water catchments, if the system is highly characterized by surface water resources, or patterns of land use, predominant water demand sectors or other features. Whatever metric is used to discretize spatially should allow for a separated analysis of all delineated units. In this study the spatial discretization is referred to as "Management Units" (MU). It allows for an evaluation of water budgets with a special focus on evaluation of potential water management issues, such as MAR and IWRM. For example, a study area might be predominantly characterized by land use in a way that a clear delineation between the urban and rural area can be conducted. This might be a suitable criterion for spatial discretization. It could be determined that the water supply of the MU might have lower requirements on water quality 
because most of it is used for irrigation purposes. While the urban MU on the other hand may depend on high quality water to cover domestic demands. This is only one example of how this measure could help in developing water allocation schemes in the following process. It must be decided whether a spatial discretization makes sense and, if so, on which parameters it should be based.

Whatever systems or sub-systems are analyzed, the key parameters are water availability and demand. As for the first, it is not to be confused with water supply. Water availability in this context means all existing sources of water that are potentially available for anthropogenic use in the study area. These include yet unused, or "untapped", water resources. For example there might be an unused potential of treated waste water that is disposed to the sea. It represents an unused water resource that might as well be applied for irrigation. The same is true for surface water discharging unused through rivers. It is vital to identify all these currently used and potential future water resources.

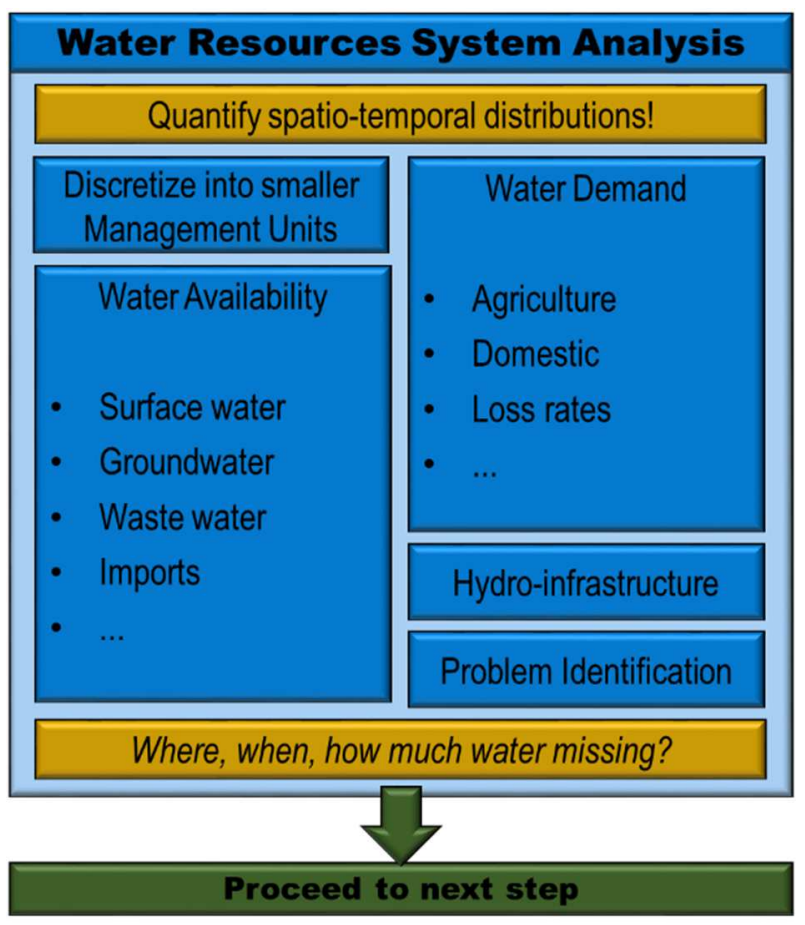

Figure 3-4: Illustration of MAR Planning Process -Step 3/10.

In most areas water plans are already existing that can help to identify these parameters. Often also projects are already in planning or even in the implementation phase that will supply the study area with additional water. They have to be included in the planning. Potential sources of water supply are, depending on the local climatic conditions, subdued to high variability. This means that in most cases it will not be possible or feasible to give mean annual values of water availability. Rather, transient time series should be acquired. Especially surface runoff in semi-arid regions is highly fluctuating from year to year. It is recommended to rely on actual monitored data. For a first 
evaluation, historic data should be used. Of course these can never be extrapolated to the future 1:1 in a satisfying manner. But for a first impression of the water resources system, and maybe also for a first scenario to later calculate, historic values can be used as an implication. If data is not available, it should be collected. In addition, to field experiments and monitoring campaigns, data could be acquired by means of simulation. For instance, if climatic data is available in abundance, it might make sense to simulate the spatial distribution of rainfall or natural recharge to the groundwater as was done in one of the case studies presented in this thesis.

A similar situation is given for the parameter water demand. While water availability data might be under strong influence by climatic variations and other external factors, water demand is mostly quite constant. At least for domestic, industrial or commercial sectors, water demand will not variate too much in between seasons in most cases. The contrary is true for irrigation water demand. It is highly linked to water availability, in terms of rainfall. In years of high rainfall, irrigation demand might be rather low, while dry years result in increased demand for additional water to satisfy local crop water needs. Since water is mostly supplied, distributed or at least monitored by a local authority, monthly data can be expected to be available most of the time. If this is not the case, also own evaluations should have been applied in the prior step. For instance, as will be shown in this thesis, irrigation water demand can be calculated with a spatio-temporal discretization based on land use and climatic data. Domestic water demand could be estimated based on assumptions for per-capita water consumption, paired with current socio-economic data and knowledge of the water distribution networks to address losses due to leakage. Also the hydro-infrastructure should be addressed. In what way are the various water sources connected to the water demand centers? How is water transport and application managed? What irrigation techniques are used? What are the resulting loss rates due to transport and application? All these matters should be covered in a water resources system analysis.

All these data should help to identify the problem. In most cases this will be an imbalance of temporal and/or spatial distribution of water availability and demand. If there is such an imbalance the questions remains whether additional storage, for example supplied by a MAR implementation, might be a potential solution to this problem. If there is no demand for MAR, or any water storage in this respect, there is no need to proceed with the study. Stakeholder contribution is the key to deliver a complete and accurate picture of the local water resources system. Making use of existing water plans, development strategies, past and ongoing water resources projects and even political agendas will increase the acceptance and validation of the final results. 


\subsubsection{Step 4: Combination of MAR Concept and IWRM Measures to integrative Strategies}

This step represents the key element of the suggested planning approach. It is the iterative development and integration of conceptual MAR planning in combination with potential IWRM measures. Figure 3-5 illustrates this twofold interactive step. On the one hand stands the delineation of conceptual MAR options, on the other hand IWRM measure are defined. Both depend on a complete understanding of the water resources system and stakeholders' plans for future development of the region as emphasized in the prior steps. This double-step is the basis and core element of the following steps. Therefore, it is the starting point of many iterations that fall back here. The suggested process of designing integrative strategies should be explained. Basically at this point it is required to give a first description of how a potential MAR implementation could be outlined. Though the planning of a MAR system may require many more factors, each of which will be accounted for in later steps. At this point it is crucial to define two major aspects of the suggested implementations: locations and operation schemes. For a first iteration both of these elements might be addressed rather superficially. Based on the analyzed data a first idea of where to strategically locate additional groundwater recharge should become obvious. For instance, if the main water source in a study area is a natural spring system, as is the case in the semi-arid case study, and the main demand center is an agricultural area downstream the groundwater flow direction of this source, the obvious first choice would be to consider MAR close to the source, using the natural groundwater flow direction to transport the additionally stored water to the demand center.

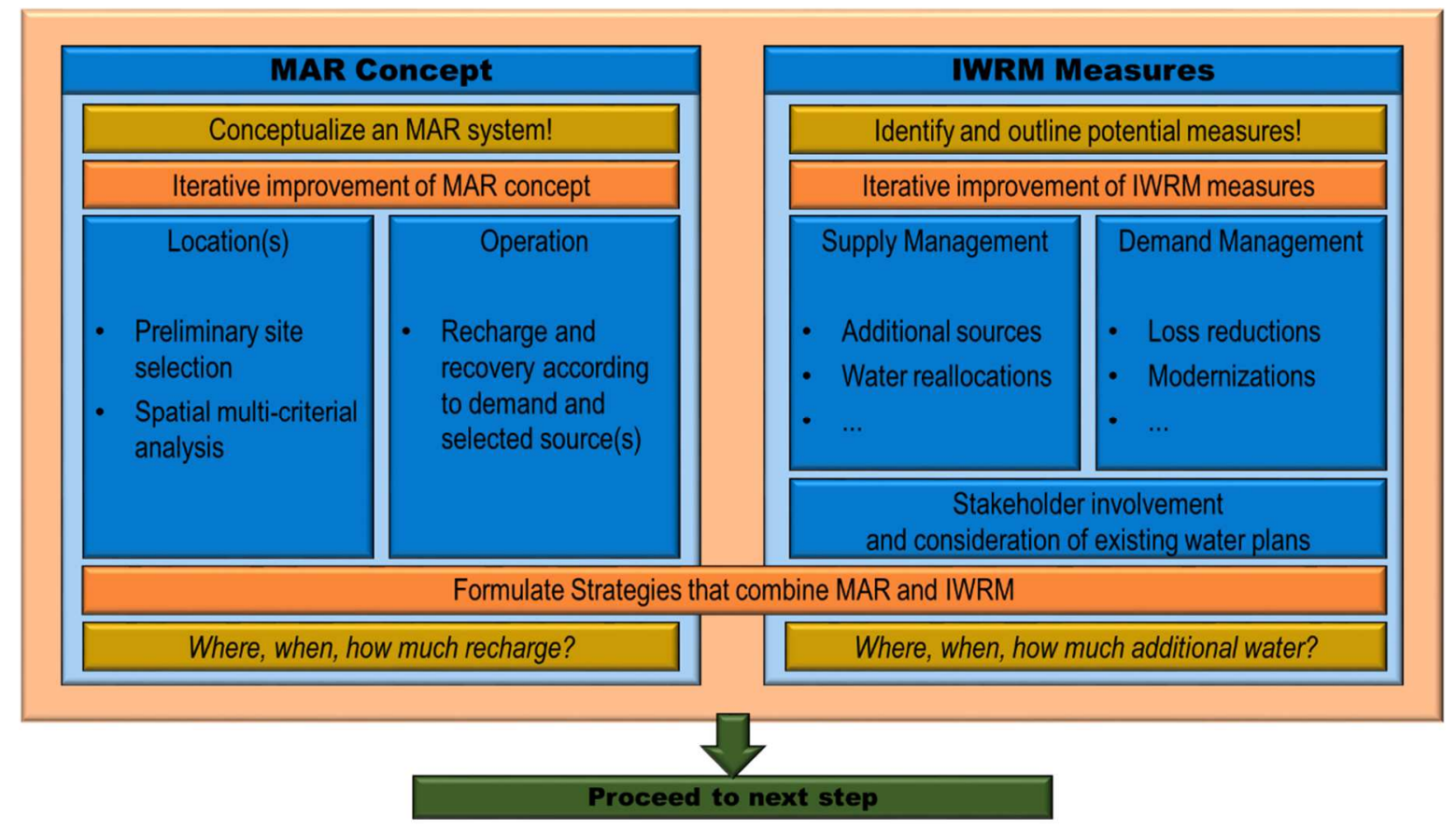

Figure 3-5: Illustration of MAR Planning Process -Step 4/10. 
The second element is the operation. In the chosen example, operation of the suggested MAR facility would be defined by the spring system's discharge and the temporal distribution of irrigation demand at the demand center. Irrigation demand during the region's dry season might be so high that it requires direct coverage by the spring discharge. During the wet season, there is a clear surplus of water availability. This surplus of water is the source of our imaginative MAR system. By means of water resources system analysis a calculation the monthly available water volumes is possible that could be recharged via MAR during this rainy season. This amount, in a temporal discretization, is exactly what we consider the operation scheme; a transient series of recharge volumes available for MAR. The combination of both, the operation scheme and the location(s) are enough at this point to proceed with the MAR planning process. It is important, however, to define a set of alternative options. Even though an option might not appeal suitable for the case study, it has a certain value for comparison. It might help setting the evaluation of potential MAR performances into perspective.

It may not be possible to define conceptual MAR options without analyzing potential new water sources by means of IWRM measures first. The order that those two interacting planning steps are presented here should not be taken as fixed. Rather both should be addressed in parallel. The IWRM measures should ideally be based on existing local and regional water plans, if available, and extend them if possible. In most cases the existing plans already include IWRM measures. IWRM measures in this study are understood as actions, implementations or likewise that aim at the management of either water availability or water demand. For example the construction of new hydro-infrastructure in terms of a pipeline that import additional water to the study area (supply management). Or the modernization of existing networks to reduce water transport losses (demand management). Ideally, MAR is already an element of such plans. If that is not the case, it should be included in a way that it does not replace any of the other planned measures but rather complements them. This is where the prior conducted water resources analysis is of major importance. Without a complete understanding of the system, backed with real data, no reliable results can be produced. The higher the uncertainty of the initial data, the higher the uncertainty of the results.

The results gained in the analyses to follow these crucial definitions should circle back to this point if results show potential for improvement. As has been shown in the literature review chapter on IWRM, iteration is fundamental to water management. Since MAR will be viewed as an integral part of IWRM in this study, the same assumption is valid here. For instance the following steps might reveal that the existing water plans and their IWRM measures, even in combination with a MAR system, will not suffice to supply the region with enough water for the next decades. By iterating back to this step, an additional strategy can be designed that includes the activation of yet another source of water. Or the implementation of another MAR facility at a different location. The potential impacts cannot be judged based on mere analysis of the existing water resources system. Rather it 
requires forecasts and calculations based on assumptions in terms of development scenarios. These will be addressed in the next step.

\subsubsection{Step 5: Development Scenarios}

A variety of scenarios for the future development of the water resources system should be established based on external factors that are beyond the control of the water manager. These external parameters are those that are not under the influence of any human planning activities, such as climatic parameters or economic scenarios that impact the population growth or agricultural extension. The design of these scenarios should be in accordance with the system. The overview in Figure 3-6 should serve as a framework for orientation regarding the outline of these scenarios. It is suggested to develop at the very least one Baseline Scenario, a Demand Development Scenario and a Dry Climate Scenario.

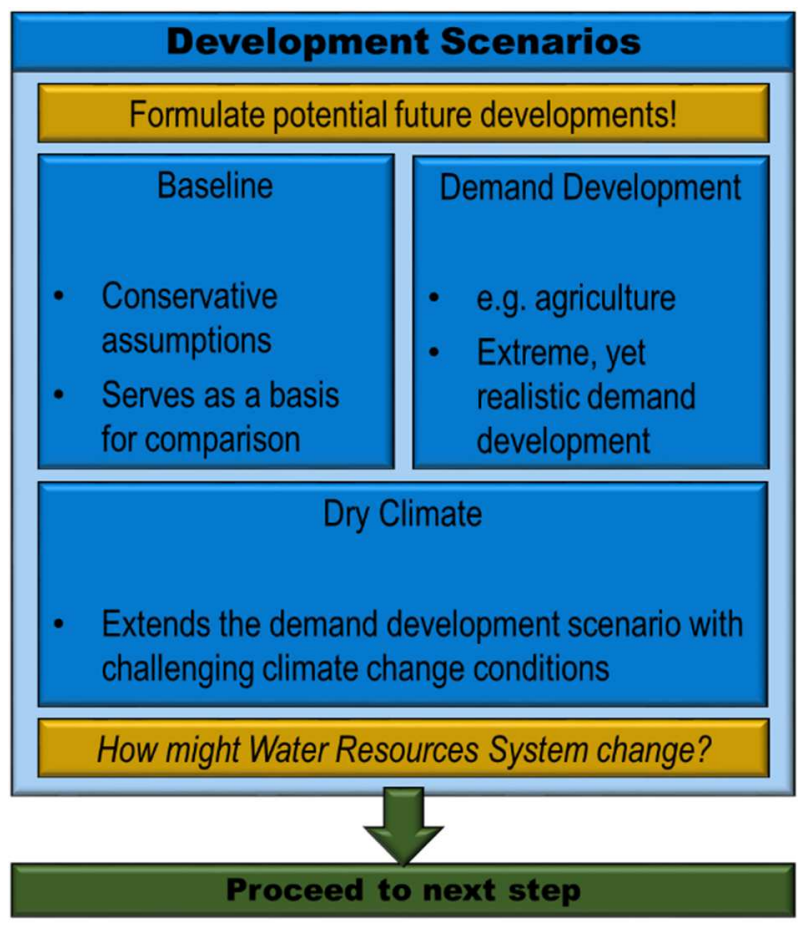

Figure 3-6: Illustration of MAR Planning Process -Step 5/10.

The Baseline Scenario serves as a basis for comparison. It should include only conservative assumptions for socio-economic growth and demand development. The historic growth rates for population and domestic demand may for example be extended to the future. The Demand Development Scenario can for example be built around the agricultural sectors. Since agriculture will in most cases be the dominant water consumer and is on the other hand a flexible factor that might change according to the market development, for example if one specific crop becomes more valuable in the future and is more water demanding. The idea is to make assumptions that are realistic on the one hand but also challenging for the water resources system with regard to increased water 
deficits. The scenarios are stress tests. The better the designed strategies perform under extreme conditions, the more suitable they may be for an actual implementation. The third development scenario concerns extreme climatic conditions in terms of reduced rainfall. The selected case studies for this thesis for example are located in the tropics on the one hand and a semi-arid environment on the other. While the one may apparently have water in abundance, the water demand has often developed in parallel and is accordingly high. Here even small changes in rainfall might have strong impacts on the supply-demand balance. Semi-arid regions often suffer from droughts and it is important to design strategies that help mitigate water scarcity under drought conditions. According to the study and its individual system, at least one challenging climatic scenario should be developed.

\subsubsection{Step 6: MAR Groundwater Budget Assessment}

Once the conceptual MAR options, IWRM measures and development scenarios are designed, a first numerical evaluation can be conducted. The goal of this step is to analyze the impact of the designed strategies under the given scenarios on the system. Since MAR is a measure to use a local aquifer as storage medium, the budget assessment should be conducted for the aquifer. All data of input and output, water availability and demand, recharge and recovery by pumping wells, should be transient with at least a monthly temporal resolution. As introduced in Step 3, there might also be a spatial discretization based on Management Units. If this is the case for the study, individual groundwater budgets for each MU might be calculated and, in addition, an overall budget for the entire study area accumulated. It is important to know what the exact parameters of in-and outflow are that should be calculated in this step, which is illustrated in Figure 3-7. Basically the in-and outflow of the groundwater budget assessment are the same sets of data that have been acquired in the prior steps and compiled in terms of future development scenarios and strategies. Knowing the system as defined under Step 3 and having developed strategies of management and scenarios, all variables of the budget are available. What is conducted here is a simple IN -OUT budget equation on at least monthly basis, depending on data availability. The IN part is the natural groundwater recharge, unmanaged recharge resulting from human activities and the new introduced or planned recharge via MAR facilities. The OUT part is the pumping from the aquifer that is selected as storage medium. It can be calculated by taking the identified water demand and subtract the volumes of water that are supplied from other sources, like surface runoff, reservoirs or import. The exact application of this step, with its formulas etc., is given in this thesis for both case studies in Chapter 4.

The results can be interpreted based on the accumulated groundwater budget. It is the sum of all monthly time steps' individual budgets. Basically, the higher this accumulated value, the better the MAR performance under the given scenario. These results can only be seen as a first estimation and should mainly serve to iterate back to Step 4 and improve the conceptual strategies. Also, the budget 
results may lead to the conclusion, that the selected IWRM measures or strategy is insufficient or, the other extreme, brings too much water into the system. In any case the IWRM strategy might be adapted, for instance by considering additional water imports or leave out one of the potential measures.

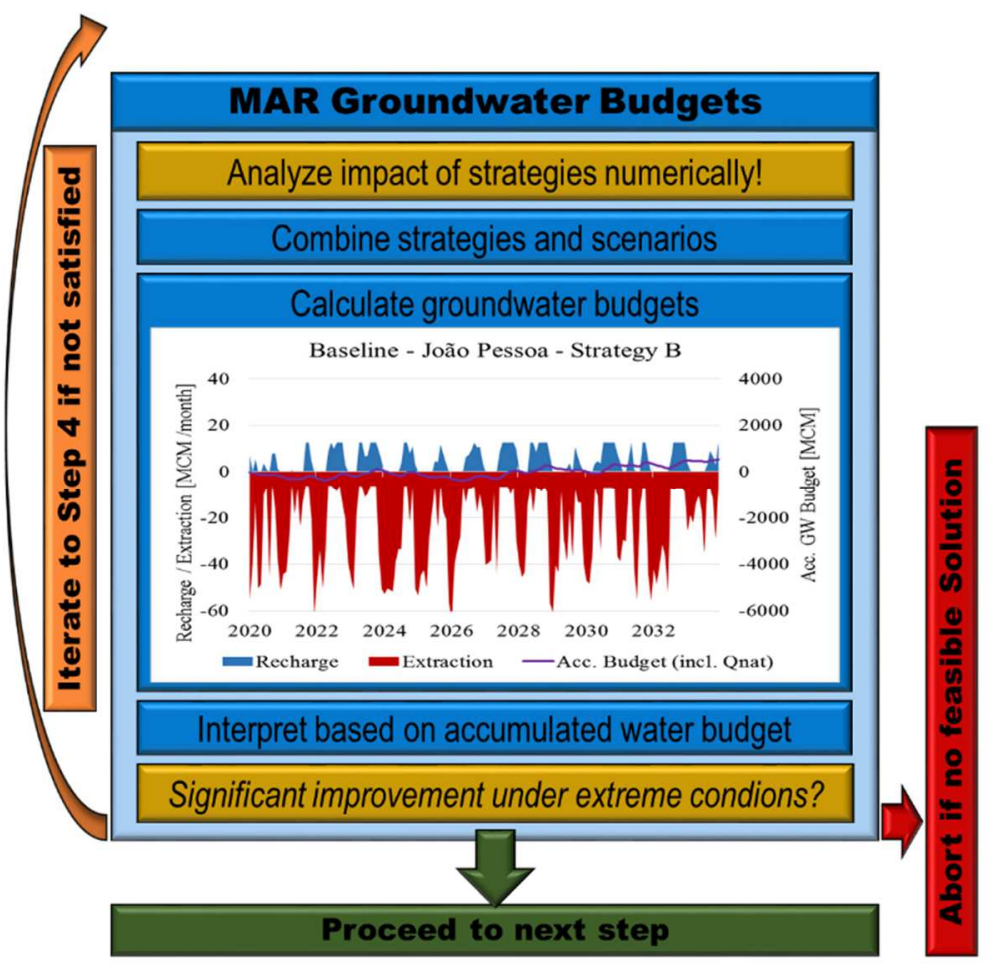

Figure 3-7: Illustration of MAR Planning Process -Step 6/10.

\subsubsection{Step 7: Groundwater Simulations}

Mere water budget calculations are insufficient to judge the potential impact that a MAR installation in combination with IWRM would have on a complex system. Therefore, it is highly recommended to develop a groundwater flow-, and ideally also transport-, model of the study area. This might be challenging for some regions with regard to data availability. If possible, groundwater simulations should be conducted. Only with models it is possible to consider the groundwater dynamics that result from any interference with the aquifer in form of pumping and recharging.

By increasing the recharge to an aquifer, the additional water will increase hydraulic gradients, resulting in higher groundwater flow rates. These on the other hand might lead to an increased flow out of the system. Natural groundwater flow directions might locally even be changed to the opposite direction when the recharging water creates a bulge in local groundwater levels. Also the strategies to be evaluated will rely on increased groundwater extractions due to agricultural growth or increased reliance on groundwater due to climatic scenarios conditions with vastly decreased rainfall. All these parameters cannot be covered by mere budget calculations as presented in the prior steps. But since 
simulations may become a quite complex and time consuming issue, the prior step is supposed to help reducing the amount of strategies to be simulated by allowing a pre-selection of favorable combinations or the selection of representative examples. The results of the simulations can be interpreted in many ways. A first evaluation of the feasibility and impact of a MAR measure can be made based on groundwater levels. By analyzing and comparing the transient results for groundwater fluctuations in the simulation of different strategy for the same scenario, the relative performance of each measure can be identified. The results should ideally lead to a reconsideration of the developed concepts and it should be iterated back to Step 4 to further improve the solutions.

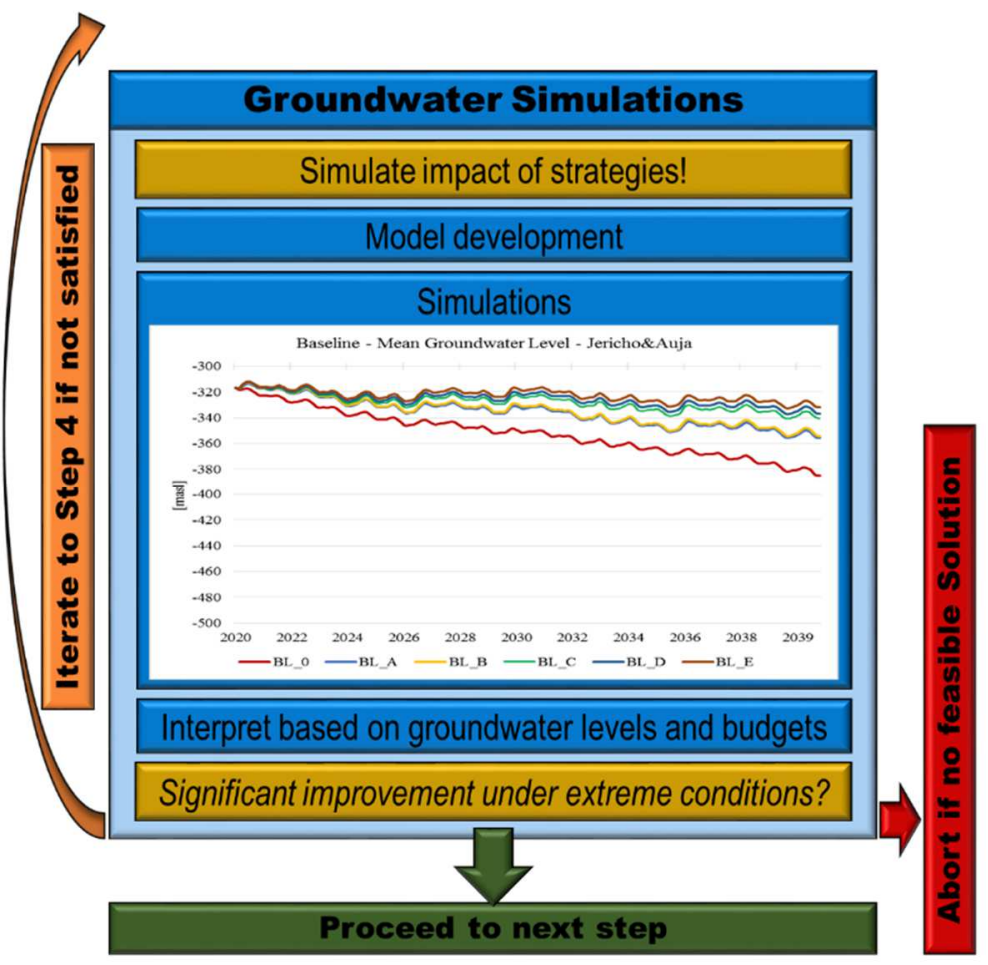

Figure 3-8: Illustration of MAR Planning Process -Step 7/10.

\subsubsection{Step 8: Performance and Impact Assessment}

Step 8 of the suggested MAR planning approach is a performance and impact assessment (Figure 3-9). Prior steps in the process already included a first impact assessment, by means of accumulated water budgets or simulated groundwater levels, making this step not really a stand-alone step but rather an implemented element of the entire process. The assessment is based on the idea to define quantifiable indicators that can be used to give a value to the individual strategies. It may be of advantage to define these indicators earlier throughout the process and use them already in the past two steps as an orientation if iteration back to Step 4 is required. Once the budget and simulation assessments are conducted and the selection of potential strategies that might be implemented in the study area is reduced to a moderate number, the defined indicators can be used to finally directly 
compare and rank the remaining options. The indicators themselves should ideally be defined in accordance to the local stakeholders' own preferences. Existing water plans can be used as a basis. They often include defined development goals, which could have been used also for the definition of scenarios, which can be translated into quantifiable indicators. They should cover at least the three main fields of sustainable development: social, economics and environment as have been addressed in Chapter 2. The assessment itself should include the actual calculations of the indicator performances and a comparison based on a defined weighting of the selected indicators. This weighting, like the indicators themselves, can be derived by stakeholder consultation. For instance, the level of achievement in the environmental sector may outrank the economic and social aspects.

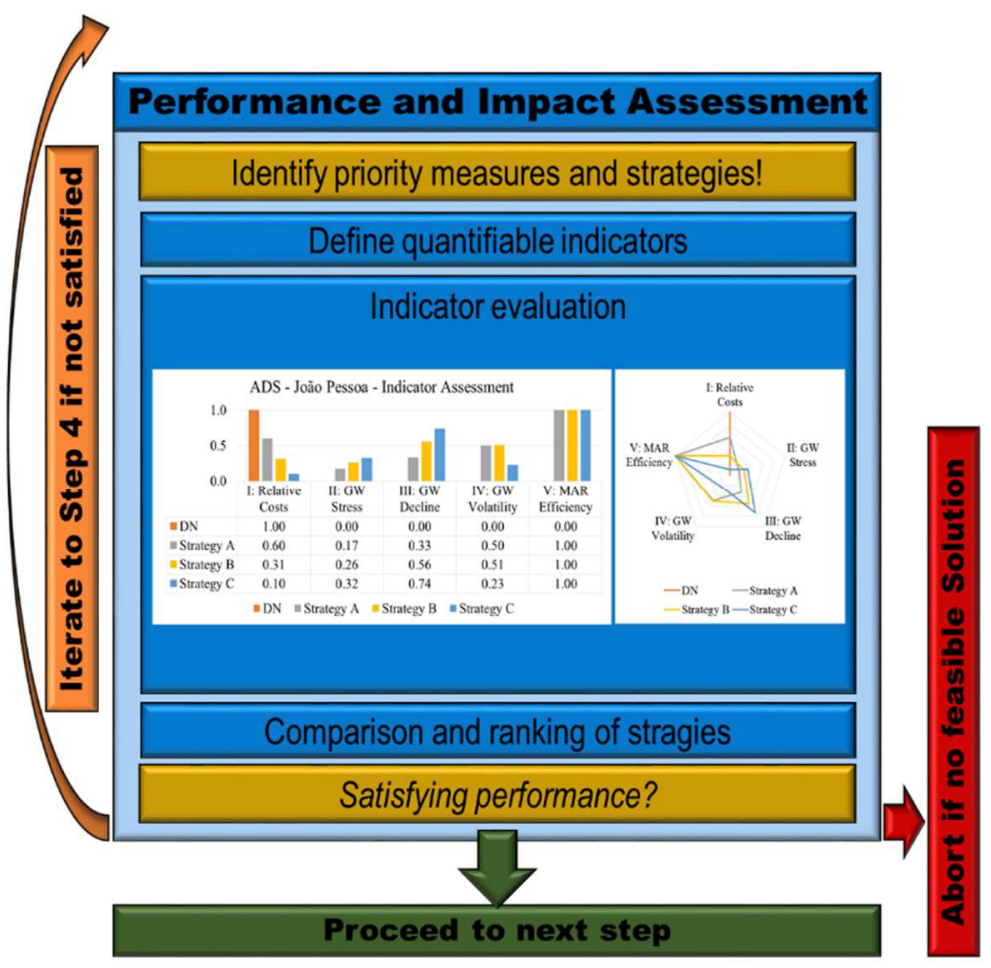

Figure 3-9: Illustration of MAR Planning Process -Step 8/10.

In order to avoid a bias of the results by adjusting the indicators and setting the weighting during the evaluation, which may lead to the unconscious attempt to strengthen the performance of a subjective strategy, these steps should ideally be conducted before the actual evaluation starts. Finally the assessment will deliver a ranking of MAR options, sorted by performance. Now ideally a priority option for a potential MAR implementation has been identified. If this is not the case and the performances are overall unsatisfactory, it should be iterated back to the definition of strategies and try to further improve these. If this also fails, it may be concluded that MAR, despite prior positive results, is not a suitable measure for the case study. 


\subsubsection{Step 9: Recommendations for Pilot Plant(s)}

If the prior steps lead to the result that one prioritized strategy could be identified for the study area that can support achieving the development goals and performs satisfactory under a variety of extreme scenarios, recommendations for the installation of one or more pilot plants in the field should be given. Step 9, as illustrated in Figure 3-10, is concerned with the compilation of all results and creating a basis to work together with engineers on the design of a long-term experimental unit.

This step is the logical next level of the MAR research. Relying solely on computer simulations cannot be sufficient. Only by testing and operating a downscaled MAR facility in the field and carefully monitor its operation, final recommendations can be given. It is recommended to include engineers in the design process and give them the general direction based on the study results. These include a definition of the operation schemes according to the listed parameters. In addition, to the design of a pilot plant, a monitoring system should be suggested. The goal of the field implementation will be to test the theoretical assumptions under real world conditions. Therefore, the behavior of the recharged water and the system's response must be quantified by means of monitoring. The recharged water could additionally be fed with a tracer in order to track the groundwater flow regime.

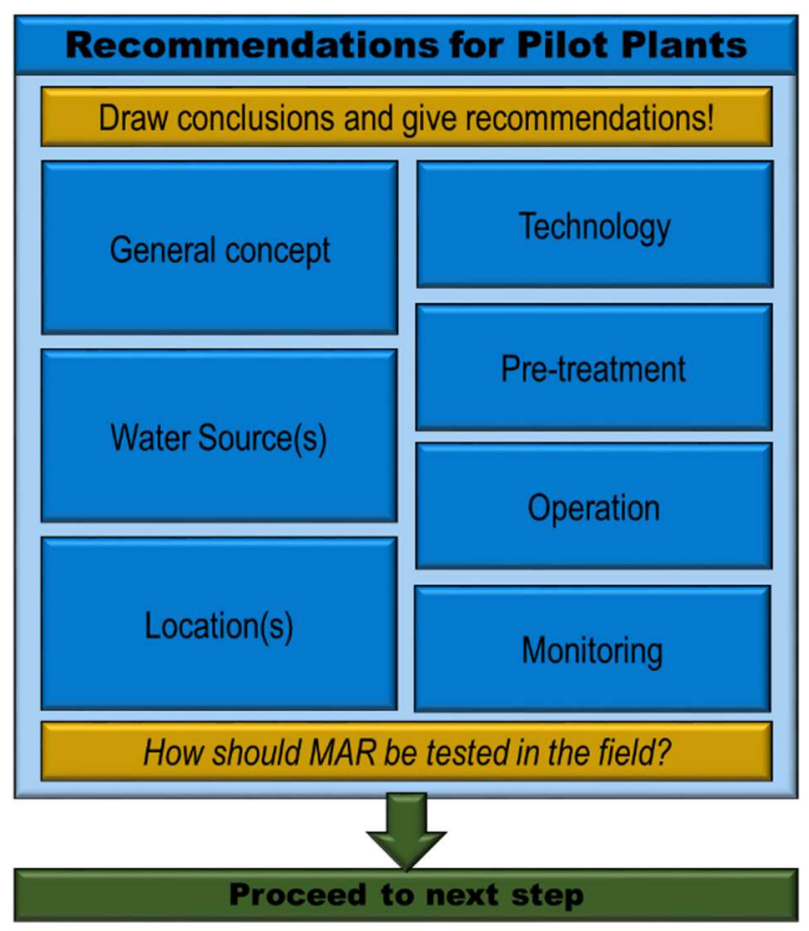

Figure 3-10: Illustration of MAR Planning Process -Step 9/10.

It can be foreclosed at this point that within the study this is where the application and testing of the suggested MAR planning process will end for both case studies. The results of this thesis will be to give recommendations for actual field implementations. 


\subsubsection{Step 10: Technical MAR Feasibility Study}

The next step in the suggested MAR planning approach will be the actual design, implementation and evaluation of the suggested pilot plant. This step requires cooperation with engineers. The design of a MAR facility is again highly depending on the site specific parameters (Patel \& Desai, 2018) and the framework that is delineated by evaluation of Step 1-9. The final goal should be a conclusion about the applicability and feasibility of a MAR system in the study area. As the illustration in Figure 3-11 shows, even now the results may and should lead to a new iteration of improving integrative MAR strategies. There is no guarantee that all theoretical work conducted at this point will actually lead to a positive result. This is why field experiments are of such an importance.

The actual design should be conducted based on the results formulated in the prior step. Close cooperation with local stakeholders must be underlined. For instance in underdeveloped regions, where most of the water users are farmers, it would be recommendable to include these farmers in the building process of the pilot plant. This increases the transparency of the conducted measures and consequently the chances of acceptance by the people.

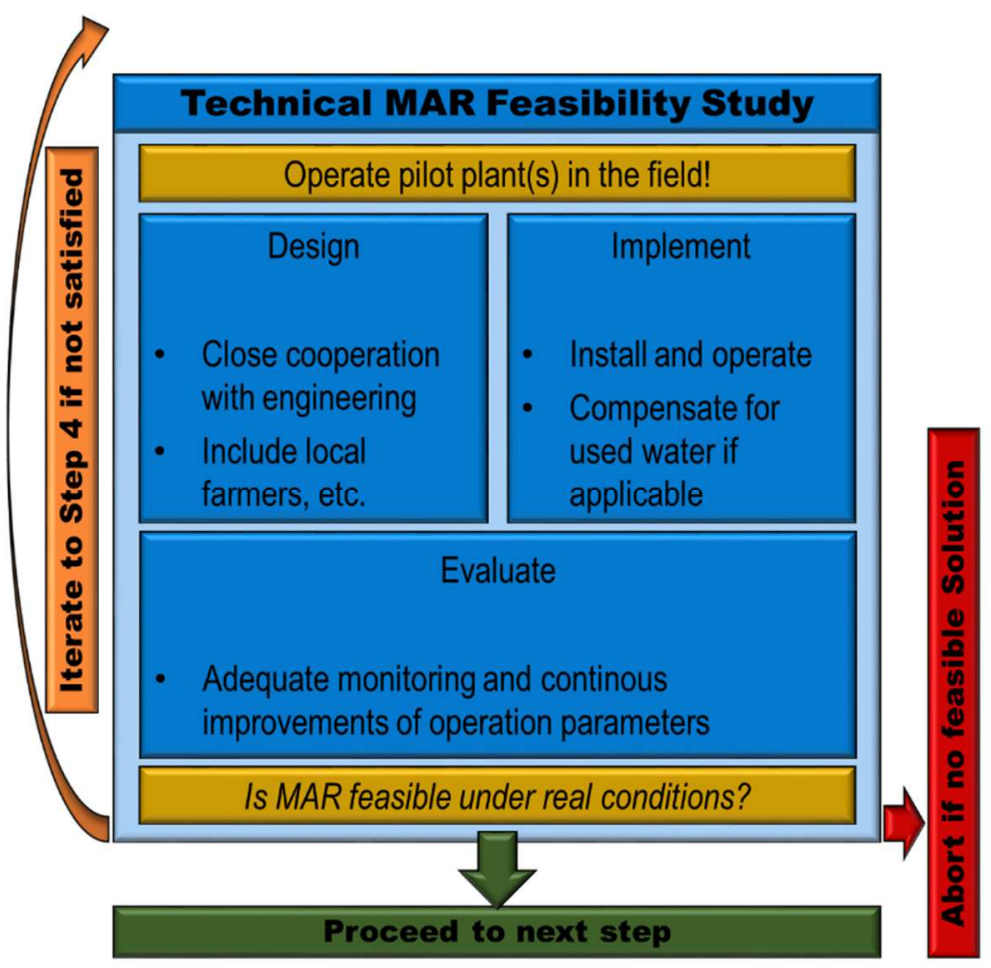

Figure 3-11: Illustration of MAR Planning Process -Step 10/10.

It is recommended that the pilot plant is located at a potential final position for a real MAR implementation. The plant might be designed in a way that its capacity can easily be increased. For instance when using surface infiltration ponds, enough additional area should be available to increase the recharge capacity if the pilot plant are transferred into an actual facility. The pilot plant should 
basically be a downscaled version of the suggested MAR facility. The experiment runtime and the type of monitoring are very site specific issues and depend on the system, the technology used, the water quality, groundwater environment, possibilities to monitor and potential political restrictions.

\subsection{Summary of the suggested Approach}

Figure 3-12 summarizes the entire suggested MAR planning approach and sets the individual steps into context. It should serve as an overview that can be consulted throughout the following applications of the process. All of the steps will be followed for both case studies and knowledge about the overall structure of the planning process will be taken as granted. Once the recommended MAR concept has been successfully tested in the field, it is necessary to disseminate the test results by giving actual recommendations for MAR implementation. This should cover all of the above results, considerations and a good documentation of the planning process. If possible, an economic evaluation should be given. One of the main questions will be who to address. If stakeholder involvement has been conducted from the beginning, this question may already be answered, since the responsible people should have been part of the entire planning process. Other ways of dissemination are the formulation of policy briefs. These short summaries of recommendations can be addressed to a variety of recipients. It should be clear who the audience will be, since addressing experts and scientists requires a different approach than addressing politicians or city planners.

Whoever the recipient of the final recommendations will be, it should now be possible to give a complete description of the conducted work and data that the results are based on. The comparison with other MAR options and IWRM strategies in the context of different scenarios for future development will allow to make a case for the selected recommendation. Therefore, these final recommendations should already include a basis for comparison, e.g. a do-nothing approach that will show the future development of local water resources system if no additional measures are conducted. 


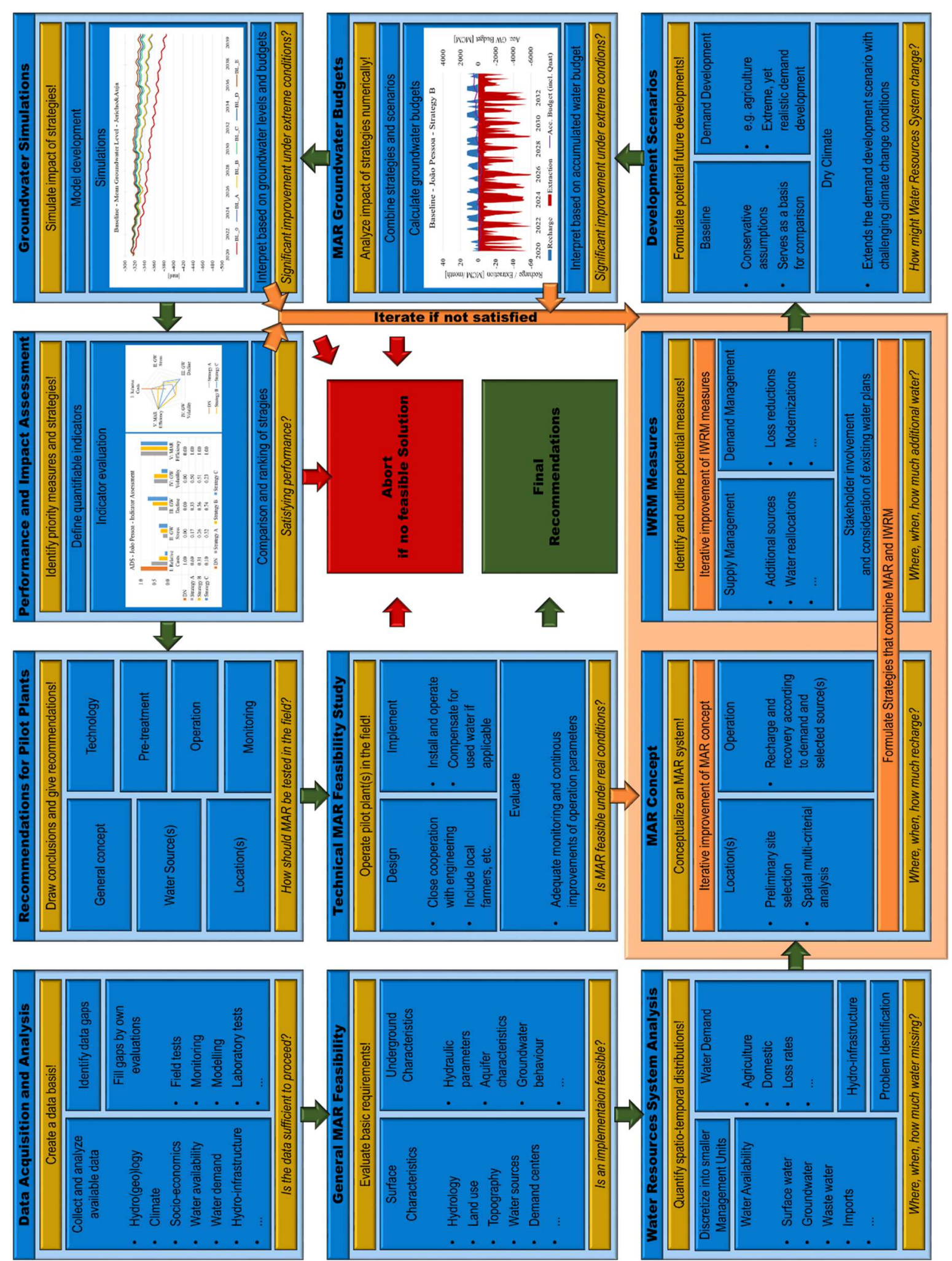

Figure 3-12: Illustration of the entire suggested MAR planning approach as a whole. 


\section{4}

Case Studies:

\section{Jỗo PessoA}

AND

\section{JERICHO-AUJA}




\subsection{Introduction}

The new developed planning approach presented in the prior chapter has been applied to two case study areas. They have been selected for their similarity in demand for advanced water management strategies and their fundamental difference in water resources characteristics. By applying and testing the approach to these contradicting conditions of tropical climate at the coast of Northeast Brazil on the one hand and semi-arid conditions within the Lower Jordan Valley on the other, its general applicability as a framework for MAR planning studies in the context of IWRM can be evaluated. After a brief introduction to each case study, this chapter will present the results of each individual planning step as presented above. The individual case study results will be described and discussed in parallel, meaning the structure of this chapter is focused primarily on the approach itself, rather than presenting the case studies one after the other. In addition, this chapter presents the results with regard to MAR planning. The following brief description are supposed to give an overview of the two case study areas. All details to the mentioned points will be elaborated in the following subchapters.

The study area of João Pessoa is characterized by extreme rainfall and surface runoff during 4-5 months of wet season per year and an extensive anthropogenic use of the local aquifer system. The main water demand sector is agriculture in the large rural area predominantly featuring sugarcane plantations. Water demand and availability are strongly depending on the annual precipitation falling directly over the coast, since the local aquifer system receives little to no horizontal recharge from the semi-arid inland. Vertical groundwater recharge is strongly restricted in the urban area due to the impermeability of the ground. The aquifer is reacting strongly to climatic variability with several meters groundwater fluctuation in between months. Both water quantity and quality must be studied carefully with regard to risks affiliated with the intense agriculture, its consumption of irrigation water and use of pesticides, as well as the domestic water systems in the rural area, with little to no treatment of waste water and many cases of unmanaged aquifer recharge from cesspits and industrial waste water. This study focusses on the quantitative aspect of a sustainable use of local water resources and the creation of a data basis that is crucial to the future planning and management of the valuable resource. MAR planning for João Pessoa and its surrounding rural area is challenged by the overall poor data situation. Though there are a variety of authorities responsible for water management and monitoring in the region (e.g. AESA, ANA), no groundwater monitoring networks were existing at the beginning of the project. Meaning no data of groundwater levels or fluctuation was available. For surface runoff, at least some data was present. In addition, water extractions from both, ground-and surface water, are not monitored. Hence, the actual consumption is not known. To rely at least on some data, completely new monitoring networks had to be designed and installed, time consuming and cost intensive. With regard to MAR in particular, Northeast Brazil has no 
experience with the technology. This might imply a decreased acceptance of MAR implementation, which is crucial for a successful implementation.

The case study of Jericho-Auja stands in contrast to the prior study area. Located in the Lower Jordan Valley (LJV), it is characterized by semi-arid conditions and high water scarcity. Unlike the Northeast of Brazil, water is not available in abundance, even throughout the rainy season. Main water sources are local springs that are fed by rainfall in the mountains. Spring discharge itself underlies very high variability. Rainfall within the study area is limited to a few storm flow events per year, with some years even completely lacking any major rainfall events. Besides the highly fluctuating spring discharge, groundwater is the main source of water for local farmers and domestic supply. In general it can be distinguished between an upper and lower aquifer, both showing high levels of salinity in some areas, with brackish groundwater conditions. The upper, shallow aquifer is already overexploited by pumping wells of unknown number. Insufficient traditional water management systems, non-efficient irrigation techniques and surface reservoirs for storage intensify the severe water resources situation. The hydrogeological situation of the aquifer system is very complex and heterogenic. The lower, deep aquifer reveals a high water potential but the installation of additional wells is costly and underlies numerous political and legal restrictions. This study will focus on the purely scientific aspects of the local water management issues, showing what would be possible taking all political obstacles aside. In contrast to the prior case study of João Pessoa, the study area of Jericho-Auja has already been subject to many studies and preceding research and development projects (e.g. SMART and SMART II). Therefore, it is not part of this study to acquire additional data by means of field work or other measures. The MAR study relies on the data and achievements of many years of cooperation of SMART and SMART-MOVE project partners. In the following, the main necessities for a successful MAR implementation in the study area are briefly addressed. This chapter will set a rough framework of the overall design of potential MAR infiltration facilities based on the site specific conditions presented here.

\subsection{Step 1: Data Acquisition and Analysis}

\subsubsection{Socio-Economics}

\section{a) João Pessoa}

João Pessoa is the capital of the federal state Paraiba in Northeast Brazil. Including the surrounding rural area, over one million people inhabit the study area. The area is characterized by a high developed urban area at the coast and a dense agricultural use further inland. Irrigated sugarcane is the dominant crop, according to own land use assessments. The coastal alluvial aquifer is under high stress due to vast water extraction rates during the dry season as will be shown under the water 
resources system analysis section. The tropical climate produces high precipitation during the rainy season, but without proper storage these resources cannot be used throughout the rest of the year.

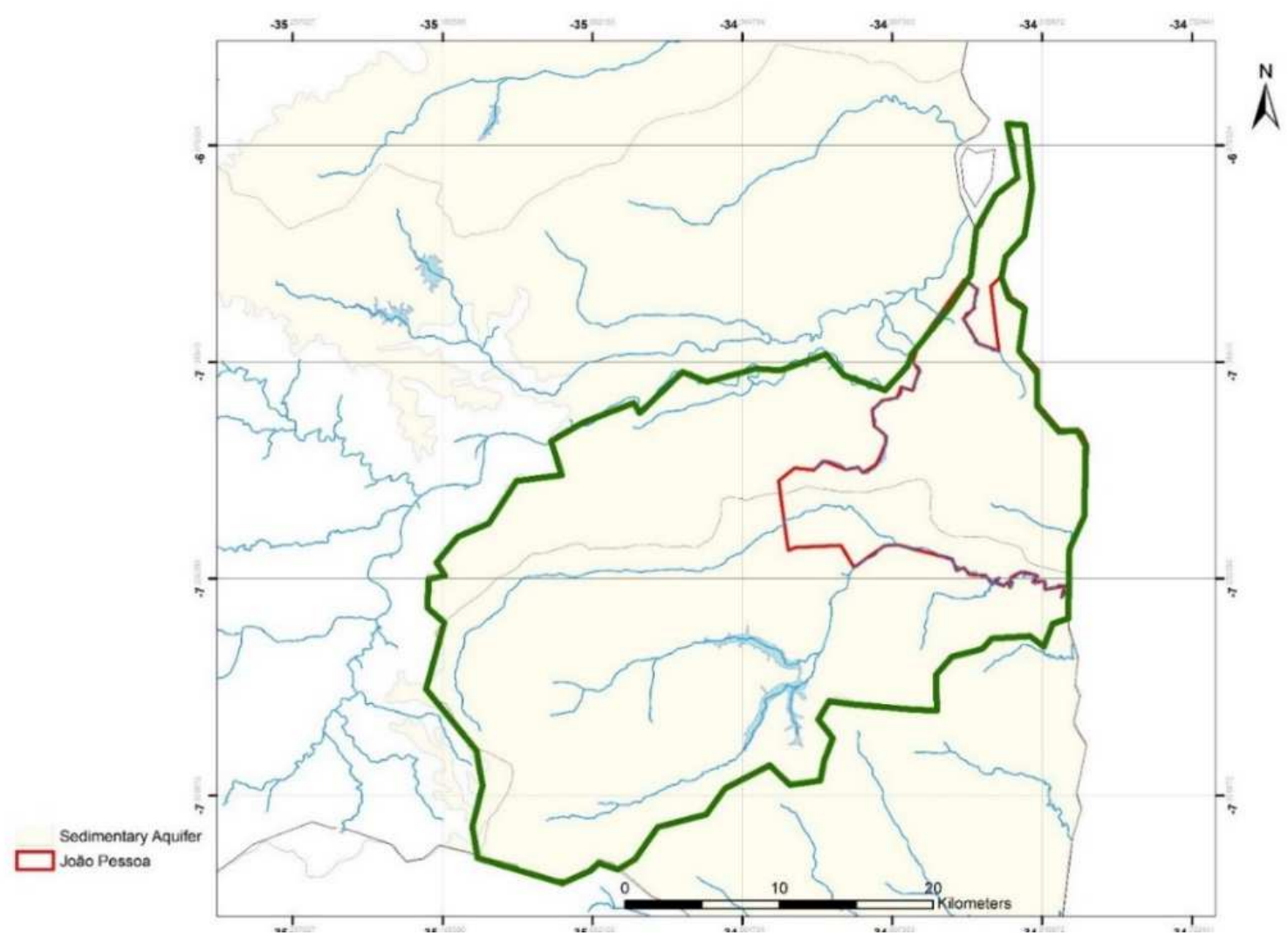

Figure 4-1: Outline of study area João Pessoa.

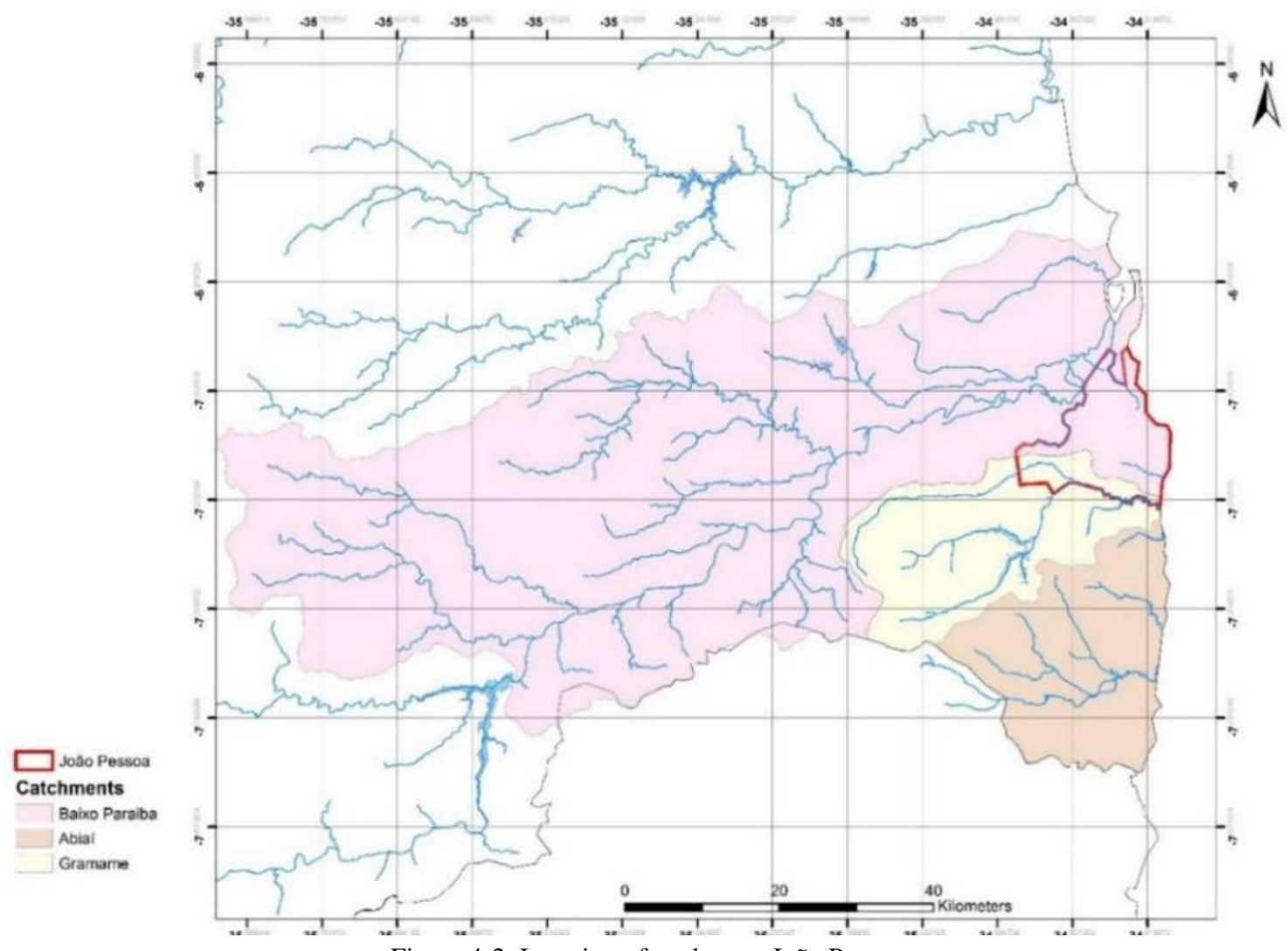

Figure 4-2: Location of study area João Pessoa. 
Figure 4-1 shows the outline of the case study area. The selected boundaries were based on numerous factors. The area includes the urban area of João Pessoa as well as the entire Gramame catchment area and a small part of the Baixo Paraiba catchment. The outline of the study area orientates on natural boundary conditions: The eastern boundary is represented by the sea. The southern boundary follows the watershed between the catchments Gramame and Abiai. To the west the change of geology from the coastal sedimentary aquifer to crystalline hard rock formations sets a limit to the aquifer. As a northern boundary the Rio Paraiba was selected.

The biggest municipality in the case study area is the city of João Pessoa. With roughly 725,000 inhabitants (as of 2010) it is the capital of the federal state Paraiba. Followed in size by Santa Rita with 120,000, Bayeux with 100,000 and Capedelo with 60,000 inhabitants respectively. Further 90,000 people are spread over another five minor municipalities the size of 6-30 thousand inhabitants each (IBGE, 2010).

Table 4-1: Municipalities in Case Study Area João Pessoa -urban and rural population (IBGE, 2010)

\begin{tabular}{|l|r|r|r|}
\hline Municipality & Urban Population & Rural Population & Total Population \\
\hline João Pessoa & 720,785 & 2,730 & $\mathbf{7 2 3 , 5 1 5}$ \\
\hline Santa Rita & 103,717 & 16,593 & $\mathbf{1 2 0 , 3 1 0}$ \\
\hline Bayeux & 98,793 & 923 & $\mathbf{9 9 , 7 1 6}$ \\
\hline Capedelo & 57,936 & 8 & $\mathbf{5 7 , 9 4 4}$ \\
\hline Pedras de Fogo & 16,358 & 10,674 & $\mathbf{2 7 , 0 3 2}$ \\
\hline Conde & 14,487 & 6,913 & $\mathbf{2 1 , 4 0 0}$ \\
\hline Alhandra & 11,153 & 6,854 & $\mathbf{1 8 , 0 0 7}$ \\
\hline Cruz do Espírito Santo & 7,440 & 8,817 & $\mathbf{1 6 , 2 5 7}$ \\
\hline São Miguel de Taipu & 2,977 & 3,719 & $\mathbf{6 , 6 9 6}$ \\
\hline Sum & $\mathbf{1 , 0 3 3 , 6 4 6}$ & $\mathbf{5 7 , 2 3 1}$ & $\mathbf{1 , 0 9 0 , 8 7 7}$ \\
\hline
\end{tabular}

Population in Case Study Area João Pessoa 2010

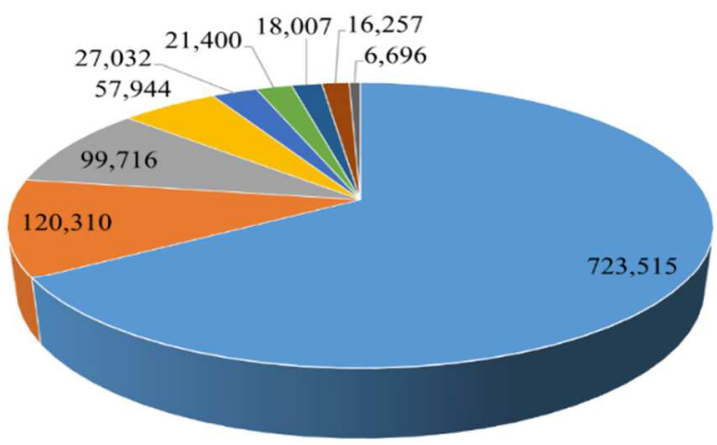

- João Pessoa
- Capedelo
- Alhandra

$$
\begin{array}{ll}
\text { = Santa Rita } & \text { " Bayeux } \\
\text { " Pedras de Fogo } & \text { " Conde } \\
\text { " Cruz do Espírito Santo } & \text { " São Miguel de Taipu }
\end{array}
$$

Urban vs Rural Population in Case Study Area 2010

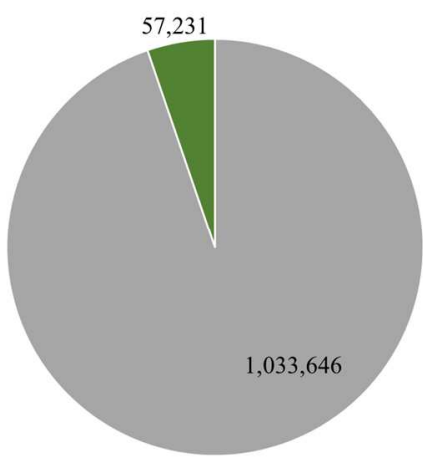

- Urban - Rural

Figure 4-3: Population the the case study area -distribution among municipalities and urban/rural. 
Table 4-1 lists all municipalities in the study area with inhabitants categorized by urban and rural population. In total about 1.1 Mio. people live in and, since some municipalities lie on the border of the selected outline, around the study area. The demography shows that the vast majority of people in the region live in urban districts. Only $5 \%$ of the population live in rural communities (IBGE, 2010). In total numbers that is 1.03 Mio. people in cities and 60,000 people living in villages or farms. Figure 4-3 illustrates this one-sided distribution.

For MAR site selection data on land use plays a pivotal role in identifying suitable areas for the implementation of recharge sites. If surface technologies such as infiltration ponds are utilized quite large areas are required. Forests or urban areas are not suitable for this purpose. Agricultural land might be purchased. Depending on the cultivated crop land costs might vary. It is also relevant in terms of irrigation demand calculations. In the study area, only estimations of irrigation water demand exist as will be discussed in the section on water demand assessment. In order to perform calculations of potential irrigation water demand, land use must be known. This allows for an analysis of spatial distribution of demands, as well as the calculation of scenarios in terms of agricultural development or change of climate conditions such as precipitation.

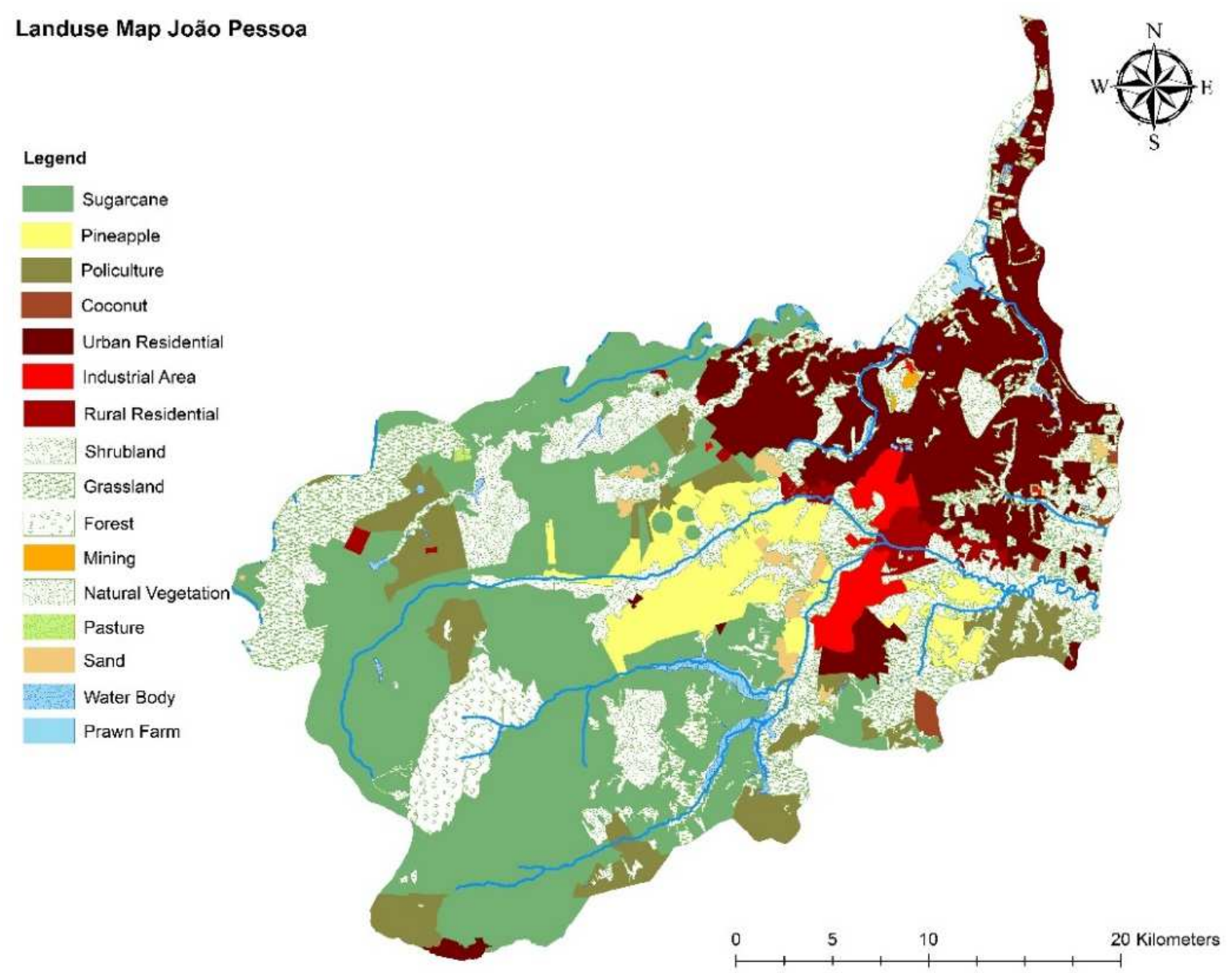

Figure 4-4: Land use map João Pessoa (Walter et al., 2018). 


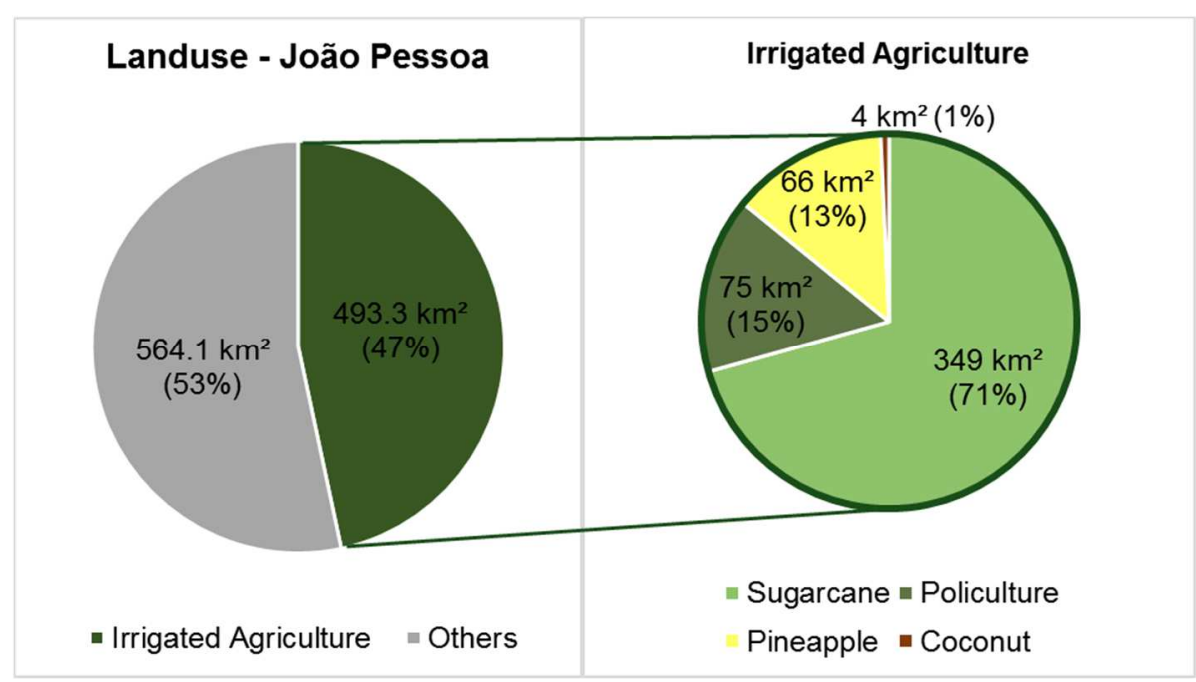

Figure 4-5: Agricultural land use in study area.

Land use of the João Pessoa case study area has been studied in cooperation with the BRAMAR project partner UFPB. Based on a pre-existing map, several field visits were conducted to update and improve the data (Walter et al., 2018). Figure 4-4 and Figure 4-5 show the results of this analysis. According to the results, irrigated agriculture makes up about $47 \%$ of the study area. Of these the major crop in the region is sugarcane (roughly $71 \%$ or $349 \mathrm{~km}^{2}$ within the outline of the study area). In total this means one third of the region consists of sugarcane fields. Being a crop with fairly high water demand, these results indicate very high agricultural water demand. This will be analyzed in detail in Chapter 4.4.3. The second biggest crop in the area is pineapple: Roughly $66 \mathrm{~km}^{2}$ (or $13 \%$ of the irrigated area) are pineapple fields. As can be seen in the land use map, these areas are concentrated in the center of the study area. Another $15 \%$ of agriculture consists of polyculture areas. These contain manioc, mango, pineapple, coconut, banana and others. It was not possible within the course of this study to collect more detailed information about those areas. Hence, they are aggregated as "polyculture". In the southeast of the study area some bigger coconut plantations can be found. However, these only make up $1 \%$ of irrigated areas.

\section{b) Jericho-Auja}

The semi-arid case study area comprises two municipalities; the city of Jericho and the Auja village, north of the city. It inhabits roughly 25,000 people. The region is of rural and agricultural character and suffers from extreme climatic conditions. With an increase of water availability and a more resilient water supply system, the area would have an enormous potential for agricultural development.

The Lower Jordan Valley (LJV) is bordered by the Jordan River to the east and mountains to the west. Towards the Dead Sea in the south, surface elevation drops steadily to more than $400 \mathrm{~m}$ below 
sea level. The city of Jericho is famous for its claim to be the world's oldest city, though archeological discoveries contradict this statement. However, today it inhabits around 22,000 people, living mainly from agriculture and tourism. Jericho is located directly at the border of the two Wadis Nueimah and Qilt and relies, amongst groundwater resources, on the discharge of the respective spring groups. North of the city the village of Auja is located. With roughly 3,000 inhabitants it is significantly smaller. Auja village receives most of its water supply from the Auja spring, which has the highest discharge, but also highest hydraulic variability, in the study area as will be presented in Chapter 4.2.3. Main source of income is the local agriculture. Due to political and economic indicators, most of the agricultural areas belong to private companies, as local farmers continuously sell their land and share on the local water rights (Walter, 2013a). Most of the associated land can be described as uncultivated.

Infrastructure is given by a main road connecting Auja with Jericho, continuing parallel to the Jordan River to the north and a road going westwards toward the mountain area an Auja Spring. Today's agricultural land is limited to less than $33 \mathrm{~km}^{2}$. With around $6 \mathrm{~km}^{2}$ located around Auja village and some $27 \mathrm{~km}^{2}$ ha around the city of Jericho. According to local development plans, so-called "water plans", there is a high potential for agricultural extension to an area of $43 \mathrm{~km}^{2}$. Limiting factor for agriculture in the study area is water availability, not land. These values have been assessed by project partners after stakeholder consultation in the context of the development of a WEAP model (Rusteberg et al., 2018a).

\subsubsection{Climate}

\section{a) João Pessoa}

The case study area lies within a "tropical monsoon climate" zone according the Köppen climate classification (category "Am", Köppen, 1918). This climate is determined by the following characteristics:

- Monthly mean temperature $>18^{\circ} \mathrm{C}$ in all months

- Pronounced dry and wet seasonality

- Precipitation $<60 \mathrm{~mm}$ in the driest month

- Precipitation > [100 -(total annual precipitation / 25)] in the driest month (McKnight \& Hess, 2000)

Figure 4-6 shows historic climate data for the city of João Pessoa from 1961-1990. Mean annual precipitation is $2,145 \mathrm{~mm}$, while the average temperature is $26.1^{\circ} \mathrm{C}$ with very limited fluctuation throughout the year. It can be observed that the mean monthly temperature never drops below $24{ }^{\circ} \mathrm{C}$. On average the months October to December are particularly dry, showing a clear seasonality of wet 
and dry periods. The dry season lasts, depending on the annual variability in rainfall, from September or October to January or March. The driest month, November, has a mean precipitation of $24.9 \mathrm{~mm}$. With a mean annual precipitation of $2,145 \mathrm{~mm}$ also the last criteria for tropical monsoon climate is fulfilled $(100-2145 \mathrm{~mm} / 25=14.2 \mathrm{~mm}<24.9 \mathrm{~mm})$.

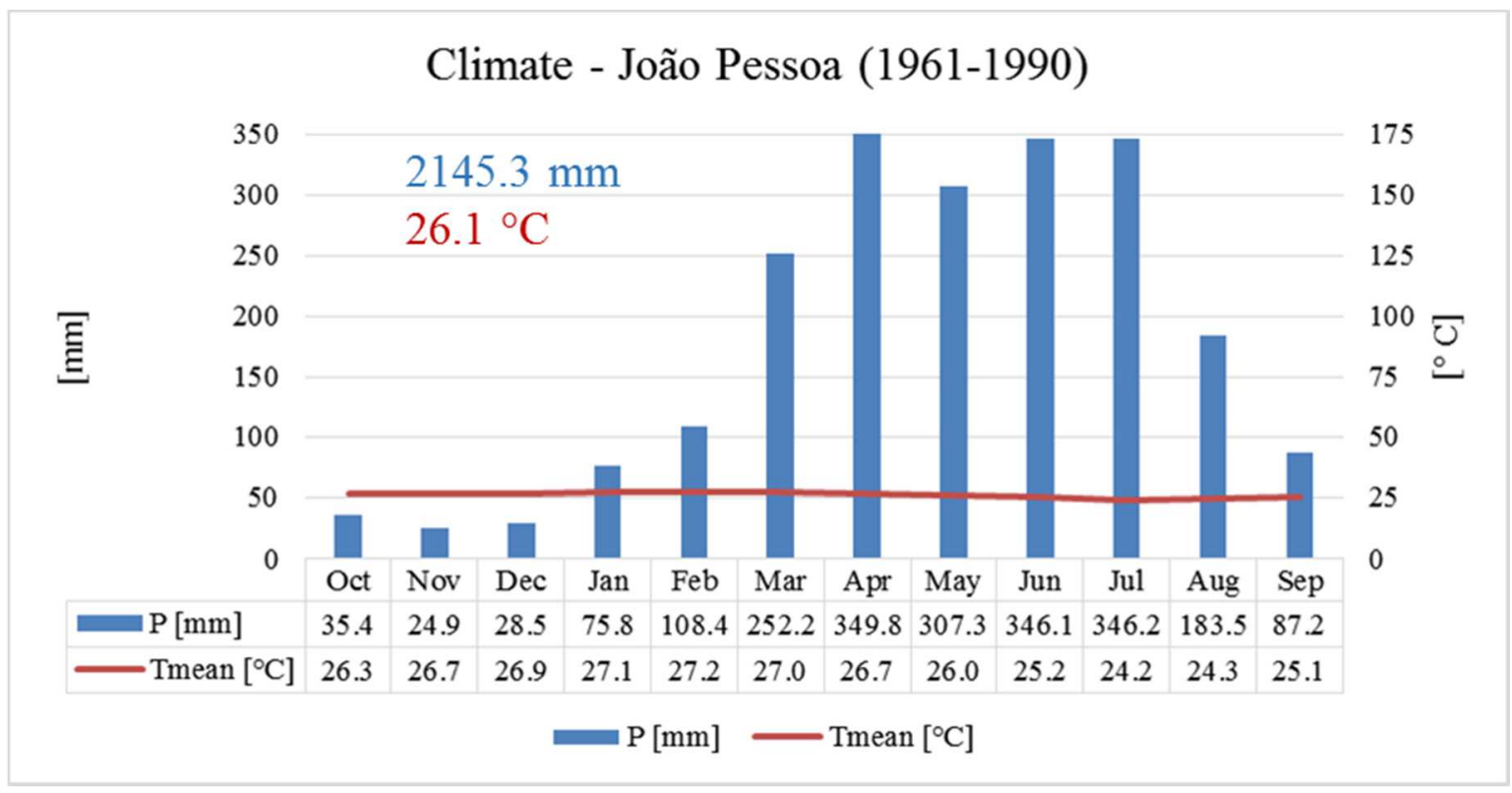

Figure 4-6: Climate Diagram João Pessoa (INMET, 2017 and INMET, 2017b).

For precipitation a rather satisfying monitoring network has already been installed. It is the best monitored parameter in the region. In order to further improve the network, the BRAMAR project added several new precipitation stations. Also for these, the local partner at UFPB took over responsibility for operation and maintenance. The available data sets were used as input for the hydrological model of the project partner (Schimmelpfennig et al., 2018).

The case study's specific data situation requires calculations of the irrigation water demand. For this purpose data on potential evapotranspiration is required. Within the study area some climate stations were already installed. The BRAMAR project added one additional station to the region, being operated and maintained by the UFPB. The available data sets were primarily used for the development of the hydrological model developed by the project partner TU Braunschweig (Schimmelpfennig et al., 2018). The model delivered, amongst other relevant data, time series for potential evapotranspiration that was used for the calculation of irrigation water demand, being presented in the next step: The water resources system analysis. 


\section{b) Jericho-Auja}

Climate in the Palestinian territories is strongly heterogeneous. It is characterized by several microclimate zones ranging from humid in the western heights to extremely arid in the south over a relatively small spatial extension (Striem \& Rosenan, 1973). In general, average temperatures increase from west to east and from north to south (Dudeen, 2001), while average annual rainfall decreases with the same spatial distribution (EXACT, 1998). Climate is highly influenced by the central mountain range, the North African Desert to the south, and the Jordan-Syrian Desert to the east (PCBS, 2010). Hence, the western semi-coastal region can be described as sub-humid climate, changing to humid conditions with the beginning of the mountain area, at the western slopes. The central heights within the mountain range can be characterized as semi-arid, while its eastern heights are mildly arid. The Lower Jordan Valley east of the mountain range is generally determined by semi-arid to arid climate (Striem \& Rosenan, 1973).

Figure 4-7 shows average climatic data for the Jericho district in the south of the study area. The average annual precipitation of $184.4 \mathrm{~mm}$ is far below average potential evapotranspiration rates of $2120.6 \mathrm{~mm} / \mathrm{a}$ (Shawanah, 2010). Rainfall is strongly limited to October to April, with a peak during winter months at a maximum average of $53.7 \mathrm{~mm}$ in January. Rainfall mainly occurs in short events of very high intensity. These events periodically trigger storm floods, as high quantities of water discharge in short time and the dry soils are not able to take up much of the water. Thus, the area is strongly characterized by these storm floods' flow paths: The Wadis. Potential evapotranspiration rates outrange precipitation all over the year, with maximum rates during summer, reaching average values close to $300 \mathrm{~mm}$ in July. Temperatures in the study area range from $13.3{ }^{\circ} \mathrm{C}$ in January to $30.0^{\circ} \mathrm{C}$ in July on the monthly average level. Mean annual temperature is $22.5^{\circ} \mathrm{C}$.

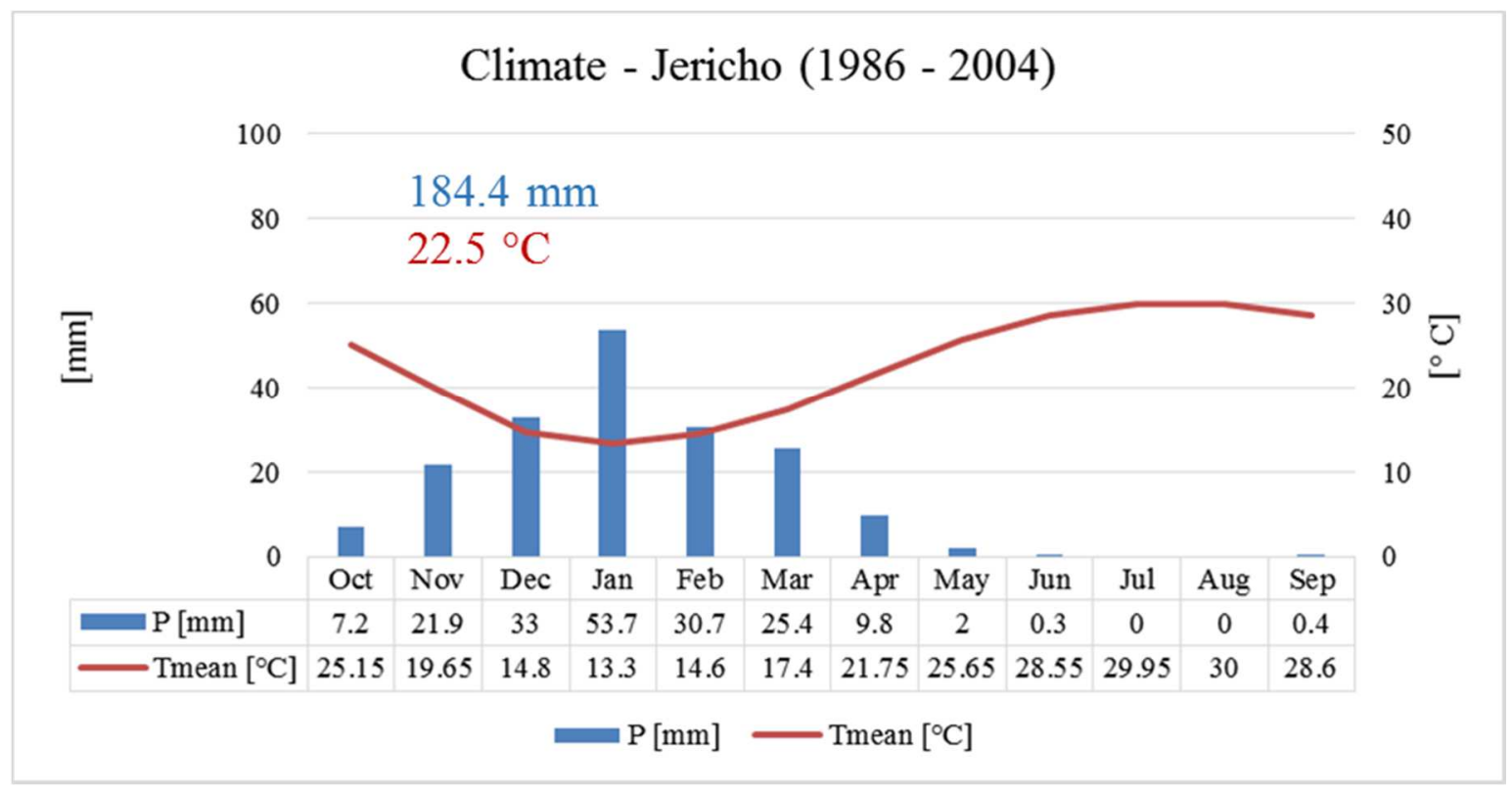

Figure 4-7: Climatic Diagram -Jericho (modified after Shawanah, 2010). 


\subsubsection{Hydrology}

\section{a) João Pessoa}

Located in the coastal part of the state Paraíba, the region of the Lower Paraíba River Course is narrowed by the basin of Mamanguape and Miriri to the north, by the Atlantic Ocean to the east, by the Gramame subbasin and the state of Pernambuco to the south and the East Course region of the Paraíba River to the west. It spans from latitudes $6^{\circ} 55^{\prime} 13$ " to $7^{\circ} 30^{\prime} 20$ " South and longitude $34^{\circ} 47^{\prime} 37$ " to $35^{\circ} 55^{\prime} 23$ " West of Greenwich. In the City of Cabadelo, the Paraíba River flows into the Atlantic Ocean, after its lower course drained an area of $3940 \mathrm{~km}^{2}$ (Costa et al., 2007).

On the south coast of the State of Paraíba there is the basin of the Rio Gramame, which has an area of ca. $589 \mathrm{~km}^{2}$. It is located between latitudes $7^{\circ} 10^{\prime} 27$ " and $7^{\circ} 24^{\prime} 23$ "South and longitude $34^{\circ} 48^{\prime} 12$ " and $35^{\circ} 10^{\prime} 46$ " west of Greenwich. The main river of the Rio Gramame and its tributaries form the hydrographic network of the basin which is studied. Mumbaba, Mamuaba and Gramame are the main sub-basins of the Gramame River, while the Utinga River, Rio Pau Brazil, Pitanga Creek, Ibura Creek, Piabuçu Creek and the River Good Water form the main tributories on the right bank and the Riacho Santa Cruz, Stream of Quizada, Bezerra do Riacho Angelim do Riacho, Botamonte Creek, Rio Mamuaba, Camaço Rio and Rio Mumbaba on the left Figure 4-8. The course of the main water basin is $54.3 \mathrm{~km}$ long and is not too subject to flooding (Costa et al., 2007).

Sub-Catchments Panta Rhei - João Pessoa

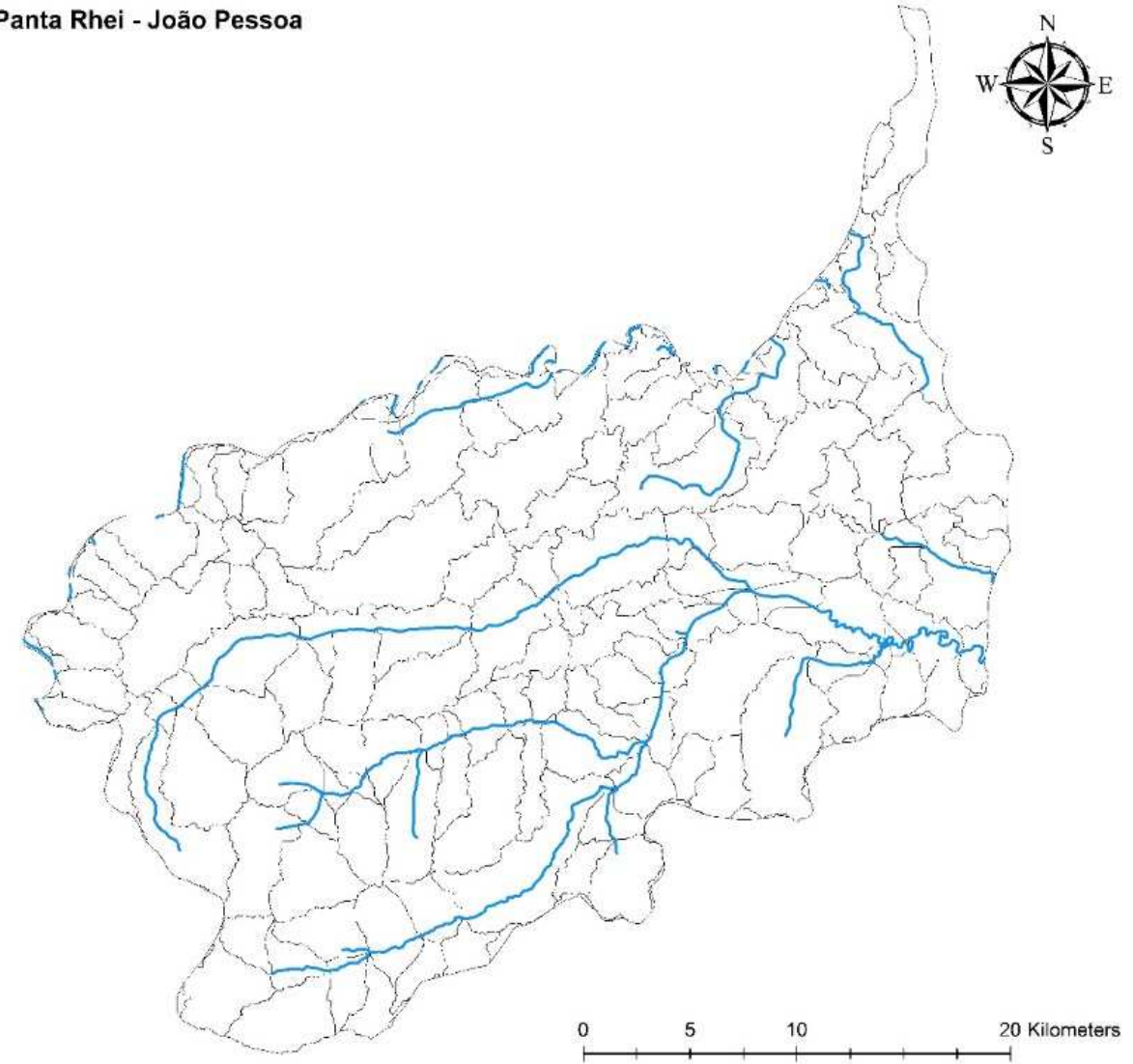

Figure 4-8: Sub-Catchments of Panta Rhei Hydrological Model (modified after Schimmelpfennig et al., 2018). 
Nearly no active surface runoff gauges could be found within the study area. Within the course of the BRAMAR project, several new gauges to measure surface runoff have been installed by project partners. Operated also by UFPB, these gauges deliver valuable data on water availability. As for the above introduced parameters, surface runoff data was implemented in the hydrological model (Schimmelpfennig et al., 2018). For the purpose of MAR planning, the model generated time series of surface runoff that were used for this study. Virtual gauges were established within the model area as illustrated in Figure 4-8. Quantities of surface runoff will be discussed in Chapter 4.4.2.

\section{b) Jericho-Auja}

There are no major surface water bodies in the region. Wadis represent the only surface freshwater supply for the region due to rainfall events which occur irregular and variable in intensity. The Jordan River, east of the study area, flowing from Lake Tiberias north of the study area to the Dead Sea in the south is the only surface water body in the region. Palestinians, however, have no access to this water source as it lies within Israeli territory. The two municipalities of Jericho and Auja cross three main wadis: Wadi Auja to the north, Wadi Nueimah and Wadi Qilt in the south (Figure 4-9). Due to the difficulty of translating Arabic names into English, literature contains a variety of different ways to spell these names (e.g. Auja/Uja, Nueimah/Nuwei'ma, Qilt/Qelt to name only a few).

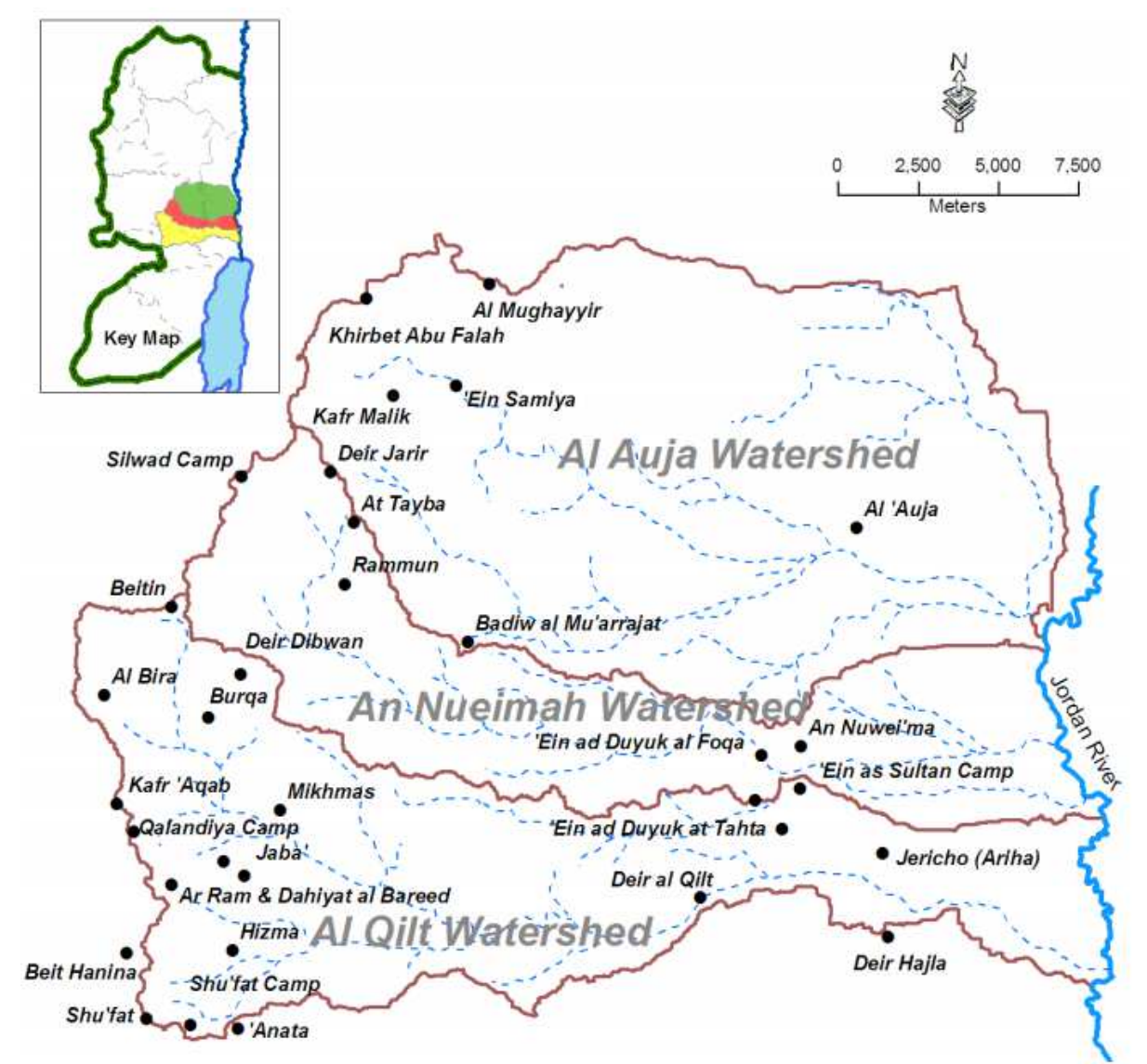

Figure 4-9: Delineation of the three major watersheds in the study area (Abu Sadah \& Tamimi, 2011). 


\subsubsection{Hydrogeology}

\section{a) João Pessoa}

An overview of the aquifer systems in the state of Paraiba and its geology are given in Figure 4-10. The Sedimentary Basin Paraiba is characterized by the light brown color. At the coastal area it consists of three Sub-Basins which are from north to south: Miriri, Alhandra and Olinda. The Miriri Sub-Basin is devided from the Alhandra Sub-Basin by the Itabaiana Fault (Falha de Itabaiana).The Golana Fault (Falha de Golana) devides the Sub-Basins Alhandra and Olinda. The Mamanguape Fault (Falha de Mamanguape) marks the northern boundary of the Sedimentary Basin. This fault is part of the Patos Shear Zone (Zona de Cisalhamento de Patos). To the south, the basin is bounded by the Pernambuco Shear Zone (Zona de Cilahamento de Pernambuco). Sedimentary soils are predominant here. They are sandy and clay deposits. At the edge of the Paraiba Basin there are also cretaceous sedimentary formations. These mainly arise on steep slopes (Santos et al., 2013). The sedimentary aquifer system covers the entire coastal region of Northeast Brazil. This enables the extrapolation of results from this case study to several similar areas along the coast.

The study area is located within the vicinity of the sedimentary basin Paraiba (Figure 4-11 and Figure 4-12). The sedimentary aquifer is defined by four layers: the Barreiras, Farinha, Gramame and Beberibe. The sediments of the Barreiras Formation derived primarily from weathering of the crystalline basement and are located more to the interior of the continent. In the state of Paraíba this foundation is composed of crystalline rocks of the Plateau of Borborema. Sedimentological analyzes in the Paraíba Barreiras revealed granites, gneisses and schists, which are the predominantly lithologies of the Plateau of Borborema, to be the sources of the sediments (Gopinath et al., 1993). According to Alheiros et al. (1991), the upper formation is characterized by quartz sands and clays subarcoseanas, which have a highly variable thickness in the state of Paraíba and can reach up to $80 \mathrm{~m}$. The deposits vary from gravel and coarse sand to fine, feldspathic compositions with interbedded microclasts of clay/silt with a yellowish cream color (Pereira da Silva, 2006). Due to the absence of fossils in this group, there are uncertainties in their age. Some authors consider the Tertiary East to Pleistocene, Oligocene to Pleistocene (Mabesoone et al., 1972) and Lower to Upper Pliocene (Suguio et al., 1986). 


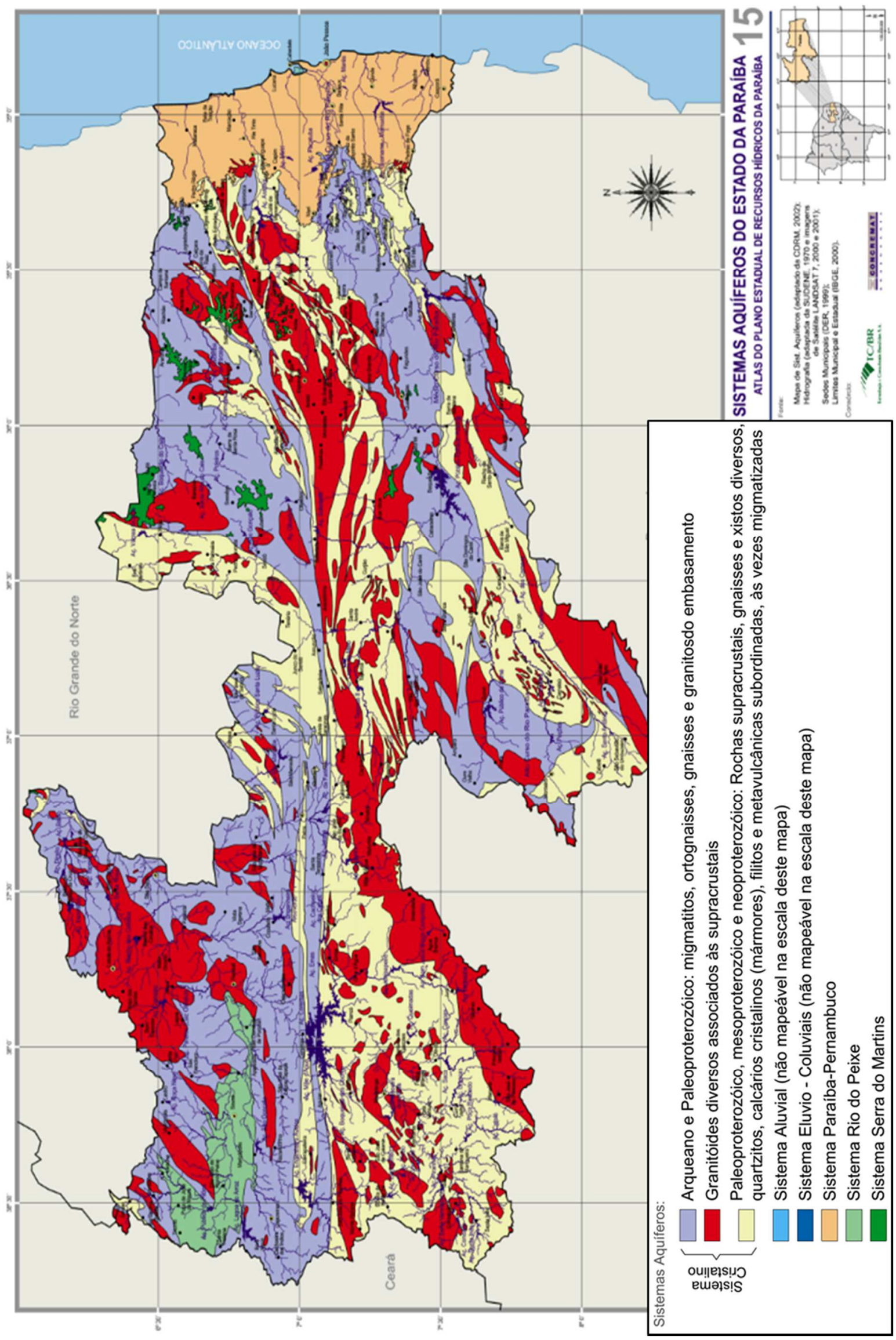

Figure 4-10: Aquifer Systems and River Network -State of Paraiba (modified after: AESA, 2015). 


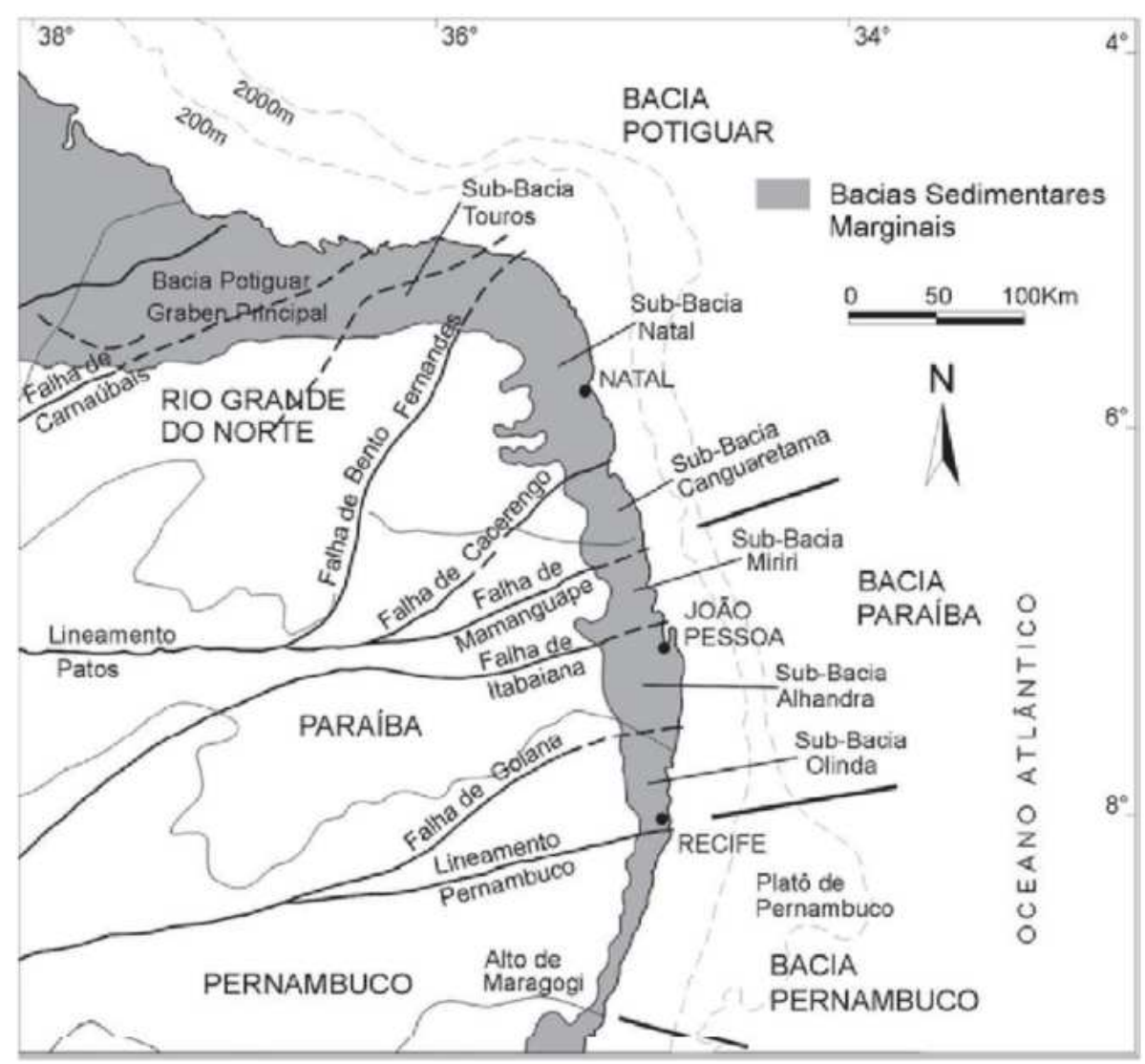

Figure 4-11: Sedimentary Basin Paraiba (Barbosa et al., 2003; in: Coelho, 2011).

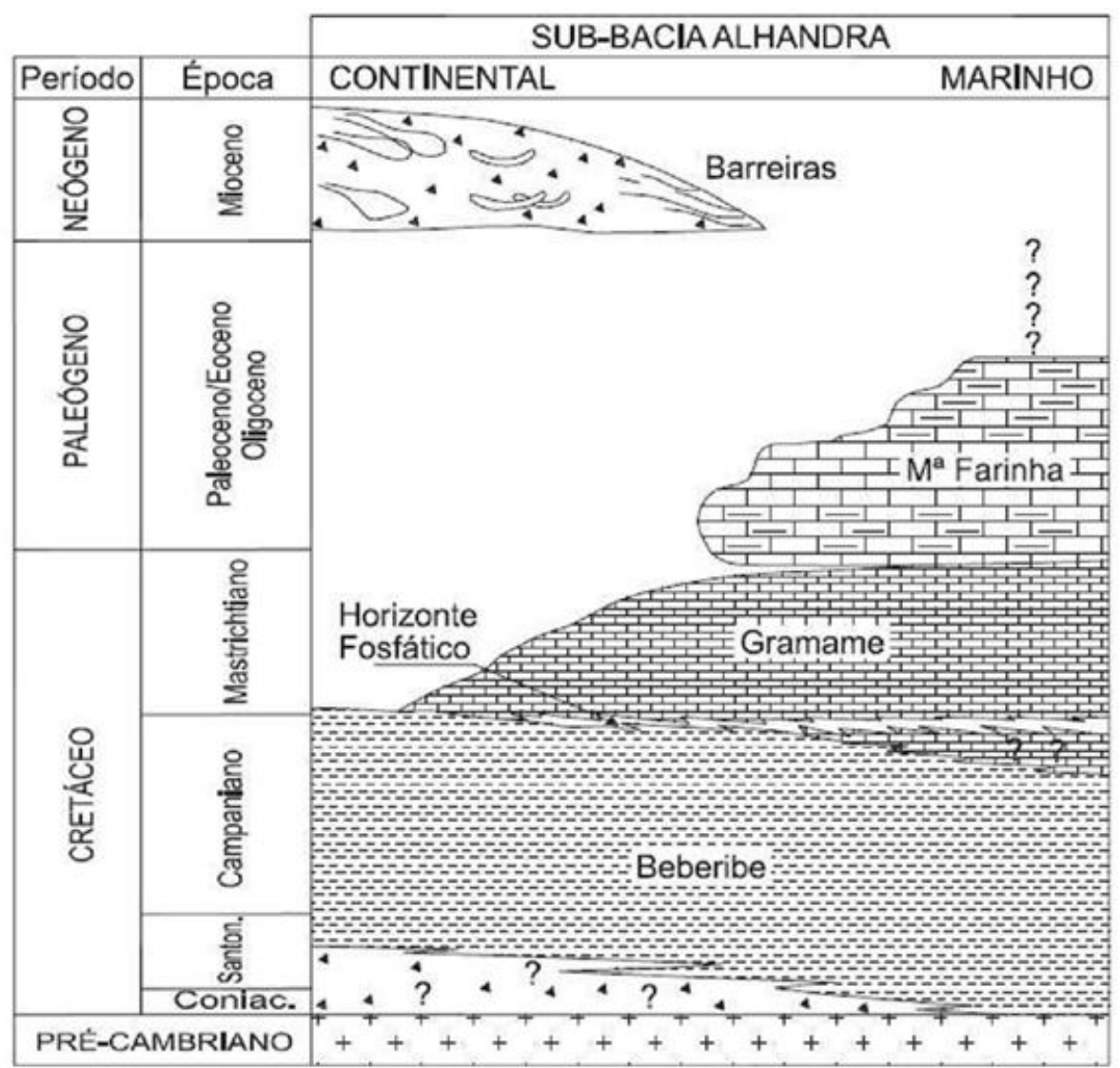

Figure 4-12: Stratigraphy of Alhandra Sub-Basin (Furrier et al., 2006; in: Coelho, 2011). 
Table 4-2: Overview lithologic formations João Pessoa

\begin{tabular}{|c|c|c|c|}
\hline Formation & Material & $\begin{array}{r}\text { Thickness } \\
{[\mathrm{m}]} \\
\end{array}$ & $\begin{array}{r}\mathbf{K} * \\
{[\mathbf{m} / \mathbf{d}]}\end{array}$ \\
\hline Barreiras & $\begin{array}{r}\text { alluv. sediments and sandstone, } \\
\text { partially clay }\end{array}$ & $\begin{array}{r}<? \text { (west) } \\
0-90 \text { (east) } \\
\text { mean: } 20 \text { (east) }\end{array}$ & $<3$ \\
\hline Gramame & clayey limestone & $\begin{array}{r}0-160 \\
\text { mean: } \mathbf{5 5} \\
\end{array}$ & \\
\hline Beberibe & sandstone & $\begin{array}{r}60-290 \\
\text { mean: } 185\end{array}$ & $<8$ \\
\hline
\end{tabular}

The Barreiras Group occurs consistently along the Brazilian coast from the state of Amapá to the northern part of the state of Rio de Janeiro (DaSilva Santos, 2011). Despite the great extent of this group their deposits are still poorly understood, both with regard to its sedimentary characteristics and mainly about their tectonic features. The name "Barreiras" has been used with a stratigraphic meaning in order to describe sandy and clayey deposits of varying colors. Dating of paleomagnetic mirco-pollen indicates Miocene to Pliocene age. For a long time the Barreiras Group was considered essentially of continental origin. Some authors have revealed the presence of marine fossils and coastal vegetation debris in its strata (DaSilva Santos, 2011).

Due to the climatic conditions and the resulting weathering zone of the northeastern forest, the outcrops distinction both of the Beberibe and those of the Barreiras Formation have always been considered and continue to be a mapping challenge. The Barreiras can be recognized by its characteristics: poor selection, irregular stratification and tendency to wheather in varying colors. In Paraíba, the Barreiras Group crops out over a vast area in the eastern part of the state, mainly covering the sedimentary basin Pernambuco-Paraíba (DaSilva Santos, 2011). This carbonate unit of shallow marine environment has an average thickness of less than $55 \mathrm{~m}$, of which more than two thirds are represented by gray argillaceous limestones (Leal and Sá, 1998). This layer was deposited from the slow subsidence of the continent and the consequent rise in sea level in the Upper Cretaceous (Furrier, 2011). Maria Farinha is the continuation of the limestone sequence of the Gramame Formation, being differentiated only by their fossil content, which is considered to be of Paleocene to younger Eocene age (Mabesoone, 1994). This layer offers a maximum thickness of $35 \mathrm{~m}$, partially eroded by subaerial exposure prior to the deposition of continental sediments of the Barreiras Formation (Leal and Sá, 1998).

According to Brito Neves et al. (2009), at various points of the geological section WE between Alto da Boa Vista and Tambaú, there are portions where the Gramame Formation could not be found, such as the area comprising the Alto neighborhood Matthew in João Pessoa. However, in areas where this formation has been found, it appears quite failed, conspicuously influencing the thickness and relief from Barreiras (Furrier, 2011). The arrangement of limestone in the metropolitan area of João 
Pessoa offers a sub-horizontal stratification, which is not very pronounced, and characterized through rough banks or otherwise forming compact masses, with fracturing and groundwater dissolution (Lummertz, 1977). These fault planes contribute to water percolation triggering a chemical reaction, which is able to slowly dissolve the lime, finally resulting in dolinas (Furrier, 2011). Brito Neves et al. (2009) state that the Gramame Formation consists of clear carbonate rocks, argillaceous limestone and calcareous sandstones, some with a basal phosphatic horizon. In contrast, the limestone facies are always homogeneous, grey to cream in color, with calcareous marl with thin clay films (DaSilva Santos, 2011). The Beberibe Formation varies in grain and thickness with a maximum of $360 \mathrm{~m}$ and average 230 -280 m (Leal and Sá, 1998). It mostly occurs in the subsurface mainly along the coastal strip between the river Goiana and the Canguaretama Fault. On the surface, the Beberibe Formation proves difficulty to distinguish from the Barreiras Formation. According to Furrier (2007) they had similar genetic processes and show many similarities in grain size and texture of the sediments, ranging from a moderate to weak selection and sub-angular to sub-rounded grains (DaSilva Santos, 2011). However, the sediments of Beberibe often have a better selection, a higher proportion of clastic or recrystallized quartz and clear homogeneous color compared to the Barreiras sediments (Brito Neves et al., 2009 in: DaSilva Santos, 2011).

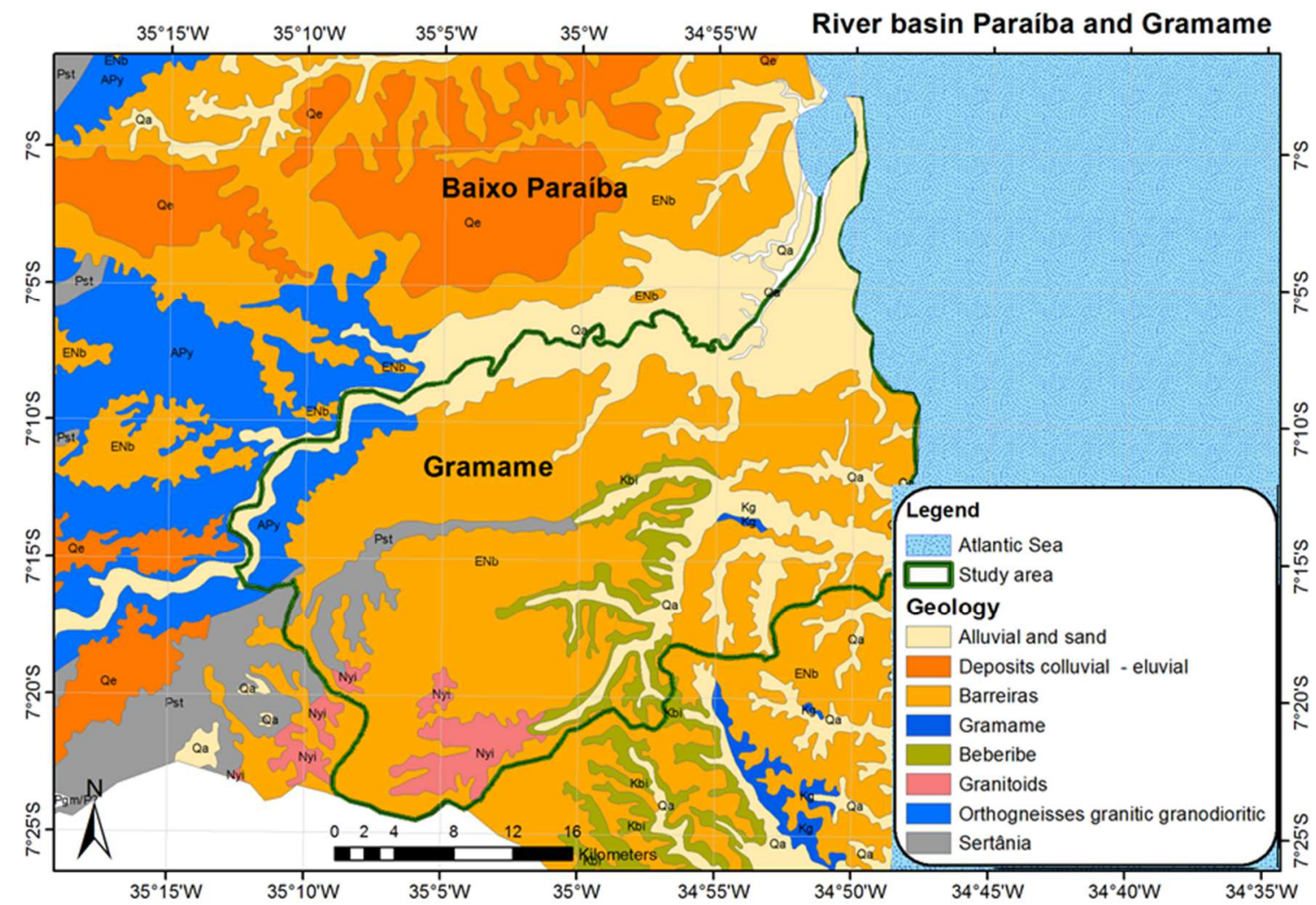

Figure 4-13: Geological map of study area with outcrops of impermeable Gramame formation (dark blue) (PDRH, 2000). 
By this it can be conclude that the aquifer is unconfined but the Gramame formation divides the Barreiras and Beberibe formations in the east. The hydraulic connectivity between the upper and lower aquifer is still subject to research. To the west, where the Gramame formation cannot be found, the two aquifer layers are directly connected. The exact location of the fault that separates the combined aquifer in the west and the layered aquifer in the east is still subject to further research.

For the local groundwater conditions only very scarce data was available (e.g. Coelho, 2011). To fill this data gap, a new groundwater monitoring network has been implemented in close cooperation with the UFPB and TUBS. Figure 4-14 shows the outline of the network of 13 automated and 19 manual groundwater level gauges. The UFPB maintains the monitoring and collects data on a monthly basis. Some of the results gained were used at a later point of this study. Unfortunately, the overall time series of collected data was not sufficient to support modelling of the study area in a satisfying manner. Another goal of the groundwater monitoring is a better understanding of natural groundwater recharge, which is at present estimated by means of hydrological simulations (Schimmelpfennig et al, 2018). There are several methods available to estimate natural groundwater recharge from water table fluctuation (Rama et al., 2018). According studies are currently under development based on the new groundwater monitoring data.

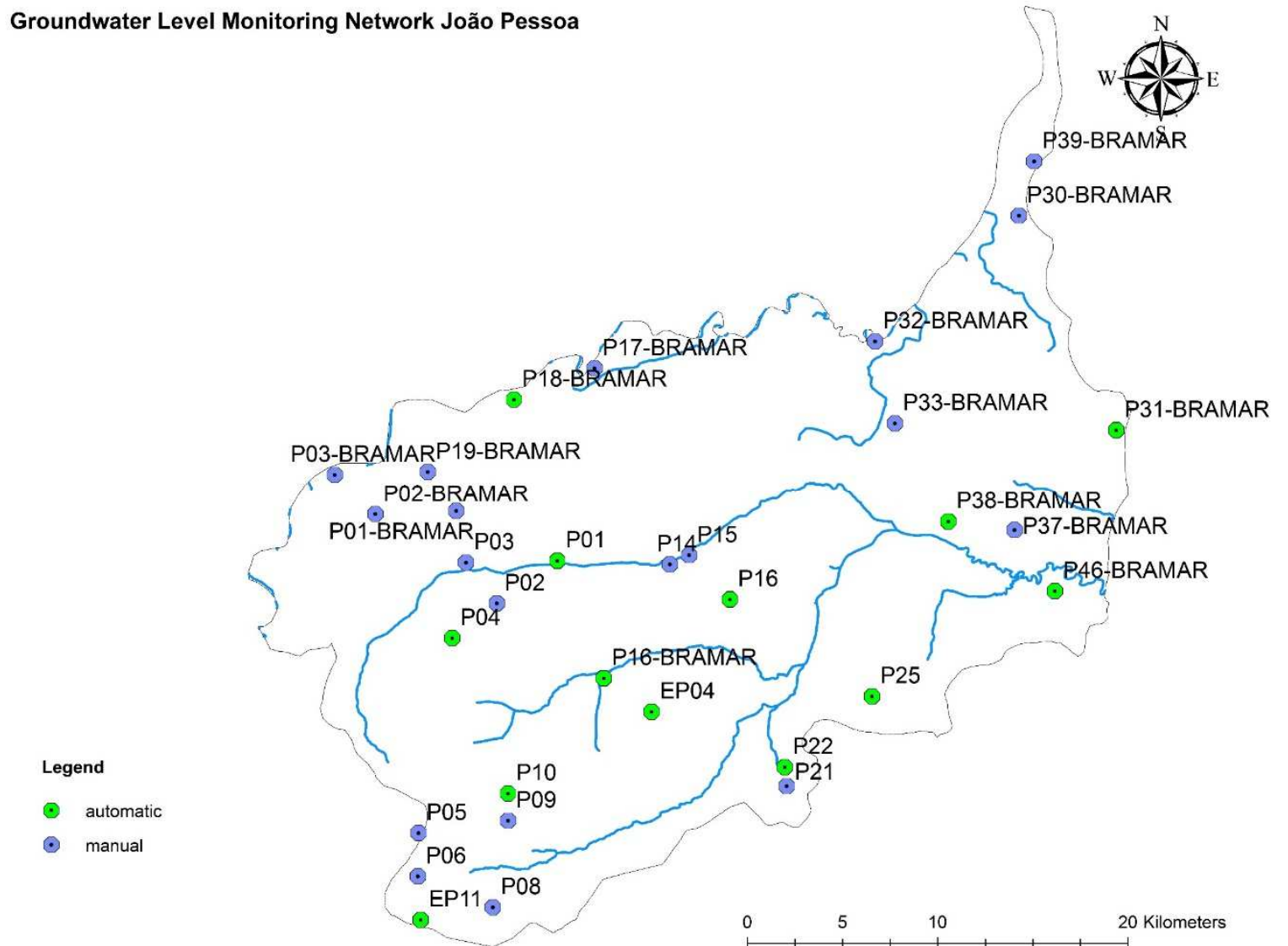

Figure 4-14: New groundwater monitoring network of the BRAMAR project (BRAMAR, 2018). 


\section{b) Jericho-Auja}

Three main aquifers can be identified in the Westbank (Table 4-3) referred to as the "uppermost", "upper" and "lower" aquifer (Messerschmid \& Sawalhi, 1999). They are mainly comprised of limestone and dolomite, intersected by formations of chalk and mar. The Auja catchment is the recharge zone of the upper and uppermost aquifer, and accumulation zone of the lower aquifer. The Jerusalem formation provides high recharge potential and transmissivity due to fractures and karst formations (Messerschmid \& Nazzal, 2008).

Table 4-3: Main aquifers of the Westbank (after Messerschmid \& Sawalhi, 1999)
\begin{tabular}{|l|l|l|}
\hline Aquifer & Formations & Age \\
\hline 'Uppermost' & Jerusalem & Turonian \\
\hline 'Upper' & $\begin{array}{l}\text { Bethlehem } \\
\text { Hebron }\end{array}$ & Cenomanian \\
\hline 'Lower' & $\begin{array}{l}\text { Lower Beit Kahil } \\
\text { Upper Beit Kahil }\end{array}$ & Albian \\
\hline
\end{tabular}

Figure 4-15 depicts geological formations and Figure 4-15 the stratigraphy of Wadi Auja. Unfortunately the map distributed by the Israeli Geological Survey does not cover the entire study area as parts to the east and south are missing. Besides outcrops of Cretaceous formations, Senonian (orange) and Turonian (green), the area is dominated by Quarternary sediments of the Holocene and Plio-Pleistocene. These include limnic silts and deposits of Dead Sea predecessors, the Lisan formation (Gropius, 1999). The Lisan formation, in contrast to the coarse clastic alluvial sediments, shows very low hydraulic conductivity values, close to impermeability. The Lisan covers the alluvial aquifer at the eastern part of the study area. General groundwater flow direction in Wadi Auja is west to east, downstream to the Jordan River and north to south, towards the Dead Sea (Ali et al., 2009).

In the study area Jericho-Auja the SMART-MOVE project delineates between the "shallow/alluvial" and "deep" aquifer. The shallow aquifer refers to a set of alluvial fans of coarse gravel and sand formations with high hydraulic conductivity. Infiltration tests and geophysical measurements wit GPR (ground penetrating radar) have been conducted in Wadi Auja within the course of the SMART II project. The geophysical results suggest a geometry and hydraulic characteristics of the alluvial basin west of Auja Village that make it suitable for subsurface storage, measuring values of more than ten $\mathrm{m} / \mathrm{d}$ for hydraulic conductivity (Haaken \& Kemna, 2012). The shallow aquifer is recharged mostly by lateral flow from the upper mountain aquifer and some vertical flow from the deep aquifer. For most parts the shallow aquifer is unconfined. Towards the east it is confined by the Lisan formation (Khayat, 2005). Deposits of the Jordan River with very low hydraulic conductivity and high salinity. Lenses of the Lisan formation can be observed within the alluvial aquifer. The underlying, deep Cenomanian limestone aquifer ("upper aquifer" of the Westbank) is characterized by intercalations of marl or flint bearing chalk beds, which by weathering form karstic or protokarstic formations with sinkholes and karstic caves (Singer, 2007). 


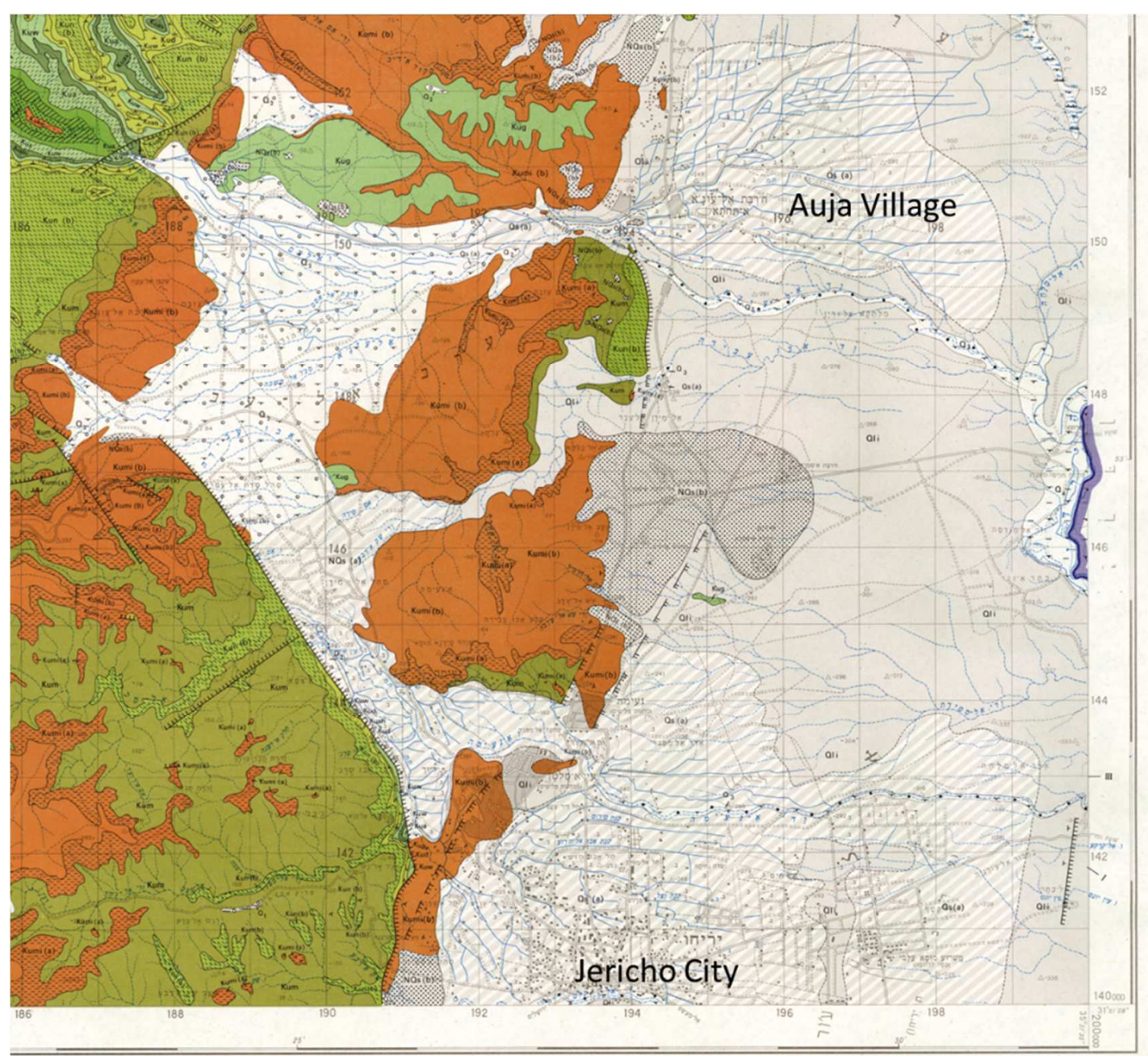

Figure 4-15: Geological Formations -Wadi Auja

(for legend see Figure 4-15; modified after Geological Survey Israel, 1973).

\section{STRATIGRAPHY}

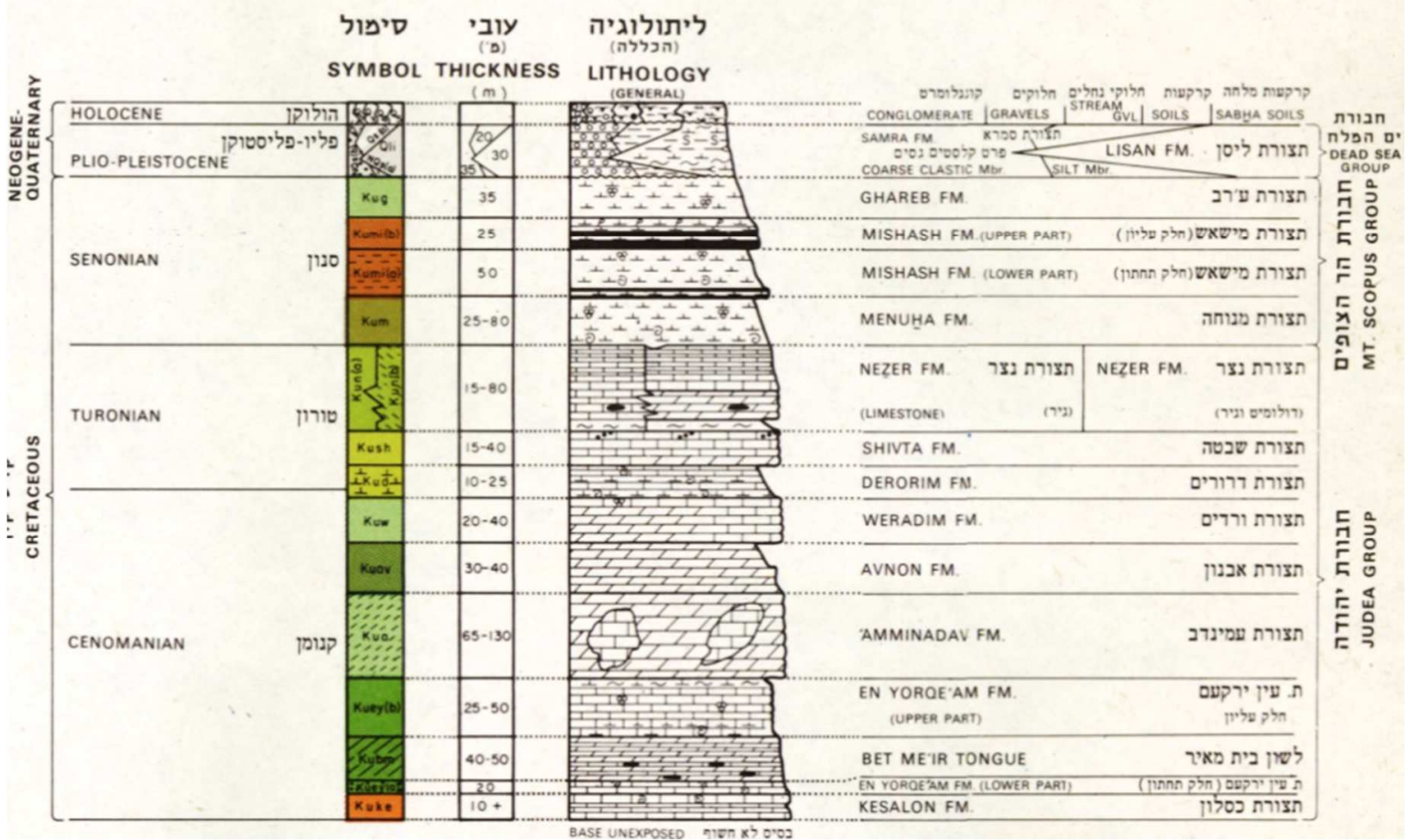

Figure 4-16: Stratigraphy of case study area Jericho-Auja (Geological Survey Israel, 1973). 


\subsection{Step 2: General MAR Feasibility Assessment}

\subsubsection{Surface Characteristics}

\section{a) João Pessoa}

The data situation for the case study of João Pessoa presented itself as very poor. As briefly introduced before, next to no data regarding water resources were available when this study started. Groundwater monitoring was, besides few measurements by earlier studies, factually non-existent. The same goes for runoff measurements in the rivers. Mainly historic time series were available. Existing data revealed to be flawed in many ways. The best available data was for precipitation, for which a working monitoring network is established and some climate data. Communication with local authorities for water resources management revealed limited interest in improving the groundwater monitoring. Several offers of cooperation in establishing and maintaining a new network were rejected citing lack of manpower and funds. The first conclusion of an overall assessment of the data situation was therefore that the initial research objectives must be extended to the implementation of at least some minimal data monitoring. According to local partners (UFPB), the study area is now one of the best monitored regions of Northeast Brazil with regard to surface and groundwater resources. This was only possible due to the funding by BMBF. In the following the individual parameters are introduced and pre-existing data situation as well as extensions to these networks or field tests are described. Based on the data now available, conclusions for the general feasibility of implementing a MAR system are given. The analysis of available surface and underground characteristics revealed huge data gaps. A lot of effort had to be given to fill these gaps, in cooperation with the BRAMAR project partners. In some cases, approximations had to be derived. Within the course of the study at least a fundamental data basis could be established.

Land use analysis reveals a clear cut between urban centers and rural agricultural areas. Only very limited areas remain without anthropogenic use. For a potential installation of MAR via infiltration ponds rather large surface space is required. In the case study, this would lead to the requirement of utilizing existing agricultural areas for MAR purposes, leading to increased installation and maintenance costs for MAR since land has to be purchased or rented from local farmers for that purpose. For the large urban areas infiltration ponds will not be a feasible MAR technology. Here, injection wells would be required. Meteorological data revealed rather high rates of potential evapotranspiration typical for tropical climate. High irrigation water demand during the dry season is indicated. These will be calculated in detail in Chapter 4.4.3. The resulting loss rate for surface water storage must also not be neglected. MAR stores water in the underground, making the negative effect of evaporation losses obsolete. Rainfall patterns and quantities show a very high potential of water availability. Without proper storage of these amounts, most water will get lost for the study area. There is a strong temporal imbalance in rainfall with clear defined rainy and dry season. Surface runoff results by project partners reveal vast quantities of water during the rainy season, as will be 
discussed in Chapter 4.4.2. Higher amounts of water than would be required. It can be concluded that water availability, in the rainy season, is not a limiting factor for any further MAR planning.

\section{b) Jericho-Auja}

For the Jericho-Auja case study, interpretation of the available data from many years of research and development projects in the region revealed a generally high potential for the implementation of any infrastructures and measures towards water resources management. This assessment neglects the current political restrictions, which is not a topic for this thesis. It can be concluded that the existing hydro-infrastructure is not very efficient and suffers from high loss rates. Also, the distribution of water for irrigations follows old, traditional operational patterns based on a time-sharing approach (Walter, 2013a). Lots of water resources remain unused or inefficiently managed so far. The surface characteristics would favor the implementation of a MAR system utilizing the springs as main source for recharge. Their location groundwater upstream of the areas of demand and the beneficial topographic conditions favor a MAR implementation. Land use is scarce and many areas would be available for installing surface infiltration measures such as infiltration ponds. Existing hydroinfrastructure, such as canals that transport water from the springs to the demand centers, or the Auja dam, could be integrated in the planning of a MAR system, though they will require modernization to decrease losses. There is a high potential for the use of infiltration ponds for MAR. This technology requires, depending on the soil characteristics and quantities of desired recharge, quite large surface space. Combined with passive infiltration wells, it could be a hybrid low cost technology that is suitable for the study area. That is, if the used water source for recharge is of good water quality and does not require extended pre-treatment measures. This surface infiltration technology is mostly challenged by clogging caused by sediment loads. Settling pits could reduce this load.

\subsubsection{Underground Characteristics}

\section{a) João Pessoa}

The hydrogeological survey revealed a large alluvial aquifer system with high potential of additional storage by means of MAR. However, certain limitations must be taken into account. The major rivers in the study area are connected directly to the groundwater, acting like boundaries for additional recharge. Any recharge groundwater upstream of the major rivers will unavoidably discharge through the rivers. Also the connectivity of the free alluvial aquifer west of the major fault in the aquifers east of the fault is not fully understood due to lack of data. This aspect requires further research. It must be assumed, since it is not indicated otherwise, that the entire aquifer system is completely connected. The deep eastern aquifer is being recharged from the free western alluvial aquifer. It can be concluded 
that a general potential and feasibility of the study area for the implementation of a MAR system is given. How this MAR system could be designed will be further studied in the following.

\section{b) Jericho-Auja}

Like the João Pessoa case study, the case study of Jericho-Auja has high potential with regard to storage capacities in the underground. Though the local aquifer is more complex in its composition than it is the case in the prior case study. The hydrogeological situation is very complex and the risk of contaminating recharged water by mixing with local brackish groundwater is high. Also, the interface with the carbonate aquifer to the west and the limitations given by the Lisan formation in the east require further studies and implementation of MAR test facilities. This study will assume that local aquifer conditions are indeed suitable for MAR and develop recommendations for test facilities.

\subsection{Step 3: Water Resources System Analysis}

\subsubsection{Subdivision of Study Area into Management Units}

\section{a) João Pessoa}

The identification of water surpluses and deficits is a basic step when it comes to MAR planning. For this purpose, water demands and availability must be known on spatial and temporal level. With this information, very basic groundwater budget calculations can be performed that reveal when and where MAR might be a solution to limit groundwater depletion and increase the systems resilience against increased water stress (Grönwall \& Oduro-Kwarteng, 2018). Due to vast data scarcity in the study area, main source of spatio-temporal data was the hydrological model developed within the BRAMAR project, introduced in the prior chapters (Schimmelpfennig et al., 2018). The study is based on a meteorological data set of 14 years from 2000-2014 with a monthly resolution. Special attention has been given to the agricultural water demand. Existing data has been updated by means of field investigations to create an up-to-date land use map. In combination with climate data derived from the hydrological model (Schimmelpfennig et al., 2018), irrigation demand has been calculated according to FAO standards (FAO, 1977).

The study area with its more than $1,000 \mathrm{~km}^{2}$ is quite large and calculating water budgets on a monthly scale for the whole area proved to be impractical. This is due to the high spatial variation in water demand. Domestic water demand is highly concentrated in urban areas. Especially the city of João Pessoa, comprising of roughly $70 \%$ of the total population in the study area, centralizes the domestic water demand sector within a comparably small area. In addition, domestic water demand, in contrast to agricultural water demand, is not subjected to the very high temporal variations; domestic water 
demand is not highly affected by rainfall patterns. Also the agricultural water demand is not distributed evenly over the study area. Land use patterns show high spatial concentrations of different crops, especially sugarcane, pineapple and forest structures. The latter does not require irrigation, while the first requires the most irrigation as will be shown in the following. For an effective MAR planning it is therefore necessary to differentiate between the water demands on a spatial distribution.

For this purpose the study area is subdivided into 11 so called Management Units (MUs). Figure 4-17 shows the outline of the color coded MUs. The selection of MUs has been based on data availability. As surface runoff is the source for MAR planning in this study, watersheds are used as a basis for water budget calculations. Selecting these specific sub-catchments was due to the availability of runoff data at the respective outlets. These origin from the hydrological model (Schimmelpfennig et al., 2018). Since actual runoff data is scarce, the decision had been made to base MAR budget calculations on the results of the developed model. It combines all available hydrological data in the study area and is therefore the best available source to base this analysis on. The hydrological model suffers from lots of uncertainties. Hence, all data used in this study are mere approximations as will be further elaborated in Chapter 5 .

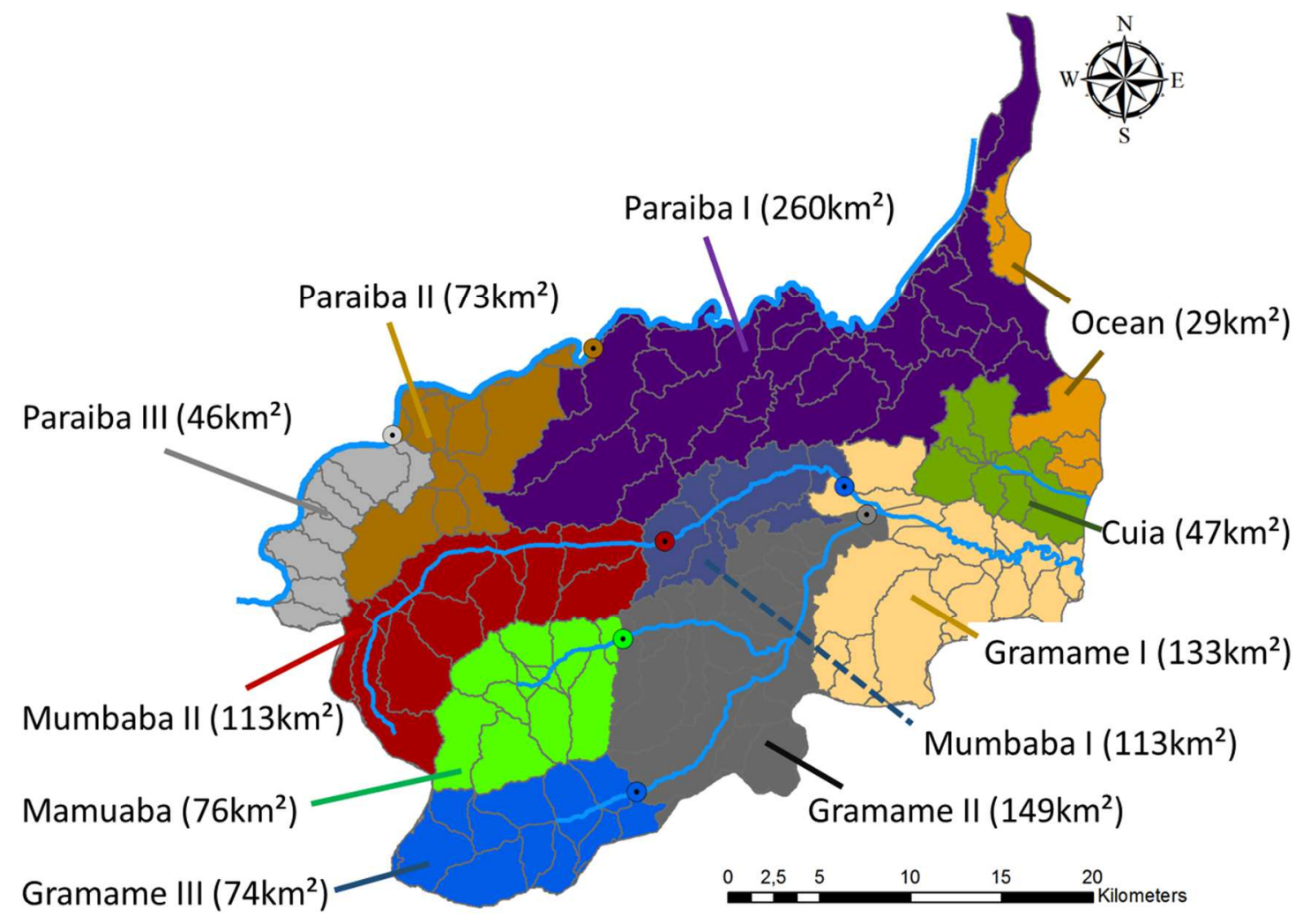

Figure 4-17: Delineation of Management Units for João Pessoa.

The model delivers runoff data for a set of specific virtual gauges in the study area. The selected outlines of the MUs orient directly at these virtual stations. This way, the water budgets calculated 
for each MU can directly be set into relation with the respective runoff at the respective outlet. When considering water extraction from the river at a certain spot within the MU, these extractions can be subtracted from runoff data for the MU downstream.

For the MUs Paraiba I, Cuia, Gramame I and Ocean no simulated, or measured, runoff data is available. This is due to the fact that the tidal influence on the flow behavior does not allow for accurate estimation close to the sea. Besides, the small catchments of Cuia River and the direct runoff within the city are not relevant enough to be subjected to monitoring. This is also why the MU Paraiba I is comparably large. For planning purposes it would have been beneficial to further divide the MU between mostly urban area in the east and agricultural area in the west. Unfortunately, the runoff station at Paraiba II ("Ponte de Batalha") is the easternmost reliable data source for model calibration. That is why further division of the MU is impractical. For groundwater simulation purposes, the spatial distribution of water demands can still be further discretized by appointing the domestic demand to the eastern part, and simulating water extraction for irrigation purposes to the western half of the MU.

\section{b) Jericho-Auja}

The Water Resources System Analysis, as an important step in the MAR planning approach, follows the same overall concept as in the prior case study. Unlike the João Pessoa study, no own data acquisition had to be undertaken. All data was supplied by local authorities or received from the predecessor projects SMART I and SMART II. The following analysis will underline how site specific water management and, especially, MAR planning is conducted. The boundary conditions of Jericho-Auja are completely different to those of the prior study.

In the prior case study of João Pessoa, the study area was divided into Management Units (MUs) based on the availability of surface runoff data. This was due to the fact that for a potential MAR system at that area, surface runoff could be considered the main, if not only, source of water for enhanced recharge. In the semi-arid study area of Jericho-Auja, surface water resources can be nearly neglected. However, the local watersheds, the Wadis, nevertheless represent a good orientation for dividing the study area in terms of MUs for several reasons. For one, data for water demand is available on the basis of municipalities. The two only municipalities in the study area are the city of Jericho and the Auja Village. Auja Village is mainly supplied by the Auja Spring, while Jericho city covers its water demand from several springs. This allows to view Auja and Jericho as two separate, yet interacting units. Jericho city is located at the watershed of Wadi Nueimah and Qilt. Since water supply comes from sources within both Wadis, a separation between Wadi Nueimah and Wadi Qilt in terms of a Management Unit would not be beneficial. Furthermore, the region can be subdivided 
on a management level in terms of mountain and valley areas. This study focusses on the municipalities in the valley. This results in two MUs: Auja and Jericho as illustrated in Figure 4-18.

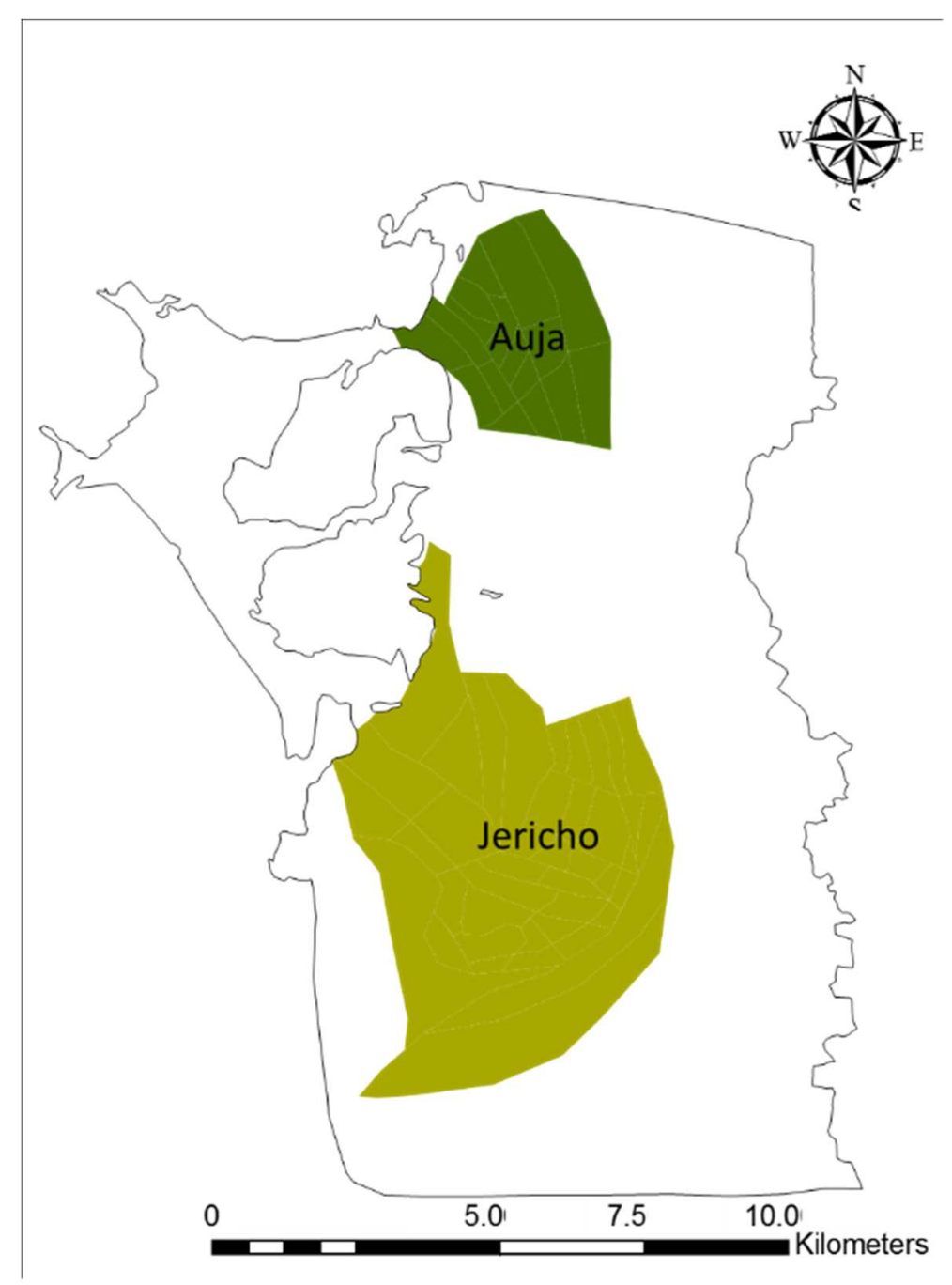

Figure 4-18: Delineation of Management Units for Jericho-Auja.

\subsubsection{Water Availability}

\section{a) João Pessoa}

The results of the water availability evaluation, derived by hydrological modelling (Schimmelpfennig et al., 2018) for the case study João Pessoa are given in Figure 4-19. The simulated surface runoff for all MUs is given in detail in Appendix 1. The values represent mean average monthly quantities. The year 2020 has been set as a mean of reference for all budget calculations to follow. As can be seen there is a vast amount of surface runoff, peaking during the winter months (southern hemisphere) of May to July. This observation directly correlates with the climatic values given in Chapter 4.2.2. Surface runoff in the two major rivers (Paraiba and Gramame) and their contributors sum up to an average of 680 MCM (Mio. Cubic Meter) per year. Together with an 
average annual groundwater recharge of $280 \mathrm{MCM} / \mathrm{a}$, they represent a water availability of 960 $\mathrm{MCM} / \mathrm{a}$. Please note that this quantity is a mere potential and does not represent the amount of actually used or activated water resources. The spatial distribution of this water potential is illustrated in Figure 4-20. As can be seen the Rio Paraiba discharges the highest quantities. Most discharge outside the rainy season comes from groundwater that is discharging through the rivers. This strong interaction of ground-and surface water has been addressed before and creates a challenge for MAR planning, since MAR should ideally occur during both, the rainy and dry season, and hence requires a certain distance from the rivers in order not to directly lose the recharged water back to the rivers.

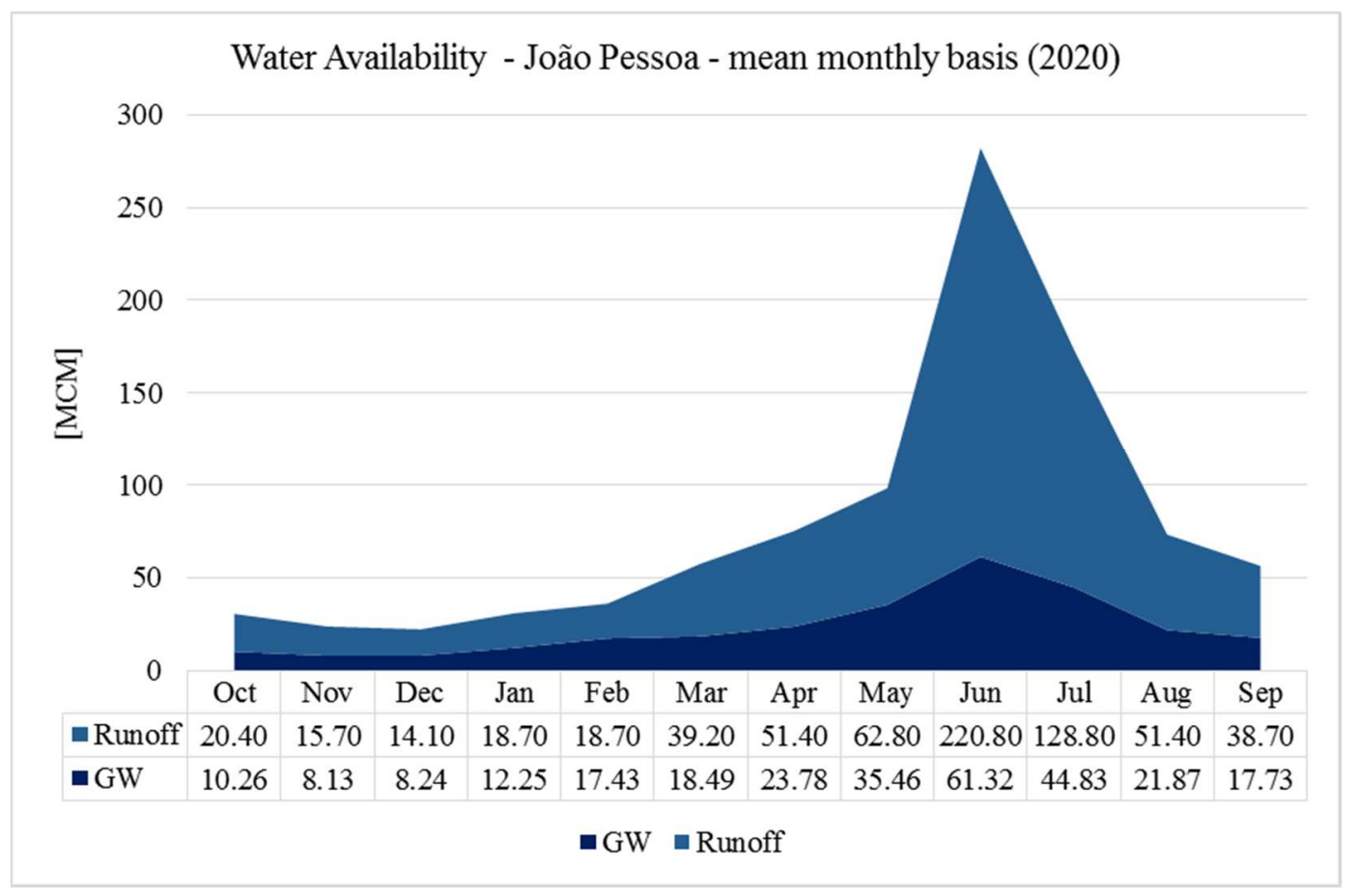

Figure 4-19: Total average water availability -João Pessoa.

Surface runoff is the main potential source of water for MAR measures that are analyzed in this study. The raw data for surface runoff was derived by hydrological simulations (Schimmelpfennig et al., 2018). Based on the simulated runoff data for the virtual runoff gauges, mean values are presented here. Due to high variability over the years, the median was used to derive theses values in order to eliminate the impact of extreme discharge events. Results show a clear seasonality in runoff. In coherence with the precipitation patterns as described in the previous chapter, a clear rainy season from March/April to August/September can be identified. With its peak in June/July where runoff easily exceeds four times the monthly average. Paraiba River in general has a much higher discharge rate than Gramame River. With peak discharges of several hundred MCM during the rainy season. Gramame River discharge in comparison peaks below $50 \mathrm{MCM}$. Both rivers show relative steady flow behavior during the dry season. The water discharging in those months is mostly 
groundwater leaving the system since there is a strong interaction between ground-and surface water in the area. In total, runoff in the study area can be quantified with more than $680 \mathrm{MCM}$ per year. This is, for the most part, water that leaves the system into the sea without being utilized.

For a complete water budget analysis not only the availability and demand during a specified time step must be balanced, but it must also be taken into consideration whether already available storage facilities have an impact on the temporal distribution of water availability. This means that by storing water in the system surpluses from one time period, e.g. one month, can be transferred into the next to a certain amount. That is the core idea of MAR and will be considered in detail during the MAR groundwater budget calculations. The case study area has two major storage facilities; the big Gramame-Mamuaba Surface Reservoir and the smaller Marés Reservoir, both operated by AESA. The reservoir is located within the MU Gramame II. The main contributors are the Gramame and Mamuaba Rivers. The capacity of the reservoir is 56.9 MCM. The Marés Reservoir is located close to the urban area of João Pessoa within the MU Paraiba I. Its capacity is 2 MCM. Unfortunately only the change in storage volume is monitored for the reservoirs, not the actual in-and outflow. Hence, the exact operation scheme for the reservoirs is not known and only rough approximations with regard to the actual water supply can be made. Both reservoirs are mainly used for domestic water supply.

Natural groundwater recharge has also been approximated by the hydrological model (Schimmelpfennig et al., 2018). Available data (annual basis) has been transferred to a monthly scale following the mean rainfall distribution. The data shows generally high quantities of groundwater recharge. It accumulates to roughly $250 \mathrm{MCM}$ per year. Its spatial distribution has been simulated on the same level as the precipitation and surface runoff as introduced before. Natural groundwater recharge is defined by the volume and intensity of rainfall. This means during the dry period and draught years, the already strongly exploited aquifer system suffers additionally from decreased recharge, creating an even higher water stress. 


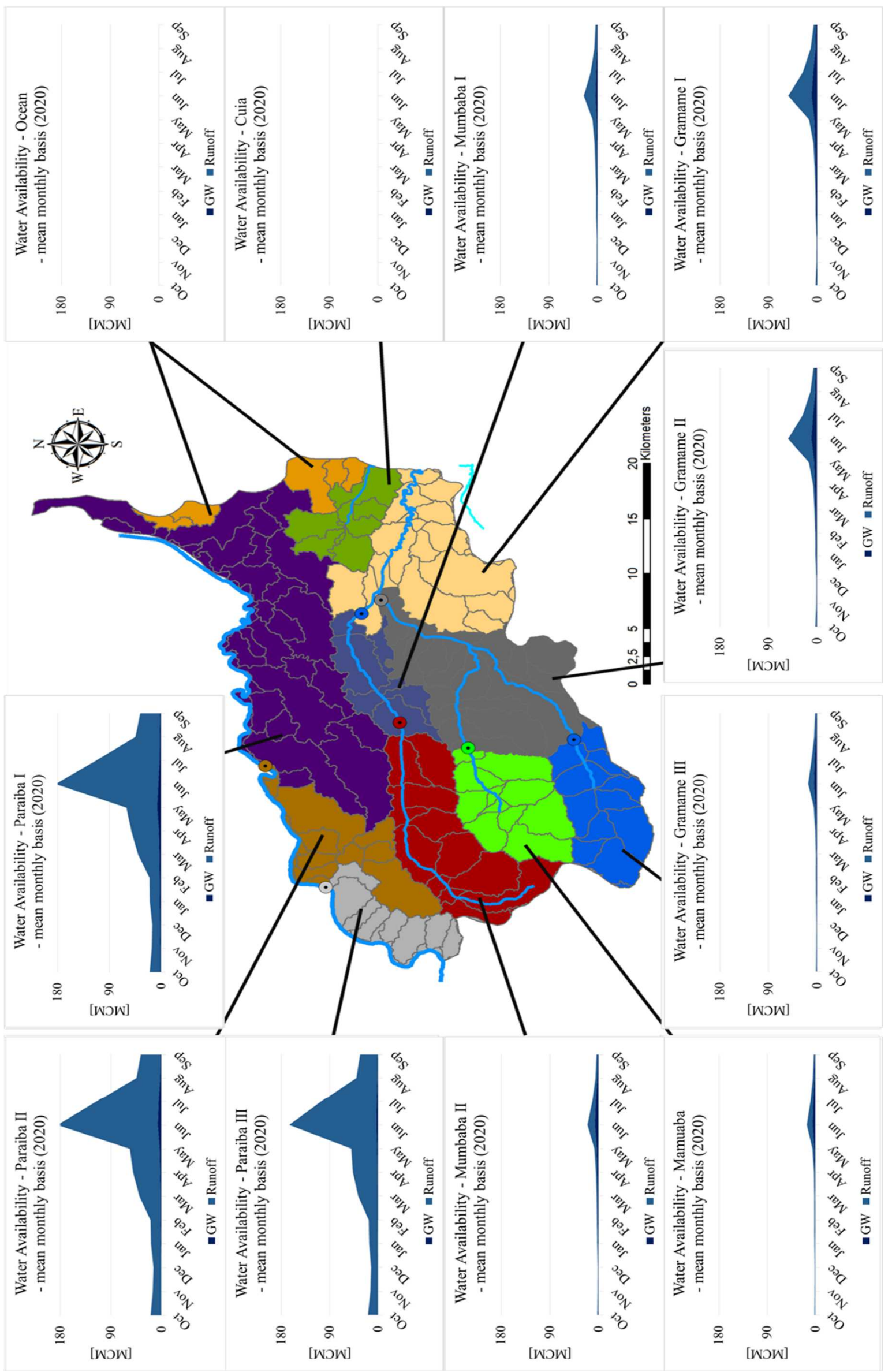

Figure 4-20: Spatial distribution of water availability -João Pessoa. 
Besides natural groundwater recharge from rainfall, local groundwater resources also receive water from anthropogenic sources. This is included in the given groundwater recharge values. Return flow from irrigation and leakage of water distribution networks must be considered. When discussing the potential benefits of Managed Aquifer Recharge, we can refer to these processes as Unmanaged Aquifer Recharge (UMAR). For an environmentally sustainable use of the aquifer system the withdrawal from the aquifer must not be higher than the recharge on a long-term average basis. MAR is a measure to increase the groundwater recharge and increase the systems resilience for periods of enhanced groundwater pumping. UMAR originates from irrigated agriculture and domestic water distribution networks. Recharge by return flow from irrigated agriculture is the amount of water used for irrigation purposes that percolates to the aquifer. In case of irrigation with pumped groundwater this creates a circle of withdrawal and recharge to some extent. For the case study a return flow of $5 \%$ is assumed. Like the agricultural return flow, leakage from water distribution networks in urban areas adds to the groundwater recharge. It is assumed that distribution networks in the study area have very poor efficiency rates. The rest of the water is lost during transport by leakage and some part of it can percolate back into the aquifer system. For this analysis a recharge rate of $20 \%$ from leakage is assumed for the urban area. This recharge is spatially limited to the cities and villages in the study area. For the rural area a return flow from domestic demand of $90 \%$ is assumed. This is due to the fact that most villages lack sewage systems and waste water simply infiltrates unmanaged into the soil. Actual quantities of unmanaged recharge will be presented in Chapter 4.4.3.

\section{b) Jericho-Auja}

The water availability situation in the Jericho-Auja case study has been thoroughly analyzed and reassessed within the long course of the SMART projects (e.g. Rusteberg et al., 2011, Rusteberg et al., 2014a). The most recent results of the water availability evaluation for the case study Jericho-Auja underline the fundamental difference between the two case studies. As can be seen in Figure 4-21, the magnitude of mean monthly values is much lower than in the prior case. Surface runoff is almost neglectable with a maximum of $0.58 \mathrm{MCM}$ in December. In total the available water resources sum up to an average of $32 \mathrm{MCM} / \mathrm{a}$. In contrast, for João Pessoa with its tropical climate this value was about $680 \mathrm{MCM}$. The most abundant source of water is the discharges from the various spring groups. In addition, these discharge amounts underlie extreme fluctuations from year to year. These numbers must not be confused with actual water use or activated sources. Treated Effluent (TE) for instance is currently not fully used for irrigation purposes. The same goes for Treated Effluent form El Bireh, a Palestinian city in the mountain area and the deep groundwater resources, which are yet mostly untapped. Figure 4-22 illustrates the spatial distribution of these water potentials. Spring discharge is the main source of water for the study area. Figure 4-23 gives an overview of the springs' locations. 
For some springs, actual discharge data is available. Within the course of the SMART-MOVE project, discharge measurements have been conducted by project partners (e.g. Schmidt, 2018).

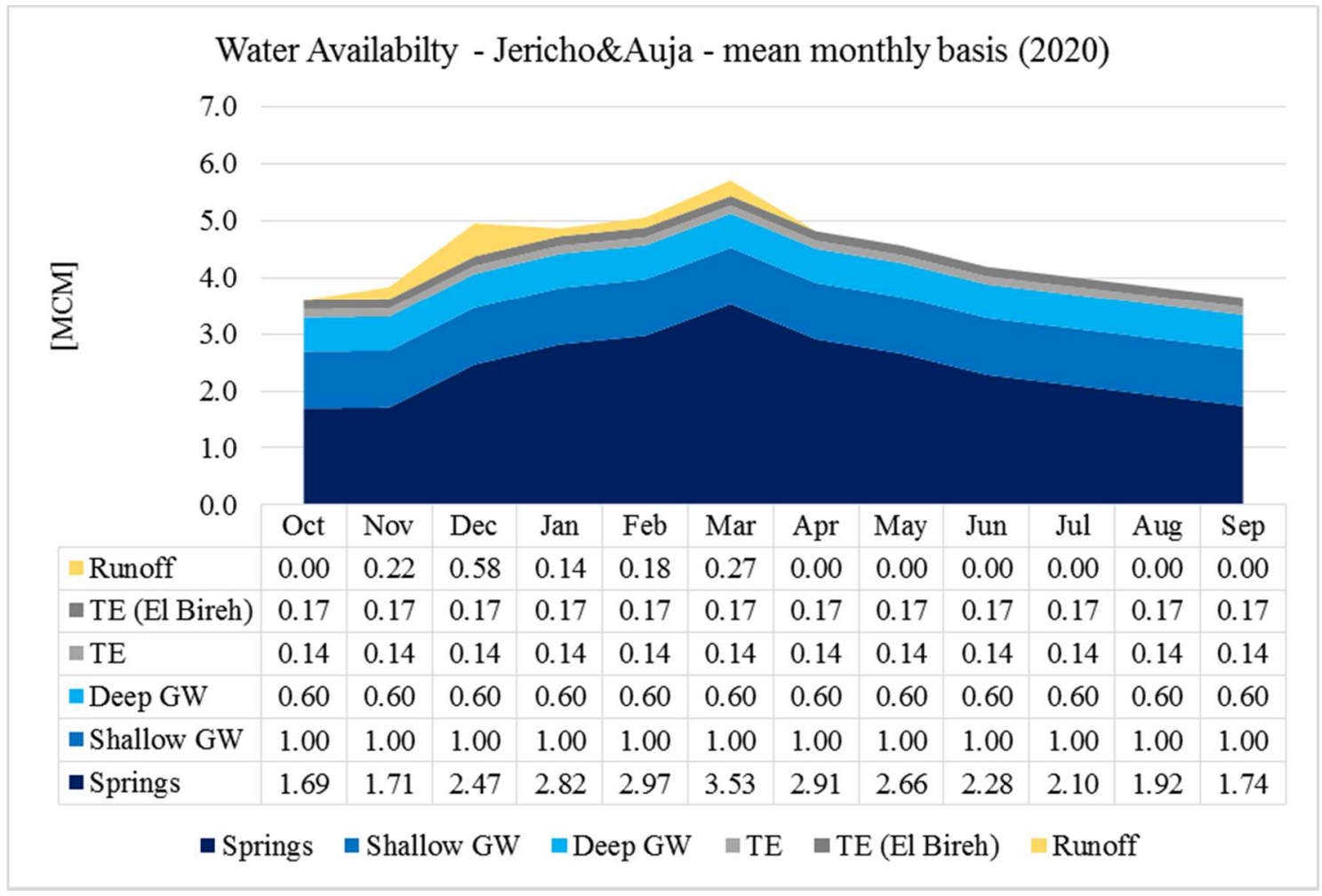

Figure 4-21: Total average water availability -Jericho-Auja (based on Schmidt, 2018 and Rusteberg et al., 2018a).

For this study, available historic discharge values are used as a basis for water availability calculations. Figure 4-24 shows available historic data sets for all springs. The available data sets were not complete. Missing values have been filled in with arithmetic means of neighboring values. As can be observed, Auja spring is the most productive of all, but also one of the most variable in terms of discharge. With an average of $9.63 \mathrm{MCM} / \mathrm{a}$ it makes up for roughly $30 \%$ of the total available spring discharge in the region (PWA, 2007). Followed be the Fawwar \& Qilt spring group, with also very high fluctuations of discharge. Sultan spring, located directly in the vicinity of Jericho city, has very steady discharge quantities around 5.6 MCM/ in average (PWA, 2007). Also the minor springs show relative stable discharge conditions. In total roughly $30 \mathrm{MCM} / \mathrm{a}$ of spring discharge are available for the study area (PWA, 2007). However, due to the high fluctuation of the major springs, this value can be decreased to $17 \mathrm{MCM} / \mathrm{a}$ (for example in the hydrologic year 1978/79) or reach peaks of up to $46 \mathrm{MCM} / \mathrm{a}$ (as was the case in 1992/93, PWA, 2017). This vast water potential must be managed in a sustainable manner. MAR might be a suitable measure to increase the system's resilience against such drought year and ensure a long-term storage of high water surpluses in very wet years. These values do not account for loss rates during transport and application which are very high in the study area yet. 


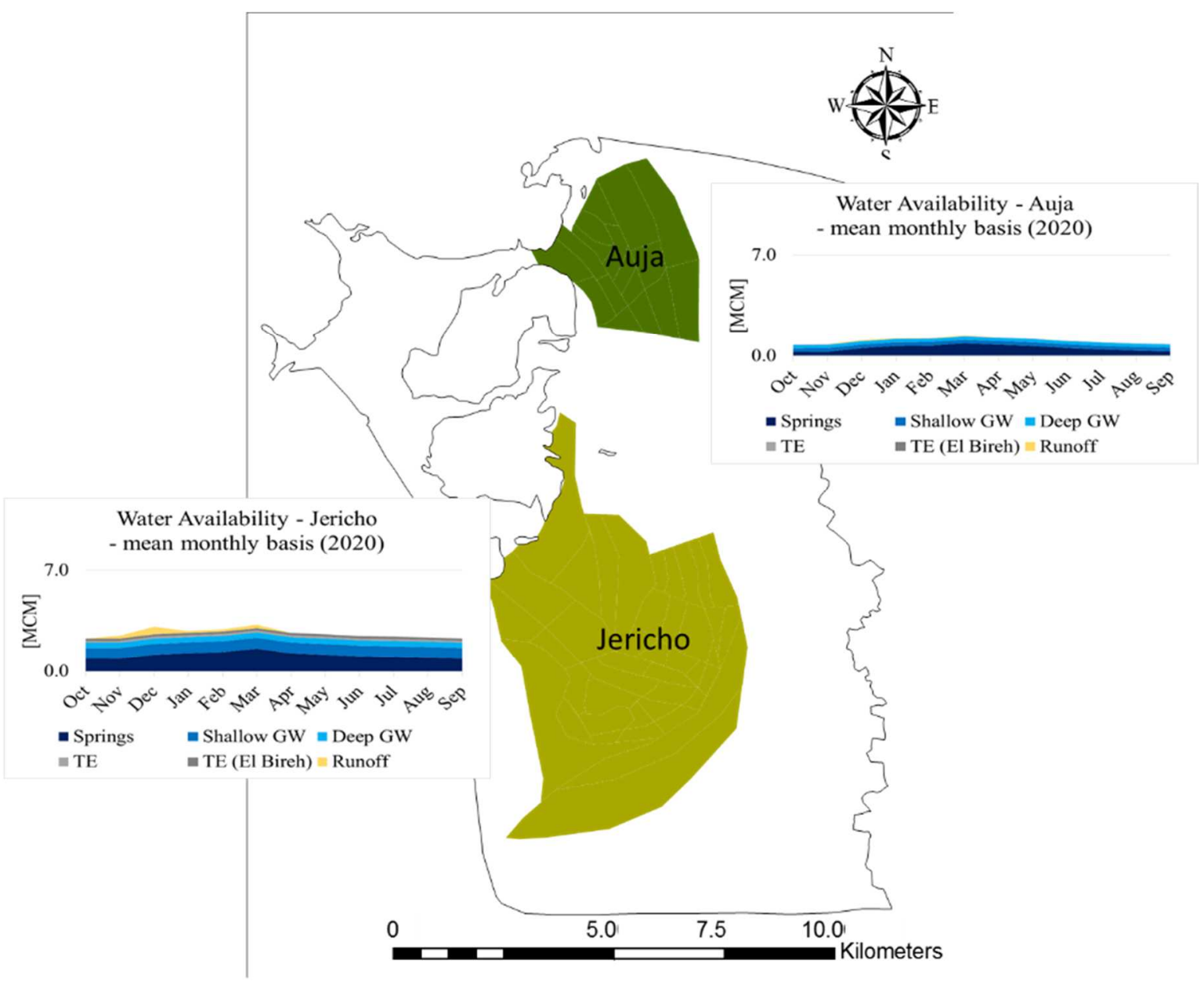

Figure 4-22: Spatial distribution of water availability -Jericho-Auja.

Surface Runoff in the study area is very scarce. It occurs in terms of flash floods with varying intensity and frequency. In many years no significant surface runoff events occur, while some years extreme events happen. These values should only give a very coarse approximation of surface water potential. In Wadi Auja a surface reservoir is installed. A simple earth dam, constructed in a sidearm of the Wadi that can hold back some water during storm events. It is located in the west, upstream of the village. With a storage capacity of $0.5 \mathrm{MCM}$, it serves as a surface water harvesting facility. The water is partially extracted directly from the dam's basin (Abdel Ghafour, 2005). Due to lack of sealing, high quantities of the dam water infiltrate to the ground and evaporate. For an efficient application of storm water for MAR measures, its access requires modernization and extension of the existing harvesting facilities. The storm water is naturally high of sediment load. The heavy rainfall leading to storm floods takes up high amounts of sediment by flowing through the Wadi. Due to the high infiltration rates at the reservoir, this facility could be seen as a MAR infiltration site.

The local shallow aquifer system receives natural recharge mainly by lateral inflow from the karstic mountain aquifer. Due to the highly variable hydrological conditions, this recharge underlies very 
high fluctuations. This recharge was implemented as a time series in the groundwater flow model applied for this study (Abu Sadah, 2017). As before, these mean values can only be seen as a coarse approximation, since annual variability in quantities is extremely high in the study area. However, for water resources management this means the local shallow groundwater system has a sustainable yield of roughly $12 \mathrm{MCM} / \mathrm{a}$. Water extraction above this value can be seen as an unsustainable use of the aquifer, leading to overexploitation.

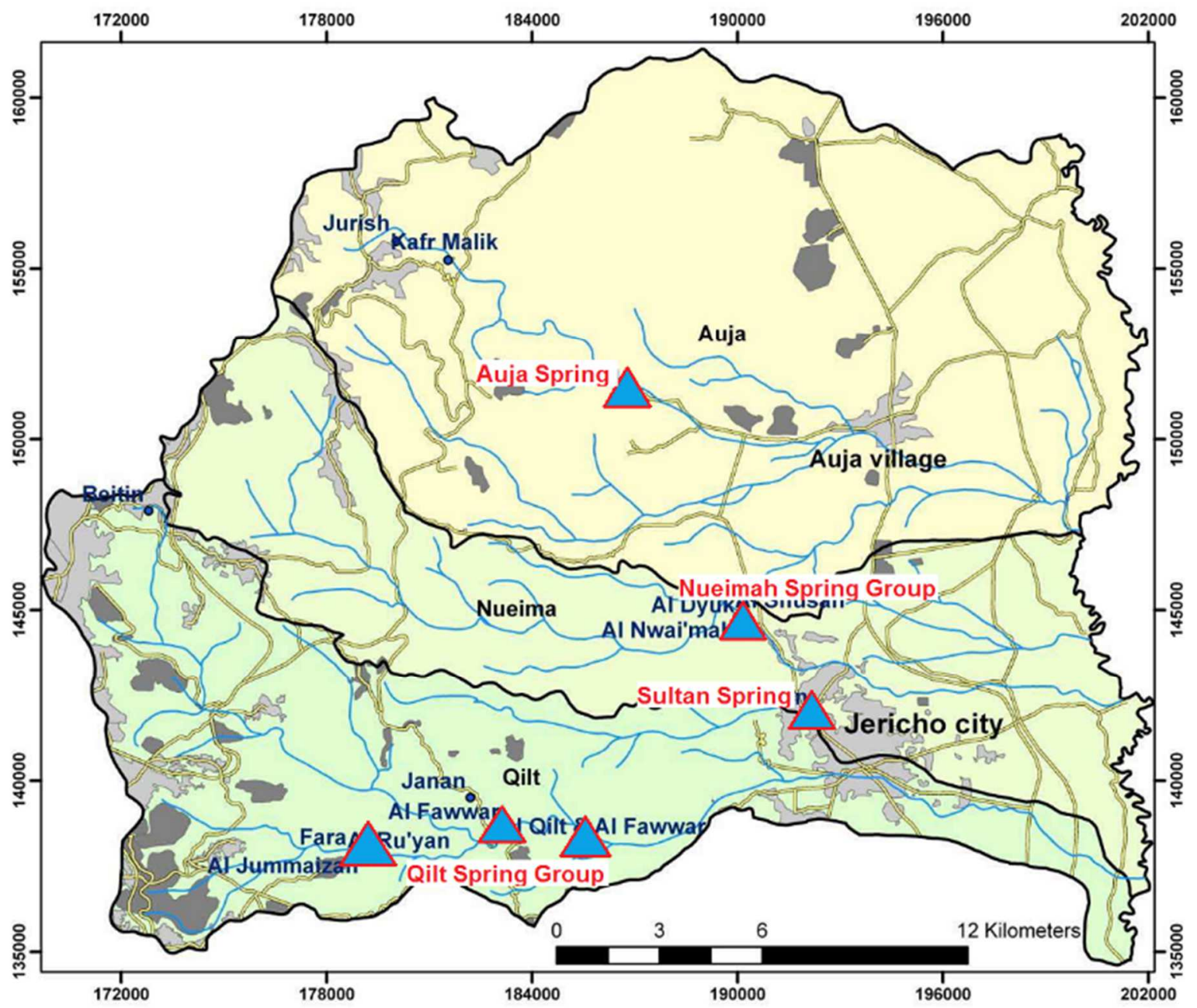

Figure 4-23: Locations of main spring groups in the study area (modified after Rusteberg et al., 2014b).

Overall there are five sources of UMAR. It is assumed that $7.5 \%$ of spring discharge, since poorly managed, is recharged to the shallow aquifer through leakage in the transport channels (Abu Sadah, 2017). During storm events a rough ten $\%$ of runoff is approximately percolating to the groundwater. Only a very low $3 \%$ of irrigation water might recharge the aquifer, since evaporation rates in the study area are extremely high (Abu Sadah, 2017). This value is substantially higher for leakage from cesspits. Since parts of the study area do not possess a centralized waste water treatment plant, households are connected to small cesspits. These crude systems recharge an estimated $50 \%$ of locally produced waste water to the aquifer (Abu Sadah, 2017). Cesspits are especially present in 
Auja village area. Due to lack of treatment, these cesspits are an enormous source of contamination for local groundwater quality. Leakage from fresh water supply from the local water distribution networks accumulates to a rough $15 \%$ of the domestic supply (Abu Sadah, 2017).

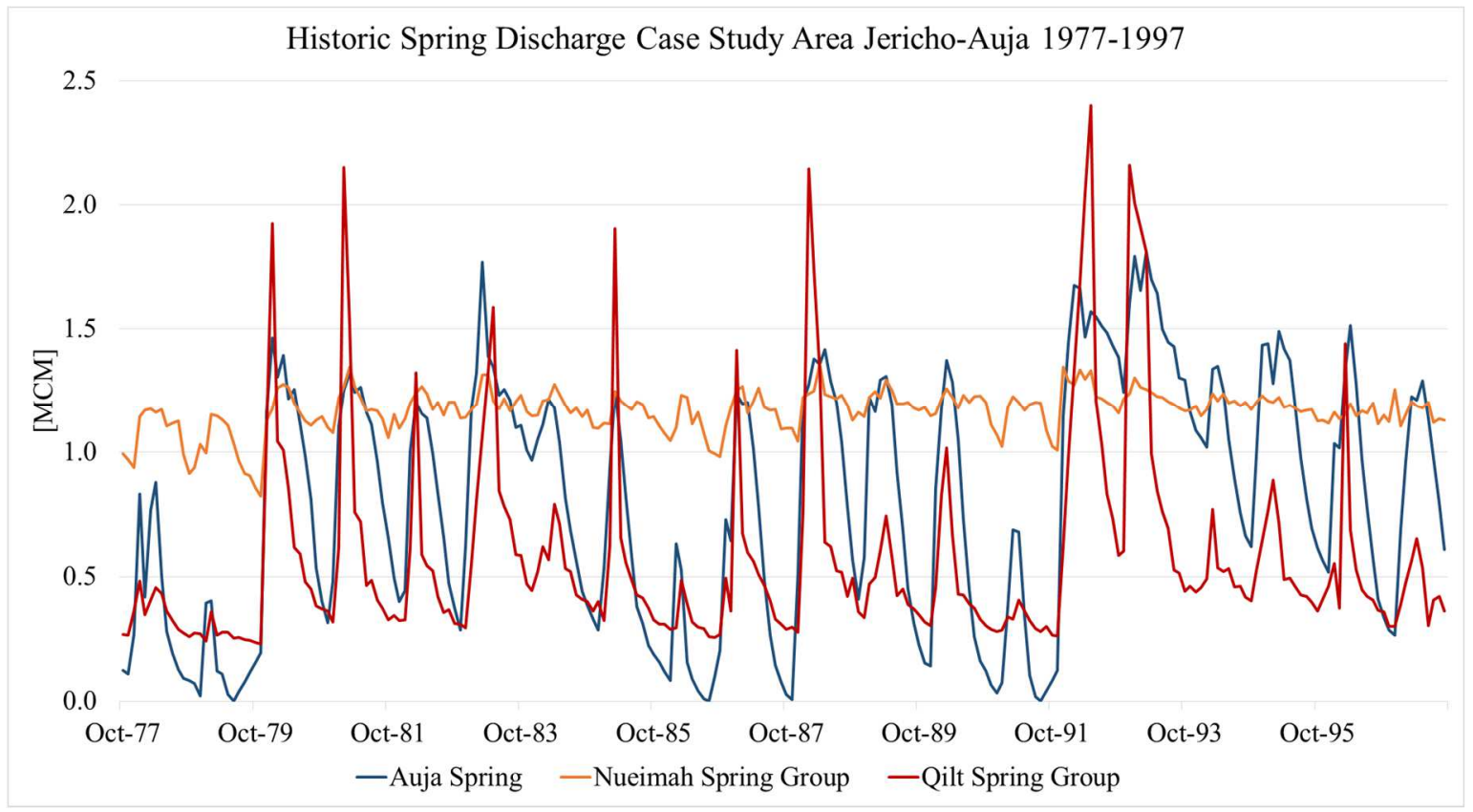

Figure 4-24: Historic time series of springs in the study area (modified after PWA, 2007).

As of today, loss rates from domestic and irrigation water supply networks are quite high. The local water distribution networks, especially in the very rural Auja village region, are outdated. They urgently require modernization, resulting in vast reductions of loss rates. Present water losses are assumed to be up to $60 \%$ for utilization of spring discharge. As a potential goal a reduction of water losses due to transport and application to around $35 \%$ is possible. This measure would substantially increase water availability, but would require high investments in the local water management. This factor and its impact on the water budgets will be analyzed as one primary goal for IWRM implementation in the area.

Besides the shallow aquifer, a deeper aquifer is present in the study area. In the course of the SMART-MOVE project this aquifer is commonly referred to as the "Deep Aquifer". It has a substantial groundwater potential. Usage by Palestinians is restricted due to political issues. However, according to (Rusteberg et al., 2018a) the deep aquifer would hold a potential 7.2 MCM/a to be additionally extracted in the study area by Palestinians. According to Rusteberg et al. (2018a), a total of $1.7 \mathrm{MCM} / \mathrm{a}$ of treated waste water from Jericho city is presently unused. This high quantity of poor quality water could be used directly for irrigation. It is not recommended to be used for aquifer recharge, e.g. by means of Soil Aquifer Treatment. Rather, the treated effluent of the waste water treatment plant Jericho could be directly applied to the fields, lowering the irrigation water 
demand from other sources. A decrease in irrigation demand would, in return, increase the availability of fresh water for MAR purposes. In addition, another $2.0 \mathrm{MCM} / \mathrm{a}$ of treated effluent could be imported from the city of El Bireh (Rusteberg et al., 2018a).

\subsubsection{Water Demand}

\section{a) João Pessoa}

Figure 4-25 summarizes the results of water demand assessment. Total water demand in the study area accumulates to 517 MCM per year on average. As seen in the Irrigation Water Demand (IWD) analysis, rainfall has a high impact on the demand for additional irrigation. Since rainfall is highly variable over the years, so is the demand for irrigation water. Figure 4-27 illustrates the distribution of water demand among the different demand sectors. It becomes clear that the IWD, on the mean annual average, makes up nearly $75 \%$ of the total demand in the study area. This underlines the dependency of the local water resources system on climate and land use factors. According to the demand sectors and land use patterns in the MUs of the study area, also high spatial variability of water demand has been identified. It is illustrated in Figure 4-26. Water demand in the study area is characterized by high need for irrigation in the rural western part, with certain hot spots of high sugarcane density, and concentrated domestic water demand in the urbanized eastern coastal region. Most domestic demand is located in the MU Paraiba I, where the highest urbanization density is located with the city of João Pessoa as well as the municipalities Santa Rita, Bayeux and Capedelo. Together these sum up to about $96 \%$ of total Domestic Water Demand (DWD) in the area.

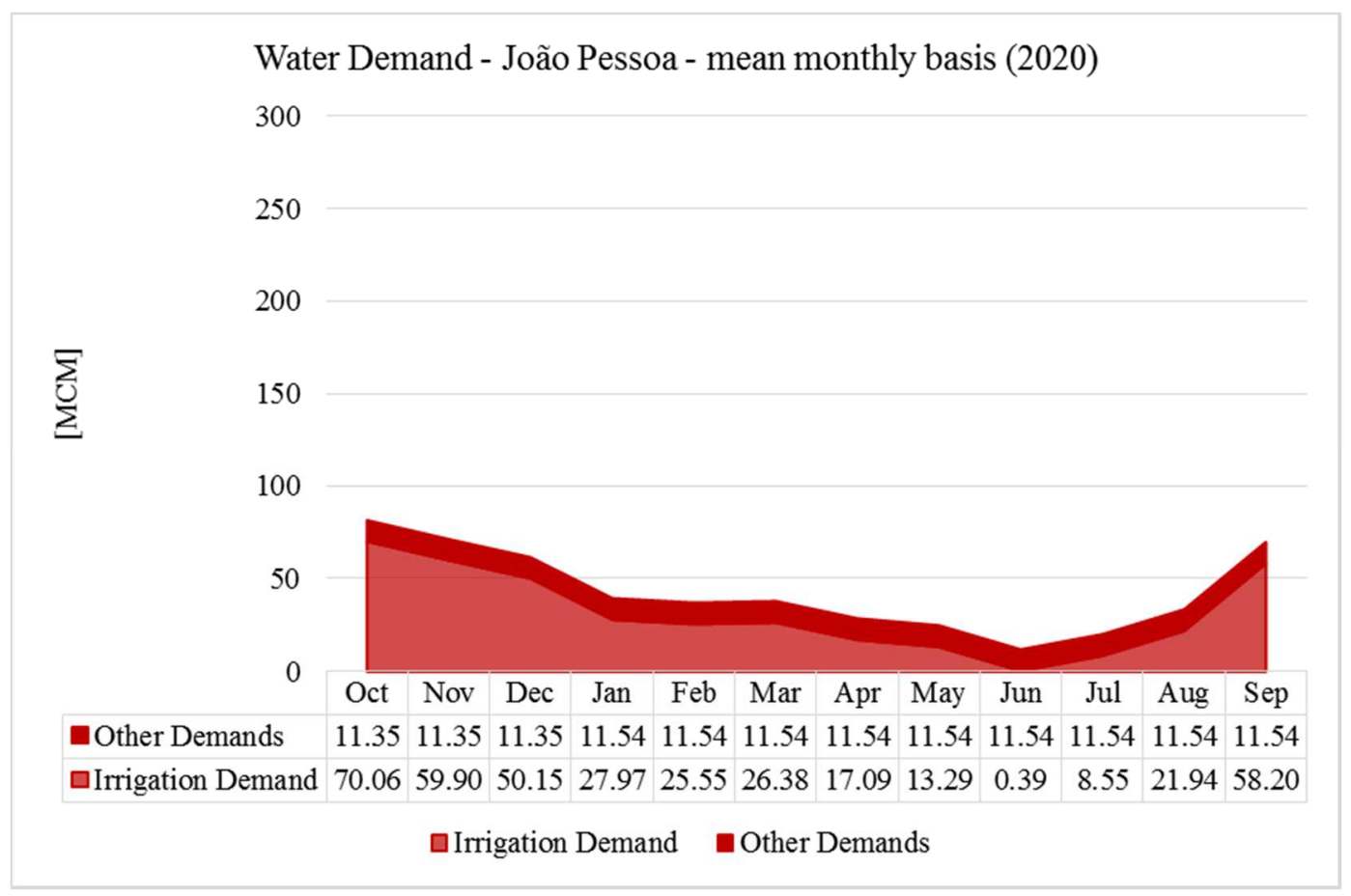

Figure 4-25: Total average water demand -João Pessoa. 

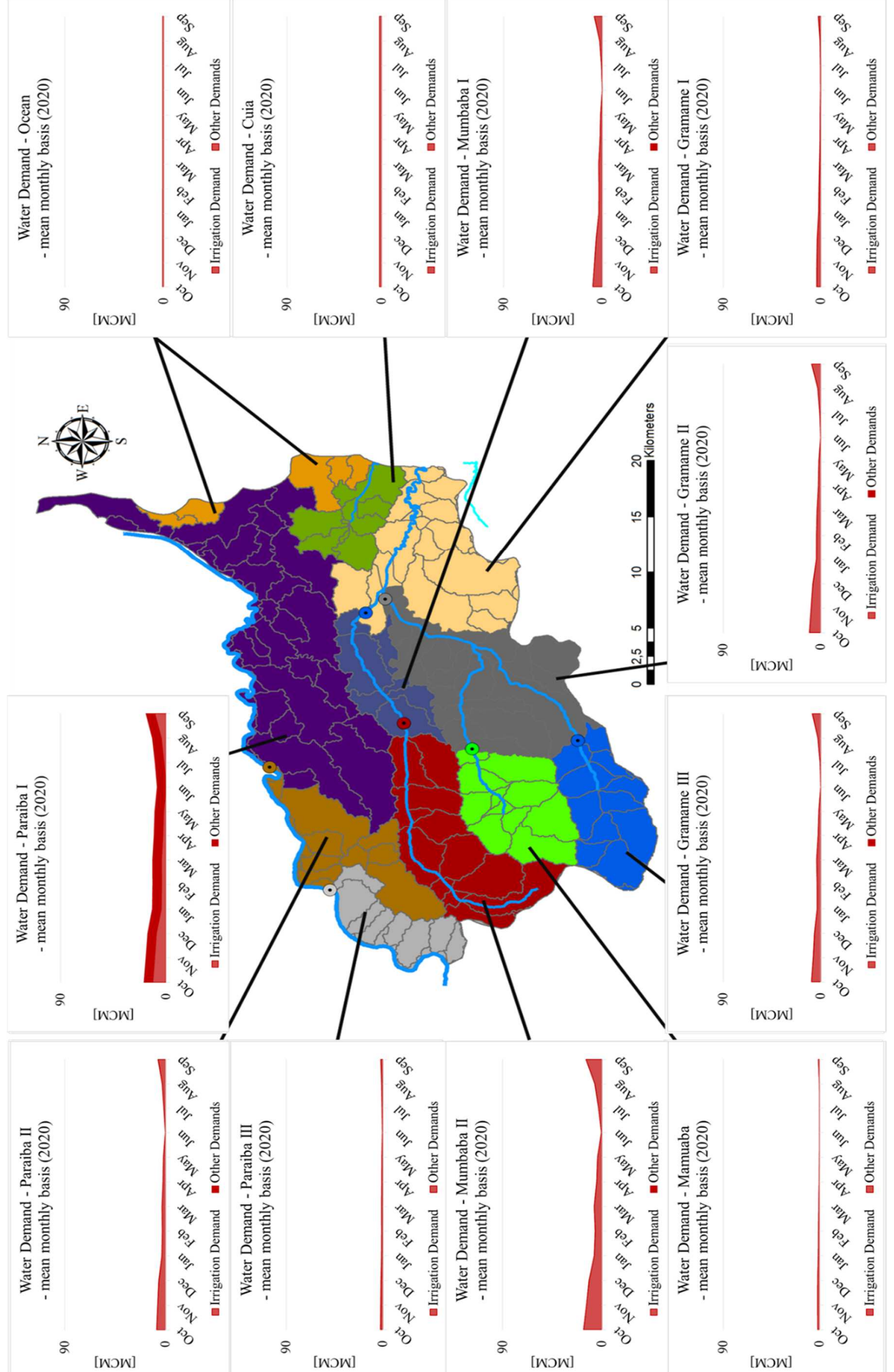

Figure 4-26: Spatial distribution of water demand -João Pessoa. 


\section{Total Water Demand Study Area João Pessoa mean annual values [MCM]}

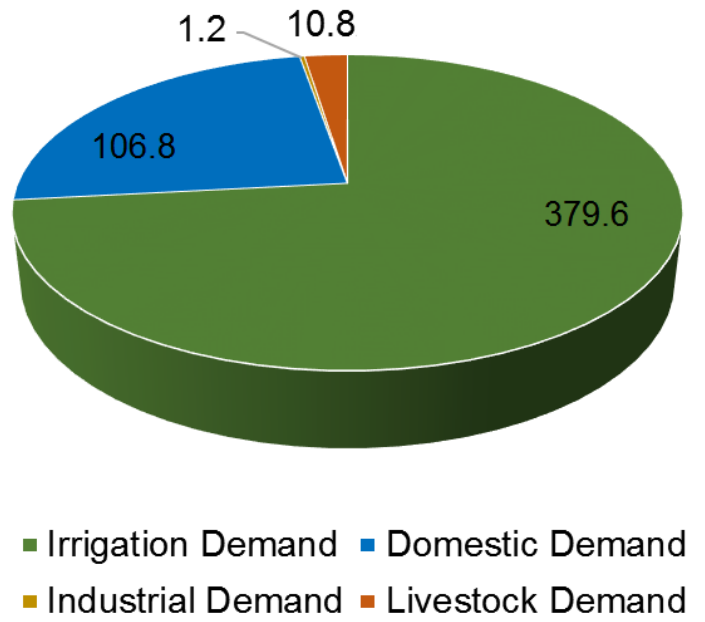

Figure 4-27: Distribution of mean annual water demand in study area among demand sectors.

As the land use analysis indicates, the study area is a characterized by intensive agriculture (Figure 4-27). By far the most occurring crop in the area is sugarcane, followed by pineapple with about. Other crops like manioc, banana, mango or coconut are mostly grown on comparably small fields or in polycultures. The water demand situation in the study area has been estimated in prior studies, especially in the course of water masterplans for the region. However, it was found that the numbers given in those reports are difficult to reconstruct. In order have a more complete picture of the actual situation and being able to calculate certain agricultural and climatic scenarios in Chapter 4.6, the irrigation water demand has been re-calculated.

The method used for calculation was derived from the recommendations of the FAO and is following their standards (FAO, 1977). All calculations presented in the following have been done on a spatial distribution based on available land-use data and the spatial resolution of the hydrological model developed by Schimmelpfennig et al. (2018) for the introduced time period from 2000-2014. Following the FAO approach, first the crop water need ( $\left.\mathrm{ET}_{\text {crop }}\right)$ is calculated. It is defined as the depth (or amount) of water needed to meet the water loss through evapotranspiration:

$$
\begin{gathered}
E T_{0} * K_{C}=E T_{C R O P}\left[\frac{h}{t}\right] \\
\text { with } \quad \mathrm{ET}_{0}=\text { reference evapotranspiration } \\
\mathrm{K}_{\mathrm{c}}=\text { type specific crop factor } \\
\mathrm{ET}_{\text {crop }}=\text { specific crop water need }
\end{gathered}
$$

The crop water need represents the total amount of water that is required for a specifc standard crop to grow and develop under ideal conditions. A standard crop in this context is defined as uniform, actively growing, completely shading the ground, free of diseases and having favorable soil conditions, including fertility and water (FAO, 1977). The crop water need depends on the climate, 
the crop type and the growth stage of the crop. It is not to be confused with the irrigation demand, which will be calculated later.

Reference crop evapotranspiration $\left(\mathrm{ET}_{0}\right)$ represents the influence of climate on crop water needs. The reference crop is grass. The major climatic factors which influence the crop water needs are sunshine, temperature, humidity and wind speed. Methods to derive the reference evapotranspiration are the experimental pan evapotranspiration method or the numerical Blaney-Criddle Method. For the case study the later has been applied by Schimmelpfennig et al. (2018) for the model calibration. The Blaney-Criddle Method is based on the following formula (FAO, 1977):

$$
E T_{0}=p *\left(0.46 * T_{M E A N}+8\right)
$$

$\begin{array}{ll}\text { with } & \mathrm{p}=\text { mean daily percentage of annual daytime hours } \\ \mathrm{T}_{\text {mean }}=\text { mean daily temperature }\left({ }^{\circ} \mathrm{C}\right)\end{array}$

The crop factor, $\mathrm{K}_{\mathrm{c}}$, mainly depends on the type of crop, the growth stage of the crop (fully developed plants use more water than in the initial stage) and the climate, humidity and wind speed. The total growing period (in days) is the period from sowing or transplanting to the last day of the harvest. It mainly depends on the type and variety of the crop, the climate, and the planting date. The total growing period is divided into four growth stages (FAO, 1977):

1. Initial Stage (from sowing or transplanting until the crop covers about $10 \%$ of the ground)

2. Crop development stage (until the ground cover $70-80 \%$ has been reached)

3. Mid-season stage (until maturity; includes flowering and grain-setting)

4. Late season stage (until the last day of the harvest; includes ripening)

Table 4-4 shows $K_{c}$ values for the five most represented crops in the study area. Note that the table only covers three instead of the prior introduced four growth stages. This is due to a lack of literature values for those crops. With a development and mid-season stage of 180 days and a corresponding $\mathrm{K}_{\mathrm{c}}$ of 1.25 , sugarcane is the most demanding of the crops. Pineapple has a quite low water demand and a very long mid-season stage.

Table 4-4: $\mathrm{K}_{\mathrm{c}}$ values of crops present in João Pessoa study area depending on growth stages (Initial Stage, Development Stage or Mid-Season and Late Season)

\begin{tabular}{|c|c|c|c|c|c|c|c|}
\hline \multirow[t]{3}{*}{ Crop } & \multicolumn{6}{|c|}{ Growth Stage } & \multirow[t]{3}{*}{ Source } \\
\hline & \multicolumn{2}{|c|}{ Initial Stage } & \multicolumn{2}{|c|}{ Developm. / Mid S. } & \multicolumn{2}{|c|}{ Late Season } & \\
\hline & $\mathrm{Kc}$ & Days & Kc & Days & $\mathrm{Kc}$ & Days & \\
\hline Sugarcane & 0.40 & 50 & 1.25 & 180 & 0.75 & 60 & FAO, 1977 \\
\hline Pineapple & 0.50 & 60 & 0.60 & 720 & 0.30 & 10 & FAO, 1977 \\
\hline Mango & 0.92 & 25 & 0.83 & 30 & 0.70 & 30 & Teixeira et al., 2008 \\
\hline Coconut & $*$ & $*$ & 0.54 & $*$ & $*$ & $*$ & Jayakumar, et al., 1988 \\
\hline Manioc & 0.30 & 150 & 1.10 & 150 & 0.50 & 60 & FAO, 1977 \\
\hline
\end{tabular}

* no available data 


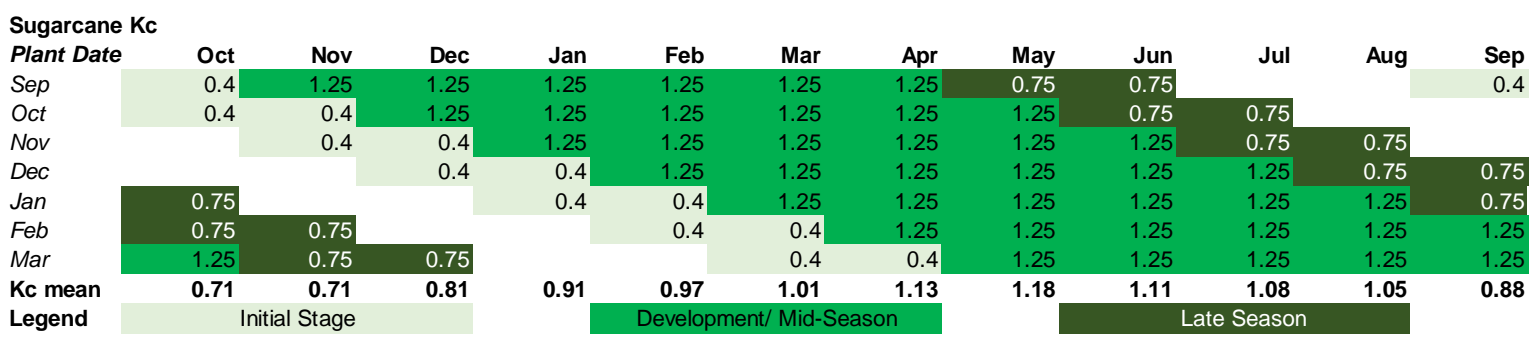

Figure 4-28: Distribution of growth stages over the year to derive mean Kc values for sugarcane (after FAO, 1977).

It was not possible within the course of this study to obtain actual operational data on the plantations. The reason was that for the vast majority, no data was available. Farmer irrigation their crops have groundwater access by means of wells. Some of those are registered by local authority AESA and are allowed a specified amount of water extraction per year. But none of them are monitored. Field investigations revealed that most farmers let the installed pumps run for some hours and flood their fields (Walter, 2013a). Only vague information has been made available on when there is a harvest season or when new crops are planted. To obtain an average $\mathrm{K}_{\mathrm{c}}$ value for each crop and month, some assumptions had to be made. Figure 4-28 illustrates the approach that has been conducted on the example of sugarcane. The equivalent tables for the other crops are found in Appendix 1.

Typical plantation dates for sugarcane are September-March, with an initial growth stage of around 50 days ( 2 months), followed by a mid-season stage of around 180 days ( 6 months) and a final stage of another 60 days (2 months) (FAO, 1977). The illustrations shows the respective $\mathrm{K}_{\mathrm{c}}$ values based on the different plant months, with an average value for each months assuming that there is a homogeneous distribution of plant dates over the study area. The same calculation has been made for each of the main crops of the region, with exception of the trees, Mango and Coconut. Table 4-5 shows the result of the $\mathrm{K}_{\mathrm{c}}$ calculations for each month. For all plantations in the study area these average $\mathrm{K}_{\mathrm{c}}$ values have been applied.

Table 4-5: Calculated average $\mathrm{K}_{\mathrm{c}}$ values for each crop and month according to growth stages

\begin{tabular}{|l|r|r|r|r|r|r|r|r|r|r|r|r|}
\hline & Oct & Nov & Dec & Jan & Feb & Mar & Apr & May & Jun & Jul & Aug & Sep \\
\hline Sugarcane & 0.71 & 0.71 & 0.81 & 0.91 & 0.97 & 1.01 & 1.13 & 1.18 & 1.11 & 1.08 & 1.05 & 0.88 \\
\hline Pineapple & 0.33 & 0.30 & 0.30 & 0.30 & 0.30 & 0.30 & 0.30 & 0.30 & 0.30 & 0.33 & 0.37 & 0.37 \\
\hline Manioc & 0.50 & 0.70 & 0.90 & 1.10 & 0.95 & 0.80 & 0.60 & 0.40 & 0.35 & 0.30 & 0.30 & 0.30 \\
\hline Mango & 0.83 & 0.83 & 0.83 & 0.83 & 0.83 & 0.83 & 0.83 & 0.83 & 0.83 & 0.83 & 0.83 & 0.83 \\
\hline Coconut & 0.54 & 0.54 & 0.54 & 0.54 & 0.54 & 0.54 & 0.54 & 0.54 & 0.54 & 0.54 & 0.54 & 0.54 \\
\hline Policulture* & 0.62 & 0.69 & 0.76 & 0.82 & 0.77 & 0.72 & 0.66 & 0.59 & 0.57 & 0.56 & 0.56 & 0.56 \\
\hline
\end{tabular}

* average value of manioc, mango and coconut combined

The Irrigation Water Demand (IWD) is the quantity of water required by the crop after precipitation. It is the water that needs to be artificially irrigated to the field. Consequently it is calculated by subtracting the precipitation from the crop water need: 
with

$$
E T_{C R O P}-P=I W D\left[\frac{h}{t}\right]
$$

$\mathrm{ET}_{\text {crop }}=$ Crop Water Need

$\mathrm{P}=$ Precipitation

As a basis for IWD calculations the land use map introduced in Chapter 4.2 was used. Rainfall and evaporation data was supplied by the hydrological model (Schimmelpfennig et al., 2018). Figure 4-29 shows the overlay of both spatial datasets. For each of the outlined polygons the crop water need and irrigation water demand was calculated on a monthly basis.

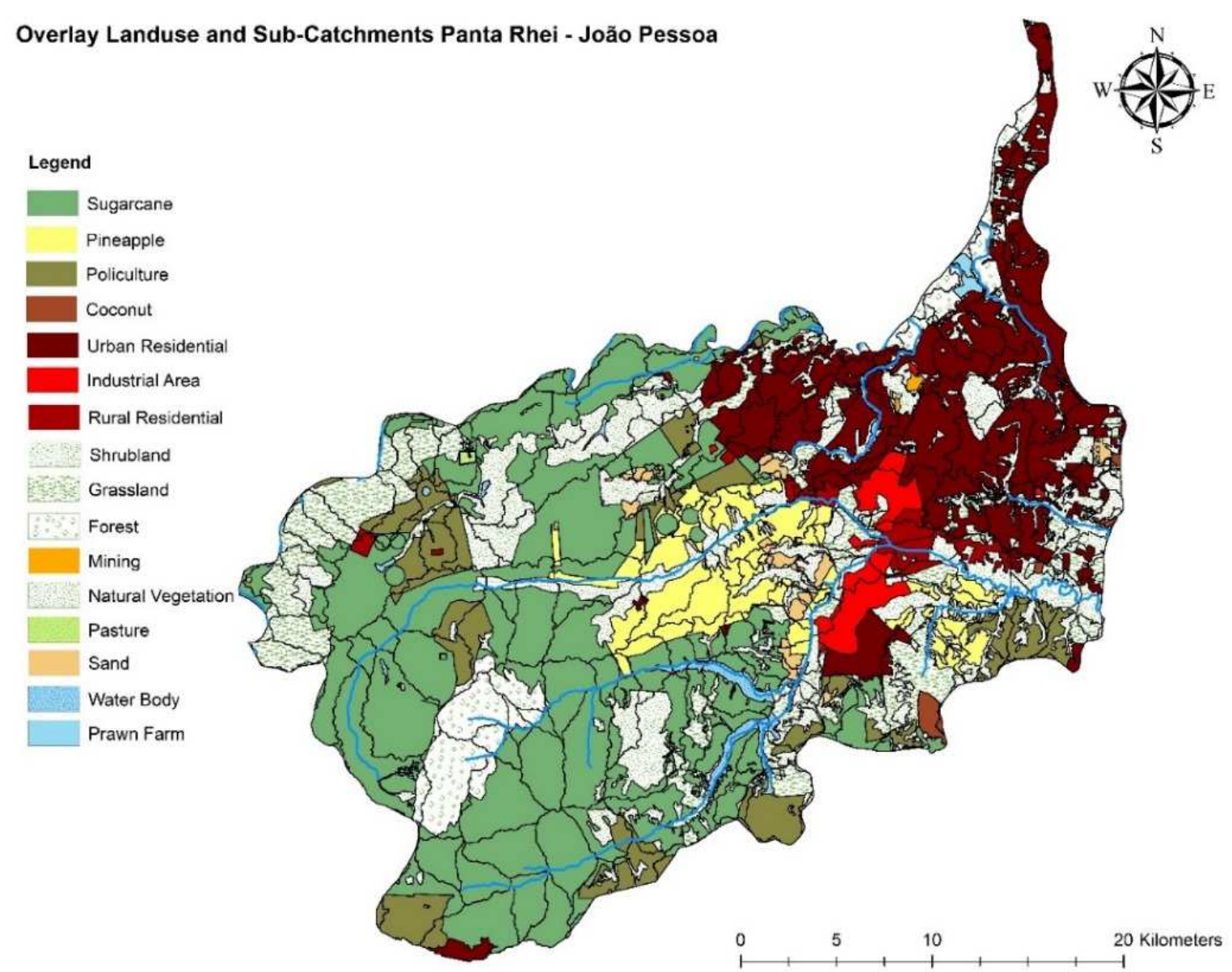

Figure 4-29: Overlay of sub-catchments from hydrological model (Schimmelpfennig et al., 2018) and land use map (Walter et al., 2018).

The present Irrigation Water Demand (IWD) has been calculated following the above described approach on a monthly basis for the years 2000-2014. A clear seasonality can be observed (Figure 4-31). This reflects the precipitation patterns in the area as presented before, with its typical rainy season with no or very limited irrigation demand and dry seasons with irrigation demands of up to more than $10 \mathrm{MCM}$ per month. These results are under the assumptions that $100 \%$ of agricultural areas are irrigated. Within the course of actual budget and scenario calculations this value will be adjusted, as it can be assumed that only $70 \%$ of the plantations are irrigated with groundwater. 
To determine the spatial distribution of this demand the former introduced MUs are used. In order to plan for MAR, it is essential to know when and where water is pumped from the aquifer. Figure 4-26 gives an overview of the spatial distribution of IWD based on this MU approach. It can be observed that there are specific "hotspots" for irrigation demand. The areas with highest concentration of sugarcane plantations show the highest agricultural water demands. Urban areas show little to no demand for irrigation purposes. Note that watering of gardens and parks falls under domestic demand. Especially the MU "Mumbaba_II" shows an IWD that alone reaches to more than $10 \mathrm{MCM}$ per month, depending on the year.

Also note that the values given here and in the figures are absolute values in MCM and not relative values in $\mathrm{mm}$. Using absolute values allows an easier assessment of different water demand sectors. For example the domestic or industrial water demand are not quantities that are relative to an area. Domestic water demand is calculated based on liters per capita and in no relation to hydrologic parameters such as rainfall or evaporation, both quantities of relative value measured in mm. Hence for all demand and supply quantities in this study we will refer to absolute values in MCM.

The IWD calculated above does not account for water losses during transport and application yet. No system has a $100 \%$ efficiency. Some irrigation techniques are more efficient than others. One of the most efficient ones is drippling irrigation, a system where irrigation water is brought directly very close to the crops roots. However, in the study area most irrigation is done by sprinklers. By spraying the irrigation water into the air, the water is subjected to high evaporation rates. An average efficiency of $60 \%$ is assumed for the study area. This means the IWD without losses as presented above represents only $60 \%$ of the total IWD. This is the actual amount of water that must be supplied for the agricultural sector. These values assume that $100 \%$ of the agricultural areas are indeed irrigated. Different levels of irrigation coverage will be analyzed in the chapters on scenarios.

Table 4-6 shows the population and annual DWD for each municipality in the study area. The DWD has been calculated by BRAMAR project partners (Braga et al., 2018). The distribution of DWD is in accordance with the size of municipalities and number of inhabitants. Biggest consumer of domestic water is the city of João Pessoa with 85.6 MCM per year. In comparison the DWD of Santa Rita, despite being about 1/6 of the size of João Pessoa, is significantly lower. With roughly $8 \mathrm{MCM}$ per year it is less than $1 / 10$ of the prior. This means the smaller municipalities have a lower per capita water demand than the coastal city. The difference can be explained in a lesser degree of urbanization and poorer connectivity to the water distribution network. Also the city of João Pessoa includes more parks and gardens as a result of the bigger centralization of wealth in the city, in addition with tourism, increasing its water consumption. In total João Pessoa makes up for roughly $80 \%$ of the total DWD in the region besides being home to only $66 \%$ of the population. This imbalance in DWD 
distribution is illustrated in Figure 4-30. The same imbalance can be observed with regard to the demand distribution between urban and rural areas; despite $5.2 \%$ of the population living in rural areas, the DWD for those areas makes up only less than $2 \%$ of the total DWD.

Since DWD has not been assessed on a monthly basis, some approximations had to be made with regard to its temporal distribution. It is assumed that the DWD is not strongly influenced by climate conditions. Hence it is assumed that DWD is constant throughout the year, without seasonal variations.

Table 4-6: Population and Domestic Water Demand in the study area 2010 (including losses)

\begin{tabular}{|l|r|r|r|r|r|r|}
\hline Municipality & \multicolumn{3}{|l|}{ Population (2010* } & \multicolumn{2}{l|}{ Demand [MCM/a] * } \\
\hline & Urban & Rural & Total & Urban & Rural & Total \\
\hline João Pessoa & 720,785 & 2,730 & $\mathbf{7 2 3 , 5 1 5}$ & 85.50 & 0.10 & $\mathbf{8 5 . 6 0}$ \\
\hline Santa Rita & 103,717 & 16,593 & $\mathbf{1 2 0 , 3 1 0}$ & 7.38 & 0.61 & $\mathbf{7 . 9 9}$ \\
\hline Bayeux & 98,793 & 923 & $\mathbf{9 9 , 7 1 6}$ & 5.63 & 0.03 & $\mathbf{5 . 6 6}$ \\
\hline Capedelo & 57,936 & 8 & $\mathbf{5 7 , 9 4 4}$ & 3.30 & 0.00 & $\mathbf{3 . 3 0}$ \\
\hline Pedras de Fogo & 16,358 & 10,674 & $\mathbf{2 7 , 0 3 2}$ & 0.93 & 0.39 & $\mathbf{1 . 3 2}$ \\
\hline Conde & 14,487 & 6,913 & $\mathbf{2 1 , 4 0 0}$ & 0.82 & 0.25 & $\mathbf{1 . 0 8}$ \\
\hline Alhandra & 11,153 & 6,854 & $\mathbf{1 8 , 0 0 7}$ & 0.64 & 0.25 & $\mathbf{0 . 8 9}$ \\
\hline Cruz do Esp. Santo & 7,440 & 8,817 & $\mathbf{1 6 , 2 5 7}$ & 0.42 & 0.32 & $\mathbf{0 . 7 5}$ \\
\hline São Miguel d. Taipu & 2,977 & 3,719 & $\mathbf{6 , 6 9 6}$ & 0.14 & 0.14 & $\mathbf{0 . 2 8}$ \\
\hline \hline Total & $1,033,646$ & 57,231 & $\mathbf{1 , 0 9 0 , 8 7 7}$ & 104.77 & 2.09 & $\mathbf{1 0 6 . 8 5}$ \\
\hline
\end{tabular}

* Braga et al., 2018

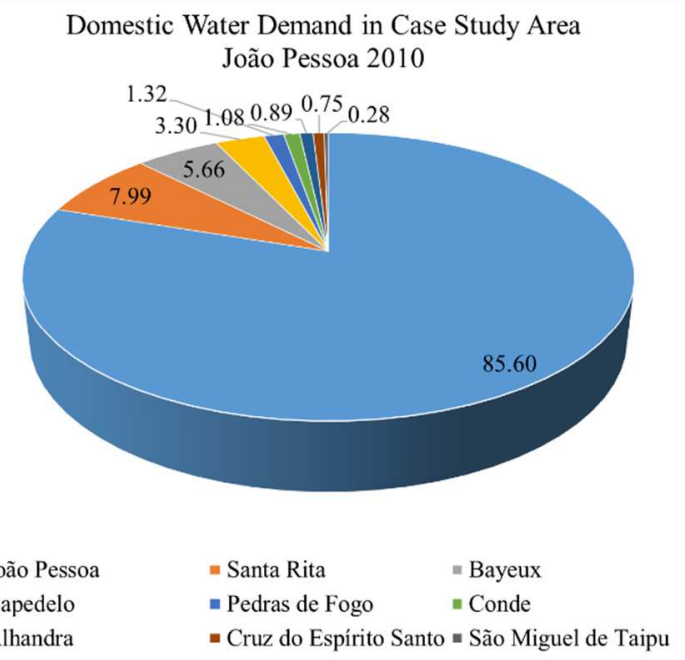

Urban vs Rural Domestic Demand in Case Study Area 2010

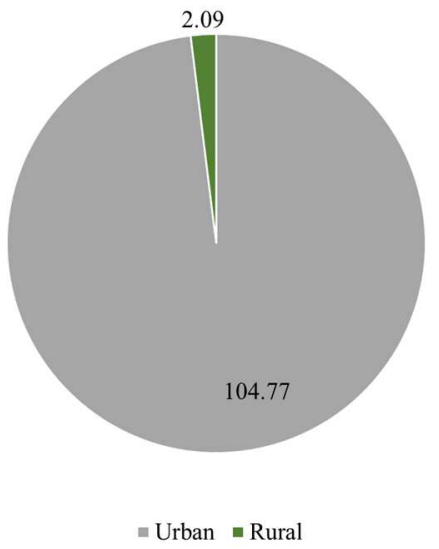

Figure 4-30: Domestic Water Demand per municipality and comparison urban and rural demand [MCM/a].

Some municipalities lie in between Management Units and/or on the border of the study area. For sake of a conservative approach, $100 \%$ of the DWD of municipalities located at the rim of our proclaimed study area are considered to be covered within the budget realm of the case study. For the spatial MU-approach the DWD of municipalities that lie between several MUs has been 
distributed among the MUs according to their share in area. These values already include water losses due to transport and distribution. For Northeast Brazil an averagely poor efficiency of $20 \%$ is assumed for domestic water distribution networks.

Like the domestic demand, Industrial Water Demand in the case study area has been analyzed by (Braga et al., 2018). For the study area, being a highly agricultural region and less of an industrial location, this demand is marginal. About 1.2 MCM per year, that is less than $1 \%$ of the total water demand in the study area, can be accounted for the industrial sector. Main industrial branches in the region are ethanol production from sugarcane and a small number of cement industries, exploiting the eastern outcrops of the limestone Gramame formation. Though the industrial demand sector is only marginal in comparison, the industrial areas are concentrated and lay mostly within the same Management Unit. Hence they will not be neglected for water budget calculations on the MU scale. As industrial water demand is not dependent on rainfall, but relatively constant throughout the year, the assumption has been made that the temporal distribution of industrial water demand is homogeneous over the months, just like in the case of domestic demand.

Another small water demand sector in the region is the supply of livestock: water for cattle, goats and chicken. Similar to industrial demand, the livestock sector is only of minor importance for the region as a whole, while socially important for many small farmers. Braga et al. (2018) analyzed the Livestock Water Demand as roughly $11 \mathrm{MCM}$ per year. This amount is required by farmers in addition, to rainfall in order to provide for livestock, making up only less than $3 \%$ of total mean water demands in the study area. This is a value with a lot of uncertainty since lots of small farms or villagers have some unknown minor number of livestock. In order to allocate the demand spatially, areas with the land use patterns grassland and scrubland have been identified and the demand distributed accordingly. Most cattle in the area is on open land. Accordingly, the water demand to supply the cattle was, similar to irrigation water demand, assumed in relation to rainfall behavior: During months with strong rainfall less water is required for the animals. Hence, the temporal distribution of the water demand has been calculated according to the rainfall patterns.

\section{b) Jericho-Auja}

While the total water demand in João Pessoa appears to be very low in comparison to the water availability, the semi-arid case study again reveals a contrast. The results of the water demand evaluation are presented in Figure 4-31. Similar to the prior case study, also this regions water demand is dominated by irrigation. With a mean annual demand of $33 \mathrm{MCM}$, it is six times as high as all other demands combined, making up $85 \%$ of the total water demand of $38 \mathrm{MCM} / \mathrm{a}$. 


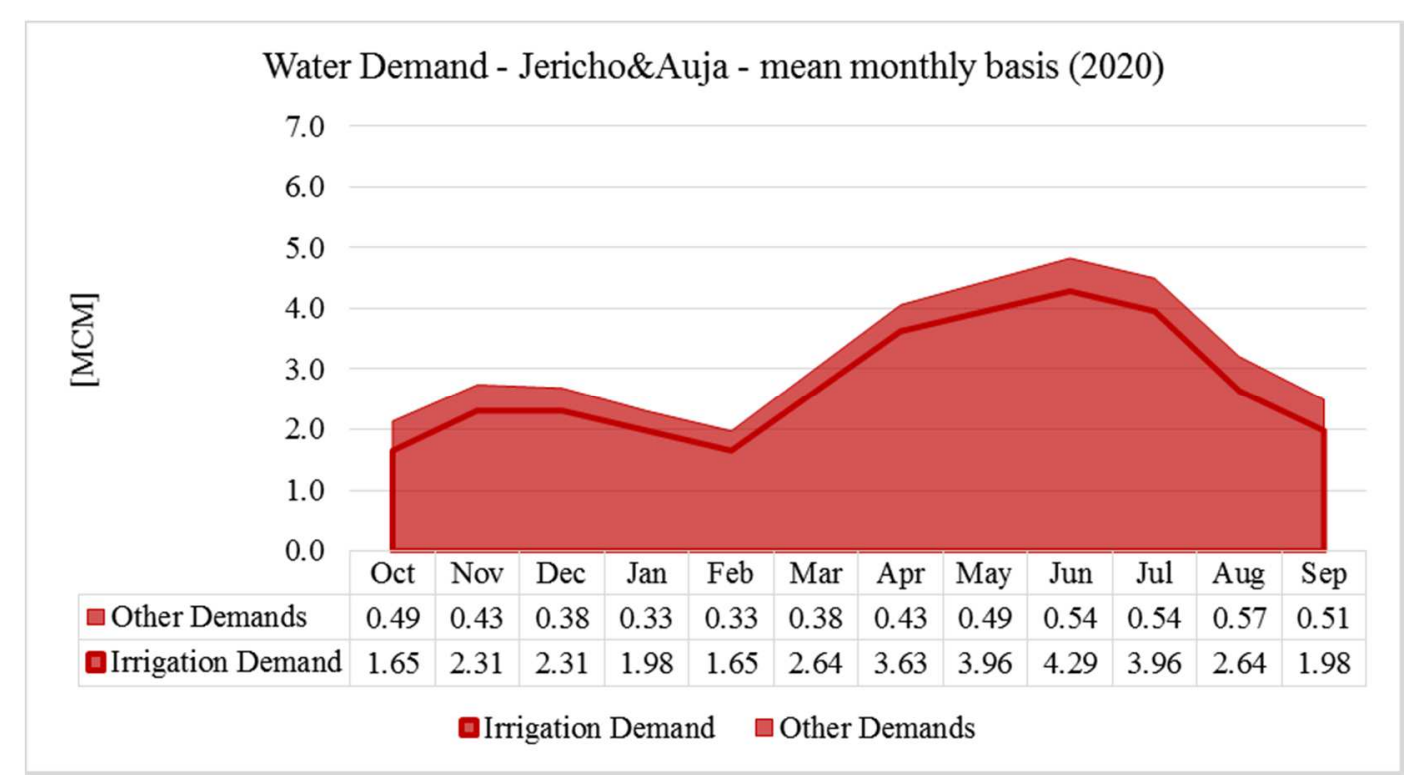

Figure 4-31: Total average water demand -Jericho-Auja.

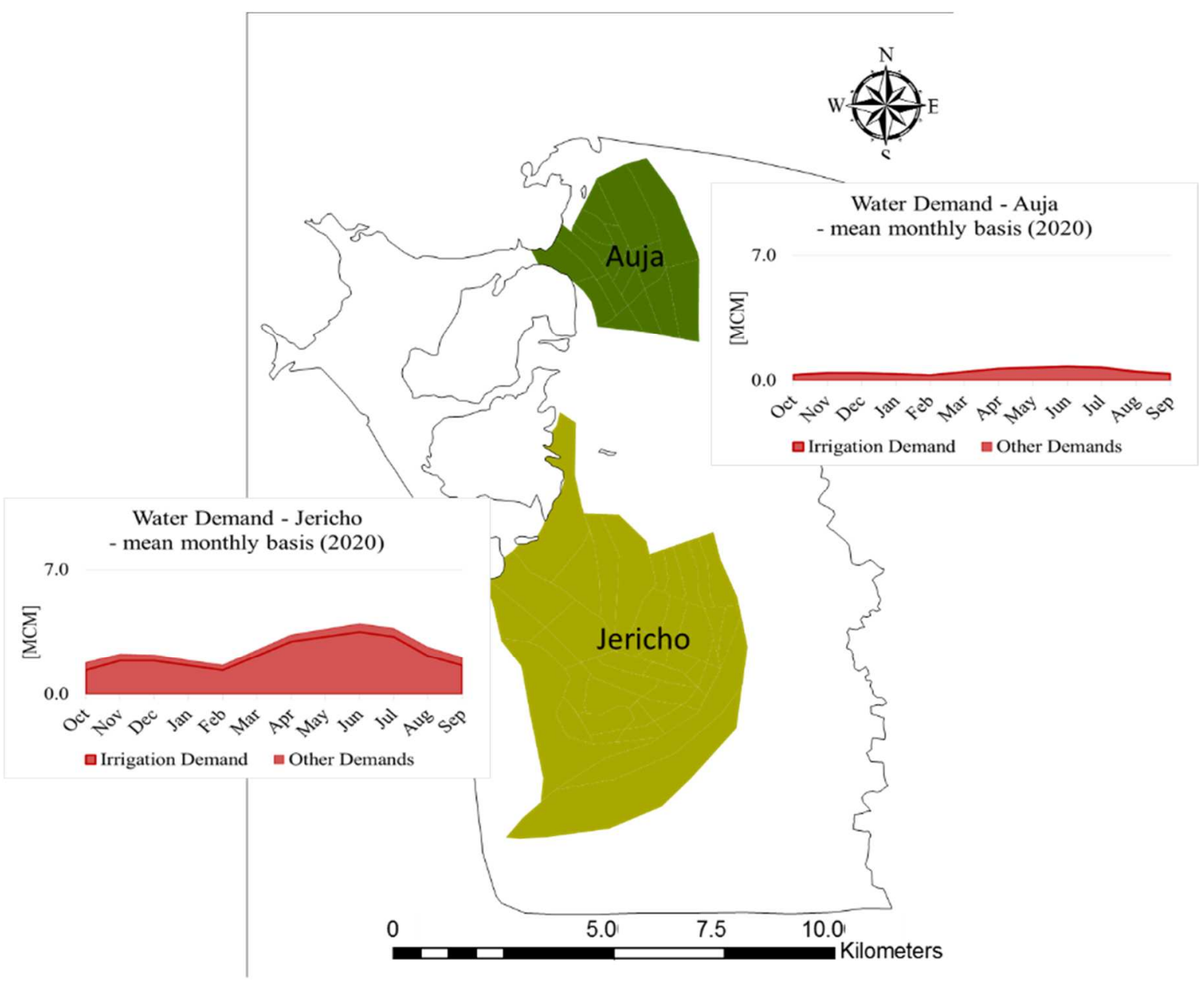

Figure 4-32: Spatial distribution of water demand -Jericho-Auja.

As described above, the study area is a highly rural one with a vast potential for agriculture. Main crops of the region are palm trees, numerous vegetables, herbs, grain, grapes and citrus fruits. Some 
agricultural production is conducted in greenhouses (Walter, 2013a). Data for irrigation demand has been supplied by Rusteberg et al. (2018a). Irrigation demand for the Management Unit (MU) Auja sums up to $6 \mathrm{MCM} / \mathrm{a}$, whereas the MU Jericho has an irrigation water demand of around $26 \mathrm{MCM} / \mathrm{a}$. Both MUs have a high potential for agricultural extension with regard to land availability and fertility. The limiting factors is water availability. This circumstance will be further analyzed in the following chapters when calculating a scenario for agricultural development.

Compared to irrigation water demand, other demand values for the study area are significantly lower. For the study, there is no benefit in distinguishing between actual domestic, public or commercial demand. Hence, given here are the accumulated values for all other demand sectors in the study area. Figure 4-32 summarizes these demand values on a mean level for each MU. The more developed MU Jericho shows about five times higher demands than the rural MU Auja. The distribution over the year is fluctuating with a peak in the summer months, when it nearly doubles.

\subsubsection{Hydro-Infrastructure}

\section{a) João Pessoa}

The above presented water sources and demand centers are connected by certain hydroinfrastructural installations. In order to activate or improve the supply from sources or reduce the losses during the transport and application at the demand centers, some suggestions can be made that would be required in order to use the full potential of the discussed units. Table 4-7 summarizes the findings and suggestions for the case study João Pessoa.

Table 4-7: WRS Analysis - Hydro-Infrastructure João Pessoa

\begin{tabular}{|l|l|l|}
\hline $\begin{array}{l}\text { Water source } \\
\text { / Demand center }\end{array}$ & Existing hydro-infrastructure & Suggested hydro-infrastructure* \\
\hline Surface runoff & $\begin{array}{l}\bullet \text { Surface reservoirs } \\
\text { Pumping stations }\end{array}$ & $\begin{array}{l}\bullet \text { MAR facilities (see Chapter 4.5.1) } \\
\text { Additional pumping stations at the rivers } \\
\text { Pipelines or canals from rivers to MAR } \\
\text { facilities }\end{array}$ \\
\hline Groundwater & $\bullet$ Extraction wells & $\bullet$ - \\
\hline Treated effluent & $\bullet$ Wastewater treatment plants $(2$ step) & $\begin{array}{l}\bullet \text { Additional treatment step(s) } \\
\text { Pipelines for disposal to prevent UMAR }\end{array}$ \\
\hline Rain water & $\bullet$ None & $\begin{array}{l}\bullet \text { Rainwater harvesting in urban area for direct } \\
\text { injection (see Chapter 4.5.1) }\end{array}$ \\
\hline Irrigation demand & $\begin{array}{l}\bullet \text { Sprinkler irrigation } \\
\bullet \text { Drip irrigation } \\
\bullet \text { Flooding irrigation }\end{array}$ & $\begin{array}{l}\text { Replacement of sprinkler by extended drip } \\
\text { irrigation to reduce loss rates }\end{array}$ \\
\hline Domestic demand & $\bullet$ Water distribution network & $\bullet$ Modernization to reduce loss rates \\
\hline
\end{tabular}

* to activate / improve the respective water supply 
As the main water sources in the study area, surface runoff in the rivers and the local groundwater system have been identified. Surface runoff at present is extracted at several pumping stations throughout the study area. It is recommended to use the abundant surface runoff to feed several MAR facilities as will be presented in detail in Chapter 4.5.1. For this purpose additional pumping stations and pipelines or canals will be required to transport the water. To recover the recharged water of the MAR systems, a high number of groundwater extraction wells are already in existence. It can be assumed that the number of wells is sufficient. Treated effluent is considered of no interest for the water management strategies to be developed. However, the uncontrolled recharge of secondary treated waste water can be considered a risk for groundwater contamination. It is suggested to introduce additional treatment steps and discharge the effluent without harm for the groundwater resources. At present no major facilities for rainwater harvesting are known. It is suggested to consider the implementation of such a system in the urban area and use the rainwater for controlled recharge of the aquifer in terms of direct injection, as will be discussed in more detail. Water demand may be reduced for both, irrigation and domestic sectors. While the exact numbers could not be quantified, a substantial number of irrigation systems in the study area rely on sprinkler technology. It is recommended to replace these with a more efficient technology, such as drip irrigation. The local water distribution networks in the villages and urban areas should be modernized to reduce transport losses.

\section{b) Jericho-Auja}

Table 4-8 summarizes the recommendations for the WRS at case study Jericho-Auja. The suggestions are based on prior works that have been compiled by Rusteberg et al. (2018a). In contrast to the prior case study, surface runoff plays a minor role in the water supply of Jericho-Auja. Main supplier are the numerous natural springs within the study area. While some of these springs are not connected to the water distribution networks yet, other like the Auja spring are connected by open canals. These have considerably high loss rates during transport due to spilling and evaporation. It is recommended to connect all springs to the supply networks and modernize the transport infrastructure by means of pipes, reducing the transport losses. For the very scarce and irregular surface runoff in the wadis, some minor retention measures are implemented. Furthermore, Auja comprises a surface reservoir to store some of the runoff. In order to efficiently use this source, additional retention measures, such as earth damns are recommended. A supply network is required to transport captured runoff to the irrigated areas. Treated effluent from the Jericho treatment plant also requires an extended distribution network to efficiently irrigate some of the area with this steady source. For groundwater extraction, more wells are highly recommended. That includes the yet untapped deep aquifer. These so called deep wells are of major importance to the WRS of the study area. Agricultural irrigation is already very effective with a lot of areas being covered by greenhouses 
and application of drip irrigation. However, especially spring discharge is often used to flood the fields in an inefficient manner (Walter, 2013a). This method should be abandoned.

Table 4-8: WRS Analysis - Hydro-Infrastructure Jericho-Auja (Rusteberg et al., 2018a)

\begin{tabular}{|l|l|l|}
\hline $\begin{array}{l}\text { Water source } \\
\text { / Demand center }\end{array}$ & Existing hydro-infrastructure & Suggested hydro-infrastructure * \\
\hline Spring discharge & $\begin{array}{l}\bullet \text { Open canal (Auja) } \\
\bullet \text { Pipelines (Jericho) }\end{array}$ & $\begin{array}{l}\bullet \text { MAR facilities (see Chapter 4.5.1) } \\
\bullet \text { Pipelines to MAR facilities }\end{array}$ \\
\hline Surface runoff & $\begin{array}{l}\bullet \text { Surface reservoir Auja } \\
\bullet \text { Minor retention measures } \\
\bullet \text { Small reservoirs / ponds of local farmers }\end{array}$ & $\begin{array}{l}\text { Additional retention measures (e.g. earth } \\
\text { damns) }\end{array}$ \\
\hline Treated effluent & $\bullet$ Wastewater treatment plant (Jericho) & $\begin{array}{l}\bullet \text { Extended treatment } \\
\text { Supply network to agricultural areas } \\
\bullet \text { Import of TE from El Bireh by pipeline }\end{array}$ \\
\hline Shallow GW & $\bullet$ Extraction wells & $\bullet$ More wells \\
\hline Deep GW & $\bullet-$ & $\bullet$ Deep wells \\
\hline Irrigation demand & $\bullet$ Greenhouses with drip irrigation & $\bullet$ Extend greenhouses and drip irrigation \\
\hline Domestic demand & $\bullet$ Wlooding irrigation & $\bullet$ Modernization to reduce loss rates \\
\hline
\end{tabular}

* to activate / improve the respective water supply

\subsubsection{WRS Budgets and Problem Identification}

\section{a) João Pessoa}

Figure 4-33 summarizes the results for the case study João Pessoa. Water budget analyses showed a strong spatial and temporal imbalance between water demand and availability in the case study area. Vast surpluses and floods during the rainy season stand in contrast to highly increasing water demands during the dry season. The system shows extreme high sensitivity towards rainfall quantities. The creation of additional water storage will in any case increase the water resources systems resilience. Though the annual budget is positive, the values given here are total values of water availability and do not represent the actual use. Availability includes also the unused but potentially available water.

Most of the surface runoff discharges to the ocean unused. Rather, the local aquifer system is immensely used to cover demands. Comparing not the total water availability but the groundwater recharge with the demand values, it reveals that even though there are vast amounts of water in the tropical case study, the groundwater could be subject to overexploitation if the resources are not properly managed. Local aquifers are the most important storage facilities and sources of water to close the gap between rainy and dry season. They are under enormous stress with high fluctuations of the water table and need to be protected in order to preserve a sustainable water supply of the 
entire study area. MAR might be a suitable and feasible instrument to achieve this goal. The analyzed time series showed an immensely improvement of the systems resilience towards dry periods.

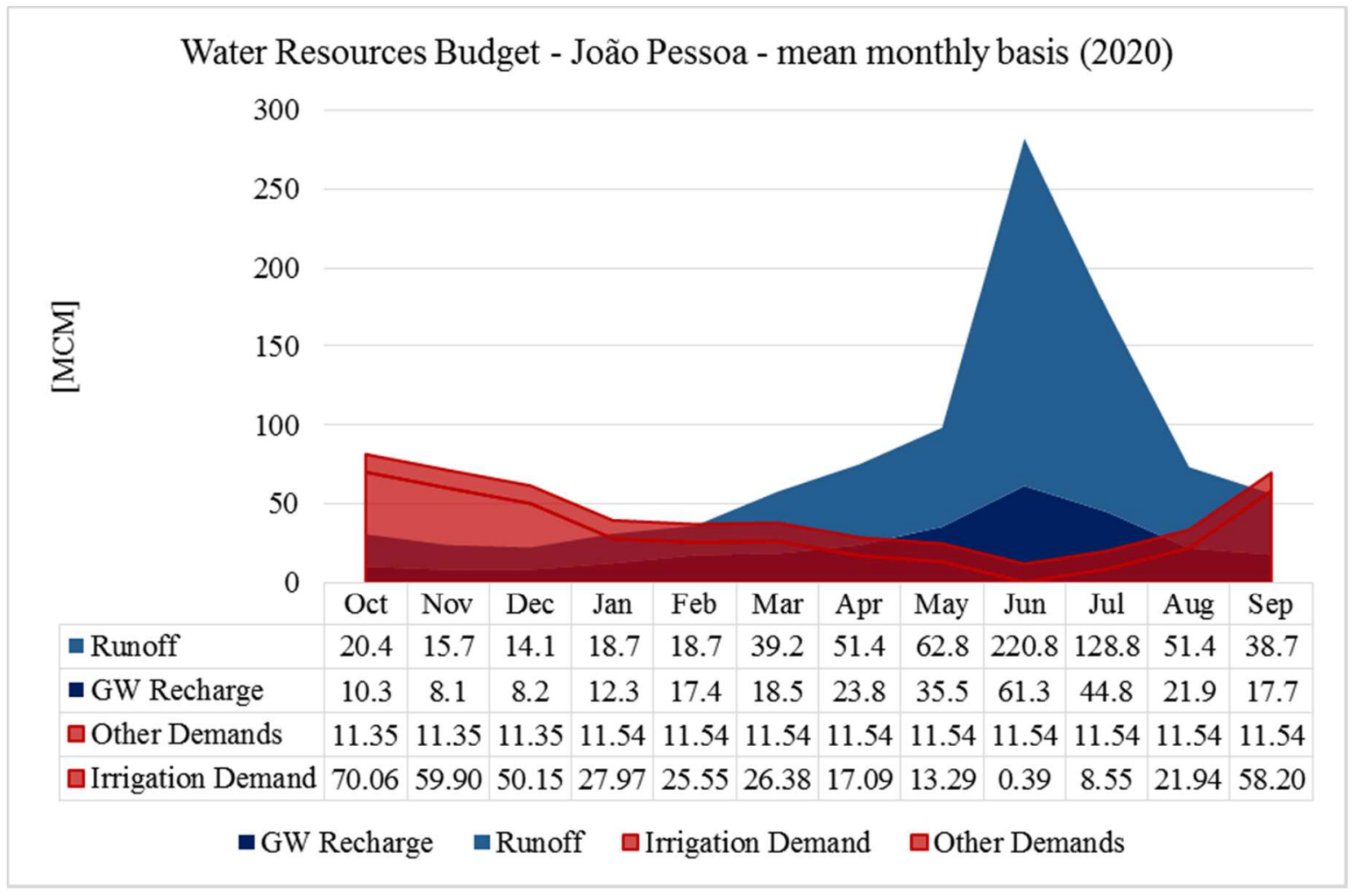

Figure 4-33: Total water budget on average basis -João Pessoa.

The high spatial heterogeneity in water demand and availability lead to the conclusion that MAR should be installed in a decentralized manner. Recharge facilities must be distributed according to local water extraction rates from the aquifer within the rural area. Main source for MAR should be surface runoff during the rainy season. A sufficient distance to rivers must be considered in order to avoid directly losing the recharged water to the streams. Effective water retention methods in the rural area are recommended to increase local recharge. Rain water harvesting solutions can be beneficial for the study area. In addition, minor Soil Aquifer Treatment facilities might support local groundwater balances, though the effect on local groundwater budgets is questionable since unmanaged recharge of wastewater is occurring already at present. These measure might, however, add to a sustainable management in terms of groundwater quality management.

\section{b) Jericho-Auja}

Figure 4-34 summarizes the findings of the analysis presented in this chapter. The water resources system analysis revealed a high water potential of the local springs. At present these springs are not 
managed efficiently, resulting in rather high loss rates. Surface runoff occurs very infrequently but presents itself as a high potential additional water sources if adequate measures are being installed to harvest this resource. Further additional water sources can be found in the deep aquifer, offering a high potential to increase water availability. However, this valuable resource's usage is restricted by high investment costs and legal and political issues. A more accessible additional water source is the treated waste water of Jericho city that could be directly applied as field irrigation water. The local shallow aquifer, that is today used to cover all water deficits in the study area, reveals a sustainable yield of around 5MCM/a. As water demand analysis shows, the currently activated water resources cannot cover demand peaks during some months of the year, putting pressure on the shallow aquifer. This might lead to further overexploitation in the future.

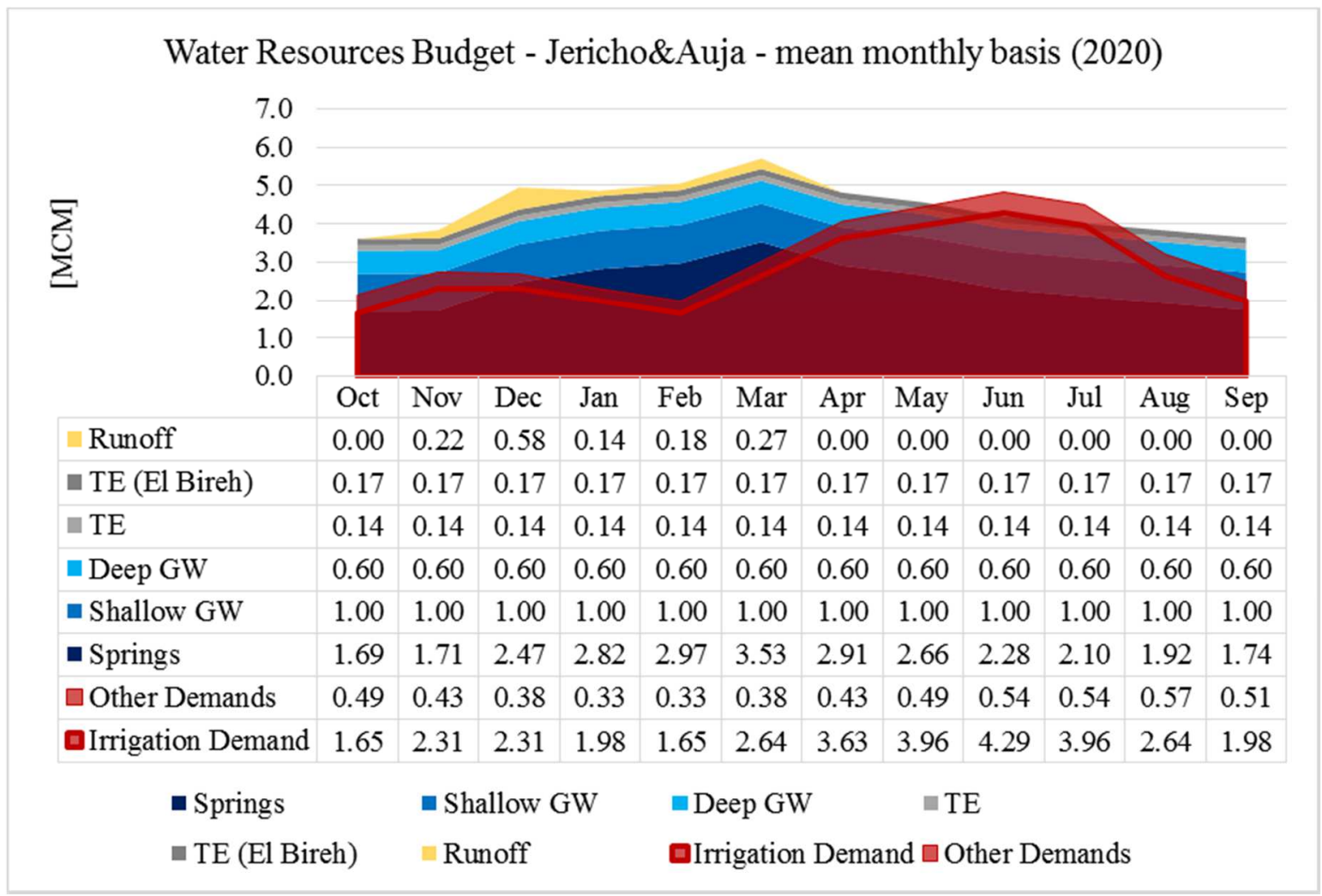

Figure 4-34: Total water budget on average basis -Jericho-Auja.

To conclude, the results of this chapter revealed an apparent overexploitation of the local shallow groundwater system at one hand and a high potential of additional water resources on the other. This indicates that with adequate water management measures increased water surpluses can be generated. These would in return allow for the implementation of a MAR system that might increase the local system's resilience towards dry periods. Potential measures might be reduction of loss rates by modernization of the water supply networks or activation of additional water sources, especially in terms of extractions from the deep aquifer. 
The water resources analysis for the case study revealed a present overexploitation of the local shallow alluvial aquifer. The main source of water for the study area are natural springs. These are associated with heavy fluctuations in discharge quantity and consequently low reliability of water support. Main water user in the area is the local agriculture. Due to the climatic conditions with high potential evapotranspiration and low rainfall with a very uneven temporal distribution, the irrigation demand is very high constantly throughout the year. The use of the spring discharge, especially in Auja, is based on traditional systems of water distribution among the farmers. The water losses during transport, intermediate storage in cisterns, and application on the fields mainly by flooding are very high. All these factors lead to an increased pumping of groundwater to fill the demand gap. Analysis showed that the natural groundwater recharge is not sufficient to cope with the demands, meaning the groundwater resources in the shallow aquifer are overexploited. Furthermore there is a problem with groundwater quality in the region. This is due to naturally brackish groundwater conditions in parts of the area and the uncontrolled leakage of untreated waste water from cesspits.

The analysis also revealed high potentials of additional water sources that can currently be considered as unused. These are groundwater from the deep aquifer, treated waste water for irrigation and the enhanced retention of the scarce surface runoff. All of these will be addressed as potential IWRM strategies that can be combined with MAR.

\subsection{Step 4: Combination of MAR Concept and IWRM Measures to integrative Strategies}

\subsubsection{MAR Implementation Concept}

\section{a) João Pessoa}

In this chapter the basic development scenarios for the study area are defined. A focus will be set on variations in land management and climate change. Since surface water is available in abundance during the rainy season, the main question is rather where to infiltrate additional water to the underground, than how to activate additional water resources.

The selection of feasible locations for MAR facilities depends on a variety of criteria (Rahman, 2011). On the one hand, additional aquifer recharge should of course be planned for locations that would potentially benefit from an increase in groundwater level. It is primarily a question of local groundwater budgets. That is why a preliminary selection of potential MAR locations has to be done in order to calculate the positive effects of those measures on a spatial context. It does not make sense to infiltrate additional quantities of water at a location where there is no pressure on the groundwater resources. This aspect of MAR site selection, the purely numerical analysis of groundwater level decline and recharge, will be addressed in the next chapter. Those results will then be further analyzed by means of groundwater flow modelling. Each of the steps might reveal new, more beneficial sites. 
MAR site selection is a very iterative approach. Therefore, the results of this chapter should not be seen as final recommendations, but rather a first step in identifying suitable locations.

The suitability of locations for an actual, physical implementation of MAR is depending on several site specific parameters. Among these are:

- Land use

- Infiltration rate

- Hydraulic conductivity

- Depth to water table

- Water pollution sources

- Slope / terrain

- Residence time

- Distance to rivers

- Groundwater quality

These physical parameters, without guarantee for completeness, decide over the general feasibility and suitability of locations for MAR facilities. Some of the criteria, e.g. slope or land use, are of minor importance when looking for locations to implement direct injection wells. They are, however, of high importance for the planning of infiltration ponds, which require large areas and benefit economically from initially flat terrain. For the study a spatial-multi-criteria tool is used for MAR site selection. The tool is part of the BRAMAR-IDSS (Information and Decision Support System) developed by project partners from RWC in the course of the BRAMAR project (Rusteberg et al., 2018). The system utilizes the above listed criteria for a two-step analysis; the Constraint Mapping and Suitability Mapping. In the following both will be briefly introduced, selected thresholds for this study are presented and the results of tool application will be discussed.

In the Constraint Mapping a first selection of feasible areas for MAR implementation is conducted. By eliminating areas with criteria outside a specified range of thresholds, only feasible areas remain in the analysis. The tool applies values of either 0 (not feasible) or 1 (feasible) to areas, depending on whether the site specific criteria are within the defined thresholds or not. Table 4-9 shows the selected criteria and thresholds for Constraint Mapping. A minimum depth to the groundwater table of $20 \mathrm{~m}$ has been selected. The values refers to a mean groundwater level as interpolated from groundwater monitoring data. Since the main time for recharge via MAR is supposed to be during rainy season, it can be expected that the mean water level is already closer to the surface than the average value suggests. In addition, any recharge via MAR facilities, be it via infiltration ponds or 
direct injection by wells, will raise the groundwater level even higher. Sufficient storage space must be existent in order guarantee an efficient operation of any MAR facility.

Table 4-9: Selected criteria and thresholds for Constraint Mapping

\begin{tabular}{|l|r|r|}
\hline Criteria & min. & max. \\
\hline Depth to water table & $20 \mathrm{~m}$ & - \\
\hline Distance to pollution source & $500 \mathrm{~m}$ & - \\
\hline Distance to rivers & $500 \mathrm{~m}$ & - \\
\hline Slope & - & $5 \%$ \\
\hline \hline & feasible & not feasible \\
\hline Land use & Agriculture & Water bodies \\
& Grassland & Urban areas \\
& Fallow Land & Forests \\
\hline
\end{tabular}

Distance to potential pollution sources, in this case the industrial facilities in the study area, is a qualitative issue. A lot of industrial waste water is already infiltrating the aquifer. This means an already existing recharge on the one hand, and presumably decreased groundwater quality in general at those locations. A safety distance of $500 \mathrm{~m}$ should prevent influences with those unmanaged recharge locations. Distance to Rivers is a crucial criteria in the case study. Due to the lack of groundwater flow simulation results at this point of the study, it is the only indicator for how long the infiltrated water would actually be available for recovery from the aquifer. Since in the study area the rivers are directly connected to the groundwater, it was assumed that any additional groundwater recharge close to the rivers will lead to a quick loss of those resources through the streams. A sufficient distance to rivers allow the water table to locally rise some meters without directly discharging into the surface runoff network. With average hydraulic conductivity values of around $3 \mathrm{~m} / \mathrm{d}$, a distance of $500 \mathrm{~m}$ to the nearest river would ensure the recharged water to remain for roughly 167 days or 5.5 months within the area of interest, depending on the hydraulic gradient. The slope has an influence on the suitability of a location for the construction of infiltration ponds. The basic assumption for the rural area of the case study is to use at least a hybrid-technology of passive infiltration wells within large infiltration ponds. This criteria would not affect the suitability of a location for direct injection wells, since they do neither require big areas, nor is their construction strongly influenced by surface characteristics. In order to keep construction costs relatively low, a maximum slope of $5 \%$ might be considered suitable here (Rahman, 2011). Land use is another surface characteristic that primarily influences the selection of suitable sites for infiltration ponds. Due to land costs, preservation of natural vegetation and the impossibility to recharge on water bodies (except riverbed filtration was considered) suitable sites were restricted to areas that are currently under agricultural use, grassland or unused fallow land. Urban areas and maybe forests might still be used for direct injection measures via pumping wells.

The results depicted that most parts of the rural area would potentially be feasible for the implementation of infiltration ponds for MAR under the assumption of above introduced criteria and 
thresholds. Figure 4-35 illustrates the results. For the urban area in the east, space for infiltration ponds is very limited. Given the results, recharge via direct injection wells is considered a feasible option at those locations. In addition a decentralized MAR system would be required since the rivers act as barriers for groundwater flow.
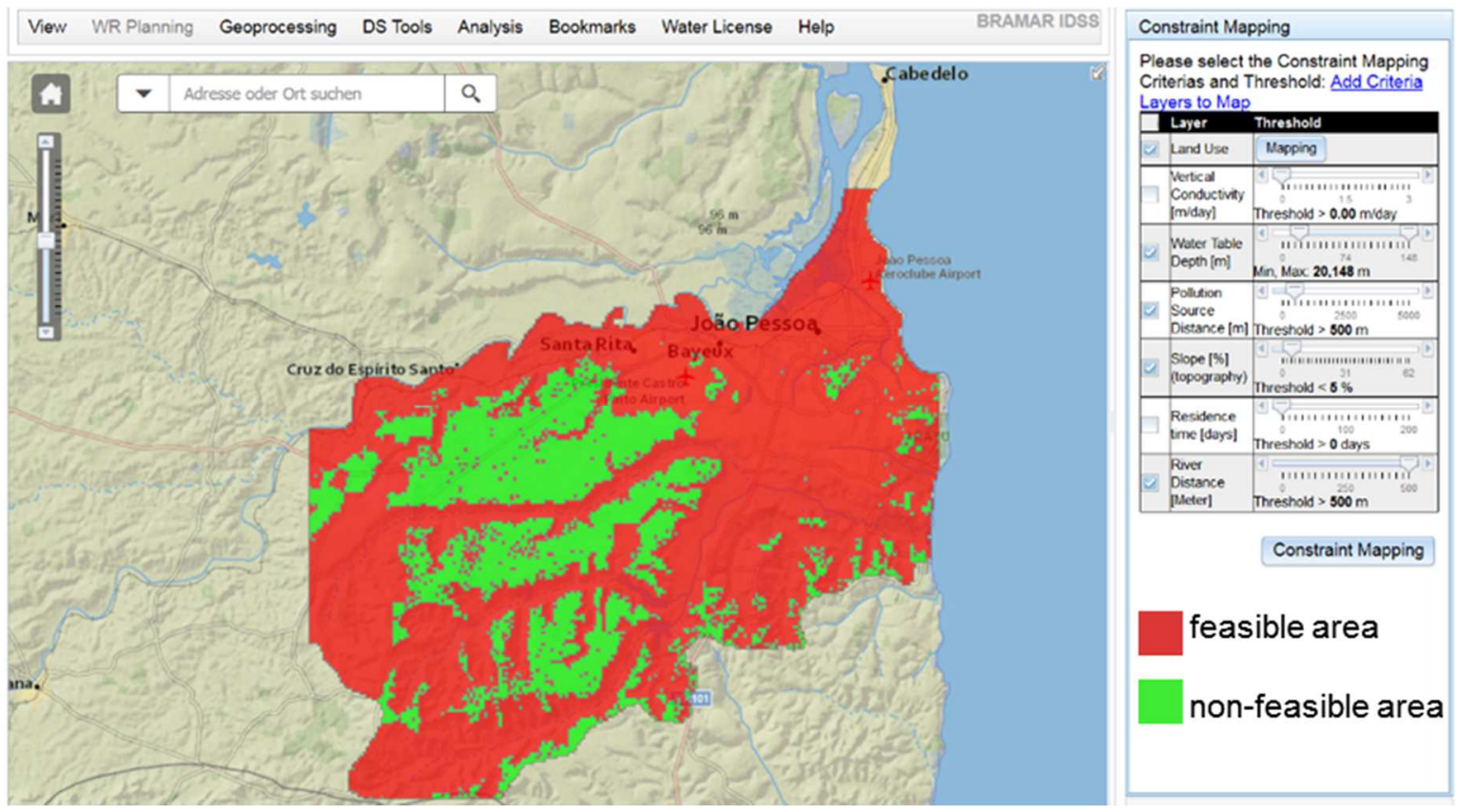

Figure 4-35: Constraint mapping results (Rusteberg et al., 2018).

Similar to the Constraint Mapping procedure, the Suitability Mapping rates the spatial mesh according to defined criteria and thresholds. In contrast to the prior approach, the locations are not distinguished into feasible and non-feasible but rated on a scale from $0 \%$ (unsuitable) to $100 \%$ (fully suitable). The BRAMAR-IDSS (Rusteberg et al., 2018) tool for Suitability Mapping offers the selection of criteria as described in Table 4-10. However, since the data situation is too poor to utilize this range of criteria, for this analysis only slope and depth to groundwater can be taken into consideration. Data about potential recharge rates, aquifer thickness and residence time, as well as relevant quality data, is not available on a spatial scale. The results lead to a preliminary selection of potential locations for MAR recharge. These are presented in Figure 4-37.

Table 4-10: BRAMAR-IDSS Criteria for Suitability Mapping

\begin{tabular}{|l|l|}
\hline Category & Criteria \\
\hline Surface Characteristics & Potential recharge rate \\
\hline & Slope \\
\hline Underground Characteristics & Aquifer thickness \\
\hline & Depth to groundwater table \\
\hline & Residence time \\
\hline Groundwater Quality & Chloride concentration \\
\hline & Nitrate concentration \\
\hline & $\mathrm{pH}$ \\
\hline & Sulphate concentration \\
\hline
\end{tabular}



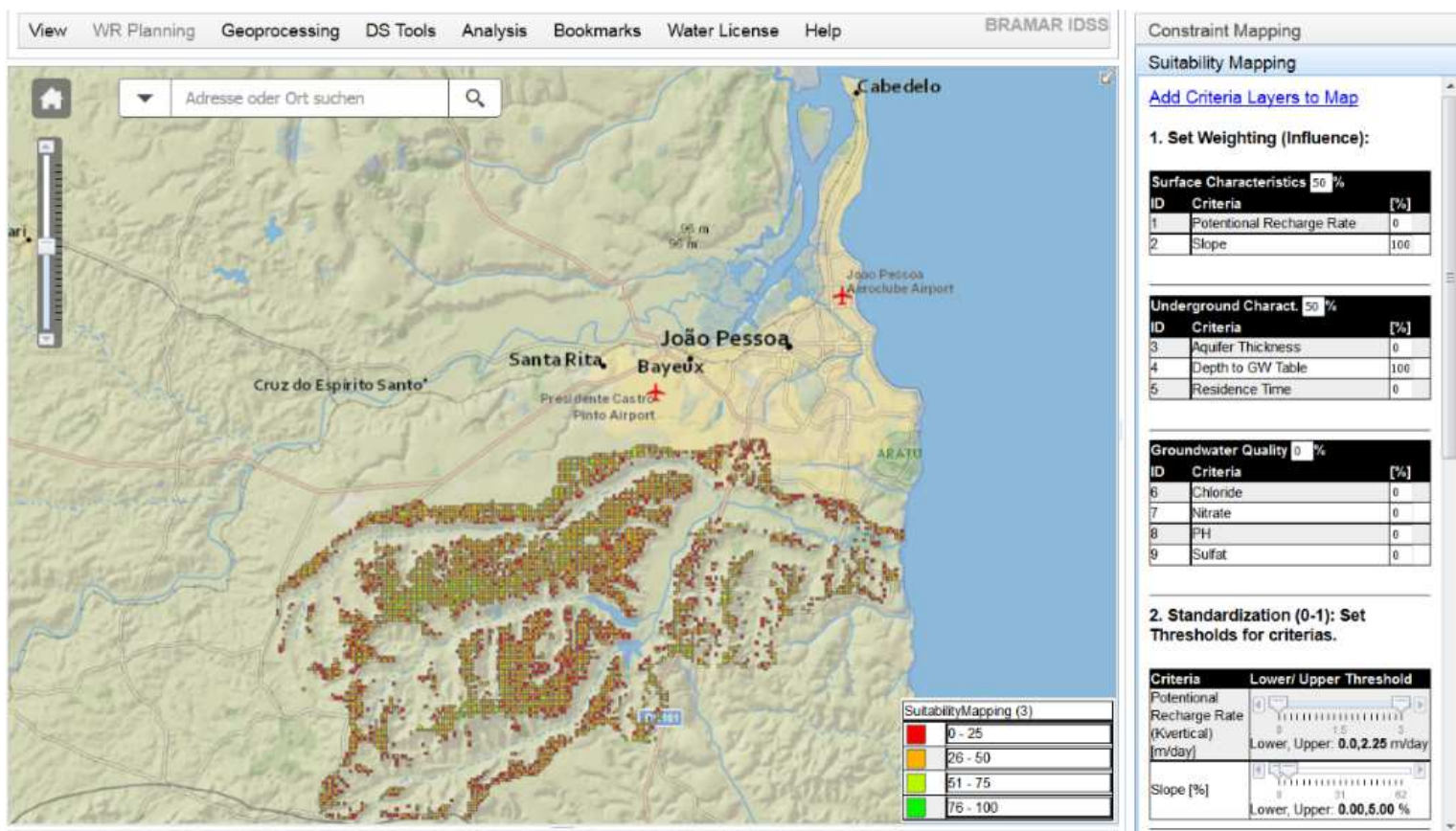

Figure 4-36: Suitability Mapping Results (Rusteberg et al. 2018).

Application of the tools revealed that for a real multi-criteria analysis, insufficient spatial data is available. The results for Constraint Mapping are satisfying, while the output of Suitability Mapping is insufficient to make a statement about final recommendations for MAR implementation. It is strongly recommended to obtain the required spatial data of groundwater quality and hydraulic parameters. Preliminary results of the BRAMAR project suggested that more data needs to be collected (BRAMAR, 2018). However, the results of this brief analysis show the potential and basic concept of MAR site selection. The selected sites for MAR recharge will be used for water budget calculations, establishing operation schemes for suggested MAR measures. For Managed Aquifer Recharge, the prior site selection process revealed the necessity to plan for decentralized solutions. Based on the MU scale and following the available simulated runoff data, as well as the connection between rivers and groundwater acting like a barrier to groundwater flow, it is assumed that MAR could be implemented at seven locations simultaneously. These locations are, for the following budget calculations, assumed to be close to the virtual runoff gauges introduced earlier. Figure 4-37 shows the rough locations of potential MAR sites as assumed for this analysis.

The quantity of MAR has been calculated based on the available runoff data. It is assumed that each facility can recharge a maximum of $1.8 \mathrm{MCM}$ per month. This might be achieved via infiltration ponds or direct injection. The actual monthly recharge is calculated based on the runoff data, allowing for enough water to flow further downstream. If total runoff is low, no water will be extracted for MAR. The median monthly discharge $\mathrm{Q}_{50}$ serves as a threshold. Below the $\mathrm{Q}_{50}$ value, no water will be extracted for MAR. As introduced in the prior chapter, different sources of Unmanaged Aquifer Recharge (UMAR) are present in the study area. These are natural groundwater recharge, return flow 
from irrigated agriculture and leakage from domestic water supply networks. All three sources of unmanaged aquifer recharge are included in the water budget calculations.

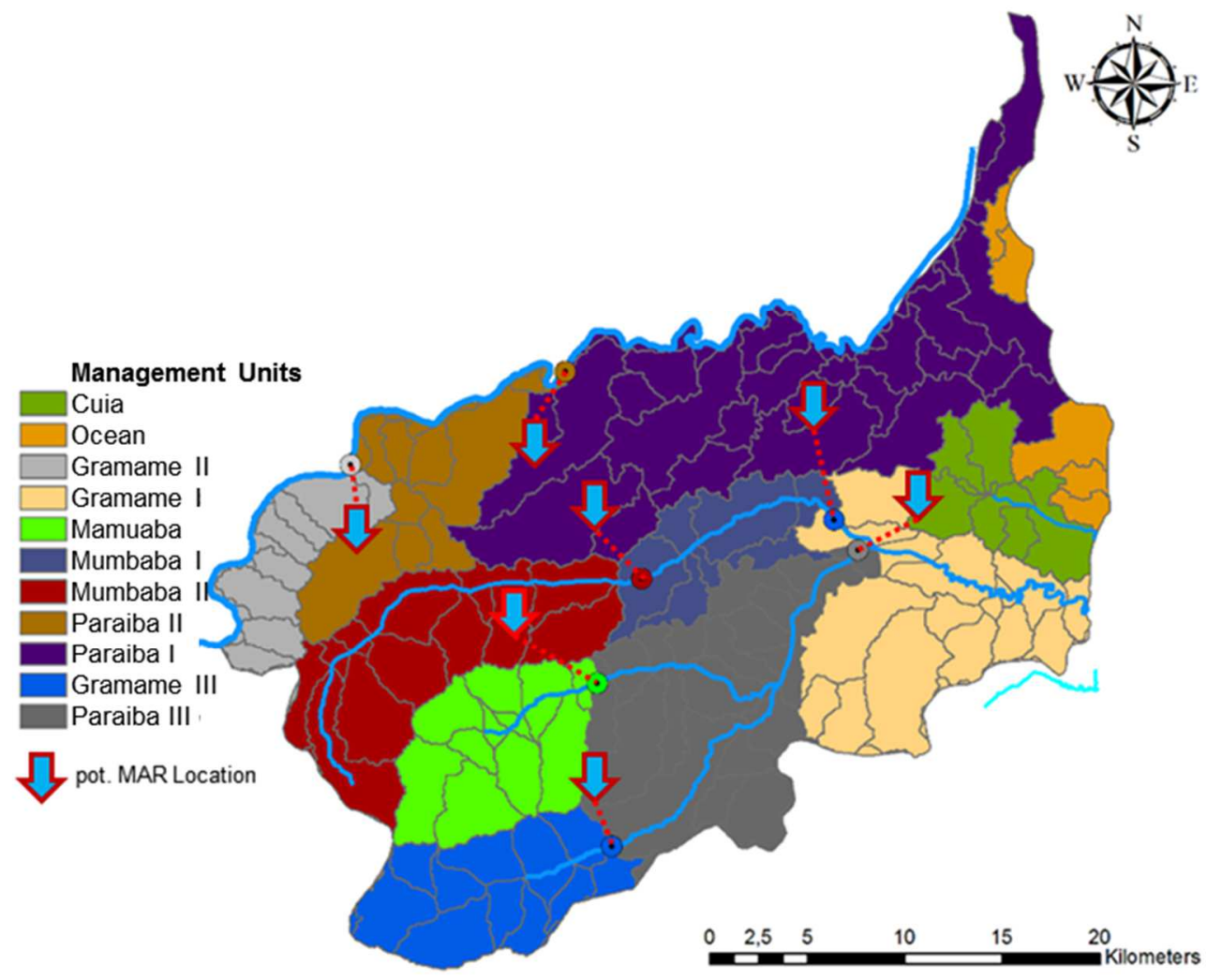

Figure 4-37: Schematic preliminary selection of MAR locations based on constraint and suitability mapping.

After the potential locations for MAR and the framework of the water resources system were defined, the remaining factor were the actual operation of these facilities in order to account for potential impacts of the measures. Note that other planning parameters such as the choice of technology or required pre-treatment measures were considered as equally important. Since the focus of this method was clearly set on quantitative impacts of water management issues, technological and qualitative details must be evaluated by means of specific studies. The compiled results suggested to conduct field experiments that built up on the quantitative analyses. First the water manager should know where and when water could be artificially recharged to the aquifer and what the expected impacts will be. Only then it makes sense to design field experiments to focus on these other aspects.

\section{b) Jericho-Auja}

For MAR budget analyzes at the case study Jericho-Auja, a special focus was given on the implementation of IWRM measures. This means activating new water sources for the region. In combination with MAR, the surpluses that may result from these measures can be stored in the 
alluvial aquifer. In addition, scenarios of hydrological variability should be analyzed. These considered various scenarios of a varying spring discharge and overall water availability. It was analyzed how the resilience of the system against longer drought periods will increase by implementing an additional water storage via MAR. A very important factor for the region, in accordance with local development plans and strategies, is the extension of agricultural areas. For comparison this study only gives results for a full extension of agricultural areas as introduced below. The combinations of these three main factors (water sources, hydrological variability and agricultural development) defined the studied MAR scenarios.

In contrast to the João Pessoa case study, the focus of the Jericho-Auja study was set on a maximization of irrigated agricultural land. Preliminary budget calculations revealed that an increased resilience and stability of the water resources system can be achieved very easily with a basic MAR scheme. This set the focus, in accordance with the development plans of local authorities on agricultural development. Therefore, this study set a focus first on some general assumptions regarding a MAR implementation and then analyzed what impact the activation of additional water sources in terms of IWRM strategies have on the system and if a full extension of agricultural land can be irrigated under those conditions.

No decision support tool for MAR site selection was available for the study area Jericho-Auja. However, some prior studies were conducted dealing with MAR site selection in the region (e.g. (Lutz, 2011, Walter, 2013). Based on these studies and some trial and error approach with the available groundwater flow model developed by Abu Sadah (2017), three preliminary suggestions for infiltration sites have been selected. The criteria for a first site selection were very general. Since spring discharge is the main potential source of water in the study area, it was decided to delineate MAR locations in the vicinity of those springs. Also, due to the high uncertainty regarding the underground characteristics and groundwater flow dynamics, the locations should be as close to the recovery wells as possible. The slope should be below $5 \%$ ideally in order to reduce construction costs and the land should be available for MAR. Since no spatial tool could be applied, creating Constraint and Suitability Maps as in the prior case study, only a simplified site selection was conducted.

Figure 4-38 illustrates the selected locations for further MAR analysis based on above mentioned criteria. These locations, one for MU Auja and two for MU Jericho, were used for the below presented groundwater and MAR budget calculations and groundwater flow simulations. These locations have already undergone a trial and error approach with the available groundwater flow model. They appear to give the best results in terms of simulated groundwater recharge. Future studies in the area will need to install test facilities and conduct tracer tests to verify the suitability 
of these preliminary selections. Also, the application of a spatial-multi-criteria-analysis as in the João Pessoa case study is highly recommended. For the following assessments it was assumed that all monthly surpluses can be recharged via MAR. The surplus available for recharge was calculated on the individual monthly budget for each MU in the next step. In contrast to the prior case study, available volumes for potential recharge do not reach that extreme values. Therefore, it was assumed that actually all of the monthly surplus can be recharged, after accounting for typical loss rates. In addition to the MAR measures, the sources of unmanaged aquifer recharge (UMAR) were also considered for budget calculations. These are return flow from agriculture (3\%), surface runoff (10 $\%$ ), leakage from cesspits (50\% of waste water in the rural area) and leakage from domestic supply networks (15\% of other demands). These return flows were already included in the budget calculations. As for the other case study, the actual operation schemes for each MAR locations were assessed by means of budget calculations based on a set of IWRM strategies under different future scenarios.

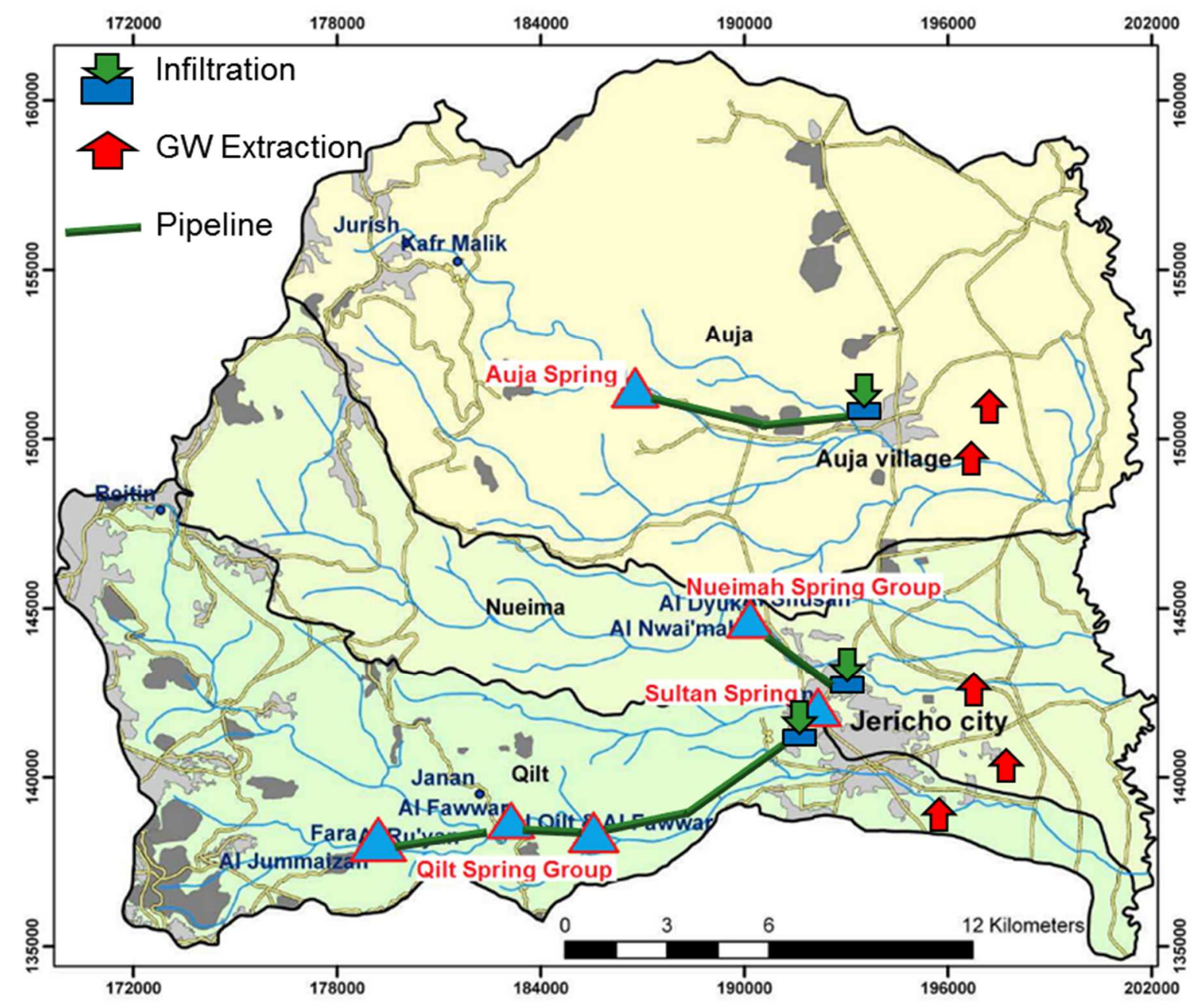

Figure 4-38: Schematic of preliminary MAR site selection for simulations (modified after Rusteberg et al., 2012). 


\subsubsection{Integrative MAR-IWRM Strategies}

\section{a) João Pessoa}

In this section the actual framework for MAR operation schemes are defined. The potential available water sources in the case study areas have already been discussed. The presented quantities do not necessarily represent the actually used or activated values, but rather potential, untapped water resources. Since a future installation of MAR facilities was assumed, the actual sources of water and their allocation for these options had to be considered. For this purpose a set of IWRM strategies has been designed. They were developed in a way, that each strategy represents an extension of the prior. Therefore, not sets of alternative measures were evaluated, but rather the cumulative benefit of a combined implementation. For all strategies presented here, it was a basic assumption that the resulting water surpluses of each month would be artificially recharged according to the prior introduced boundary conditions of locations and basic assumptions. Since the suggested approach that is tested here is of a highly iterative character, the strategies presented in the following have already been revised several times by evaluation of the steps to follow. It would not be beneficial for this thesis to actually give the results of each iteration that finally lead up to this stage of development. Approximately 12 iterations of evaluating this step have been conducted before the results that are shown here were finalized.

Before addressing the actual strategies, some basic assumptions should be named concerning water allocation in the area. There is an extraction of water directly from the surface runoff of an unknown quantity. Without proper modelling of both ground-and surface water in an integrative way, the exact extend of interaction between both systems can only be approximated. To avoid an overestimation of the potential of MAR in the region, values were estimated very conservatively. It was therefore assumed that only $60 \%$ of the remaining irrigation demand is indeed covered by groundwater extraction. The same applied for industrial and livestock water demand. The surface reservoirs Gramame-Mamuaba and Marés were considered as suppliers of Domestic Water Demand (DWD). To simplify matters, and due to lack of data, it was assumed that the aquifers supply a steady amount to the urban districts and therefore directly decrease the DWD by $50 \%$. Hence, only $50 \%$ of the above introduced domestic demand was assumed to be covered by groundwater pumping.

Table 4-11: Overview of developed strategies for case study João Pessoa

\begin{tabular}{|c|c|c|c|}
\hline Strategy & $\begin{array}{c}\text { MAR at 7 locations } \\
\text { with surface runoff } \\
\text { and a max. capacity of } \\
\mathbf{1 . 8} \text { MCM /month }\end{array}$ & $\begin{array}{c}\text { Modernization } \\
\text { of irrigation networks } \\
\text { to reduces losses by 10\% }\end{array}$ & $\begin{array}{c}\text { MAR at 7 locations } \\
\text { with surface runoff } \\
\text { and a max. capacity of } \\
\mathbf{3 . 6} \text { MCM /month }\end{array}$ \\
\hline A & $\mathrm{X}$ & - & - \\
\hline B & $\mathrm{X}$ & $\mathrm{X}$ & - \\
\hline C & - & $\mathrm{X}$ & $\mathrm{X}$ \\
\hline
\end{tabular}


Within this framework a total of three strategies of integrative IWRM and MAR implementation have been designed and were used for the following steps. They are presented in Table 4-11. Strategy A considers the implementation of seven decentralized MAR facilities spread throughout the entire study area (see Figure 4-37). Each of these location would receive water from the nearest main river. The strategy assumes an active operation of these facilities according to available runoff quantities. The volume of recharge is defined by the actual measured runoff in the rivers. For this purpose a design is necessary that allows on site measurement of the current runoff, e.g. by means of a simple water level measurement in the river. Depending on the current discharge, some of the surface runoff can be relocated to flow to the defined MAR location where it is infiltrated, e.g. via ponds. The choice of technology can be neglected at this point. Merely the range of values should be within the vicinity of what is potentially possible. Strategy A assumes a maximum capacity, which is only achieved during the rainy season with its extreme runoff quantities, of $1.8 \mathrm{MCM}$ per month. To give a dimension, this quantity could be supplied by a $60 \mathrm{~cm}$ wide canal or a $40 \mathrm{~cm}$ diameter pipe, assuming a mean flow velocity of $5 \mathrm{~m} / \mathrm{sec}$. The system could be designed passively by means of an overflow weir and a canal, relying on gravity and the pressure of water. This capacity would be sufficient under present day conditions to increase groundwater recharge in a sustainable manner as shown in Chapter 4.7.

Strategy B suggests a modernization of existing irrigation networks. Many sugarcane plantation are irrigated by sprinkler systems. A technology that is characterized by very high evaporation losses during application. Fine films of water get sprayed in the air, sometimes more than ten $m$ above the ground, creating an artificial rain on the fields. Under the given climatic conditions this irrigation technology must be considered as ineffective. Strategy B therefore extends Strategy A by a decrease in irrigation losses by ten $\%$. This value is purely an assumption. Many plantation already make use of drip irrigation, a highly recommended technology since, if correctly installed and applied, it reduces water losses to a minimum and requires limited to no active management once installed. The exact number and distribution of irrigation techniques is not known.

Strategy $\mathrm{C}$ is a combination of $\mathrm{A}$ and $\mathrm{B}$, with the modification that a maximum capacity of 3.6 MCM per month for each MAR location is assumed. This means a doubling of the capacity during the rainy season. As before this volume is only an assumption based on the knowledge gained by many iterations of the MAR planning approach. These are maximum values that are only reached during months of extreme rainfall. The actual extraction from the rivers is calculated in the next step in detail on a monthly basis for each location, over the course of 14 years. 


\section{b) Jericho-Auja}

In contrast to the prior case study, the water resources system of Jericho-Auja proved to be much more complex. Not only surface runoff and groundwater must be considered as feasible sources of water, but many more factors must be considered to manage the system in a sustainable manner. At present the main water source of the region is spring discharge from the several spring groups of the region. Therefore, the very first IWRM/MAR implementation considered was to use this abundant source of naturally discharging groundwater from the mountain aquifer system as source for MAR (Table 4-12). Three locations of MAR infiltration have already been introduced. It was assumed that all monthly surpluses can be infiltrated at those locations. Since the spring discharge is highly variable, so is the potential recharge at the MAR sites. Like for the other case study, these schemes of monthly operation were calculated very detailed in the next step under different scenarios of future development. Strategy A would require the installation of pipes to modernize the existing channels which suffer from high evaporation and spill losses in order to efficiently transport the water from the springs to the selected MAR sites. Before any implementation of IWRM measures, in terms of activating new water sources, should be considered, an effort should be undertaken to modernize the existing hydro-infrastructure and reduce the currently very high loss rates in water transport, storage and application. Current loss rates for the use of spring discharge accumulate to roughly $60 \%$. It was therefore assumed that for all strategies calculated these losses are reduced to $35 \%$. As before, this values is only an assumption and requires further studies. Any of the measures will also require a high social acceptance in order to change the traditional water sharing policy of the local farmers. Strategy B includes the activation of all springs for MAR purposes and adds an improvement of the surface water retention measures that are implemented at present.

Table 4-12: Overview of developed strategies for case study Jericho-Auja (after Rusteberg et al., 2018)

\begin{tabular}{|c|c|c|c|c|c|c|}
\hline $\begin{array}{c}\text { IWRM } \\
\text { Strategy }\end{array}$ & $\begin{array}{c}\text { Spring } \\
\text { Discharge }\end{array}$ & $\begin{array}{c}\text { Surface } \\
\text { Runoff } \\
\text { Retention }\end{array}$ & Deep Wells & $\begin{array}{c}\text { Local } \\
\text { Treated } \\
\text { Effluent }\end{array}$ & $\begin{array}{c}\text { Treated } \\
\text { Effluent } \\
\text { Import }\end{array}$ & $\begin{array}{c}\text { Import of } \\
\text { remaining } \\
\text { deficits* }\end{array}$ \\
\hline A & $\mathrm{X}$ & - & - & - & - & - \\
\hline B & $\mathrm{X}$ & $\mathrm{X}$ & - & - & - & - \\
\hline C & $\mathrm{X}$ & $\mathrm{X}$ & $\mathrm{X}$ & - & - & - \\
\hline D & $\mathrm{X}$ & $\mathrm{X}$ & $\mathrm{X}$ & $\mathrm{X}$ & - & - \\
\hline E & $\mathrm{X}$ & $\mathrm{X}$ & $\mathrm{X}$ & $\mathrm{X}$ & $\mathrm{X}$ & - \\
\hline F & $\mathrm{X}$ & $\mathrm{X}$ & $\mathrm{X}$ & $\mathrm{X}$ & $\mathrm{X}$ & $\mathrm{X}$ \\
\hline
\end{tabular}

* varies according to scenario and resulting deficits, therefore $\mathrm{F}(\mathrm{i})$ and $\mathrm{F}(\mathrm{ii})$ were distinguished

Close to Auja village a dam had already been constructed. Additional smaller retention measures, simple earth dams along the wadis, are recommended to capture as much of the sporadically occurring storm flood events. Even though the water resources system analysis showed that this resource is highly variable and there may be many years without any significant runoff event, it is the first and most natural source of additional water that should be addressed. 
Strategy $\mathrm{C}$ adds a very important source of additional water that is much less volatile than the prior. It is recommended to install several wells into the deep aquifer. In accordance to the SMART-MOVE project they are referred to as Deep Wells (DW). The underlying deeper aquifer has a very high natural recharge and has the potential to increase the water availability by several MCM per year. This resources at present is unused by Palestinians due to political issues. It is a valuable resource that must not be ignored if a sustainable water management in the Lower Jordan Valley should be achieved. The installation of additional wells is a key issue and prioritized before the activation of further resources.

The next considered source is the complete and efficient reuse of treated wastewater from local sources considered in Strategy D. This water source should not be infiltrated by means of Soil Aquifer Treatment technologies, but rather be applied to the fields directly. Thus decreasing the irrigation water demand accordingly, leaving more fresh water resources, e.g. spring discharge, for actual infiltration via MAR. Strategy E additionally considers the import of treated effluent from the wastewater treatment plant of El Bireh, a Palestinian city in the mountain region. This import option was suggested by local stakeholders and project partners.

Strategy $\mathrm{F}$ assumes that any remaining deficits that will be detected by the following groundwater budget assessment, would be covered by additional water imports. The source of this import will not be defined here, for it is purely speculative. Also the quantity is variable and was assumed to cover the calculated deficits over the next 20 years, as identified by the groundwater budget assessments under Chapter 4.7. The reason this strategy has been included is that local water plans focus on very ambitious goals for agricultural extension. Even under consideration of all local water sources will still not be sufficient to cover the demands that would arise from the desired extension of agricultural areas. It is neither the aim nor the objective of this study to question national water plans. Rather, means and strategies should be developed and analyzed that might help achieving the goals that were set. Therefore, the following analyses reveal results that Strategy F is a measure to emphasize how many additional imports would be required to fulfill the goals under consideration of all other potential IWRM measures in combination with MAR. It is therefore rather a way of showing what would additionally be required to meet the development goals, than saying that the goals might have to be lowered. 


\subsection{Step 5: Development Scenarios}

\subsubsection{Baseline Scenario}

\section{a) João Pessoa}

The next step is the definition of scenarios for future development to evaluate the developed strategies. It would not be sufficient to simply recalculate the water resources system on a mean average values. Both case studies underlie strong seasonal and inter-annual variability in hydrological conditions. The system of water sources and demands is under constant fluctuation. By means of storing water surpluses during periods of high water availability and making it available during periods of increased water demand, it is the idea of a MAR implementation to increase the resilience of the system against this volatility of resources. To evaluate this spatio-temporal effect of MAR on the system it was therefore required to go into the evaluation of actual time series of future scenarios.

Table 4-13: Water resources system parameters and corresponding scenarios -João Pessoa

\begin{tabular}{|l|c|c|c|}
\hline Parameter & Baseline & $\begin{array}{c}\text { Agricultural } \\
\text { Development }\end{array}$ & Dry Climate \\
\hline Domestic demand & + & + & + \\
\hline Agricultural demand & 0 & + & ++ \\
\hline Water availability & 0 & 0 & -- \\
\hline \multicolumn{2}{c|}{ as present + increase ++ strong increase -decrease -- strong decrease }
\end{tabular}

Table 4-13 gives an overview of the designed scenarios for the case study João Pessoa and the corresponding parameters that where adjusted in order to create these scenarios. The Baseline (BL) describes the very basic assumption of future development for the entire study area. It was assumed that all relevant parameters continue the way they were for the past years. This includes population growth and the correlating domestic demand, land use patterns and the corresponding crop water need, as well as rainfall, impacting the actual irrigation demand and natural and anthropogenic groundwater recharge. This means the Baseline scenario represents a sort of blueprint that can be used to evaluate the impact of any measure if things continue exactly the way they were in the past years.

The second scenario is the Agricultural Development Scenario (ADS). A challenging development of the vast agricultural lands around João Pessoa was assumed. Based on the land use study conducted, the assumption was that the remaining pineapple plantations, being relatively low in water demand, will be replaced by the much more profitable but highly water demanding sugarcane. This would directly impact the irrigation water demand and change its spatial distribution.

The third and last scenario, the Dry Climate Scenario, builds up on the prior scenario and extend it by decreased rainfall. To keep the assumptions conservative, an overall reduction of rainfall by a 
$10 \%$ will be assumed. All scenarios for João Pessoa begin with the year 2020 and end at 2034, covering a total of 14 hydrological years (October -September).

As a basis for all scenarios input from the hydrological model developed by Schimmelpfennig et al. (2018) was used. This includes surface runoff into the major rivers and spatio-temporal rainfall distribution, as well as groundwater recharge rates. The model had been calibrated and validated for a 14 years time series (2000-2014). For the scenarios this time period of discharge and rainfall were transposed to the future. The data has been presented in Chapter 4.4.2. Observed data for validation of these simulated values are scarce. Therefore, it would not be beneficial to develop synthetic time series for the future. The simulated historic data set represents the most reliable recreation of the natural system that was available at this point. The selected hydrological time series determines the irrigation water demand, since it was derived from the rainfall as has been presented in detail before. It also determines the amount of natural groundwater recharge and the available surface runoff that can be used for MAR as described above.

The socio-economic water demand such as domestic drinking water or industrial water demand on the other hand are not directly influenced by the hydrological time series. For this demand, simple assumptions of population growth have been taken into consideration. Accordingly the increase of domestic water demand was calculated in direct correlation to this growth rate. Figure 4-39 illustrates the resulting development of domestic water demand. Domestic demand was assumed to increase linearly over the analyzed time period. It is identical for all scenarios. The ADS and Dry Scenario will change with regard to irrigation demand and water availability.

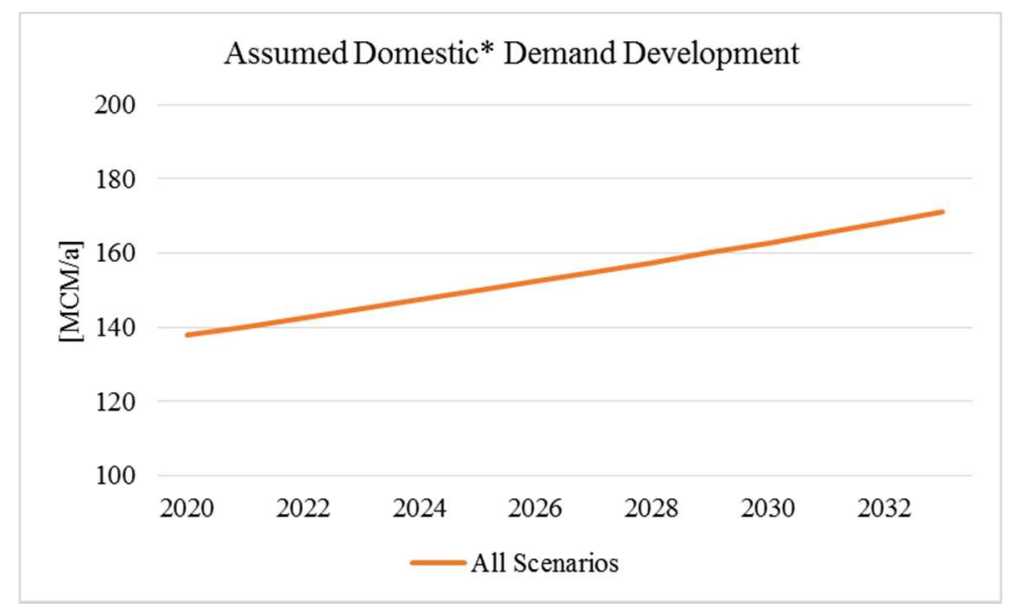

Figure 4-39: Assumed domestic demand development -João Pessoa (* incl. other minor demand sectors). 


\section{b) Jericho-Auja}

For the semi-arid case study a similar approach was used to design the scenarios. Again, three fundamental development scenarios will be analyzed as presented in Table 4-14. Similar to the João Pessoa case study they also include a Baseline, Agricultural Development and Dry Climate Scenario. In contrast to the prior study, the Baseline Scenario does not transpose historic hydrological data into the future. Rather, a set of synthetic time series were developed by Schmidt (2018). These data sets are based on actual long term observations of the local spring discharge. As has been shown in Chapter 4.4.2, the most abundant source of water in the study area is the discharge from local spring groups, which is fed by precipitation in the mountains. Schmidt (2018) derived synthetic spring discharge values by means of precipitation runoff modelling. From a combination of mean-dry-wetmean (MWDM) climate conditions, a time series of 20 years was derived. For the Baseline Scenario the synthetic values represent a series of five average years, followed by five years with above average water availability, five years of near drought conditions and finally another five years of average conditions. This is a good representation of the case study conditions. The mean annual water availability over the 20 years period remains the same average value from historic data.

Table 4-14: Water resources system parameters and corresponding scenarios -Jericho-Auja

\begin{tabular}{|l|c|c|c|}
\hline Parameter & Baseline & $\begin{array}{c}\text { Agricultural } \\
\text { Development }\end{array}$ & Dry Climate \\
\hline Domestic Demand & + & + & + \\
\hline Agricultural Demand & 0 & + & ++ \\
\hline Water Availability & 0 & 0 & -- \\
\hline \multicolumn{2}{|c|}{ o as present + increase ++ strong increase -decrease -- strong decrease }
\end{tabular}

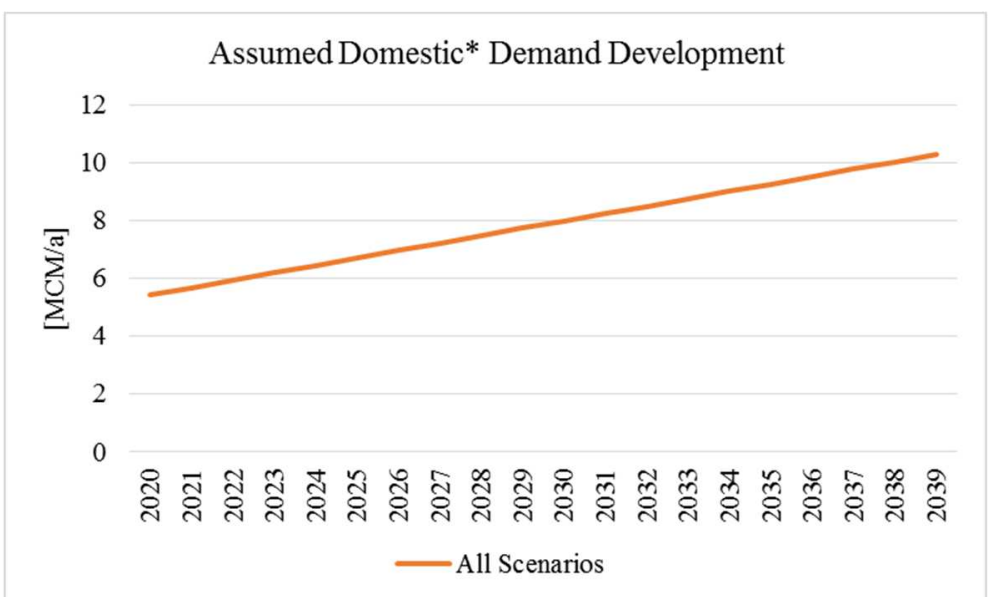

Figure 4-40: Assumed domestic demand development -Jericho-Auja (* incl. other minor demand sectors).

For socio-economic development, meaning increases in domestic and public water demand, no variations of scenarios were analyzed. Rather, a basic growth assumption was used. As introduced before, this values were considered as minor in comparison to irrigation demand in the study area. In total it is assumed that the demand will linearly increase from 5.4 MCM/a to $10.3 \mathrm{MCM} / \mathrm{a}$ within the 20 years time period as shown in Figure 4-40. 


\subsubsection{Agricultural Development Scenario}

\section{a) João Pessoa}

The second scenario is based on the same hydrological and socio-economic parameters as the BL. However, the ADS assumed an aggressive extension of the already overrepresented sugarcane plantations by extending to the valuable areas that are presently used for pineapple cultivation. Figure 4-41 shows the resulting increase in irrigation water demand. These values were calculated following the same methodology as the prior irrigation demand calculations according to FAO recommendations (FAO, 1977).

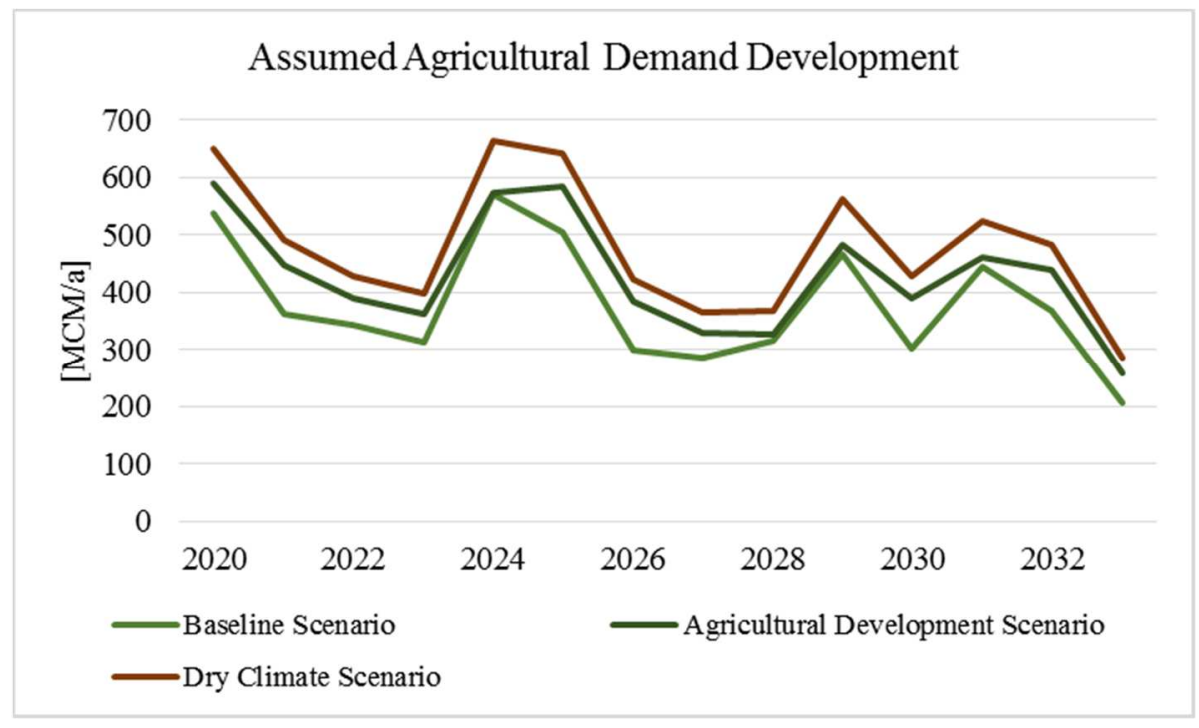

Figure 4-41: Assumed agricultural demand development -João Pessoa.

\section{b) Jericho-Auja}

The ADS for Jericho-Auja orientates on the local water and development plans. Rusteberg et al. (2018a) delineated the potential agricultural extension in the two municipalities within the context of a water allocation assessment conducted in the SMART-MOVE project. In accordance to local water authorities the development of irrigation water demand was assumed as depicted in Figure 4-42. The assumption for the ADS was, that Jericho could linearly extend its irrigated areas within ten years until 2030 to $30 \mathrm{~km}^{2}$, resulting in a mean irrigation demand of $30 \mathrm{MCM} / \mathrm{a}$. For the Auja village the irrigated agriculture was supposed to extend at the same pace within ten years and reach a maximum of $13 \mathrm{MCM} / \mathrm{a}$ in 2030, remaining constant until the end of the analyzed time period. The assumption was that other demands will develop in the same manner as in the Baseline Scenario. Also the same hydrological conditions were assumed, meaning the same time series of spring discharge and surface runoff will be used. Irrigation demand for both the ADS and Dry Scenario is identical, since rainfall in the study area is so scarce to begin with that it has no impact on the irrigation demand. The crop water need in all cases is covered by $100 \%$ by irrigation, neglecting the few rainfall events. 


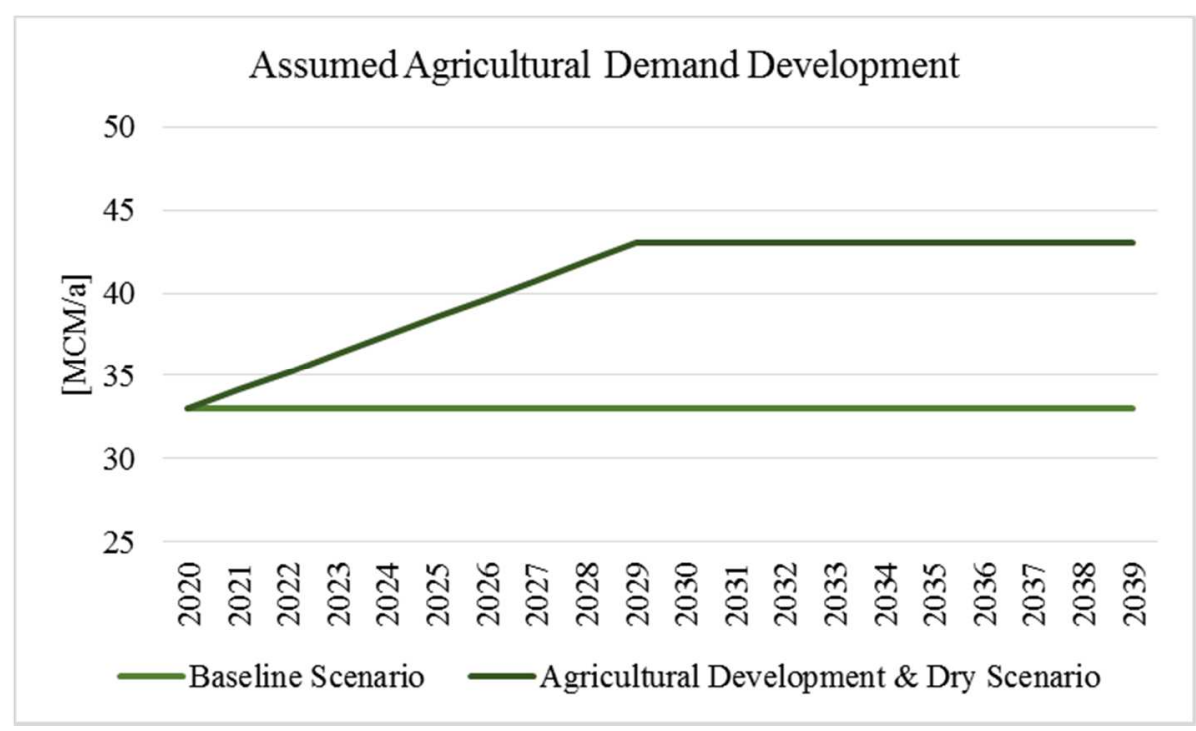

Figure 4-42: Assumed agricultural demand development -Jericho-Auja.

\subsubsection{Dry Climate Scenario (Dry)}

\section{a) João Pessoa}

The potential impact of climate change on water demands and availability was analyzed in a very simplified manner. In order to identify the potential impacts of a changing climate on the system, simplified estimations with regard to decreased rainfall were analyzed as the Dry Climate Scenario. This scenario uses the prior ADS as a basis, assuming an extension of sugarcane plantations, and adds a decrease of $10 \%$ rainfall, surface runoff and natural groundwater recharge as an additional parameter. This led to yet another increase in irrigation water demand which has been re-calculated using the same methodology (Figure 4-41).

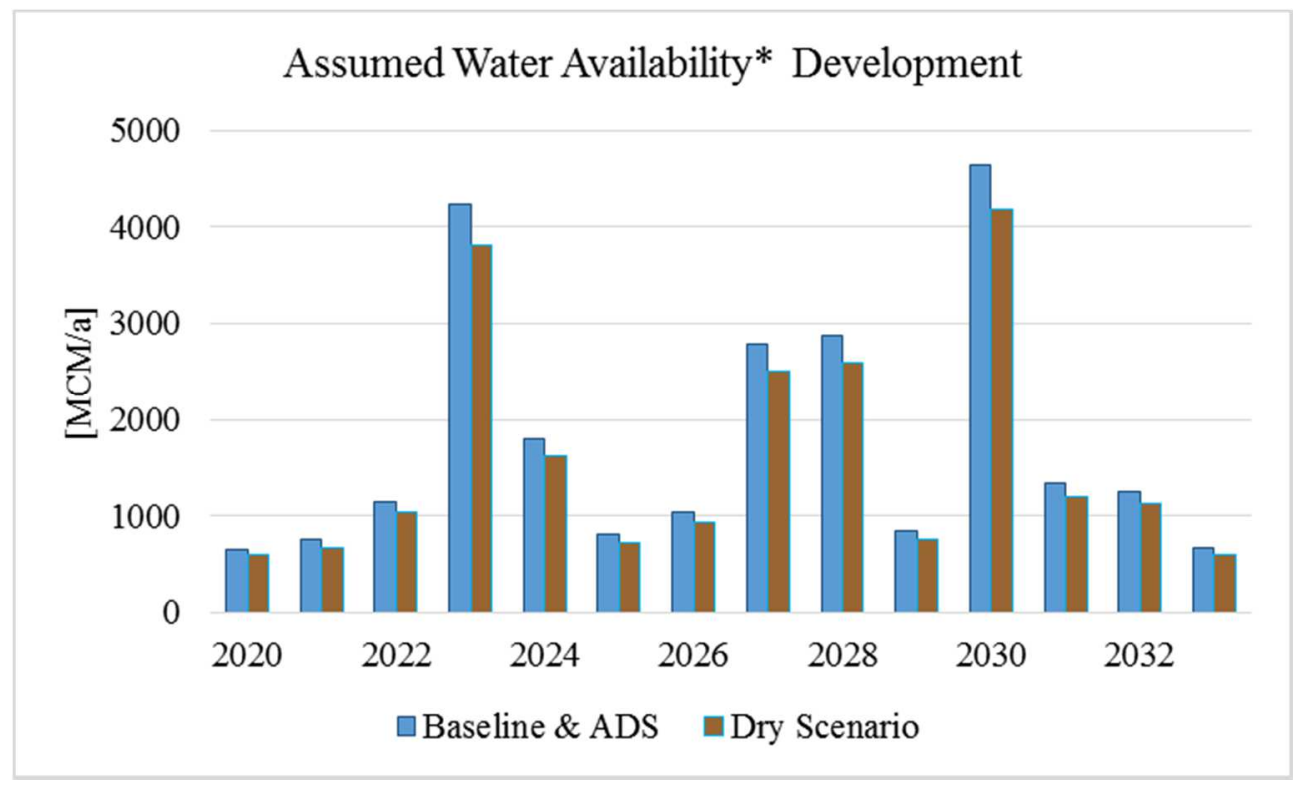

Figure 4-43: Assumed water availability development -João Pessoa

(*including surface runoff, spring discharge and natural groundwater recharge). 
In addition to the ADS also water availability is affected by this scenario. Figure 4-43 gives an overview of the resulting change in water availability in comparison to the Baseline and ADS. As presented in Chapter 4.4.2, some years of extremely high surface runoff can be detected (esp. 2023 and 2030) that might be explained by poor data to calibrate the hydrological model (Schimmelpfennig et al., 2018) from which the basic data set of runoff was derived (years 20002014).

\section{b) Jericho-Auja}

The last scenario that was evaluated was the Dry Climate Scenario for which the prior introduced synthetic spring discharge time series (Schmidt, 2018) was used as well. But instead of a moderate climatic MWDM (mean-wet-dry-mean conditions) scenario, an MDDM (mean-dry-dry-mean) development of water availability was assumed. Meaning that after five years of mean hydraulic conditions, ten years of very dry conditions will follow. After that, the environment return to a mean state for the last five years of the 20 years time series. The Dry Climate Scenario also includes all other assumptions of the ADS. The relative difference in water availability is much more drastic than for the tropical case study. During the assumed dry period from 2025 -2035 water availability is in some years only half of what was assumed for the BL and ADS.

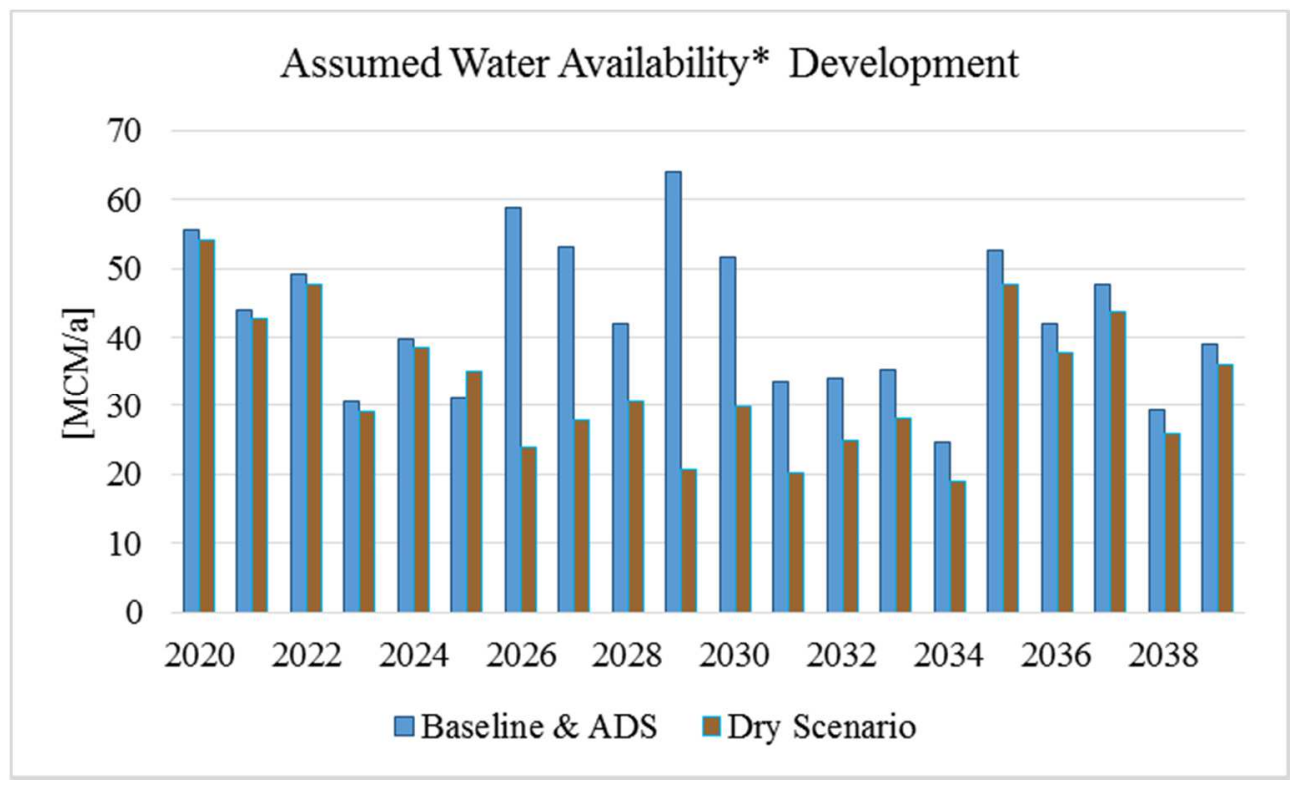

Figure 4-44: Assumed water availability development -Jericho-Auja

(* including surface runoff, spring discharge and natural groundwater recharge). 


\subsection{Step 6: MAR Groundwater Budget Analysis}

\subsubsection{Overview of Strategy-Scenario combinations to be analyzed}

\section{a) João Pessoa}

In this chapter the designed IWRM and MAR Strategies are analyzed with regard to their potential impact on the groundwater system under assumption of the various scenarios of future development. Figure 4-45 gives an overview of the MAR Groundwater Budgets that were evaluated resulting from combination of strategies and scenarios.
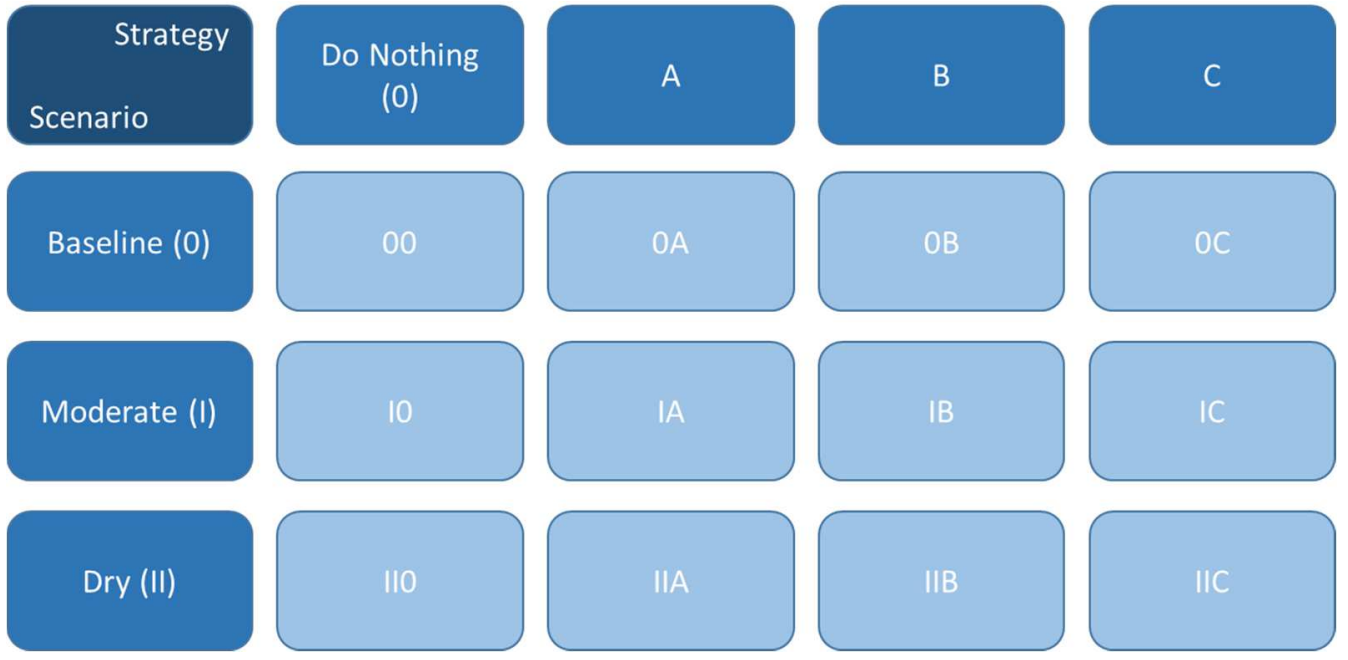

Figure 4-45: Overview of strategy-scenario combinations -João Pessoa.

Analyzing each of the strategies for each scenario, the groundwater budgets were evaluated for a total number of 12 cases. This included a Do-Nothing (DN) approach as a means of comparison for each scenario. This approach neither considers any activation of water resources in terms of the IWRM strategies, nor does it account for any MAR measures in the system. Meaning that the individual DN approach for each scenario represents the potential future development if no measures are undertaken to improve the current state of the water resources system. The respective boundary conditions of the scenarios, like increased irrigation demand etc., was considered as well. This allowed the DNs to serve as a basis for evaluation of the individual strategies' impact on the system and served as the default to calculate performance by means of indicators.

For each of these combinations, detailed operation schemes of the suggested MAR facilities were calculated on the monthly basis for the selected timeframe of 14 years between 2020 and 2034. Each Management Unit's individual groundwater budget was calculated separately in order to receive results in a spatio-temporal transient distribution. Figure 4-46 illustrates the components and parameters of these budget calculations. As a basis, the analysis focused on the aquifer system as the storage unit. The spatial dimension was given by the MUs. The aquifer receives recharge as natural 
recharge from rainfall, by return flow from irrigation water and domestic supply, as well as from MAR as an additional option (green arrows). The negative part of the equation is the water that needs to be extracted from storage, respectively groundwater that is being pumped from the aquifer, in order to satisfy the demand sectors. The MAR water budget $\Delta S$ for each MU can be expressed as:

$$
\begin{array}{cl}
\Delta S=Q_{\text {in }}+ & R_{\text {nat }}+R_{R F}+R_{M A R}-G W P-Q_{\text {out }} \\
\text { with } & \Delta S=\text { Change in Storage } \\
& \text { Qin }_{\text {in }} \text { Groundwater inflow } \\
& \mathrm{R}_{\text {nat }}=\text { natural Recharge } \\
& \mathrm{R}_{\mathrm{RF}}=\text { Recharge from Return Flow } \\
& \mathrm{R}_{\mathrm{MAR}}=\text { Recharge by MAR } \\
& \text { GWP = Groundwater Pumping } \\
& \text { Qout }=\text { Groundwater outflow }
\end{array}
$$

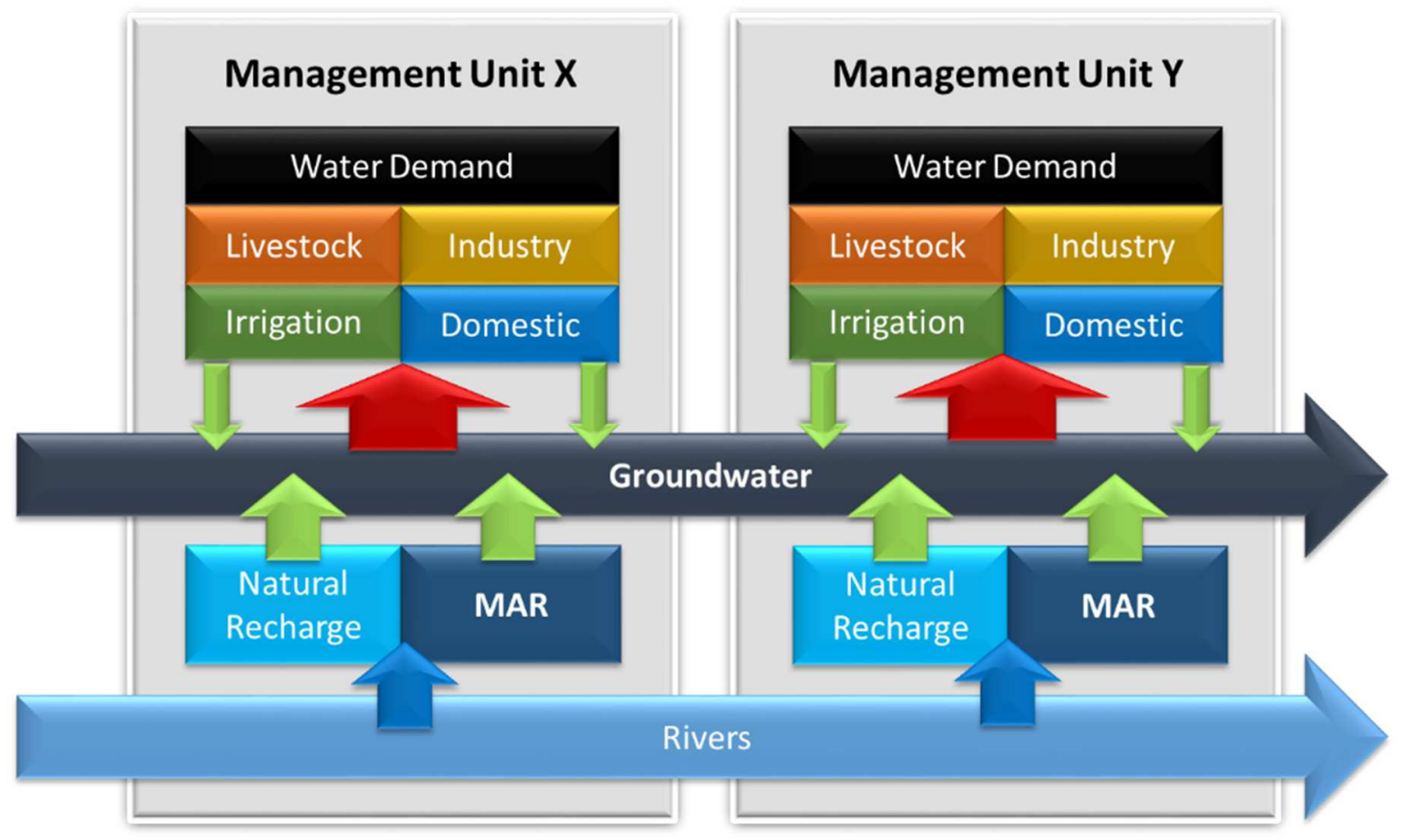

Figure 4-46: Schematic of MAR Budget parameters.

\section{b) Jericho-Auja}

The budget situation for the semi-arid case study was in many ways simpler than in the prior. For instance, the study area was divided into only two instead of eleven MUs. Also these two run parallel in terms of water availability. The individual transient water availability for each unit is independent of the other. Whereas in the prior case study the rivers were used as main source of water for MAR, in this case study the discharge of the local spring groups was considered. Auja and Jericho both have their own springs to cover local demands. If one unit consumes all water from their source, it does not impact the other MU since they are not downstream each other. In the João Pessoa case study, any withdrawal from the rivers must be considered for the water budget of the downstream 
MU. That simplified the equation for budgeting in this case. The groundwater on the other hand still is a connected system. Any drawdowns or increases in local groundwater level of one MU will inevitably cause an according reaction in the other MUs groundwater system. To evaluate this interaction, mere budget calculations are not sufficient. This is where groundwater flow modelling is required. Figure 4-47 gives an overview of the combinations of strategies and scenarios to be evaluated in the following.

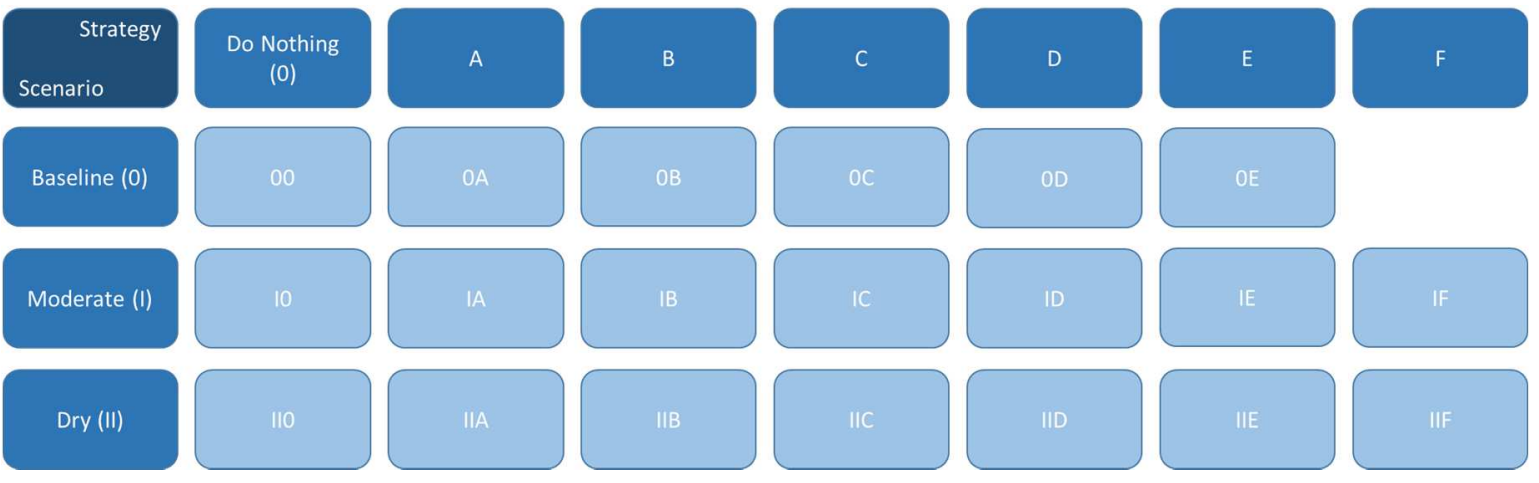

Figure 4-47: Overview of strategy-scenario combinations -Jericho-Auja.

Due to the high variety of potential IWRM strategies that could be implemented to cope with water deficits in the study area, the total number of possible combinations was accordingly higher in this case. Including the Do-Nothing approaches for each scenario (DN), a total of 20 combinations was evaluated. The overall concept and idea follows the same structure as for the other case study.

\subsubsection{Groundwater Budgets for selected Scenarios and Strategies}

\section{a) João Pessoa}

\section{Baseline Scenario}

Though groundwater budgets have been calculated for this approach on the spatial resolution of Management Units (MU), results will be presented here as accumulated values. Otherwise it would be necessary to present the results of 132 calculated time series (12 combinations of scenarios and strategies for eleven MUs) of 14 years. Therefore, the results are presented in this section by means of accumulated values. For each month, the recharge time series of all seven suggested MAR locations, as well as the calculated abstraction rates by groundwater pumping are added and displayed in one combined graph. Figure 4-48 gives these aggregated results for the Baseline Scenario under assumption of the Do-Nothing (DN) approach. The detailed results for each MU are given in Appendix 3. 


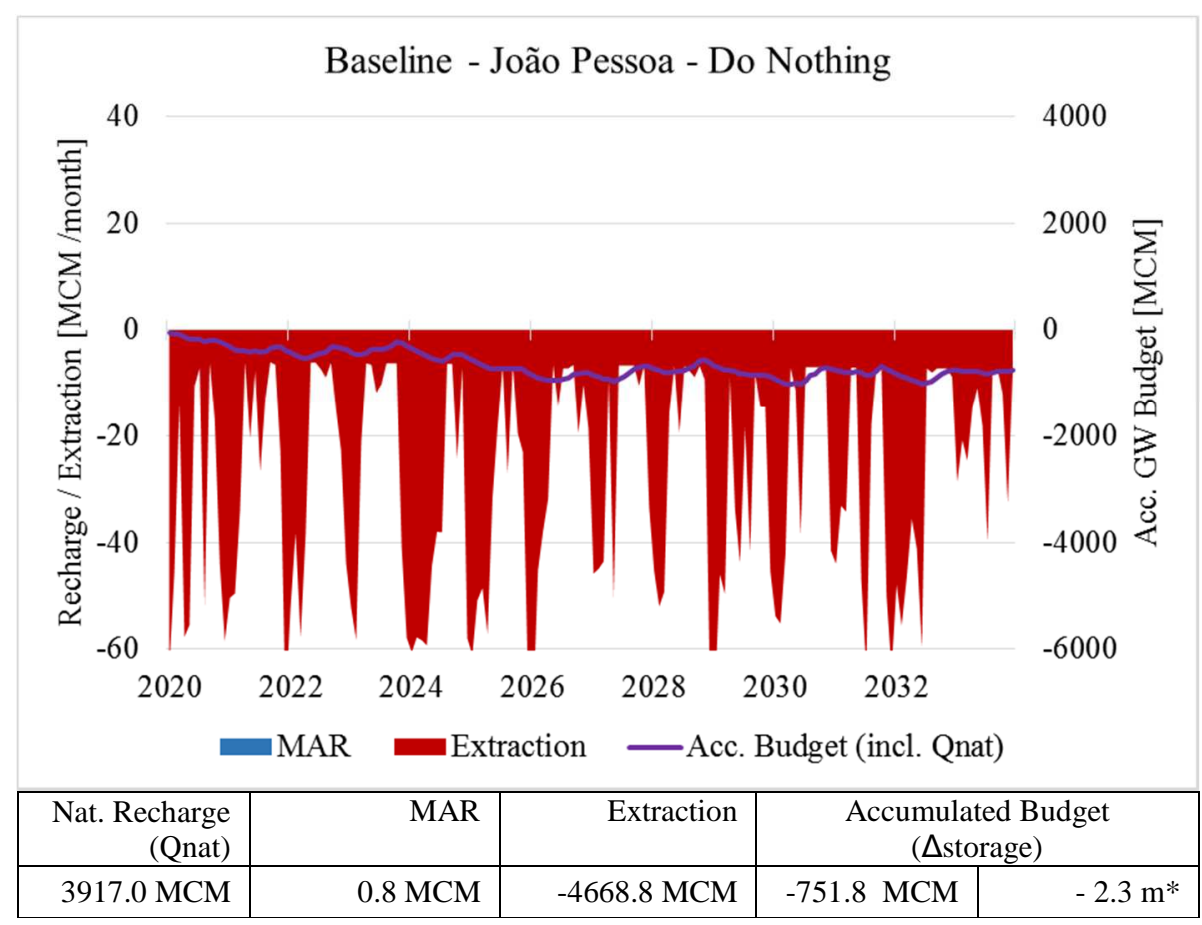

* hypothetical, assuming infinite groundwater capacity

Figure 4-48: Groundwater budget Baseline Scenario João Pessoa -DN.

The red area represents the volume of water extracted from the groundwater by means of pumping. These values have been calculated followed the prior described methodology and assumptions for demand coverage. As introduced, the values represent accumulated values for the entire case study area of João Pessoa. First, the DN should be reviewed. It can be observed that groundwater extraction peaks up to more than $60 \mathrm{MCM} /$ month during the dry seasons to cover irrigation demands, domestic supply, as well as livestock and industry. For means of comparison, the accumulated values over the 14 years time period were be used. Total extraction in case of the DN under the Baseline scenario is $-4668.8 \mathrm{MCM}$. The purple line represents the accumulated groundwater budget during each month. It is the result of the individual monthly budget calculation considering the budget of the prior month. Thus it represents the calculated development of the groundwater storage without consideration of natural groundwater outflow from the system. It is a strong indicator whether the groundwater is managed in a sustainable manner. Sustainability in this regard would mean that the withdrawal from the aquifer over time should not exceed the recharge. Recharge in this case includes natural groundwater recharge, unmanaged aquifer recharge from leakage and return flows, as well as Managed Aquifer Recharge. Though in case of the DN, no MAR was considered. This will be added in Strategy A. Results of the DN show that under the defined assumptions and boundary conditions, the local groundwater system would potentially accumulate a negative budget of -751.8 MCM over the course of these 14 years, not considering natural flow of groundwater leaving the system to the ocean, the north or south. To account for these parameters, a groundwater flow model was required. Given the aquifer characteristics and geometry, this deficit would translate to an overall mean 
hypothetical groundwater level drawdown of $-2.25 \mathrm{~m}$ (Eq. 4.5), assuming an area of $1,113 \mathrm{~km}^{2}$ and porosity of 0.3 .

$$
\Delta h=\frac{\Delta \text { storage }}{A * p}
$$

$$
\begin{array}{ll}
\text { with } & \Delta \mathrm{h}=\text { hypothetical change in groundwater level }[\mathrm{m}] \\
\Delta \text { storage }=\text { accumulated budget }\left[\text { Mio. } \mathrm{m}^{3}\right] \\
\mathrm{A}=\text { study area }\left[\mathrm{m}^{2}\right] \\
p=\text { porosity }
\end{array}
$$

This value would be influenced by groundwater interaction with areas outside the study area. Strong drawdown leads to an increased hydraulic gradient and might therefore subsequently cause more inflow from surrounding systems. In this case, since the aquifer system ends at the western boundary of the delineated study area, no additional inflow could occur from there. Any deficits created in the study area would potentially cause increased inflow form north and south to the aquifer.

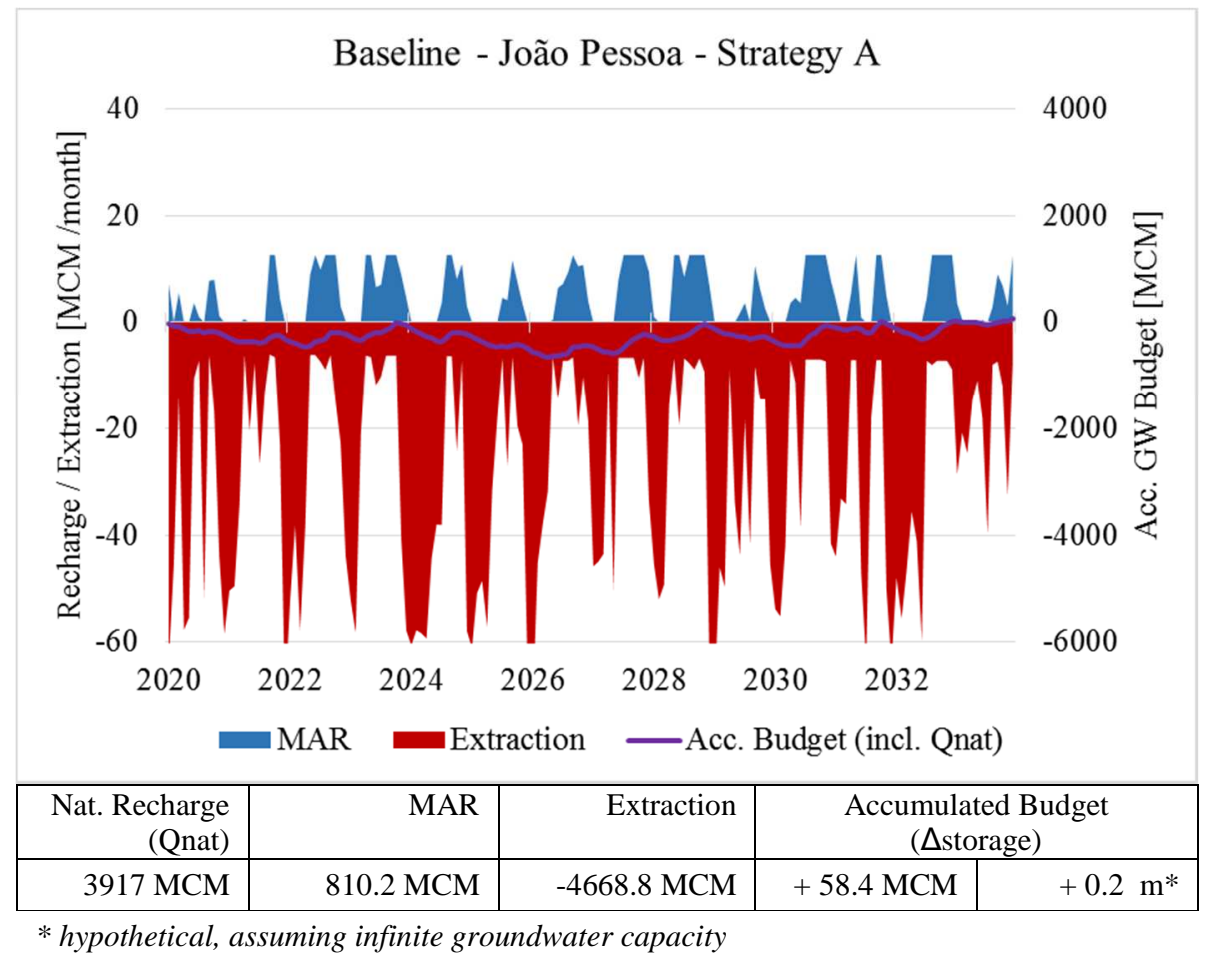

Figure 4-49: Groundwater budget Baseline Scenario João Pessoa -Strategy A.

Since these neighboring regions are subject to intense agriculture and depend on the local groundwater resources, a sustainable management of the system should result in at least a neutral budget for the study area, preferably even a positive one. This mean calculated potential drawdown might intensify locally. Interviews conducted with local farmers during the many field investigations as part of this study revealed that most small wells that local farmers depend on are quite limited in depth, often not more than 2-3 m (Walter, 2016). Many farmers reported of time periods where groundwater drops to levels that leave their wells dry. As has been seen in the water resources system 
analysis, groundwater withdrawal concentrates in some areas with intense agricultural activity. Now that the basis for comparison has been established for the Baseline Scenario, revealing indeed an indication for demand of an improved water resources management, the potential impact of the suggested MAR implementation should be discussed.

Figure 4-49 gives the same plot structure of illustration for the accumulated results of Strategy A. It can be observed, that the graph now includes values for additional recharge to the aquifer (blue). This only refers to recharge via MAR. The natural recharge (Qnat) however, is included in the budget calculation of the accumulated groundwater budget curve, but not represented graphically. Meaning that all blue areas refer to actual recharge via MAR facilities. As the strategy was defined with a maximum capacity of $1.8 \mathrm{MCM} /$ month for each MAR facility, the total maximum value for all seven suggested locations combined is $12.6 \mathrm{MCM} /$ month. As can be observed, recharge via MAR does only occur during some months of the year. This is due to the direct correlation of surface runoff to actual infiltration by MAR. Outside the rainy season there is too little runoff in the rivers to be accounted for in the MAR operation schemes. The extraction rates are exactly the same as in the DN approach, since Strategy A does not include any decrease in water demand or reduction of required pumping from the aquifer system. The accumulated groundwater budget over the 14 years time period actually remains positive. With a final value of $+58.37 \mathrm{MCM}$, the system remains in a sustainable state within the selected period. Referring the budget to groundwater level fluctuation, this value would translate to roughly $0.2 \mathrm{~m}$ of overall groundwater increase. These results require further analysis by means of groundwater simulations. Lots of factors come into play that cannot be accounted for by mere groundwater budgeting. These results can, however, be taken as an indication of the potential performance of a MAR implementation. Even so, the accumulated groundwater budget curve reaches minimum values of around $-1,000 \mathrm{MCM}$, translating roughly to a temporary decrease of the overall groundwater table of more than $3 \mathrm{~m}$.

Strategy B introduces the concept of reducing irrigation losses to the case study. Figure 4-50 gives the respective results for this advanced combination of IWRM and MAR. In contrast to the prior, Strategy B has an impact on the quantities that are pumped from the aquifer. The reduction of application losses during irrigation by ten \%, e.g. by reducing the amount of sprinkler irrigation and replace it with more efficient techniques like drop irrigation, would theoretically result in a reduction of pumping, since less water will be needed during the dry season to irrigate all crops.

The effect on the accumulated groundwater budget for the entire study area of João Pessoa is to observe: an increase of the total budget value to + 541.43 MCM over the course of 14 years. Meaning a theoretical increase of the potential groundwater level by $1.6 \mathrm{~m}$ on average, with an absolute minimum value of $-398 \mathrm{MCM}$, or $-1.6 \mathrm{~m}$ of groundwater decrease. The final stage potentially 
recommendable MAR implementation considers an increase of the MAR facilities' capacities from 1.8 MCM/month to a doubled $3.6 \mathrm{MCM} /$ month. This might require the installation of advanced infiltration technology, such as active pumping of water into the surface, which increases potential implementation costs in comparison to rather low-cost solution of infiltration ponds

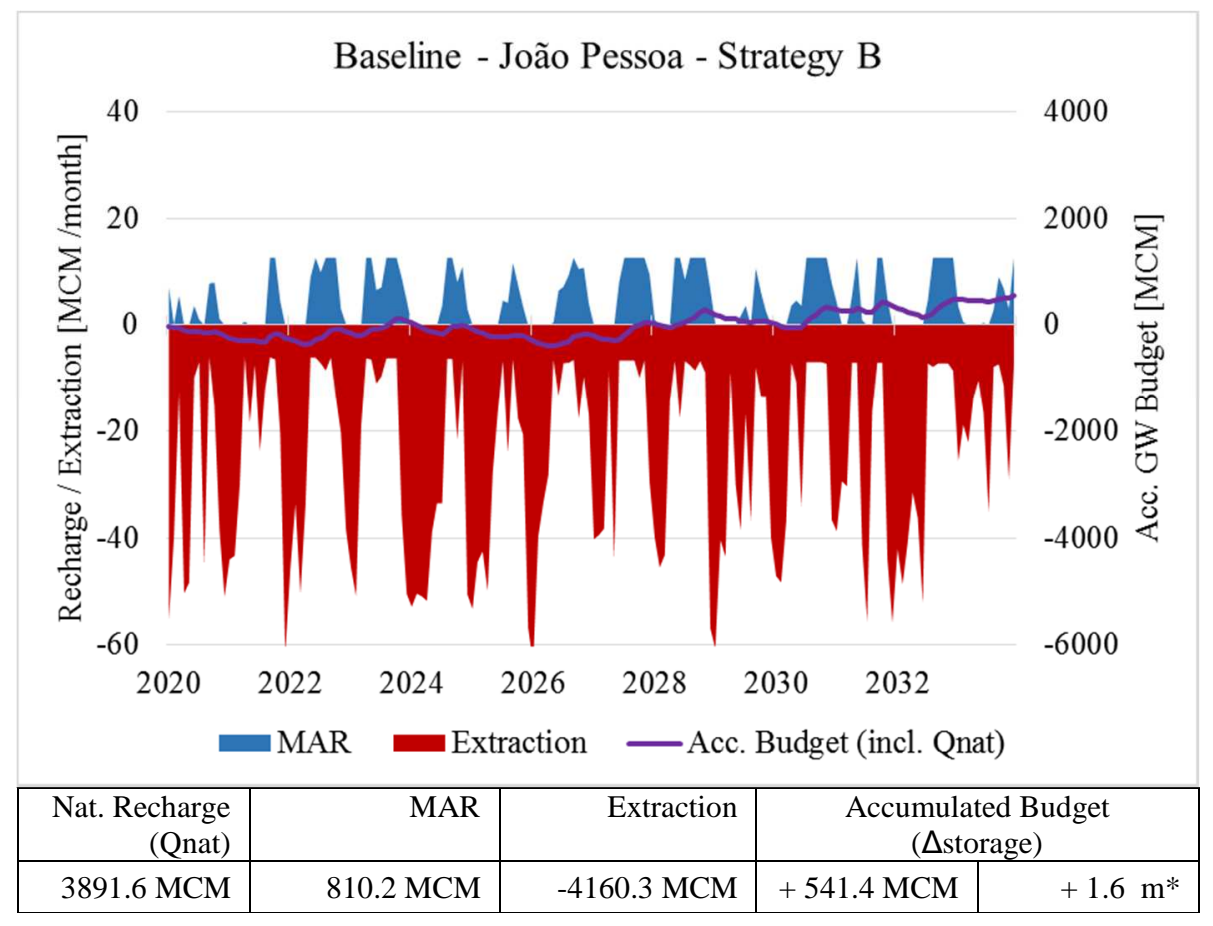

* hypothetical, assuming infinite groundwater capacity

Figure 4-50: Groundwater budget Baseline Scenario João Pessoa -Strategy B.

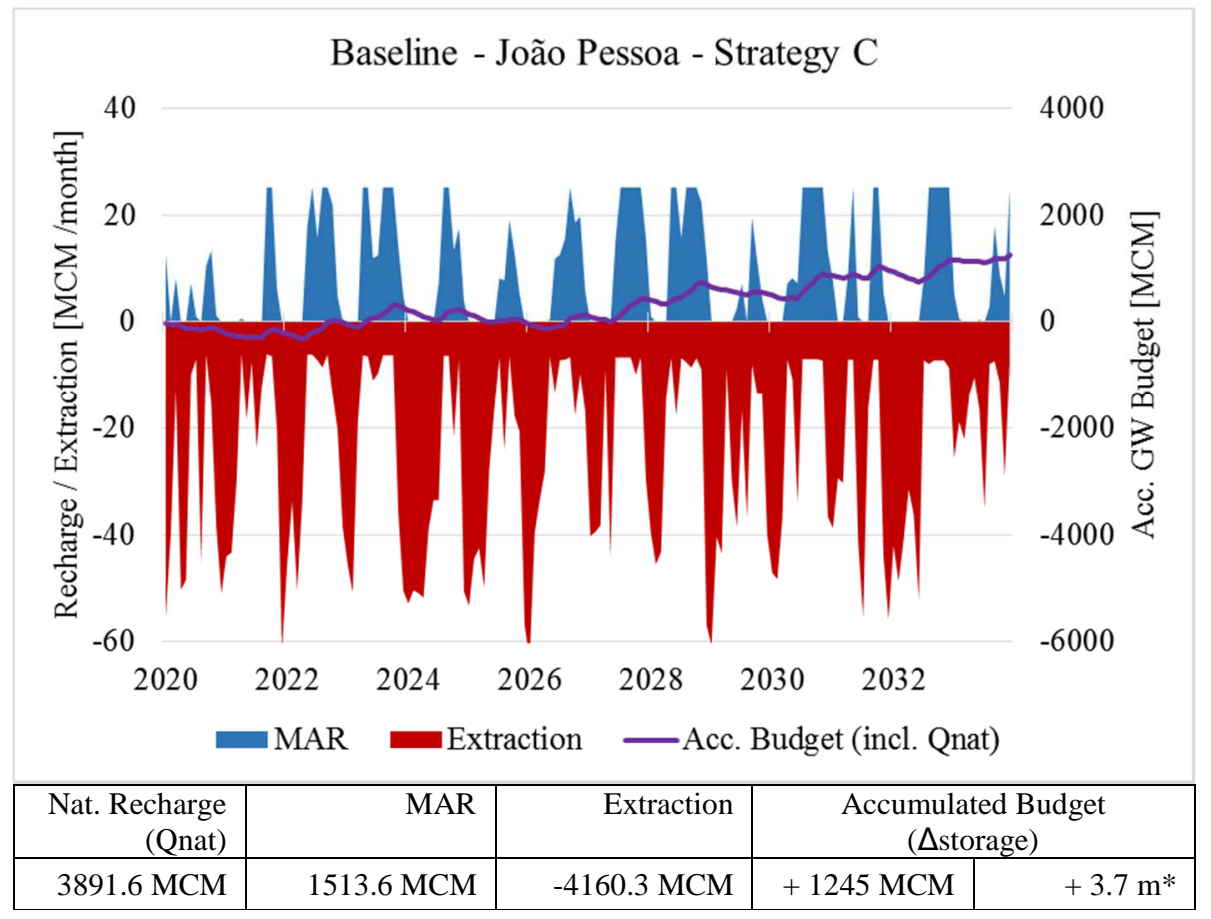

* hypothetical, assuming infinite groundwater capacity

Figure 4-51: Groundwater budget Baseline Scenario João Pessoa -Strategy C. 
Strategy $\mathrm{C}$ further considers the reduction of irrigation water losses by $10 \%$ as introduced under Strategy B. Results given in Figure 4-51 indicates the impact of the increased capacities on the volumes of water that might actually be recharged to the aquifer via MAR. Whereas in some years this new accumulated maximum of $25.2 \mathrm{MCM} /$ month is not met, due to insufficient runoff in the rivers, it still has a significant impact on the accumulated overall groundwater budget after 14 years. The measure would, under the given scenario, increase the total volume of artificial recharge to $1513 \mathrm{MCM}$, resulting in a budget of $+1244.88 \mathrm{MCM}$, or roughly $+3.7 \mathrm{~m}$ of groundwater level increase (Table 4-15). Again, this values does not represent the actually expected increase of groundwater, since outflow from the system is not considered in these calculations and the given value should only help setting these huge volumes into perspective. Under the assumption of Strategy $\mathrm{C}$ under the Baseline Scenario, the minimum value of budget is only $-326 \mathrm{MCM}$, or $-1.1 \mathrm{~m}$ of groundwater decrease. Under these assumptions, the Strategy appears to be extremely beneficial for the region and reveals a very high potential benefit.

Table 4-15: Summary of groundwater budgets for Baseline Scenario -João Pessoa

\begin{tabular}{|l|r|r|r|r|r|}
\hline \multirow{2}{*}{$\begin{array}{l}\text { Baseline } \\
\text { Scenario }\end{array}$} & \multirow{2}{*}{ Nat. Recharge } & MAR & Extraction & \multicolumn{2}{|c|}{ Accumulated Budget } \\
\cline { 4 - 5 } & & & & {$[\mathrm{MCM}]$} & {$[\mathrm{m}] *$} \\
\hline DN & $3917.0 \mathrm{MCM}$ & $0.00 \mathrm{MCM}$ & $-4668.8 \mathrm{MCM}$ & -751.8 & -2.3 \\
\hline Strategy A & $3917.0 \mathrm{MCM}$ & $810.2 \mathrm{MCM}$ & $-4668.8 \mathrm{MCM}$ & 58.4 & 0.2 \\
\hline Strategy B & $3891.6 \mathrm{MCM}$ & $810.2 \mathrm{MCM}$ & $-4160.3 \mathrm{MCM}$ & 541.4 & 1.6 \\
\hline Strategy C & $3891.6 \mathrm{MCM}$ & $1513.6 \mathrm{MCM}$ & $-4160.3 \mathrm{MCM}$ & 1244.9 & 3.7 \\
\hline * hypothetical, assuming infinite groundwater capacity \\
\hline
\end{tabular}

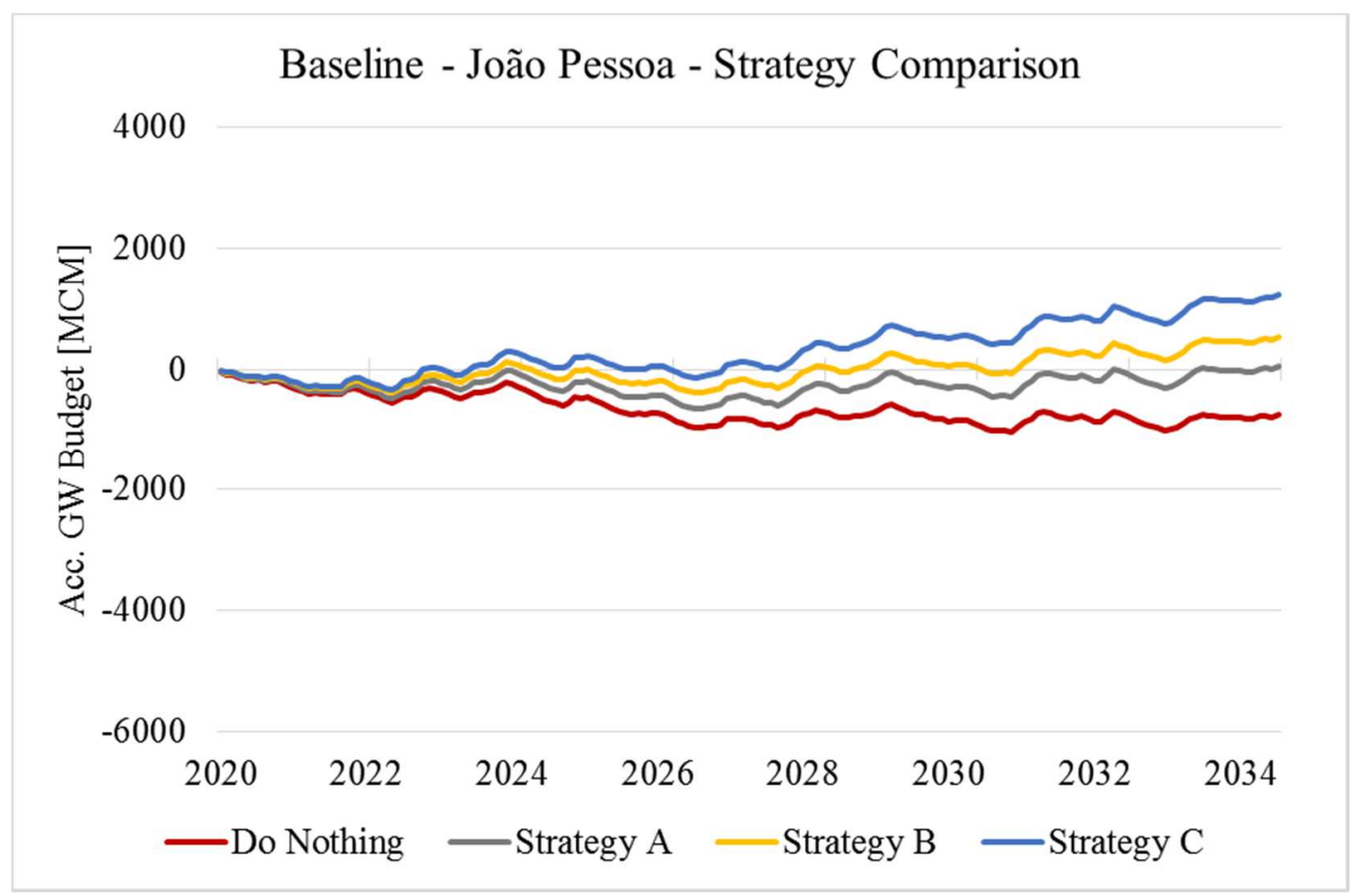

Figure 4-52: Direct comparison of strategies under Baseline Scenario -João Pessoa. 
As the assessment shows, a significant improvement of the overall mean groundwater budget could be achieved by means of MAR implementation in the suggested manner. Furthermore the combination of the method with a water management action such as the chosen example of reducing irrigation water losses by promoting more efficient irrigation techniques in the area analyzed as Strategy B, would potentially bring a comparably big additional benefit to the system. Figure 4-52 illustrates the potential relative impact of the individual strategies on the system in direct comparison to another. The individual lines represent the accumulated groundwater budget over the selected time series as has been shown before. The direct comparison underlines the performance difference of the strategies. An ideal groundwater budget would remain positive values throughout the entire study period.

These first results should only be understood as a comparative performance assessment and the given transformation of budget volumes into meters of groundwater fluctuation are only approximations. The Baseline Scenario assumes a moderate future development of the study area without change in water availability by rainfall and natural groundwater recharge, nor changes in the socio-economic growth rate or alternative ways of agricultural land use. Therefore, it is necessary to review these strategies under changed boundary conditions. The strategies intrinsic structure and idea remains the same for the next two scenario analyses. Only the boundary conditions change. By design, the chosen scenarios should result in an overall intensified groundwater withdrawal on the one hand, and less recharge on the other. This way, the positive impacts of the suggested measures can be evaluated under increased groundwater stress situations.

\section{Agricultural Development Scenario}

The results for the two other scenarios should be discussed in a less details, since the overall idea and operation of each strategy remains the same. Therefore, the results are discussed less detailed and a focus is on the difference in performance. Figure 4-53 gives the results for each strategy under the assumed scenario. There is an increase in groundwater pumping under this scenario, since the assumption was that valuable agricultural areas that are presently cultivated with pineapple, will also be used for sugarcane in the future. The scenario assumes that the land use change is already conducted in 2020. The induced stress on the groundwater can be observed in the DN approach. For this solution the accumulated groundwater budget over the 14 years is $-1,203.7 \mathrm{MCM}$, or roughly -3.6 m over the entire study area. As a base for comparison, the DN budget for the Baseline Scenario was $-751.8 \mathrm{MCM}$, meaning the scenarios boundary conditions led to an increased groundwater withdrawal of around $450 \mathrm{MCM}$ over 14 years, around $32 \mathrm{MCM} / \mathrm{a}$ of additional pumping from the groundwater. As the results show, the mere implementation of decentralized MAR facilities as suggested under Strategy A would no longer be sufficient to maintain a sustainable groundwater 
budget, in contrast to the BL. Strategy B however, reducing irrigation water losses, in combination with decentralized MAR facilities, shows a higher potential. Though even under this solution, the groundwater budget barely remains positive. Strategy C still outperformance the prior two and shows that only by changing the management of the presently available water resources, can bring huge benefits for the region, in comparison to a do nothing strategy (Table 4-16). Figure 4-54 underlines these differences in performance. Appendix 4 holds the results for each MU.

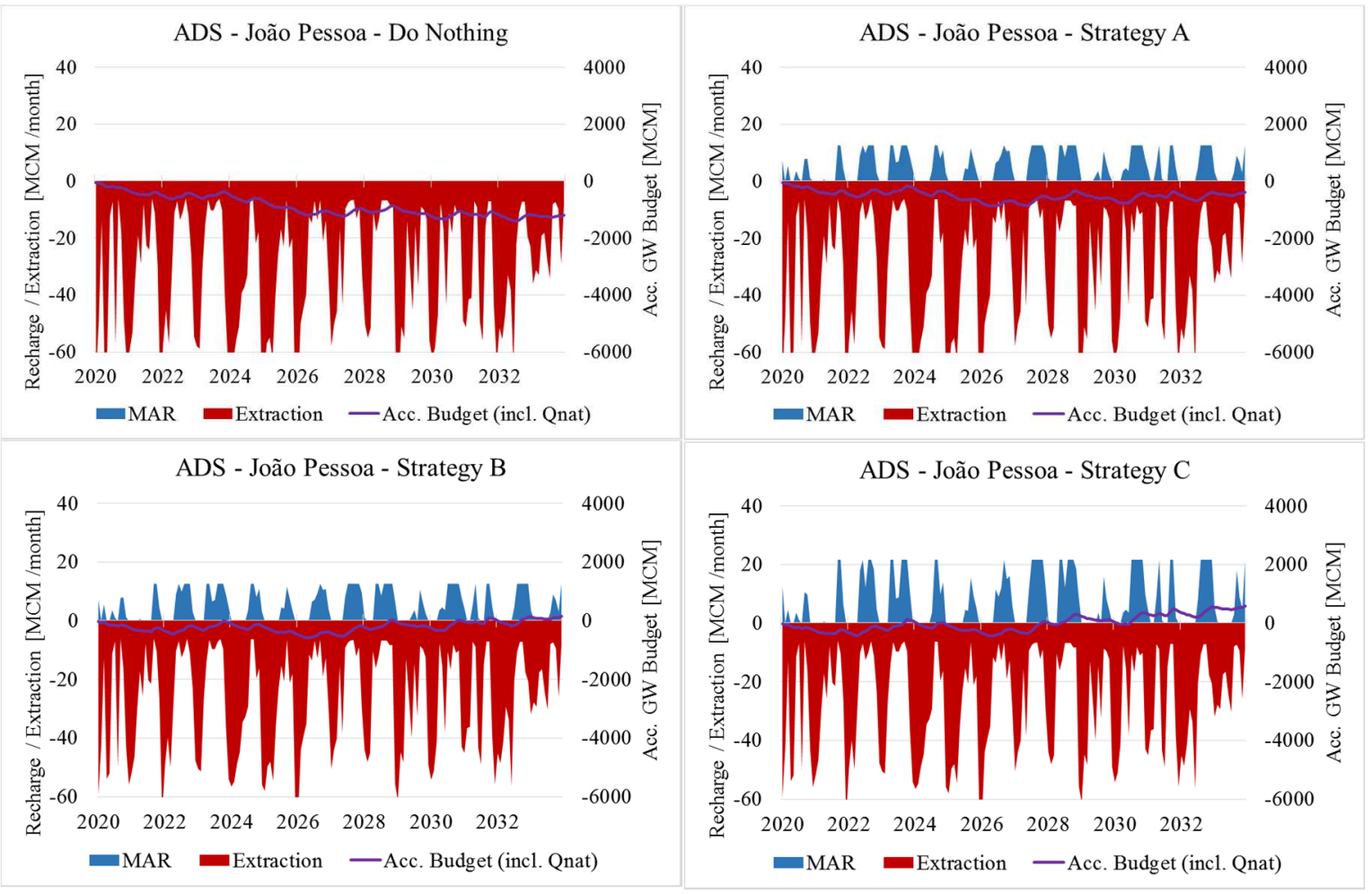

Figure 4-53: Groundwater budget ADS João Pessoa.

Table 4-16: Summary of groundwater budgets for ADS -João Pessoa

\begin{tabular}{|c|c|c|c|c|c|}
\hline \multirow{2}{*}{$\begin{array}{l}\text { Agricultural } \\
\text { Development } \\
\text { Scenario }\end{array}$} & \multirow[t]{2}{*}{$\begin{array}{r}\text { Nat. Recharge } \\
\text { (Qnat) }\end{array}$} & \multirow[t]{2}{*}{ MAR } & \multirow[t]{2}{*}{ Extraction } & \multicolumn{2}{|c|}{$\begin{array}{c}\text { Accumulated Budget } \\
(\Delta \text { storage })\end{array}$} \\
\hline & & & & [MCM] & {$[\mathrm{m}] *$} \\
\hline $\mathrm{DN}$ & $3940.8 \mathrm{MCM}$ & $0.00 \mathrm{MCM}$ & $-5144.5 \mathrm{MCM}$ & -1203.7 & -3.6 \\
\hline Strategy A & $3940.8 \mathrm{MCM}$ & $810.2 \mathrm{MCM}$ & $-5144.5 \mathrm{MCM}$ & -393.5 & -1.2 \\
\hline Strategy B & $3912.0 \mathrm{MCM}$ & $810.2 \mathrm{MCM}$ & $-4568.1 \mathrm{MCM}$ & 154.1 & 0.5 \\
\hline Strategy C & $3912.0 \mathrm{MCM}$ & $1249.7 \mathrm{MCM}$ & $-4568.1 \mathrm{MCM}$ & 593.7 & 1.8 \\
\hline
\end{tabular}

\footnotetext{
* hypothetical, assuming infinite groundwater capacity
} 


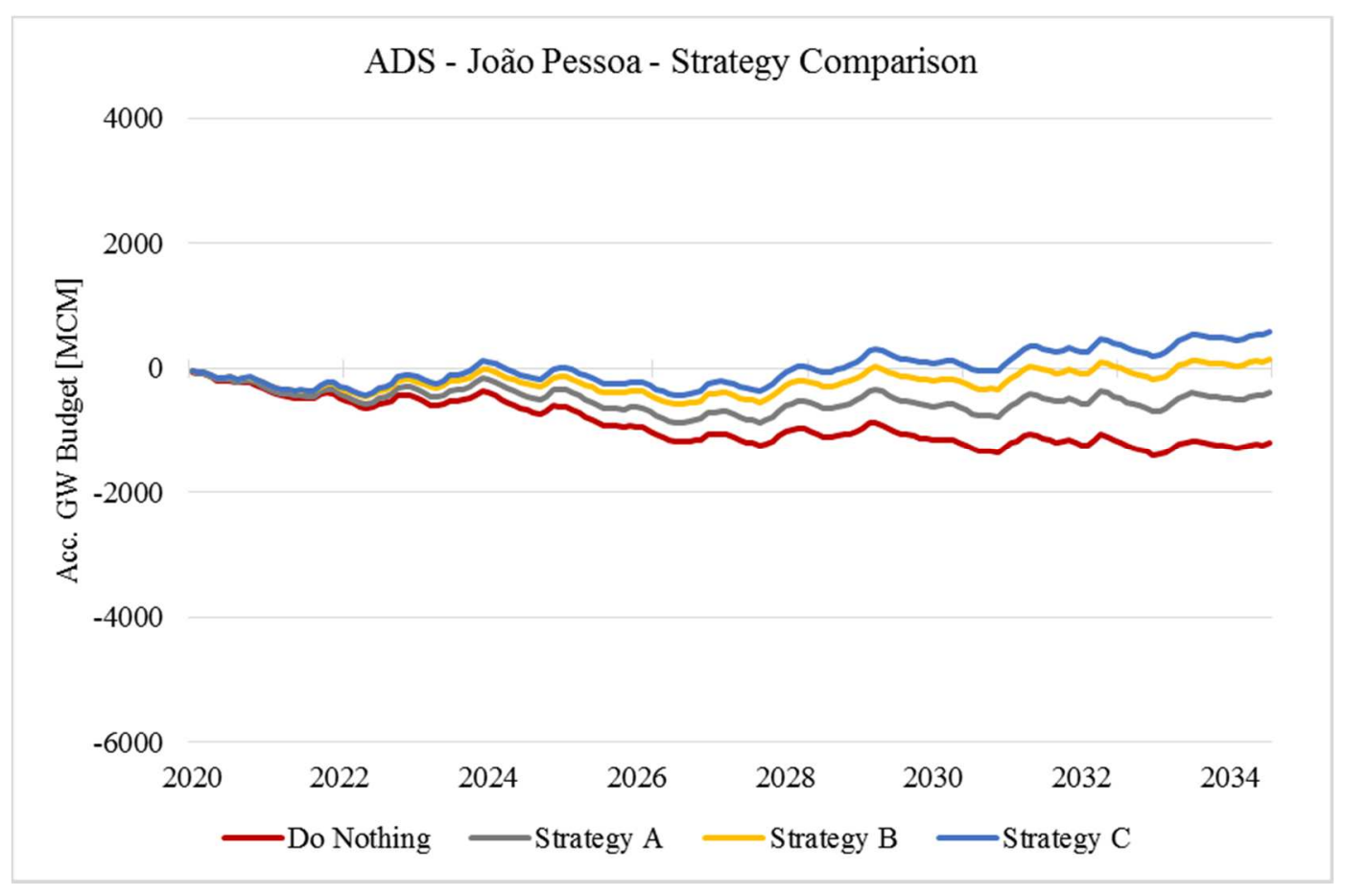

Figure 4-54: Direct comparison of strategies under ADS -João Pessoa.

\section{Dry Climate Scenario}

The last scenario evaluated was the Dry Climate Scenario. It combines the agricultural development of the prior scenario and extends it by a reduced water availability by $-10 \%$. This impacts both irrigation water demand and surface runoff, as well as natural groundwater recharge. Figure 4-55 gives the results for the individual strategies under the scenario. For the DN, an accumulated groundwater budget of $-1,725 \mathrm{MCM}$ was calculated. This would translate to more than $-5 \mathrm{~m}$ of groundwater drop over the entire study area, under the simplified assumptions of Eq. 4.5. Neither Strategy A, nor B would now be sufficient to stop this groundwater depletion (Table 4-17). The spatial scale can best be interpreted from the results given in Appendix 5.

Even under Strategy C, reduction of irrigation water losses in combination with advanced MAR facilities distributed over the study area, the groundwater budget could only be raised to +244 MCM, with most of the time series remaining below 0 , meaning a temporal drop of groundwater levels by an average of $-1.8 \mathrm{~m}$, which of course is locally higher or lower depending on the spatial distribution of water demands as presented in the water resources system analysis (Figure 4-56). The results can still be seen as very promising under the developed assumptions with regard to the general positive effect of IWRM and MAR measures in the region. 


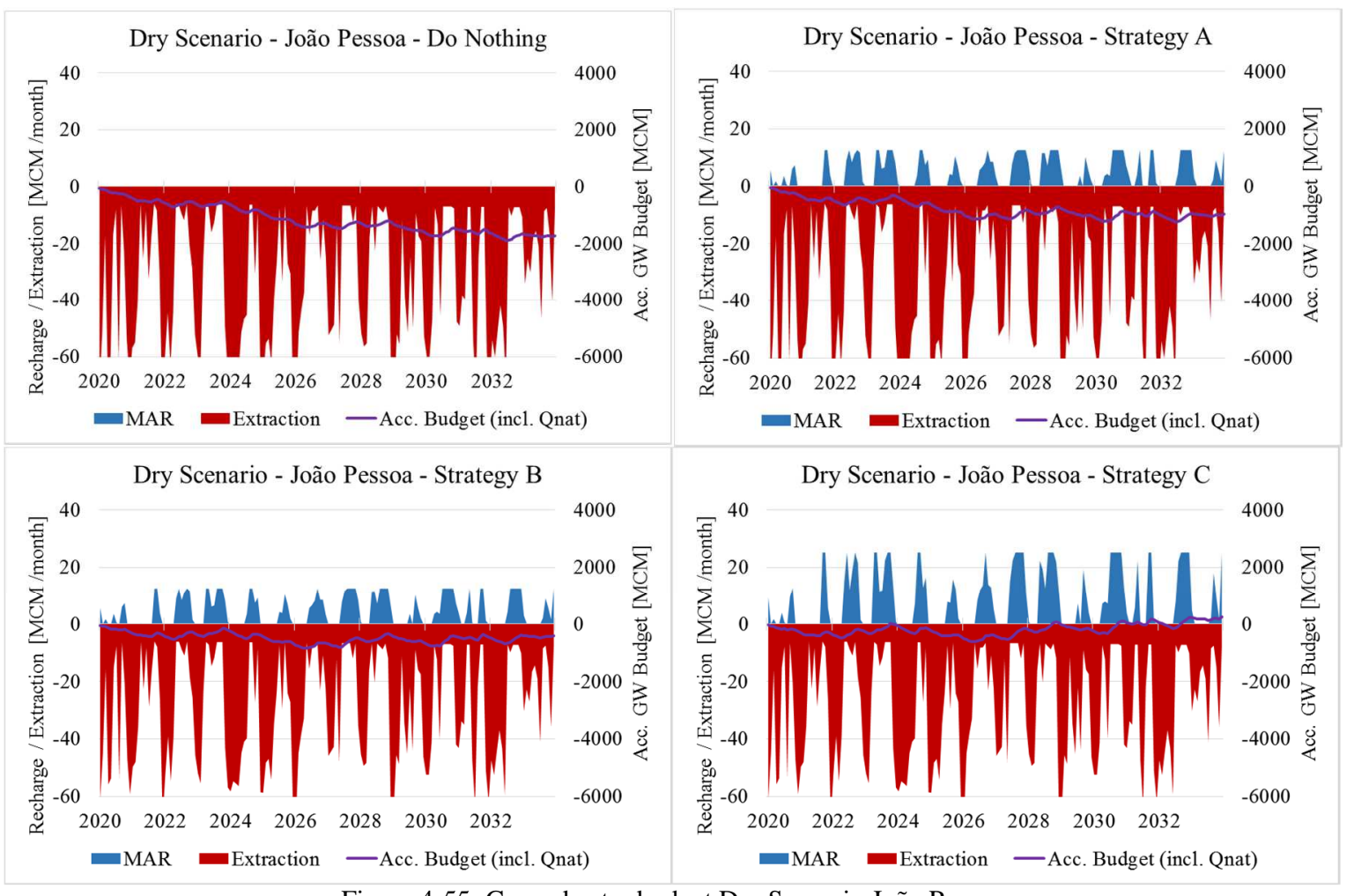

Figure 4-55: Groundwater budget Dry Scenario João Pessoa.

Table 4-17: Summary of groundwater budgets for Dry Scenario -João Pessoa

\begin{tabular}{|l|r|r|r|r|r|}
\hline $\begin{array}{l}\text { Dry Climate } \\
\text { Scenario }\end{array}$ & $\begin{array}{r}\text { Nat. Recharge } \\
\text { Qnat) }\end{array}$ & & MAR & Extraction & \multicolumn{2}{|c|}{$\begin{array}{c}\text { Accumulated Budget } \\
(\Delta \text { storage })\end{array}$} \\
\cline { 4 - 6 } & $3640.5 \mathrm{MCM}$ & $0.00 \mathrm{MCM}$ & $-5365.4 \mathrm{MCM}$ & -1725.0 & -5.2 \\
\hline DN & $3640.5 \mathrm{MCM}$ & $751.9 \mathrm{MCM}$ & $-5365.4 \mathrm{MCM}$ & -973.0 & -2.9 \\
\hline Strategy A & $3610.1 \mathrm{MCM}$ & $751.9 \mathrm{MCM}$ & $-4757.4 \mathrm{MCM}$ & -395.4 & -1.2 \\
\hline Strategy B & $3610.1 \mathrm{MCM}$ & $1391.3 \mathrm{MCM}$ & $-4757.4 \mathrm{MCM}$ & 243.9 & 0.7 \\
\hline Strategy C & & & & \\
\hline
\end{tabular}

* hypothetical, assuming infinite groundwater capacity

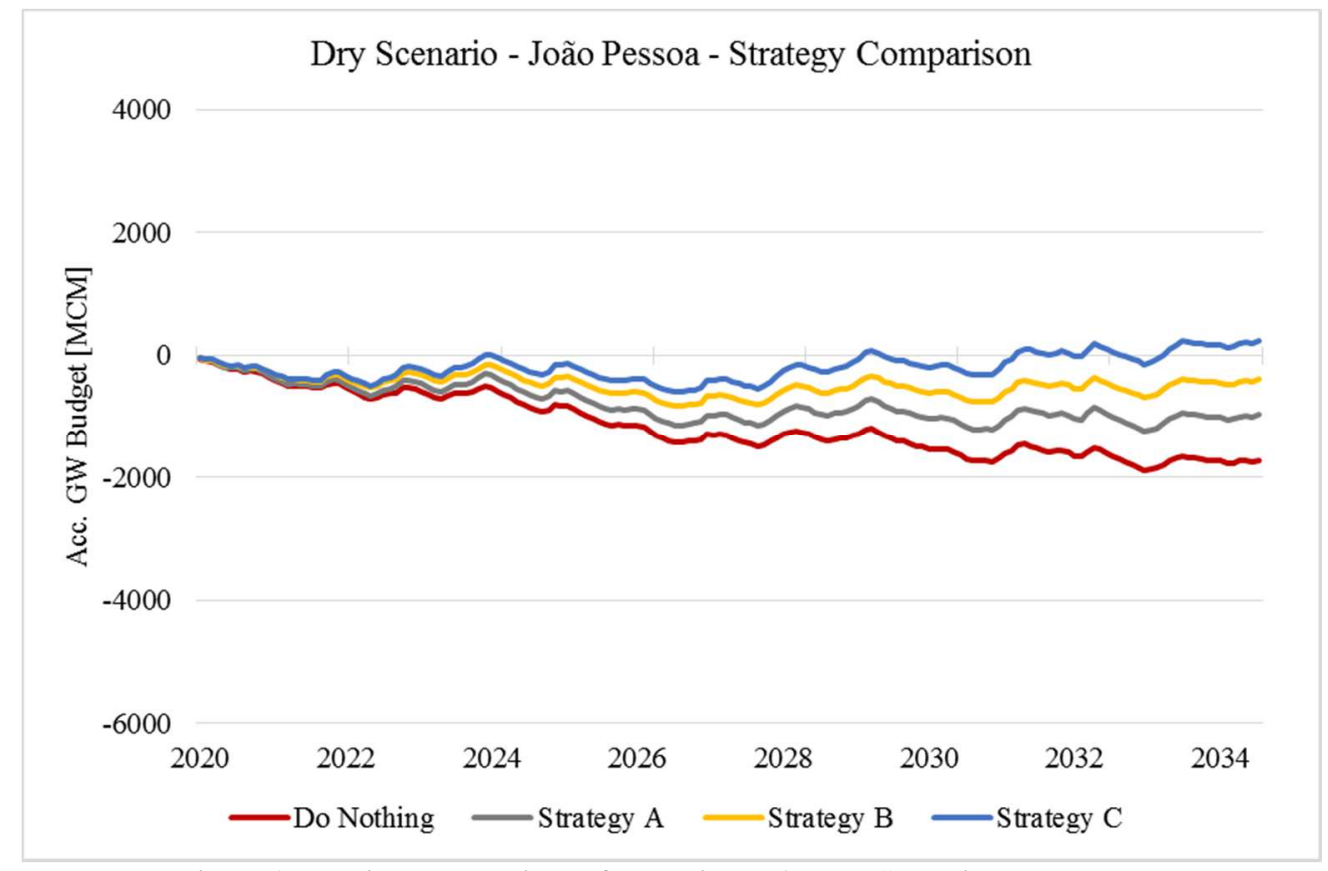

Figure 4-56: Direct comparison of strategies under Dry Scenario -João Pessoa. 


\section{b) Jericho-Auja}

\section{Baseline Scenario}

As in the prior case study, first the specific Baseline Scenario for Jericho-Auja should be analyzed and the strategies' impact on the groundwater budget discussed in more detail. Figure 4-57 illustrates the results for the DN approach. It can be observed that extraction from the aquifer by means of groundwater pumping is much less volatile than in the prior case study. Though there is a difference in groundwater extraction between the rainy and dry season, it is not as extreme as in the tropical study. This is due to the circumstance that the study area is, by its semi-arid nature, generally drier that the former, resulting in a more steady dependence on the groundwater resources. As before, the detailed spatial results are compiled in Appendix 6.

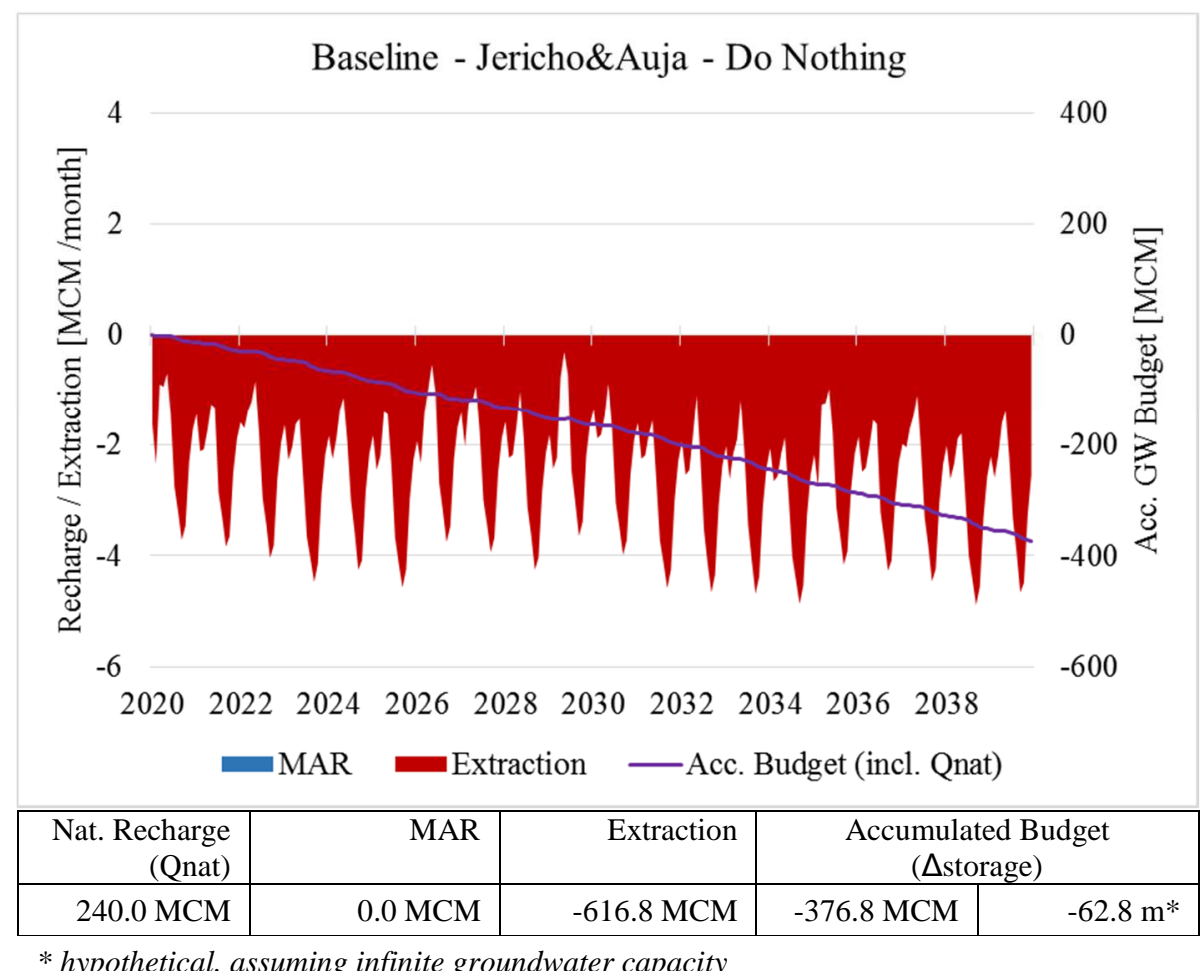

Figure 4-57: Groundwater budget Baseline Scenario Jericho-Auja -DN.

The very limited rainfall does not impact the irrigation water demand in a way, that seasonal variation becomes dominant in the water resources system. What can also be observed is that even under Baseline Scenario assumptions, the local groundwater is potentially highly overexploited. With an accumulated deficit of $-376.8 \mathrm{MCM}$ over 20 years, it reveals a mean annual overuse of around 19 MCM. Assuming a very small area of actual groundwater extraction, as is given by the size of agricultural lands, of only $25 \mathrm{~km}^{2}$ and an effective porosity of 0.3 , this would result in a hypothetical groundwater drawdown of more than $-50 \mathrm{~m}$ (Eq. 4.5). 


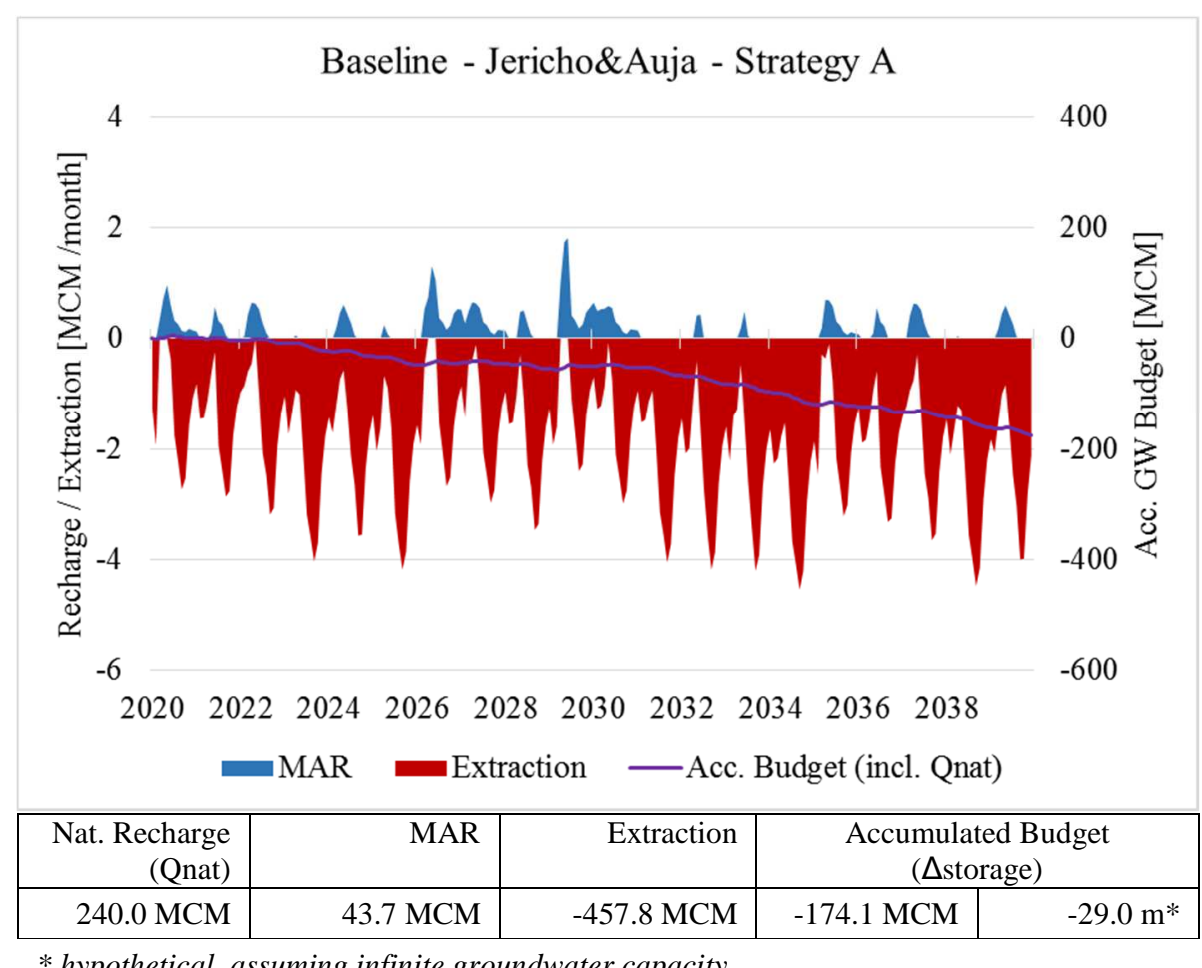

* hypothetical, assuming infinite groundwater capacity

Figure 4-58: Groundwater budget Baseline Scenario Jericho-Auja -Strategy A.

These values are only valid within the frame of assumptions and boundary conditions within which the groundwater budget calculations were performed. In reality this huge overexploitation would not be possible. Rather, the given deficits would result in unsuccessful harvests since there would simply not be enough water stored in the aquifer system to be exploited to this extend. Agricultural areas could not be irrigated and would run dry as a result. Since areas of this character usually have emergency plans for droughts, prioritizing the drinking water supply, usually bigger harm to the local population is prevented. For sake of comparability of the potential impact on the system of each strategy, we will assume an infinite groundwater availability for the budget calculations. The impact of Strategy A on the system can be seen in Figure 4-58. With only some limited water management measures and the implementation of a MAR system for surpluses, the potential calculated impact on the budget could be significant. Though the accumulated groundwater deficit over 20 years is still remarkably high with $-174.1 \mathrm{MCM}$, or roughly $-23 \mathrm{~m}$ of groundwater depletion, it is only half as much as for the DN approach. Strategy A comprises the modernization of hydro-infrastructure for the use of spring discharge in combination with a use of surplus water use for MAR. As can be seen, MAR would only occur during the wet season during some years.

Strategy B for the Jericho-Auja case study extends the MAR implementation by an advanced surface runoff retention network. This measure would activate additional water for storage depending on the occurrence of storm flood events in the wadis. Figure 4-59 illustrates the resulting groundwater budget. Under the BL, which assumes a synthetic rainfall time series of mean, wet, dry and mean 
hydrological periods (MWDM) as introduced in Chapter 4.6, this would potentially add another 23.3 MCM over the course of 20 years to the budget. Recharge by MAR shows stronger peaks during the rainy seasons, assuming that the storm floods could efficiently be harvested. The overall benefit to the groundwater budget of the area is rather low, reducing the negative accumulated budget to 150.8 MCM, or a hypothetical drop of $-20 \mathrm{~m}$ in groundwater level. The problem with surface runoff harvesting in the study area is the high volatility of actual rainfall and runoff events. The five years dry period in the scenario between 2030 and 2035 reveals no significant increase in recharge volumes compared to Strategy A.

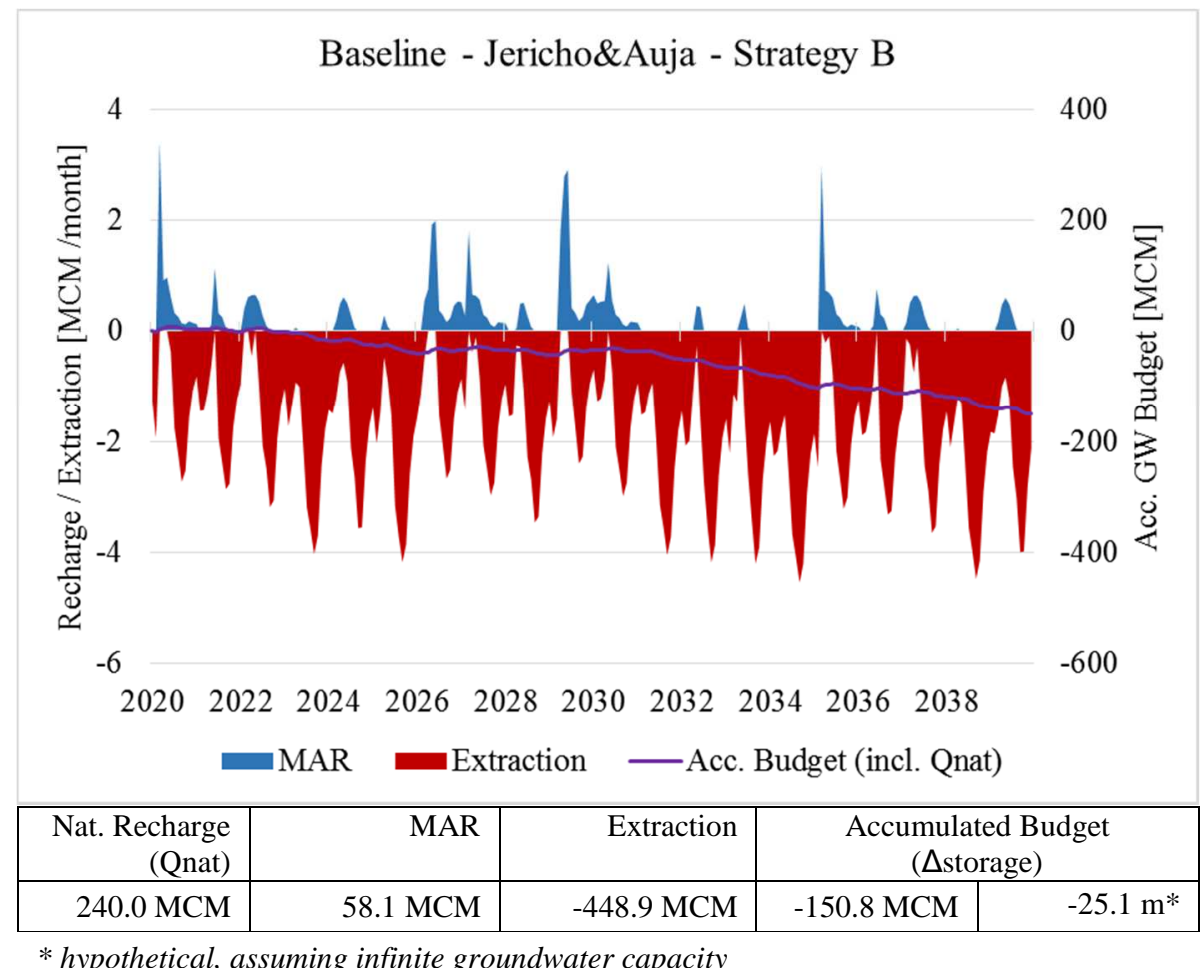

Figure 4-59: Groundwater budget Baseline Scenario Jericho-Auja -Strategy B.

Strategy $\mathrm{C}$ includes the implementation of new wells, extracting water from the deep aquifer. The very strong positive impact of this potent new source of water can be observed in Figure 4-60. The required extraction rates from the shallow alluvial aquifer is reduced by roughly 85 MCM over 20 years. In addition, recharge by MAR facilities increases by $45 \mathrm{MCM}$, resulting in an accumulated groundwater budget of $-42 \mathrm{MCM}$, or $-5.7 \mathrm{~m}$. Though still negative, the result is an enormous improvement. At the beginning of the scenario's dry period (2030-2035), the accumulated budget is even positive. It has to be kept in mind that this dry period makes even the Baseline Scenario a very challenging one in terms of water demand. The idea behind the new deep wells is not to pump water from the deep aquifer for re-injection to the shallow aquifer. Rather, the deep wells should primarily be used directly for irrigation and drinking water supply, reducing the demand for spring discharge. Therefore, the MAR facilities assumed for the strategies are the same with regard to design and 
required hydro-infrastructure, yet the volumes of spring discharge that is available for infiltration will vary depending on the demand coverage of agriculture and others from other sources. The implementation of deep wells to cover huge amounts of these demands in a very stable way without much volatility, consequently increases the amount of spring discharge that can be used for MAR purposes.

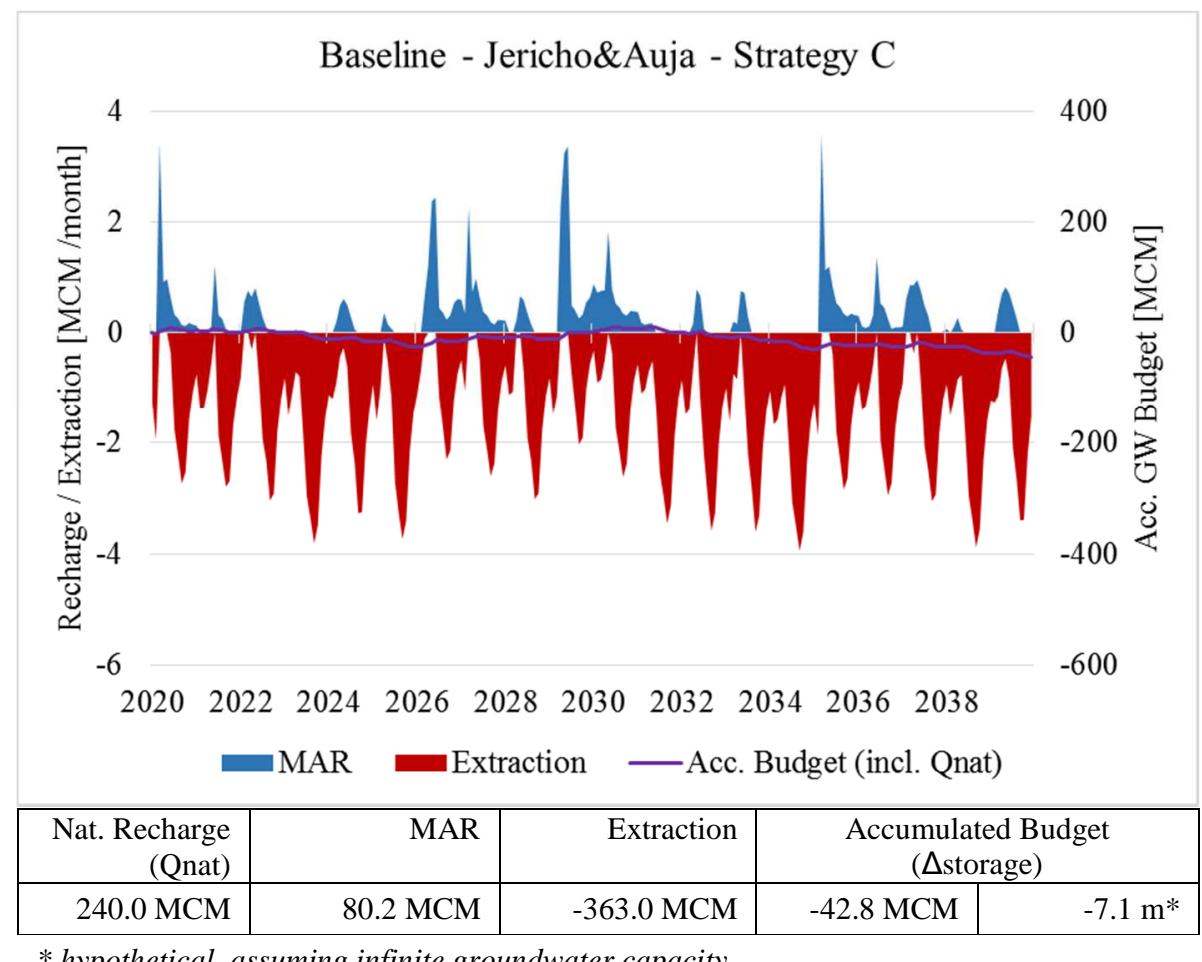

* hypothetical, assuming infinite groundwater capacity

Figure 4-60: Groundwater budget Baseline Scenario Jericho-Auja -Strategy C.

Strategy D adds an efficient use of local waste water availability for irrigation on the fields. As can be seen in Figure 4-61, this measure might add only limited benefits to the water resources system. The overall accumulated groundwater budget might be improved to $-8.8 \mathrm{MCM}$, or $-1.2 \mathrm{~m}$ groundwater decrease. The strategies build up on each other: Strategy D includes the deep well suggestion and rainwater harvesting. The reason this measure is introduced after the apparently much more expensive measure of deep well installation is that the application of treated effluent for irrigation on the fields underlies certain restrictions. To some amount, treated effluent is already used for irrigation at present. The suggested method would increase the effectiveness and volumes of waste water reuse. Not all crops can be irrigated with the available treated waste water. There are some religious and social obstacles as well. When activated and managed effectively, the treated effluent appears to be a good and reliable addition to the prior IWRM measures in combination with MAR. 


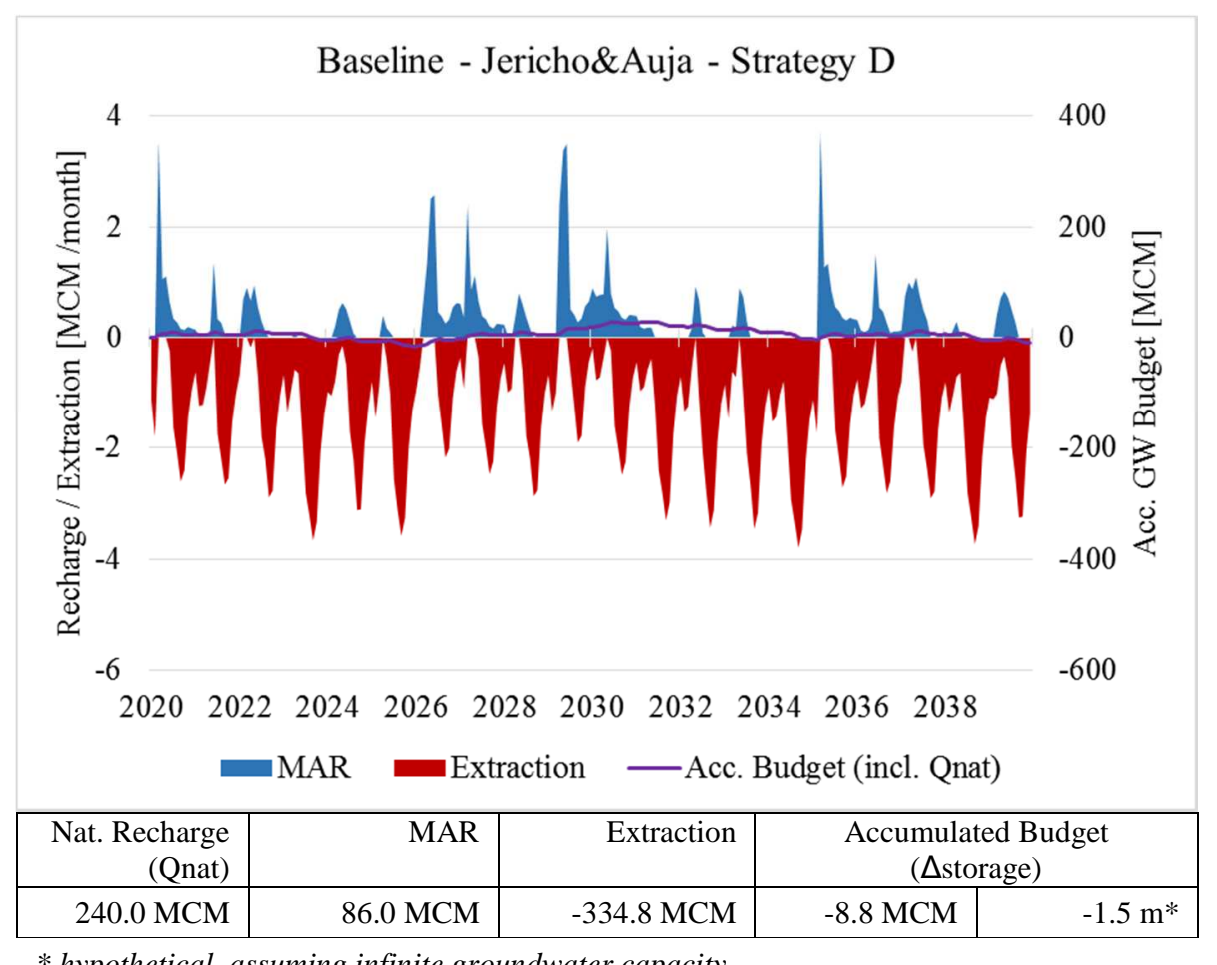

* hypothetical, assuming infinite groundwater capacity

Figure 4-61: Groundwater budget Baseline Scenario Jericho-Auja -Strategy D.

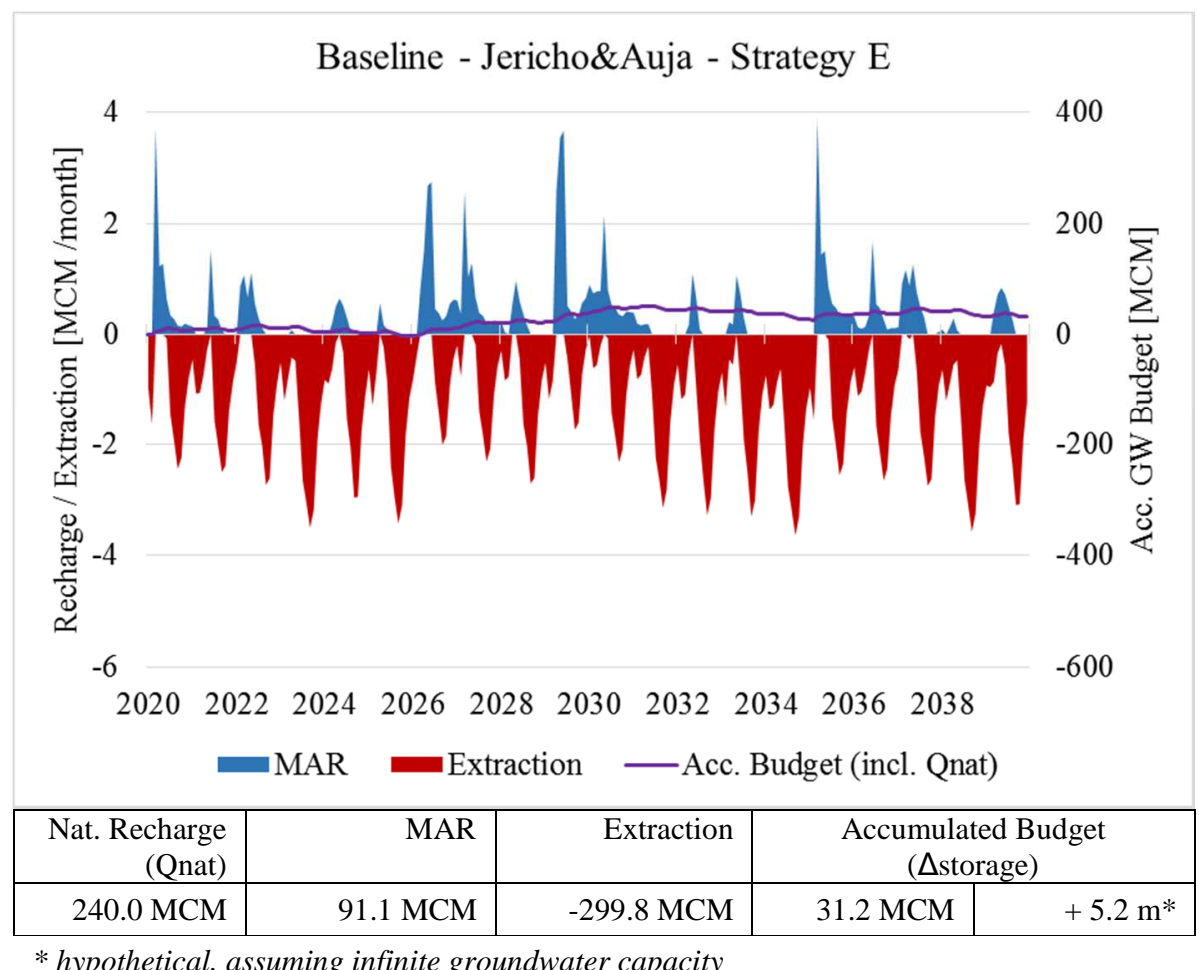

Figure 4-62; Groundwater budget Baseline Scenario Jericho-Auja -Strategy E.

The final stage of IWRM and MAR implementation in the study area Jericho-Auja is the activation of imported treated effluent from the city of El Bireh in the mountain area of Palestine. This potential future plan of local water authorities would add another $2 \mathrm{MCM}$ of water supply to the area. The 
overall accumulated groundwater budget would consequently be improved to $+31.2 \mathrm{MCM}$ over 20 years, resulting in a potential increase of the local groundwater level by $4.2 \mathrm{~m}$. Furthermore, this potent steady supply of treated effluent would result in a positive groundwater budget throughout the entire time period from 2020 to 2040. Assuming this level of IWRM implementation in combination with MAR, the Jericho-Auja case study area could be managed in a sustainable manner under the BL Scenario. In comparison to the DN approach presented initially, no losses of harvest would have to be expected even under the harsh five years drought period.

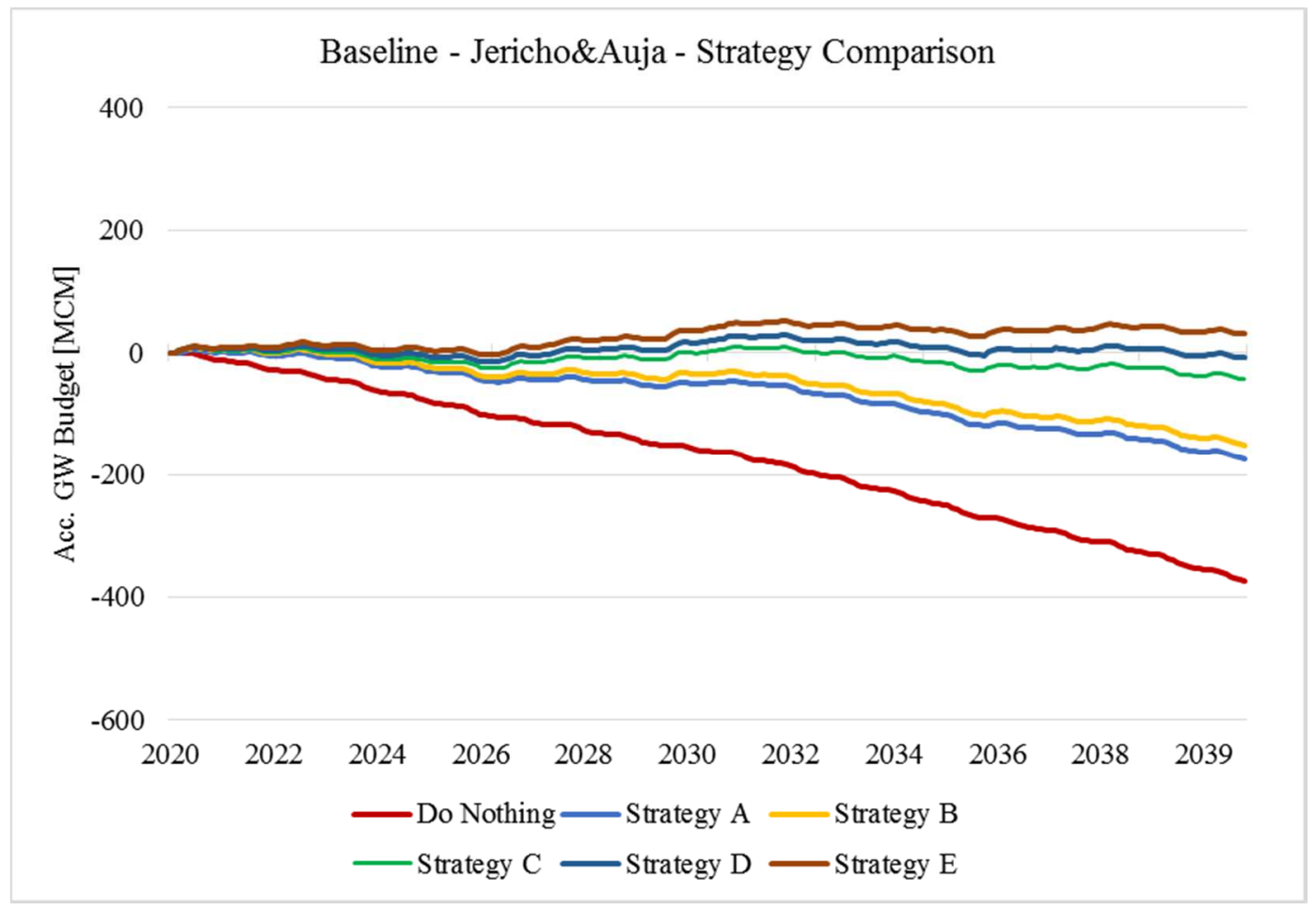

Figure 4-63: Direct comparison of strategies under Baseline Scenario -Jericho-Auja.

\section{Agricultural Development Scenario}

The Agricultural Development Scenario (ADS) had been thoroughly introduced before. It contains assumptions for the extension of irrigated agricultural land following the development plans of local authorities and stakeholders (Rusteberg et al., 2018a). The irrigation water demand is assumed to increase linearly over the course of ten years from 2020 to 2030, putting enormous additional pressure on the water resources system. Since the single strategies and their potential relative impact have been presented in the last section, all results will directly be compared for the ADS. Table 4-18 and Figure 4-64 summarize the budget evaluation results for the DN approach and Strategies A-E. For the spatial distribution of these results see Appendix 7. 


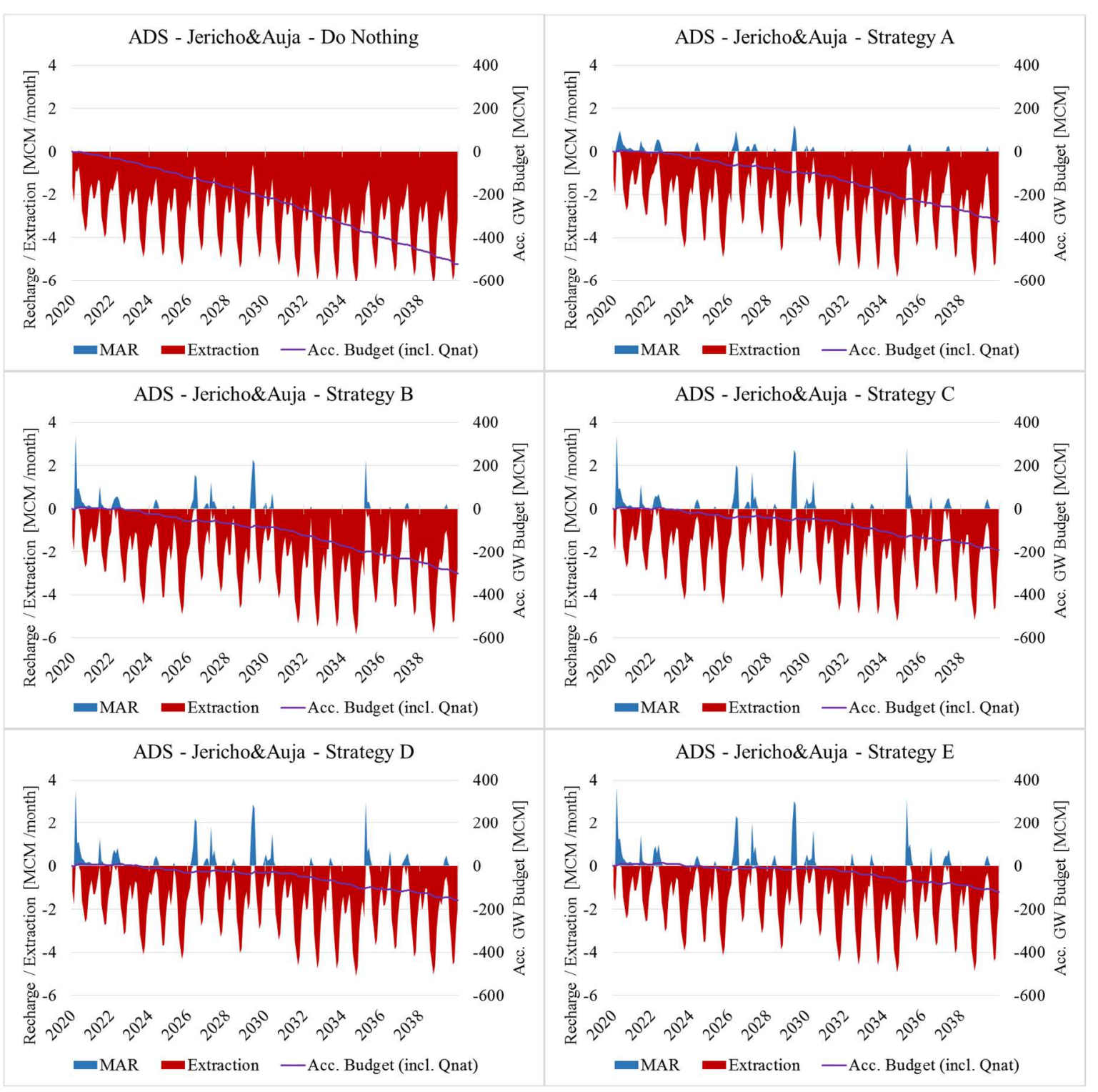

Figure 4-64: Groundwater budgets ADS Jericho-Auja.

The DN approach will serve as a basis of comparison for performance. As the results show, the accumulated groundwater budget over the 20 years period is $-524 \mathrm{MCM}$. For comparison, under the BL Scenario it was -376 MCM. This would hypothetically translate to an overall drawdown of $-70 \mathrm{~m}$ over the area of interest (Eq. 4.5). Since this extreme drawdown would not be possible in reality, this values would actually translate to massive losses in harvests since the crops could simply not be irrigated. This point has been discussed before, but it is important not to confuse a negative result in groundwater budget and actual resulting drawdown in groundwater levels. The values given here should only illustrate and set the absolute numbers in relation. For a good estimation of actual groundwater fluctuation, the application of a groundwater flow model is necessary. 


\begin{tabular}{|c|c|c|c|c|c|}
\hline \multirow{2}{*}{$\begin{array}{l}\text { Agricultural } \\
\text { Development } \\
\text { Scenario }\end{array}$} & \multirow{2}{*}{$\begin{array}{r}\text { Nat. Recharge } \\
\text { (Qnat) }\end{array}$} & \multirow[t]{2}{*}{ MAR } & \multirow[t]{2}{*}{ Extraction } & \multicolumn{2}{|c|}{$\begin{array}{c}\text { Accumulated Budget } \\
(\Delta \text { storage })\end{array}$} \\
\hline & & & & [MCM] & {$[\mathrm{m}]^{*}$} \\
\hline $\mathrm{DN}$ & $240.0 \mathrm{MCM}$ & $0.0 \mathrm{MCM}$ & $-764.0 \mathrm{MCM}$ & -524.0 & -87.3 \\
\hline Strategy A & $240.0 \mathrm{MCM}$ & 16.6 MCM & $-581.0 \mathrm{MCM}$ & -324.4 & -54.1 \\
\hline Strategy B & $240.0 \mathrm{MCM}$ & $29.6 \mathrm{MCM}$ & $-570.7 \mathrm{MCM}$ & -301.1 & -50.2 \\
\hline Strategy C & $240.0 \mathrm{MCM}$ & $39.9 \mathrm{MCM}$ & $-473.0 \mathrm{MCM}$ & -193.1 & -32.2 \\
\hline Strategy D & $240.0 \mathrm{MCM}$ & 44.1 MCM & $-443.2 \mathrm{MCM}$ & -159.1 & -26.5 \\
\hline Strategy E & $240.0 \mathrm{MCM}$ & 48.9 MCM & $-407.9 \mathrm{MCM}$ & -119.1 & -19.8 \\
\hline
\end{tabular}

* hypothetical, assuming infinite groundwater capacity

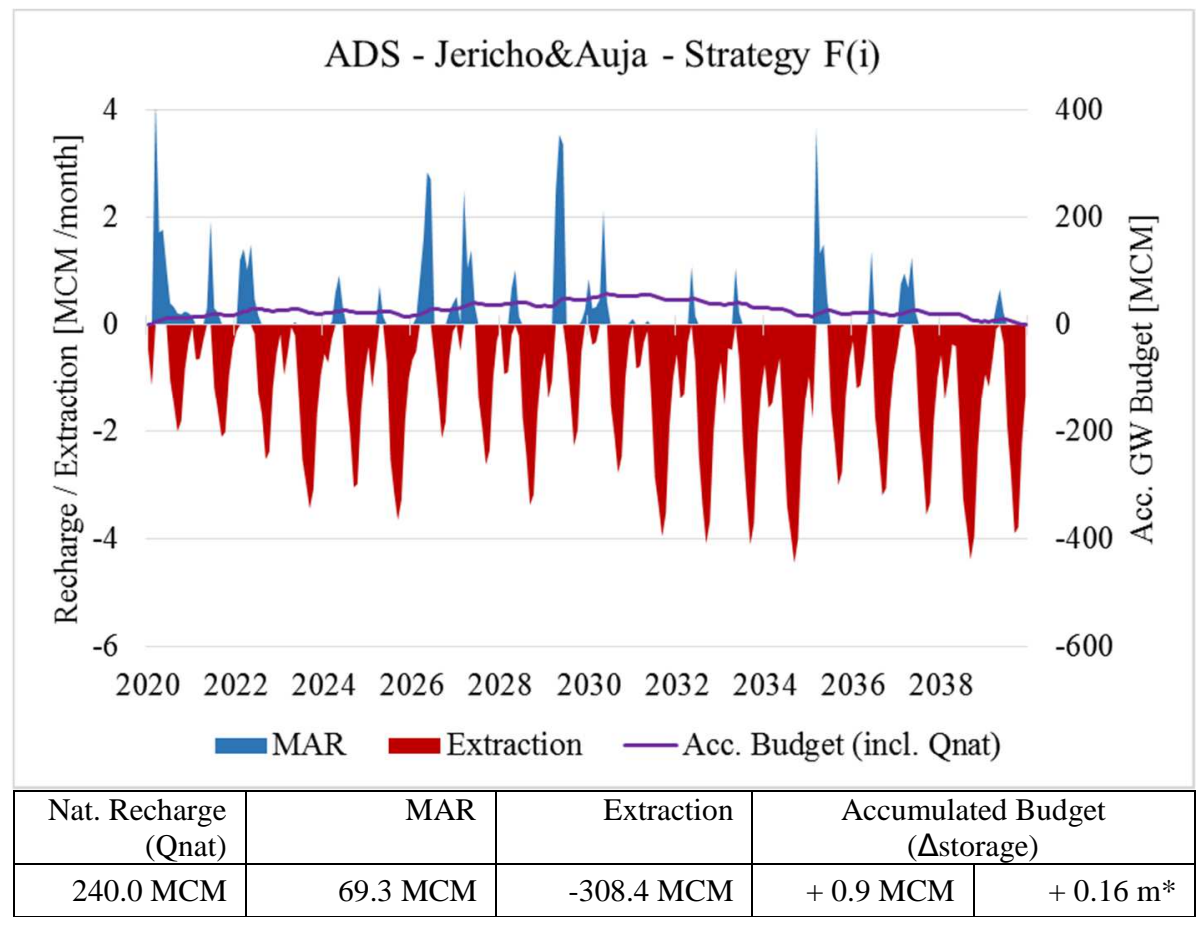

* hypothetical, assuming infinite groundwater capacity

Figure 4-65: Groundwater budget ADS Jericho-Auja -Strategy F(i).

The overview of results given here illustrates the potential impacts of the different strategies. The ADS is very challenging with regard to water demand. As before the biggest improvement could be achieved by the implementation of deep wells beginning with Strategy C. But even under consideration of the additional activation of local and imported treated waste water in Strategy E, the shallow aquifer could not be managed in a sustainable manner under assumption of full agricultural extension and under the selected hydrological conditions. The hydrological input time series was the same as in the Baseline Scenario. Hence, also in this case a drought period of five years occurs between 2030 and 2035. It can clearly be observed in the graph for Strategy E that the groundwater budget remains in a sustainable state up until the drought period. This result can be seen as a first success towards sustainable management. However, ideally the system should also be able to 
withstand long lasting drought events. The results gained by this analysis can therefore be used to develop a final Strategy.

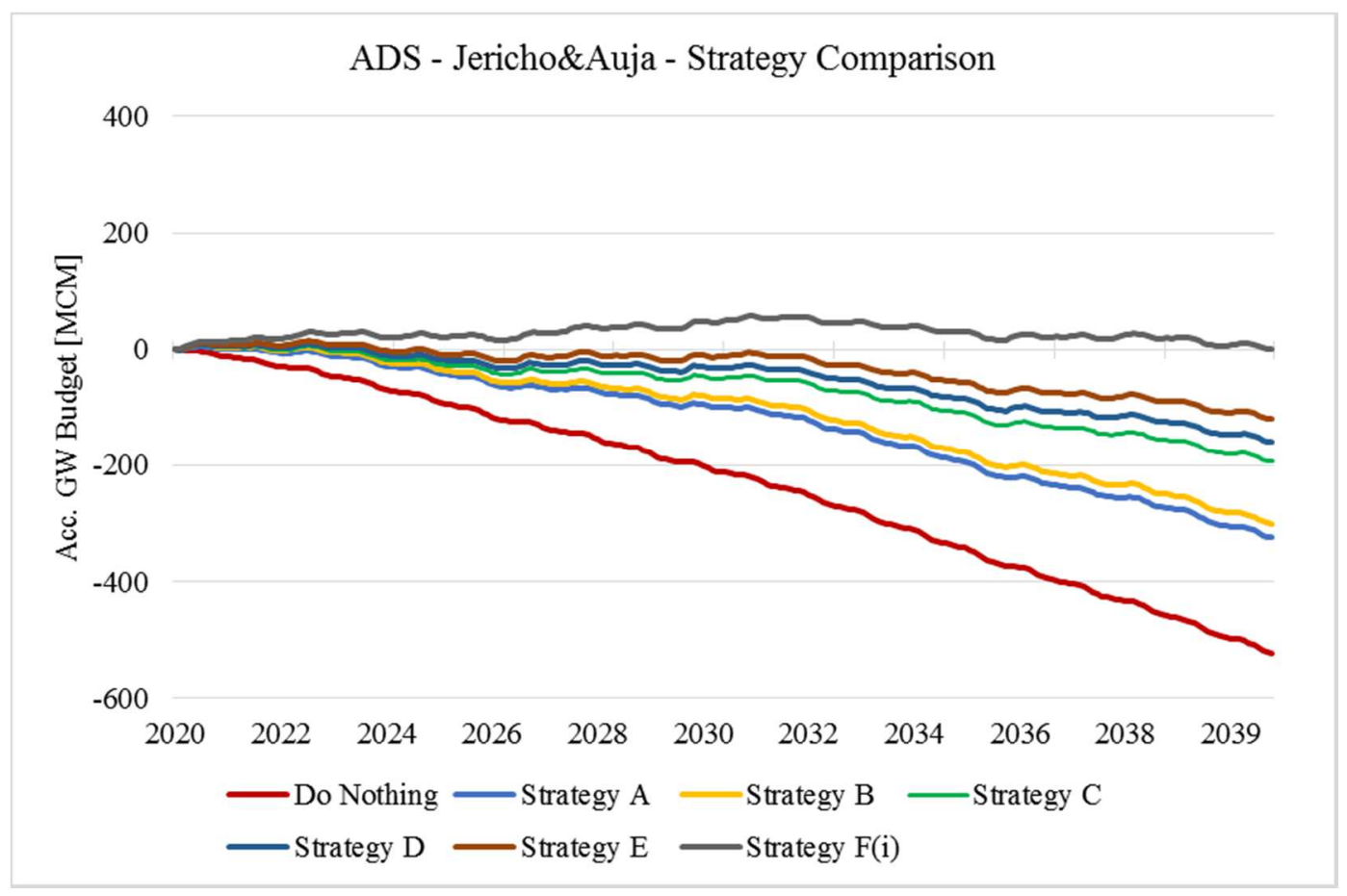

Figure 4-66: Direct comparison of strategies under ADS -Jericho-Auja.

Strategy F(i), presented in Figure 4-65, is a result of the groundwater budget assessment for all available possible water management strategies. This solution has been established by backwards calculation of Strategy E. Since the activation of all available sources would not be sufficient to maintain a positive groundwater budget, two choices were left. One possibility was to reduce water demand. Since all feasible measures to reduce water losses in the region have already been addressed in the strategies, the only possibility would be to reduce agricultural areas as defined in the ADS. It would therefore be possible to conclude that the agricultural extension as desired by local stakeholders is not feasible with the resources and should therefore be reduced to an extent that can sustainably be managed. On the other hand the conclusion can be that, to give a priority on the positive agricultural development of the region in order to increase its wellbeing, additional water has to be imported to the region. Strategy F(i) therefore considers the results of Strategy E and adds water imports in the volume of calculated deficits, on a steady monthly basis. This means an assumed import of 5.3 MCM per year to the study area. This water could potentially be additionally supplied by Israel or Jordan, neglecting political issues. The resulting accumulated groundwater budget is $+0.9 \mathrm{MCM}$ after 20 years, resulting in a potentially steady groundwater environment, not accounting for natural outflow. As given in Figure 4-66, the accumulated groundwater budget would potentially even stay positive throughout the entire time period. Managing the water resources system in this 
manner, by combination of IWRM and MAR does have the potential to even withstand five years of drought events under full irrigation of feasible lands according to the local development plans.

\section{Dry Climate Scenario}

The last scenario that was assessed is the Dry Climate Scenario. It is a combination of the prior ADS and the introduction of an extreme drought period of ten years. Already the prior Baseline climatic assumptions had a drought period included, but only for five years from 2035 to 2040. In this extreme scenario the drought period lasts from 2030 to 2040, replacing also the prior assumed overly wet period from 2030 to 2035. Appendix 8 summarizes the results for each MU individually.

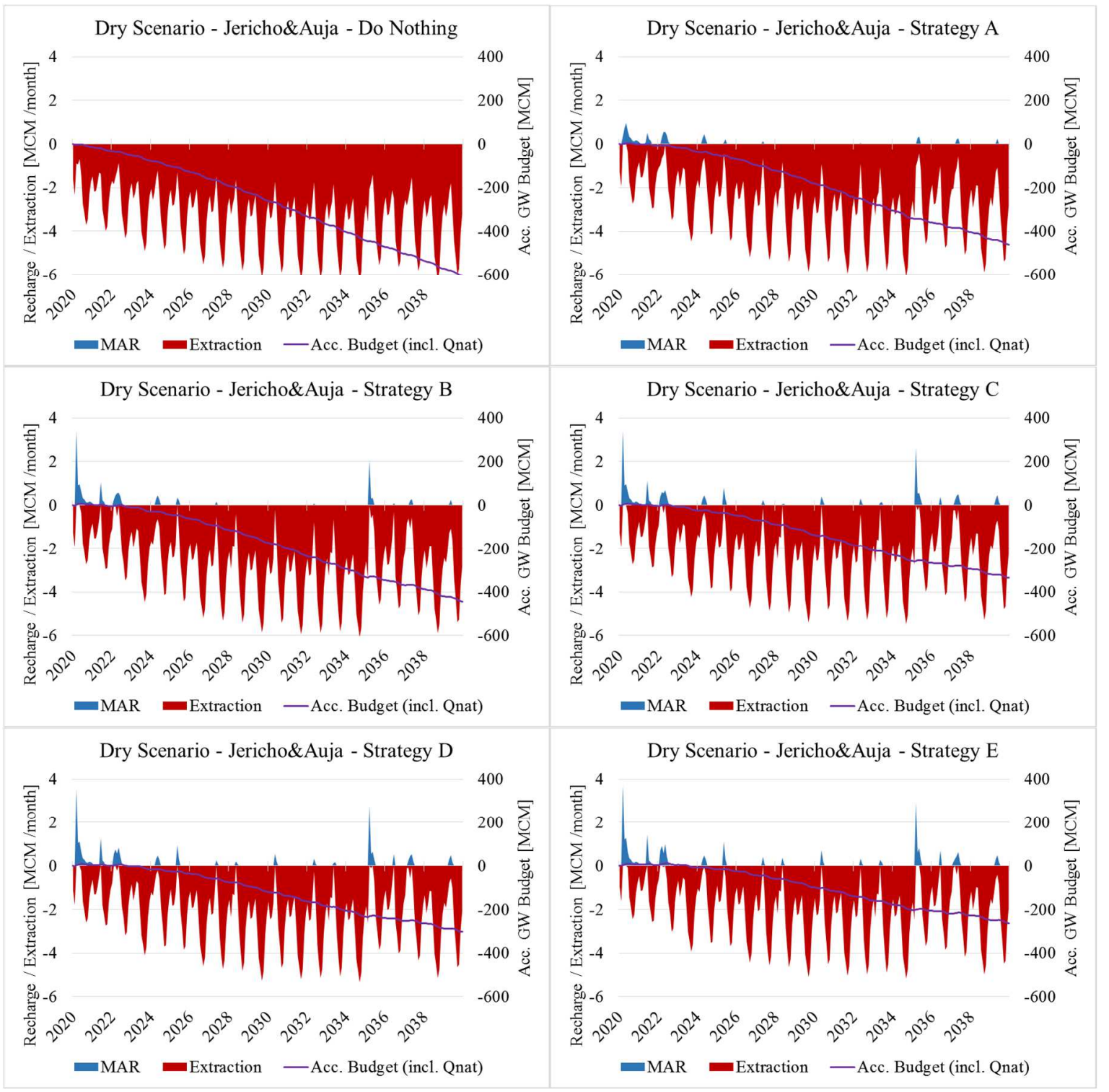

Figure 4-67: Groundwater budgets Dry Scenario -Jericho-Auja. 
The results are again shown for the DN and Strategies A-E in the familiar way in Figure 4-67 and Table 4-19. It can be observed that this extreme scenario strongly decreases the potential for agricultural extension due to immense water shortage. The accumulated groundwater budget turns negative and remains negative from the first year on under the DN assumption. The implementation of MAR measures under Strategy A and the stepwise extension of the IWRM measures can at least lead to some improvement of the water resources system within the first years. But the very long drought period cannot be sustainably managed even under activation of all available sources.

Table 4-19: Summary of groundwater budgets for Dry Scenario -Jericho-Auja

\begin{tabular}{|l|r|r|r|r|r|}
\hline $\begin{array}{l}\text { Dry Climate } \\
\text { Scenario }\end{array}$ & $\begin{array}{r}\text { Nat. Recharge } \\
\text { (Qnat) }\end{array}$ & & MAR & Extraction & \multicolumn{2}{|c|}{$\begin{array}{r}\text { Accumulated Budget } \\
(\Delta \text { storage })\end{array}$} \\
\cline { 5 - 6 }$\left[\begin{array}{l}\text { DN } \\
\text { DN }\end{array}\right.$ & $214.0 \mathrm{MCM}$ & $0.0 \mathrm{MCM}$ & $-819.8 \mathrm{MCM}$ & -605.8 & -101.0 \\
\hline Strategy A & $214.0 \mathrm{MCM}$ & $9.6 \mathrm{MCM}$ & $-684.5 \mathrm{MCM}$ & -460.8 & -76.8 \\
\hline Strategy B & $214.0 \mathrm{MCM}$ & $16.6 \mathrm{MCM}$ & $-674.7 \mathrm{MCM}$ & -444.1 & -74.0 \\
\hline Strategy C & $214.0 \mathrm{MCM}$ & $22.0 \mathrm{MCM}$ & $-572.1 \mathrm{MCM}$ & -336.1 & -56.0 \\
\hline Strategy D & $214.0 \mathrm{MCM}$ & $24.4 \mathrm{MCM}$ & $-540.5 \mathrm{MCM}$ & -302.1 & -50.4 \\
\hline Strategy E & $214.0 \mathrm{MCM}$ & $27.2 \mathrm{MCM}$ & $-503.4 \mathrm{MCM}$ & -262.1 & -43.7 \\
\hline
\end{tabular}

* hypothetical, assuming infinite groundwater capacity

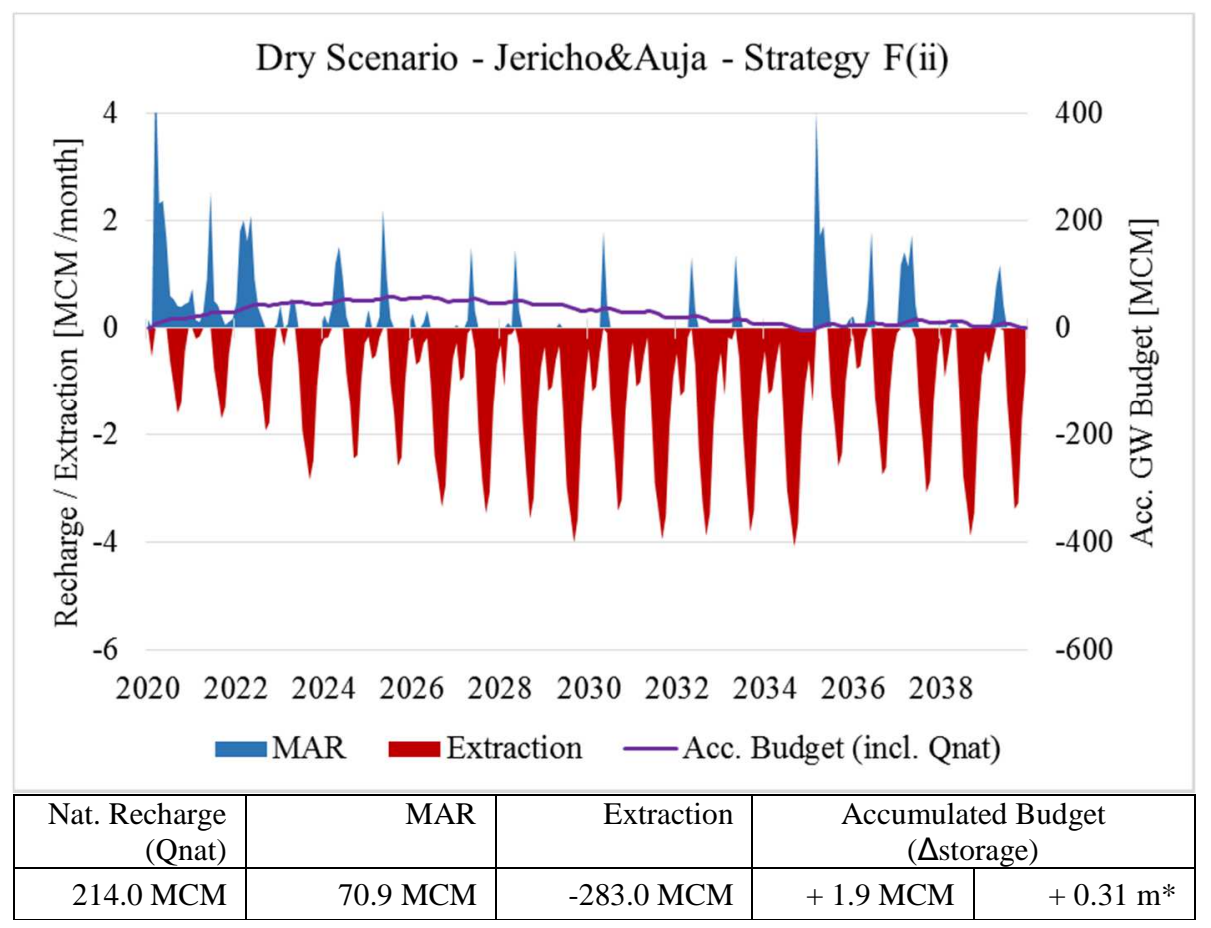

* hypothetical, assuming infinite groundwater capacity

Figure 4-68: Groundwater budget Dry Scenario Jericho-Auja -Strategy F(ii).

It had already been concluded in the prior scenario that the activation and effective management of all available local water sources, plus the discussed import of treated effluent from El Bireh, would 
not be sufficient to sustainable develop the region in accordance to the level of agricultural extension as desired by local stakeholders. The results were used to calculate backwards the amount of additional import of water that would be required. In addition the prior introduced Strategy F(i) for the ADS, the Dry Scenario was used to develop Strategy F(ii). The results are given in Figure 4-68.

This final strategy includes all the prior assumptions and measures and adds the import of 10.1 MCM/a. As can be seen in the results, this import of additional water to cover parts of the water demand will be required in order to sustainably manage the local groundwater resources. Additional, interregional IWRM studies will be required to analyze possibilities to import this water to the region. Figure 4-69 underlines the need for additional water import, after the activation of all local sources if the agricultural extension is supposed to be developed as planned and the system shall be resilient against massive drought events.

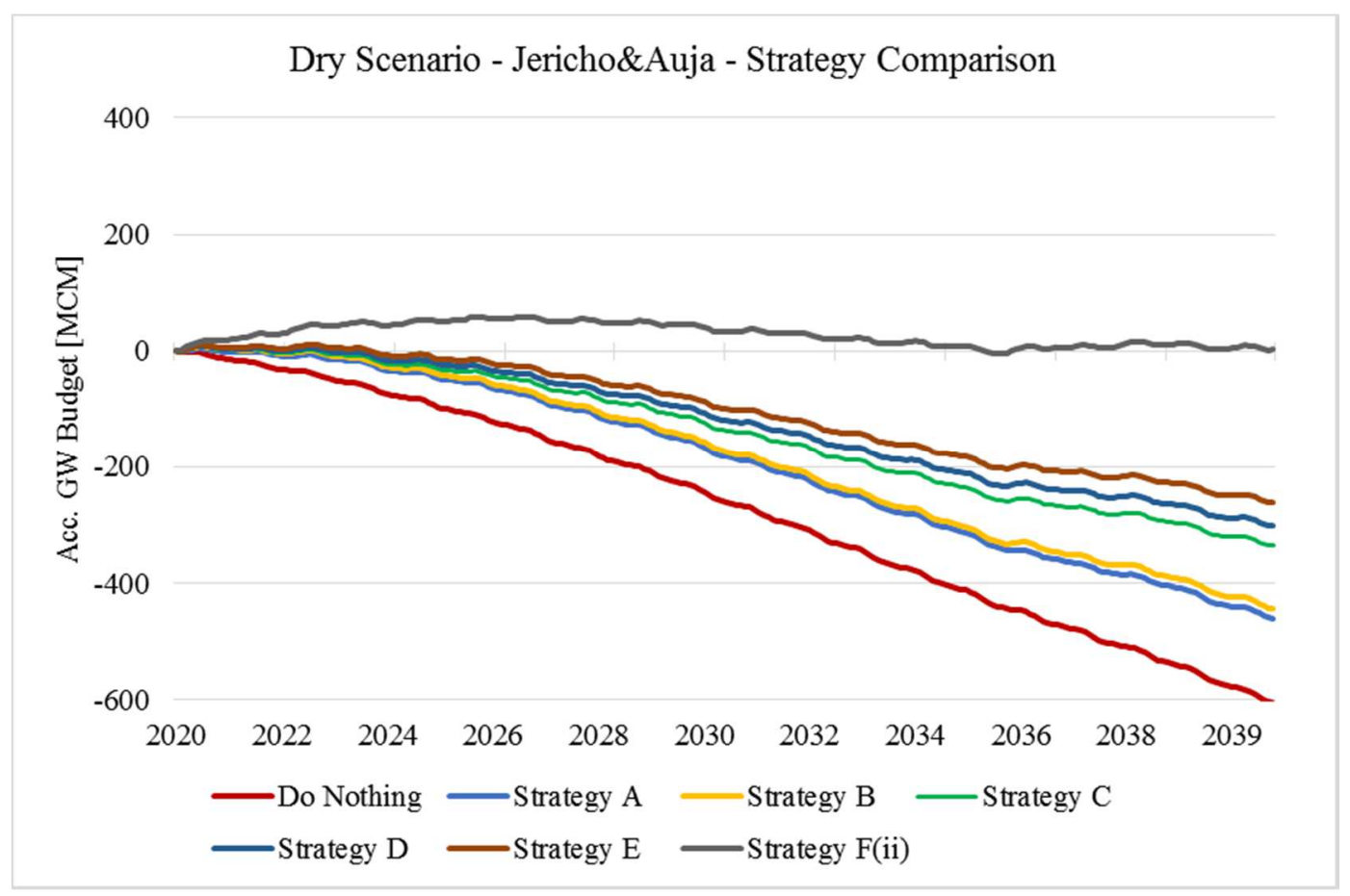

Figure 4-69: Direct comparison of strategies under Dry Scenario -Jericho-Auja.

\subsection{Step 7: Groundwater Simulations}

\subsubsection{Overview of conducted Simulations and Model Setup}

This step of the suggested MAR planning approach will only be applied to the case study of JerichoAuja. Unfortunately it was not possible within the BRAMAR project to calibrate and validate a groundwater flow model for the case study João Pessoa in a satisfying manner. 
To evaluate the introduced MAR strategies and scenarios for the case study Jericho-Auja, a groundwater flow model was utilized. The model has been developed by Abu Sadah (2017). The model was developed with GMS Modflow. It is a finite difference model. Only limited groundwater data was available for model calibration and validation. Also for hydrogeological parameters only scarce data was available and the very complex interactions of alluvium and the clayey Lisan formation required some simplifications with regard to hydraulic conductivity and other parameters. Consequently the model was kept very simple and contains only one layer representing the alluvial aquifer and, characterized by very low hydraulic conductivity, the Lisan formation to the east, close to the Jordan River. Boundary conditions have been set as general head boundaries according to Figure 4-70 to represent the interface of the alluvium with the mountain aquifer, where it receives groundwater recharge and also for the south and northeast to allow for groundwater outflow from the study area.

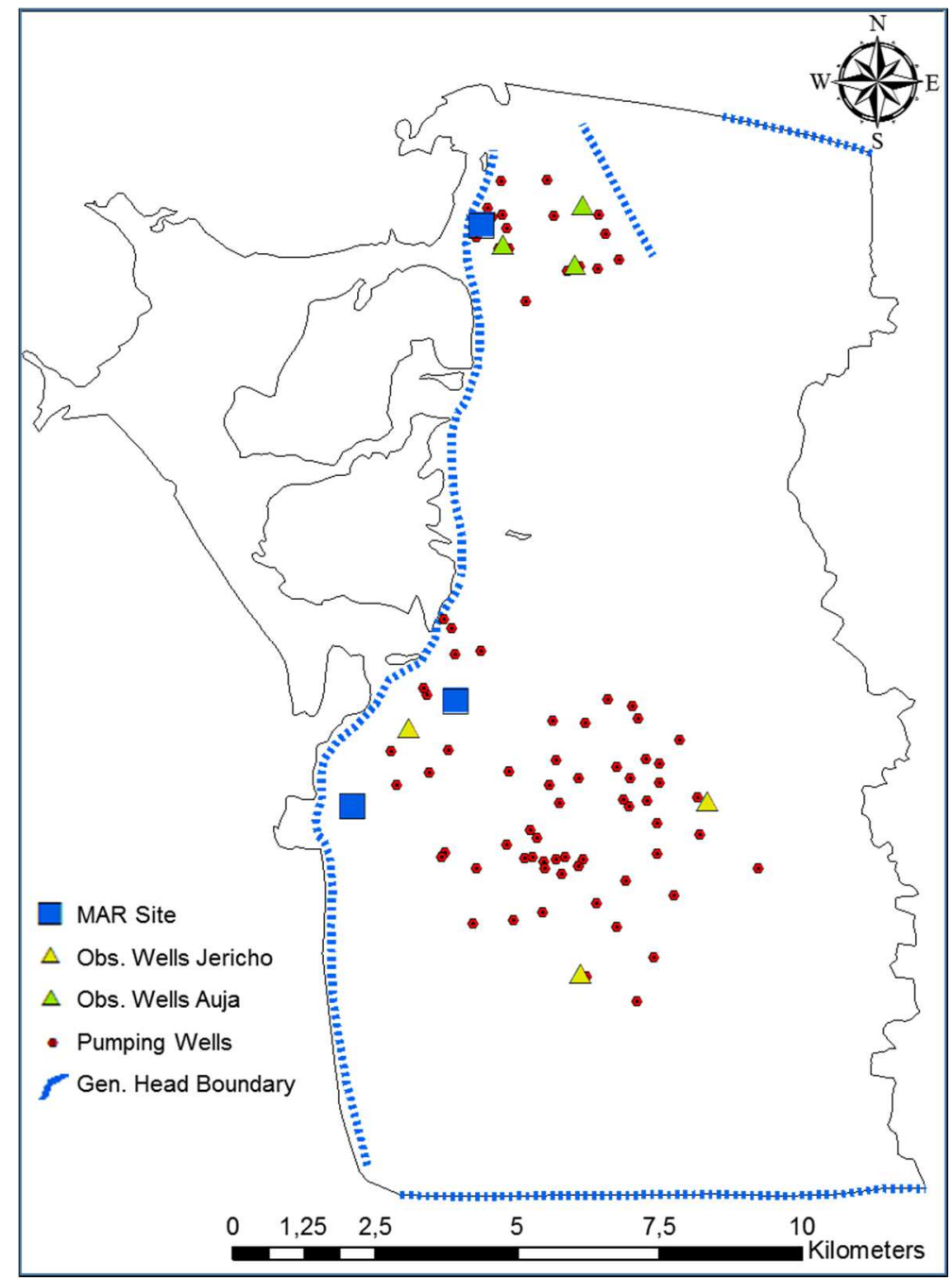

Figure 4-70: Model environment with boundary conditions and virtual observation wells. 
Since the alluvial aquifer does not reach the Jordan River, being disconnected by the Lisan formation, no boundary condition has been defined there. Recharge by MAR is located at the prior selected locations, one for Auja and two for Jericho. The operation schemes, the actual recharge happening at each facility, is directly derived from the prior presented budget calculations. In the model the recharge was actually represented by injection wells. This was due to simplification reasons. Modflow does not represent the vadose, or unsaturated zone. Therefore, it does not make a difference with regard to the simulation results. The figure also gives the locations of assumed pumping wells. There are plenty of wells that have been added for simulation reasons, which are not existent in reality. This is required, since the strategies and scenarios simulated assume much higher groundwater extraction rates over a larger area than is the case today. The main reason being the extended agricultural area that is assumed for the ADS and the Dry Climate Scenario. The highlighted observation wells are used in the following to evaluate the mean variation in groundwater levels by triangulation for each Management Unit (MU).

The need for modelling is given by the requirement of analyzing MAR impacts on local groundwater dynamics. Both, natural and artificial recharge to the alluvial aquifer, as well as monthly operation schemes as introduced in the water budget analysis deliver the input to simulate each strategy and scenario. As could already be shown on a purely numerical scale, MAR can be a suitable solution to the increased water demands and their unfavorable temporal distribution. However, the dynamics of local groundwater fluxes cannot be evaluated by means of budget analyses. That is why the calculated results for groundwater depletion are so high in the prior section, reaching more than $100 \mathrm{~m}$ for some scenario-strategy combinations. In a natural system, extreme drawdown by strong overexploitation will lead to an increased hydraulic gradient and, if available, accordingly increased groundwater inflow from outside the system. For the prior studies, a constant natural flux to the system has been assumed. In order to account for these issues of groundwater hydraulics and dynamics, the application of a model is required. The focus will again be on the exact same combinations of scenarios and strategies as analyzed before. To account for the spatial dimension, the results of both MUs will be given for comparison. Final results of the simulations will be discussed as accumulated values for the entire study area. A special focus was set on the simulated depletion of groundwater resulting from the groundwater budget as simulated by the model. All input parameters are the same as for the groundwater budget calculations, except in-and outflow of the model environment. Abu Sadah (2017) set the boundaries of the model as general head boundaries: The recharge from the adjacent carbonate aquifer will be calculated by the model according to changes in groundwater levels and steep hydraulic gradients will provoke increased inflow. For this purpose it must be assumed, also since other data and information is lacking at this point, that the potential recharge from the mountain aquifer can be infinite. 


\subsubsection{Simulation Results for selected Scenarios and Strategies}

\section{Baseline Scenario}

Figure 4-71 and Table 4-20 summarize the groundwater simulation results of the Baseline Scenario (BL) for each of the designed strategies (A-E) and the corresponding Do Nothing approach (0). The figure shows the average development of the mean groundwater level resulting from triangulation of the above introduced observation wells' virtual measurements of each MU's area of interest as a geometrical mean value for each month over the 20 years time period of simulation. The table reflects this mean groundwater fluctuation and adds accumulated values of the water budgets calculated by the model.

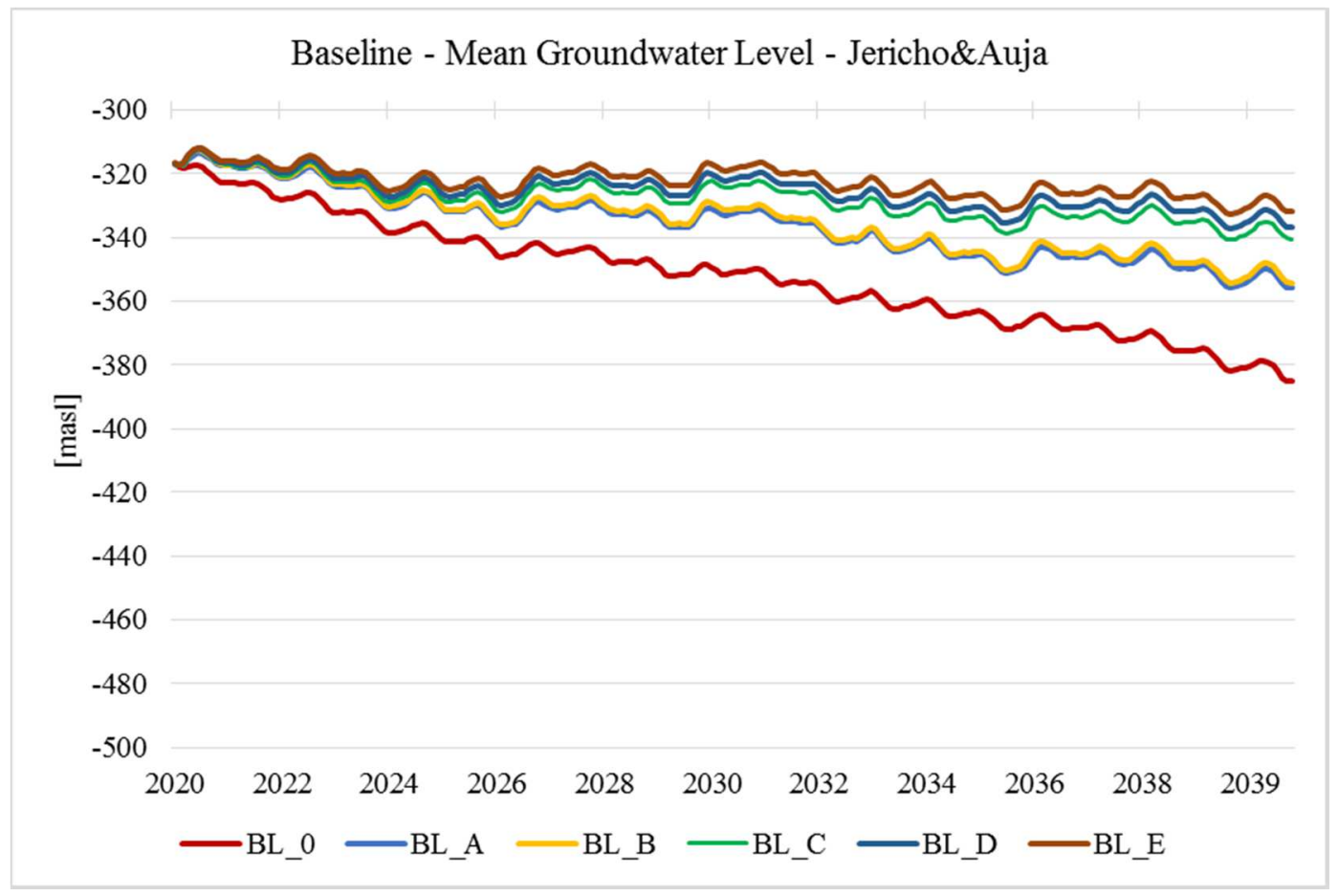

Figure 4-71: Direct comparison of strategies under Baseline Scenario, simulated -Jericho-Auja.

Under the assumption of the BL and a DN approach, groundwater level would potentially drop by $-68 \mathrm{~m}$ over 20 years according to simulation results. As in the prior budget calculation this extreme result requires further explanation since it is not realistic. It is based on the assumption that water would continuously be extracted from the aquifer, regardless of dropping groundwater levels. The wells in the model all reach the bottom of the aquifer. In reality this is not the case. Groundwater pumping would in reality stop the minute that groundwater levels fall below the wells' reach. Consequently, as has been explained before, irrigation water would simply be missing and the field could not be irrigated. Losses of harvests would be the results. For this analysis, the hypothetical drop in groundwater was used as a measure of impact and performance of the individual strategies under assumption of MAR implementation. For the budget calculations it was therefore necessary to calculate the total deficit of water, in order to evaluate the quantities that are missing in the region to 
sustainably manage the aquifer system. If the calculations would assume a stop in groundwater extraction, every time the groundwater drops below a certain threshold, the results could not be compared with each other, since the boundary conditions would be changed. The same basic assumption must be applied for the simulations. If for instance, the wells were included in the model with limited screens, a more realistic result could be achieved regarding groundwater depletion. But for the analysis we require the hypothetical potential drop of groundwater levels in order to be able to compare and evaluate the impact of the IWRM and MAR strategies.

Table 4-20: Direct comparison of strategies under Baseline Scenario, simulated -Jericho-Auja

\begin{tabular}{|l|r|r|r|r|r|}
\hline Strategy & \multicolumn{1}{|c|}{ Qin -Qout } & \multicolumn{1}{c|}{ MAR } & Extraction & $\begin{array}{c}\text { Budget } \\
(\Delta \text { storage })\end{array}$ & $\begin{array}{c}\text { GW Level } \\
\text { Potential* }\end{array}$ \\
\hline DN & $436.7 \mathrm{MCM}$ & $0.0 \mathrm{MCM}$ & $-625.8 \mathrm{MCM}$ & $-189.1 \mathrm{MCM}$ & $-67.9 \mathrm{~m}$ \\
\hline A & $303.6 \mathrm{MCM}$ & $49.7 \mathrm{MCM}$ & $-464.8 \mathrm{MCM}$ & $-111.5 \mathrm{MCM}$ & $-39.0 \mathrm{~m}$ \\
\hline B & $291.3 \mathrm{MCM}$ & $58.2 \mathrm{MCM}$ & $-455.8 \mathrm{MCM}$ & $-106.3 \mathrm{MCM}$ & $-37.4 \mathrm{~m}$ \\
\hline C & $219.9 \mathrm{MCM}$ & $80.5 \mathrm{MCM}$ & $-368.8 \mathrm{MCM}$ & $-68.4 \mathrm{MCM}$ & $-23.7 \mathrm{~m}$ \\
\hline D & $197.3 \mathrm{MCM}$ & $86.2 \mathrm{MCM}$ & $-340.2 \mathrm{MCM}$ & $-56.7 \mathrm{MCM}$ & $-19.9 \mathrm{~m}$ \\
\hline E & $171.3 \mathrm{MCM}$ & $91.3 \mathrm{MCM}$ & $-304.8 \mathrm{MCM}$ & $-42.2 \mathrm{MCM}$ & $-15.3 \mathrm{~m}$ \\
\hline
\end{tabular}

* hypothetical, assuming infinite groundwater capacity

To compare the simulation results with the prior conducted groundwater budget assessment, one more important point must be adressed. The deficit for the Baseline-DN combination was calculated to be -376.8 MCM with an estimated potential groundwater drop of $-62.8 \mathrm{~m}$ (Figure 4-57). That value was assuming a constant inflow of groundwater of $240 \mathrm{MCM}$ (over 20 years). The model on the other hand does account for groundwater dynamics. It calculated a positive budget of $436.7 \mathrm{MCM}$ for in-and outflow of groundwater, not accounting for MAR, which is 0 for the DN anyway, or extraction by pumping wells. Meaning that natural groundwater inflow under the assumption of BL and DN, outnumbers natural outflow by $+436.7 \mathrm{MCM}$ over the course of 20 years. Since outflow of the system has been neglected in the groundwater budget assessment, this values stands in contrast to an assumed inflow of $240 \mathrm{MCM}$ for the prior assessment. Meaning that the model calculated an inflow of groundwater which is relatively nearly twice as high as was assumed in the budget assessment. This underlines the benefit of applying a groundwater model rather than relying merely on budget calculations that require more assumptions and generalizations. The result is that the model calculated only half as much water leaving the storage (-189.1 MCM in comparison to -376.8 MCM). As was assumed, the increasing hydraulic gradient, resulting from the drop in groundwater level, increased the volume of inflow from the connected mountain aquifer. This observation will apply to all the results presented in the following and explains the absolute difference, yet relative similarity of the two assessments. The extraction rates given here for the simulations are by some percentage higher than in the budget assessment results. This is due to a conversion error from the calculated 
required pumping and the model input. One of the systems applied runs with a default length of 30 days per month, while the other uses the actual calendric number of days. This error has only been detected after all simulations were conducted. Since the transition error is minor and the relative comparability of results with each other is more important than the comparison of budget assessment with simulations, it has been decided to neglect but address this circumstance.

The results themselves show a high similarity in relative comparison as the prior evaluation. With every additional measure introduced by a new strategy, the groundwater situation quantifiably improves. While the DN resulted in a drop in groundwater potential of $-70 \mathrm{~m}$ in average over both management units, Strategy E improves this situation to a mere drop of $-15.3 \mathrm{~m}$. This is where the effect of groundwater dynamics can be observed. The prior assessment resulted in a positive budget for Strategy E, even being able to raise the potential groundwater level (Figure 4-62). Apparently the immense recharge via the MAR facilities decreased natural groundwater inflow to the system during time periods of high MAR activity in the simulation. It is the reversed effect of the phenomenon discussed before. Potential groundwater inflow is subsequently reduced by roughly 70 MCM when comparing the results in detail. This shows that nearing the real world conditions by means of groundwater modelling, an actual ideal value for aquifer recharge cannot be determined by groundwater budget calculations alone. By using these simulation results and applying a trial and error approach, the ideal recharge volumes could be calculated, leading at least under these simulation assumptions to a sustainably managed aquifer system. This underlines the importance of recreating the system as detailed as possible and the necessity to perform actual long term field experiments prove or disprove the assumptions made.

It can be observed that the implementation of MAR alone under Strategy A, without any further activation of water sources, would result in a great benefit for the study area. By artificially recharging approximately $50 \mathrm{MCM}$ and reducing pumping by $60 \mathrm{MCM}$ over 20 years, the simulated budget improves by roughly $80 \mathrm{MCM}$, comparing simulated budgets of DN and Strategy A according to Table 4-20. That these values do not add up to an improvement of $110 \mathrm{MCM}$ is again due to groundwater dynamics and the resulting variability of groundwater inflow. Strategy B adds the effective harvesting of surface runoff during storm events. Its impact is, as in the prior assessment, comparably low. Strategy $\mathrm{C}$ again brings the highest relative improvement of performance, adding the installation of deep wells. The model environment does not include the deep aquifer and only represents the shallow alluvial aquifer as storage unit. The idea of Strategy $\mathrm{C}$ is that constant extraction from the underlying deep aquifer will add to the demand coverage in the study area, reducing both pumping from the shallow aquifer and increasing the volume of spring discharge water to be infiltrated in the MAR facilities. For an evaluation of Strategies D and E the spatial differentiation of groundwater levels are given in Figure 4-72. 

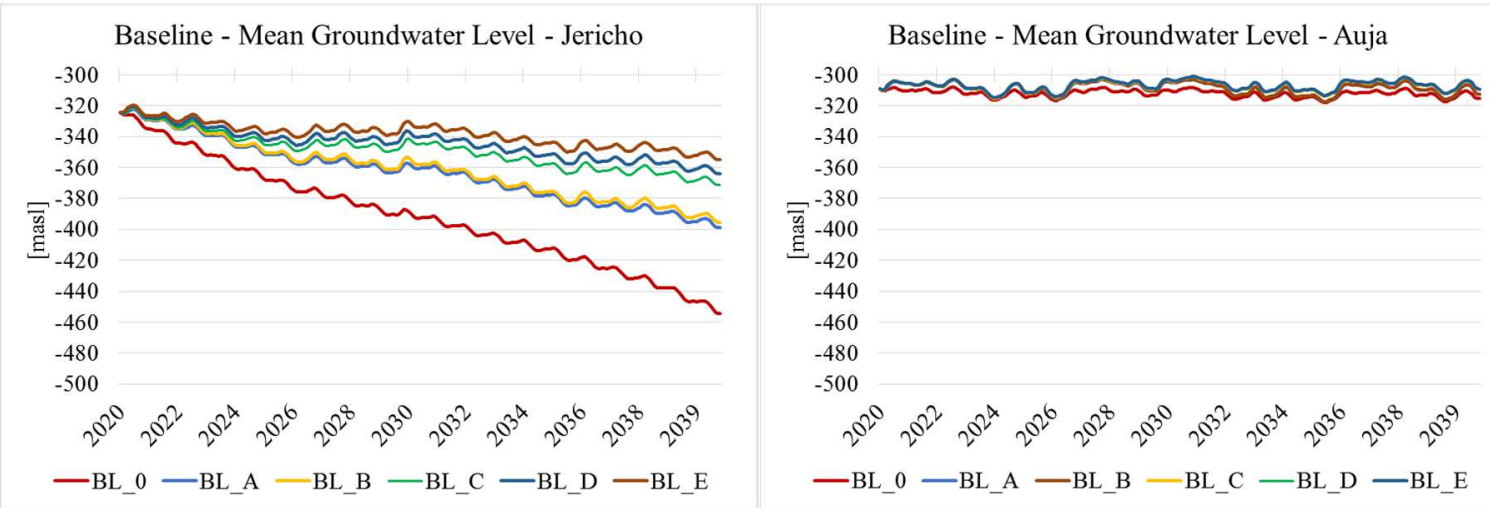

Figure 4-72: Direct comparison of strategies under Baseline Scenario, simulated -Jericho \& Auja separated.

The figure shows the spatial dimension of the simulated groundwater budget and corresponding virtually observed hypothetical groundwater potentials. On the left the curves for Jericho are given, on the right those for Auja. It is obvious that, within the model environment, Jericho suffers from much more groundwater stress than Auja. While in Auja even for the DN approach no depletion in groundwater potential can be observed, it is the Jericho area that reveals these extreme negative values over the 20 years simulation period. This observation is easily explained when looking back at the water resources system analysis and the spatial distribution of water demand (Figure 4-32). It had been evaluated that the mean annual water demand in Jericho is five times as high as that of the rural Auja area. This is directly reflected in the spatial groundwater budget results presented here. As the results show, for Auja the implementation of Strategy D would potentially be sufficient to achieve sustainability in water management under the BL Scenario. Therefore, the additional import of treated effluent from El Bireh, considered under Strategy E would only be used for the irrigated agriculture of Jericho. In contrast to the prior numerical assessment, the simulations do not show a sufficient coverage of water demand to achieve sustainability for the Jericho area despite the implementation of Strategy E. Strategy F, assuming additional import of water from outside the study area, will be analyzed together with the prior strategies under assumption of the ADS, the Agricultural Development Scenario.

\section{Agricultural Development Scenario}

The results for the simulations of the ADS are summarized in Figure 4-73 and Table 4-21. For this scenario Strategy F(i) had been introduced, assuming the import of additional water from outside the study area. The results in general reflect the respective numerical budget assessment conducted before. The scenario assumes the extension of agricultural lands within ten years from 2020 to 2030 . The impact on the water resources system can clearly be observed in the illustrated mean simulated groundwater levels. For this scenario and its result, the same principle assumptions and explanations given above regarding the nature of the displayed groundwater level are valid. 


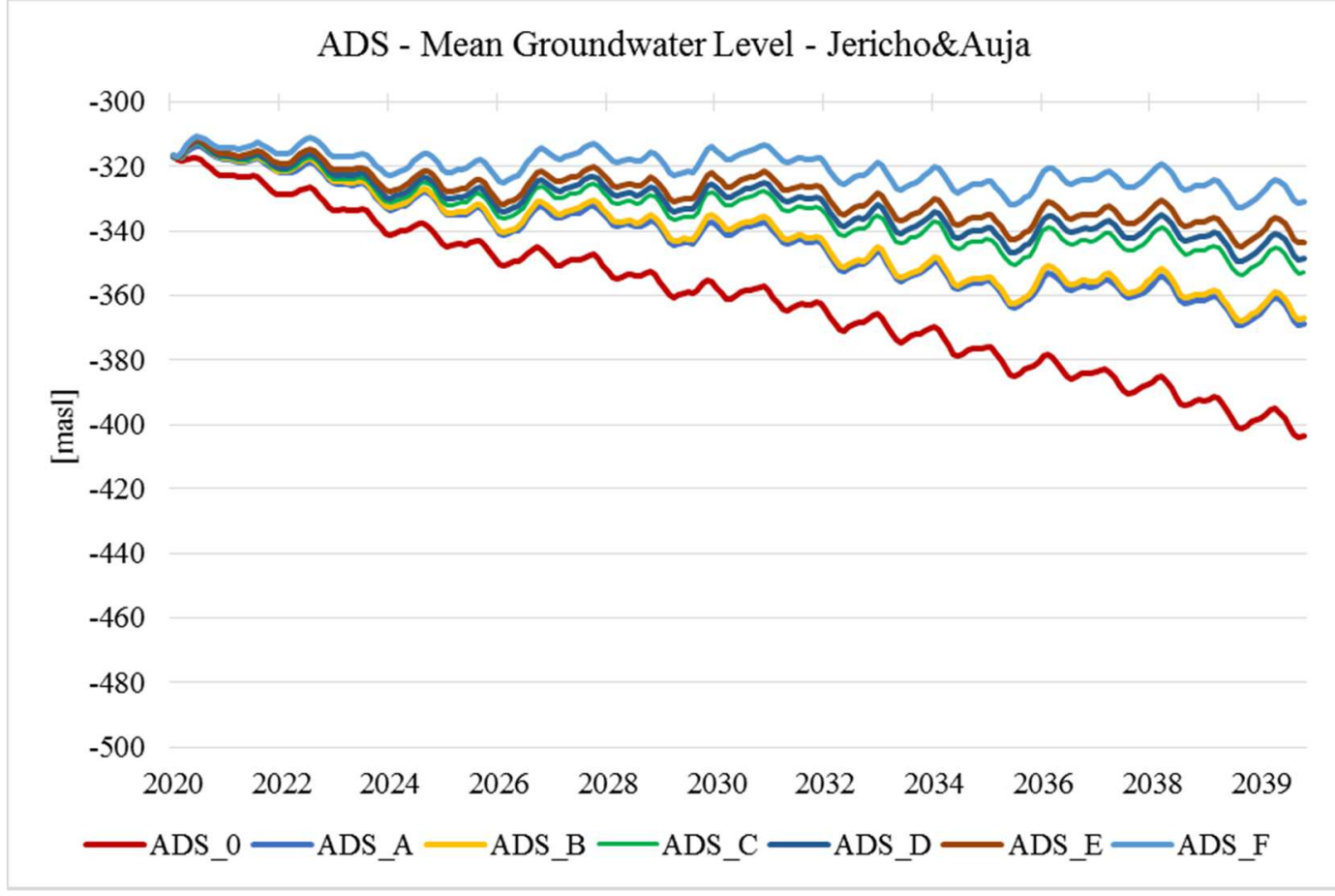

Figure 4-73: Direct comparison of strategies under ADS, simulated -Jericho-Auja.

Results confirm that in order to develop the agricultural sector of the region, which is one major goal of the local stakeholders and authorities, cannot be accomplished by activation of local water sources and the implementation of MAR alone. Though these measure can have a very high potential impact on the system, additional imports will be required. Even under Strategy F(i) which had been designed according to the results of the groundwater budget assessment proves insufficient under simulation conditions. This can be explained with changing groundwater dynamics: Increased recharge leading to decreased natural inflow and even increased groundwater flow out of the system. By artificially recharging the aquifer according to the strategies, with high volumes during a short time period, a temporal bulge in local groundwater level is created. This has the reverse effect of a cone of depression, creating a steeper hydraulic gradient in the opposite direction, thus creating stronger groundwater flow radially away from the infiltration site. As the numbers show, the balance between natural lateral in-and outflow for Strategy F(i) is only 215 MCM, while it was 548 MCM for the DN approach.

The spatially distributed results given in Figure 4-74 underline the prior observations. The high difference in total water demand between the Jericho and Auja area was even intensified by the assumed agricultural extension. To repeat the assumptions introduced in Chapter 4.6 the irrigation water demand for Jericho is assumed to increase from 27 MCM in 2020 to 30 MCM in 2030, while the increase in Auja is from $6 \mathrm{MCM}$ to $13 \mathrm{MCM}$, significantly lower in relation. As prior simulations of the BL Scenario revealed, the local water resources of Auja achieve a level of near sustainability 
by implementation of Strategy D alone. This was confirmed by the simulations of the ADS, All imports considered by Strategy E and F(i) are allocated directly to Jericho.

Table 4-21: Direct comparison of strategies under ADS, simulated -Jericho-Auja

\begin{tabular}{|l|r|r|r|r|r|}
\hline Strategy & \multicolumn{1}{|c|}{ Q in $-Q_{\text {out }}$} & \multicolumn{1}{c|}{ MAR } & Extraction & $\begin{array}{c}\text { Budget } \\
(\Delta \text { storage })\end{array}$ & $\begin{array}{c}\text { Groundwater } \\
\text { Level }\end{array}$ \\
\hline DN & $548.1 \mathrm{MCM}$ & $0.0 \mathrm{MCM}$ & $-775.0 \mathrm{MCM}$ & $-226.9 \mathrm{MCM}$ & $-86.5 \mathrm{~m}$ \\
\hline A & $429.8 \mathrm{MCM}$ & $16.8 \mathrm{MCM}$ & $-589.8 \mathrm{MCM}$ & $-143.2 \mathrm{MCM}$ & $-52.0 \mathrm{~m}$ \\
\hline B & $412.8 \mathrm{MCM}$ & $29.7 \mathrm{MCM}$ & $-579.3 \mathrm{MCM}$ & $-136.8 \mathrm{MCM}$ & $-50.3 \mathrm{~m}$ \\
\hline C & $346.1 \mathrm{MCM}$ & $40.0 \mathrm{MCM}$ & $-480.4 \mathrm{MCM}$ & $-94.3 \mathrm{MCM}$ & $-35.9 \mathrm{~m}$ \\
\hline $\mathrm{D}$ & $324.5 \mathrm{MCM}$ & $44.3 \mathrm{MCM}$ & $-450.1 \mathrm{MCM}$ & $-81.3 \mathrm{MCM}$ & $-31.7 \mathrm{~m}$ \\
\hline E & $299.5 \mathrm{MCM}$ & $49.1 \mathrm{MCM}$ & $-415.0 \mathrm{MCM}$ & $-66.4 \mathrm{MCM}$ & $-26.8 \mathrm{~m}$ \\
\hline $\mathrm{F}(\mathrm{i})$ & $215.3 \mathrm{MCM}$ & $69.8 \mathrm{MCM}$ & $-313.5 \mathrm{MCM}$ & $-28.4 \mathrm{MCM}$ & $-14.6 \mathrm{~m}$ \\
\hline
\end{tabular}

* hypothetical, assuming infinite groundwater capacity
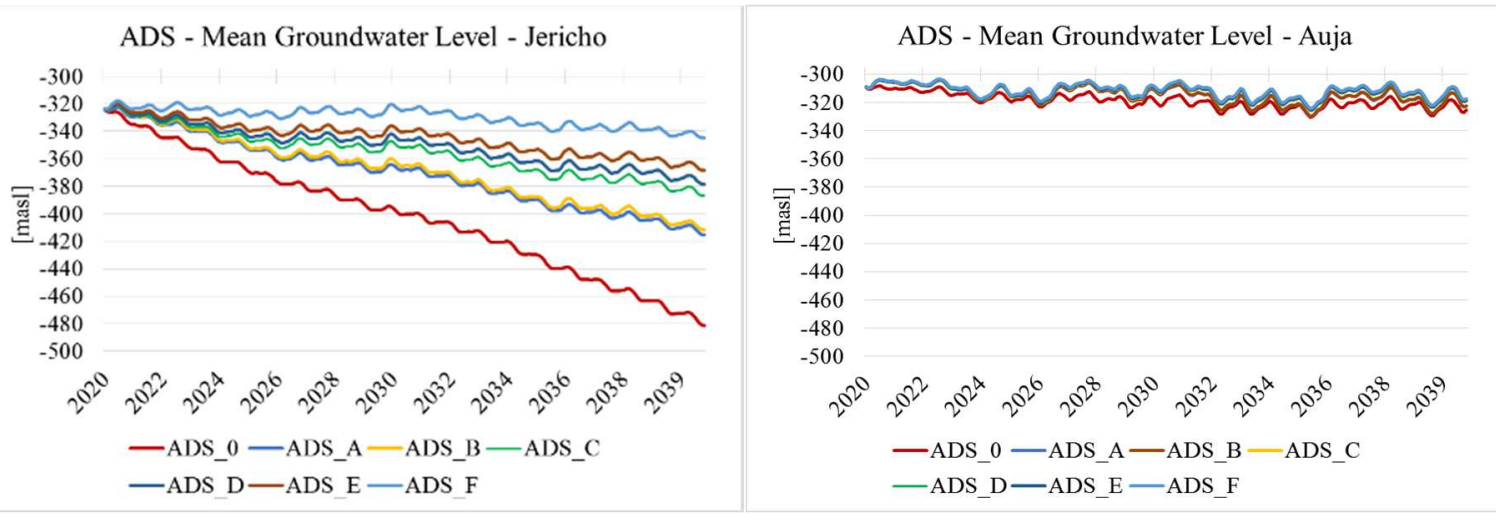

Figure 4-74: Direct comparison of strategies under ADS, simulated -Jericho \& Auja separated.

The results show that the full implementation of IWRM measures and MAR in combination with additional imports from outside the area have a huge potential impact on the system. Even the Jericho district achieved acceptable results, if not totally sustainable with a potential drop of -15 m after 20 years. It may be deducted that for a sustainable management of the water resources, under parallel extension of agricultural land to the desired outline, even further imports would be required in order to prevent groundwater depletion. Or that the agricultural extension cannot be sustainably conducted, if these additional resources are not available. The results might be used to calculate backwards the maximum sustainably possible area of irrigated agriculture.

\section{Dry Climate Scenario}

Finally the Dry Climate Scenario was simulated, applying the same strategies. Note that Strategy $\mathrm{F}$ (ii) is an extension of $\mathrm{F}(\mathrm{i})$ from the ADS, that was designed using the groundwater budget assessment in order to perform a neutral accumulated budget, or no potential depletion in 
groundwater level, after the 20 years period. As has been shown in the ADS simulations, this neutral value, representing a sustainable groundwater management, could not be achieved via simulation due to the impact of groundwater dynamics. Results for the Dry Scenario led to similar conclusions. As seen in Figure 4-75 and Table 4-22, for this very extreme scenario with its ten years drought condition from 2025 to 2035, even the import of 10 MCM per year from outside the study would not suffice to sustainably manage the aquifer under the selected assumptions of agricultural development and water supply.

With an overall groundwater depletion of $-10 \mathrm{~m}$ after ten years of drought followed by five years of moderate hydraulic conditions, Strategy F(ii) still showed a comparably very good performance. The idea behind this assessment is to illustrate the level of improvement an integrated implementation of IWRM and MAR can accomplish for the study area. The results showed very clearly that even without additional imports, the groundwater situation would potentially increase significantly by these combined measures. Based on these results it can be calculated by trial and error simulations what volume of additionally imported water would be required in order to achieve sustainability even after these extreme conditions and a full extension of agricultural areas. As Figure 4-76 illustrates, even though the assumed imports would be allocated to the Jericho area, leading to an increase MAR activity at that location, the impact of the additional infiltration via MAR can still be measured in the Auja vicinity, at least in simulation.

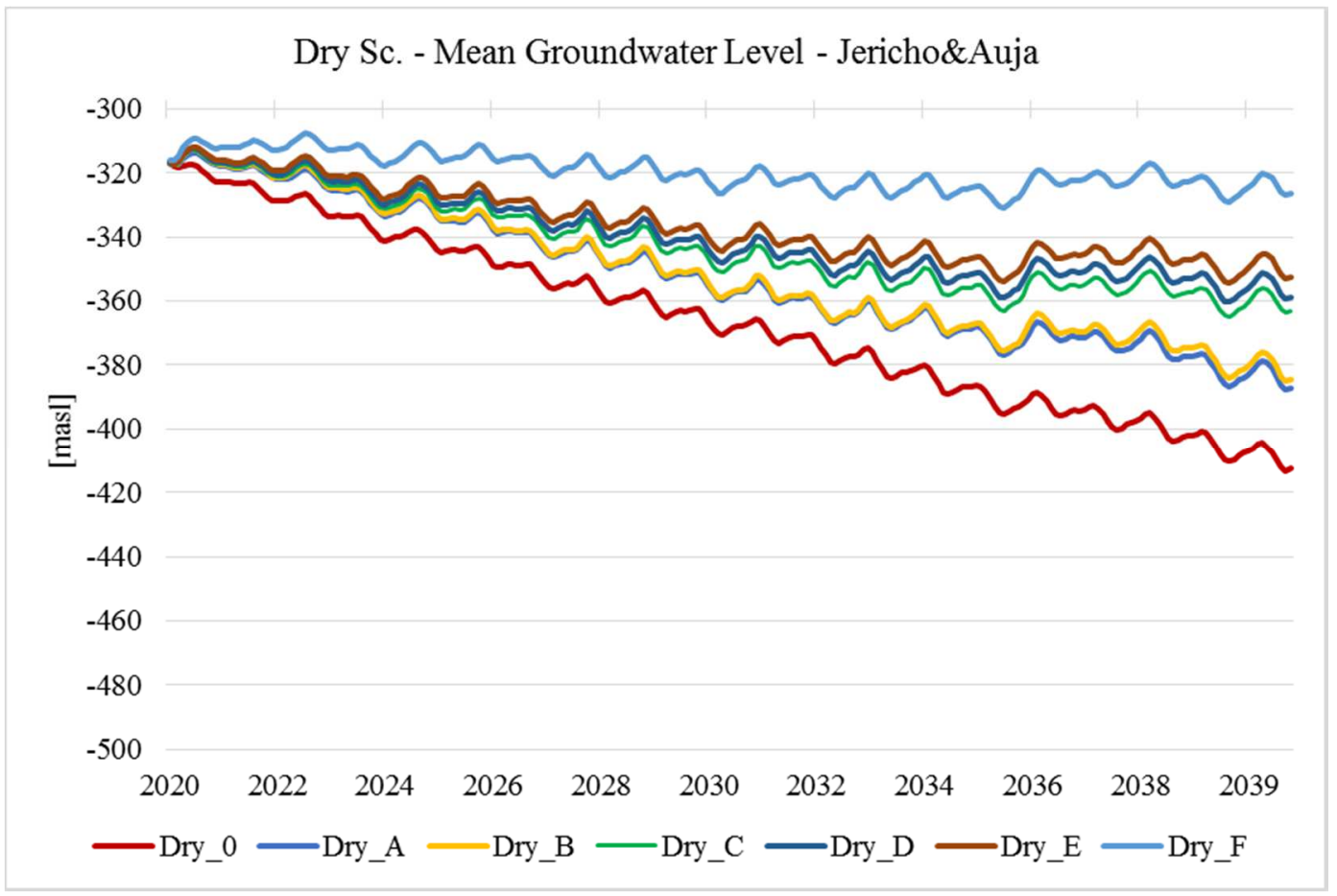

Figure 4-75: Direct comparison of strategies under Dry Scenario, simulated -Jericho-Auja. 
Table 4-22: Direct comparison of strategies under ADS, simulated -Jericho-Auja

\begin{tabular}{|l|r|r|r|r|r|}
\hline Strategy & \multicolumn{1}{|c|}{ Qin -Qout } & MAR & Extraction & $\begin{array}{c}\text { Budget } \\
(\Delta \text { storage })\end{array}$ & $\begin{array}{c}\text { Groundwater } \\
\text { Level* }\end{array}$ \\
\hline DN & $578.2 \mathrm{MCM}$ & $0.0 \mathrm{MCM}$ & $-831.6 \mathrm{MCM}$ & $-253.4 \mathrm{MCM}$ & $-95.7 \mathrm{~m}$ \\
\hline A & $497.3 \mathrm{MCM}$ & $9.7 \mathrm{MCM}$ & $-694.7 \mathrm{MCM}$ & $-187.7 \mathrm{MCM}$ & $-70.7 \mathrm{~m}$ \\
\hline B & $475.2 \mathrm{MCM}$ & $16.8 \mathrm{MCM}$ & $-663.4 \mathrm{MCM}$ & $-172.4 \mathrm{MCM}$ & $-67.9 \mathrm{~m}$ \\
\hline C & $429.1 \mathrm{MCM}$ & $22.0 \mathrm{MCM}$ & $-581.0 \mathrm{MCM}$ & $-129.9 \mathrm{MCM}$ & $-46.4 \mathrm{~m}$ \\
\hline D & $410.8 \mathrm{MCM}$ & $24.5 \mathrm{MCM}$ & $-549.0 \mathrm{MCM}$ & $-113.7 \mathrm{MCM}$ & $-42.0 \mathrm{~m}$ \\
\hline E & $316.6 \mathrm{MCM}$ & $27.4 \mathrm{MCM}$ & $-511.3 \mathrm{MCM}$ & $-94.3 \mathrm{MCM}$ & $-35.7 \mathrm{~m}$ \\
\hline F(ii) & $200.6 \mathrm{MCM}$ & $71.5 \mathrm{MCM}$ & $-290.8 \mathrm{MCM}$ & $-18.7 \mathrm{MCM}$ & $-10.3 \mathrm{~m}$ \\
\hline
\end{tabular}

* hypothetical, assuming infinite groundwater capacity
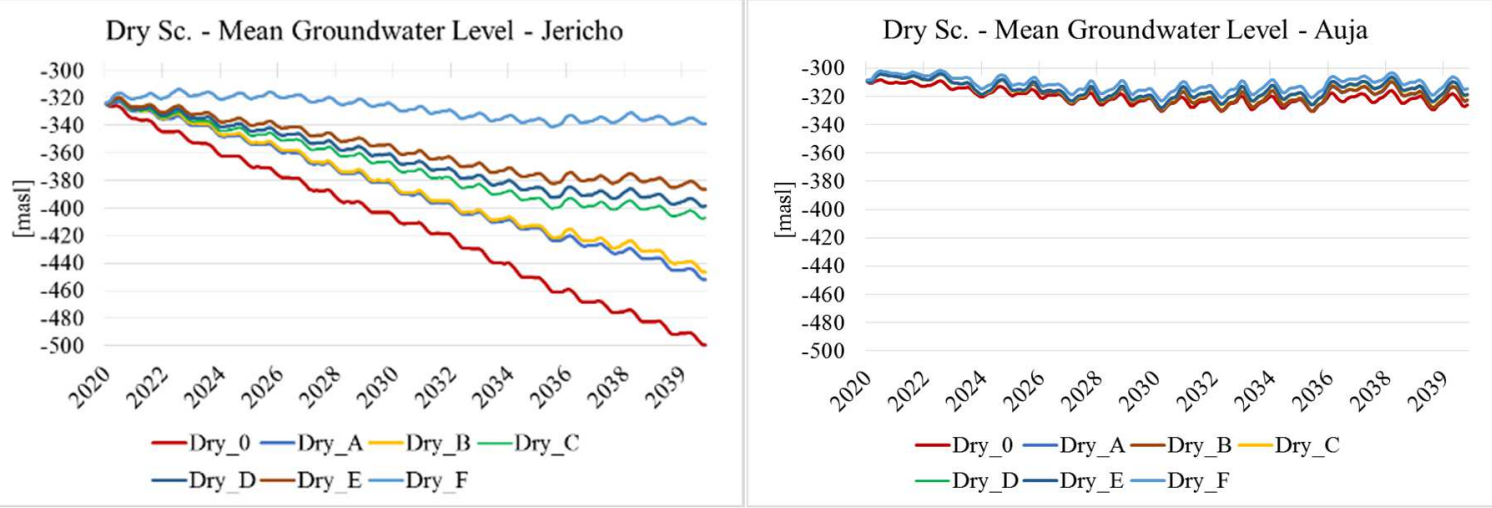

Figure 4-76: Direct comparison of strategies under ADS, simulated -Jericho \& Auja separated.

\subsection{Step 8: Performance and Impact Assessment}

\subsubsection{Definition of Indicators}

After the evaluation of the individual strategies for IWRM and MAR implementation in the two case studies, the achieved results were used in this section in order to quantify the relative performance of each strategy under the three scenarios. For this purpose a set of five indicators has been developed to illustrate one potential way to evaluate the performance. These indicators, introduced in the following, were derived from comparison with other IWRM studies (Chapter 2.2).

$$
\text { Ind. } I=\text { Vol }_{\text {add }}
$$

with $\quad \mathrm{Vol}_{\text {add }}=$ volume of additionally activated water resources

The first indicator rates the Relative Costs. For a complete assessment it is highly recommended to perform a complete cost-benefit analysis. Unfortunately that was not possible as part of this study. In a cost-benefit analysis there are numerous factors that influence the result. It has to be accounted for the complete list of expected costs of implementing the required hydro-infrastructure, such as canals, pipelines, pumping stations, MAR facilities, monitoring and controlling devices, pretreatment facilities, their maintenance and operation costs. On the other hand these costs must be balanced with the expected added benefits by means of monetary profits resulting from the additional 
irrigated lands and the crops harvested there, social parameters such as employment rates and others. It was tried within the course of this research to obtain at least some cost parameters, but finally a complete cost-benefit analysis would have exceeded the scope of this study. Hence, a simplified indicator has been developed as presented in Eq. 4.6. The parameter concentrates solely on the costs and simplifies the assessment by approximating expected relative costs of the different strategies by assuming a unit cost per additional $\mathrm{m}^{3}$ of water supplied by the strategy. This very coarse approximation of relative costs is only possible, since the developed strategies are created in a way that each strategy builds up on the prior one. Meaning that with each strategy, an additional cost will occur that can safely be assumed to be linearly proportional to the amount of water that the measures provide. It is clear that a strategy that adds one measure, like the implementation of addition earth dams to capture surface runoff, or the modernization of parts of the irrigation network, is in relation more expensive than a strategy that neglects this specific measure. Since the benefits of additional water are the potential to grow, harvest and sell more crops with the available irrigation water, they are reflected indirectly in the performance of the following indicators. It must be kept in mind that for all strategies and scenarios the basic assumption is that all field are irrigated to satisfy all irrigation water demands to their fullest. But the lower the hypothetical groundwater levels given in this study drop, the less fields could be irrigated in reality. Therefore, the benefit factor is represented indirectly by the stability of groundwater levels and the sustainability of the system.

$$
\text { Ind. } I I=\frac{Q_{\text {out }}}{Q_{\text {in }}}
$$

$$
\begin{array}{ll}
\text { with } \quad \text { Qout }=\text { groundwater pumping } \\
\\
\text { Q }_{\text {in }}=\text { groundwater inflow }+ \text { MAR }
\end{array}
$$

The second indicator addresses the Groundwater Stress and is described in Eq. 4.7. For this study groundwater stress was defined as the ratio of accumulated groundwater outflow over inflow for the respectively selected time period. Groundwater outflow combines natural flow leaving the outlined system and extraction by pumping, a value that has been one focus of the prior evaluations. The groundwater inflow includes the natural inflow to the system, natural groundwater recharge, any return flow entering the groundwater (which for simplification have before been included in the natural recharge values) and artificial recharge by MAR. Summarizing it accounts for all volumes that enter or leave the groundwater within the analyzed time period. Groundwater stress should be 1 or below in order to have a sustainable system.

$$
\text { Ind. } I I I=\Delta h_{\text {mean }(i)}
$$

$$
\begin{aligned}
& \text { with } \Delta \mathrm{h}_{\mathrm{i}}=\text { difference in groundwater level at time step i } \\
& \mathrm{i}=\text { last time step of simulation/budgeting period }
\end{aligned}
$$

The third indicator uses the level of Groundwater Decline over the selected period. As described in Eq. 4.8, it is defined as the difference in groundwater head at the last time step of the analysis in comparison to the initial head. This value has been presented before also as the accumulated 
groundwater budget or the storage change $(\Delta \mathrm{S})$. It was used to design the Strategy $\mathrm{F}$ for the JerichoAuja case study as well. The overall drop in groundwater over time should ideally be zero or positive.

$$
\text { Ind. } I V=\sigma=\sqrt{ } \frac{(x-\bar{x})^{2}}{(n-1)}
$$

with $\quad \sigma=$ standard deviation of mean groundwater fluctuation $\mathrm{x}=$ mean groundwater level

Groundwater Volatility is the fourth indicator that was used for the performance assessment. Independent of the overall drop or increase of groundwater level, it describes the ratio within which groundwater fluctuates around its mean level. Mathematically, as given in Eq. 4.9, it can be described as the standard deviation of the groundwater level curve. For evaluation, the mean groundwater level over the entire study area was used as presented before. It is desirable that volatility of groundwater levels is low. A high volatility, e.g. groundwater that fluctuates by $+/-5 \mathrm{~m}$ on a daily basis, represents a high risk for the short term water availability. Some shallow wells of local farmers might run dry on a regular basis. In order to guarantee an undisturbed supply by pumping wells, volatility should therefore be as low as possible.

$$
\text { Ind. } V=\frac{\Delta S}{V o l_{\text {add }}}
$$

$$
\begin{array}{ll}
\text { with } & \Delta \mathrm{S}=\text { storage change } \\
& \text { Vol add }=\text { volume of additionally activated water resources }
\end{array}
$$

The last indicator should judge the efficiency of the suggested MAR implementation itself. As described in Eq. 4.10, it is defined as the volume of storage change over the volume of additionally activated water resources resulting from the implementation of the respective strategy. It should give an impression of how much the local groundwater system actually benefits per volume of newly supplied water. An ideal value for efficiency, which is of course never achieved in reality, would be 1 .

\subsubsection{Indicator Evaluation}

\section{a) João Pessoa}

\section{Baseline Scenario}

For the tropical case study of João Pessoa unfortunately no groundwater flow simulations could be conducted due to difficulties within the course of the BRAMAR research project. This is most unsatisfying since the application of a groundwater flow model for the Jericho-Auja case study revealed many advantages of such a tool and resulted, by means of man iterations, in a better understanding of the water resources system, the interaction of all components and finally the development of many more IWRM and MAR strategies and, most important, a first verification of 
the suitability of potential MAR locations. The following indicator evaluation could only be conducted with the numerical results of the groundwater budget assessment from Chapter 4.6.

Figure 4-77 summarizes the results for the BL Scenario. The performance of each strategy under the scenario has been normalized on a scale from 0-1. Normalization has been conducted with the same thresholds for all three scenarios in order to allow for a direct comparison between scenarios. On the left these values are listed and illustrated by bars. On the right a radar chart serves the purpose of illustration and comparability of performance. The outermost line represents the ideal value 1 . The relatively ideal solution would therefore follow the outline of the outermost pentagon.

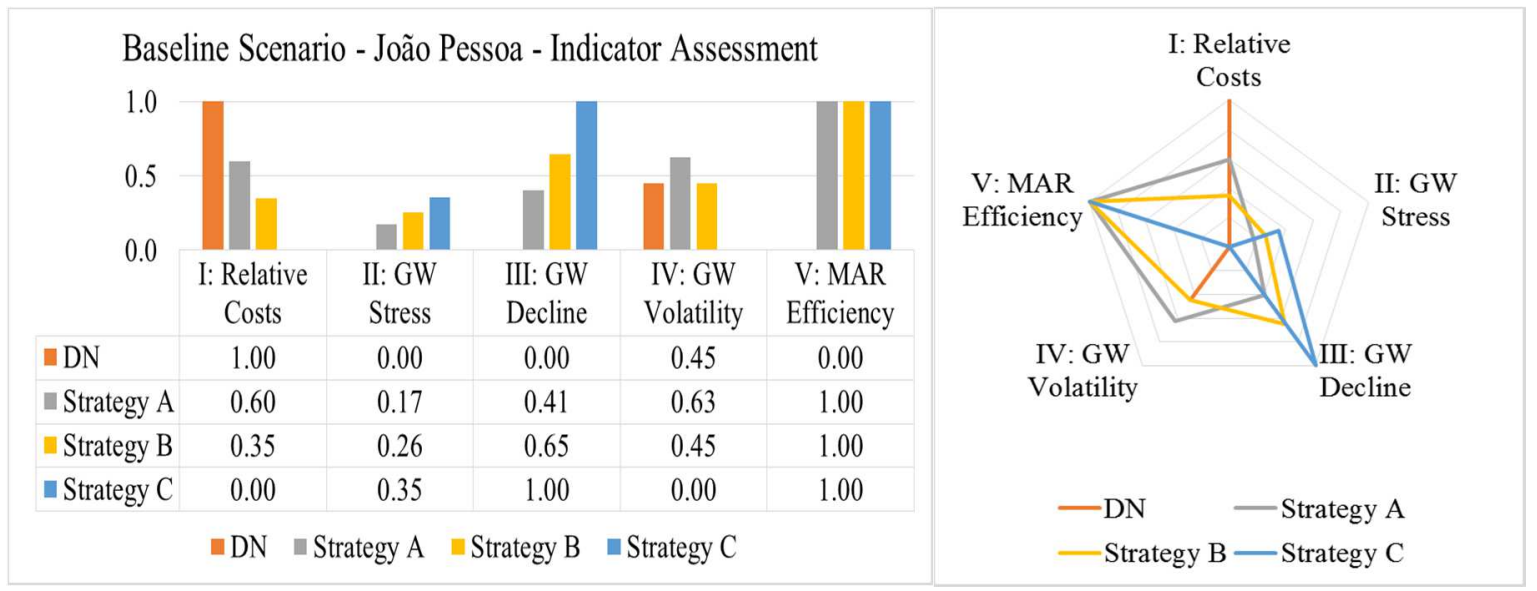

Figure 4-77: Indicator assessment Baseline Scenario -João Pessoa.

Results show a quite diverse performance by the three strategies. The corresponding DN approach is represented too. For the first indicator, relative costs, the DN achieves the highest relative rating since it does not create any costs. At the same time it does not create any benefits, well represented in the other indicators. Since the strategies are designed in a way that each one builds up on the other, as has been stressed before, the relative costs increase as well. This does not mean that the strategies are not cost-efficient. This would require a complete cost-benefit analysis that is highly recommended but cannot be performed within the course of this thesis. Indicator I merely states that, purely by costs, the do nothing approach is the cheapest and Strategy C, including the implementation of large MAR facilities with capacities of up to $3.6 \mathrm{MCM}$ per month and the modernization of irrigation networks is the most expensive.

Indicator II represents the stress on the groundwater. Results show that Strategy C outperforms the others. The amount of additional recharge decreases groundwater stress significantly. The same goes for Indicator III on groundwater decline. Groundwater volatility, expressed in Indicator IV gives a contrasting result. Only Strategy B, the combination of MAR and the reduction of irrigation water losses, appears to have a beneficial effect on volatility in the relative comparison for the BL Scenario. 
Strategy $\mathrm{C}$, with the otherwise highest performance due to the high supply of additional water to the groundwater, has the worst relative performance. Groundwater levels seem to variate stronger around their mean value as a result of the increased recharge. If the overall mean groundwater level is still higher than for the other strategies, this must not necessarily be interpreted as a negative result. Similar to the relative costs indicator, results must be seen as a whole and in context. A high volatility means only that the groundwater underlies stronger fluctuations around its mean value. If the mean groundwater level is generally higher than for the other strategies, then that circumstance will weigh higher in the final ranking, according to the priorities of the decision makers and stakeholders.

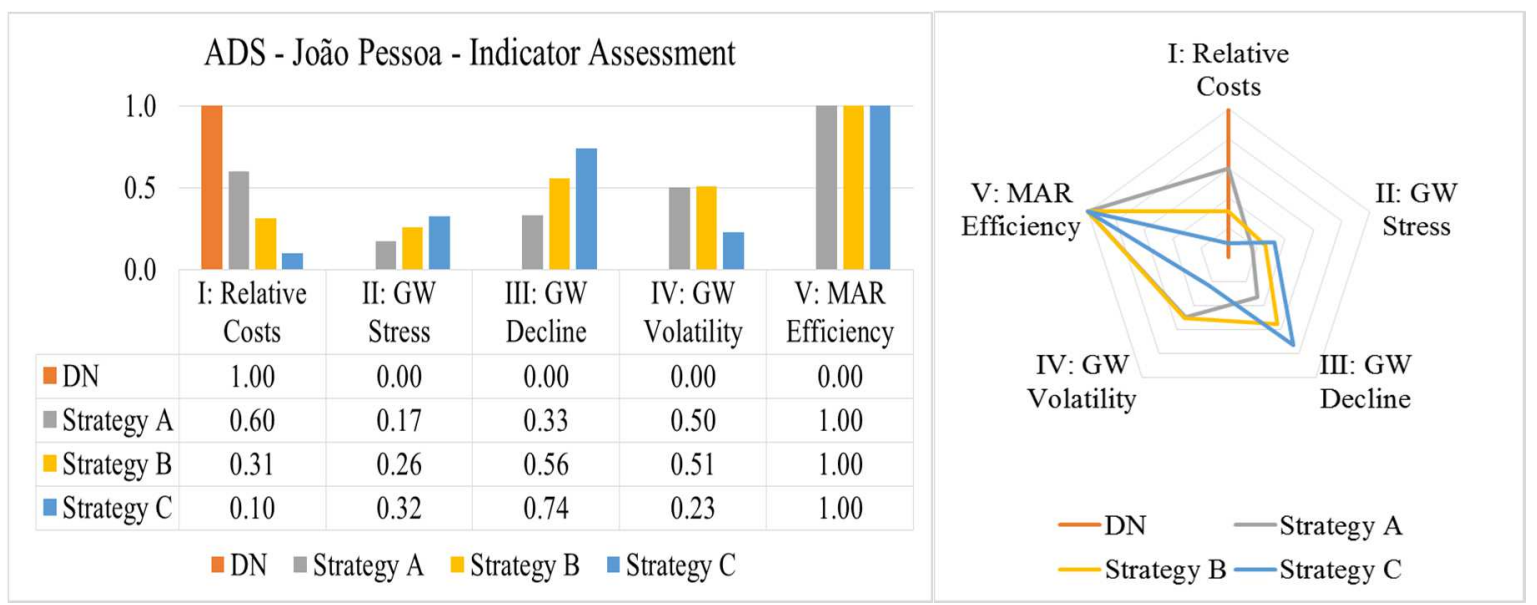

Figure 4-78: Indicator assessment ADS -João Pessoa.

The evaluation for the Agricultural Development Scenario (ADS) is given in Figure 4-78. The approach is the same as for the prior scenario, all values are normalized to the same thresholds, with a value of 1 representing the individual ideal solution. Results for Indicator I did not change, since the amount of additionally activated water volumes, which are the basis for this calculation of this indicator, do not change from scenario to scenario. The most obvious difference in relative performances occurs for Indicator IV. In contrast to the BL, Strategy C performs actually better than the DN approach. Although Strategies A and B still outperform C by far, Strategy C outperforms the others with regard to the general groundwater level decline represented in Indicator III. As before, Indicator $\mathrm{V}$ is 1 for all strategies due to the nature of the groundwater budget assessment that these results are based on. Since the budget calculation assumes that all additional volumes are available and contribute to the budget, the efficiency is set as 1 per default. Simulations by means of groundwater modelling are required to analyze this indicator.

Finally the relative performances of the Dry Climate Scenario are presented in Figure 4-79. As before there was no change for the relative costs and very limited changes in Indicators II and III. Indicator 
IV, however, shows a strong increase in relative performance for Strategy C, now outperforming Strategy A, but not reaching the level of supply safety of Strategy B.

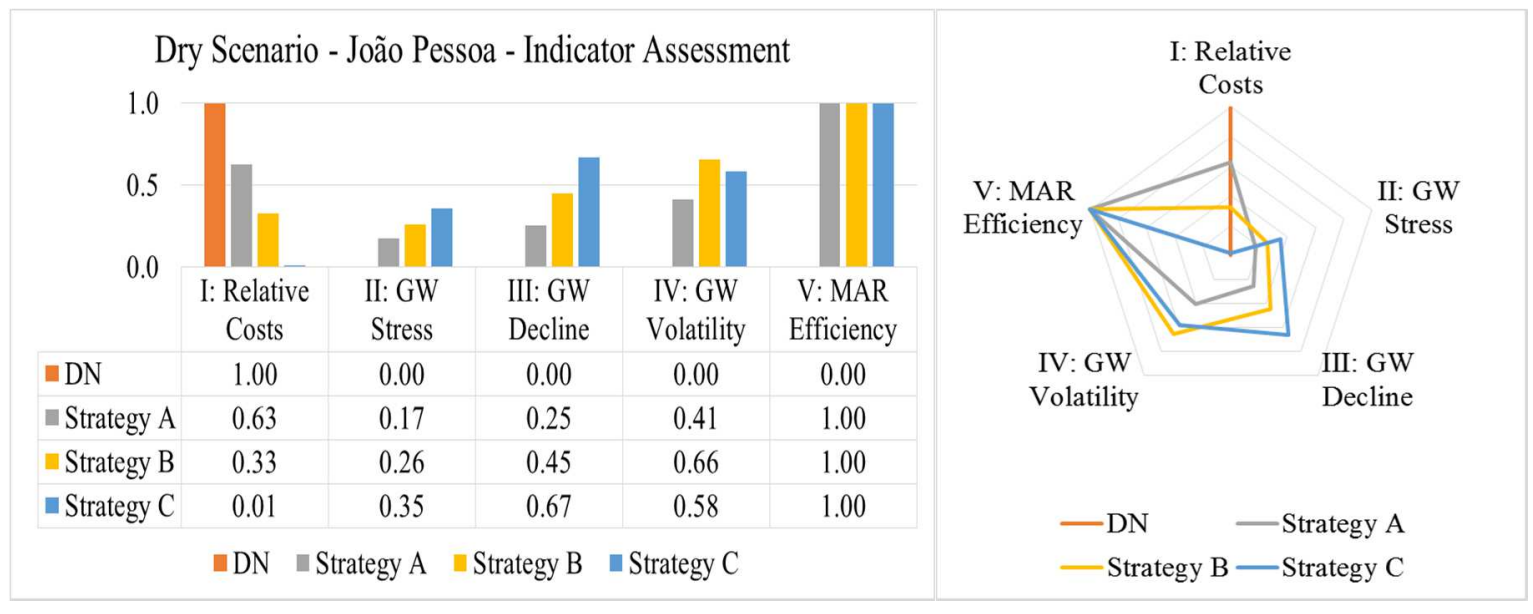

Figure 4-79: Indicator assessment Dry Scenario -João Pessoa.

\section{b) Jericho-Auja}

\section{Baseline Scenario}

For the semi-arid case study of Jericho-Auja also groundwater simulations could be conducted, improving both the variety and performance of the developed strategies by repetitive improvement in many iterations. The results presented and discussed here are based on the simulations, since groundwater budget calculations are mainly an intermediate step to get from the conceptual planning to the application of a groundwater flow model.

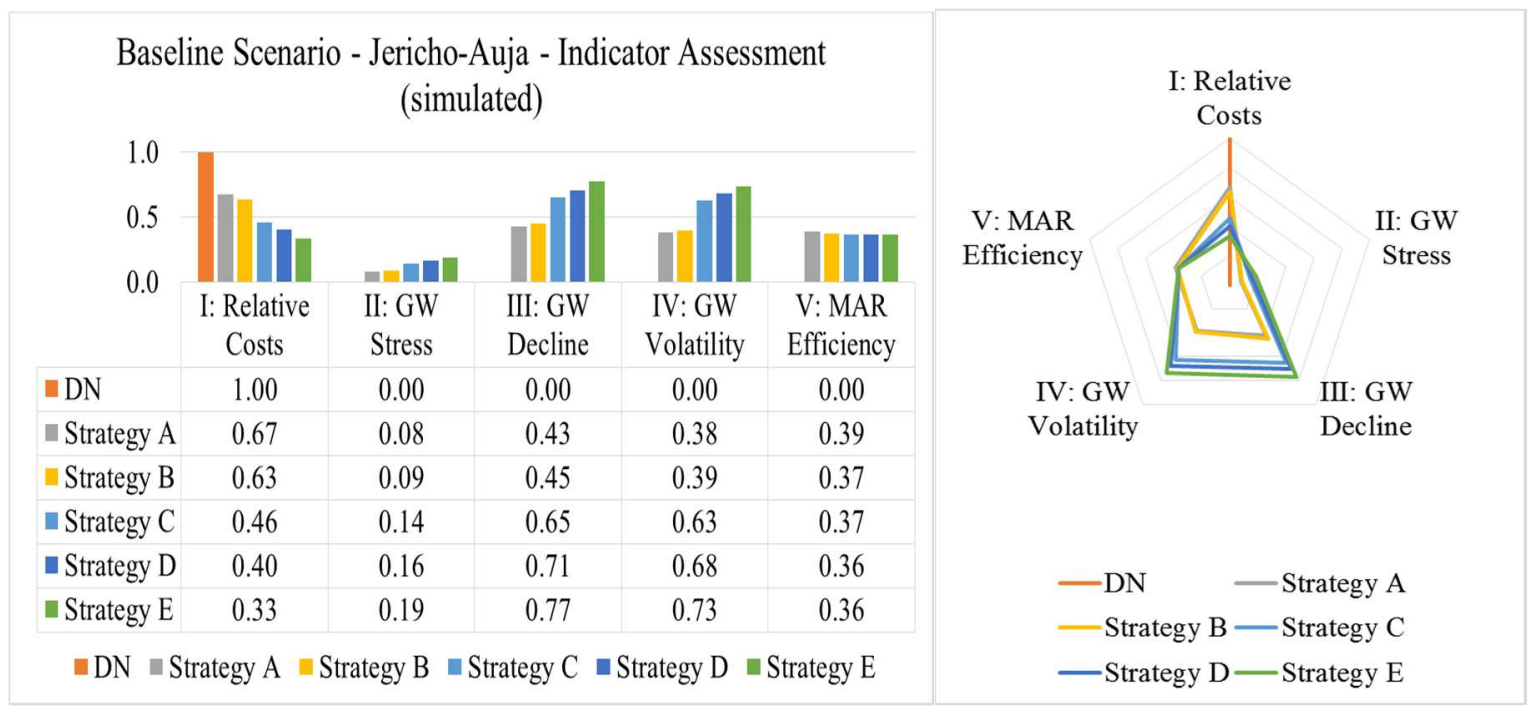

Figure 4-80: Indicator assessment Baseline Scenario -Jericho-Auja. 
Figure 4-80 gives the results for the BL Scenario. Since the underlying methodology is the same for both case studies, also in this case the relative costs become higher, thus the respective Indicator I lower, with every additional IWRM measure introduced to the strategies. For the BL Scenario the performance of Strategy E, utilizing all available local water sources plus an extra import of treated effluent from the city of El Bireh, was deemed sufficient to achieve satisfying results for the study area. In contrast to the tropical case study of João Pessoa, it also outperforms the other strategies in groundwater volatility, Indicator IV. A significant improvement in overall performance can already be observed in the step from Strategy B to C, introducing the implementation of additional deep wells, penetrating the underlying deep aquifer.

Analyzing the results it may be questioned why the strategies are developed as stepwise improvements of each other rather than individual strategies that can be compared as alternatives. The iterative analysis of potential actions revealed that a parallel comparison of isolated measures will never lead to a satisfying performance with regard to the fixed development goals of the case study. As for Jericho-Auja, water plans foresee the extension of agricultural lands, for both economic and political reasons. But regardless of the motives, if local stakeholders, decision makers and authorities have set goals for the local development, it should be the task of the water resources manager to show ways of achieving these goals. In this study it was tried to show what might be possible and feasible under activation of all local water resources. The results can be used to either calculate backwards the maximum volumes of irrigation volumes that can be planned with, respectively the maximum area of land that could sustainably be irrigated, or calculate the amount of water that would have to be additionally imported to the region to fulfill the set goals. In accordance to the objectives of this study, the second possibility was chosen. That is why the strategies build up on each other, in an order that is assumed to be the most logical with regard to practicability. Finally Strategy $\mathrm{F}$ is introduced, revealing the required additional volumes of water for the region. Hence the idea behind this assessment is to show the high gap between what is possible with local resources and what might be accomplished by importing additional water from a yet unknown source, described as scenario $\mathrm{F}$.

Scenario $\mathrm{F}$ is introduced for the ADS. The indicator assessment results are summarized in Figure 4-81. Results show a strong variation in Indicator V, the MAR efficiency. This indicator could not accurately be addressed for the prior case study due to the lack of a groundwater flow model. These results underline the impact of groundwater dynamics that cannot be accounted for by mere budgeting. In contrast to the prior case study, both groundwater levels and volatility perform better with every step of implementation. This can be explained again by groundwater dynamics. The additional recharge via MAR is very local. The effect on the overall groundwater level is therefore not that extreme during an episode of recharge: The water will require some time to evenly distribute 
over the area, buffering the effect on groundwater level. Within the budget calculations on the contrary, the added quantity to the groundwater is immediately accounted for as a rise in the budget, resulting in an apparently high volatility of the groundwater level. The results for the Dry Scenario are overall very similar in performance to those of the ADS (Figure 4-82). With the exception of Indicator V; MAR Efficiency. It seems that with the very high pressure that the scenario puts on the water resources system, the overall efficiency of any MAR measure increases.

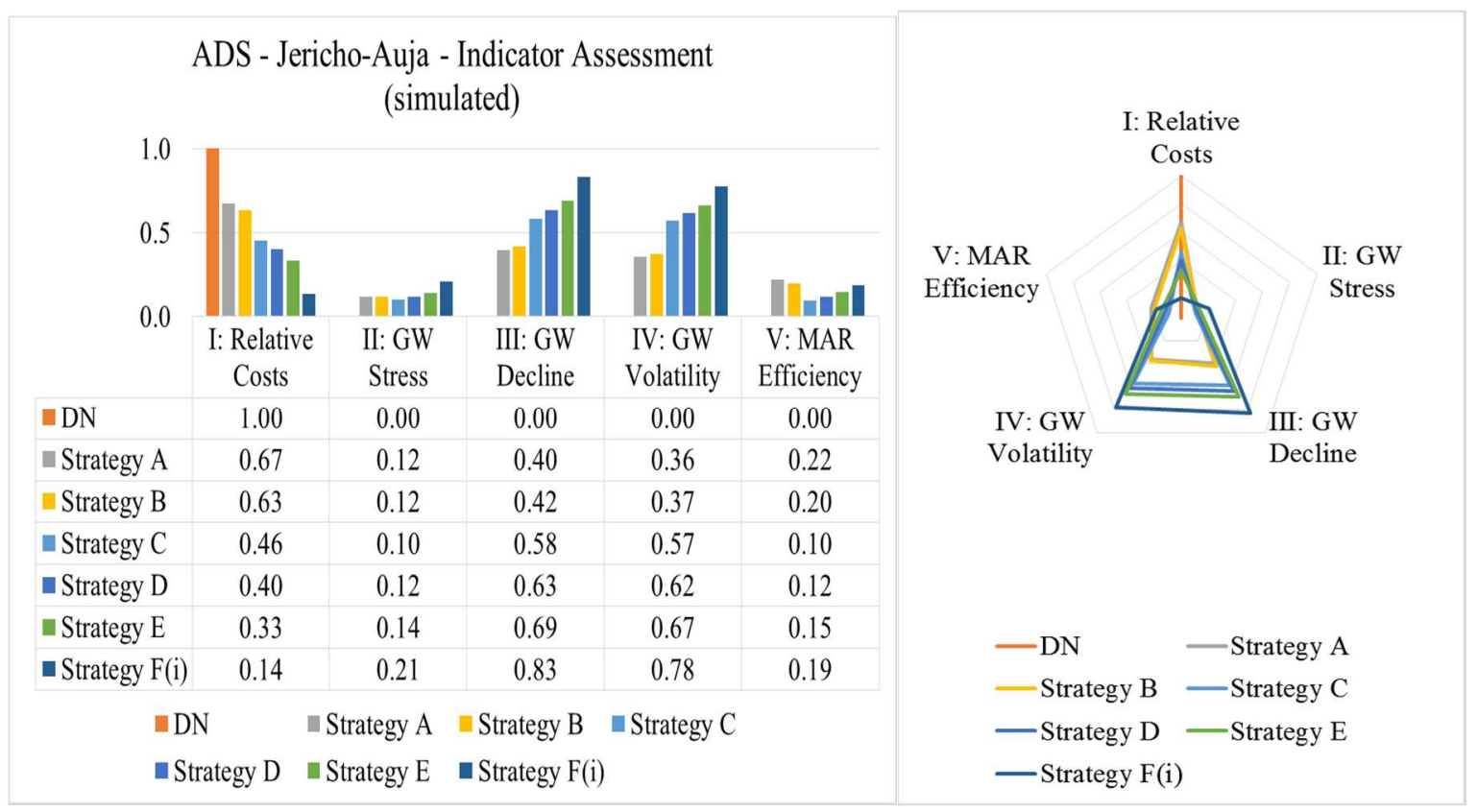

Figure 4-81: Indicator assessment ADS -Jericho-Auja.

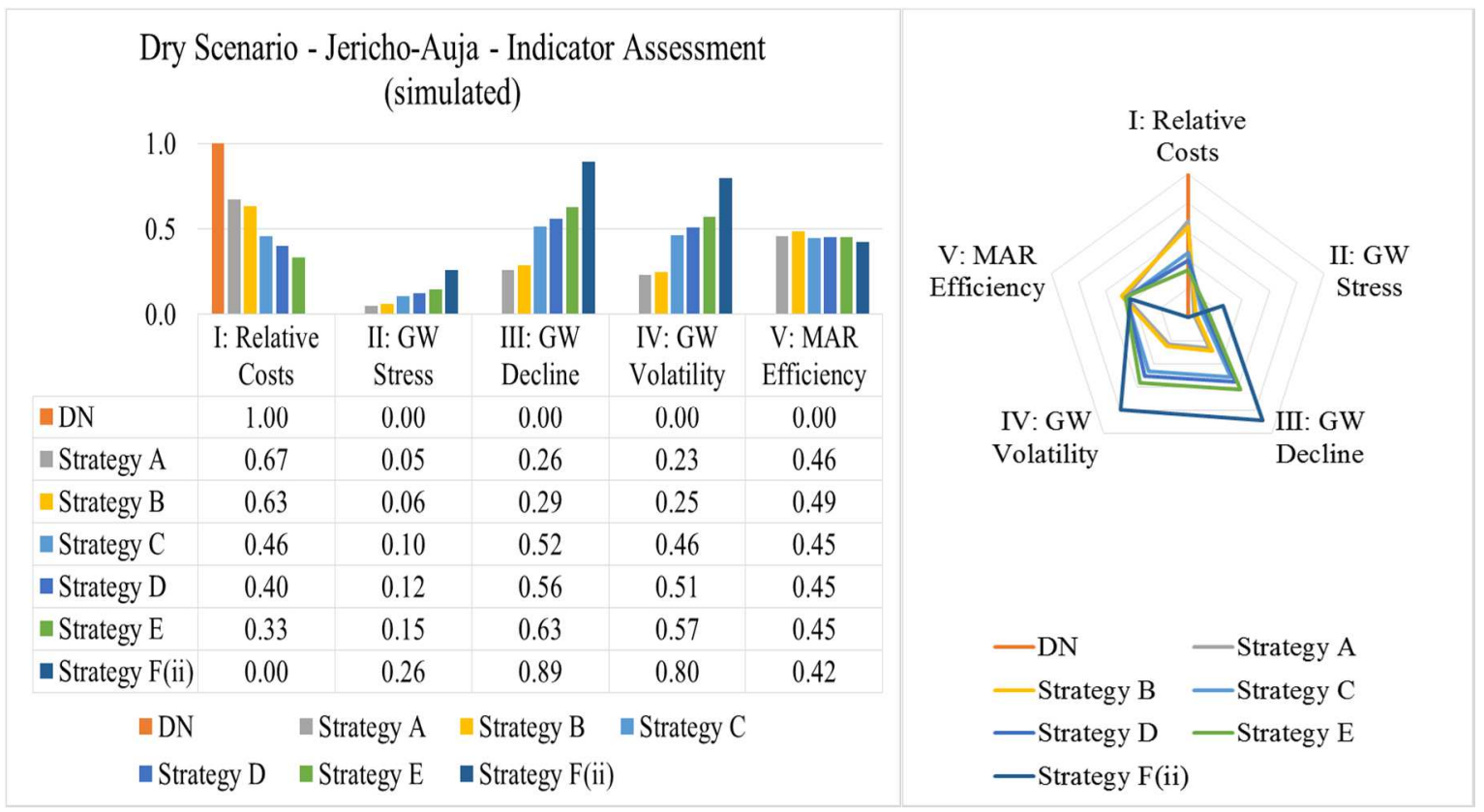

Figure 4-82: Indicator assessment Dry Scenario -Jericho-Auja. 


\subsubsection{Performance Matrices and Ranking of Strategies}

\section{a) João Pessoa}

In this section the results of prior indicator assessment are summarized and an overall ranking conducted. It should be kept in mind that the application of the suggested MAR planning process for the two case studies is mostly for demonstration purposes and to check the applicability of the approach. The thesis does not compare alternative strategies but rather different levels of development. Therefore, it is not surprising that the strategy that represents the highest level of water management implementation also receives the highest ranking. The difference in relative performance of the strategies however, does reflect the performance of each measure that is added from one strategy to the next. Not the absolute final value of this assessment, but rather the relative distance between total performance points is of the highest interest. The assessment can help identifying both, the overall performance of a combined strategy and the individual performance of a single measure at the same time. Figure 4-83 and Table 4-23 summarize the final results of this assessment. The overall performance has been calculated by means of a weighted average. For the weighting some random values have been selected for illustration. All indicators have been weighted similar with $15 \%$, except for the overall development of the groundwater table, represented by Indicator III, which has been accounted for with $40 \%$ to set a focus on the sustainable management of the groundwater.

Table 4-23: Performance matrix -João Pessoa

\begin{tabular}{|c|c|c|c|c|c|c|}
\hline Indicator & I & II & III & IV & $\mathbf{V}$ & Total \\
\hline Weighting & $15 \%$ & $15 \%$ & $40 \%$ & $15 \%$ & $15 \%$ & $100 \%$ \\
\hline \multicolumn{7}{|l|}{ Strategy A } \\
\hline $\mathrm{BL}$ & 60 & 17 & 41 & 63 & 100 & 52 \\
\hline ADS & 60 & 17 & 33 & 50 & 100 & 47 \\
\hline Dry & 63 & 17 & 25 & 41 & 100 & 43 \\
\hline Mean & 61 & 17 & 33 & 51 & 100 & 48 \\
\hline \multicolumn{7}{|l|}{ Strategy B } \\
\hline $\mathrm{BL}$ & 35 & 26 & 65 & 45 & 100 & 57 \\
\hline ADS & 31 & 26 & 56 & 51 & 100 & 53 \\
\hline Dry & 33 & 26 & 45 & 66 & 100 & 52 \\
\hline Mean & 33 & 26 & 55 & 54 & 100 & 54 \\
\hline \multicolumn{7}{|l|}{ Strategy C } \\
\hline $\mathrm{BL}$ & 0 & 35 & 100 & 0 & 100 & 60 \\
\hline ADS & 10 & 32 & 74 & 23 & 100 & 54 \\
\hline Dry & 1 & 35 & 67 & 58 & 100 & 56 \\
\hline Mean & 4 & 34 & 80 & 27 & 100 & 57 \\
\hline
\end{tabular}

The results show that Strategy C outperforms the other strategies only by a few percentage. The DN is not represented here since it is the basis of comparison and only outperforms the others in terms of relative costs. Overall the results show that a MAR implementation in the study area would bring huge benefits with regard to groundwater stress, volatility and depletion. But the difference between the three stages of development for the combined IWRM and MAR strategies is not that significant. Under assumption of the BL Scenario, the implementation of MAR, without any further IWRM 
measures, will bring a sufficient improvement to the region as could be shown in the above studies. With the aid of a groundwater flow model these results could have been demonstrated and even improved much more.

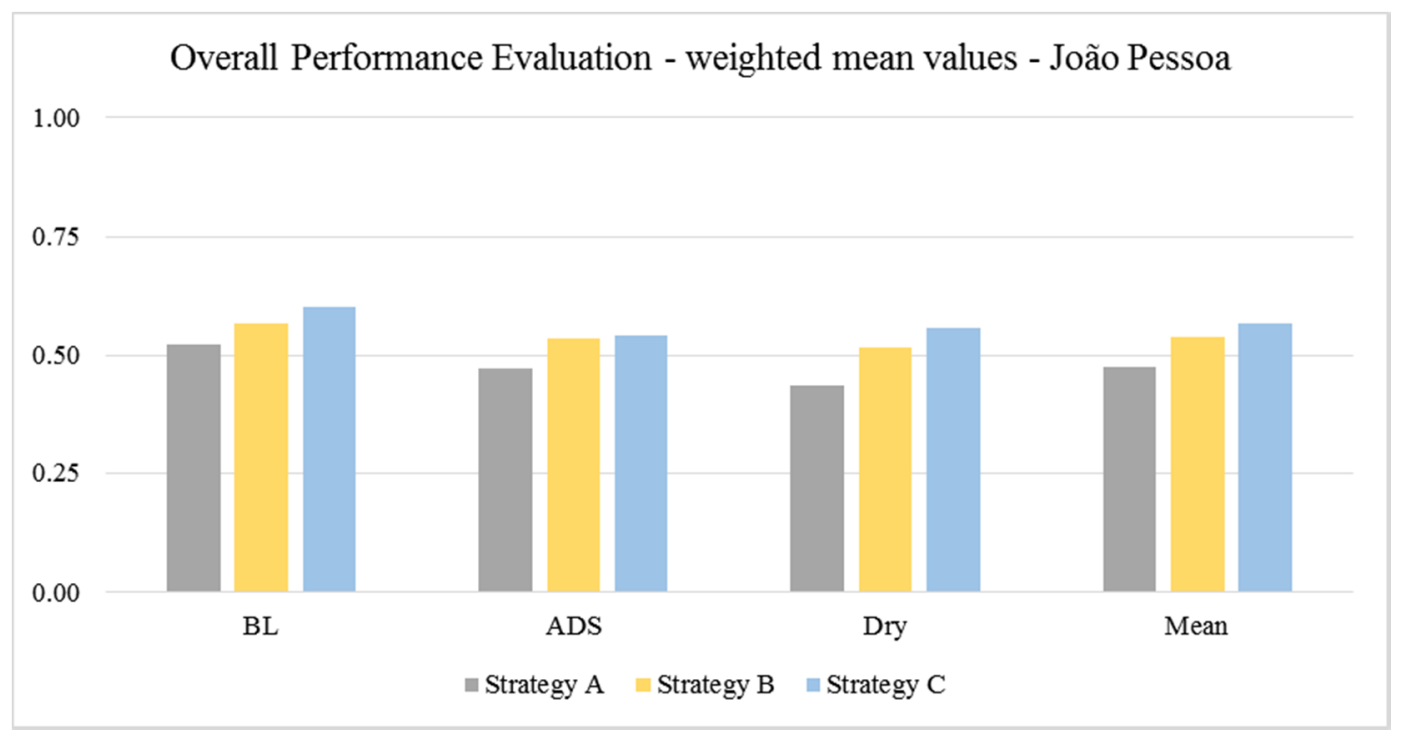

Figure 4-83: Overall performance of strategies -João Pessoa.

\section{b) Jericho-Auja}

The variety of strategies analyzed for the semi-arid case study of Jericho-Auja resulted in much more differentiated performance values as shown in Figure 4-84 and Table 4-24. The weighting of indicators has been set in the same manner as for the other case study to again allow for comparison. As before the general benefit of MAR implementation becomes clear, given by the relative performance value of Strategy A with an overall rating of $36 \%$. The step to the next stage, Strategy $\mathrm{B}$, is only $1 \%$, indicating that the additional harvest of surface runoff, which is the potential innovation suggested by Strategy B, would not bring much of an overall benefit to the region. Very much in contrast to the implementation of deep wells. Strategy C performs with $45 \%$, making a visible leap from the former strategies. This indicates the value and importance of additional wells in the study area as a key measure for IWRM.

The analysis also revealed that without additional water imports to the area, the desired extension of agricultural land is not feasible, even under consideration of all other sources, including deep wells. To sustain the groundwater regime against drought periods at least $10 \mathrm{MCM}$ of annual import would be required as is assumed in Strategy F for the Dry Climate scenario. 
Overall Performance Evaluation - weighted mean values - Jericho-Auja

1.00

0.75

0.50

0.25

0.00

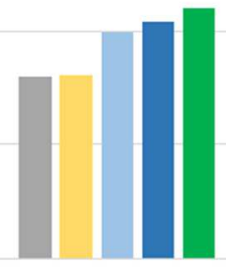

BL

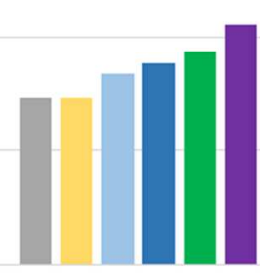

ADS

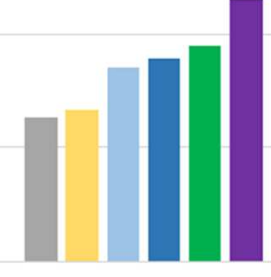

Dry

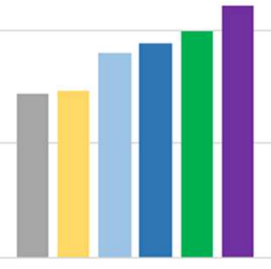

Mean

$\square$ Strategy A $\quad$ Strategy B $\backsim$ Strategy C $\backsim$ Strategy D $\square$ Strategy E $\backsim$ Strategy F

Figure 4-84: Overall performance of strategies -João Pessoa.

Table 4-24: Performance matrix -Jericho-Auja

\begin{tabular}{|c|c|c|c|c|c|c|}
\hline & I & II & III & IV & $\mathbf{V}$ & Total \\
\hline Weighting & $15 \%$ & $15 \%$ & $40 \%$ & $15 \%$ & $15 \%$ & $100 \%$ \\
\hline \multicolumn{7}{|l|}{ Strategy A } \\
\hline BL & 67 & 8 & 43 & 38 & 39 & 40 \\
\hline ADS & 67 & 12 & 40 & 36 & 22 & 37 \\
\hline Dry & 67 & 5 & 26 & 23 & 46 & 32 \\
\hline Mean & 67 & 8 & 36 & 32 & 36 & 36 \\
\hline \multicolumn{7}{|l|}{ Strategy B } \\
\hline $\mathrm{BL}$ & 63 & 9 & 45 & 39 & 37 & 40 \\
\hline ADS & 63 & 12 & 42 & 37 & 20 & 37 \\
\hline Dry & 63 & 6 & 29 & 25 & 49 & 33 \\
\hline Mean & 63 & 9 & 39 & 34 & 35 & 37 \\
\hline \multicolumn{7}{|l|}{ Strategy C } \\
\hline $\mathrm{BL}$ & 46 & 14 & 65 & 63 & 37 & 50 \\
\hline ADS & 46 & 10 & 58 & 57 & 10 & 42 \\
\hline Dry & 46 & 10 & 52 & 46 & 45 & 43 \\
\hline Mean & 46 & 12 & 58 & 55 & 30 & 45 \\
\hline \multicolumn{7}{|l|}{ Strategy D } \\
\hline $\mathrm{BL}$ & 40 & 16 & 71 & 68 & 36 & 52 \\
\hline ADS & 40 & 12 & 63 & 62 & 12 & 44 \\
\hline Dry & 40 & 12 & 56 & 51 & 45 & 45 \\
\hline Mean & 40 & 14 & 63 & 60 & 31 & 47 \\
\hline \multicolumn{7}{|l|}{ Strategy E } \\
\hline $\mathrm{BL}$ & 33 & 19 & 77 & 73 & 36 & 55 \\
\hline ADS & 33 & 14 & 69 & 67 & 15 & 47 \\
\hline Dry & 33 & 15 & 63 & 57 & 45 & 48 \\
\hline Mean & 33 & 16 & 70 & 66 & 32 & 50 \\
\hline \multicolumn{7}{|l|}{ Strategy F } \\
\hline $\mathrm{BL}$ & - & - & - & - & - & - \\
\hline ADS & 14 & 21 & 83 & 78 & 19 & 53 \\
\hline Dry & 0 & 26 & 89 & 80 & 42 & 58 \\
\hline Mean & 7 & 23 & 86 & 79 & 31 & 55 \\
\hline
\end{tabular}




\subsection{Conclusions for MAR Implementation in the Case Studies} (Step 9: Recommendations for MAR Pilot Plants)

\subsubsection{Concept of MAR Pilot Plants}

The idea of MAR pilot plants, or test facilities, is to conduct long term field experiments based on the theoretical analyses in order to confirm or reject and consequently improve the concepts of MAR implementation in reality. They should be designed in a way that they represent the suggested approach, if necessary on a smaller scale, ideally already in full scale. Basically they are infiltration tests over a long period of time with a corresponding monitoring network that allows for evaluation of the experiments. The pilot plants should be located at or close to one or more of the suggested sites and operated according to the specific parameters used for this study. Ideally they should cover several years with a variation of hydrologic conditions. By constant re-evaluation the test facilities should provide new data to this planning process leading to more sophisticated solutions in the integrated IWRM and MAR planning. In parallel the experiments would result in better understanding of the local groundwater system and its hydrogeological characteristics to help develop or improve groundwater flow and transport models.

In the following for each of the two case studies suggestions are given for several aspects of the pilot plants based on the accumulated results of this study. The parameters include source of water for MAR, location of the pilot plants, technology to test, pre-treatment measures to consider, how the plants should ideally be operated and how the whole experiment should be monitored to obtain valuable results.

\subsubsection{Source of Water}

\section{a) João Pessoa}

The study revealed surface runoff from the rivers as the only sensitive option for MAR in the case study of João Pessoa. The vast runoff quantities during the rainy season show a major potential for aquifer recharge during the wet season. The dry season is characterized by limited surface runoff which mainly consists of groundwater leaving the system through the streams. Part of that water can be re-infiltrated by MAR, if sufficient runoff is available. The extractions from the rivers must always be considered in order to prevent water deficits downstream. Therefore, the assumptions made in this study limit the volumes of water extracted from the rivers in two ways. On the one hand there must at any time be enough water in the rivers left. On the other hand the capacity of potential MAR facilities, especially when considering surface infiltration measures, limit the volumes of potential recharge. 
Treated waste water was also considered an additional water source for MAR, to be used via an SAT system. Studies with secondary treated waste water from the area were conducted in the BRAMAR project, using soil column tests to check for the potential of natural attenuation under local conditions in the unsaturated zone (Da Silva, 2016). The result where not satisfying, revealing a high demand of additional pre-treatment measures if the local waste water resources should be considered for a sustainable MAR application. In addition, the available runoff volumes in the local rivers are sufficiently high, so that this additional source of water would only have limited impact on the system. Furthermore, an unknown yet presumably high amount of this insufficiently treated waste water already infiltrates uncontrolled into the aquifers. To protect the groundwater it should be considered turning this Unmanaged Aquifer Recharge into a proper MAR system. But with regard to quantities and impact on the budget, this study came to the conclusion that this potential source of water can be dismissed for the case study.

To conclude, the suggested MAR pilot plants should be fed with water from the rivers during the rainy season and other months of sufficiently high discharge accounting for water extraction downstream the point of withdrawal.

\section{b) Jericho-Auja}

For the semi-arid of Jericho-Auja, surface runoff is not available in abundance. Rather it is a scarce resource. As the analysis showed, the most abundant source of water is the spring discharge from numerous local springs, being fed from the aquifer that receives its recharge in the mountain area. This source, besides the, at present, overexploited shallow alluvial aquifer, is the main supplier of water to the region today. The study showed that numerous potential new sources could be activated. Among these are, most importantly, the installation of additional wells that pump water from the deep aquifer. Also an increased harvesting of the scarce surface runoffs, mostly occurring in flash flood events, has been considered, together with the enhanced reuse of treated effluent from local sources and the city of El Bireh in the mountains. Finally the study revealed that, in order to be able to satisfy the growing agricultural irrigation demand, if the region develops according to the water plans, additional imports from outside the study area must be considered. All these additional sources shall not be used directly for MAR purposes. Rather they are supposed to become part of the local water management and support a re-allocation of water resources. It is the spring discharge that should actually be used for MAR according to this study. All other new sources should only lower the water demand of agriculture, domestic, industry, livestock and other sectors.

For a potential pilot plant it will be difficult to use spring discharge as a source, since water resources are scarce for the moment. From a social standpoint it might also be difficult to receive support from 
local farmers in a semi-arid region for purposely allowing valuable water to freely infiltrate the ground. The pilot plant should therefore be considered to be implemented in combination with another of the suggested IWRM measures to supply additional water to the region in parallel to conducting the experiment. The installation of a deep well is highly recommended to accompany the pilot plant.

\subsubsection{Location}

\section{a) João Pessoa}

By iterative analysis of groundwater budgets and comparison of different strategies on a spatial scale according to the delineated Management Units (MUs), a total number of seven locations have been identified to be operated with MAR facilities in parallel. This decentralized approach is mainly a result of the size of the study area with its more than $1,000 \mathrm{~km}^{2}$ and the strong interaction between ground-and surface water bodies. The main rivers are all perennial streams: They are connected to and fed by the groundwater. For groundwater management via MAR this means a sufficiently high distance to the rivers is required in order not to lose most of the artificial recharge directly do the next stream. The rivers act as boundaries for groundwater flow and thus separate the groundwater into different compartments.

For the installation of MAR pilot plants at least two different locations should be tested in parallel. Since no groundwater flow model could be applied to the study area, no precise locations can actually be recommended. The selection of test sites should therefore orientate on the preliminary site selection illustrated in Figure 4-37. It is recommended to install one test facility within the rural area and one within the urban district of João Pessoa. Due to land use, costs and infiltration capacities, the study recommends the installation of infiltration ponds within the rural area and the parallel installation of injection wells in the urban area. Therefore, the recommendation is to conduct long term tests by means of MAR pilot plants in both areas, putting both technologies to the test.

Of course the selected locations must fulfill the objectives and criteria of the site selection presented in this study: sufficient distance to the next river and to the groundwater table, low slope, preferably no agriculture, etc.

\section{b) Jericho-Auja}

For Jericho and Auja a total of three locations for potential MAR facilities have been selected and evaluated by means of groundwater flow simulations: one in the village of Auja and two in the city of Jericho. The approximate locations are illustrated in Figure 4-38. The locations have been selected 
since they are close to the main agricultural areas and along potential transport paths for the spring discharge following the topography of the area.

It is recommended to implement at least one MAR pilot plants in either of the two municipalities to conduct a longtime experiment. The implementation of a MAR pilot plant will have to address several challenges. For local support of such an enterprise, which is of very high importance in any IWRM project, additional water should be supplied in parallel. Based on the data analyzed for this study, the village of Auja would be better suited to implement the pilot plant. It could be combined with the local Auja dam, maybe by using the dam as a basis for the infiltration ponds and enhancing the captured water with spring discharge, since the dam is only filled during storm flood events. The dam is located about $1 \mathrm{~km}$ west, upstream, of the suggested location.

\subsubsection{Technology}

\section{a) João Pessoa}

The area would be suitable for the use of infiltration ponds. These require comparatively big areas. Land for these ponds would have to be bought for expectedly high prizes, since some of the suggested locations are cultivated with valuable sugarcane. One potential alternative would be dug wells, which are already used in some parts of Northeast Brazil. These passive wells allow rather high infiltration rates with significantly lower demand for surface area. In addition, especially close to or within the urban area, active injection via pumping wells into the aquifer would be possible. The recommendation is to design pilot plants for both technologies, surface infiltration and direct injection. A test facility in the rural area could be implemented in cooperation with a local farmer. The required land could be leased from the farmer. The location should require the possibility to connect it to the nearest main river, ideally not crossing other farmers' land. Two small infiltration ponds could be installed in parallel. One might be additionally equipped with a passive infiltration well as described above to allow for higher infiltration rates.

The second facility should be implemented in the urban district of João Pessoa, using active injection wells. This pilot facility will require higher investment costs, since it will rely on the drilling of a new well and active pumping and injection under high pressure directly into the aquifer. Also this second facility will require higher pre-treatment measures than a simple infiltration pond for the surface runoff water would directly be injected to the ground, increasing the risk of groundwater contamination. Both technologies and locations require the extraction of surface runoff from the nearest river and transport to the MAR sites. For this purpose a small pipeline would have to be installed and equipped with a pump. The entire facility and its hydro-infrastructure arises a need for protection against thievery and vandalism, as experience in the study area showed. It might also be 
possible to test bank filtration as a MAR technology. This measure increases the recharge from the river directly into the aquifer, e.g. by pumping and creating a stronger hydraulic gradient away from the river. It will be required to run elaborated cost analyses and intense research for exact feasible locations to install the test facilities. According to site specific parameters it must be decided which technology might best be suited to the location.

\section{b) Jericho-Auja}

With regard to the scarce land use in the study area and the comparably low volumes of required, or rather available, recharge water, simple infiltration ponds would suffice to conduct the experiment. Land would presumably be available for rather low costs and the low recharge volumes do not require much area for infiltration. Basically the recommendations regarding infiltration ponds are the same as for the rural area of the tropical case study. If possible, two infiltration ponds should be operated in parallel, allowing for maintenance of one pond while the other is operated. In addition, the enhancing effects of a passive infiltration well to increase infiltration rates could be tested in the facility. Direct injection would not be required to be tested in the study area, since the potential volumes for recharge are not that high and the surface reveals a very high potential for passive infiltration. The issue of evaporation losses from the ponds requires further assessment.

\subsubsection{Pre-Treatment}

\section{a) João Pessoa}

Unfortunately it was not possible within this study to conduct actual water quality assessments or the monitoring of water quality parameters. The evaluation presented here as an exemplary application of the newly developed planning process focusses purely on quantitative aspects of integrated water resources management. Therefore, only assumptions could be made with regard to required pretreatment measures for potential recharge water in the case study. In general it can be assumed that surface runoff contains a large amount of suspended solids. These inevitably would lead to clogging in recharge facilities, a very common and widespread issue in MAR. The effect of clogging cannot fully be avoided and requires constant maintenance of the recharge facilities. Nevertheless, the effect can be reduced by pre-treatment measures such as settling pits. These are small basins in which the recharge water is stored for some time, allowing the particles in suspension to sink to the bottom of the basin. Qualitative analyses of both, the rivers and the groundwater, must be conducted before the planning of MAR test facilities in order to identify the necessary level of pre-treatment in the case study of João Pessoa. 


\section{b) Jericho-Auja}

Most of the above is also true for the semi-arid Jericho-Auja case study. No qualitative analyses could be conducted. It is, however, known that large parts of the shallow alluvial aquifer show brackish conditions. This aspects requires further investigation and an adequate groundwater quality assessment. The spring discharge as water source for MAR is of good quality but in the past showed signs of E. coli contaminations. This aspect requires special attention in order not to contaminate the existing groundwater resources.

\subsubsection{Operation}

\section{a) João Pessoa}

The operation of the suggested test facilities in the João Pessoa study area must be adjusted to the water availability. Active management will be required. The volume of recharge or injection should sufficiently high in order to measure its impact. The individual facility might already be designed for the analyzed maximum capacity of $1.8 \mathrm{MCM}$ per month during the rainy season. The transport of these volumes from the rivers to the infiltration site would require a pipe of at least $40 \mathrm{~cm}$ width, assuming a steady flow of $5 \mathrm{~m} / \mathrm{sec}$. For an initiative site selection a minimum distance of $500 \mathrm{~m}$ from rivers was assumed. For sake of cost efficiency and assuming that the test facility would run with a lower capacity, this distance might be reduced. Anyway the operation will require a pump and pipe transport infrastructure and active regulation of the extraction rates from the river. For the budget calculations it has been assumed that a certain threshold of minimum river discharge must be left for downstream water supply. Maybe a suitable section of the river could be equipped with a weir that allows an automatic regulation of the amount of water that is extracted, presuming that a runoff curve is created for the site, allowing the quantification of runoff based on water level in the river. Finally, these question must be addressed by engineers in designing the test facility and is beyond the scope of this thesis. In general the operation of the test facilities should follow the idea of the presented budget calculations. Whenever there is sufficiently high discharge in the river, water should be extracted and infiltrated, respectively injected, at the test facility.

\section{b) Jericho-Auja}

Operation of a potential MAR pilot plant in the Jericho-Auja vicinity will also require flexible management of the facility. If spring discharge is used as recommended, it will be required to manage the water re-allocation similar to the João Pessoa case study. The existing management of the spring discharge for the Auja spring for example is based on a traditional system similar to time sharing. There are several farmers and families that own the right to a specific amount of time per day to direct the stream of spring discharge flowing through the channel in the direction of their farms (Walter, 2013). They apply as much water as possible to their fields and additionally store water in 
ponds. These ponds suffer from high evaporation losses. If possible, a potential MAR test facility may make use of this existing system and buy some time of water supply from one of the local farmers, while in parallel activate some additional water resources by means of deep well installation.

\subsubsection{Monitoring}

In addition to the above given recommendation for the implementation and operation of MAR test facilities, it is of key importance to monitor the experiments of both case studies. These recommendations are equally valid for both study areas and their respective experimental setups. A combination of groundwater level and quality measurements around the test site should be installed. The infiltrated or injected water should be diluted with a tracer substance. At least three observation wells should be placed around the infiltration site, creating a triangular. Another two observation wells are recommended groundwater downstream. All of these wells should monitor the groundwater level and, in adequate time steps, groundwater quality parameters with regard to the selected tracer. This way, a number of data can be obtained from the pilot plants. On the one hand the general feasibility of MAR can be confirmed, or falsified. On the other hand many aspects of potential benefits from MAR can be determined. Also, new information on the groundwater flow behavior and dilution processes can be gained. It is recommended to implement the monitoring some time before the actual MAR pilot plants start operation. This way the data obtained allows for an actual impact assessment similar to the theoretical do nothing approaches used in this study. Without proper monitoring, the installation of MAR pilot plants would be in vain. It is this data obtained by the monitoring network that will help improve, respectively develop, proper groundwater flow and transport models for the study areas and subsequently contribute massively to a proper planning of the MAR facilities. Following the suggested MAR planning approach that this thesis is based on, the results of these long term field experiments, which should run at least for 2-3 years, should serve the iterative improvement of the developed potential strategies of IWRM and MAR implementation.

\subsubsection{Outlook to Step 10: Technical MAR Feasibility Study}

The final step of the suggested MAR planning approach comprises the actual design, conduction, monitoring and evaluation of the long term MAR field tests with pilot plants as suggested in the prior section. Depending on the complexity of the specific case, this step could be an entire additional project. Designing a MAR facility, even on a small scale, would require the assistance of engineering expertise. This study, or rather the approach suggested in this study, can only supply the overall framework of the above described points from water source to monitoring. To implement these suggestions in the field will also require enhanced communication with local stakeholders, farmers, decision makers and authorities. Especially in rural areas such as in both of the case studies, the 
support by local communities can immensely benefit the project. That is why it is of such importance to plan and design the initial IWRM and MAR strategies in close cooperation with stakeholders and orienting them on their needs and future development plans. These field experiments should aim at reproducing the suggested MAR facility in a smaller scale. The time period of running and monitoring the experiment should cover some years. While the experiments are running, further iterative improvements should be conducted on the strategy development, on groundwater flow and transport models and the overall understanding of the system. The time could also be used to conduct workshops with locals and introduce the new technology to the farmers to increase social acceptance.

The suggested minimum monitoring requirements should also be extended to collect as many data on the water resources system as possible and not be restricted to the MAR pilot plant itself. To conclude the MAR feasibility study, a final formulation of recommendations is required. These recommendations should be backed with all of the analytical assessments conducted in all prior steps and an intense testing of the approach in the field by means of MAR pilot plants. It must be considered who to address with these recommendation before the research is finished. It has been addressed at many points throughout this thesis that stakeholder participation is key from Step 1 on. The recommendation should include all the points addressed by Step 9 - the recommendations for MAR pilot plants. Potential benefits but also challenges and limits of a MAR implementation must be given with full transparency of the process that lead to these recommendations. By knowing who the addressee of these recommendation will be, for example a ministry, a funding agency or a local authority, they can be formulated accordingly. The results of this thesis for instance are used to formulate policy briefs to local authorities in order to promote enhanced monitoring and the support for the implementation of MAR pilot plants by means of follow-up projects. 
AND

\section{DISCUSSION}




\subsection{Review of Objectives and Hypothesis}

In this chapter the initial objectives and the formulated hypothesis will be reviewed in order to evaluate the results of this thesis. The overall objectives of the studies were formulated in Chapter 2 :

1. Development of an overall, transferable and integrative MAR planning approach and application of the approach for both projects and their respective case studies,

2. Formulation of recommendations for the two case studies that aim to improve of the water resources situation under consideration of MAR and IWRM strategies.

The development of an overall integrative MAR planning approach has been thoroughly introduced in Chapter 3. The definition of most promising MAR planning options for the case studies João Pessoa and Jericho-Auja have been identified by applying the suggested planning approach and are given in the prior Chapter 4. The fulfillment of these objectives was coupled to the following research hypothesis, as presented in Chapter 2:

The suggested integrative MAR planning approach is transferable and generalized enough to be (a) successfully applied to two inherently different research areas and may serve as a guideline for similar studies, but also specific, effective and goal-oriented enough to successfully develop, test, compare and consequently (b) recommend combined MAR and IWRM strategies and additional measures for both case studies, that aim at the improvement of the local water resources system and the sustainable development of the respective region.

Whether the objectives have been met and the underlying hypothesis can be verified must finally be evaluated. The methodology is directly linked to the suggested MAR planning process itself, correlating with the first objective. By addressing the quality of findings, obstacles and advantages discovered by applying the method to the two inherently different case studies, its quality and general applicability is discussed. Secondly, the actual results with regard to the individual case studies and the resulting recommendations of MAR planning options are evaluated. Building on the prior findings, each step and its application for the individual case studies is discussed. It is important to identify problems that occurred and restrictions that can be concluded from this study. 


\subsection{Evaluation and Discussion of Methodology and Main Results}

\subsubsection{Step 1: Data Acquisition and Analysis}

The first step of the suggested approach is a general data acquisition and analysis of that data. It means that all data that is publicly available for the case study and has a relevance for the approach should be collected and reviewed first. This is a very basic step that should be trivial for the start of any research. Anyway, for sake of completeness and to allow for an evaluation of the methodology it must be listed. Table 5-1 summarizes and compares the main positive and negative remarks that can be made based on the application of the method to both case studies. The table, as the ones to follow, is color coded red and green for either negative or positive annotations. This template of evaluation sheet will be used for each of the steps to evaluate and discuss the main problems and benefits of the suggested MAR planning approach.

The table shows that especially for the case study João Pessoa quite a lot of data was not available, such as irrigation demand and others. Some data, such as actual groundwater and surface water extraction, are only available in terms of licenses, so called outorgas (English: grants, licences). Unfortunately these only give a coarse idea of the annual extraction of licensed wells and pumping stations. They completely lack a temporal discretization and the precision of actual monitoring data, such as water clocks. Other data, such as land use, required update. Fortunately the local partners in the BRAMAR project supplied any data acquisition activities. The most important measures, as have been introduced in this thesis, were the mutual planning and implementations of monitoring networks for surface runoff and groundwater levels. Without such a strong cooperation with the local partners this project could not have been conducted. At the beginning of the research though, trust had to be gained first. It was noticed that it is of major importance to be as transparent as possible in the evaluations that are conducted. Partners could hold valuable information and data back if they fear misuse of the data. This becomes especially difficult if most of the publications dealing with the study area are written in Portuguese, creating a dependency on local partners. Overall it can be said that in the João Pessoa case study a lot of effort by all project partners has finally lead to the beginning of a good database. Important impulses could be given, resulting in the introduction of long-term monitoring and field experiments. Unfortunately all these measure are both time and money consuming. In the case study it was not the lack of willingness or knowledge, but rather of funding that caused the severe lacks in data.

Regarding the second case study of Jericho-Auja, the data situation was little different. The SMARTMOVE project was the third project of its kind in ten years of research between more or less the same partners. A basis of trust had already been established and many investigations conducted. Hence, much more data was available from the beginning. Although it must be addressed that a lot of data that was finally work with is based on assumptions and estimations by the project partners. Therefore, 
a high degree of uncertainty must be assumed. The involvement of stakeholders was given at all times, guaranteeing a higher level of acceptance of the results produced.

Table 5-1: Evaluation Sheet for Planning Step 1

\begin{tabular}{|c|c|c|c|}
\hline \multicolumn{4}{|c|}{$\begin{array}{l}\text { Step 1: Data Acquisition and Analysis } \\
\text { Creation of a data basis }\end{array}$} \\
\hline \multicolumn{2}{|c|}{ João Pessoa } & \multicolumn{2}{|c|}{ Jericho-Auja } \\
\hline \multicolumn{4}{|c|}{ Task 1: Collection and Analysis of available Data } \\
\hline $\begin{array}{l}\text { - Domestic demand } \\
\text { - Industry demand } \\
\text { - Precipitation } \\
\text { - Climate data } \\
\text { - Hydrogeology }\end{array}$ & $\begin{array}{l}\text { - Irrigation demand } \\
\text { - Current land use } \\
\text { - GW pumping } \\
\text { - GW recharge } \\
\text { - GW levels } \\
\text { - Surface runoff } \\
\text { - SR extraction } \\
\text { - GW \& SR quality }\end{array}$ & $\begin{array}{l}\text { - Spring discharge } \\
\text { - Domestic demand } \\
\text { - Irrigation demand } \\
\text { - Land use } \\
\text { - GW recharge } \\
\text { - Surface runoff } \\
\text { - SR retention }\end{array}$ & $\begin{array}{l}\text { - Hydrogeology } \\
\text { - GW pumping } \\
\text { - GW levels } \\
\text { - GW \& SR quality }\end{array}$ \\
\hline \multicolumn{4}{|c|}{ Task 2: Identification of Data Gaps } \\
\hline $\begin{array}{l}\text { - Strong support by local } \\
\text { partners after trust was } \\
\text { gained }\end{array}$ & $\begin{array}{l}\text { - Difficulties to gain } \\
\text { overview of available } \\
\text { data (language, trust) } \\
\text { - Several months of data } \\
\text { acquisition }\end{array}$ & - & $\begin{array}{l}\text { Even available data } \\
\text { often based on } \\
\text { assumptions } \\
\text { - Assumptions changed } \\
\text { several times over the } \\
\text { project (re-calculations } \\
\text { required) } \\
\end{array}$ \\
\hline \multicolumn{4}{|c|}{ Task 3: Filling gaps by own Evaluations } \\
\hline $\begin{array}{l}\text { - Interaction of project } \\
\text { partners to fill data gaps: } \\
\text { - Pumping tests } \\
\text { - Infiltration tests } \\
\text { - GW monitoring } \\
\text { - SR monitoring } \\
\text { - Climate monitoring } \\
\text { - SAT suitability } \\
\text { - Land use assessment } \\
\text { - Farmer interviews } \\
\text { - Hydrological model by } \\
\text { project partner }\end{array}$ & $\begin{array}{l}\text { - Groundwater model } \\
\text { could not be finished by } \\
\text { project partner due to } \\
\text { insufficient data }\end{array}$ & $\begin{array}{l}\text { - Interaction of project } \\
\text { partners to fill data gaps } \\
\text { (e.g. model, spring } \\
\text { discharge series) } \\
\text { - Stakeholder } \\
\text { participation }\end{array}$ & $\begin{array}{l}\text { No own assessments } \\
\text { were conducted, all data } \\
\text { was supplied by partners }\end{array}$ \\
\hline
\end{tabular}

\subsubsection{Step 2: General MAR Feasibility Assessment}

The second step of the suggested MAR planning approach is a general MAR feasibility study based on available data. It should merely state whether or not MAR could be implemented in the area at all. Again, Table 5-2 summarizes the main conclusions for this step. Basically in both case studies a general suitability for a MAR implementation could be identified. Infiltration rates are in both cases high enough to allow for an efficient implementation of surface technologies such as infiltration ponds. Some characteristics may limit the choice of location for the MAR facilities. The hydrogeology in Jericho-Auja is very complex and inhomogeneous. The most important issue here is the lack of any distributed water quality data. Leaving this study with only the quantitative aspect of MAR. 
Table 5-2: Evaluation Sheet for Planning Step 2

\begin{tabular}{|c|c|c|c|}
\hline \multicolumn{4}{|c|}{$\begin{array}{c}\text { Step 2: General MAR Feasibility Assessment } \\
\text { Evaluation of basic requirements }\end{array}$} \\
\hline \multicolumn{2}{|c|}{ João Pessoa } & \multicolumn{2}{|c|}{ Jericho-Auja } \\
\hline \multicolumn{4}{|c|}{ Task 1: Assessment of Surface Characteristics } \\
\hline $\begin{array}{l}\text { - High infiltration rates } \\
\text { possible after excavation } \\
\text { of soil } \\
\text { - Flat topography } \\
\text { - Rivers as water source } \\
\text { well distributed }\end{array}$ & $\begin{array}{l}\text { - High land use density } \\
\text { - Demand centers highly } \\
\text { distributed and } \\
\text { inhomogeneous } \\
\text { (requires decentralized } \\
\text { MAR) } \\
\text { - Water quality not } \\
\text { available }\end{array}$ & $\begin{array}{l}\text { - Relatively low land use } \\
\text { - High infiltration rates } \\
\text { possible after excavation } \\
\text { of soil } \\
\text { - Springs as water source } \\
\text { uphill (transport by } \\
\text { gravity possible) } \\
\text { - Demand centers } \\
\text { centralized }\end{array}$ & $\begin{array}{l}\text { - Topography limits } \\
\text { applicability to wadis } \\
\text { - Water quality not } \\
\text { available }\end{array}$ \\
\hline \multicolumn{4}{|c|}{ Task 2: Assessment of Underground Characteristics } \\
\hline $\begin{array}{l}\text { - Hydraulic parameters } \\
\text { - Large aquifer for storage } \\
\text { - GW flow behavior }\end{array}$ & $\begin{array}{l}\text { - GW quality not } \\
\text { available }\end{array}$ & - Hydraulic parameters & $\begin{array}{l}\text { - Hydrogeology very } \\
\text { complex } \\
\text { - GW quality not } \\
\text { available }\end{array}$ \\
\hline
\end{tabular}

\subsubsection{Step 3: Water Resources System Analysis}

The water resources system analysis is one of the most important steps. It is the bridge between the mere data acquisition and analysis to the actual development of MAR concepts and IWRM measures that might potentially improve the system. Table 5-3 summarizes the remarks on Step 3 for both case studies. The spatial discretization of the study areas into Management Units was not a problem in both cases, though the results for João Pessoa were quite complex with eleven MUs to analyze separately. But the criteria for discretization were properly selected in both cases. They basically oriented on the data availability. As for João Pessoa, the most important parameter for analyses was the surface runoff in the rivers. Therefore, the locations of existing historic and virtual simulated runoff gauges were used to delineate sub-catchments that represent the MUs. In Jericho-Auja the situation was much simpler with a comparably small study area to begin with. Also the area includes two municipalities, both with their own water supply from different springs. In between there is no proper land use. It was hence trivial to separate the area in two MUs: Jericho and Auja.

For the actual budget parameters both studies suffered immensely from the lack of proper monitoring. Irrigation demand, which makes up around $75 \%$ of the water demand in the João Pessoa case study, had to be calculated based on the conducted land use evaluations in combination with hydrological simulation results from project partners. This introduces a high level of uncertainty, since none of the calculations can be verified by observed data. The same goes for groundwater levels, -recharge and surface runoff in the study. For Jericho-Auja more data was available and processed. Nevertheless, lots of the data sets supplied suffer from high degrees of uncertainty. Based on the available and collected data for both case studies a general problem of spatio-temporal availability and demand could be detected that might be accounted for via MAR and further IWRM measures. This indication was stronger for the semi-arid cases study Jericho-Auja. In João Pessoa, the negative 
effects of the current water management, or rather lack of water management, are not as pressing. Rather, the suggested implementations can help mitigate water scarcity issues in that study area before they occur. For Jericho-Auja, the situation is already alarming. The approach helped identifying the situation in both case studies and illustrating it to stakeholders.

Table 5-3: Evaluation Sheet for Planning Step 3

\begin{tabular}{|c|c|c|c|}
\hline \multicolumn{4}{|c|}{$\begin{array}{c}\text { Step 3: Water Resources System Analysis } \\
\text { Quantification of spatio-temporal water demand and availability distribution }\end{array}$} \\
\hline \multicolumn{2}{|c|}{ João Pessoa } & \multicolumn{2}{|c|}{ Jericho-Auja } \\
\hline \multicolumn{4}{|c|}{ Task 1: Spatial discretization into smaller "Management Units" } \\
\hline $\begin{array}{l}\text { Based on sub- } \\
\text { catchments according to } \\
\text { runoff gauges }\end{array}$ & $\begin{array}{l}\text { 11 MUs to analyze, that } \\
\text { interact with regard to } \\
\text { water availability (SR) }\end{array}$ & $\begin{array}{l}\text { - Discretization by } \\
\text { watershed and socio- } \\
\text { economics } \\
\text { - Only two MUs to } \\
\text { analyze }\end{array}$ & - \\
\hline \multicolumn{4}{|c|}{ Task 2: Assessment of Water Availability and Potentials } \\
\hline $\begin{array}{l}\text { - Hydrological model } \\
\text { results available } \\
\text { - Only one practicable } \\
\text { water source for MAR } \\
\text { (SR) }\end{array}$ & $\begin{array}{l}\text { - Limited actual } \\
\text { measurements available } \\
\text { - No proper monitoring } \\
\text { (except rainfall) }\end{array}$ & $\begin{array}{l}\text { - One practical source for } \\
\text { MAR (spring discharge) } \\
\text { but several sources for } \\
\text { additional demand } \\
\text { coverage (waste water, } \\
\text { deep wells, SR retention, } \\
\text { imports) }\end{array}$ & $\begin{array}{l}\text { - High level of uncertainty } \\
\text { - Political restrictions } \\
\text { must be neglected } \\
\text { - No proper monitoring } \\
\text { (except some springs) }\end{array}$ \\
\hline \multicolumn{4}{|c|}{ Task 3: Assessment of Water Demand Sectors } \\
\hline $\begin{array}{l}\text { Socio-economic } \\
\text { demands from project } \\
\text { partners }\end{array}$ & $\begin{array}{l}\text { - Irrigation demand } \\
\text { calculation very intricate } \\
\text { with high uncertainties } \\
\text { - No proper monitoring }\end{array}$ & $\begin{array}{l}\text { - All demand values } \\
\text { supplied by project } \\
\text { partners }\end{array}$ & $\begin{array}{l}\text { - High level of uncertainty } \\
\text { - No proper monitoring }\end{array}$ \\
\hline \multicolumn{4}{|c|}{ Task 4: Assessment of existing and required Hydro-Infrastructure } \\
\hline $\begin{array}{l}\text { Manageable units of } \\
\text { hydro-infrastructure for } \\
\text { transport (because water } \\
\text { is directly extracted } \\
\text { from rivers/GW where } \\
\text { required) }\end{array}$ & $\begin{array}{l}\text { - Large number of surface } \\
\text { storages / damns with } \\
\text { insufficient monitoring } \\
\text { and data (only water } \\
\text { levels, no in-and outflow } \\
\text { measurements) }\end{array}$ & $\begin{array}{l}\text { Clear overview of } \\
\text { hydro-infrastructure }\end{array}$ & $\begin{array}{l}\text { - Numerous investments } \\
\text { required to implement } \\
\text { suggested measures and } \\
\text { strategies }\end{array}$ \\
\hline \multicolumn{4}{|c|}{ Task 5: Problem Identification } \\
\hline $\begin{array}{l}\text { - Solutions can be } \\
\text { implemented before } \\
\text { water shortage becomes } \\
\text { a pressing issue }\end{array}$ & $\begin{array}{l}\text { No pressing need for } \\
\text { MAR or IWRM } \\
\text { identified, only in long- } \\
\text { term }\end{array}$ & $\begin{array}{l}\text { - Strong overuse of } \\
\text { shallow GW identified } \\
\text { High demand for } \\
\text { additional water supply }\end{array}$ & $\begin{array}{l}\text { - High uncertainty due to } \\
\text { high level of estimations }\end{array}$ \\
\hline
\end{tabular}

\subsubsection{Step 4: Combination of MAR Concept and IWRM Measures to integrative Strategies}

The central step in the entire planning approach is the development of a MAR concept that fits in with potential IWRM measures, resulting in integrative strategies for the case study. Table 5-4 summarizes the evaluation of this step. The selection of suitable locations for MAR was hindered in the João Pessoa case study by the lack of a solid groundwater flow model. Rather, the preliminary selection of locations was supported by a spatial multi-criteria tool that is part of the BRAMARIDSS, decision support tool developed in the course of the BRAMAR project (Rusteberg et al., 2018). 
Table 5-4: Evaluation Sheet for Planning Step 4

\begin{tabular}{|c|c|c|c|}
\hline \multicolumn{4}{|c|}{$\begin{array}{c}\text { Step 4: Combination of a MAR Concept and IWRM Measures to formulate integrative Strategies } \\
\text { Formulation of Strategies that consider MAR as part of IWRM }\end{array}$} \\
\hline \multicolumn{2}{|c|}{ João Pessoa } & \multicolumn{2}{|c|}{ Jericho-Auja } \\
\hline \multicolumn{4}{|c|}{ Task 1: Location(s) for MAR } \\
\hline $\begin{array}{l}\text { - Spatial multi-criteria- } \\
\text { assessment tool by } \\
\text { project partner for MAR } \\
\text { site selection } \\
\text { - High homogeneity of } \\
\text { aquifer characteristics }\end{array}$ & $\begin{array}{l}\text { - Could not be verified by } \\
\text { groundwater modelling } \\
\text { - WRS requires } \\
\text { decentralized } \\
\text { implementation at many } \\
\text { locations (seven have } \\
\text { been selected) }\end{array}$ & $\begin{array}{l}\text { - Small area of interest } \\
\text { results in limited choice } \\
\text { for locations } \\
\text { - Iterative improvement of } \\
\text { locations by } \\
\text { groundwater modelling }\end{array}$ & $\begin{array}{l}\text { - Only broad knowledge } \\
\text { on hydrogeology (high } \\
\text { heterogeneity can cause } \\
\text { local unsuitability for } \\
\text { MAR) }\end{array}$ \\
\hline \multicolumn{4}{|c|}{ Task 2: Operation Schemes for MAR } \\
\hline $\begin{array}{l}\text { Based on simulated } \\
\text { runoff time series by } \\
\text { project partner at several } \\
\text { virtual gauges } \\
\text { (correlating with MUs) }\end{array}$ & $\begin{array}{l}\text { Hydrological model } \\
\text { revealed some } \\
\text { weaknesses due to data } \\
\text { insufficiency for } \\
\text { calibration and } \\
\text { validation }\end{array}$ & $\begin{array}{l}\text { Based on synthetic } \\
\text { spring discharge time } \\
\text { series from project } \\
\text { partner }\end{array}$ & $\begin{array}{l}\text { - Based also on several } \\
\text { assumptions for water } \\
\text { availability that cannot } \\
\text { be validated (no proper } \\
\text { monitoring) }\end{array}$ \\
\hline \multicolumn{4}{|c|}{ Task 3: IWRM Measures for Supply Management } \\
\hline $\begin{array}{l}\text { - Water potential is } \\
\text { abundant (SR) }\end{array}$ & $\begin{array}{l}\text { - High level of uncertainty } \\
\text { regarding runoff time } \\
\text { series and assumptions } \\
\text { for sustainable } \\
\text { withdrawal rates (no } \\
\text { proper monitoring) }\end{array}$ & $\begin{array}{l}\text { Numerous potential } \\
\text { additional water sources }\end{array}$ & $\begin{array}{l}\text { - Many assumptions and } \\
\text { estimations (no proper } \\
\text { monitoring) } \\
\text { - Political restrictions } \\
\text { must be neglected }\end{array}$ \\
\hline \multicolumn{4}{|c|}{ Task 4: IWRM Measures for Demand Management } \\
\hline- & $\begin{array}{l}\text { Based on assumptions } \\
\text { and estimations that } \\
\text { cannot be validated (no } \\
\text { proper monitoring) }\end{array}$ & $\begin{array}{l}\text { - Inefficient water } \\
\text { network allows for vast } \\
\text { improvement by } \\
\text { modernization (loss } \\
\text { reduction) }\end{array}$ & $\begin{array}{l}\text { - High investments } \\
\text { required } \\
\text { - Political restrictions } \\
\text { must be neglected }\end{array}$ \\
\hline \multicolumn{4}{|c|}{ Task 5: Stakeholder Involvement and Consideration of existing Plans } \\
\hline $\begin{array}{l}\text { Socio-economic growth } \\
\text { estimations taken from } \\
\text { official water plans }\end{array}$ & $\begin{array}{l}\text { - No plans regarding } \\
\text { agriculture or water } \\
\text { management so far }\end{array}$ & $\begin{array}{l}\text { - Stakeholders directly } \\
\text { involved in the project } \\
\text { - Assumptions and results } \\
\text { could be discussed many } \\
\text { times }\end{array}$ & - \\
\hline \multicolumn{4}{|c|}{ Task 6: Integration of MAR and IWRM to Strategies } \\
\hline $\begin{array}{l}\text { MAR alone can vastly } \\
\text { improve water resources } \\
\text { system without } \\
\text { additional measure }\end{array}$ & - & $\begin{array}{l}\text { MAR as key IWRM } \\
\text { measure important for } \\
\text { the strategies to work }\end{array}$ & - \\
\hline
\end{tabular}

In the Jericho-Auja case on the other hand, the number of possibilities for locations was limited from the beginning. The high concentration of the demand centers and topography as well as connection to available water sources left little choice for MAR locations. Also, the preliminary selection could be verified by means of groundwater simulations and refined in the process by several iterations back to this step. Regarding operation of MAR facilities in João Pessoa, surface runoff from the rivers has been identified as the most abundant source, with extremely high availability during the rainy season. The limiting factor, in contrast to the semi-arid case study is not the water availability but the capacity of MAR facilities. Hence there is a high difference in the design of IWRM measures in both areas. For João Pessoa it was simply not required to develop a large set of measures, while the semi-arid case study is in urgent need for new water sources without which a positive future development cannot be managed. Also for demand management there is barely a case in the João Pessoa study. 
Though the positive effects and high potential of a modernization of irrigation techniques could be identified and is recommended, it is not a high priority measure. While in Jericho-Auja the reduction of losses is seen as a fundamental measure with absolute priority.

Stakeholder participation could especially be achieved in the Jericho-Auja study, as has been explained under the first steps. Therefore, the resulting strategies combine some of the local authorities' development plans with new ideas. For the João Pessoa case study, some cooperation with local authorities has been tried to achieve but did not meet much interest. It became clear that the current situation of water supply and future development is not acute enough for awaking much interest. The more important it is, from the view of the author, that adequate measures and potential future deficits are analyzed now before any damage to the system manifests itself.

\subsubsection{Step 5: Development Scenarios}

The MAR planning approach tested in this study suggests the design of at least three scenarios for the future development of the case studies. This goal could be achieved for both studies. As summarized in Table 5-5 for both studies a Baseline, Agricultural Development and Dry Climate Scenario has successfully been designed. For the Baseline Scenario the semi-arid case study there was an advantage by the supply of synthetic spring discharge and correlating surface runoff time series by a project partner (Schmidt, 2018). The designed hydrological scenario represents a series of moderate years, followed by above average wet years, followed by drought conditions and returning back to moderate conditions. The idea was to reflect the high heterogeneity and variance in water availability in the study area to evaluate potential strategies under these conditions. The underlying hydrological assumptions for the João Pessoa case on the other hand was actually designed for the years 2000-2014 in the course of hydrological modelling for the BRAMAR project (Schimmelpfennig et al., 2018). This series has been transposed to the future. An actual prognosis of future climate conditions would have been preferable but could not be designed within the course of the project. The selected synthetic time series of runoff can still accepted as representative since although the seasonal variation is very strong in the tropical coastal case study, the variation between years is not that extreme as in the semi-arid case study. For the Dry Climate Scenario a more sophisticated input would have been preferred for the tropical case study. To analyze at least a rough dry scenario, the prior selected hydrologic time series has simply been reduced by $10 \%$. This in return led to increase irrigation demands, decreased natural groundwater recharge and decreased surface runoff that has been calculated individually for each MU. The analysis showed that the system reacts very sensitive to depletion in rainfall volumes. A valuable result that can be combined and extended with the current state of official climate change scenarios and might trigger awareness for potential threats to the water resources system. For the semi-arid case study again a synthetic 
series of spring discharge and surface runoff was designed by Schmidt (2018), allowing the analysis of a severe drought of ten years duration as is realistic for the region.

Table 5-5: Evaluation Sheet for Planning Step 5

\begin{tabular}{|c|c|c|c|}
\hline \multicolumn{4}{|c|}{$\begin{array}{l}\text { Step 5: Scenarios of future Development } \\
\text { Assumptions for Changes in the Water Resources System }\end{array}$} \\
\hline \multicolumn{2}{|c|}{ João Pessoa } & \multicolumn{2}{|c|}{ Jericho-Auja } \\
\hline \multicolumn{4}{|c|}{ Task 1: Baseline Scenario } \\
\hline $\begin{array}{l}\text { Based on historical } \\
\text { socio-economic growth } \\
\text { rates }\end{array}$ & $\begin{array}{l}\text { - SR time series based on } \\
\text { simulated results for } \\
\text { historic values }\end{array}$ & $\begin{array}{l}\text { - Based on synthetic time } \\
\text { series of representative } \\
\text { variable hydrological } \\
\text { conditions from project } \\
\text { partner }\end{array}$ & - \\
\hline \multicolumn{4}{|c|}{ Task 2: Agricultural Development Scenario } \\
\hline $\begin{array}{l}\text { - Irrigation demand } \\
\text { assessment allowed } \\
\text { spatio-temporal } \\
\text { recalculation according } \\
\text { to assumption }\end{array}$ & $\begin{array}{l}\text { - No development plans } \\
\text { available }\end{array}$ & $\begin{array}{l}\text { - Based on evaluations of } \\
\text { project partner oriented } \\
\text { on official development } \\
\text { plans }\end{array}$ & $\begin{array}{l}\text { - Very demanding } \\
\text { scenario } \\
\text { - Allows only for little } \\
\text { adjustments } \\
\text { - Hard to manage }\end{array}$ \\
\hline \multicolumn{4}{|c|}{ Task 3: Dry Climate Scenario } \\
\hline $\begin{array}{l}\text { System reacts very } \\
\text { sensitive to variations in } \\
\text { rainfall }\end{array}$ & $\begin{array}{l}\text { - No proper climate } \\
\text { change data, just a } \\
\text { coarse assumption }\end{array}$ & $\begin{array}{l}\text { - Based on synthetic time } \\
\text { series of extreme dry } \\
\text { hydrological conditions } \\
\text { from project partner }\end{array}$ & $\begin{array}{l}\text { - Extreme water shortage, } \\
\text { makes study area } \\
\text { unmanageable without } \\
\text { additional resources }\end{array}$ \\
\hline
\end{tabular}

For both studies the local agriculture has been selected as the main driver of the demand scenario. For Jericho-Auja luckily development plans were existing that outline the desired extension of agricultural areas and the corresponding increase in water demand. It was decided to base the scenario on these assumptions in order to show to what extend agricultural development would be feasible and what measure, or strategies, would need to be implemented in order to achieve these goals. However, the development goals are very ambitious and can barely be managed with the water resources even under consideration of all the designed IWRM measures in combination with MAR. This led to the extended result that in order to achieve the desired level of growth in the region, additional water imports would be required, after all local sources are activated. The priority is still set on the local resources, especially the implementation of deep wells. The analysis of scenarios brought a huge benefit to the planning of MAR and IWRM measures.

\subsubsection{Step 6: MAR Groundwater Budget Analysis}

Step 6, the numerical assessment of MAR groundwater budgets was the most demanding of all steps. It bridges the design of MAR concept and IWRM measure to simulations and final recommendation. As presented in Table 5-6 in both case studies the step led to at least 12 iterations back to Step 4, the design of MAR concept and IWRM measures. This shows the high value of this assessment. With each iteration improvements on the suggested strategies could be achieved before these were actually simulated. The only negative remark about this step could be for the João Pessoa case study where 
the discretization into eleven MUs resulted in a very high complexity of the calculation process. For the future it is recommended to develop a tool for this step that simplifies the process. Overall the step vastly increased the understanding of the system.

For the first task, the combination of strategies and scenarios no remarks have been added, since this is merely a merging of the prior results and input time series that neither created any difficulties nor brought any specific advantage.

Table 5-6: Evaluation Sheet for Planning Step 6

\begin{tabular}{|c|c|c|c|}
\hline \multicolumn{4}{|c|}{$\begin{array}{l}\text { Step 6: MAR Groundwater Budget Assessment } \\
\text { Numerical Analysis of Strategies and Scenarios }\end{array}$} \\
\hline \multicolumn{2}{|c|}{ João Pessoa } & \multicolumn{2}{|c|}{ Jericho-Auja } \\
\hline \multicolumn{4}{|c|}{ Task 1: Combination of Strategies and Scenarios } \\
\hline- & - & - & - \\
\hline \multicolumn{4}{|c|}{ Task 2: Calculation of Groundwater Budgets } \\
\hline $\begin{array}{l}\text { - Spatial discretization } \\
\text { allows for differentiated } \\
\text { analysis } \\
\text { Increased understanding } \\
\text { of the water resources } \\
\text { system gained }\end{array}$ & $\begin{array}{l}\text { High complexity } \\
\text { (11 Management Units) }\end{array}$ & $\begin{array}{l}\text { - Revealed high deficits } \\
\text { and insufficiency of } \\
\text { present water resources } \\
\text { to supply agriculture } \\
\text { - Simple to analyze and } \\
\text { adjust }\end{array}$ & - \\
\hline \multicolumn{4}{|c|}{ Task 3: Interpretation of Results and Iteration to Step 4 if necessary } \\
\hline $\begin{array}{l}\text { - Roughly a dozen } \\
\text { iterations conducted }\end{array}$ & - & $\begin{array}{l}\text { - Several dozen iterations } \\
\text { conducted }\end{array}$ & - \\
\hline
\end{tabular}

\subsubsection{Step 7: Groundwater Simulations}

Step 7 reveals the consequences of a bad data availability. Even though a lot of effort has been put into own data collections under Step 1, for the case study João Pessoa the strong deficit in data availability manifested itself in the lack of a fully calibrated and validated groundwater model as the summary in Table 5-7 reveals. Consequently no simulations of the designed strategies could be performed within the timeframe of this study. However, It therefore is the hope of this study that the selected approach and the data acquisition that has been started within the course of the respective research and development project, will consequently lead to increased investments in monitoring of the water resources system of both case studies. Both, the existing groundwater model for JerichoAuja and the unfinished model for João Pessoa can be extended and improved by additional knowledge, actually restarting parts of the suggested approach and leading to improvement of the suggested strategies.

Concerning the application of the groundwater flow model for the case study Jericho-Auja, it can be concluded that the application added to the gained knowledge of the prior step, the numerical assessment. The application of a transient model allow for the consideration of groundwater dynamics, as has been stressed many times in this thesis. Assessment by simulations is therefore the 
logical extension of the numerical assessment and must be given special attention. It should also be kept in mind that the final goal of the assessments is the implementation of at least pilot plants for MAR and some of the IWRM measures in the field. This requires an intense planning and design before spending money on expensive long-term experiments. It is the key benefit of groundwater model application to be able to test suggestions and strategies before implementation. As the study showed, it is also a very time consuming step for each run of simulations must be adjusted according to the results of the prior steps. Each iteration back to the development process of strategies results in the setup of a completely new simulation scenario. But, as the results showed, it is a very important step in the MAR planning process and cannot be replaced by the numerical analysis as the next step revealed.

Table 5-7: Evaluation Sheet for Planning Step 7

\begin{tabular}{|c|c|c|c|}
\hline \multicolumn{4}{|c|}{ Step 7: Groundwater Simulations } \\
\hline \multicolumn{2}{|c|}{ João Pessoa } & \multicolumn{2}{|c|}{ Jericho-Auja } \\
\hline \multicolumn{4}{|c|}{ Task 1: Model Development } \\
\hline- & $\begin{array}{l}\text { Aborted by project } \\
\text { partner }\end{array}$ & $\begin{array}{l}\text { Groundwater flow } \\
\text { model developed by } \\
\text { project partner in close } \\
\text { cooperation }\end{array}$ & $\begin{array}{l}\text { - Poor data for calibration } \\
\text { and validation available }\end{array}$ \\
\hline \multicolumn{4}{|c|}{ Task 2: Simulation of Groundwater Dynamics } \\
\hline - & - Could not be conducted & $\begin{array}{l}\text { Results improved MAR } \\
\text { site selection and } \\
\text { understanding of the } \\
\text { system }\end{array}$ & $\begin{array}{l}\text { - High level of uncertainty } \\
\text { due to insufficient data } \\
\text { (no proper monitoring) }\end{array}$ \\
\hline \multicolumn{4}{|c|}{ Task 3: Interpretation of Results and Iteration to Step 4 if necessary } \\
\hline - & - Could not be conducted & $\begin{array}{l}\text { Roughly half a dozen } \\
\text { iterations conducted }\end{array}$ & $\begin{array}{l}\text { - Extremely time } \\
\text { consuming }\end{array}$ \\
\hline
\end{tabular}

\subsubsection{Step 8: Performance and Impact Assessment}

For the performance and impact assessment of the designed strategies under assumption of the developed scenarios, identical indicators have been formulated for both case studies. As negatively mentioned in Table 5-8 it was not possible to conduct a proper cost-benefit assessment that could be used as an indicator. Rather it was tried to at least compare relative costs by accounting unit costs per additional volume of activated additional water resources. The benefit part of the equation could be interpreted by the achieved stability in groundwater level and the subsequently increased security of water supply that allows for an extension of agricultural lands (Jericho-Auja) or the full irrigation of existing agriculture without damaging the groundwater system (João Pessoa). Since for all strategies and scenarios the same agricultural demand is assumed, the benefit part of the equation would potentially stay constant since a full irrigation is assumed regardless of actual water availability. This issue has been thoroughly discussed in the respective chapters on water budgets and performance assessment. 
Table 5-8: Evaluation Sheet for Planning Step 8

\begin{tabular}{|c|c|c|c|}
\hline \multicolumn{4}{|c|}{$\begin{array}{c}\text { Step 8: Performance and Impact Assessment } \\
\text { Identification of prioritized Strategies }\end{array}$} \\
\hline \multicolumn{2}{|c|}{ João Pessoa } & \multicolumn{2}{|c|}{ Jericho-Auja } \\
\hline \multicolumn{4}{|c|}{ Task 1: Definition of quantifiable Indicators } \\
\hline $\begin{array}{l}\text { - In accordance to water } \\
\text { plans and stakeholder } \\
\text { priorities }\end{array}$ & $\begin{array}{l}\text { - No proper cost-benefit } \\
\text { analysis could be } \\
\text { conducted }\end{array}$ & $\begin{array}{l}\text { - Identical to other case } \\
\text { study (same indicators) }\end{array}$ & $\begin{array}{l}\text { - Identical to other case } \\
\text { study (same indicators) }\end{array}$ \\
\hline \multicolumn{4}{|c|}{ Task 2: Indicator Evaluation } \\
\hline - Differentiated results & $\begin{array}{l}\text { - Based on numerical } \\
\text { assessment, not } \\
\text { simulations }\end{array}$ & $\begin{array}{l}\text { - Based on simulations } \\
\text { - Differentiated results }\end{array}$ & - \\
\hline \multicolumn{4}{|c|}{ Task 3: Comparison and Ranking of Strategies } \\
\hline $\begin{array}{l}\text { Allowed prioritization of } \\
\text { strategies as wells as } \\
\text { individual measures by } \\
\text { direct comparison }\end{array}$ & $\begin{array}{l}\text { - Weighting of indicators } \\
\text { not consolidated with } \\
\text { stakeholders }\end{array}$ & $\begin{array}{l}\text { Allowed prioritization of } \\
\text { strategies as wells as } \\
\text { individual measures by } \\
\text { direct comparison }\end{array}$ & $\begin{array}{l}\text { - Weighting of indicators } \\
\text { not consolidated with } \\
\text { stakeholders }\end{array}$ \\
\hline
\end{tabular}

For the tropical case study João Pessoa, the performance assessment by indicator evaluation had to be performed based on the numerical assessment. In contrast, the case study Jericho-Auja allowed for an evaluation of simulation results which can be considered much closer to the real system since groundwater models try to mimic actual groundwater dynamics leading to a more differentiated evaluation. The assessment allowed on the one hand the evaluation of absolute performance of the constructed strategies, but also an interpolation to the performance of individual measures. The strategies have been developed in a way that each one adds another IWRM measure to the prior. Therefore, it is logical that the last strategy, which combines all the others and adds one additional measure, will outperform the prior strategies. It is important to read the results presented in this thesis correctly: It is not the absolute performance of a strategy that if of importance, but the relative improvement of performance over the prior strategy.

Finally the evaluation allowed to identify priority measures and suggests strategies that would potentially allow for the sustainable management of local water resources, with special focus on groundwater, under the selected scenarios. The final ranking in this thesis was not actually consolidated with stakeholders regarding the distribution of weights for each indicator. This would require thorough interviews and the distribution of questionnaires to the entirety of stakeholders in order to adequately weigh the indicators. The application in this thesis should therefore be considered as a demonstration of the possibilities that the suggested planning approach offers.

\subsubsection{Step 9: Recommendations for Pilot Plants}

The application of the suggested MAR planning approach was concluded in this thesis with Step 9. Basically all results of the prior steps were summarized to formulate actual recommendations for MAR pilot plants. The step was restricted and resulted in benefits in the same topics as that have been addressed before. Table 5-9 summarizes the main comments to the step. 
Issues that have not yet been addressed are formulated in Tasks 6 and 7. The operation of the suggested pilot plants should generally follow the same assumptions as were outlined in the MAR groundwater budget assessments and simulations. However, since pilot plants would potentially be designed on a smaller scale, some adjustments would be required.

Table 5-9: Evaluation Sheet for Planning Step 9

\begin{tabular}{|c|c|c|c|}
\hline \multicolumn{4}{|c|}{$\begin{array}{l}\text { Step 9: } \text { Recommendations for Pilot Plant(s) } \\
\text { Conceptual Suggestions for the Implementation of Test Facilities in the Field }\end{array}$} \\
\hline \multicolumn{2}{|c|}{ João Pessoa } & \multicolumn{2}{|c|}{ Jericho-Auja } \\
\hline \multicolumn{4}{|c|}{ Task 1: General Concept } \\
\hline $\begin{array}{l}\text { - Overall concept } \\
\text { formulated }\end{array}$ & $\begin{array}{l}\text { High complexity and } \\
\text { demand distribution } \\
\text { demands decentralized } \\
\text { solution } \\
\end{array}$ & $\begin{array}{l}\text { - Complete } \\
\text { conceptualization } \\
\text { formulated }\end{array}$ & - \\
\hline \multicolumn{4}{|c|}{ Task 2: Definition of Water Source $($ s) } \\
\hline $\begin{array}{l}\text { - SR as only sensitive } \\
\text { choice }\end{array}$ & $\begin{array}{l}\text { - Uncertainty regarding } \\
\text { volumes }\end{array}$ & $\begin{array}{l}\text { High variety of potential } \\
\text { additional sources, yet } \\
\text { only one directly for } \\
\text { MAR (spring discharge) }\end{array}$ & $\begin{array}{l}\text { - Availability extremely } \\
\text { volatile }\end{array}$ \\
\hline \multicolumn{4}{|c|}{ Task 3: Potential Location(s) } \\
\hline - & $\begin{array}{l}\text { - No verification by } \\
\text { model possible }\end{array}$ & $\begin{array}{l}\text { - Verified by groundwater } \\
\text { simulation }\end{array}$ & - Limited possibilities \\
\hline \multicolumn{4}{|c|}{ Task 4: Recommended Technology } \\
\hline $\begin{array}{l}\text { - Clear recommendations } \\
\text { (infiltration ponds and } \\
\text { injection wells) } \\
\end{array}$ & - & $\begin{array}{l}\text { - Clear recommendations } \\
\text { (infiltration ponds) }\end{array}$ & - \\
\hline \multicolumn{4}{|c|}{ Task 5: Required Pre-Treatment Measures } \\
\hline - & $\begin{array}{l}\text { Could not be identified } \\
\text { due to lack of water } \\
\text { quality data }\end{array}$ & - & $\begin{array}{l}\text { Could not be identified } \\
\text { due to lack of water } \\
\text { quality data }\end{array}$ \\
\hline \multicolumn{4}{|c|}{ Task 6: Suggested Operation of the Plant(s) } \\
\hline $\begin{array}{l}\text { Water availability in } \\
\text { abundance (SR), no } \\
\text { problems expected }\end{array}$ & $\begin{array}{l}\text { - Pumping of water from } \\
\text { river to MAR site } \\
\text { required (several 100m) } \\
\text { - Active operation } \\
\text { management needed }\end{array}$ & $\begin{array}{l}\text { Parts of existing hydro- } \\
\text { infrastructure could be } \\
\text { utilized (Auja dam and } \\
\text { canal) }\end{array}$ & $\begin{array}{l}\text { - Difficult to implement } \\
\text { due to water shortage } \\
\text { situation } \\
\text { - Recommended to } \\
\text { activate additional water } \\
\text { first (e.g. implement a } \\
\text { deep well) } \\
\text { - Active operation } \\
\text { management needed }\end{array}$ \\
\hline \multicolumn{4}{|c|}{ Task 7: Outline of Monitoring Setup } \\
\hline $\begin{array}{l}\text { - Clear recommendations } \\
\text { give for general outline } \\
\text { (observation wells and } \\
\text { tracer injection, quality } \\
\text { monitoring) }\end{array}$ & - High investment costs & $\begin{array}{l}\text { - Same as for the other } \\
\text { case study }\end{array}$ & $\begin{array}{l}\text { - High investment costs } \\
\text { - Political restrictions }\end{array}$ \\
\hline
\end{tabular}

The strategies designed in this thesis assume a full implementation of the suggested IWRM measure which includes the implementation of new hydro-infrastructure as well as the activation of additional water sources. For the case study João Pessoa it would not be sensitive to install a pipeline of 40-50 $\mathrm{cm}$ diameter over some hundred meters in order to perform a field experiment. Rather it might be more suitable to operate the test facility on a smaller scale and applying less water for recharge. Lower quantities could be supplied to the test facility by a much smaller tube, not requiring the implementation of an entire pipeline. For the semi-arid case study many problems with regard to 
operation have been mentioned before. Social and political restrictions may impact the test facilities and their operation. It was therefore recommended to combine a potential test facility with the activation of some additional water for the region, for example by means of implementing one additional deep well. This way water from the springs could be used for a MAR pilot plant without giving the impression of wasting precious water from the farmer. Rather the new well would compensate them directly, increasing social acceptance immensely. Of course these plans are highly restricted by the political circumstances that are not a focus of this study. The additional implementation of a small monitoring system in both cases will also face difficulties but is urgently required in order to properly evaluate the tests. 


\section{CONCLUSION}

AND

\section{RECOMMENDATIONS}




\subsection{Summary}

The studies presented in this thesis led to an increased understanding of the water resources system of two case studies; the tropical coastal city of João Pessoa with its rural surrounding and vast sugarcane plantations in Northeast Brazil and the semi-arid city of Jericho and its neighboring Auja village suffering from very volatile and scarce water resources in the Lower Jordan Valley, Palestine. In order to define, test, evaluate and recommend combined strategies of Managed Aquifer Recharge (MAR) in the context of Integrated Water Resources Management (IWRM) for both case studies, a new Integrated MAR Planning Approach has been developed. This thesis put the new approach to the test and evaluated its suitability for water management planning under different conditions. Based on the studies presented in this thesis it can be concluded that the developed approach may indeed serve as a framework for water resources management studies that aim to address MAR as an integral part of IWRM. The introduced approach is a step-by-step guideline that aims at a complete assessment of the current water supply and demand situation, management and hydro-infrastructural measures that are required to activate new sources of water and the potential impact these measure would have on the system under consideration of MAR as a mean to temporary store water surpluses in the underground, based on a variety of scenarios for future development, supported by groundwater monitoring and a final indicator driven assessment and comparison.

The results varied for each of the selected case studies. The tropical case study of João Pessoa is characterized by an extreme rainy season that provides water in abundance. During the dry season there is still a significant amount of rainfall and surface runoff. It is this surface runoff that has been identified as the most potent source for MAR in the region. Water demand on the other hand is dominated by the strong agriculture, mostly consisting of sugarcane with a very high irrigation demand. Though rainfall is nearly sufficient to satisfy the high crop water need during the southern hemispherical winter, a high dependency on groundwater pumping could be detected. But also the domestic water demand, being strongly focused in the urban area along the coast, leads to a massive exploitation of local groundwater resources. Unfortunately the monitoring of either, water availability and demand, is highly insufficient. In order to close data gaps and perform an adequate assessment, a lot of effort has been put into monitoring and field experiments, in close cooperation with partners of the BRAMAR research and development project that supplied the framework for this and many other studies in the region. Even with the efforts conducted over the 3.5 years of project duration, the collected data was insufficient for one of the partners to fully calibrate and validate a groundwater flow model, which would have resulted in a strong improvement of the results. Even so, the studies conducted in this thesis and related efforts in the BRAMAR project, with valuable support of local partners, were able to improve the understanding of the water resources system and create valuable insights for follow-up research. Under the assumption of various scenarios for future development, no pressing threat to the groundwater system could be detected. Which does not mean 
that there is no room for improvement. Scenarios of unfavorable development in agriculture and climate revealed a high sensitivity of the system towards precipitation that might potentially lead to the danger of overexploitation and subsequent depletion in the mean groundwater table over the entire study area of more than $1,000 \mathrm{~km}^{2}$. The potential solutions designed in this study, relying on a decentralized MAR system in combination with at least partial modernization of irrigation techniques in order to reduce water losses, could help mitigate these hazards.

The semi-arid case study of Jericho-Auja in many ways stands in contrast to the tropical one. The two municipalities are both suffering from very volatile and scarce water availability. The discharge of local springs being the main source of water, the system is very sensitive towards hydrologic variability. The springs recharge in the mountain area west of the study area. The municipalities themselves receive only limited, volatile and extremely intense water by heavy rainfall events. These occur very irregular and there may be many years in a row without any significant runoff in the three wadis discharging in the area. Data on the case study was provided by partners within the context of the research and development project SMART-MOVE. Water budget assessments revealed a strong indication for the need of additional water sources. Even under conservative assumptions for the present situation and future development, the system revealed vast deficits in covering the water demands, mainly resulting from agriculture. The budgets showed an extreme potential overexploitation of the shallow local aquifer which in reality manifests itself by insufficient irrigation of the existing agricultural lands and subsequently high losses in harvests. The planned development for the region even aims at an extension of the agricultural land. Budget assessments showed that these goals could only be achieved by activation of numerous additional water sources. The most abundant additional source was identified as wells that would penetrate the deep aquifer, underlying the shallow alluvial aquifer. Even under activation of all local water sources, including treated waste water to be applied directly for irrigation and the import of waste water from a city in the mountain area, which had been defined as one possible option by local project partners, the study area would depend on additional water imports. By means of a backwards calculation, the minimum required additional imports have been determined under assumption of two future climate scenarios. Also for this case study, recommendations have been formulated for the implementation of MAR pilot plants. They even extend the MAR considerations by directly linking them to the recommendation of implementing at least one deep well in parallel.

Both case studies suffer from pressure regarding water resources system that has either manifested itself already (Jericho-Auja) or will do so within the next decades (João Pessoa) might potentially be addressed by the implementation of a Managed Aquifer Recharge solution, which has to be designed individually to each case. Some of the results presented and elaborated in this thesis may support their realization. 
Both case studies also suffer from a lack in data. Partially the selected methodology had to be applied under assumptions and estimations for some parameters. If the approach could not fulfill its purpose to identify water management strategies to a full extend, it at least revealed data deficits that should be accounted for by means of new and extended monitoring campaigns.

\subsection{Conclusion}

After evaluation of the individual steps of the new integrative MAR planning approach some conclusions can be made with regarding its applicability and the resulting suggestions for MAR implementation. It became clear that the approach could not be followed to its full extend in both case studies. Rather, some improvisation had to be performed that can be judged as sufficient for some of the tasks but unfortunately insufficient for others. The reason for some of the steps not producing satisfying results can be found in the inadequate availability of data. Especially with regard to monitoring of key components of the water resources system monitoring and available long term data was insufficient to fully apply the approach. On the one hand it was an objective of this thesis to develop an approach that is flexible enough to be applied to a broad variety of case studies. Since water shortage often impacts underdeveloped regions that did not or cannot invest much in the management of water resources, a certain lack of data availability must always be assumed. On the other hand the approach should also serve as a framework that helps identifying weaknesses in the current water and data management and aims at improving these. The approach should show what would be possible if investments in the right measures would be increased. These measures do not primarily mean IWRM measure as addressed in the study, but first and foremost the investment in monitoring and other evaluations. This became especially obvious in the João Pessoa case study where the pressure on the water system and on the responsible stakeholders is not yet indicated but very likely a problem that will manifest itself in the future. Here, adequate monitoring of the available water availability (surface and groundwater) and the actual extraction and consumption of water is highly required. If the suggested approach can help underlining the importance of data acquisition as a fundamental basis to build any IWRM or MAR planning upon, then the approach does not fail its objective. On the other hand there is a case study like Jericho-Auja, where the bad water resources situation becomes very obvious even without proper monitoring. Here the approach was able to supply stakeholders with information on what could be possible with regard to a positive development of the region and what measure this would require.

The suggested planning approach was able to identify deficits and produce quite a list of recommendations for both case studies. The high level of uncertainty of the results given in this thesis are foremost a problem of data scarcity. The application presented here was primarily for illustrative purposes, which does not mean that the final recommendations are not valid. But they can be valid 
only within the frame of valid data. Additional studies, such as the highly anticipated implementation of pilot plants and parallel water quality monitoring campaigns, will be required in order to give final statements about the applicability of Managed Aquifer Recharge as a key measure to help mitigate the water scarcity (present or future) in both case studies.

Overall the approach can be considered a mere framework and a guideline. It succeeded in joining MAR and IWRM as a strategic unit with regards to water planning. It failed in providing all the tools and individual methods that are required to successfully implement each of the ten steps. The initially mentioned MARSOL project (TU Darmstadt, 2018) produced many valuable results for the promotion of Managed Aquifer Recharge and was conducted mostly in parallel to this study, starting roughly one year before the works on this thesis. Hence, its results were not available for this study until the last year of its runtime. Evaluation of the MARSOL products revealed that it developed, in contrast to this thesis, much more detailed suggestions for data acquisition, field and laboratory tests and other specific measures with regards to MAR implementation, operation and optimization. They were mainly developed around eight different MAR case studies (TU Darmstadt, 2018). But they do not address an overall MAR planning framework in the scope of the one presented in this thesis. The newly developed approach does not address specific thresholds or parameters but gives a direction and orientation for the planning of a MAR project on a broader scale. As was initially pointed out, in literature there are some regulations and guidelines presented and discussed within other studies (e.g. Dillon et al., 2009, Asano \& Cotruvo, 2004, Wang et al., 2014, González et al., 2015) but they are very specific for one region or country. The results of this thesis underline the impossibility to present universally valid thresholds or list of parameters that can be applied to any case study. A framework and guideline such as the approach presented in this thesis should be used foremost in order to identify what these site specific parameters and data deficits are. Then they should be addressed in an appropriate manner with tools and methods, as for example developed by the MARSOL project (TU Darmstadt, 2018). The developed approach helped identifying the data gaps in the two case studies. It can be used to identify those of other case studies, bring them to the attention of local stakeholders and initiate adequate, more specific measures to address those gaps.

\subsection{Recommendations}

Both case studies revealed one major important key factor with regard to water resources management: the availability of data. It became clear that available data on groundwater resources can be very scarce, even in regions for which local groundwater resources are of major importance for the water supply. A region that does not have a fully functional, at least basic, monitoring network of the major elements of its water budget, cannot establish valid water plans for its future development. Therefore, the main recommendation that will be given in this thesis is to focus future 
research on the establishment of monitoring networks and their evaluation. By applying the suggested MAR planning approach to these data scarce regions, results could only be given within a certain range of uncertainty. The higher the uncertainty of available data, the more assumptions and approximations had to be undertaken to receive some results, the higher the uncertainty of the results themselves.

For the tropical case study of João Pessoa the only control on water extractions from the local aquifer system and the rivers is by means of license values, so called outorgas. These do reflect the legally allowed annual extraction of water, e.g. for pumping wells, but do neither reflect the temporal operation of the facility, nor the actual extraction which might vary from the license. One very important recommendation is at least the installation of water clocks or similar tools to monitor the actual withdrawal from both, the aquifer and rivers. A similar recommendation can be given for the numerous surface reservoirs in the study area and the entire northeast of Brazil. For these only water levels are recorded. These do reflect the current status of water storage but not the volume of in-and outflow of the storage. Quantities that are of major importance in order to manage and optimize these storage facilities. This directly correlates with surface runoff in the rivers. Only very scarce data is available on the actual discharge. There was some coherent data available from prior studies, but the official monitoring of surface runoff lacks continuity and precision. Mostly it is based on rods, installed and calibrated some years ago that are read out by locals on a daily basis who send the readings to the responsible authority by letter once a month. This system is in urgent need of additional funding and modernization. The project installed some automated runoff level gauges in cooperation of local and German partners. As has been presented, also groundwater level gauges have been installed by the project and are supported by manual readings in additional wells by local partners. This monitoring also requires the support and funding from the responsible authorities. The study showed that at least a coarse monitoring network of ground-and surface water resources would immensely benefit the region and its development with regard to upcoming challenges in water resources management. The results from this study will therefore be used to formulate policy briefs for the responsible local and national authorities.

For the semi-arid case study of Jericho-Auja more pressing recommendations can be given. Since water shortage is an acute problem in the area, it is highly recommended to set a focus on the activation of new water sources. An improved retention of surface runoff will bring relatively small benefits. Rather the installation of additional wells, withdrawing water from greater depth than the local shallow aquifer, is highly recommended as the potential IWRM measure with the greatest positive impact for the region. This measure will require high investment costs but is, based on the conducted impact assessments of this study, the measure with the highest benefit and allows for a vast increase in water security and the extension of agricultural lands, which might result in economic 
and social benefits for the region. In addition, before any extended IWRM measures are considered, the local water management and hydro-infrastructure is in dire need of modernization. Water losses due to transport, storage and application are very high and must be reduced. The current system of water distribution in Auja village requires reformation. Monitoring of groundwater levels and quality must be implemented.

For both case studies the implementation of MAR pilot plants is recommended, a rough concept of which is given in the thesis. For João Pessoa at least two pilot plants are suggested. One should be located in the rural area, running on a surface infiltration technology, such as infiltration ponds, if suitable in combination with passive infiltration wells to increase infiltration rates. The other in the urban vicinity by means of direct injection due to the requirement for higher recharge rates and the lack of suitable and available surface area. Both plants should be fed with surface runoff from the nearest river that must be pre-treated at least with regard to sediment load to reduce clogging and, in the case of direct injection, with regard to contaminants which must be monitored in order to avoid contamination of the groundwater resources. For Jericho-Auja at least one pilot plant is recommended to be installed near Auja village. By using parts of the existing hydro-infrastructure, the costs of implementation should be reduced. For its operation water from the Auja spring should be utilized. In order to compensate local farmers for the apparent withdrawal of water it is highly recommended to combine the pilot plant with the construction of a deep well, increasing the water supply for the village and thus the acceptance of the experiment. The pilot plants in both cases should be monitored in and adequate manner and operated for at least two years. The results are supposed to be used to set up, respectively improve, local groundwater models and improve the knowledge on the underground system. This study could not address the very important issue of groundwater quality and focused on quantitative aspects of water resources management. It is highly recommended to evaluate water quality data in both case studies and include the results in the assumptions and considerations of this thesis.

Finally it can be said that the suggested approach can be viewed as a recommendation and guideline for future studies that address the complex issue of Integrated Water Resources Management in an environment suitable for the implementation of Managed Aquifer Recharge. Further research on the topic of integrating MAR to the IWRM concept is required. 


\section{REFERENCES}


Abdel-Ghafour D. (2005): Water Resources Development in Jordan Valley. Concept Paper for: Small-Scale Storm Water Harvesting in Wadi El-Qilt Jericho-West Bank, PWA, Ramallah, Palestine.

Abels, A., Freitas, M., Pinnekamp, J., Rusteberg, B. (2018): BRAMAR Project. Water Scarcity Mitigation in Northeast Brazil. RWTH Aachen - Institut für Siedlungswasserwirtschaft. ISBN: 978-3-00-059926-2

Abu Sadah (2017): Development of a Modflow groundwater model Jericho-Auja. Unpublished report, SMART-MOVE Project. HEC Ramallah, Palestine.

Abu Sadah, M., \& Tamimi, A. (2011): Demand Assessment for Al Qilt, An Nueimah and Al Auja. PHG, Ramallah, Palestine.

Alheiros, M.M. e Lima Filho M.F. (1991): Formação Barreiras -Revisão Geológica da Faixa Sedimentar Costeira de Pernambuco, Paraíba e Rio Grande do Norte Centro de Tecnologia da UFPE, Recife.

Ali, W., Geyer, S., Ghanam, M., Haddad, M., \& Hötzl, H. (2009): Hydrochemistry and isotope hydrogeology in the Jericho area / Palestine. In H. H., P. Möller, \& E. Rosenthal (Eds.), The water of the Jordan Valley-Scarcity and Deterioration of Groundwater and its Impact on the Regional Development. Springer, Berlin Heidelberg.

Arduino, G., Bono, P., Giang, N. V., Thoa, N. T. K., \& Vuong, B. T. (2008): Management of aquifer recharge - Groundwater storage in the sand dunes of Viet Nam. Special Feature: Water Harvesting Technologies; Published in Tech Monitor.

Asano, T., \& Cotruvo, J. A. (2004): Groundwater recharge with reclaimed municipal wastewater: health and regulatory considerations. Water Research, 38, 1941-1951. https://doi.org/10.1016/j.watres.2004.01.023

ASCE. (2001): Standard Guidelines for artificial recharge of ground water. Environmental and Water Resource Institut (U.S.); by the American Society of Civil Engineers (ASCE).

Barbosa, J. A.; Souza, E. M. de.; Lima Filho, M. F.; Neumann, V. H. (2003): A Estratigrafia da Bacia Paraíba: uma Reconsideração. Estudos Geológicos. v.13, p.89108.

Bekele, E., Page, D., Vanderzalm, J., Kaksonen, A., Gonzalez, D. (2018): Water Recycling via Aquifers for Sustainable Urban Water Quality Management: Current Status, Challenges and Opportunities. Water 2018, 10, 457; doi: 10.3390/w10040457

Bindu, C. A., \& Mohamed, A. R. (2016): Water Bodies as a Catalyst to Growth and DevelopmentThe Case of Kodungallur Town, Kerala. Procedia Technology, 24, 1790-1800. https://doi.org/10.1016/j.protcy.2016.05.222

Bouwer, H. (1996): Issues in Artificial Recharge. Water Science and Technology 33; IAWQ, Great Britain. 
Braga C. F. C., Braga, A. C. F. M., Galvao, C. d. O., Ribeiro, M. M. R., Fernandes, R. d. O., Cunha, J. E., Figueiredo, E. A., Felinto, C. M. R., De Araujo, M. D. (2018): Climate Change and socioeconomic "Scenarios". In: Abels, A., Freitas, M., Pinnekamp, J., Rusteberg, B. (2018): BRAMAR Project. Water Scarcity Mitigation in Northeast Brazil. RWTH Aachen - Institut für Siedlungswasserwirtschaft. ISBN: 978-3-00-059926-2

Brito Neves, B. B.; Albuquerque, J. P. T.; Coutinho, J. M. V.; Bezerra. F. H. R. (2009): Novos Dados Geológicos e Geofísicos para a Caracterização Geométrica e Estratigráfica da Sub-bacia de Alhandra (Sudeste da Paraíba): Revista do Instituto de Geociências - USP, Série Científica, São Paulo, v. 9, n. 2, p.63-87.

Capone, F., Bonfanti, M. E. (2015): Legislative Framework Review and Analysis. Deliverable D17.1 MARSOL Project. http://www.marsol.eu/files/marsol_d17-1_legislative_20150321.pdf

Casanova, J., Devau, N. \& Pettenati, M. (2016): Managed Aquifer Recharge: An Overview of Issues and Options. in Integrated Groundwater Management 413-434 (Springer International Publishing, 2016): doi:10.1007/978-3-319-23576-9_16

Chidammodzi, C. L., \& Muhandiki, V. S. (2017): Water resources management and Integrated Water Resources Management implementation in Malawi: Status and implications for lake basin management. Lakes \& Reservoirs: Research \& Management, 22(2), 101-114. https://doi.org/10.1111//re.12170

Chittoor, V., Jiang, Y., Berg, M., Hunkeler, D., \& Schirmer, M. (2016): An integrated spatial snapshot monitoring method for identifying seasonal changes and spatial changes in surface water quality. Journal of Hydrology, 539, 567-576. https://doi.org/10.1016/j.jhydrol.2016.05.017

Choi, J., Skibniewski, M. Shim, Y.-G. (2018): Economics of alternative water resources with an emphasis on aquifer storage and recovery. Open Access. doi: 10.2166/ws.2017.137

Coelho, V. H. R. (2011): Monitoramento e análise da variação do nível d água para estimativa da recarga do aqüífero livre da bacia do Rio Gramame - PB, 147. Retrieved from http://tede.biblioteca.ufpb.br:8080/handle/tede/5451

Costa, W. D., Albuquerque, J. P., Castelo Branco, R. L. (2007): Estudo de caracterização e verificação da disponibilidade hídrica da vertente litorânea do estado da Paraíba. Estudos Hidrogeológicos. Relatório Final. Tomo I - Texto. Ministério da Integração Nacional, 125p.

DaSilva, E. B. (2016): Use of soil column tests in bench scale for assessing the feasibility of a Soil Aquifer Treatment (SAT) with river and secondary effluent of a Wastewater Treatment Plant in João Pessoa, Paraiba (Brazil): Master thesis. Technical University Dresden.

DaSilva Santos, M., (2011): Characterizacao geomorfologica e do quadro fisico da carta topografica de Pittimbu-PB, 1:25000. Dissertacao apresentada ao Programa de Pos-graduacao em Geografia -PPGG. Universidade Federal da Paraiba, em cumprimento as exigencies para obtencao do grau de Mestre em Geogragia. 
De Gilio, O., Caggiano, G., Apollonio, F., Marzella, A., Brigida, S., Ranieri, E., Lucentini, L., Uricchio, V. F., Montagna, M. T. (2018): The aquifer recharge: an overview of the legislative and planning aspect. Ann Ig 2018; 30: 34-43 doi:10.7416/ai.2018.2193

Dillon, P. (2005): Future management of aquifer recharge. Hydrogeology Journal, 13(1), 313-316. https://doi.org/10.1007/s10040-004-0413-6

Dillon, P., Pavelic, P., Page, D., Beringen, H., \& Ward, J. (2009): Managed aquifer recharge: An Introduction. Retrieved from https://recharge.iah.org/files/2016/11/MAR_Intro-Waterlines2009.pdf

Dillon, P., \& Arshad, M. (2016): Managed Aquifer Recharge in Integrated Water Resource Management. In Integrated Groundwater Management (pp. 435-452): Cham: Springer International Publishing. https://doi.org/10.1007/978-3-319-23576-9_17

Dudeen, B. (2001): The soils of Palestine (The West Bank and Gaza Strip): Current Status and Future Perspectives. In P. Zdruli, P. Steduto, C. Lacirignola, \& L. Montanarella (Eds.), Options mediterraneennes, Soil Resources of Southern and Eastern Mediterranean Countries. Serie B. Studies and Research, Nr.34. CIHEAM, 203-233. Paris. France.

EXACT. (1998): Overview of Middle East Water Resources. Water Resources of Palestinian, Jordanian and Israeli Interest. Executive Action Team - Middle East Water Data Banks Project. U.S. Geological Survey.

FAO. (1977): Guidelines for predicting crop water requirements. FAO Irrigation and Drainage Paper, 24 (Editors J. Doorenbos, W.O. Pruitt).

Fatema, S., Marandi, A., Zahid, A., Hassan, M. Q., Hossain, M. A., Schüth, C. (2018): Seawater intrusion caused by unmanaged groundwater uses in a coastal tourist area, Cox's Bazar, Bangladesh. Springer-Verlag GmbH Germany, part of Springer Nature 2018. Environmental Earth Sciences (2018) 77:75. https://doi.org/10.1007/s12665-018-7260-6

Fatkhutdinov, A., Stefan, C. (2018): Multi-Objective Optimization of Managed Aquifer Recharge. National Ground Water Association. Groundwater. doi: 10.1111/gwat.12793

Frasier, C. M., Kalin, R. M., Rivett, M. O., Nkhata, M. P., Kanjaye, M. (2018): A national approach to systematic transboundary aquifer assessment and conceptualisation at relevant scales: A Malawi case study. Journal of Hydrology: Regional Studies (2018), https://doi.org/10.1016/j.ejrh.2018.04.001

Furrier, M., De Oliveira Vital, S. R. (2011): A Formacao de Dolina em Areas Urbanas: o Caso do Barirro de Cruz das Armas em João Pessoa-PB. Revista Brasileira de Geografia Fisica 01 (2011) 161-173.

Gale, I. N., Macdonald, D. M. J., Calow, R. C., Neumann, I., Moench, M., Kulkarni, H., Palanisami, K. (2006): Managed Aquifer Recharge : an assessment of its role and effectiveness in watershed management, 84. Retrieved from http://nora.nerc.ac.uk/7453/1/CR06107N.pdf 
Geological Survey Israel. (1973): Geological Map Jericho.

Georg-August-Universtiy Göttingen. (2018): smart-move project website. Retrieved from http://www.iwrm-smart-move.de/ on May 21, 2018

Gibson, M. T., Campana, M. E., Nazy, D. (2018): Estimating Aquifer Storage and Recovery (ASR) Regional and Local Suitability: A Case Study in Washington State, USA. Hydrology 2018, 5, 7; doi:10.3390/hydrology5010007

González V. F., Cruickshank V. C, Palma Nava A, Mendoza M. A (2015): Recarga Artifiial de Acuíferos en México. Revista H2O, del Sistema de Aguas de la Ciudad de México. Año 2. Enero-Marzo

Google Inc. (2018): Google Earth Pro. Version 7.3.1.4507 (64-bit) . Mountain View, USA. Retrieved on $05 / 05 / 2018$.

Gopinath, T. R.; Costa, C. R.S; Júnior, M. A. S. (1993): Minerais pesados e processos deposicionais dos sedimentos da Formação Barreiras, Paraíba. In: Simpósio de Geologia do Nordeste, 15. Natal 1993. Anais. Natal. Sociedade Brasileira de Geologia /Núcleo Nordeste, pp.47-48.

Grizzetti, B., Lanzanova, D., Liquete, C., Reynaud, A., \& Cardoso, A. C. (2016): Assessing water ecosystem services for water resource management. Environmental Science and Policy, 61, 194-203. https://doi.org/10.1016/j.envsci.2016.04.008

Grönwall, J., Oduro-Kwarteng, S. (2018): Groundwater as a strategic resource for improved resilience: a case study from peri-urban Accra. Open access. Environmental Earth Sciences (2018) 77:6. https://doi.org/10.1007/s12665-017-7181-9

Gropius, M. (1999): Hydrogeological and Geophysical Investigation in Jericho Area, Palestine.

GWP -Global Water Partnership (2000): Integrated Water Resources Management. Global Water Partnership, Stockholm, Sweden. ISBN: 91-630-9229-8.

Haaken, K. and Kemna, A. (2012): Geophysical surveys at selected hot spots. Unpublished project report. Deliverable D403. SMART Project.

Hartog, N., \& Stuyfzand, P. J. (2017): Water quality considerations on the rise as the use of managed aquifer recharge systems widens. Water (Switzerland), 9(10), 7-12. https://doi.org/10.3390/w9100808

Hundecha, Y., Arheimer, B., Donnelly, C., \& Pechlivanidis, I. (2016): A regional parameter estimation scheme for a pan-European multi-basin model. Journal of Hydrology: Regional Studies, 6, 90-111. https://doi.org/10.1016/j.ejrh.2016.04.002

Huskova, I., Matrosov, E. S., Harou, J. J., Kasprzyk, J. R., \& Lambert, C. (2016): Screening robust water infrastructure investments and their trade-offs under global change: A London example. Global Environmental Change, 41, 216-227. https://doi.org/10.1016/j.gloenvcha.2016.10.007

IBGE. (2010): Dados Populacionais: Censeo Demográfico. Retrieved from https://censo2010.ibge.gov.br 
ICWE -International Conference on Water and Environment (1992): The Dublin Statement on Water and Sustainable Development. International Conference on Water and the Environment. Waterlines 10, 4-5.

INMET - Brazilian National Institute of Meteorology. (2017a): Precipitação Acumulada Mensal e Anual (mm). Retrieved August 30, 2017, from http://www.inmet.gov.br/webcdp/climatologia/normais/imagens/normais/planilhas/Precipitac ao-Acumulada_NCB_1961-1990.xls

INMET - Brazilian National Institute of Meteorology. (2017b): Temperatura Média Compensada $\left({ }^{\circ} \mathrm{C}\right) . \quad$ Retrieved $\quad$ August $\quad 30, \quad 2017, \quad$ from http://www.inmet.gov.br/webcdp/climatologia/normais/imagens/normais/planilhas/Temperatu ra-Media-Compensada_NCB_1961-1990.xls

ISA RWTH; Institut für Siedlungswasserbau der RWTH Aachen. (2015): BRAMAR Project Website. Retrieved May 31, 2017, from http://www.bramar.net/

Jadeja, Y., Maheshwari, B., Packham, R., Bohra, H., Purohit, R., Thaker, B., Dillon, P., Oza, S., Dave, S., Soni, P., Dashora, Y., Dashora, R., Shah, T., Gorsiya, J., Katara, P., Ward, J., Kookana, R., Singh, P. K., Chinnasamy, P., Goradiya, V., Prathapar, S., Varua, M., Chew, M. (2018): Managing Aquifer recharge and sustaining groundwater use: developing a capacity building program for creating local groudnwater champions. Springer International Publishing AG, part of Springer Naure 2018. Sustainable Water Resources Management. https://doi.org/10.1007/s40899-018-0228-6

Jayakumar, M., Saseendran, S. A., \& Hemaprabha, M. (1988): Crop Coefficient for Cocounut (Cocos nucifera l.): A Lysimeter Study. Meteorology, Forest V, Elsevier Science Publishers B, 43, 235 240.

Jin, G., Deng, X., Hasan, S. S., Zhao, C., Gibson, J. (2018): Hydrological Ecosystem Services for Integrated Water Resources Management. Springer Nature Singapore Pte Ltd. 2018. X. Deng, J. Gibson (eds.), River Basin Management, Ecohydrology, https://doi.org/10.1007/978-981-100841-2_6-1

Kawo, N. S., Zhou, Y., Magalso, R., Salvacion, L. (2018): Optimization of an artificial-rechargepumping system for water supply in the Maghaway Valley, Cebu, Philippines. Springer-Verlag GmbH Germany, part of Springer Nature 2017. Hydrogeology Journal (2018) 26:963-977 https://doi.org/10.1007/s10040-017-1693-y

Kazner, C., Wintgens, T., Dillon, P. (2012): Water Reclamation Technologies for Safe Managed Aquifer Recharge. IWA Publishing. ISBN 9781843393443

Khayat S. K., (2005): Hydrochemistry and Isotope Hydrogeology in the Jericho Areal Palestine; thesis for the degree of Doctor of Natural Sciences; Faculty of Civil Engineering, Geosciences and Environmental Sciences, University of Karlsruhe, Germany.

Kiparsky, M., Fisher, A. T., Hanemann, W. M., Bowie, J., Kantor, R., Coburn, C., Lockwood, B. (2018): Recharge Net Metering To Enhance Groundwater Sustainability. Center for Law, Energy \& the Environment Publications. 51. htts://scholarship.law.berkeley.edu/cleepubs/51 
Köppen, Wladimir (1918): Klassification der Klimate nach Temperatur, Niederschlag and Jahreslauf. Petermanns Geographische Mitteilungen. 64.

Kübeck, C., Nottebohm, M. (2016): Guideline for Water Quality Requirements at MAR sites. Deliverable D14.4 MARSOL Project. http://www.marsol.eu/files/marsol_d14-4_waterquality-requirements.pdf

Kübeck, C., Jimenez, N., Rossetto, R., De Filippis, G., (2017): Guideline for Contaminants Modelling at MAR Sites. Deliverable D14.5 MARSOL Project. http://www.marsol.eu/files/marsol_d14-5_contaminants-modelling_final.pdf

Kumar, S. N., Bai, K. V. K., Rajagopal, V., \& Aggarwal, P. K. (2008): Simulating coconut growth, development and yield with the InfoCrop-coconut model, (2003), 1049-1058.

Leal E Sá, L. T. (1998): Levantamento geológico-geomorfológico da Bacia Pernambuco-Paraíba, no trecho compreendido entre Recife-PE e João Pessoa-PB. 1127f. Dissertação (Mestrado) Centro de Tecnologia, Universidade Federal de Pernambuco, Recife.

Linton, J. (2014): Modern water and its discontents: a history of hydrosocial renewal. Wiley Interdisciplinary Reviews: Water, 1 (January/February), 111-120. https://doi.org/10.1002/wat2.1009

Lummertz, F. B. (1977): Aspectos da hidráulica subterrânea na área da Grande João Pessoa. Dissertação (Mestrado) UFPE/Escola de Geologia, Recife.

Lutz, B. A. (2011): Managed Aquifer Recharge (MAR ) Planning in the Jericho Region, Palestine. Master Thesis. Georg-August-University Göttingen.

Mabesoone, J. M., Tinoco, I. M., Coutinho, P. N. (1972): The Mesozoic-Tertiary Boundary in Northeastern Brazil. Palaeogeography, Palaeoclimatology, Palaeoecology. 4: p.161-185.

Mabesoone, J. M. (1994): Sedimentary basins of northeast Brazil. Recife UFPE/CT/DG, 310p. (Publicação Especial):

McKnight, T. L., \& Hess, D. (2000): Physical Geography: A Landscape Apprectiation. Upper Sadle River, NJ: Prentice Hall.

Messerschmid, C., \& Nazzal, M. (2008): Site Investigation Report for the proposed landfill site located in Palestine, SI 08/0353.

Messerschmid, C., \& Sawalhi, B. (1999): Hydrogeological study on Al-Mughayir and Khirbet Abu Falah. Proposed boreholes.

Mortimer, E. (2014): The Water Report Managed aquIfer recharge An overview of Laws Affecting Aquifer Recharge in several western States. Retrieved from http://www.idahowaterengineering.com/wp-content/uploads/2015/01/Managed-AquiferRecharge-Part-1-by-Evan-Mortimer-Sep-15-2014.pdf 
Moeck, C., Affolter, A., Radny, D., Dressmann, H., Auckenthaler, A., Huggenberger, P., Schirmer, M. (2018): Improved water resources management for a highly complex environment using three-dimenstional grundwater modelling. Springer-Verlag GmbH Germany 2017. Hydrogeol J (2018) 26:133-146. DOI 10.1007/s10040-017-1640-y

Nava, A. P., Villarreal, F. J. G., Mata, A. M. (2018): The development of a managed aquifer recharge project with recycled water for Chihuaha, Mexico. Open access publication. Sustainable Water Resources Management. https://doi.org/10.1007/s40899-018-0234-8

Page, D., Gonzalez, D., Naumann, B., Dillon P., Vanderzalm, J., and Barry, K. (2013): Stormwater Managed Aquifer Recharge Risk-Based Management Plan, Parafield Stormwater Harvesting System, Stormwater supply to the Mawson Lakes Recycled Water Scheme, Industrial Uses and Public Open Space Irrigation. Goyder Institute for Water Research Technical Report (Vol. 13/18): Adelaide, South Australia. Retrieved from http://www.goyderinstitute.org/_r114/media/system/attrib/file/105/2_Parafield Stormwater MAR Risk-Based Management Plan Goyder June 2014.pdf

Page, D., Bekele, E., Vanderzalm, J., Sidhu, J. (2018): Managed Aquifer Recharge (MAR) in Sustainable Urban Water Management. Water 2018, 10, 239; doi: 10.3390/w10030239

Parimalarenganayaki, S., Elango, L. (2019): Quantification of groundwater recharge and river bed clogging by daily water level measurements in a check dam. Saudi Society for Geosciences 2018. Arabian Journal of Geosciences (2018) 11: 174. https://doi.org/10.1007/s12517-018$3511-9$

Patel, J. N., Desai, M. (2018): Optimum Diameter of Groundwater Recharge Well Conjunction with Storm Water Drainage System. KSCE Journal of Civil Engineering (2018) 22(2):859-867. Korean Society of Civil Engineers. DOI 10.1007/s12205-017-3045-9

PCBS. (2010): Press Release on the Occasion of World Meteorological Day. Palestine Central Bureau of Statistics and Meteorological Directorate, Palestine.

PDRH. (2000): Diretor de Recursos Hídricos da Bacia do Rio Gramame. SEMARH/SCIENTEC.

Pereira da Silva, E. (2006): Mapeamento Gravimétrico e Cintilométrico das estruturas da Bacia Paraíba (Parte Oriental) entre os paralelos Ponta do Funil (PE) e Pitimbú (PB): Monografia. Universidade Federal de Pernambuco. Centro de Tecnologia e Geociências. Graduacão em Geociências.

Pulido-Velazquez, M., Marques, G. F., Harou, J. J., \& Lund, J. R. (2016): Hydroeconomic Models as Decision Support Tools for Conjunctive Management of Surface and Groundwater. In Integrated Groundwater Management (pp. 693-710): Cham: Springer International Publishing. https://doi.org/10.1007/978-3-319-23576-9_27

PWA - Palestinian Water Authority (2007): Historic spring discharge data. Unpublished internal report, SMART Project. 
Rama, F., Miotlinski, K., Franco, D., Corseuil, H. X. (2018): Recharge estimation from discrete water-table datasets in a coastal shallow aquifer in a humid subtropical climate. SpringerVerlag GmbH Germany, part of Springer Nature 2018. Hydrogeology Journal. https://doi.org/10.1007/s10040-018-1742-1

Roja, R., Commander, P., McFarlane, D., Ali, R., Dawes, W., Barron, O., Hodgson, G., Charles, S. (2018): Groundwater Resource Assessment and Conceptualization in the Pilbara Region, Western Australia. Springer International Publishing AG, part of Springer Nature 2018. Earth Systems and Environment. https://dor.org/10.1007/s417848-018-0051-0

Ross, A., Hasnain, S. (2018): Factors affecting the cost of managed aquifer recharge (MAR) schemes. Springer International Publishing AG, part of Springer Nature 2018. Sustainable Water Resources Management. https://doi.org/10.1007/s40899-017-0210-8

Rahaman, M. \& Varis, O. (2005): Integrated water resources management: evolution, prospects and future challenges, Sustainability: Sciecen, Practice and Policy, 1:1, 15-21, DOI: 10.1080/15487733.2005.11907961

Rahman, M. A., (2011): Decision Support for Managed Aquifer Recharge (MAR) Project Planning to Mitigate Water Scarcity based on Non-conventional Water Resources. PhD Thesis. GeorgAugust-University-Göttingen.

Rahman, M. A., Rusteberg, B., Gogu, R. C., Lobo Ferreira, J. P., Sauter, M. (2012): A new spatial multi-criteria decision support tool for site selection for implementation of managed aquifer recharge. Journal of Envrionmental Management 99, pp. 61 -75

Rusteberg, B. (2008): Groundwater artificial recharge by alternative sources of water to guarantee water supply in the future: The European Research Project Gabardine, Conference AQUA 2006, Water Science and Technology: Integrated Management of Water Resources, proceedings, Athens, Hellas.

Rusteberg. B., A.R. Tamimi, M.A. Rahman, B. Brauns, A.A.M. Shawahna, S. Schmidt, J. Bensabat, J. Guttman, M. Sadah, A. Jarrar, H.Hötzl, M. Sauter (2011): Practical Approach towards Integrated Management of Water Resources in the Lower Jordan Valley: Case Study Auja, West-Bank, IWRM 2011, Dresden Germany

Rusteberg, B., Rahman, M.A., J. Bear, J. Bensabat, R.C. Gogu, S. Brouyere, P. Wojda, M.A. Sadah, J.P. Lobo-Ferreira, Sauter, M. (2012): Decision support for MAR planning in the context of integrated water resources management, Chapter 23 in: Advances in Water Reclamation Technologies for Safe Managed Aquifer Recharge - Christian Kazner, Thomas Wintgens, Peter Dillon, 2012 - ISBN - 9781843393443.

Rusteberg, B., Bensabat, J., Walter, F., Riepl, D., Guttman, Y., Tamimi, A. R., Sauter, M. (2014): IWRM Strategies at local sub-basin level, sensitivity analysis and performance assessment. Unpublished report, Deliverable D803-804-805, SMART II project. Georg-August-Unviersity Göttingen. 
Rusteberg, B., Walter, F., Alkhoury, W., Tamimi, A. R., Guttman, Y., Sauter, M. (2014a): Quantification and spatial delineation of currently untapped water resources. Unpublished report, Project Deliverable D402, SMART II project. Georg-August-Unviersity Göttingen.

Rusteberg, B., Walter, F., Xanke, J., Klinger, J., Sadah, M. A., Marei, A., Salameh, E., Guttman, Y. and Tamimi, A. R. (2014b): Development, Evaluation and Ranking of Managed Aquifer Recharge (MAR) Planning Options in Case Study Areas of the Lower Jordan Valley. Unpublished report, Project Deliverable D318-320, SMART II project. Georg-AugustUniversity Göttingen.

Rusteberg, B., Farias, C. B. d. A., Almeida, C. d. N., DaSilva, G. S., Rufino, I. A. A. (2018): The BRAMAR Information and Decision Support System. In: Abels, A., Freitas, M., Pinnekamp, J., Rusteberg, B. (2018): BRAMAR Project. Water Scarcity Mitigation in Northeast Brazil. RWTH Aachen - Institut für Siedlungswasserwirtschaft. ISBN: 978-3-00-059926-2

Rusteberg, B., Tamimi, A., Saddah, M. A., Walter, F., Schmidt, S., Samhan, S., Nofal, I., Guttman, Y. (2018a): Comparison of alternative water development and planning options towards sustainable IWRM implementation in the Lower Jordan Valley based on indicator assessment. Conference presentation; EGU 2018, Vienna.

Santos, M. S., Freitas, G. A., Furrier, M. (2013): Analise morfometrica e indicios de acao neotectonica na area correspondente a folha pitimbu, litoral sul da paraiba, Nordeste do Brasil. Mestre em Geografia, Programa de Pos-Graduacao em Geografia da Universidade Federal da Paraiba - UFPB.

Sapiano, M., Schembri, M., Capone, F.., Bonfanti, M., Lazzaroni, M., Mazzanti, G. (2016): Proposal for a regulatory scheme to guide the application of MAR projects. Deliverable D17.4 MARSOL Project. http://www.marsol.eu/files/marsol_d17-4_proposal-regulatoryframework_20160920.pdf

Sapiano, M., Capone, F., Fernández Escalante, E., \& Schüth, C. (2017): Policy document for decision makers. Deliverable 17.5 MARSOL Project. https://recharge.iah.org/files/2017/10/marsol_86_d17-5_policy-document-for-decision-makers_2017.pdf

Scherberg, J., Keller, J., Patten, S., Baker, T., Milczarek, M. (2018): Modeling the impact of aquifer recharge, in-stream water saving, and canal lining on water resources in the Walla Walla Basin. Springer International Publishing AG, part of Springer Nature 2018. Sustainable Water Resources Management. https://doi.org/10.1007/s40899-018-0215-y

Schimmelpfennig, S., Meon, G., Schöniger, M., Ta, D. P., Tsuyuguchi, B. B., Braga, A. C. R., Filho, J. D. d. A. P., Nunes, F. M. S., Rego, J. C., Galvao, C. d. O., De Alcantara, H. M., Srinivasan, V. S., De Aragao, R., Almeida, C. d. N., Caicedo, N. L., Barbosa, L. R., Fernances, L. d. A., Filho, G. M. R., Gadelha, A. N., Goncalves, E. N., Da Cruz, M. S., Montenegro, S. M. G. L., Coelho, V. H. R., Paiva, A. L. R., Bertrand, G. F. (2018): Hydro(geo)logical Modelling. In: Abels, A., Freitas, M., Pinnekamp, J., Rusteberg, B. (2018): BRAMAR Project. Water Scarcity Mitigation in Northeast Brazil. RWTH Aachen - Institut für Siedlungswasserwirtschaft. ISBN: 978-3-00-059926-2 
Schmidt, S. (2018): Analysis and characterization of hydrological variability and extreme events Cluster West. Unpublished report, SMART-MOVE Project, Deliverable D101. Georg-AugustUniversity Göttingen.

Shawanah, A. (2010): Estimation the Physical Properties of the Plio-Pleistocene aquifer in Uja Area, Jericho District/occupied Palestine. Master Thesis, Al-Quds University, Palestine.

Singer, A. (2007): The soils of Israel. Springer, Heidelberg.

Singh, A. (2010): Decision support for on-farm water management and long-term agricultural sustainability in a semi-arid region of India. Journal of Hydrology, 391(1-2), 63-76. https://doi.org/10.1016/J.JHYDROL.2010.07.006

Sprenger, C., Hartog, N., Hernández, M., Vilanova, E., Grützmacher, G., Scheibler, F., \& Hannappel, S. (2017): Inventory of managed aquifer recharge sites in Europe: historical development, current situation and perspectives. Hydrogeology Journal, 1-14. https://doi.org/10.1007/s10040-017-1554-8

Stefan C, Ansems N (2017): Web-GIS global inventory of managed aquifer recharge applications. https://ggis.un-igrac.org/ggisviewer/viewer/globalmar/public/default. Accessed May 20, 2018

Striem, H. L. and Rosenan, N. (1973): Rainspells, as a climatological parameter, used in the analysis of rainfall in Jerusalem: Arch. Met. Geophy. Biokl., Ser. B, 21; 25-42.

Suguio, K.; Meis, M.R.M. \& Tessler, M.G. (1986): Atas do IV Simpósio do Quaternário no Brasil. Rio de Janeiro: CTCQ-SBG.

Teixeira, A. H. D. C., Bastiaanssen, W. G. M., Moura, M. S. B., Soares, J. M., Ahmad, M. D., \& Bos, M. G. (2008): Energy and water balance measurements for water productivity analysis in irrigated mango trees , Northeast Brazil, 148, 1524-1537. https://doi.org/10.1016/j.agrformet.2008.05.004

TU Darmstadt (2018): MARSOL Project website. www.marsol.eu. Institute of Applied Geosciences, Technische Universität Darmstadt, Germany. Retrieved June 13, 2018.

UNESCO. (2009): IWRM Guidelines at River Basin Level - PART 2-1: The Guidelines for IWRM Coordination. Retrieved from http://unesdoc.unesco.org/images/0018/001864/186418e.pdf

UN-Water (2012): Status Report on The Application of Integrated Approaches to Water Resources Management. United Nations Environment Programme. ISBN: 978-92.807-3264-1.

Walter, F. (2013): Managed Aquifer Recharge Planning by Groundwater Modelling and appropriate Decision Criteria for Wadi Auja, Palestine. Master Thesis. Georg-August-University Göttingen, Dept. Applied Geology.

Walter, F. (2013a): Interviews with local farmers in Auja, Palestine. Unpublished report, SMART II project. Georg-August-University Göttingen.

Walter, F. (2016): Interviews with local farmers in João Pessoa, Brazil. Unpublished report, BRAMAR project. Georg-August-University Göttingen. 
Walter, F., Gerold, G., Almeida, C. d. N., Barbosa, G. A., Coutinho, J. V., Braga, A. C. R., Filho, J. D. d. A. P., Tsuyuguchi, B. B., Rego, J. C., Galvao, C. d. O., De Alcantara, H. M., Montenegro, S. M. G. L., Coelho, V. H. R., Paiva, A. L. R., Bertrand, G. F. (2018): Managed Aquifer Recharge. In: Abels, A., Freitas, M., Pinnekamp, J., Rusteberg, B. (2018): BRAMAR Project. Water Scarcity Mitigation in Northeast Brazil. RWTH Aachen - Institut für Siedlungswasserwirtschaft. ISBN: 978-3-00-059926-2

Wang, W. P., Sun, X. Bin, \& Xu, Y. (2010): Recent advances in managed aquifer recharge in China. International Conference on Challenges in Environmental Science and Computer Engineering, CESCE 2010, 2, 516-519. https://doi.org/10.1109ZCESCE.2010.100

Wang, W., Zhou, Y., Sun, X., \& Wang, W. (2014): Development of Managed Aquifer Recharge in China, 125(2), 227-233.

Wolf, L., Werz, H., Hoetzl, H., Ghanem, M., \& Group, P. H. (2007): Exploring the potential of Managed Aquifer Recharge to mitigate Water Scarcity in the Lower Jordan River Basin within an IWRM appraoch, ISMAR6 Proceedings. 


\section{APPENDIX}


Appendix 1: $\quad$ Simulated surface runoff case study João Pessoa 2000 - 2014

(after Schimmelpfennig et al., 2018)

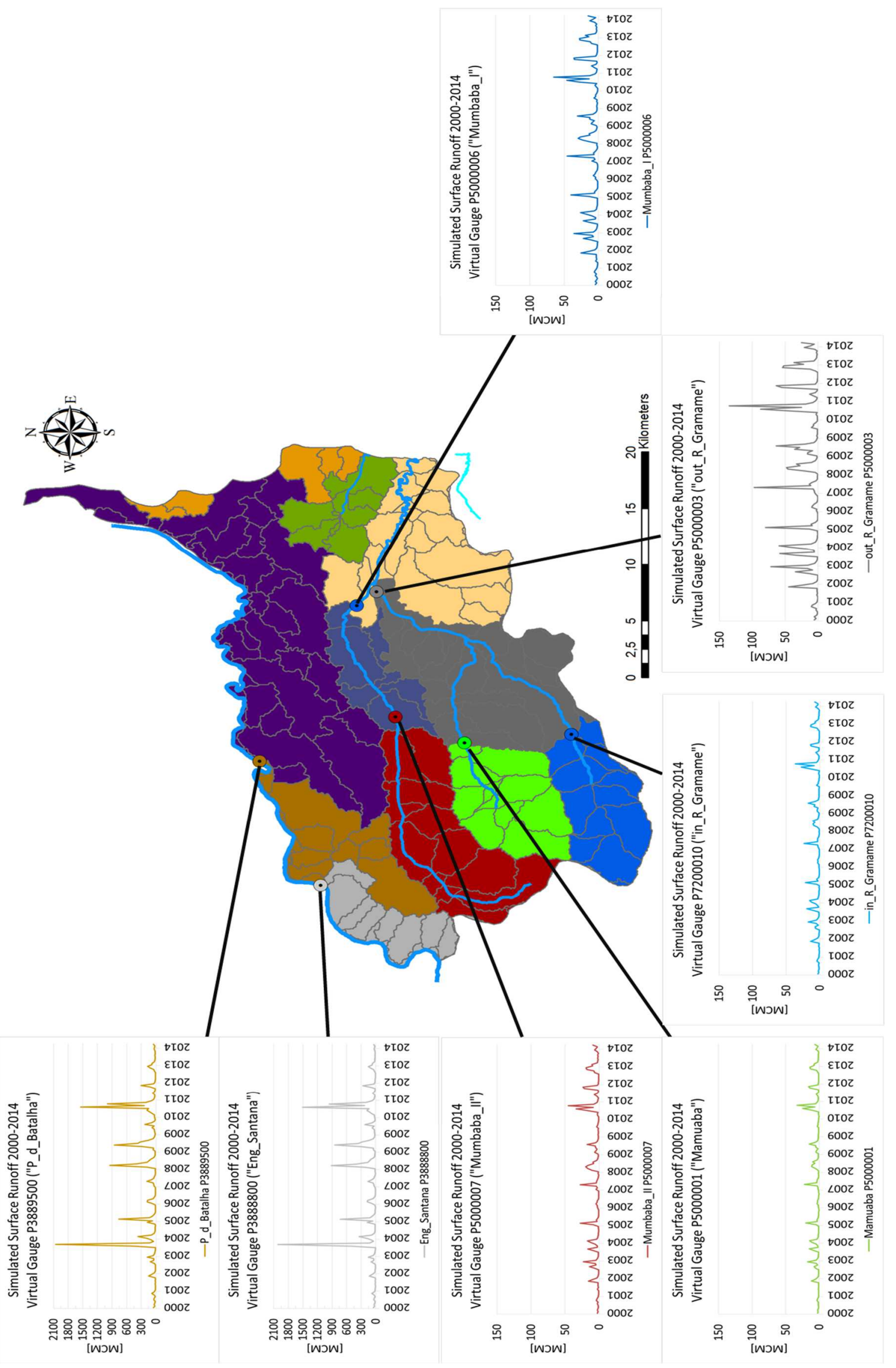


Appendix 2: Distribution of growth stages over the year to derive mean Kc values for present crops of João Pessoa case study (after FAO, 1977, Kumar et al., 2008, Jayakumar et al., 1988, Teixeira et al., 2008)

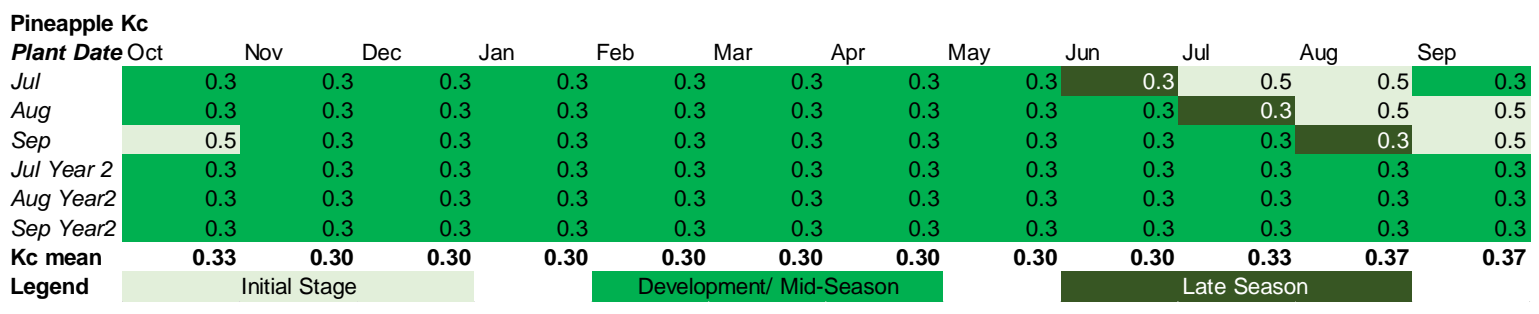

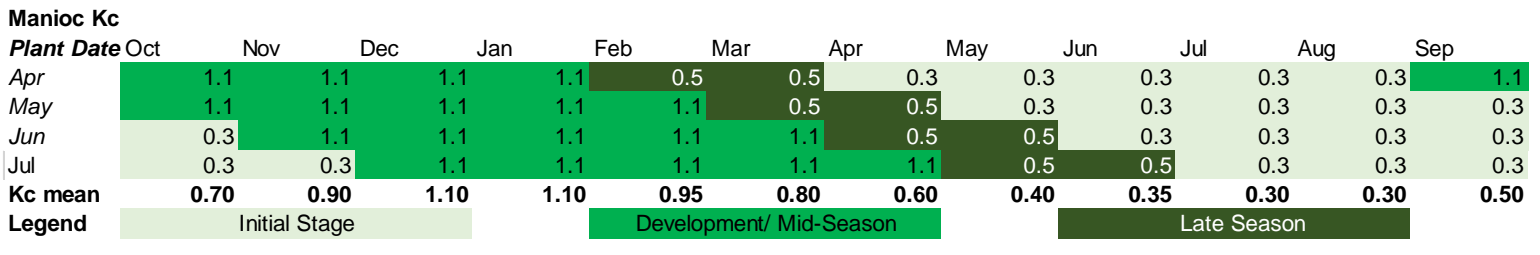

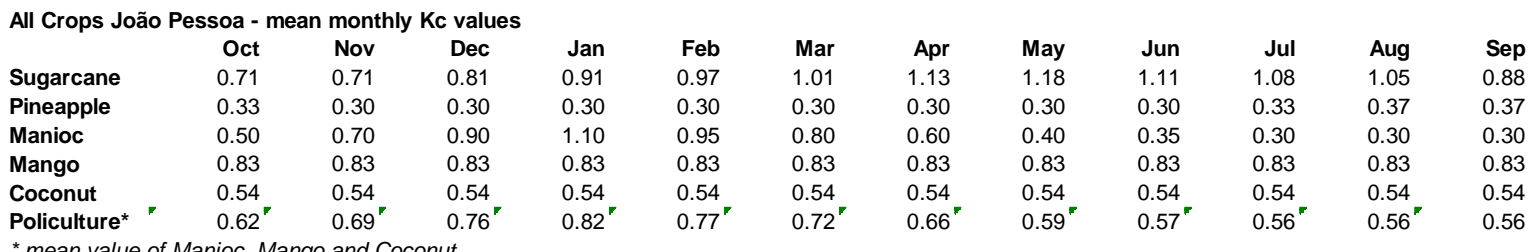




\section{Appendix 3: MAR Groundwater Budgets for João Pessoa Management Units (Baseline)}

\section{A) Baseline Scenario - Do Nothing Approach}
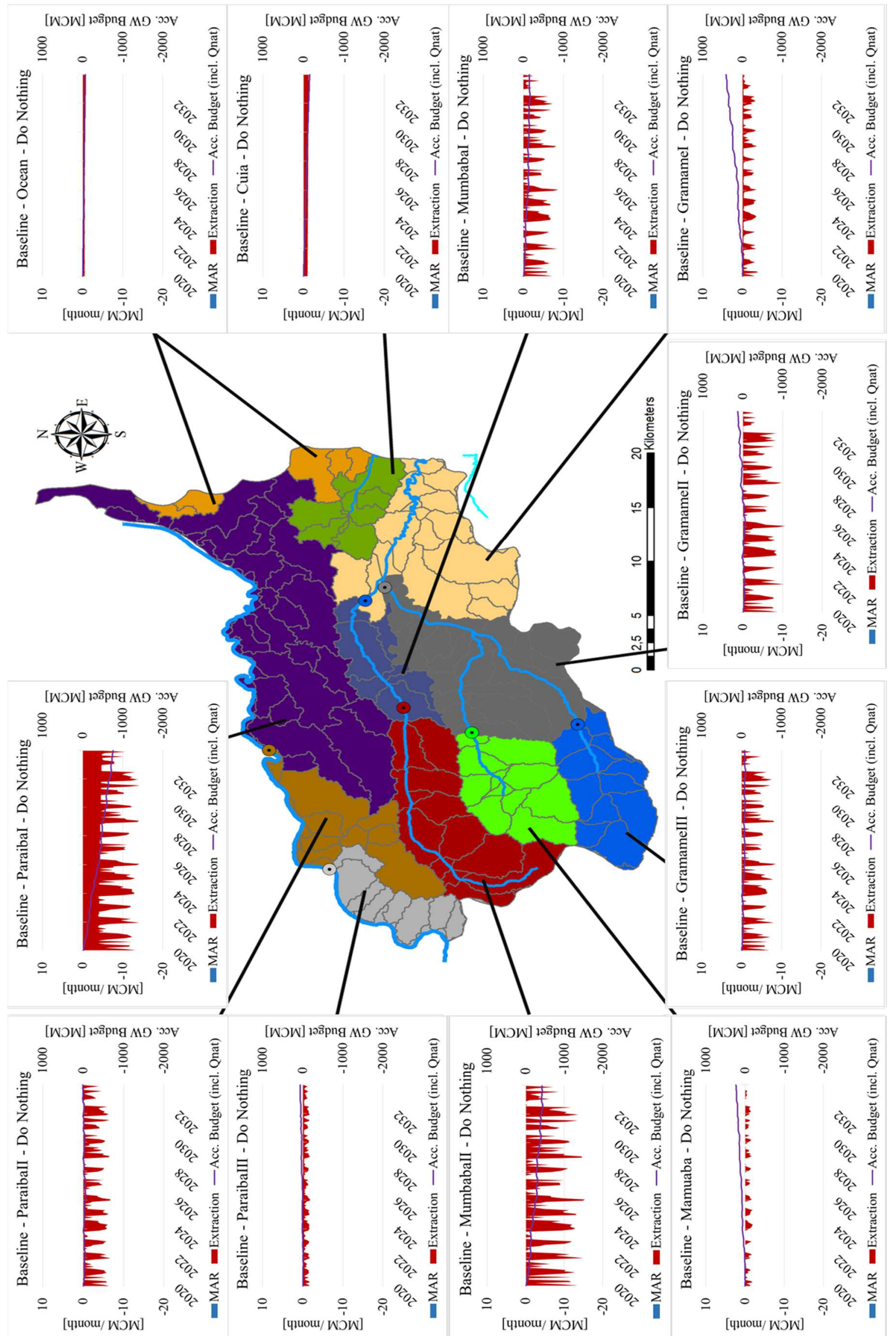


\section{B) Baseline Scenario - Strategy A}
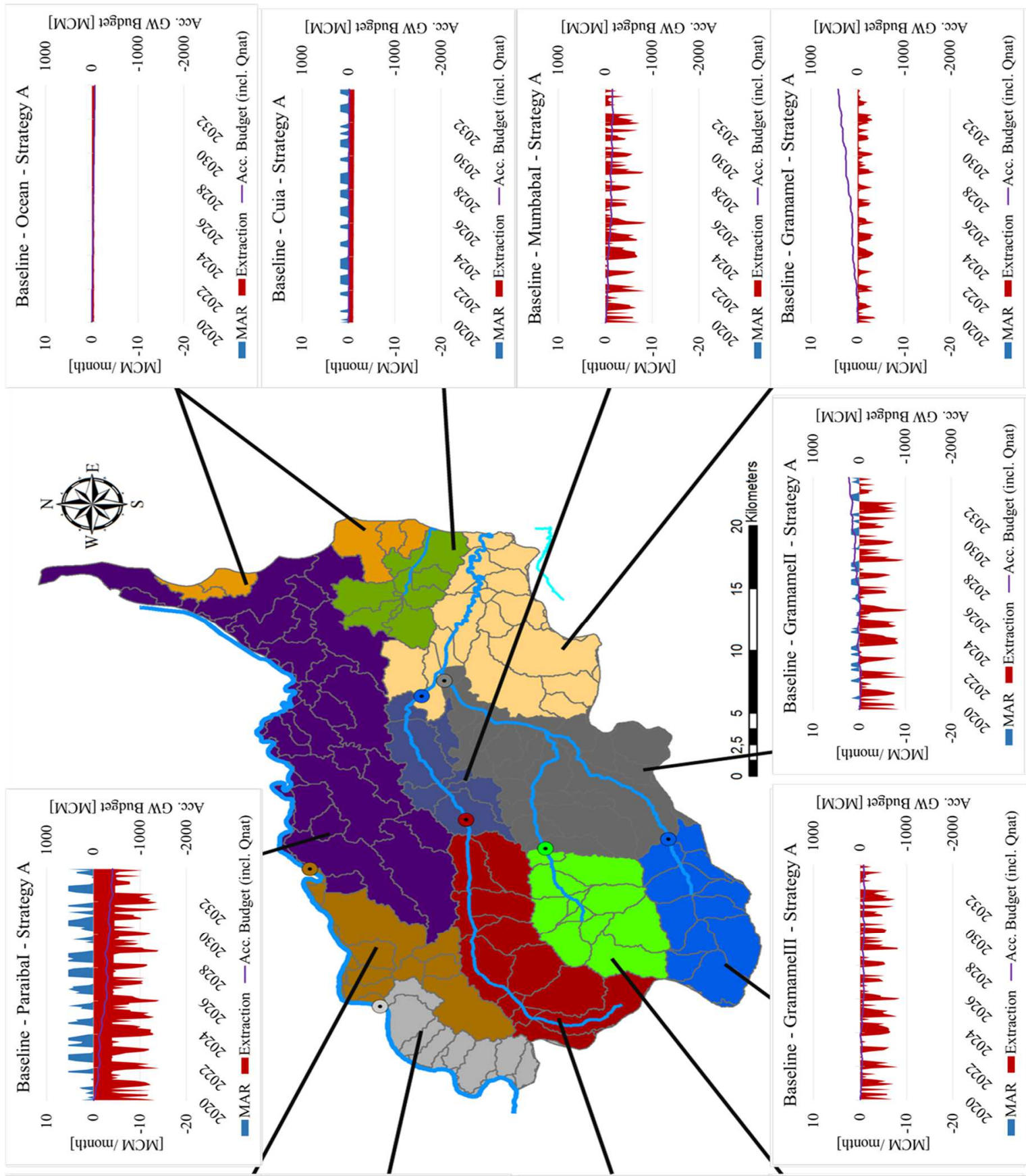

[WวW] นอธิpng $M D$ '

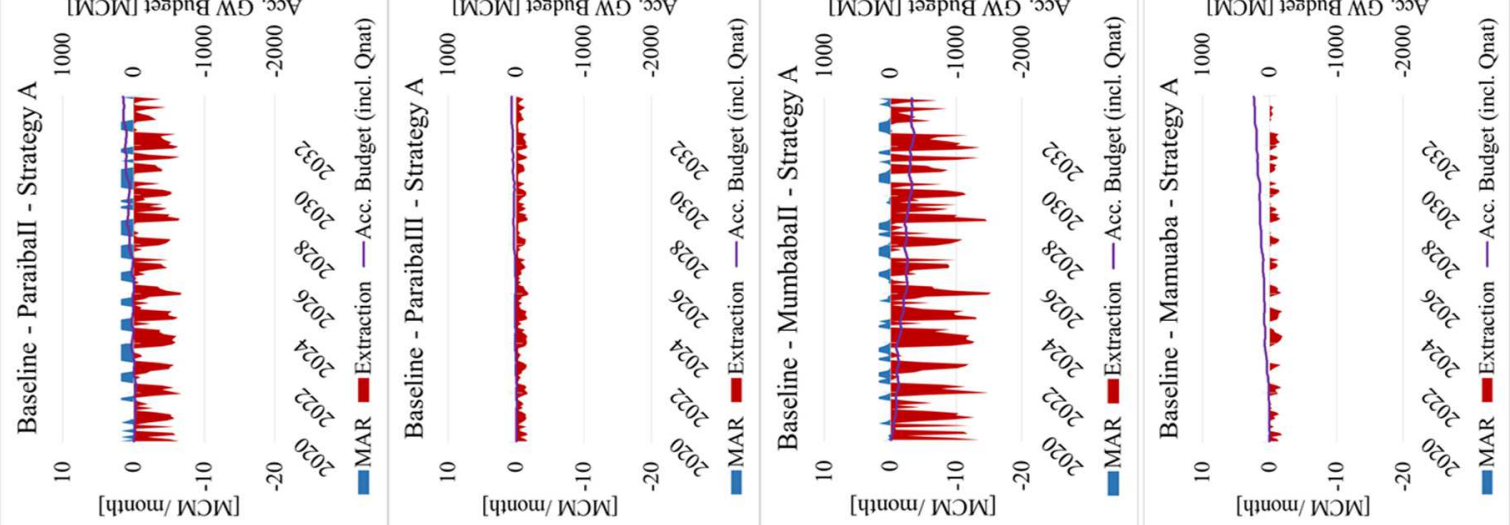




\section{C) Baseline Scenario - Strategy B}
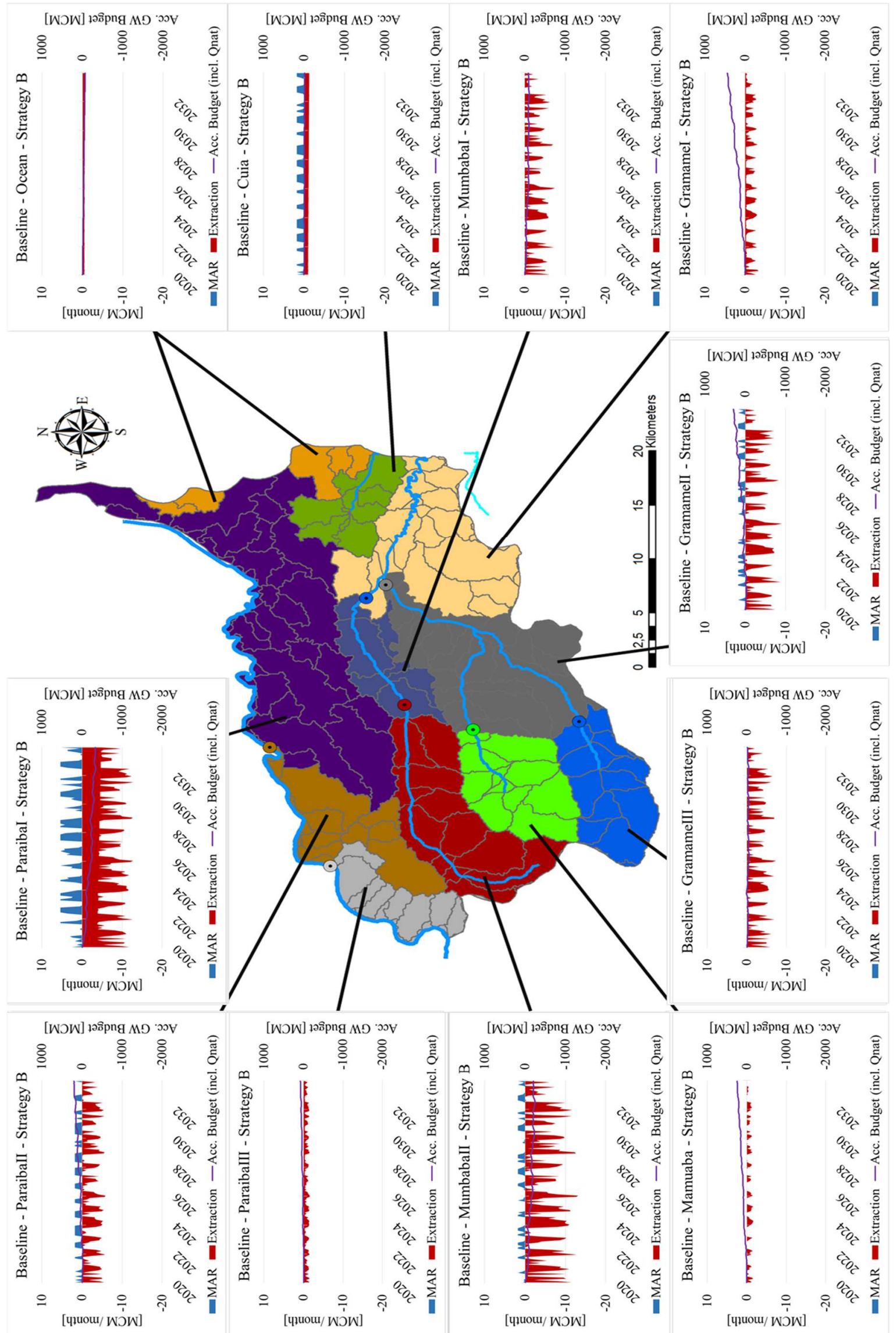


\section{D) Baseline Scenario - Strategy C}
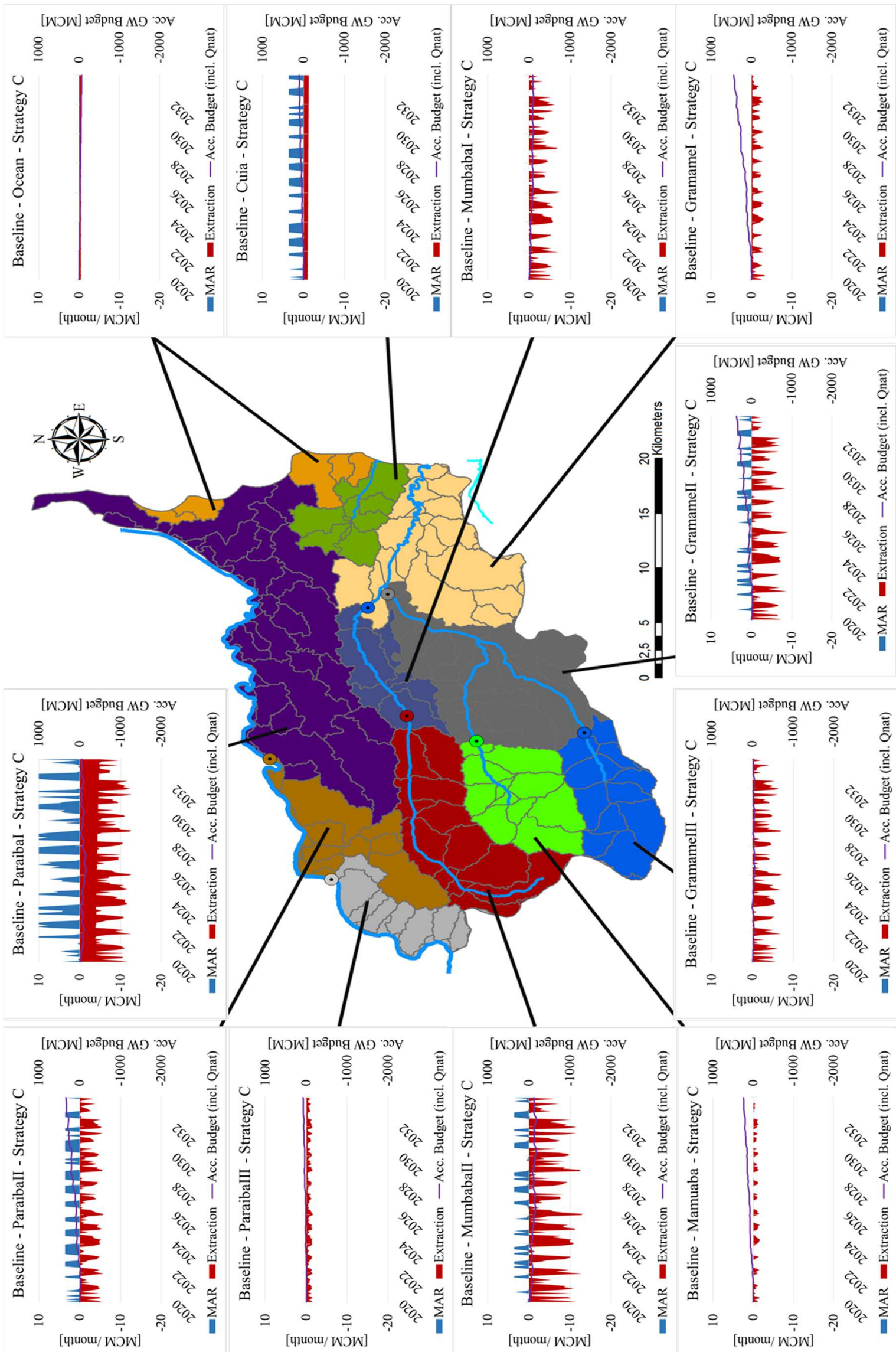


\section{Appendix 4: MAR Groundwater Budgets for João Pessoa Management Units (ADS)}

\section{A) Agricultural Development Scenario - Do Nothing Approach}

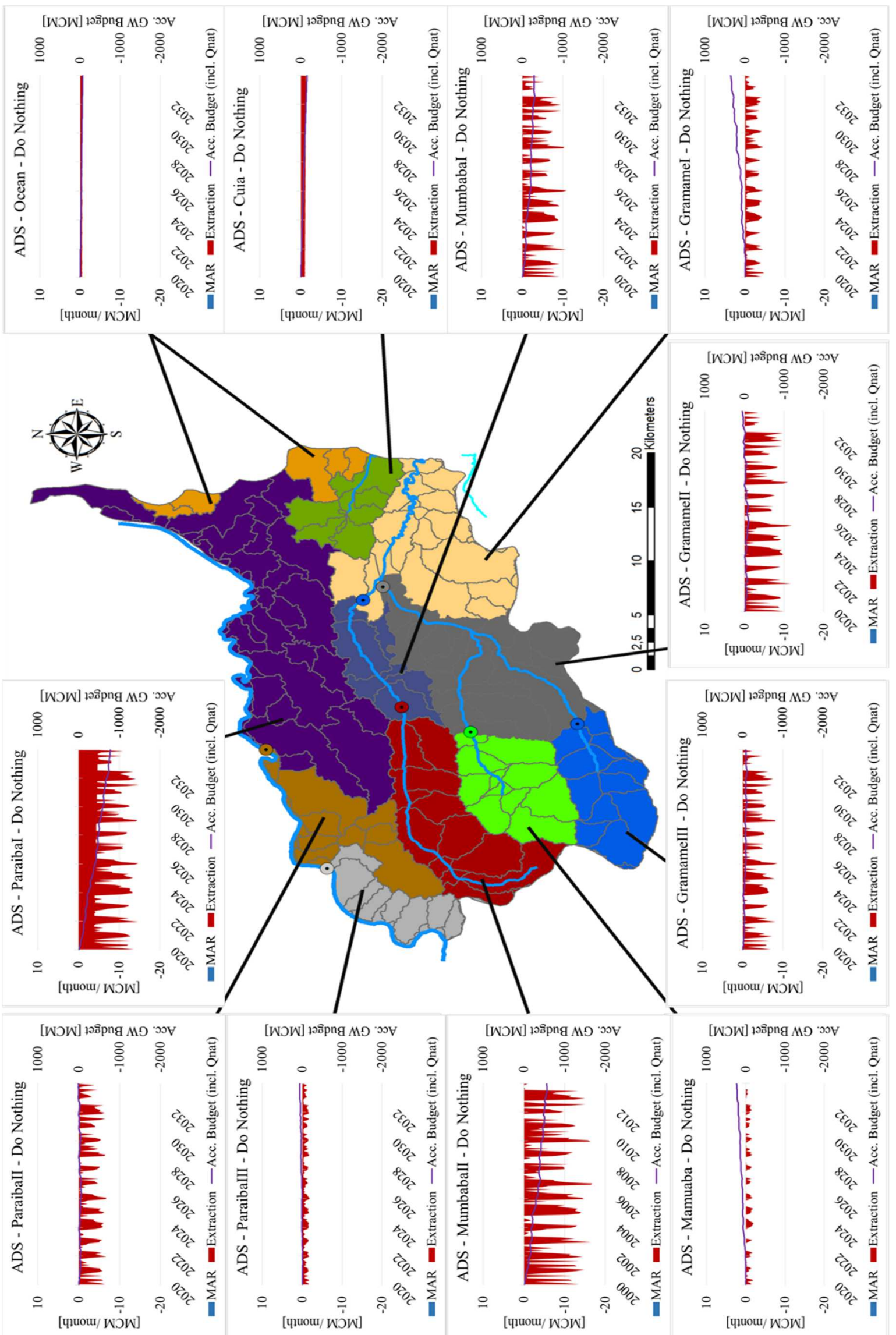




\section{B) Agricultural Development Scenario - Strategy A}
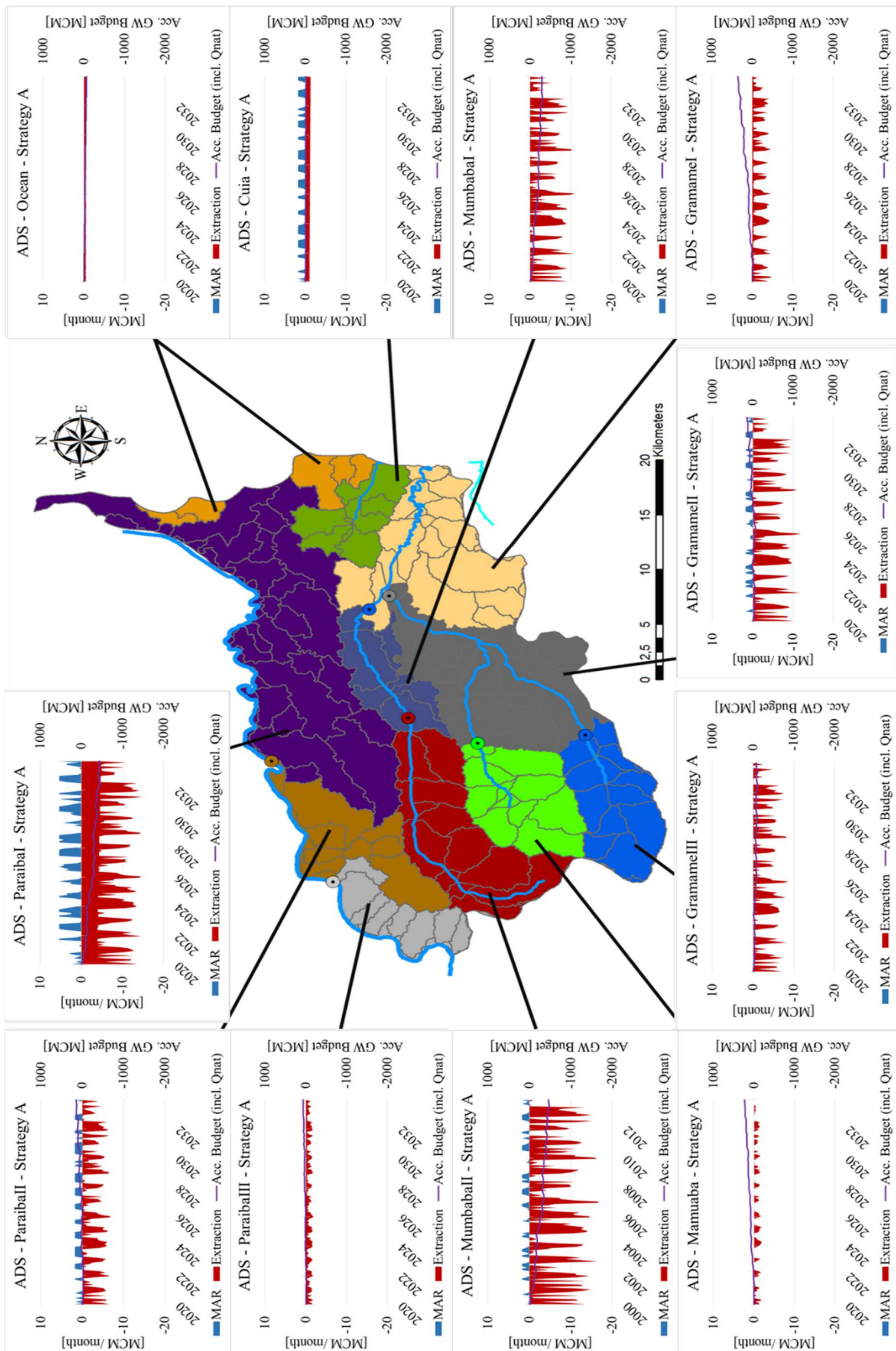


\section{C) Agricultural Development Scenario - Strategy B}

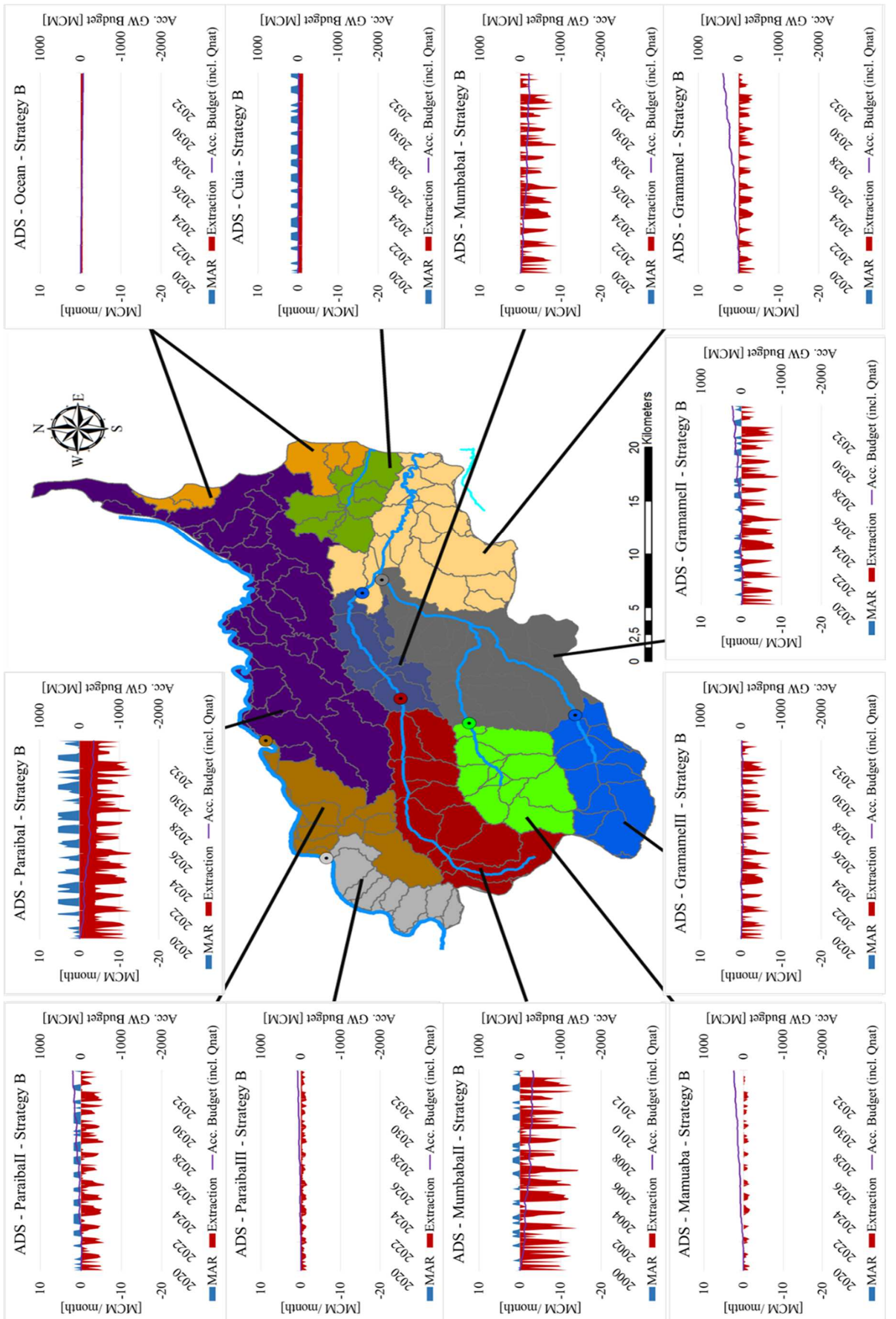




\section{D) Agricultural Development Scenario - Strategy C}

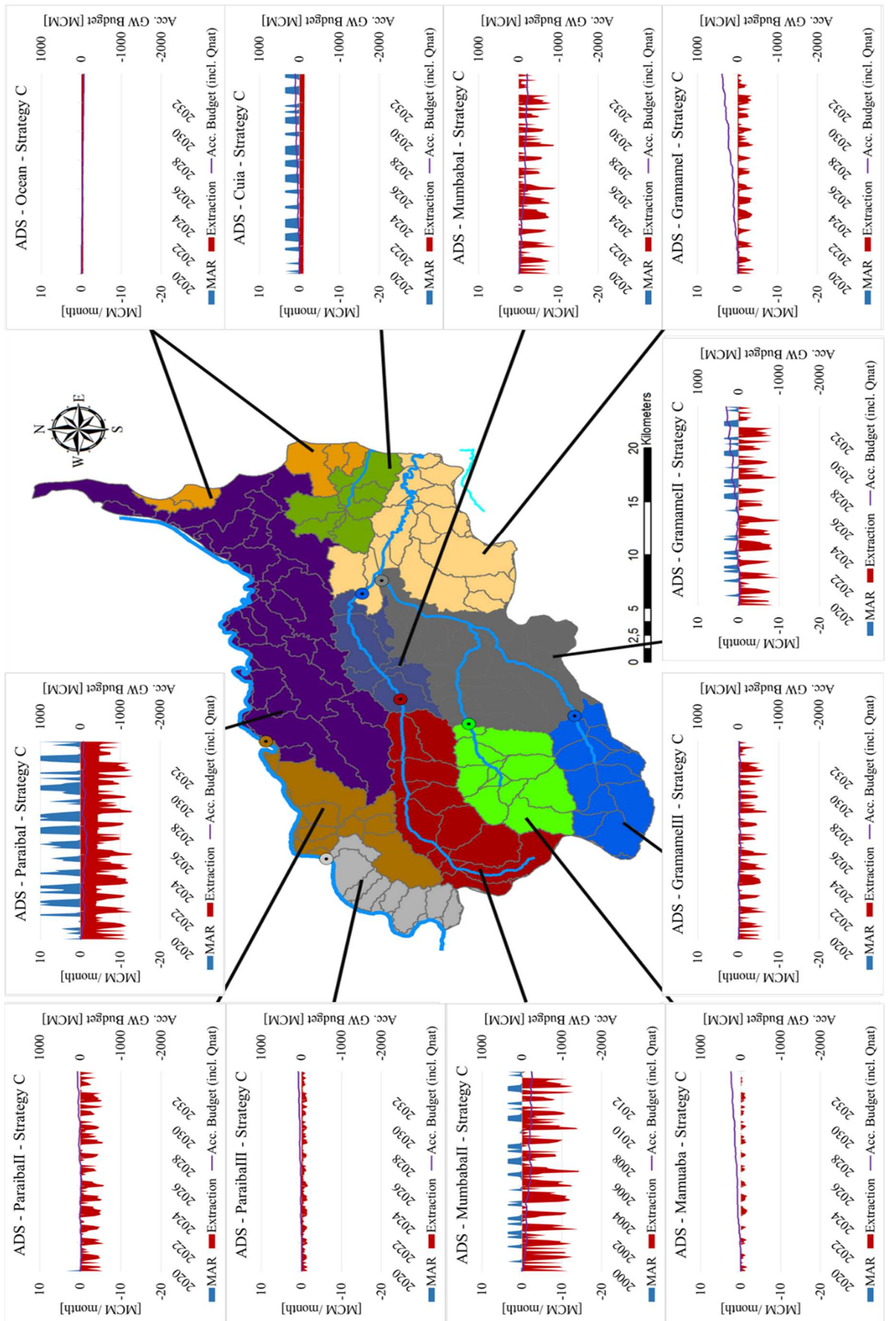




\section{Appendix 5: $\quad$ MAR Groundwater Budgets for João Pessoa Management Units (Dry)}

A) Dry Climate Scenario - Do Nothing Approach
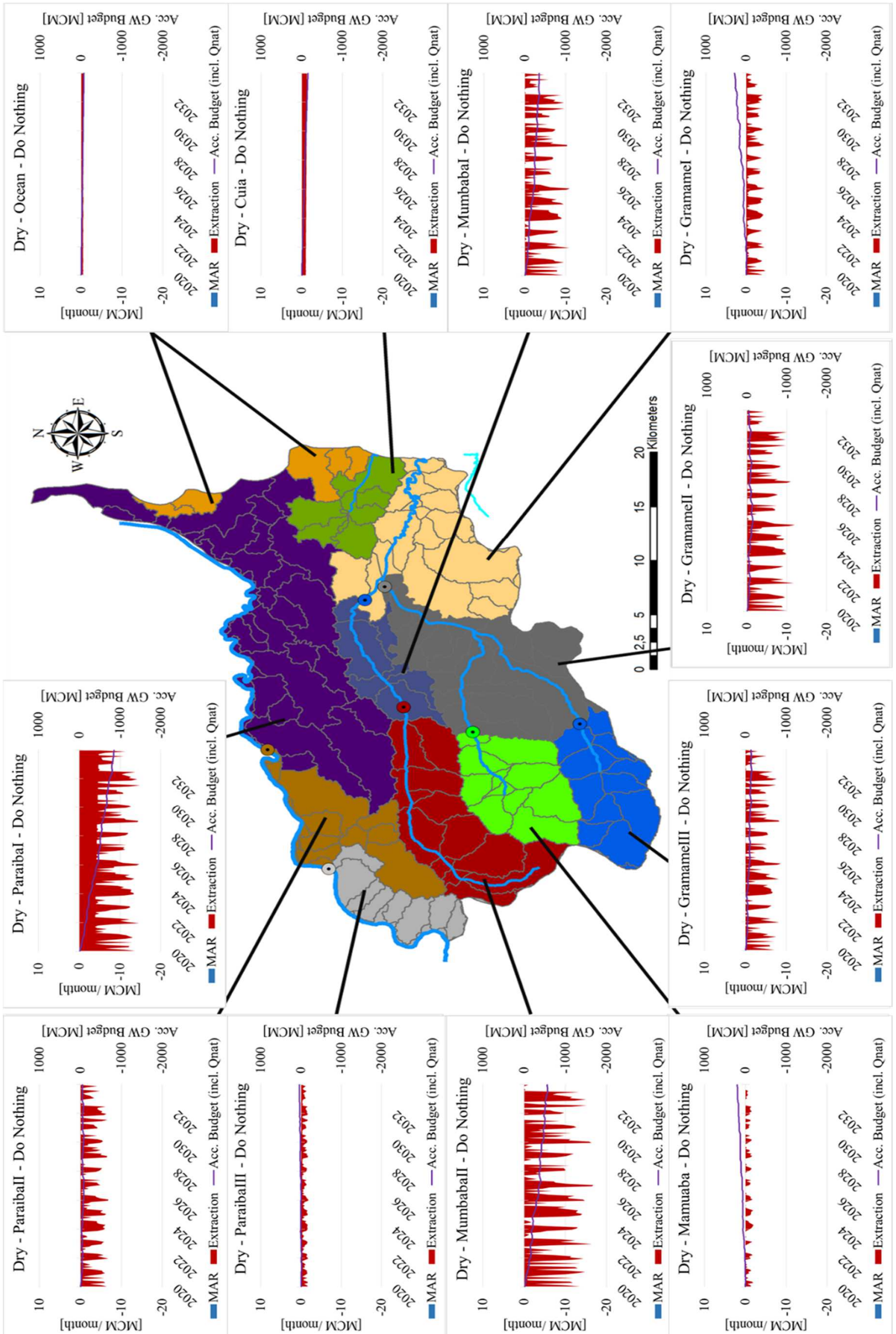


\section{B) Dry Climate Scenario - Strategy A}
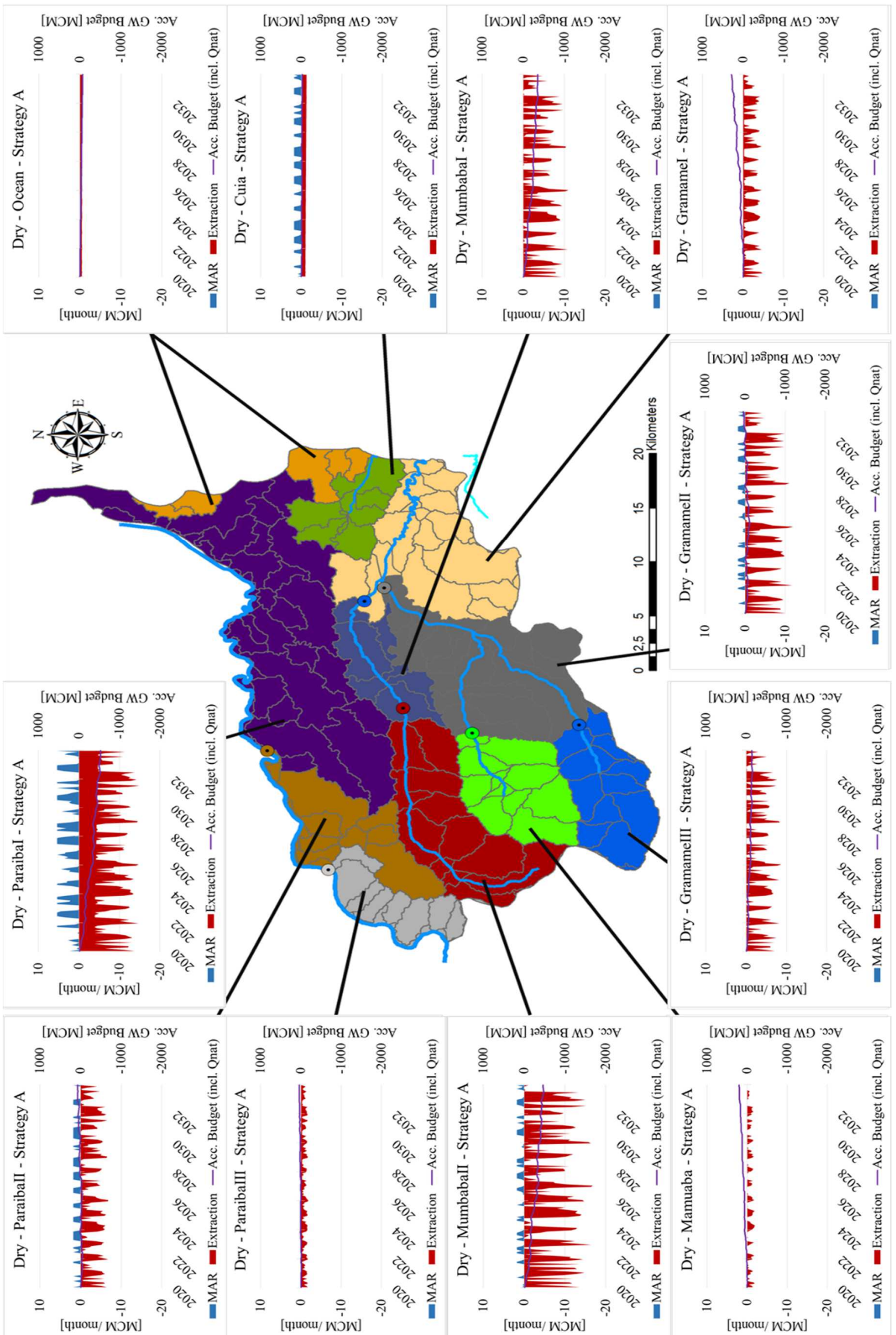


\section{C) Dry Climate Scenario - Strategy B}
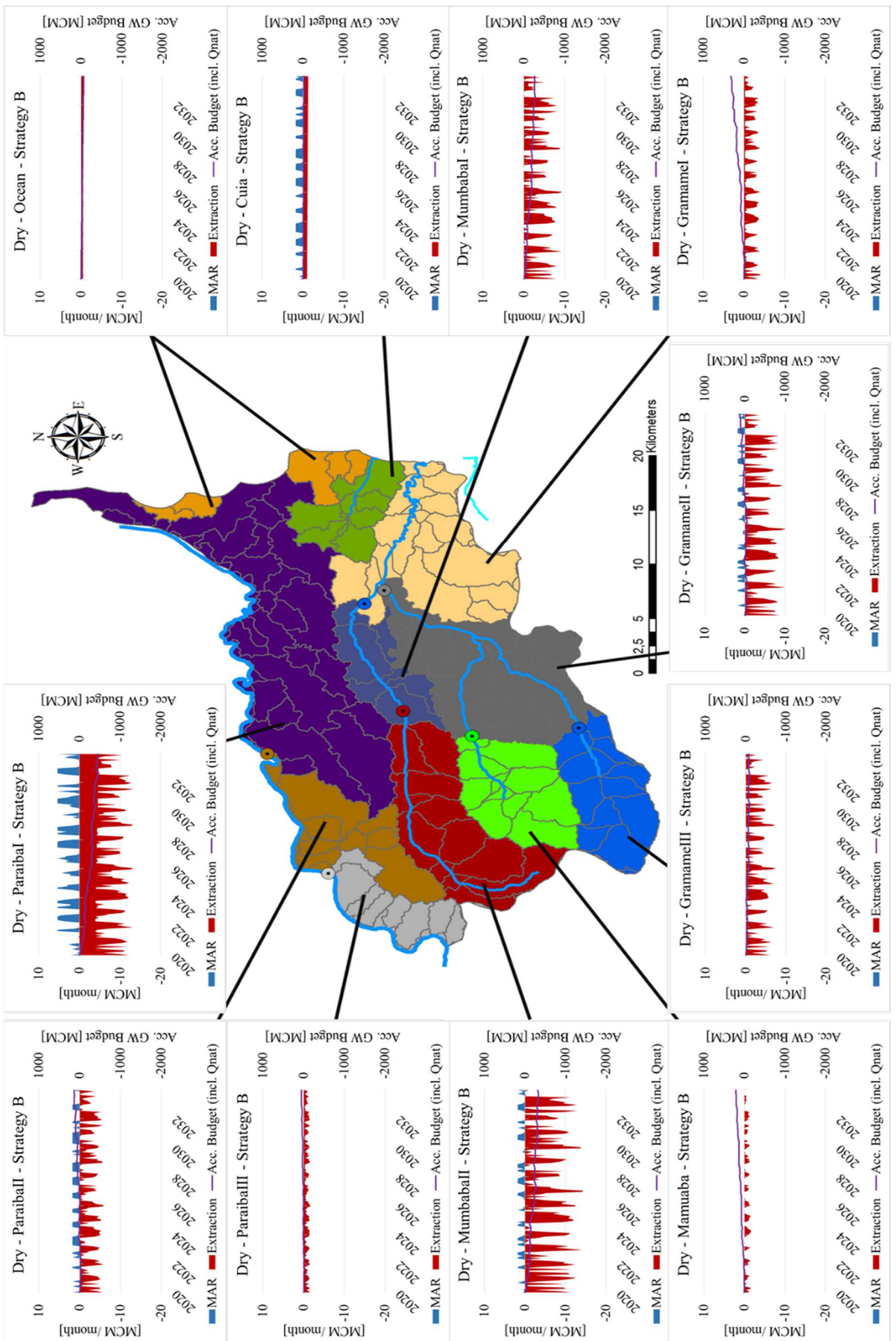


\section{D) Dry Climate Scenario - Strategy C}
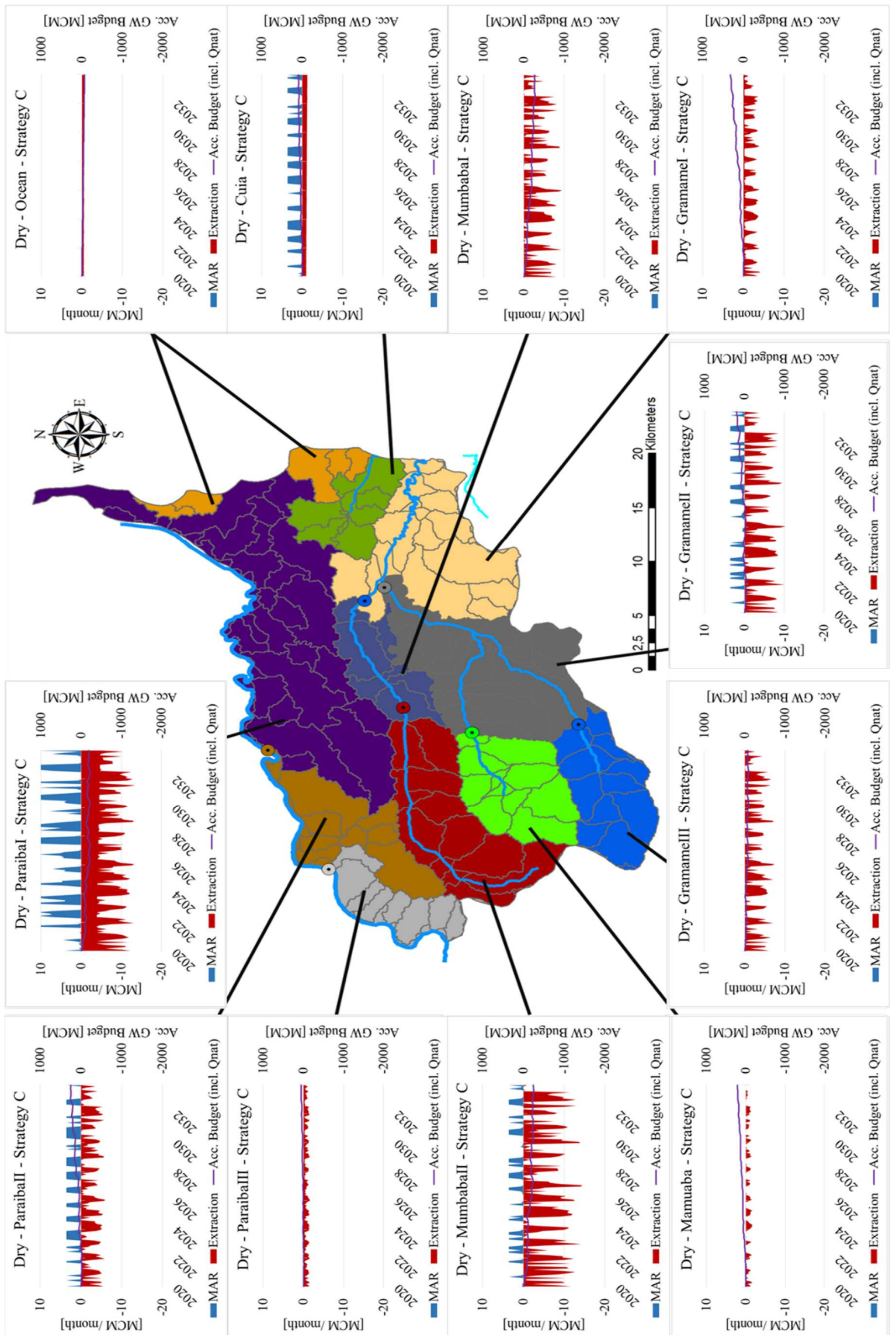
Appendix 6: MAR Groundwater Budgets for Jericho-Auja Management Units (Baseline)

A) Baseline Scenario - Do Nothing Approach

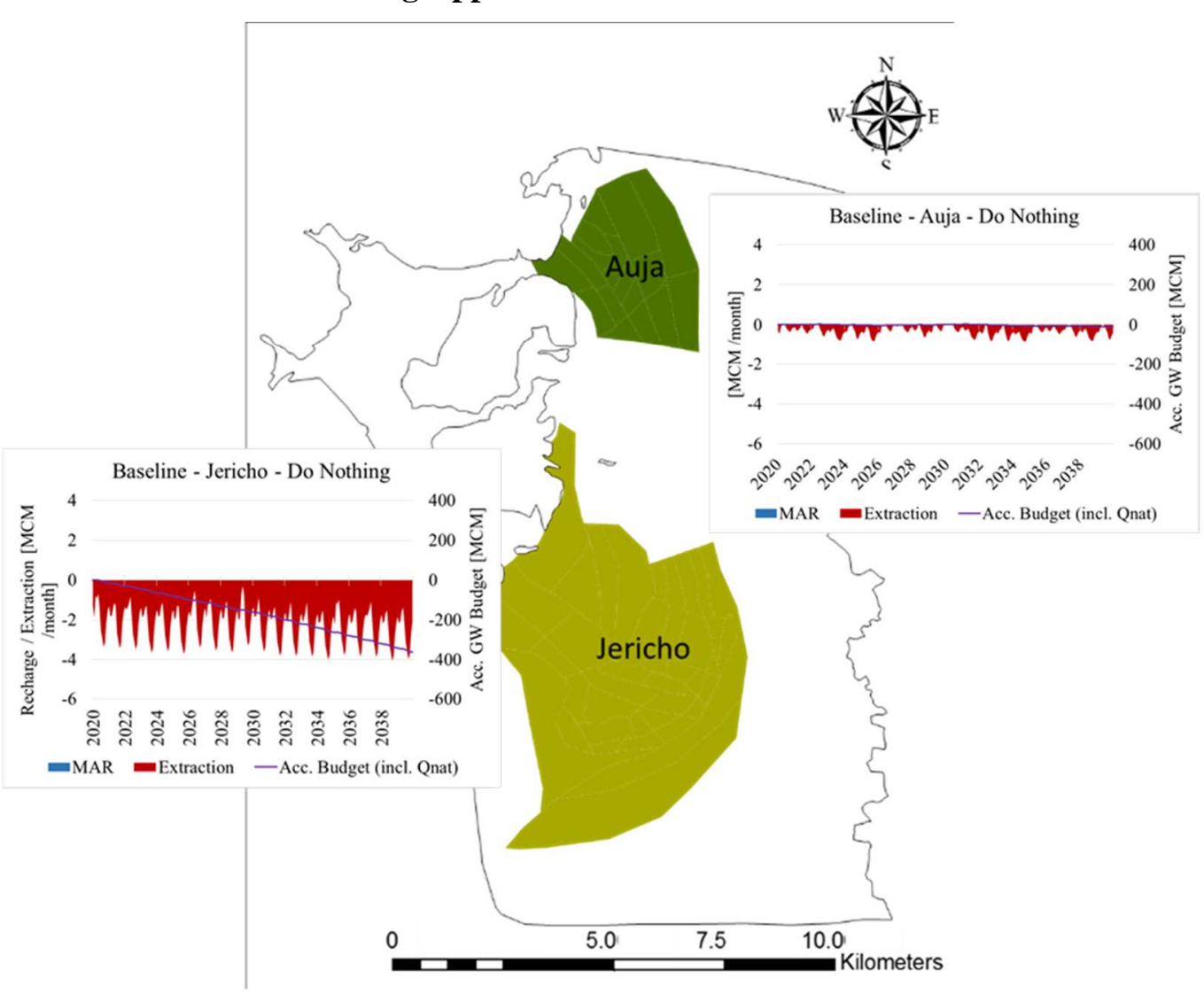

B) Baseline Scenario - Strategy A

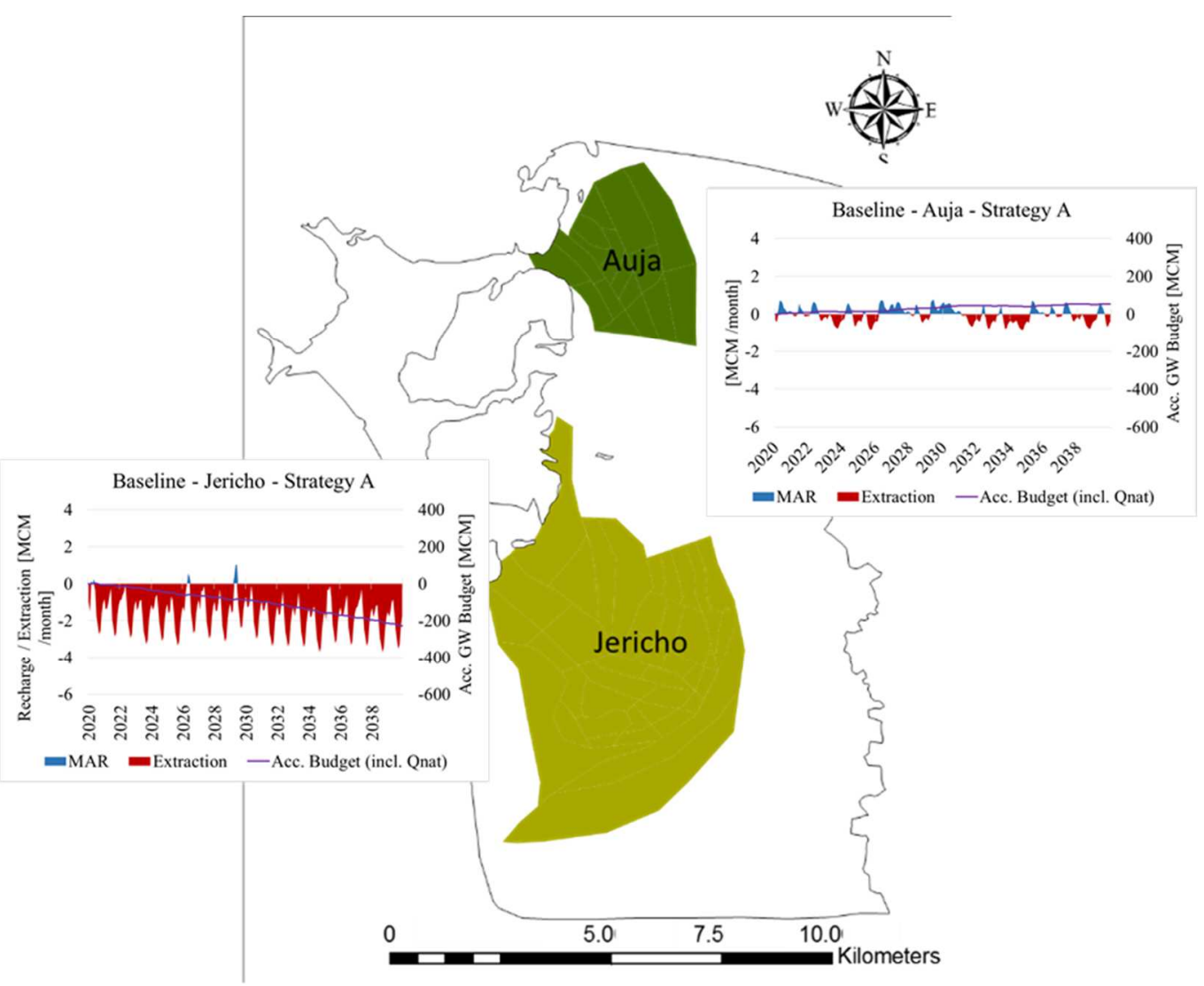




\section{C) Baseline Scenario - Strategy B}

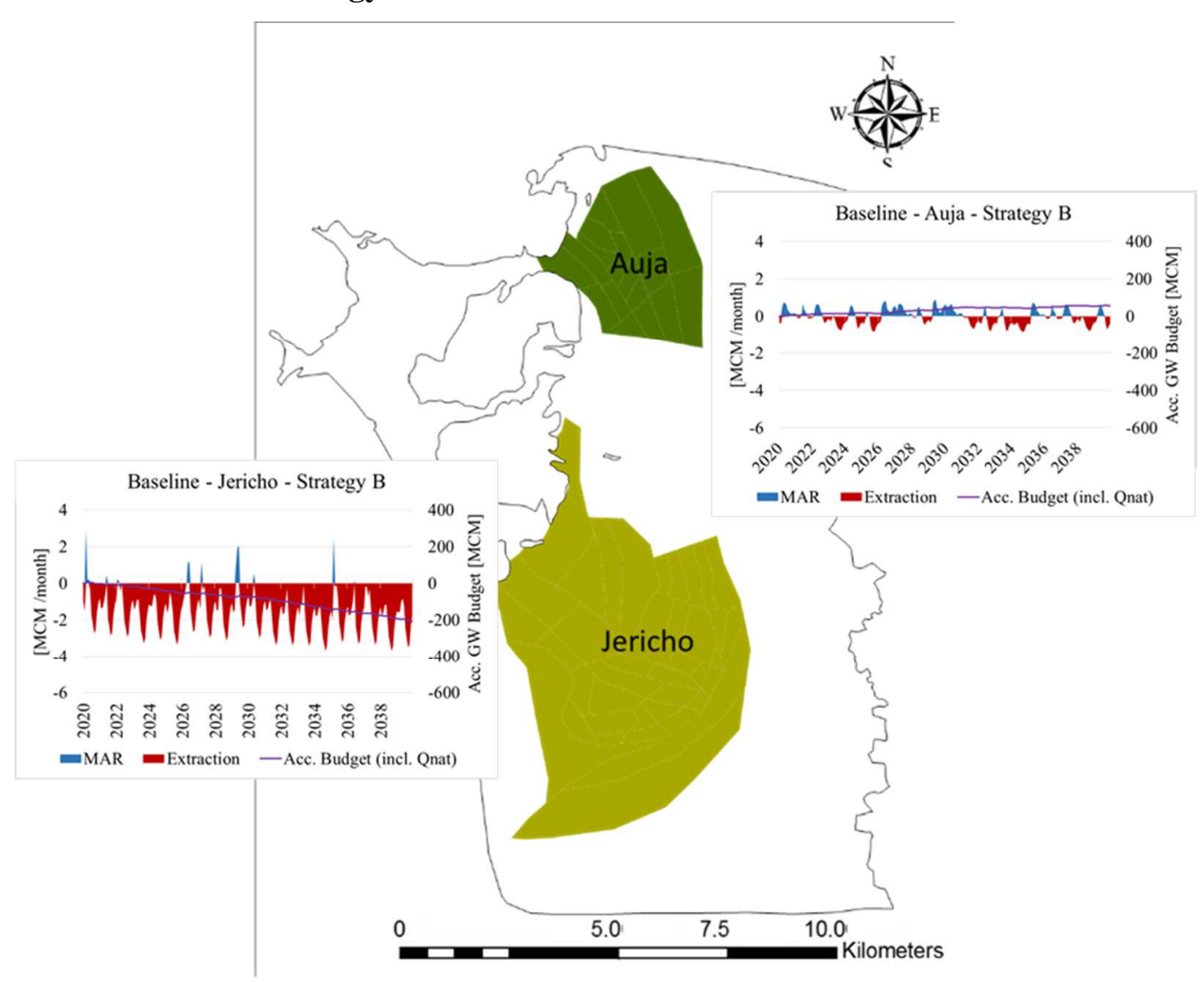

\section{D) Baseline Scenario - Strategy C}

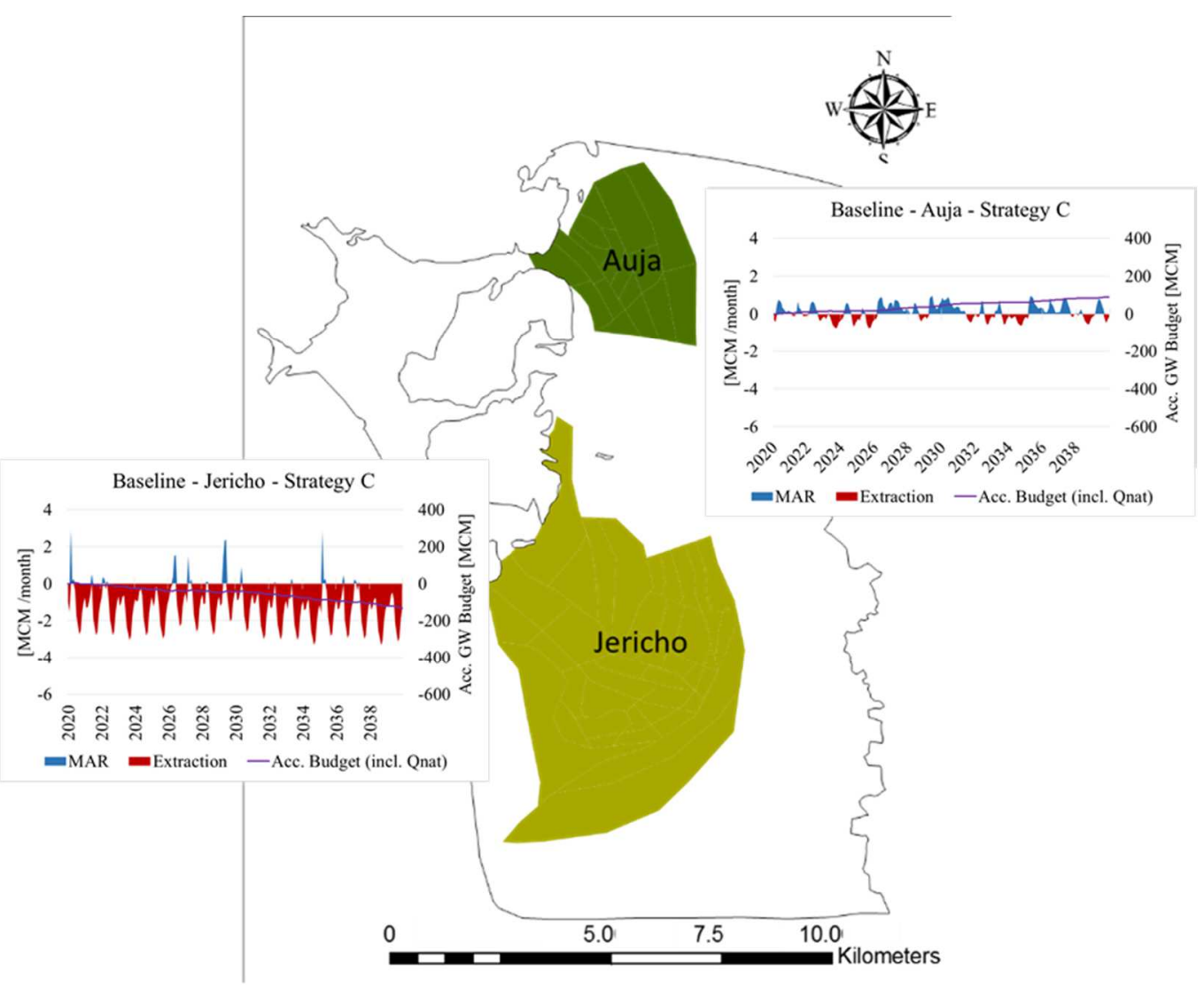




\section{E) Baseline Scenario - Strategy D}

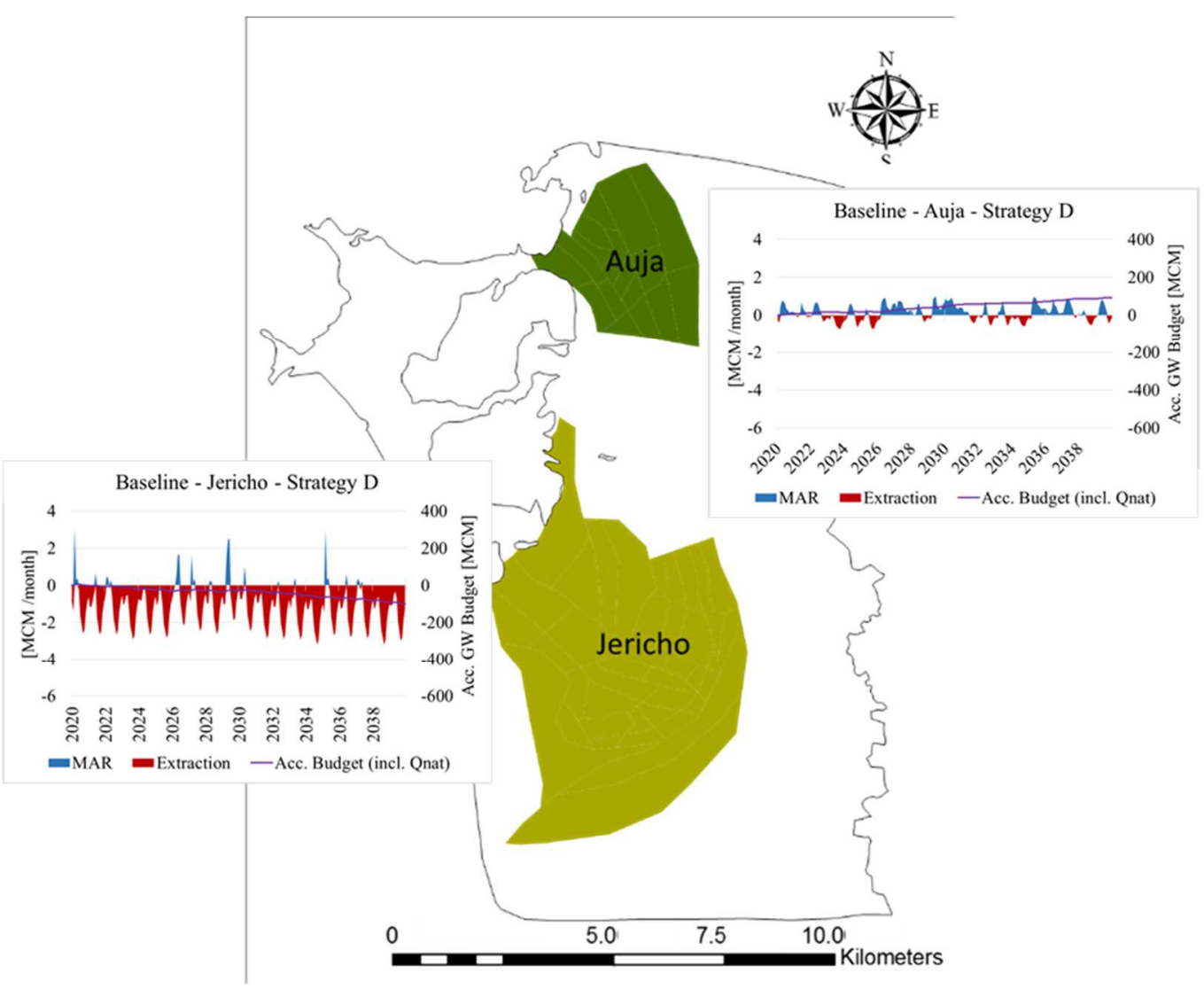

\section{F) Baseline Scenario - Strategy E}

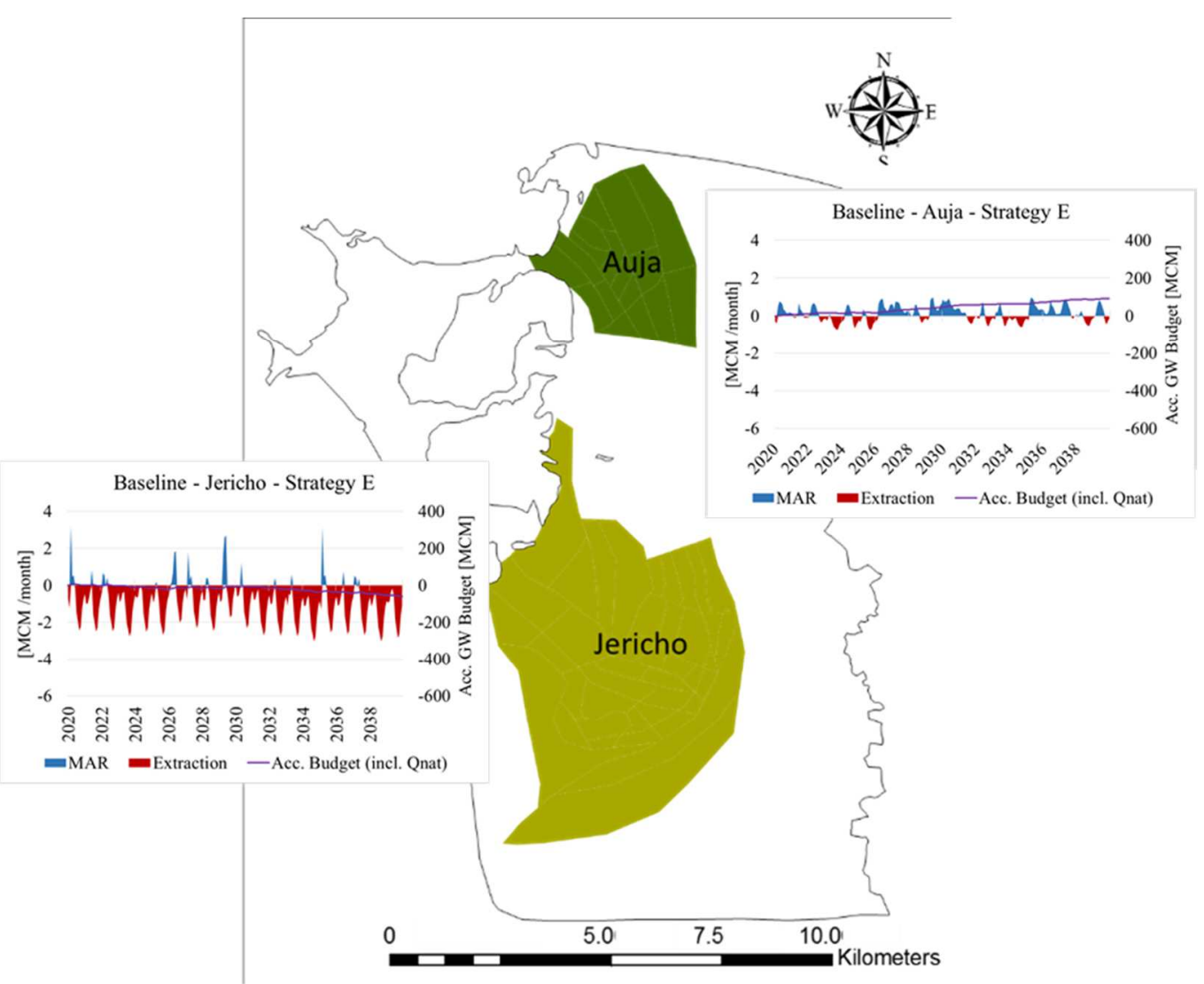


Appendix 7: MAR Groundwater Budgets for Jericho-Auja Management Units (ADS)

A) Agricultural Development Scenario - Do Nothing Approach

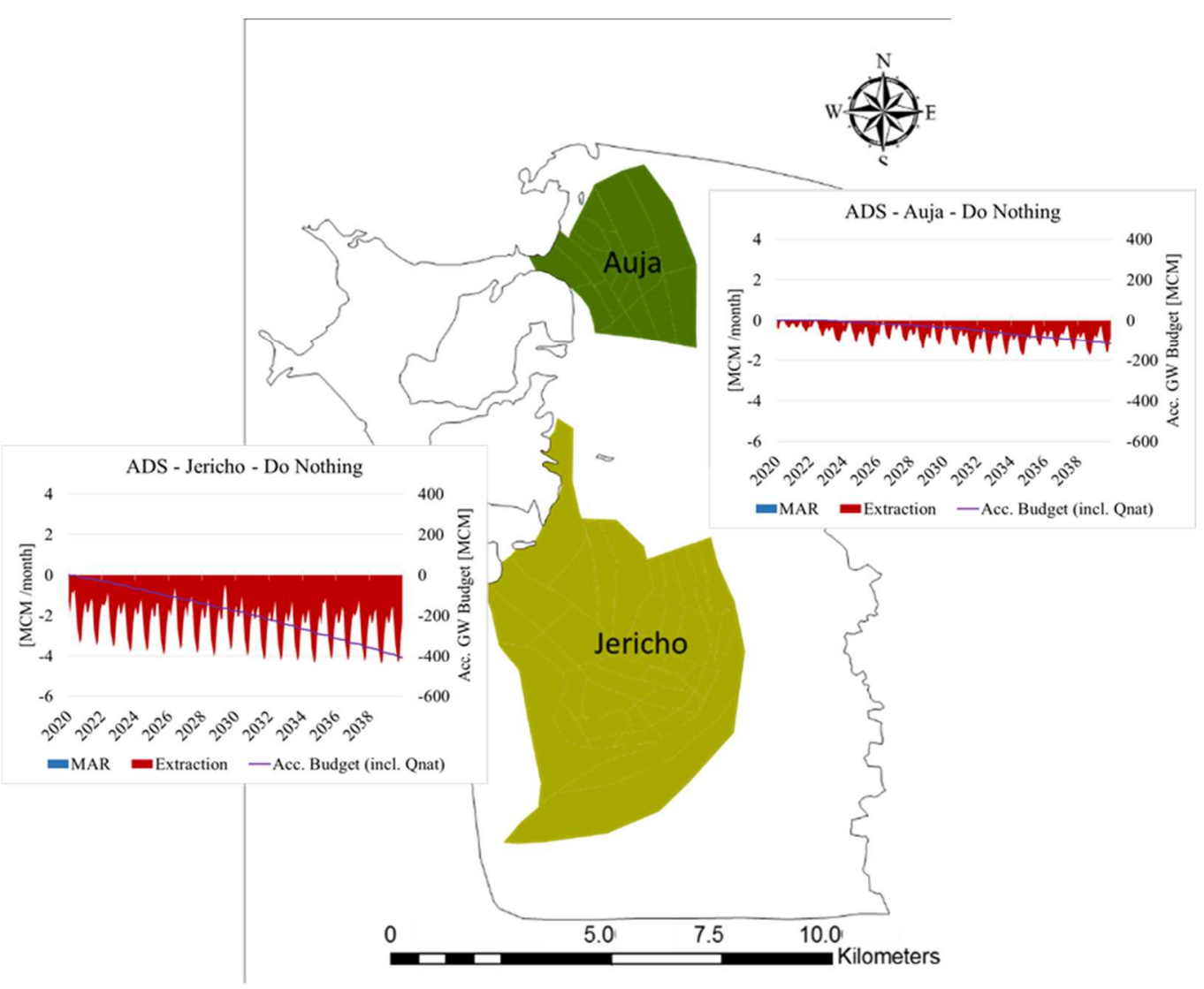

B) Agricultural Development Scenario - Strategy A

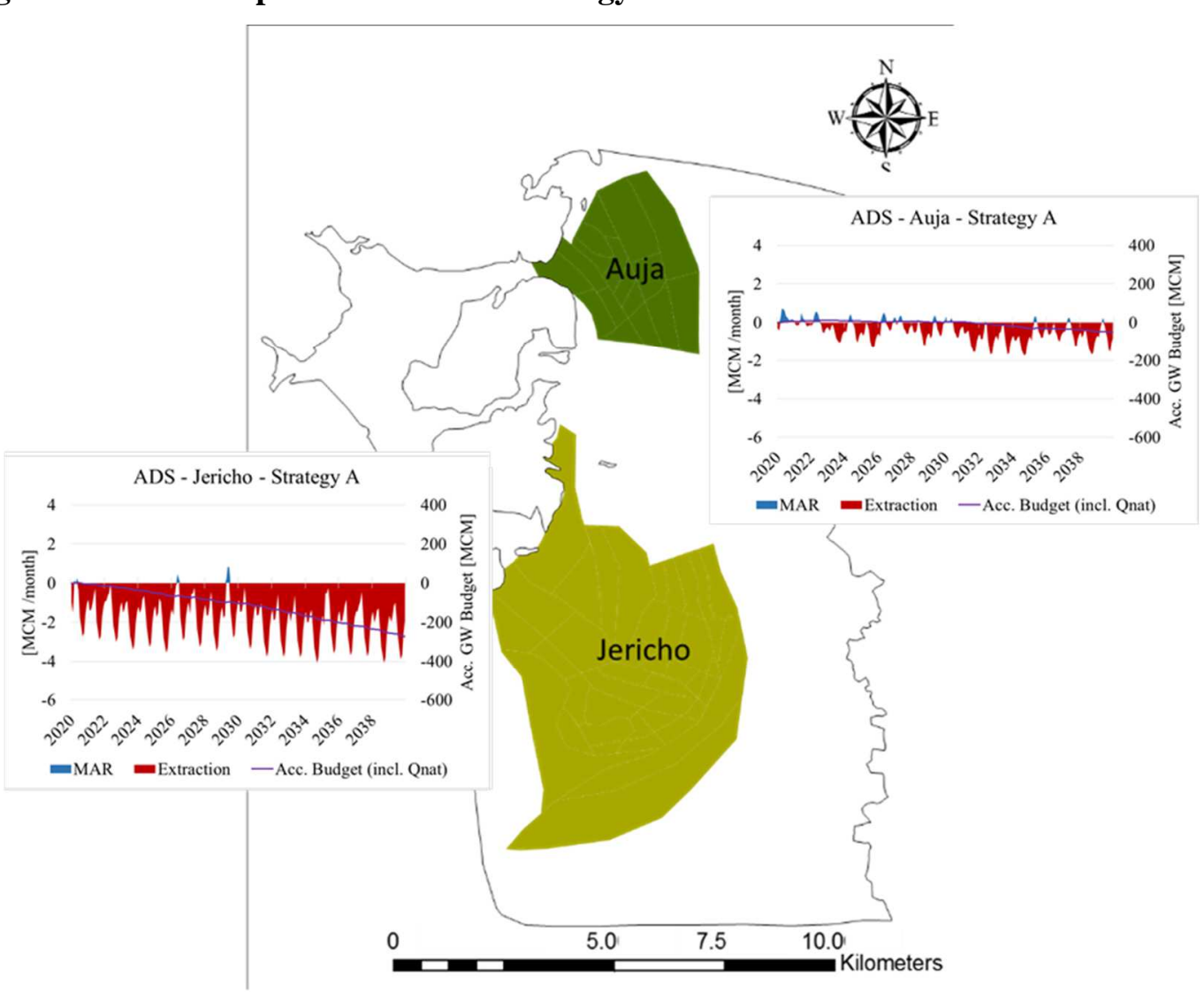




\section{C) Agricultural Development Scenario - Strategy B}

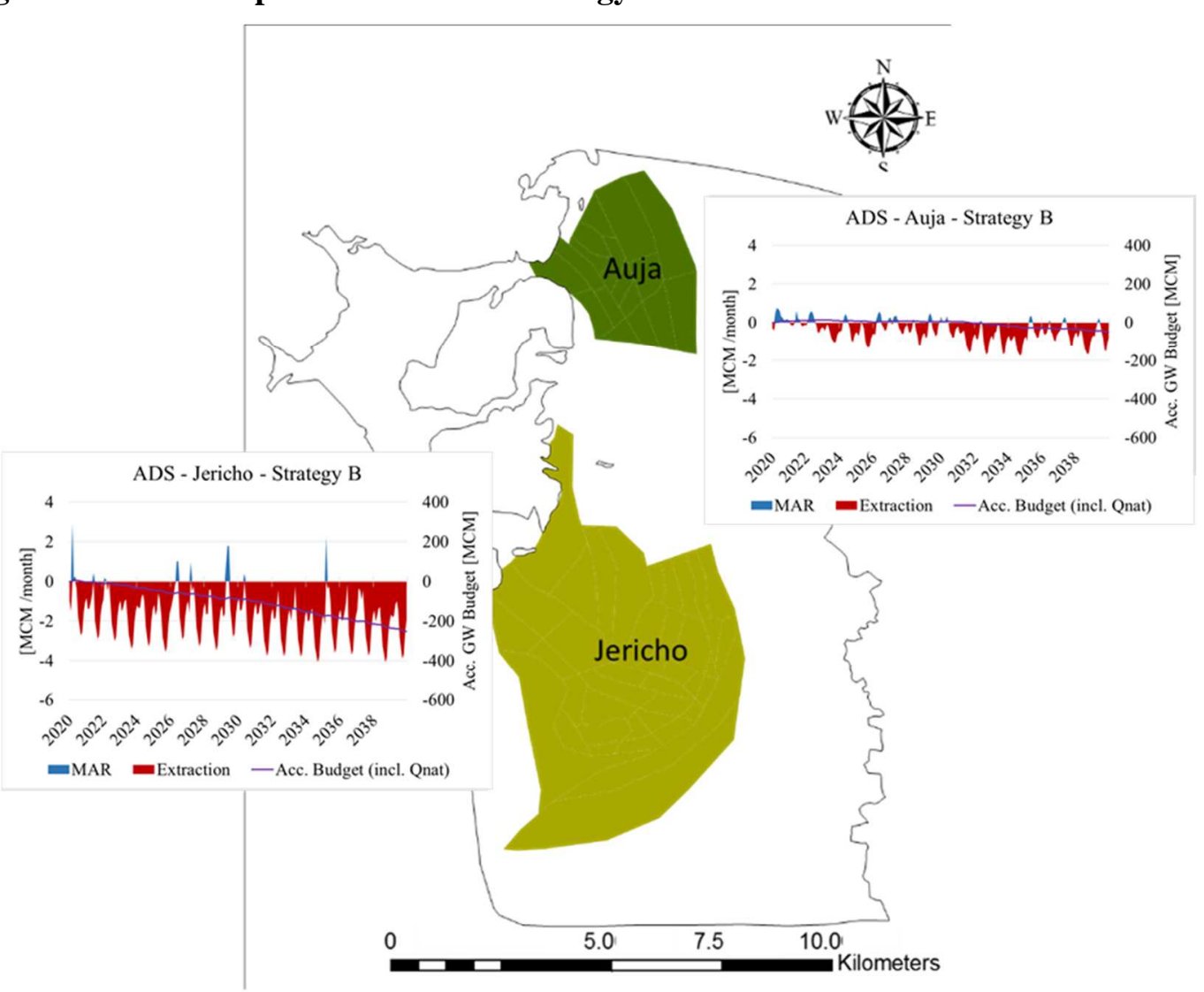

\section{D) Agricultural Development Scenario - Strategy C}

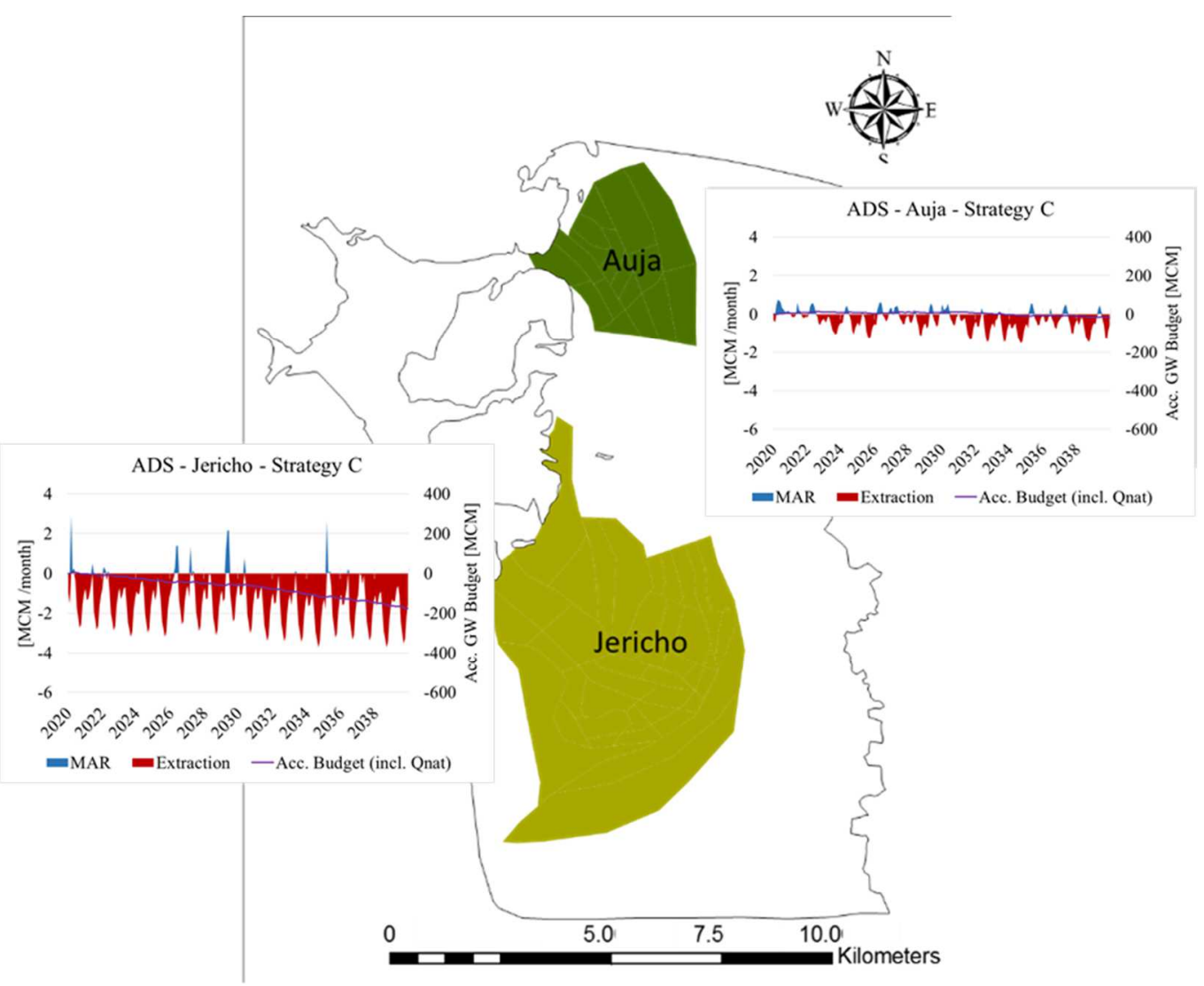




\section{E) Agricultural Development Scenario - Strategy D}

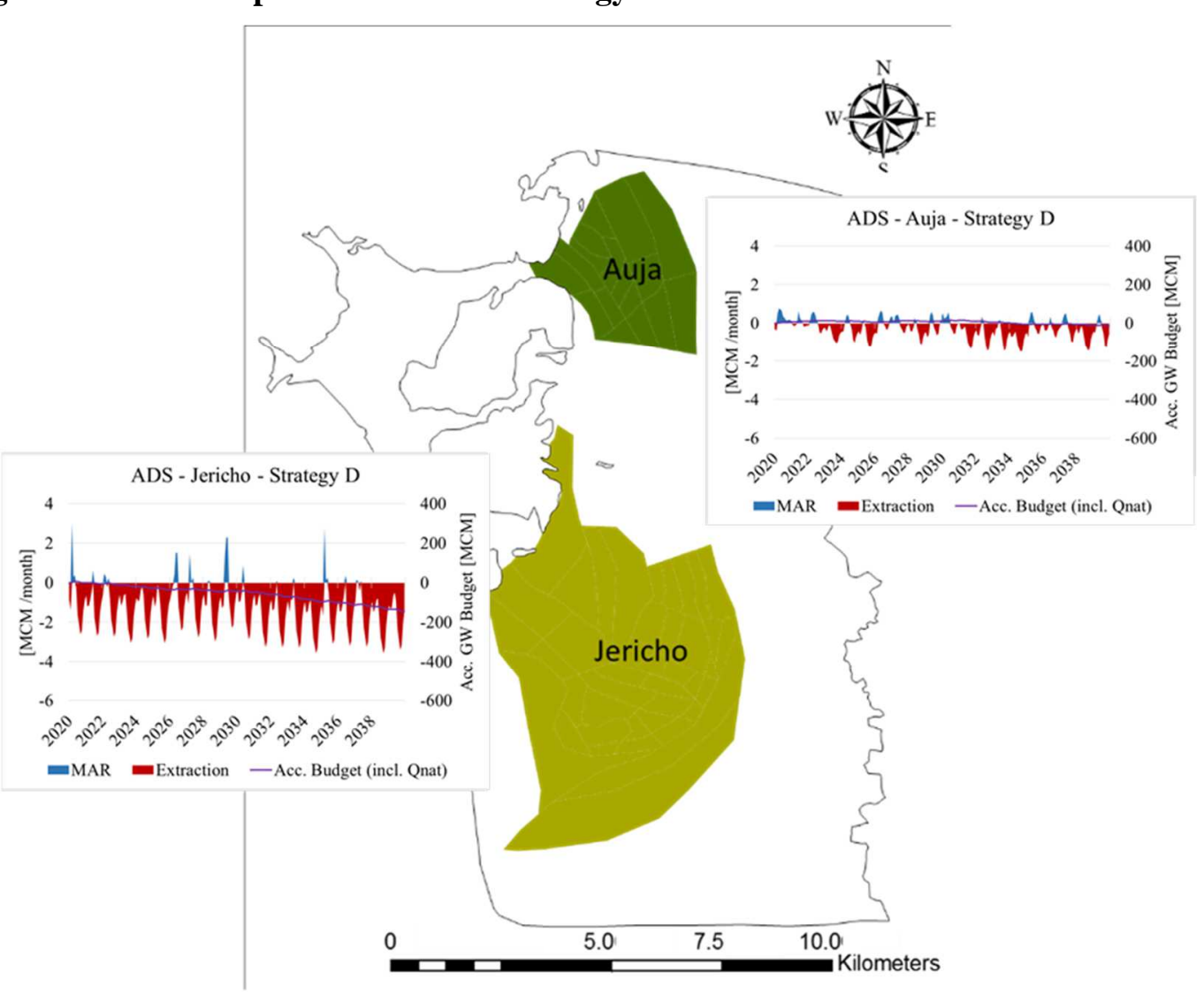

\section{F) Agricultural Development Scenario - Strategy E}

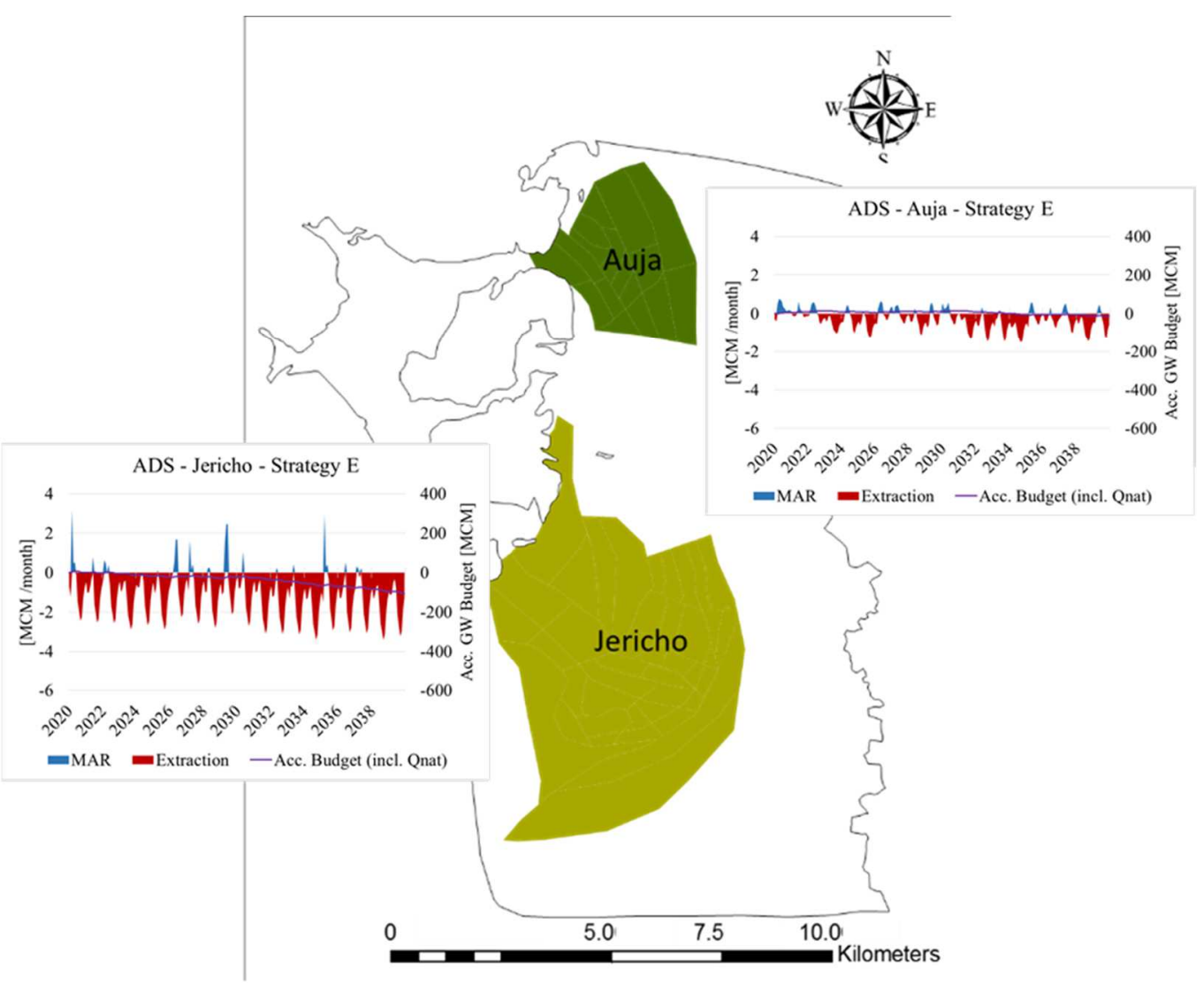




\section{G) Agricultural Development Scenario - Strategy F}

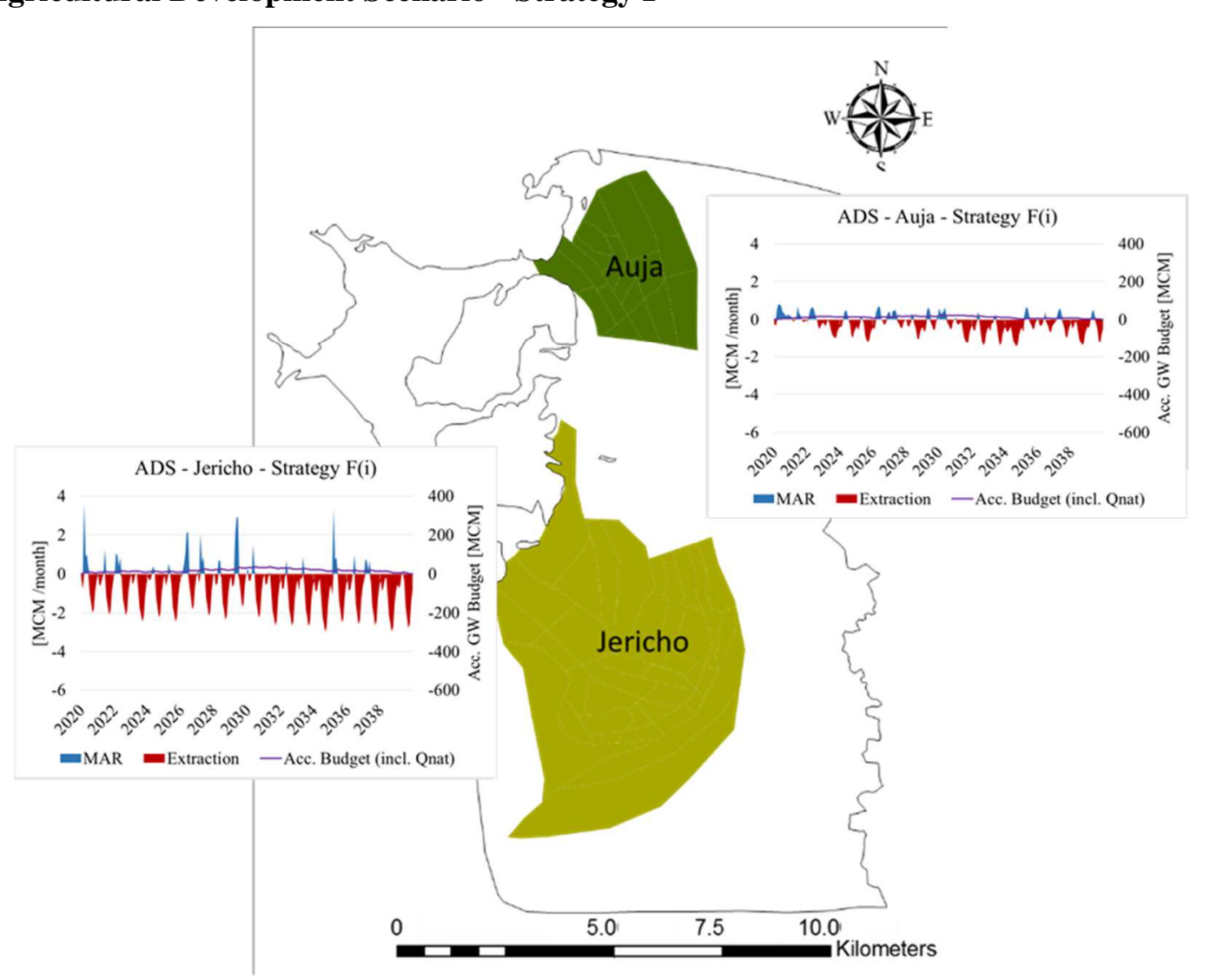


Appendix 8: MAR Groundwater Budgets for Jericho-Auja Management Units (Dry)

A) Dry Climate Scenario - Do Nothing Approach

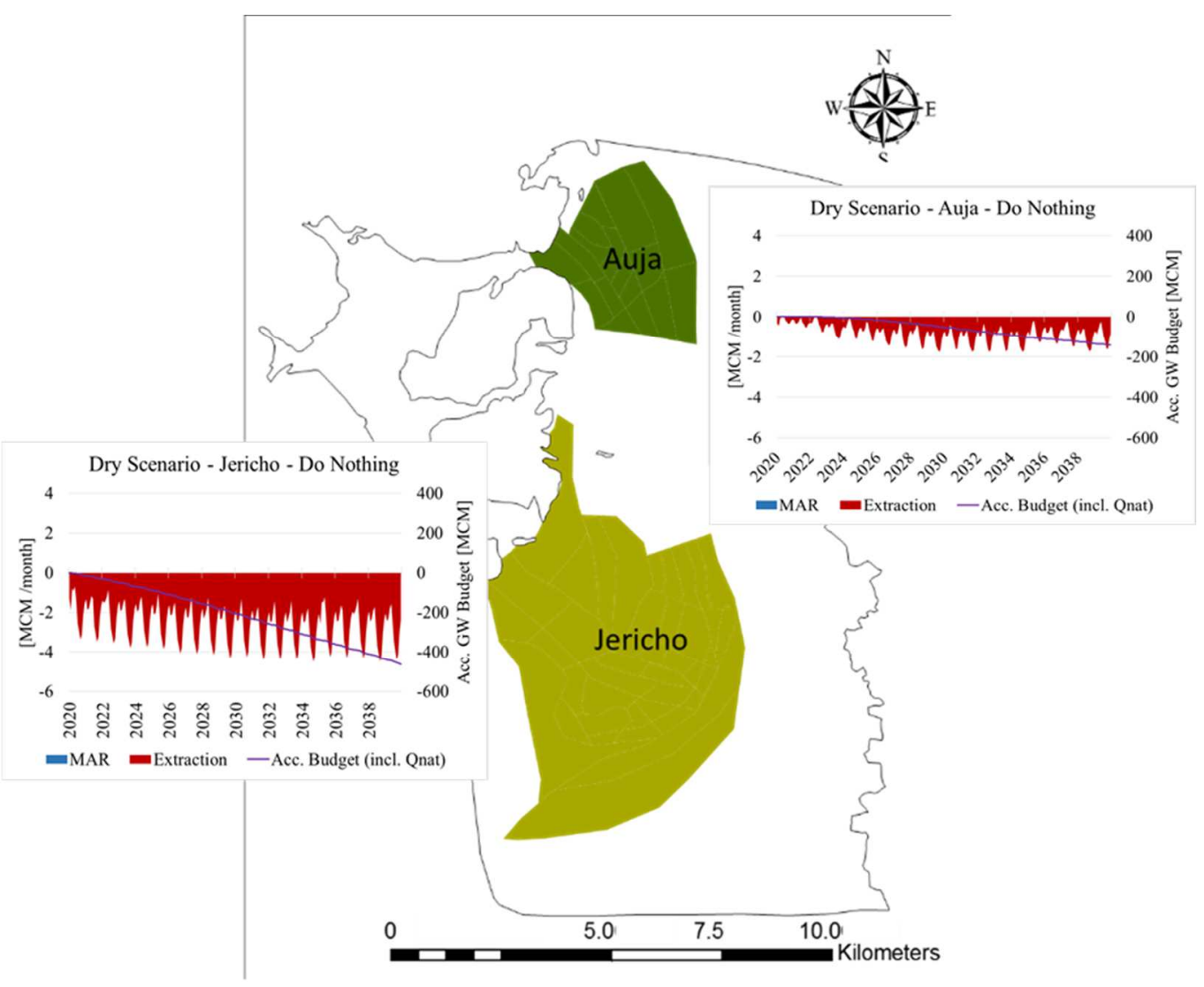

\section{B) Dry Climate Scenario - Strategy A}

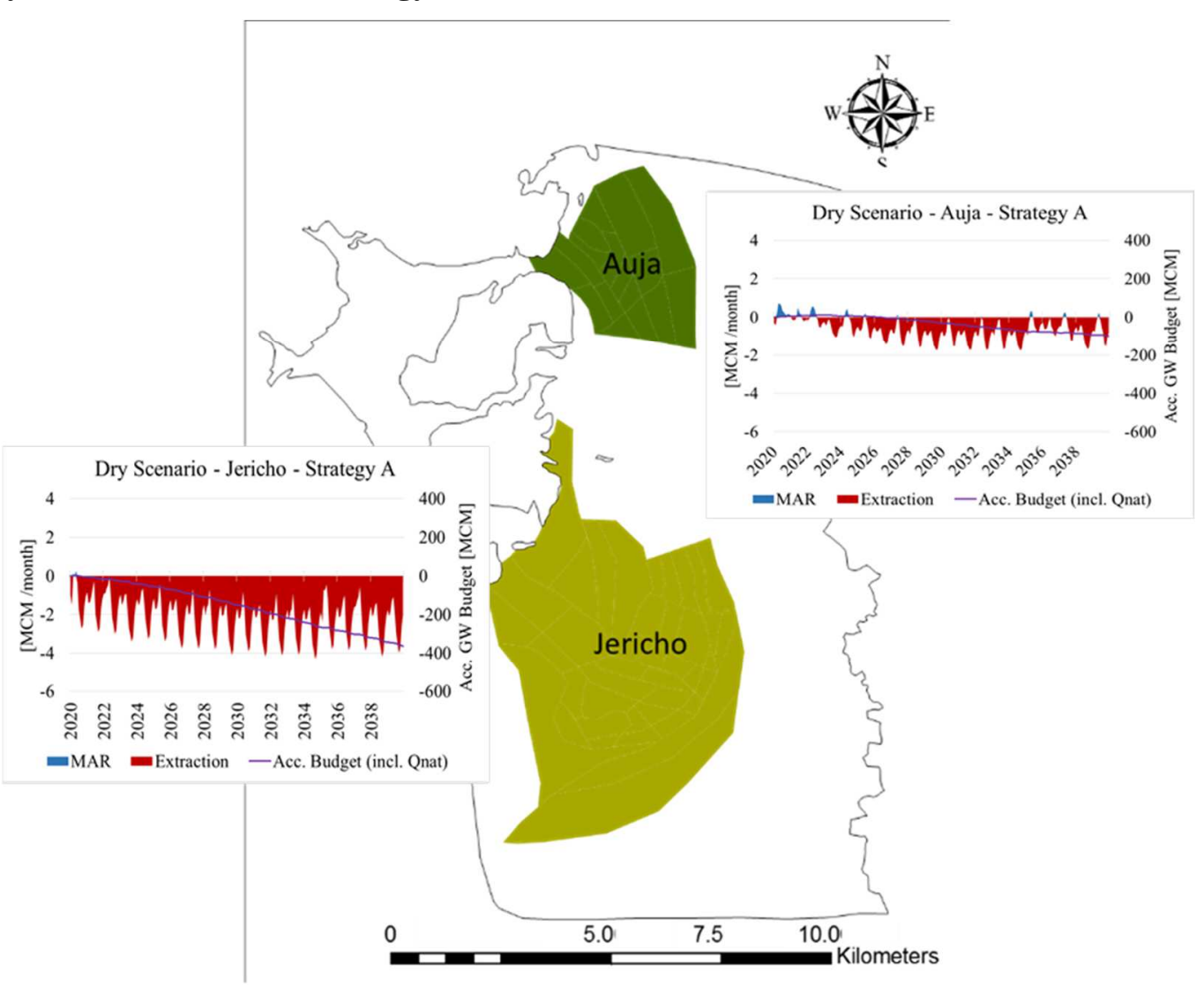




\section{C) Dry Climate Scenario - Strategy B}

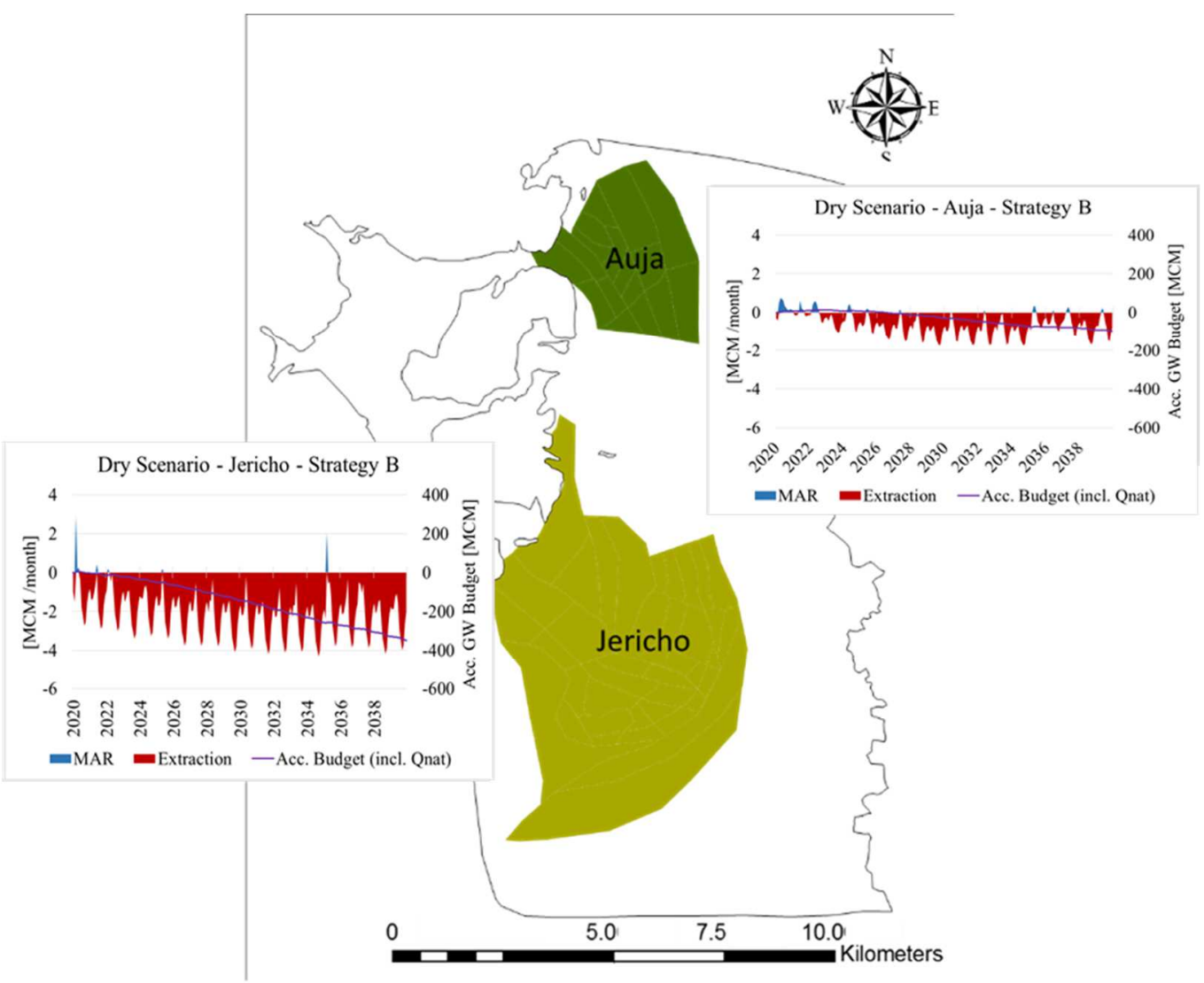

\section{D) Dry Climate Scenario - Strategy C}

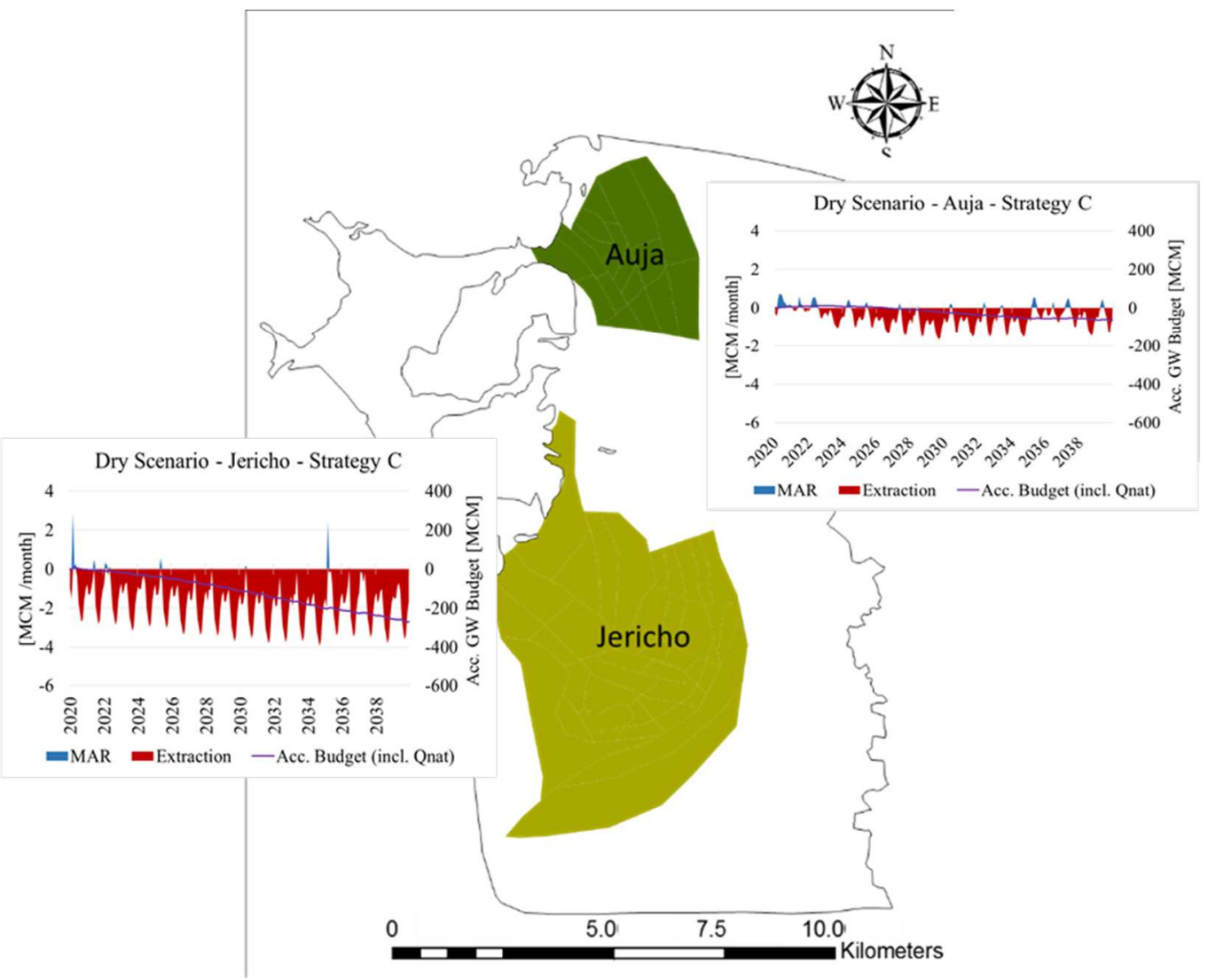




\section{E) Dry Climate Scenario - Strategy D}

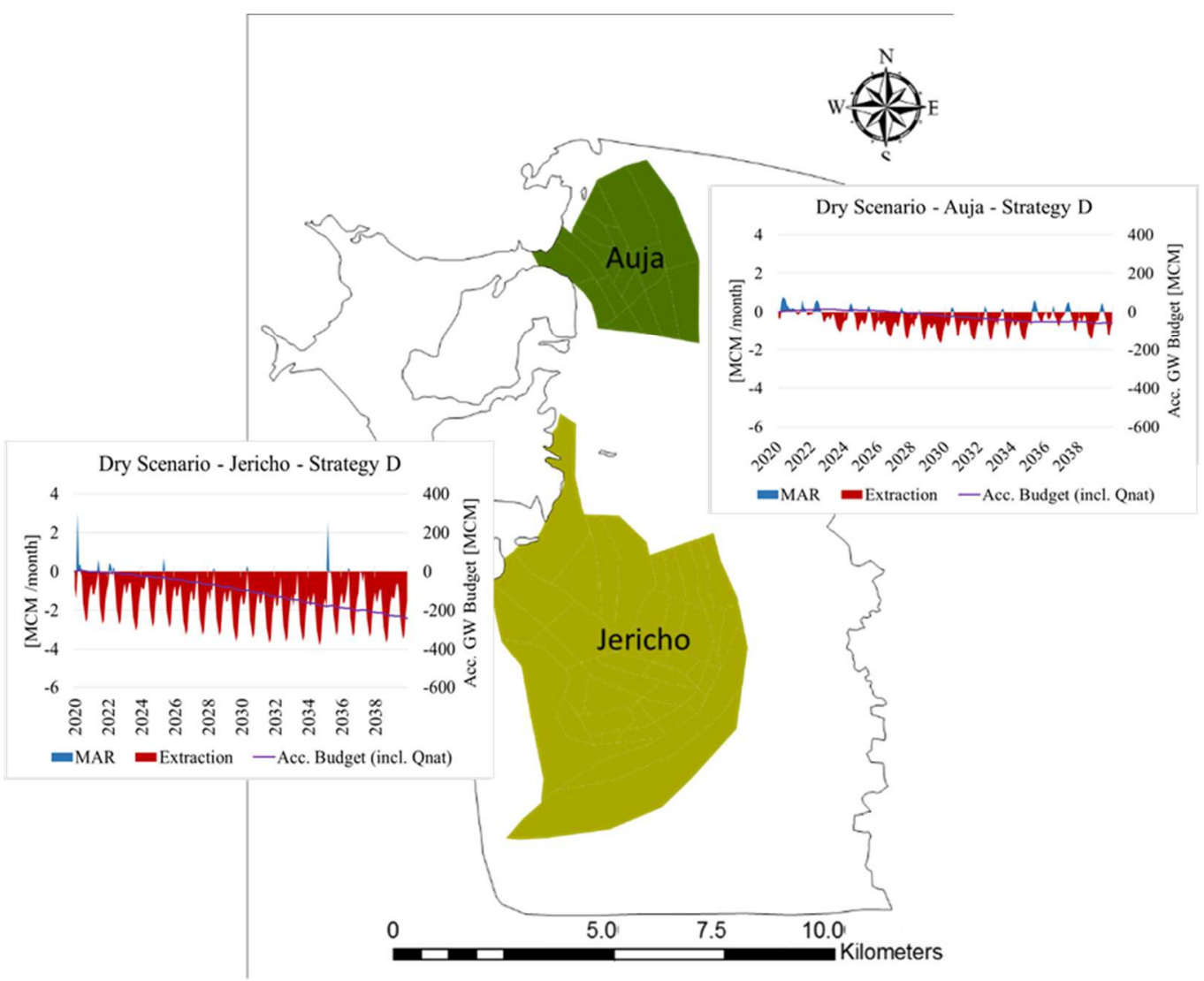

\section{F) Dry Climate Scenario - Strategy E}

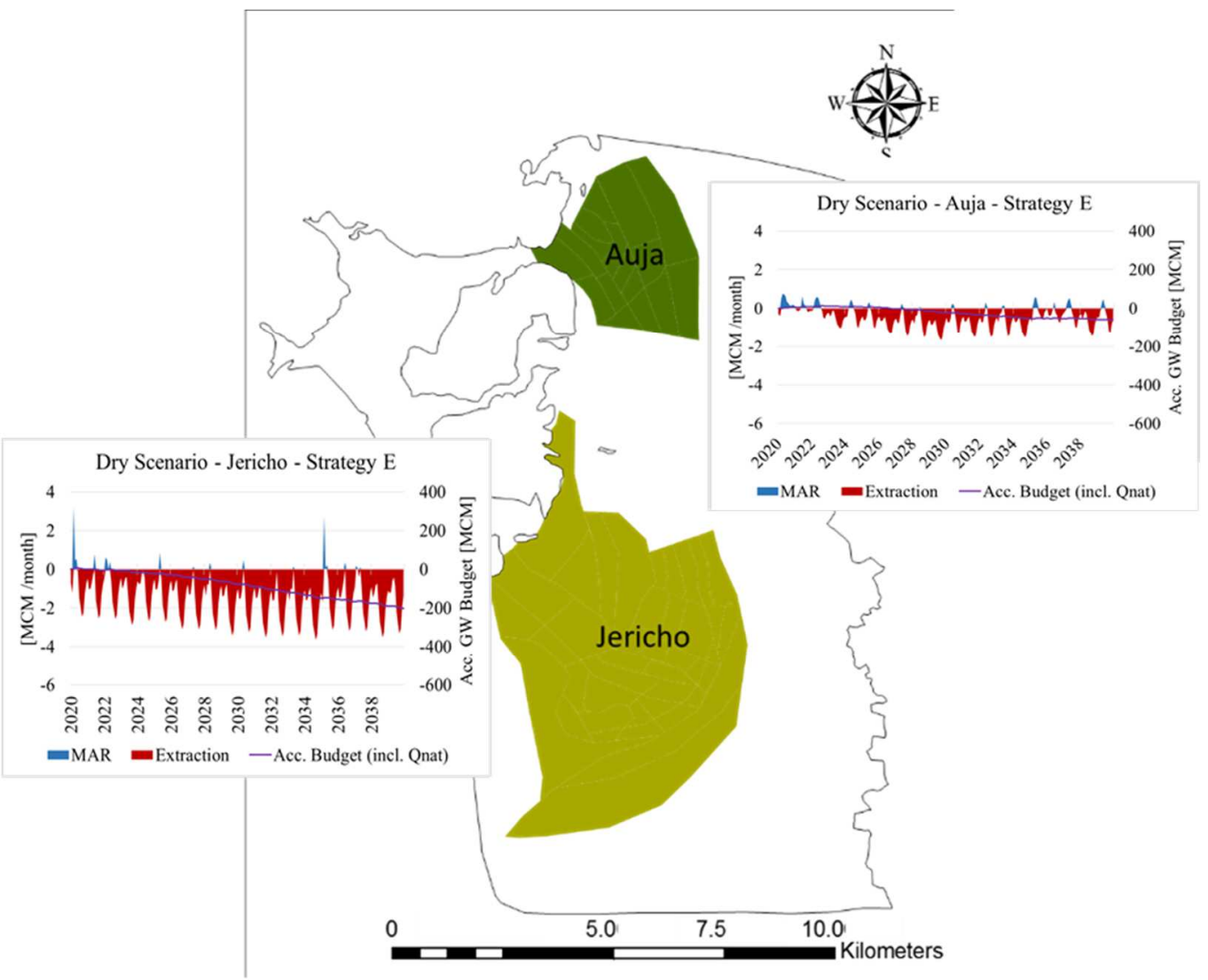




\section{G) Dry Climate Scenario - Strategy F}

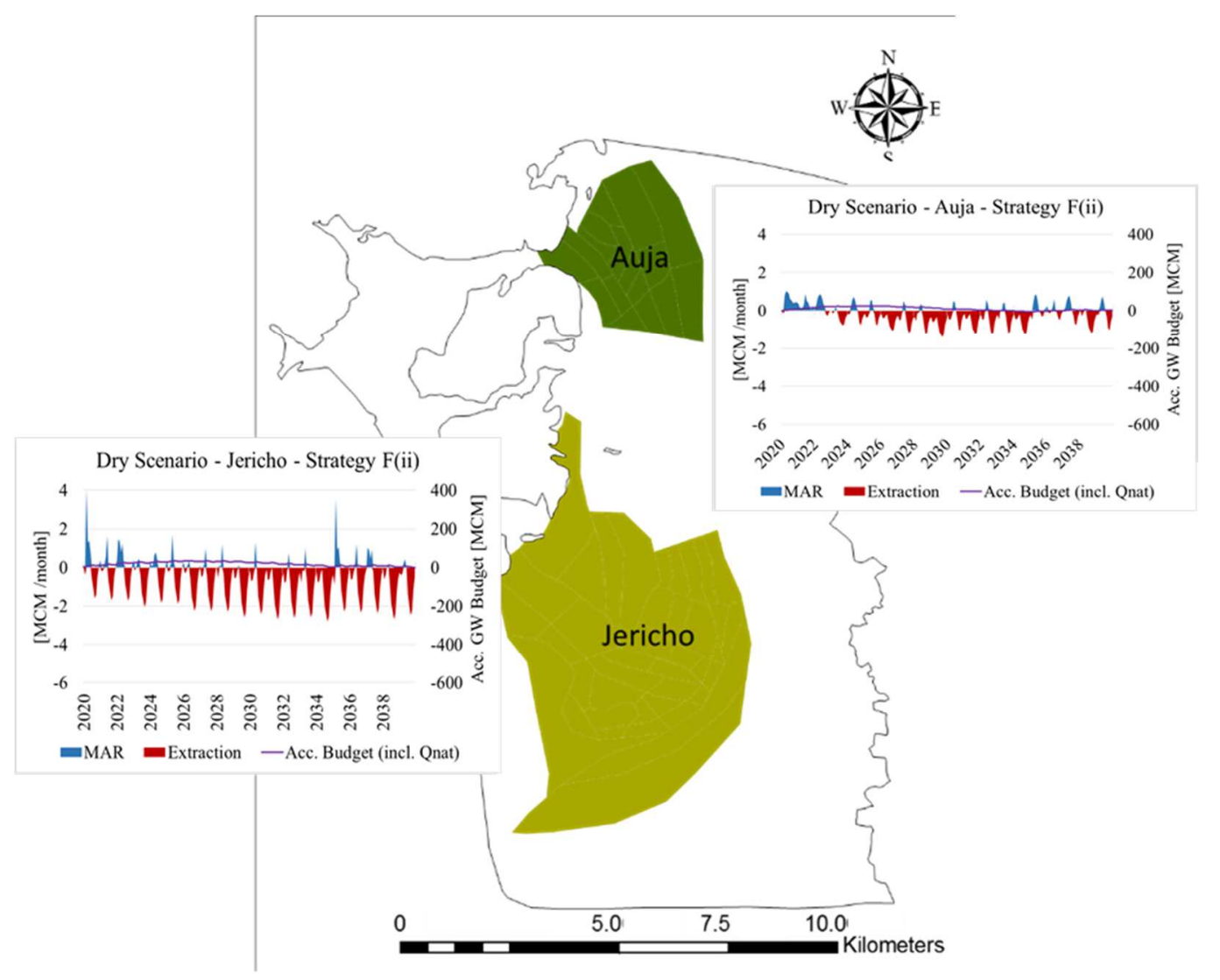




\section{SHORT}

ACADEMIC CV 


\section{Short Academic Curriculum Vitae: Florian Walter}

\section{Personal Details}

$\begin{array}{ll}\text { Name: } & \text { Florian Walter } \\ \text { Date of Birth: } & \text { August 6, 1986 } \\ \text { Place of Birth: } & \text { Göttingen, Germany } \\ \text { Civil Status: } & \text { married }\end{array}$

\section{Academic Education}

10/2014 - present day: PhD Programme Geoscience

Georg-August-University Göttingen

GAUSS - Georg-August-University School of Science

10/2010 - 09/2013: $\quad$ M.Sc. Hydrogeology and Environmental Geoscience

Georg-August-University Göttingen

Final Grade: 1.6

Title of the Thesis:

Managed Aquifer Recharge (MAR) Planning by

Groundwater Modelling and appropriate Decision

Criteria for Wadi Auja, Palestine.

10/2007 - 09/2010: $\quad$ B.Sc. Georessourcenmanagement

RWTH Aachen

Final Grade: 2.4

Title of the Thesis:

Aufbau und Anwendung eines GR4J-Modells zur

Niederschlag-Abfluss-Modellierung der Rur zwischen

Obermaubach und Stah.

(engl.: Development and Application of a GR4J-Model for

Precipitation-Runoff-Simulations of the River Rur between

Obermaubach and Stah.) 